SIGRID BARINGHORST,

VERONIKA KNEIP,

ANNEGRET MÄRZ,

JOHANNA NIESYTO (HRSG.)

\title{
Politik mit dem Einkaufswagen
}

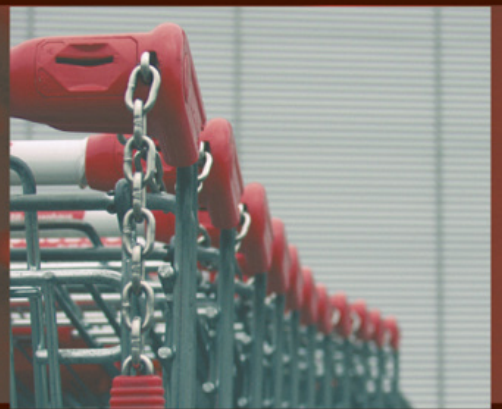

Unternehmen und

Konsumenten als Bürger

in der globalen

Mediengesellschaft 
Sigrid Baringhorst, Veronika Kneip, Annegret März, Johanna Niesyto (Hrsg.) Politik mit dem Einkaufswagen 
Die Reihe »Medienumbrüche« wird herausgegeben von Peter Gendolla. 
Sigrid Baringhorst, Veronika Kneip, Annegret März, Johanna Niesyto (Hrsg.)

\section{Politik mit dem Einkaufswagen}

Unternehmen und Konsumenten als Bürger

in der globalen Mediengesellschaft

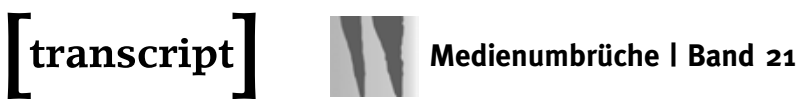


Diese Arbeit ist im Kulturwissenschaftlichen Forschungskolleg $6_{15}$ der Universität Siegen entstanden und wurde auf seine Veranlassung unter der Verwendung der von Deutschen Forschungsgemeinschaft zur Verfügung gestellten Mittel gedruckt.

\section{(ㄷ)(1) ( $(\Theta)$}

Dieses Werk ist lizenziert unter der Creative Commons Attribution-NonCommercial-NoDerivs 4.0 Lizenz (BY-NC-ND). Diese Lizenz erlaubt die private Nutzung, gestattet aber keine Bearbeitung und keine kommerzielle Nutzung. Weitere Informationen finden Sie unter https://creativecommons.org/licenses/by-nc-nd/4.o/deed.de/.

Um Genehmigungen für Adaptionen, Übersetzungen, Derivate oder Wiederverwendung zu kommerziellen Zwecken einzuholen, wenden Sie sich bitte an rights@transcript-verlag.de

\section{(C) 2007 transcript Verlag, Bielefeld}

\section{Bibliografische Information der Deutschen Nationalbibliothek}

Die Deutsche Nationalbibliothek verzeichnet diese Publikation in der Deutschen Nationalbibliografie; detaillierte bibliografische Daten sind im Internet über http://dnb.d-nb.de abrufbar.

Umschlaggestaltung: Kordula Röckenhaus, Bielefeld Umschlagabbildung: (C) Georg Rademacher, Siegen 2007

Lektorat \& Satz: Sigrid Baringhorst, Veronika Kneip, Annegret März, Johanna Niesyto

Druck: Majuskel Medienproduktion GmbH, Wetzlar

Print-ISBN 978-3-89942-648-9

PDF-ISBN 978-3-8394-0648-9

Gedruckt auf alterungsbeständigem Papier mit chlorfrei gebleichtem Zellstoff.

Besuchen Sie uns im Internet: http://www.transcript-verlag.de

Bitte fordern Sie unser Gesamtverzeichnis und andere Broschüren an unter: info@transcript-verlag.de 


\section{Inhalt}

Sigrid Baringhorst/Veronika Kneip/Annegret März/Johanna Niesyto

Verbraucher und Unternehmen als Bürger in der globalen

Mediengesellschaft. Bürgerschaft als politische Dimension

des Marktes

Michael Beetz

Verbraucheröffentlichkeit und Bürgerschaft

Jörn Lamla

Die Autonomie des Verbrauchers und ihre politischen Formen.

Bausteine einer Kulturtheorie des Consumer Citizen 53

Sigrid Baringhorst

Konsumenten als Netizens. Das Internet als ambivalentes Medium für ein Empowerment von Verbrauchern

Sigrid Baringhorst/Veronika Kneip/Johanna Niesyto

Wandel und Kontinuität von Protestkulturen seit den 1960er Jahren:

Eine Analyse ausgewählter Anti-Corporate Campaigns.

Annegret März

Protestnetzwerke im Internet - Kollektive Identitätskonstruktion in konzernkritischen Kampagnen?

Veronika Kneip/Johanna Niesyto

Politischer Konsum und Kampagnenpolitik als nationalstaatliche Steuerungsinstrumente? Das Beispiel der Kampagne Echt gerecht.

Clever kaufen

Janina V. Curbach

Unternehmen als kollektive Weltbürger 181

Karin Lukas

Menschenrechtliche Verantwortung von Unternehmen 207

Veronika Kneip

Legitimationsfaktor Bürgerschaft. Die kommunikative

Vermittlung von Corporate Citizenship .223 
Tanja Köhler

Netzaktivismus. Herausforderung für die

Unternehmenskommunikation

Christian Conrad/Benjamin Diehl

Unternehmenskommunikation als Stakeholder-Dialog...

Antoine Mach

Ethische Reputation als Börsenwert.

Lars Rademacher

Bürgerschaft und Unternehmensführung. Die praktische

Philosophie des Corporate Citizenship am Beispiel Bildung.

Simon Holler

Fairtrade als subpolitisches Konzept. Ziele, Strukturen, Herausforderungen und Strategien.

Thomas Löding/Kay O. Schulze/Jutta Sundermann

Geheimwaffe CSR - wozu braucht's noch Kampagnen?

Hans Hubbertz

Arm sein ist geil - Schnäppchenjäger und Smart Shopper in der Kampfzone 367

Autoren 389 


\section{Sigrid Baringhorst/Veronika Kneip/Annegret März/ Johanna Niesyto}

\section{Verbraucher und Unternehmen als Bürger in der globalen Mediengesellschaft. Bürgerschaft als politische Dimension des Marktes}

Mit fortschreitender ökonomischer Globalisierung im Zeichen neoliberaler Reformpolitik haben multinationale Konzerne gegenüber nationalen Regierungen und internationalen Organisationen weiter an Macht gewonnen. Innerhalb der Nationalstaaten haben sich die industriellen Beziehungen dabei deutlich zugunsten der Unternehmerseite verändert: Abbau von Unternehmensbesteuerung, Privatisierung öffentlicher Güter und forcierter Standortwettbewerb zwischen und innerhalb der Nationalstaaten sind augenfällige Zeichen einer wachsenden Durchdringung des politischen Raumes mit privatwirtschaftlichen Gewinnmaximierungsinteressen. In dem Maße, in dem Politik in die Sphäre des „Subpolitischen“ (Beck) unternehmerischer Entscheidungen abwandert, richtet sich politischer Protest nicht mehr nur gegen (nationale) politische Entscheidungsträger, sondern verstärkt auch gegen einzelne Unternehmen oder ganze Branchen. Unternehmen haben nicht nur an Einfluss gewonnen, sie sind seit den 1970er Jahren auch zunehmend Objekte öffentlicher Moralisierung und zivilgesellschaftlicher Kritik geworden - erinnert sei etwa an die Proteste gegen Nestlé, McDonald's, Siemens oder Shell. Dies gilt nicht nur, wie in der Literatur inzwischen vielfach dokumentiert wurde, für den nordamerikanischen Raum, ${ }^{1}$ sondern verstärkt auch für Unternehmen mit Firmensitz in der Europäischen Union. ${ }^{2}$ Dass auch deutsche Konsumenten in ihren Konsumentscheidungen zunehmend Kriterien jenseits von Produktqualität und Preis berücksichtigen, verdeutlicht beispielsweise eine Umsatzsteigerung um 50 Prozent bei Fairtrade-gesiegelten Produkten in Deutschland im Jahr 2006. ${ }^{3}$ Eine Studie des Instituts für Markt-Umwelt-Gesellschaft nennt zudem Informationen über die gesellschaftliche Verantwortungsübernahme von Unternehmen als relevanten Faktor der Kaufentscheidung. ${ }^{4}$

1 Vgl. z.B. Manheim: The Death of a Thousand Cuts; Bennett: „Comunicating global activism".

2 Vgl. z.B. Stolle u.a.: „Zwischen Markt und Zivilgesellschaft“.

3 Vgl. TransFair e.V./Rugmark: ,Jahresbericht 2006“, S. 7.

4 Vgl. Institut für Markt-Umwelt-Gesellschaft e.V: „CSR-Informationsbedarf von Verbauchern“, S. 43. 
In einer umfangreichen Recherche zu Anti-Corporate Campaigns in den Jahren 1995 bis 2005 hat das am Siegener Forschungskolleg Medienumbrüche angesiedelte Projekt Protest- und Medienkulturen um Umbruch 109 transnationale unternehmenskritische Kampagnen erfasst, die im deutschen Sprachraum initiiert bzw. gegen Unternehmen mit Firmensitz oder Niederlassung im deutschen Sprachraum geführt wurden. Anti-Corporate Campaigns zielen vielfach darauf, Konsumenten als Protestakteure zu mobilisieren und rufen zu Boyoder Buykottaktionen, Protestschreiben an Manager und Aufsichtsräte oder Demonstrationen vor Firmensitzen auf. Der Konsument soll sich politische Handlungsrepertoires des Bürgers zu eigen machen und auch in seiner alltäglichen Konsumhandlung als Bürger (Consumer Citizen) agieren.

Unternehmen reagierten und reagieren auf die sich in der öffentlichkeitswirksamen Skandalkommunikation manifestierende Politisierung ${ }^{6}$ bzw. Moralisierung $^{7}$ des Konsums mit einer gesteigerten Demonstration ökologischer Orientierung und sozialer Verantwortung: Sozial- und Umweltberichte sollen Transparenz über soziale und ökologische Implikationen der Produktion erzeugen, Selbstverpflichtungen in Form von Codes of Conduct die Einhaltung grundlegender wirtschaftsethischer Prinzipien belegen. Mit der Entdeckung des Stakeholder-Prinzips werden neben den Aktionären ebenso Arbeitnehmer, Konsumenten und alle anderen zur Umwelt der Unternehmen zählenden Akteure zu relevanten Adressaten unternehmerischer Selbstreflexion. Auch der Stiftungsboom floriert noch immer: Große Geldsummen werden in private Stiftungen zur Verfolgung mehr oder weniger benevolenter Zwecke investiert. $^{8}$ Vielfältige Formen des Social Sponsoring - so etwa Regenwaldschutz durch Bierkonsum oder Kinderförderung durch den Besuch von Fast-FoodKetten - sollen den Gemeinsinn von Unternehmen belegen ${ }^{9}$ und das durch Korruptionsaffären, Kündigungen und Lohndumping erzeugte Image unternehmerischer Verantwortungslosigkeit durch demonstrative Akte der Verantwortungsübernahme korrigieren. Mediengerechte Inszenierungen sozialer Initiativen und Partnerschaften sind zum festen Bestandteil sozialer Markenstrategien geworden. Ebenso wie im Kontext des Konsumenten wird hier auf den Bürgerbegriff rekurriert, um die Relevanz unternehmerischen Handelns für gesellschaftliche Belange zu verdeutlichen. Der Corporate Citizen zeigt sich als ver-

5 Für weitere Informationen zum Forschungsprojekt vgl. www.protest-cultures.unisiegen.de.

6 Vgl. Lamla: „Politisierter Konsum - konsumierte Politik“.

7 Vgl. Priddat: „Moral als Kontext von Gütern“.

8 Vgl. z.B. Gillmann: „Deutschland erlebt Stiftungsboom“; Kleine-Brockhoff: „Philantropische Republik Amerika“.

9 Vgl. Luttgefeld u.a.: „Unternehmerische Sozialkampagnen - total sozial“. 
antwortungsbewusstes Mitglied der Gemeinschaft und investiert in sein soziales Umfeld. Das Center for Corporate Citizenship am Boston College vereint mehr als 4.000 Mitglieder aus über 300 Unternehmen in einem Peer-to-Peer-Netzwerk zur Entwicklung entsprechender „citizenship strategies" ${ }^{\text {"10 }}$. In Deutschland haben die Spitzenverbände der Wirtschaft ${ }^{11}$ zusammen mit der WirtschaftsW oche im Jahr 2000 die Initiative Freibeit und Verantwortung gegründet, um das gesellschaftliche Engagement von Unternehmen als Corporate Citizens zu fördern. ${ }^{12}$

Wie sinnvoll ist analytisch wie normativ die begriffsinflationäre Einbeziehung von Wirtschaftsbürgern - von kritischen Konsumenten als Consumer Citizens und sich als sozial verantwortlich inszenierenden Unternehmen als Corporate Citizens - in die Reihe bürgergesellschaftlicher Akteure? Die sich in der Politisierung des Konsums und in der Selbstinszenierung von Unternehmen als sozial verantwortliche Bürger manifestierende gegenseitige Durchdringung von Zivilgesellschaft und Markt wirft grundlegende Fragen zur Neubestimmung des Bürgerbegriffs und zur Erweiterung des individuellen und kollektiven Handlungsrepertoires von Protestakteuren in spätmodernen Konsumgesellschaften auf. Begriffe zu hinterfragen heißt dabei sowohl ihren analytischen als auch ihren normativen Gehalt zu erschließen. Um den analytischen Wert der Übertragung des Bürgenbegriffs auf die Ebene des Marktes zu verstehen, sind die Begriffe Unternehmens- und Konsumentenbürger zunächst kategorial von anderen Varianten des Bürgerbegriffs zu differenzieren. Aus der Begriffsverwendung lassen sich wichtige Folgen für die Unterscheidung zwischen Öffentlichkeit und Privatheit und zwischen politischem und unpolitischem Handeln ableiten.

\section{Zur Entwicklung des Bürgerbegriffs}

Prima facie scheinen die Begriffe des Consumer und Corporate Citizen in ihrer Verknüpfung von Markt und Politik widersprüchlich zu sein. Betrachtet man die Geschichte des Bürgerbegriffs wird allerdings deutlich, dass mit dieser Verknüpfung die im Kontext nationalstaatlich verfasster Bürgerschaft entstandenen Ausdifferenzierungen unter neuen Vorzeichen zusammengefasst wer-

10 Vgl. Center for Corporate Citizenship: „Membership“.

11 Im Einzelnen der Bundesverband der Deutschen Industrie (BDI), die Bundesvereinigung der Deutschen Arbeitgeberverbände (BDA), der Deutsche Industrie- und Handelskammertag (DIHK) und der Zentralverband des Deutschen Handwerks (ZDH).

12 Vgl. Initiative Freiheit und Verantwortung: „Corporate Citizenship“. 
den. Während in der griechischen und römischen Tradition die Idee des Bürgers eng an die Gemeinschaft des Stadtstaates gebunden wird, sodass die Rollen des Stadt- und des Staatsbürgers nicht voneinander zu trennen sind, erfolgt im mittelalterlichen Europa eine Umgestaltung des Begriffs, der nun vor allem auf den genossenschaftlichen Zusammenschluss freier Männer und deren Rechtsprivilegien in einem eng begrenzten Stadtraum bezogen wird. ${ }^{13}$ Dies verdeutlichen sowohl der deutsche Terminus des Bürgers (burgher) als auch der aus dem Französischen stammende Begriff Bourgeois, die sich etymologisch auf die Worte bourg bzw. Burg zurückführen lassen, denen im Mittelalter auch die Bedeutung von Stadt zukam. Als Stadtbürger werden im Mittelalter Angehörige eines bestimmten Standes verstanden, wobei die Zugehörigkeit durch räumlich-territoriale, ökonomische und rechtliche Elemente markiert ist. In diesem Sinne werden Bürgerrechte erstens an die Stadtansässigkeit, zweitens an eine bestimmte ökonomische Stellung wie den Besitz von Haus und Grund in der Stadt und drittens an die Rechtsfähigkeit (Freiheit des Bürgers) geknüpft, die diesen vom Rest der Gemeinde, von den bloßen Einwohnern (Beisassen) unterscheidet. Obwohl die mittelalterliche Stadtbürgerschaft somit eindeutig an eine ökonomische Privilegierung gebunden ist, erfolgt die Abgrenzung der primär an wirtschaftlichen Interessen orientierten privaten Bürgerrolle von einer öffentlich-politischen Rolle erst im 17. Jahrhundert. Ausgehend von der im französischen Sprachraum bereits im 11. bzw. 12. Jahrhundert vorgenommenen sprachlichen Unterscheidung des Bürgers in Bourgeois und $\mathrm{Ci}$ toyen, die jedoch zunächst nicht mit unterschiedlichen Rollendefinitionen verbunden wird, entwickelt sich der Citoyen, abgeleitet vom römischen civis, unter dem Einfluss der neuzeitlichen Souveränitätslehre zum Synonym für den Bürger als Staatsbürger, während der Begriff des Bourgeois die ursprüngliche Bedeutung des ökonomisch potenten Stadt- bzw. Wirtschaftsbürgers erhält. ${ }^{14}$ So etwa in Kants Reflexionen zur Anthropologie:

Derjenige, welcher das Stimmrecht in dieser Gesetzgebung hat, heißt ein Bürger (citoyen, d. i. Staatsbürger, nicht Stadtbürger, bourgeois). Die dazu erforderliche Qualität ist, außer der natürlichen (daß er kein Kind, kein Weib sei), die einzige: daß er sein eigener Herr (sui juris) sei, mithin irgend ein Eigentum habe (wozu auch jede Kunst, Hand-

13 Vgl. Pocock: „The Ideal of Citizenship Since Classical Time“, S. 37; Riedel: „Bürger, Staatsbürger, Bürgertum“, S. 676.

14 Vgl. ebd., S. 678. 
werk oder schöne Kunst oder Wissenschaft gezählt werden kann), welches ihn ernährt. ${ }^{15}$

Ähnlich unterscheidet Garve zwischen dem Bürger als ,,jedes Mitglied der bürgerlichen Gesellschaft“" (Citoyen) und als „unadlige[r] Stadtbewohner, der von einem gewissen Gewerbe lebt ${ }^{\star 16}$ (Bourgeois). Unstrittig ist die politische Bedeutung der Begriffsvariante des Citoyen, wie aber verhält es sich mit dem Bürger als Bourgeois oder Wirtschaftsbürger? Kann auch ihm politische Relevanz zugesprochen werden? Nach Hegel schließt die Bourgeois-Dimension des Bürgerbegriffs eine politische Bedeutung explizit aus:

Die bürgerliche Gesellschaft hat zu ihrer Grundlage, ihrem Ausgangspunkt das besondere Interesse der Individuen. Die Franzosen machen einen Unterscheid zwischen bourgeois und citoyen; das erste ist das Verhältnis des Individuums in einer Gemeinde, in Rücksicht der Befriedigung seiner Bedürfnisse, hat so keine politische Beziehung, diese hat erst der citoyen. (Hier betrachten wir nur die Individuen als bourgeois. $)^{17}$

In marxistischen und neo-marxistischen Theorien erhält der von Hegel markierte Unterschied zwischen dem Bürger als partikularem Klassenbegriff und dem allgemeinen Staatsbürgerbegriff eine zentrale Bedeutung. Im Laufe des 20. Jahrhunderts verlieren jedoch Klassengegensätze nicht zuletzt durch die wohlfahrtsstaatliche Inkorporation der Arbeiter in die Gesellschaft an Relevanz für die politische Praxis wie für die sozialwissenschaftliche Analyse. Die universalistische Bedeutung von Bürger als Staatsbürger scheint sich allgemein durchgesetzt zu haben, auch wenn sich in Bezeichnungen wie z.B. bürgerliche Parteien der partikularistische Begriffssinn erhalten hat. Der Begriff des Bürgers als Staatsbürger abstrahiert von früheren Vorstellungen der Verknüpfung des ökonomischen Bürgerstatus mit spezifischen Werten wie Selbstständigkeit und Bildung oder einer spezifischen Lebensführung, gekennzeichnet u.a. durch ein bestimmtes Familienmodell. Bürger als Staatsbürger sind seit dem 18. Jahrhundert ,alle erwachsenen, mündigen Personen in Bezug auf ihre Rechte und Pflichten gegenüber der Allgemeinheit, dem Staat, dem Großen und Ganzen“. 18

15 Kant zitiert in: ebd., S. 696.

16 Garve: Versuche über verschiedene Gegenstände aus der Moral, der Litteratur und dem gesellschaftlichen Leben, S. 302.

17 Hegel: „Philosophie des Rechts“, S. 81.

18 Kocka: „Das Bürgertum als Träger von Zivilgesellschaft“, S. 16. 
Um die Übertragung des Bürgerbegriffs auf Unternehmen und Konsumenten einordnen zu können, bietet es sich an, sich mit den verschiedenen Rollenzuschreibungen von Bürgerschaft auseinanderzusetzen. Die begriffliche Unterscheidung in Citoyen und Bourgeois geht einher mit unterschiedlichen Konturierungen von Bürgerschaft, die vor allem durch die historischen Begründungslinien des Republikanismus und Liberalismus geprägt sind. ${ }^{19}$

We have, then, two different understandings of what it means to be a citizen. The first describes citizenship as an office, a responsibility, a burden proudly assumed; the second describes citizenship as a status, an entitlement, a right or set of rights passively enjoyed..$^{20}$

Während die republikanische Tradition, die ihre Wurzeln in der griechischen Antike hat, hohe Anforderungen an den Bürger als zoon politikon (Aristoteles) stellt, sehen liberale Entwürfe von Bürgerschaft das Individuum lediglich als Mitglied einer politischen Zweckgemeinschaft, durch die die Freiheits- und Eigentumsrechte des Individuums geschützt werden. Liberale Konzepte von Bürgerschaft stehen in einem historischen und inhaltlichen Zusammenhang zu Prozessen der Industrialisierung und der Durchsetzung kapitalistischer Wirtschaftsstrukturen. Sie verbinden mit der Rolle des Bürgers weniger dessen Beitrag zur res publica und die Verpflichtung, die eigenen Interessen zu Gunsten des Gemeinwohls oder eines volonté generale (Rousseau) zurückzustellen, sondern vielmehr das Recht, diese Interessen in den Wettstreit konfligierender Belange einzubringen. Während somit in der republikanischen Tradition positive Freiheitsrechte des Bürgers im Sinne politischer Partizipationsrechte eine zentrale Rolle spielen, werden in der liberalen Tradition vor allem negative Rechte als Abwehrrechte gegenüber staatlichem Zwang hervorgehoben. Der Vorstellung des Bürgers als politischer Akteur, der auf der Basis einer geteilten Identität eng in die Gemeinschaft mit anderen eingebunden ist und sich aktiv in die politischen Entscheidungs- und Willensbildungsprozesse einbringt, stehen Vorstellungen gegenüber, die den Bürger als privaten Akteur sehen, der gesamtgesellschaftlich nur insoweit verpflichtet ist, wie er sich diese Verpflichtung durch vertragliche Bindungen selbst auferlegt. ${ }^{21}$ Vor diesem Hintergrund

19 Bei dieser Zweiteilung handelt es sich um eine idealtypische Gegenüberstellung von Konzepten. Die Konzepte selbst sind in den im Folgenden genannten Aspekten nicht immer in dieser Eindeutigkeit voneinander abgrenzbar; zudem gibt es sowohl innerhalb der republikanischen als auch innerhalb der liberalen Tradition unterschiedliche Ausprägungen.

20 Walzer: „Citizenship“, S. 216.

21 Vgl. Oldfield: „Citizenship“, S. 189. 
spielen Bürgerpflichten aber auch Vorstellungen von guter Bürgerschaft im Kontext des Republikanismus eine wesentlich größere Rolle.

Mit der Entstehung des Kommunitarismus Ende des 20. Jahrhunderts haben sich neuere Konzepte von Bürgerschaft als Reaktion auf und Kritik an liberalen Vorstellungen etabliert, die republikanische Vorstellungen von Gemeinschaft aufgreifen. Die damit einhergehende Requalifizierung oder sozialmoralische Wiederaufladung des Bürgerbegriffs kann unter anderem im Zusammenhang mit sinkender politischer Beteiligung und veränderten staatlichen Handlungskompetenzen gesehen werden. So hebt im deutschen Sprachraum Herfried Münkler die Verpflichtung des Bürgers gegenüber der politischen Gemeinschaft im Sinne einer Gemeinwohlorientierung hervor. Bürger ist demnach nicht ein rechtlich privilegiertes Mitglied einer Statusgruppe, „sondern wer mit den besonderen Rechten des Bürgerstatus auch besondere Pflichten übernommen hat": 22

Bürgerschaftliche Freiheit $[\ldots]$ hat ihren Preis, und dieser Preis besteht in der Bereitschaft zum Engagement für allgemeine Aufgaben und Belange und zur Übernahme von Verpflichtungen im Hinblick auf die Gewährleistung dessen, was man als kollektive Güter bezeichnet. $^{23}$

Der Rückbindung des Bürgerbegriffs an das Gemeinwohl scheint angesichts knapper öffentlicher Kassen und einer globalisierungsbedingten umfassenden Transformation wohlfahrtsstaatlicher Inklusionsmodelle plausibel. Doch verkennt sie die mit dem Begriff des Gemeinwohls unweigerlich verknüpften Definitionsprobleme. Kaum ein anderer Terminus der politischen Theorie ist so bedeutungsoffen: Alle politischen Strömungen beziehen sich darauf, ohne inhaltlich einen Konsens darüber zu erzielen, worin das Gemeinwohl besteht. Auch ist der sozial-räumliche Bezugsrahmen mehr als unklar. Dies gilt insbesondere in Zeiten beschleunigter auch politischer Denationalisierung: Ist die Referenzgemeinschaft für bürgerliche Gemeinwohlorientierung die regionale, nationale, transnational-europäische oder globale Gemeinschaft?

Die hier angesprochenen Aspekte der Veränderung des Bürgerbegriffs werden in verschiedenen Einzelbeiträgen des Bandes im Kontext der Übertragung dieses Begriffs auf Konsumenten und Unternehmen thematisiert. Sowohl die Trennung des Bürgerbegriffs in Citoyen und Bourgeois als auch die unterschiedlichen Rollenzuschreibungen in der Tradition des Republikanismus und Liberalismus verweisen auf eine Zweiteilung in ein politisch und ein ökono-

22 Münkler: „Ehre, Amt und Engagement“, S. 23.

23 Ebd. 
misch geprägtes Bild von Bürgerschaft. Mit Vorstellungen von Consumer Citizenship und Corporate Citizenship, so scheint es, werden diese verschiedenen Komponenten wieder zusammengefügt. Diese hybride Rolle zwischen politischen und privaten Dimensionen untersucht Baringhorst in ihrem Beitrag für Konsumenten als Netizens. In Bezug auf den Corporate Citizen skizziert Kneip, inwieweit entsprechende Entwürfe sowohl an individualistische als auch an gemeinschaftsbezogene Begründungslinien von Bürgerschaft anschließen. Curbach identifiziert in ihrem Beitrag vier Rollenelemente des Corporate Citizen zwischen politischem Weltbürger und kollektivem Weltwirtschaftsbürger und stellt damit neben der Zweiteilung des Bürgerbegriffs in Citoyen und Bourgeois die globale Referenzgemeinschaft von Bürgerschaft in den Mittelpunkt ihrer Überlegungen. Insgesamt zeigen die verschiedenen Beiträge, dass die angesprochenen Spannungsfelder kaum aufgelöst werden können. Vielmehr wird in der Übertragung auf Konsumenten und Unternehmen die in den Bürgerschaftskonzepten selbst angelegte Widersprüchlichkeit zwischen privat und öffentlich sowie Gemeinschaftlichkeit und Individualismus offensichtlich. ${ }^{24}$

\section{Konsumenten und Unternehmen als Bürger}

Wie nun wird bürgerschaftliches Handeln von Konsumenten und Unternehmen empirisch fassbar, welche gesellschaftlichen und politischen Phänomene individuellen und kollektiven Handelns umfassen die Begriffe Consumer Citizenship und Corporate Citizenship?

Was den Konsumenten als Bürger betrifft, ist bürgerschaftliches Agieren an die politische Konsumhandlung gebunden: ,[...] the term ,consumer citizenship' has been used to describe the obligation of consumers to make contributions to the social good through their economic votes [...].“25 Politischer Konsum im engen Sinn kann dabei mit Micheletti ${ }^{26}$ bzw. Stolle u.a. ${ }^{27}$ als die auf ethischen oder politischen Überlegungen basierende Wahl zwischen Produkten und Herstellern mit dem Ziel, Unternehmenspolitik oder institutionelle Strukturen zu verändern, verstanden werden. Im Gegensatz z.B. zu Micheletti unterscheidet Lamla genauer zwischen „politischem Konsum“ bzw. „political consumption“ und „politischem Konsumerismus“ bzw. „political

24 Ein Überblick über sämtliche Beiträge des Bandes findet sich am Ende dieses Beitrages.

25 Dickinson/Carsky: „The Consumer as Economic Voter“, S. 28.

26 Vgl. Micheletti: ,Just Clothes?", S. 4.

27 Vgl. Stolle u.a.: „Zwischen Markt und Zivilgesellschaft“, S. 154. 
consumerism“. ${ }^{28}$ Während er unter ersterem ,individualisiertes kollektives“ und alltagsnahes Konsumentenhandeln versteht, bezeichnet er mit letzterem die Bündelung von Konsumentenmacht zur Veränderung von Unternehmenspolitik und gesetzlichen Regelungen. Ähnlich sprechen Gabriel/Lang von „consumer activism“ 29 als organisierter und kollektiver Form politischen Konsumentenhandelns. Darüber hinaus wird - vorwiegend im deutschen Sprachgebrauch - zwischen politischem und politisiertem Konsum unterschieden. Lamla und Baringhorst nutzen demgemäß beide Termini, wobei der Begriff des politisierten Konsums insbesondere verwendet wird, um den Prozess der Aufladung der Konsumhandlung mit politischen Forderungen oder Intentionen zu verdeutlichen. ${ }^{30}$

Bürgerschaftliches Handeln von Unternehmen drückt sich demgegenüber vor allem in der Verantwortungsübernahme für gesellschaftliche Probleme aus:

[...] corporate citizenship is about business taking account of its impact on both society and the environment, and about their being committed to delivering on social and environmental goods. ${ }^{31}$

Vor diesem Hintergrund sind die Begriffe Corporate Citizenship und Corporate Social Responsibility sowohl auf der konzeptionellen Ebene als auch in ihrer Verwendung durch Unternehmen eng miteinander verknüpft. Neben Beiträgen, die beide Termini synonym verwenden, ${ }^{32}$ existieren Positionen, die Corporate Social Responsibility als das umfassendere Konzept begreifen. In diesem Sinne definieren Westebbe/Logan oder Backhaus-Maul/Schubert Corporate Citizenship als freiwilliges soziales und gesellschaftliches Engagement, das über die eigentliche Geschäftstätigkeit des Unternehmens hinausgeht, während Corporate Social Responsibility sich auf die sozialen und ökologischen Folgen des operationalen Geschäfts selbst bezieht. ${ }^{33}$ Demgegenüber betrachten beispielsweise Wieland oder Thompson Corporate Citizenship als das übergeordnete Konzept. Corporate Social Responsibility ist danach integraler Bestandteil von Corporate Citizenship, wobei sich Corporate Citizenship

28 Lamla: „Politisierter Konsum - konsumierte Politik“, S. $12 \mathrm{ff}$.

29 Gabriel/Lang: The unmanageable comsumer, S. 156.

30 Vgl. Lamla: „Politisierter Konsum - konsumierte Politik“; Baringhorst: „Keine Reizwäsche aus Burma“.

31 Palacios: „Corporate citizenship and social responsibility in a globalized world“, S. 393.

32 Vgl. z.B. Lang/Solms: Geschäftsstrategie Verantwortung.

33 Vgl. Westebbe/Logan: Corporate Citizenship, S. 17; Backhaus-Maul/Schubert: „Untrnehmen und Konsumenten“, S. 78f. 
nicht in Corporate Social Responsibility erschöpft, da das Konzept der Unternehmensbürgerschaft auch den Anspruch auf die Mitgestaltung politischer und gesellschaftlicher Rahmenbedingungen beinhaltet. ${ }^{34}$

Historische Entwicklung sowie Ursachen und Auswirkungen des bürgerschaftlichen Engagements von Unternehmen und Verbrauchern stehen im Mittelpunkt verschiedener Beiträge des Sammelbandes. So skizziert Rademacher mit der Initiative Wissensfabrik ein von verschiedenen Unternehmen getragenes Bildungsprojekt und Holler stellt mit Fairtrade eine zentrale Institution zur Unterstützung des Consumer Citizen vor. Daneben thematisieren weitere Beiträge die Interaktion zwischen Unternehmen und Konsumenten bzw. Nichtregierungsorganisationen oder globalisierungskritische Bewegungen, die als Initiatoren, Unterstützer und Prüfer des bürgerschaftlichen Engagements von Unternehmen agieren. Dementsprechend beleuchten beispielsweise Löding u.a. aus der Sicht von Attac die Dynamik konzernkritischer Kampagnen und verantwortungsvollen Konzernhandelns.

Diskussionswürdig ist weiterhin - in Anlehnung an die bereits zuvor behandelte Gemeinwohlorientierung von Bürgerschaft - die Frage, inwiefern eigennutzorientierte Motive von Konsumenten und Unternehmen als bürgerschaftliches Handeln dieser Akteure verstanden werden können. Micheletti bezieht sich etwa auf Burtt, um auch Konsumentscheidungen, die aus Eigennutz gefällt werden, den Glanz des Tugendhaften zu geben, sofern sie im Effekt gemeinwohlorientierten Zielen wie etwa dem Erhalt des ökologischen Gleichgewichts oder der gesunden Ernährung dienen. ${ }^{35}$ Die von Burtt vorgeschlagene Unterscheidung zwischen öffentlichen und privaten Tugenden ließe sich vom Consumer Citizen auch auf den Corporate Citizen übertragen, bei dem das soziale Engagement weniger primäres Motiv als sekundäre Folge systemrationalen Denkens ist. Ähnlich wie Rosenkrands in der Verschmelzung der Rollen von Konsumenten und Bürgern einen neuen Idealtyp als Mischung zwischen „Homo economicus“ und „Homo politicus“36 sieht, wird auch Corporate Citizenship vielfach als „strategische Verknüpfung von Unternehmens- und Gemeinwohlinteressen“37 verstanden. Sind Konsum oder gesellschaftliche Verantwortungsübernahme tatsächlich auch dann ethisch und gar eine Tugend oder ein Ausdruck einer Gemeinwohlorientierung, wenn sie rein individuellen Nutzeninteressen entspringen? Inwiefern spielen - teilweise kaum zu überprüfende - Handlungsmotive überhaupt eine Rolle in der Beur-

34 Vgl. Wieland: „Corporate Citizenship“, S. 17; Thompson: „Global Corporate Citizenship“, S. 138ff.

35 Vgl. Micheletti: Political virtue and shopping, S. $20 \mathrm{ff}$.

36 Rosenkrands: „Policizing Homo economicus“, S. 59.

37 Backhaus-Maul: „Corporate Citizenship im deutschen Sozialstaat“, S. 27. 
teilung der ethischen Qualität individuellen oder korporativen Verhaltens? In den Einzelbeiträgen des Bandes spricht unter anderem Lukas das strategische Kalkül von Unternehmen an, selbstinitiativ menschenrechtliche Verantwortung zu übernehmen. Beetz macht demgegenüber auf die Problematik aufmerksam, Konsumentenmotive zu dechiffrieren und zwischen ökonomisch vermittelter Distinktion und politisch motivierter Aktion zu unterscheiden.

Ethisch motivierte Konsumhandlungen des Consumer Citizen und die Demonstration gesellschaftlicher Verantwortungsübernahme durch den Corporate Citizen sind gleichermaßen Phänomene, die darauf hindeuten, dass sich die klassischen Vorstellungen einer kategorialen Trennung bzw. Trennbarkeit zwischen Eigennutz und Gemeinwohl, partikularistischen und universalistischen Interessen im Zeichen einer zunehmend individualisierten und kommerzialisierten Welt nicht mehr aufrecht erhalten lassen. Das Wesen dieses zwischen Eigennutz und Gemeinsinn gelagerten Engagements hat Berking vor einigen Jahren prägnant mit dem Begriff des „solidarischen Individualismus“"38 zum Ausdruck gebracht. Darüber hinaus erscheinen jeder private Akt des Konsums und jedes Produkt bzw. privatwirtschaftliche Unternehmen als prinzipiell moralisch aufladbar und zwar im negativen wie im positiven Sinne. Dies verdeutlichen einerseits Ratgeber wie Shopping bilft die Welt verbessern ${ }^{39}$ als Vorbild moralischer Tugendhaftigkeit und andererseits Publikationen wie das Schwarzbuch Markenfirmen ${ }^{40}$ als Spiegel moralischen Versagens.

\section{Medienumbrüche und bürgerschaftliches Engagement}

Medientechnologischen Umbrüchen kommt in Bezug auf den Wandel des Bürgerbegriffs allgemein sowie im Hinblick auf die Politisierung des Konsums und die Verbreitung von Konzepten gesellschaftlicher unternehmerischer Verantwortung im Besonderen hohe Bedeutsamkeit zu. Vor dem Hintergrund sich wandelnder Medientechnologien stellt sich die Frage, inwiefern bürgerschaftliches Engagement via Medien entfaltet werden kann und inwieweit die Veränderung der medialen Umwelt auf die Vermittlung bürgerschaftlicher Verantwortung zurückwirkt. Theoretisch bedeutsam ist in diesem Kontext vor allem die Frage nach den Interdependenzen zwischen der oben erläuterten Entgrenzung privater und öffentlicher Sphären im politisierten Konsum sowie im bür-

38 Berking: „Solidarischer Individualismus“.

39 Grimm: Shopping hilft die Welt verbessern.

40 Werner/Weiss: Schwarzbuch Markenfirmen; dies.: Das neue Schwarzbuch Markenfirmen. 
gerschaftlichen Engagement von Unternehmen auf der einen und im Bereich der medialen Kommunikation auf der anderen Seite.

Folgt man den Überlegungen von Jürgen Habermas zum Strukturwandel von Öffentlichkeit ${ }^{41}$ oder auch von Richard Sennett zum Verfall und Ende des öffentlichen Lebens ${ }^{42}$, so ist massenmediale Kommunikation durch eine zunehmende gegenseitige Durchdringung der öffentlichen und privaten Sphäre gekennzeichnet. Öffentliche Kommunikation ist leitmedienabhängig und korrespondiert daher mit durch Medienumbrüche verursachten Veränderungen: So geht für Habermas in historischer Perspektive die Entstehung einer politischen, kritischen öffentlichen Sphäre mit der Herausbildung des Bürgertums einher, deren unbegrenzte Kommunikation mit dem Aufkommen der Presse und den Massenmedien erheblich eingeschränkt und refeudalisiert wird. Sennett sieht den Grund für Verfall und Ende des öffentlichen Lebens in einer Selbstversunkenheit der Gesellschaft. Privatheit und die Beschäftigung mit dem eigenem Leben und den eigenen Gefühlen werden zum Selbstzweck erhoben. Konsequenz sei, dass auch öffentliche Angelegenheiten auf der Basis von Gefühlsregungen betrieben werden. ${ }^{43}$

Tendenzen zur Privatisierung des Politischen werden in Deutschland vor allem mit der Einführung des dualen Rundfunksystems beschleunigt und verstärkt. Mit der Zunahme privater Rundfunk- und Fernsehsender vervielfachen sich seit den 1980er Jahren die Möglichkeiten werblicher Kommunikation und Prozesse der Kommerzialisierung von Medien treten verstärkt hervor. Damit werden wesentliche Grundlagen für die symbolische Aufladung von Konsum im Allgemeinen wie für die politische Aufladung von Konsum im Besonderen geschaffen. Verbunden mit einer seit dem so genannten Wirtschaftswunder der 1950er und 1960er Jahre unter dem Stichwort der Überflussgesellschaft kritisch kommentierten Ausdehnung des Konsums auf breite Konsumentenschichten und einer im Zuge gesellschaftlicher Modernisierungsprozesse fortschreitenden Enttraditionalisierung und Individualisierung erhält der private Konsums eine zunehmende Bedeutung für die individuelle wie kollektive Identitätsfindung. Im kulturellen Kapitalismus, ein Ausdruck von Rifkin, ${ }^{44}$ sind

41 Habermas: Strukturwandel der Öffentlichkeit.

42 Sennett: Verfall und Ende des öffentlichen Lebens.

43 Der Zerfall des öffentlichen Lebens hat für ihn zudem auch Konsequenzen für das Private. Die Welt intimer Beziehungen verliere alle Grenzen, weil das Persönliche in öffentlichen Angelegenheiten gesucht werde. In diesem Prozess sind für Sennett die elektronischen Medien Radio und Fernsehen einer der Faktoren, die das öffentliche Leben zerfallen lassen. Hier manifestiere sich in der Passivität der Rezeption das Schweigen. Auch wird das Paradoxon von Sichtbarkeit und Isolation deutlich: „Man sieht mehr und interagiert weniger.“ Ebd., S. 359.

44 Vgl. Rifkin: Access - das Verschwinden des Eigentums. 
wir, welche Musik wir hören, welche Marken und Kleidungsstile wir tragen oder allgemein formuliert: Wir sind, was wir konsumieren. Das Image einer Ware ist zu seinem realen Gebrauchswert geworden. ${ }^{45} \mathrm{Im}$ Beitrag von Lamla wird in diesem Sinne die Frage aufgeworfen, ob nicht ein Autonomieverlust für Verbraucher entsteht, wenn Massenmedien und Werbung zur Entgrenzung von politischen und ästhetisch-expressiven Wertfragen führen. Die kulturelle Aufladung des Konsums hat auch für die Unternehmen durchaus ambivalente Folgen. Einerseits können sie durch gezielte Markenbildung und Konsumversprechungen Gewinnvorteile erzielen, andererseits gilt für sie das Gleiche, was die politische Kommunikationsforschung auch schon für politische Wahlversprechen der Parteien festgestellt hat. Werden Versprechungen nicht eingehalten, wird die Marke als bloß inszeniert und das Vertrauen der Käufer als nur erschlichen entlarvt, kann der Kunde häufig ohne Kosten die Exit-Option $^{46}$ wählen, sofern vergleichbare Produkte anderer Anbieter auf dem Markt verfügbar sind. Die Verbindung zwischen Produkt und Image ist insofern permanent davon bedroht, dass Konsumenten ihre Zustimmung und Identifikation verweigern und sich anderen Produkten und Unternehmen zuwenden. Die gewachsene Reflexivität des Konsums, d.h. die gewachsene Souveränität des Verbrauchers, Informationen über Waren- und Dienstleistungsangebote einzuholen und Imageversprechungen kritisch zu hinterfragen, bildet die lebensweltliche Grundlage für die zunehmende Politisierung des Konsums und die damit verbundene Einführung von Aspekten wie Menschenrechten, ökologischen Überlebensfragen oder sozialen Gerechtigkeitsforderungen in die Verteilung der Güter und Dienstleistungen.

Dabei erfordert die Selektions- und Inszenierungslogik des Mediensystems von zivilgesellschaftlichen und Wirtschaftsakteuren zugleich Anpassungsleistungen, die mehr sind als bloße Verpackung und tief in die inhaltlichen Zielsetzungen und Handlungsdynamiken der Akteure hineinwirken. So weist beispielsweise der Beitrag von Hubbertz darauf hin, dass auch kirchliche Kommunikation Anpassungsleistungen an massenmediale Selektionslogiken vollbringen muss und dem vor allem durch das Fernsehen eingeläuteten iconic turn unterlegen ist. Die vom Autor initiierte Kampagne Arm sein ist Geil nutzte mit der Umdeutung der Werbebotschaft des Elektronikhändlers Saturn, Geiz ist Geil, die Strategie der ironischen Intervention, um medienwirksam auf die Folgen des Sozialabbaus im Zuge der Agenda 2010 hinzuweisen (vgl. Abbildung 1).

45 Vgl. Baringhorst: „Keine Reizwäsche aus Burma“.

46 Vgl. Hirschman: Exit, Voice, and Loyalty. 


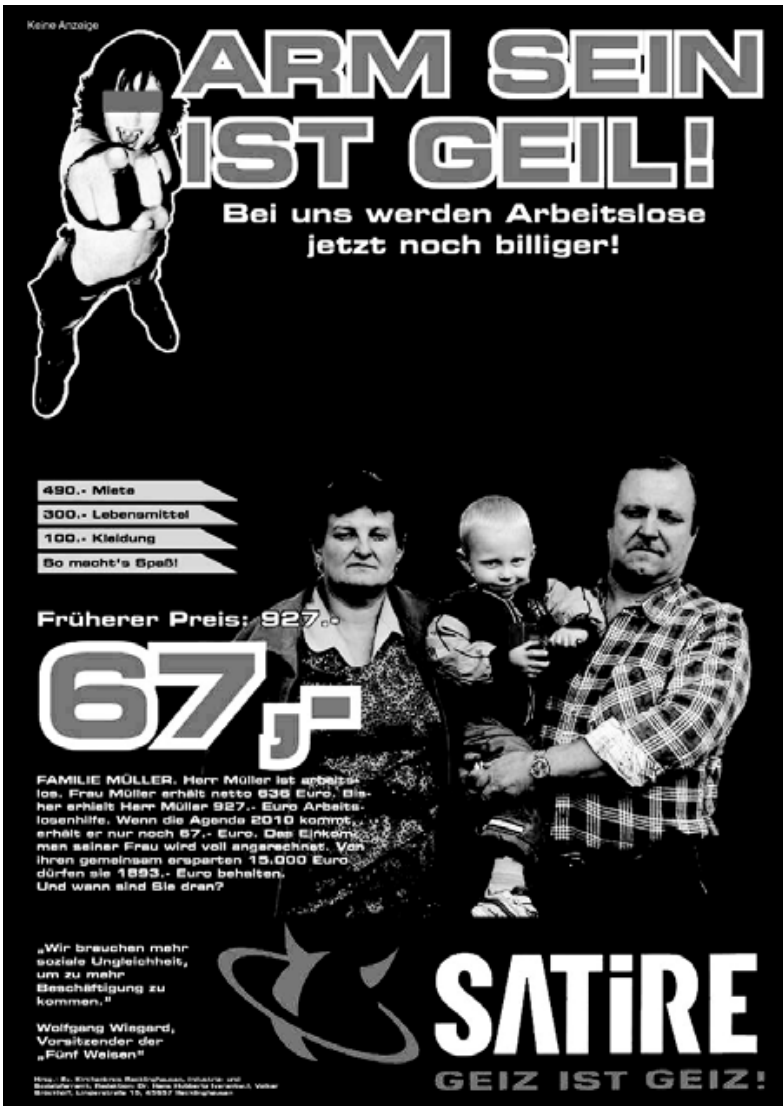

Abb. 1: Arm sein ist geil. ${ }^{47}$

Mit dem Einzug des Internets als jüngstem Medienumbruch werden schließlich sowohl Befürchtungen einer Fragmentierung von Öffentlichkeit in zahllose Teilöffentlichkeiten ${ }^{48}$ als auch Hoffungen einer Revitalisierung (inter)aktiver Bürgerschaft verbunden, ${ }^{49}$ welche schließlich in relativierenden Aussagen wie der folgenden zusammengeführt werden:

47 Quelle: Kommunisten Online: „Die Kirche kuscht vor dem Metro-Konzern“. Die Urheber der Kampagne stimmten auf Druck des Unternehmens einer Unterlassung der Weiterverbreitung der Bilder zu. Näheres zur Kampagne im Beitrag von Hubbertz in diesem Band.

48 Vgl. z.B. Hasebrink: „Politikvermittlung im Zeichen individualisierter Mediennutzung".

49 Vgl. z.B. Pendakur/Harris: Citizenship and Participation in the Information Age. 
Die Nutzung des Internet hat die Kommunikationszusammenhänge zugleich erweitert und fragmentiert. Deshalb übt das Internet zwar eine subversive Wirkung auf autoritäre Öffentlichkeitsregime aus. Aber die horizontale und entformalisierte Vernetzung der Kommunikationen schwächt zugleich die Errungenschaften traditioneller Öffentlichkeiten..$^{50}$

Während also die Kommerzialisierung der Medien die Verführungsmacht der Unternehmen steigert, trägt die fortschreitende Digitalisierung der Medien im Sinne der oben genannten horizontalen Vernetzung nicht nur zur Vervielfältigung von Selbstdarstellungschancen kommerzieller Unternehmen als Bürger bei. Vor allem die Einführung des Internets ist wesentlich verantwortlich für die Stärkung der Macht der Konsumenten im Verhältnis zur Macht der Unternehmen im Allgemeinen wie zur Stärkung der Verbraucher organisierenden und mobilisierenden Macht von Nichtregierungsorganisationen im Besonderen. „Wie habt ihr das alles recherchiert?" , geben die Autoren des neuen Schwarz̧buchs Markenfirmen eine häufig gestellte Leserfrage wieder. Ihre schlichte Antwort: „Vor allem mithilfe des Internet“. „Das Internet, das den Weltmarkt beschleunigt hat, ist gleichzeitig die stärkste Waffe der Konzernkritik“. ${ }^{51}$ Der Beitrag von Conrad und Diehl in diesem Band verdeutlicht, dass das Internet auch die mediale Komplexität für Unternehmens- und Produktmarken erheblich gesteigert hat. Aktive Konsumenten-Produzenten schränken die Kontrollfähigkeit von Markeninhabern über das Image ein. Auch werden, so die These der Autoren, Online-Dialogformen mit den verschiedenen Stakeholdern zunehmend wichtiger, um die steigende Bedeutung gesellschaftlicher Themen für die Unternehmenskommunikation aufzunehmen. Des Weiteren betont der Beitrag von Köhler die Bedeutung von Internetkommunikation für den Kontext unternehmerischer Krisen. Zusammengenommen weisen diese Beiträge darauf hin, dass zwar dezentrierte Teilöffentlichkeiten herausgebildet werden, diese allerdings durch wechselseitige Beobachtung miteinander verbunden bleiben. Auch zeigen unsere Analysen von Anti-Corporate Campaigns im deutschsprachigen Raum, dass das Internet, wenn es zum bürgerschaftlichen Engagement genutzt wird, weniger zum Ausdruck und Austausch individueller privater Meinungen dient, sondern vielmehr zur Anreicherung öffentlicher Debatten mit fachspezifischen Hintergrundinformationen und zur Darstellung kollektiven Protests. Der Beitrag von Baringhorst, Kneip und Niesyto in diesem Band verdeutlicht darüber hinaus, dass sich Leitmedien zivilgesellschaftlicher Protestakteure und der Stellenwert einer Politik mit dem Einkaufswagen seit den

50 Habermas: „Preisrede anlässlich der Verleihung des Bruno-Kreisky-Preises“.

51 Werner/Weiss: Das neue Schwarzbuch Markenfirmen, S. 12, 49. 
1960er Jahren gewandelt haben und stützt so die These, dass Medienumbrüche für die Politisierung des Konsums bedeutsam sind. Der Wandel des allgemeinen Verständnisses von Bürgerschaft sowie der empirisch nachprüfbaren Formen bürgerschaftlichen Engagements ist eng mit Prozessen des Medienwandels, wie sie durch die Einführung und Verbreitung privater Rundfunkmedien oder die Einführung und Verbreitung des Internets erzeugt werden, verbunden.

\section{$4 \quad$ Zu den Beiträgen dieses Bandes}

Politik mit dem Einkaufswagen ist ein vielschichtiges Phänomen, welches nur aus interdisziplinärer Perspektive adäquat erfasst werden kann. Ziel des Sammelbandes ist es, eine Neubestimmung des Bürgerbegriffs und seine Anwendung auf Phänomene politisierten Verbraucherverhaltens sowie sozialverantwortlichen, gemeinwohlorientierten Unternehmerverhaltens aus unterschiedlichen Perspektiven vor dem Hintergrund der Entstehung einer globalen Mediengesellschaft kritisch zu beleuchten. Um ein breites Spektrum an Sichtweisen repräsentieren zu können, wurden dazu Beiträge von Vertreterinnen und Vertretern aus Politik-, Rechts-, Wirtschaftswissenschaft und Soziologie berücksichtigt. ${ }^{52}$ Im Sinne der Einsicht Kants, wonach Begriffe ohne Anschauung blind und Anschauungen ohne Begriffe leer sind, soll einerseits die Bedeutung des Bürgerbegriffs in Konzepten von Consumer (erster Teil) und Corporate Citizenship (zweiter Teil) diskutiert, andererseits aber auch die soziale und politische Wirklichkeit untersucht werden, auf welche diese Begriffe verweisen (dritter Teil).

Im ersten Teil des Bandes richtet sich der Blick auf politischen Konsum und die Rolle des Verbrauchers. Am Beispiel der Kampagne Echt gerecht. Clever kaufen, welche vom Bundesministerium für Ernährung, Landwirtschaft und Verbraucherpolitik getragen wurde, diskutiert der Beitrag von Veronika Kneip

52 Der Band greift dabei unter anderem auf Beiträge zum Workshop Konsumenten und Unternehmen als Bürger. Bürgerschaft als politische Dimension des Marktes vom 9. November 2006 zurück. Das Projekt Protest- und Medienkulturen im Umbruch. Transnationale Corporate Campaigns im Zeichen digitaler Kommunikation des von der Deutschen Forschungsgemeinschaft geförderten Forschungskollegs Medienumbrüche an der Universität Siegen hatte Wissenschaftler unterschiedlicher Disziplinen und Praktiker aus NGOs dazu eingeladen, die Frage zu diskutieren, wieweit Konzepte von Bürgerschaft auf Verbraucher und Unternehmen anwendbar sind. An dieser Stelle sei den studentischen Hilfskräften Franziska Liebig, Henrike Libal, Kerstin Rothe und Anne-Katrin Schade für ihre Unterstützung gedankt. Ein besonderer Dank gilt zusätzlich Henrike Libal für ihre wertvolle Arbeit an diesem Band. 
und Johanna Niesyto politischen Konsum und Kampagnenpolitik als mögliche Instrumente für Nationalstaaten, um den Herausforderungen der globalisierten Politik begegnen zu können. Insbesondere im Bereich der Verbraucherpolitik sieht sich der Nationalstaat mit dezentralen, länderübergreifenden Organisationsstrukturen und wenig transparenten, über lange Wertschöpfungsketten verteilten Produktionsprozessen multinationaler Unternehmen konfrontiert, die einen (pro-)aktiven Verbraucherschutz erschweren. Auch der Beitrag von Michael Beetz setzt sich mit Fragen von Steuerung mittels Kampagnenpolitik und politischem Konsum auseinander. Er hinterfragt idealtypische Modelle einer politischen Beeinflussung der Wirtschaft durch die sanfte Macht der Verbraucheröffentlichkeit. Dagegen steht bei Jörn Lamla nicht die Frage nach Kollektivierungsprozessen im Vordergrund, sondern die Figur des Consumer Citizen. In seinem Theorieentwurf versucht Lamla sowohl auf mikro- als auch auf makrosozialer und kultureller Ebene der Autonomie des Verbrauchers nachzuspüren. Dabei wird die Perspektive der Politisierung des Konsums um den Aspekt der konsumistischen Haltung von Bürgern gegenüber dem politischen Gemeinwesen und der staatlichen Politik erweitert. Während sich die zuvor genannten Beiträge mit politischem Konsum per se auseinandersetzen, befassen sich die weiteren Beiträge dieses Teils mit den Wechselbeziehungen globaler Mediengesellschaft und Protestkulturen, die das Phänomen des politischen Konsums aufgreifen. So versucht der Beitrag von Sigrid Baringhorst, Veronika Kneip und Johanna Niesyto aus einer historisch-vergleichenden Perspektive nachzuzeichnen, wie sich Protestkulturen im Zuge veränderter Medienkonzepte und -projekte gewandelt haben. Am aktuellen Beispiel der AttacKampagne gegen Lidl wird illustriert, wie sich die Ansprache von Bürgerkonsumenten im Sinne einer diskontinuierlichen Entwicklung mit systemkritischen Deutungsmustern verbindet und dezentrale Mobilisierungsversuche bei gleichzeitiger Beibehaltung der massenmedialen Ausrichtung kampagnenförmigen Protests durch das Internet virtuell gebündelt werden. Ähnlich sieht Sigrid Baringhorst im Internet eine mediale Infrastruktur, welche sowohl von Bedeutung für die Veränderung des Konsumverhaltens als auch für die Entstehung und den Mobilisierungserfolg transnationaler unternehmenskritischer Kampagnen ist. Mit dem Phänomen der kollektiven Identität in Anti-Corporate Campaigns setzt sich schließlich der Beitrag von Annegret März auseinander.

Der zweite Teil des Bandes beschäftigt sich mit Unternehmen als bürgergesellschaftlichen Akteuren. Aus unterschiedlichen Perspektiven werden Fragen von Unternehmensbürgerschaft und unternehmerischer gesellschaftlicher Verantwortung diskutiert. Dabei nimmt Janina V. Curbach eine Abgrenzung der mit Corporate Citizenship verbundenen Begrifflichkeiten vor und differenziert Bedeutungs- und Verwendungszusammenhänge dieses Konzepts. Darüber hinaus verortet sie verschiedene Rollenelemente des Unternehmens als Welt- 
bürger, das sich als Bourgeois und Citoyen, Regierender und Regierter in einem Spannungsfeld ökonomischen Eigeninteresses und ethischer Gemeinwohlorientierung bewegt. Veronika Kneip betrachtet in ihrem Beitrag den legitimationsstiftenden Aspekt von Corporate Citizenship und thematisiert die kommunikative Vermittlung des Bürgerstatus durch Unternehmen. Dabei stellt sie öffentlichkeitsrelevante Faktoren der Dynamik von Corporate-CitizenshipKommunikation und zivilgesellschaftlicher Kritik einer Unternehmensbürgerschaft in den Mittelpunkt ihrer Überlegungen. Die weiteren Beiträge dieses Teils vertiefen Aspekte unternehmerischer Handlungsrepertoires: Tanja Köhler setzt sich in diesem Kontext mit Möglichkeiten der Krisenkommunikation von Unternehmen im Internet angesichts eines zunehmenden Netzaktivismus auseinander und stellt verschiedene netzspezifische Handlungsfelder und Kommunikationsprogramme zur Krisenprävention und Krisenbewältigung dar. Karin Lukas behandelt schließlich die menschenrechtliche Verantwortung von Unternehmen und beleuchtet dabei sowohl direkte als auch indirekte Regulationsmechanismen zur Ahndung von Menschenrechtsverletzungen durch Unternehmen. Diesen Mechanismen der hard laws stellt sie mit Eigeninitiativen von Unternehmen soft laws zur Übernahme menschenrechtlicher Verantwortung gegenüber und illustriert Chancen und Grenzen derartiger Regulierungen.

Im dritten Teil des Bandes kommen Autoren zu Wort, die von ihrer praktischen Erfahrung mit einer Politik mit dem Einkaufswagen berichten. Dabei werden sowohl Perspektiven unternehmenskritischer Kampagnen als auch die Umsetzung und Bewertung unternehmerischer Verantwortung vorgestellt. Hans Hubbertz zeichnet die übergreifenden Zusammenhänge zwischen der Geiz-ist-Geil-Mentalität der Verbraucher und den Folgen des Sozialabbaus im Zuge der Agenda 2010 nach. Der Artikel von Thomas Löding, Kay O. Schulze und Jutta Sundermann setzt sich vor dem Hintergrund ihrer Arbeit für Attac kritisch mit dem Konzept der Corporate Social Responsibility auseinander und zeigt die Probleme und Grenzen dieser Form unternehmerischer Selbstregulierung auf. Die Autoren berichten am Beispiel der Kampagne Lidl ist nicht zu billigen von ihren Erfahrungen mit Konzernkritik und stellen als Gegenentwurf zur Corporate Social Responsibility das Konzept der Corporate Accountability vor. Simon Holler befasst sich in seinem Beitrag mit der Geschichte und den Strukturen des fairen Handels, stellt die Kernelemente des Fairtrade-Standards vor und diskutiert die unterschiedlichen Strategien des Konzepts vor dem Hintergrund der Frage nach dem Einfluss politischen Konsums. Holler kommt zu dem Schluss, dass die Positionierung zur und das Selbstverständnis gegenüber der institutionalisierten Politik die größte Herausforderung an das Fairtrade-Konzept darstellt. Die weiteren Autoren rücken die Perspektive der Umsetzung von Unternehmensverantwortung ins Zentrum ihrer Betrachtungen. Die zunehmende Bedeutung der Diskussion um die Rolle von Unter- 
nehmen in der Gesellschaft sowie Veränderungen medialer Infrastrukturen durch die Entwicklung des Web 2.0 nehmen Christian Conrad und Benjamin Diebl zum Ausgangspunkt ihres Plädoyers für eine dialogorientierte StakeholderKommunikation, die sowohl austausch- also auch aktionsorientiert gestaltet werden kann. Vor dem Hintergrund der Diskussion um Corporate Citizenship stellt der Artikel von Lars Rademacher unternehmerisches Engagement für verbesserte Bildung als zentrales gesellschaftliches Anliegen heraus. Der Beitrag von Antoine Mach thematisiert den EthicalQuote, ein System des Schweizer Unternehmens Covalence zur Messung ethischer Reputation multinationaler Unternehmen. Der Autor und Mitbegründer von Covalence stellt die Idee dieses Systems vor und beschreibt die Vorgehensweise bei der Berechnung des EthikKurses als Ergänzung zum Aktienkurs von Unternehmen.

\section{Literaturverzeichnis}

Backhaus-Maul, Holger: „Corporate Citizenship im deutschen Sozialstaat“, in: Aus Politik und Zeitgeschichte, B 14, 2004, S. 23-30.

Backhaus-Maul, Holger/Schubert, Ingolf: „Unternehmen und Konsumenten. Diffuse Verantwortung und schwache Interessen“, in: Forschungsjournal Neue Soziale Bewegungen, Jg. 18, Nr. 4, 2005, S. 78-88.

Baringhorst, Sigrid: „Keine Reizwäsche aus Burma. Menschenrechte durch politisierten Konsum?‘،, in: Lamla, Jörn/Neckel, Sighard (Hrsg.): Politisierter Konsum - konsumierte Politik, Wiesbaden 2006, S. 233-258.

Bennett, Lance W.: „Communicating global activism. Strengths and vulnerabilities of networked politics“, in: Donk, Wim van de u.a. (Hrsg.): Cyberprotest. New Media, Citizens and Social Movements, London/New York 2004, S. 123-146.

Berking, Helmut: „Solidarischer Individualismus. Ein Gedankenspiel“, in: Ästhetik und Kommunikation, Nr. 85/86, 1994, S. 37-44.

Center for Corporate Citizenship: „Membership“, www.bcccc.net/index.cfm? fuseaction $=$ Page.viewPage\&pageID $=475,06.06 .2007$.

Dickinson, Roger A./Carsky, Mary L.: „The Consumer as Economic Voter“, in: Harrison, Rob u.a. (Hrsg.): The Ethical Consumer, London 2005, S. 25-36.

Gabriel, Yiannis/Lang, Tim: The unmanageable consumer, London 2006.

Garve, Christian: Versuche über verschiedene Gegenstände aus der Moral, der Litteratur und dem gesellschaftlichen Leben, Bd. 1, Breslau 1792. 
Gillmann, Barbara: „Deutschland erlebt Stiftungsboom“, in: Handelsblatt.com, www.handelsblatt.com/news/_pv/_p/200050/_t/ft/_b/1257792/ default.aspx/index.html, 15.05.2007.

Grimm, Fred: Shopping hilft die Welt verbessern, München 2006.

Habermas, Jürgen: „Preisrede anlässlich der Verleihung des Bruno-KreiskyPreises für das politische Buch 2005“, 09.03.2006, www.rennerinstitut.at/download/texte/habermas2006-03-09.pdf, 10.05.2007.

Habermas, Jürgen: Strukturwandel der Öffentlichkeit - Untersuchungen zu einer Kategorie der bürgerlichen Gesellschaft, Darmstadt 1987 [1962].

Hasebrink, Uwe: „Politikvermittlung im Zeichen individualisierter Mediennutzung. Zur Informations- und Unterhaltungsorientierung des Publikums“, in: Sarcinelli, Ulrich (Hrsg.): Politikvermittlung und Demokratie in der Mediengesellschaft, Bonn 1998, S. 359-360.

Hegel, Georg W.: „Philosophie des Rechts, Vorlesungsnachschrift von K.G. v. Griesheim 1824/1825“, in: Ilting, Karl-Heinz (Hrsg.): Vorlesungen über Rechtsphilosophie, Stuttgart-Bad Cannstatt 1974, S. 1818-1831.

Hirschmann, Albert O.: Exit, Voice, and Loyalty. Responses to Decline in Firms, Organizations, and States, Cambridge 1970.

Institut für Markt-Umwelt-Gesellschaft e.V. (Hrsg): „CSR-Informationsbedarf von Verbrauchern. Informations- und Einkaufsverhalten im Kontext von CSR“, imug1.de/pdfs/verbraucher/hp_imug_CSR_Verbraucher_Reprae sentativbefragung_2006_03_16.pdf, 06.06.2007.

Initiative Freiheit und Verantwortung: „Corporate Citizenship“, www.freiheitund-verantwortung.de/2.htm, 06.06.2007.

Kleine-Brockhoff, Thomas: „Philanthropische Republik Amerika“, in: Die Zeit, Nr. 29, 13.07.2006, S. 34.

Kocka, Jürgen: „Das Bürgertum als Träger von Zivilgesellschaft - Traditionslinien, Entwicklungen, Perspektiven“, in: Enquete-Kommission „Zukunft des Bürgerschaftlichen Engagements“ Deutscher Bundestag (Hrsg.): Bürgerschaftliches Engagement und Zivilgesellschaft, Opladen 2002.

Kommunisten Online: „Die Kirche kuscht vor dem Metro-Konzern“, www.kommunisten-online.de/blackchanel/arm_ist_geil.htm, 17.07.2007

Lamla, Jörn: „Politisierter Konsum - konsumierte Politik. Kritikmuster und Engagementformen im kulturellen Kapitalismus“, in: Lamla, Jörn/Neckel, Sighard (Hrsg.): Politisierter Konsum - konsumierte Politik, Wiesbaden 2006, S. 9-37. 
Lang, Susanne/Solms Nebelung, Frank: Geschäftsstrategie Verantwortung. Corporate Citizenship als Business Case (Reihe ,betrifft ${ }^{`}$ Bürgergesellschaft, Nr. 14), Bonn 2005.

Luttgefeld, Anja u.a.: „Unternehmerische Sozialkampagnen - total sozial? Eine Untersuchung am Beispiel der Krombacher Regenwald-Kampagne“, in: Röttger, Ulrike (Hrsg.): PR-Kampagnen. Über die Inszenierung von Öffentlichkeit, Wiesbaden 2006, S. 313-326.

Manheim, Jarol B.: The Death of a Thousand Cuts. Corporate Campaigns and the Contemporary Attack on the Corporation, Mahwah, NJ 2001.

Micheletti, Michele: „Just Clothes? Discursive Political Consumerism and Political Participation." Paper der ECPR Joint Sessions, Workshop „Emerging Repertoires of Political Action“, Uppsala, 14.-18.04.2004.

Micheletti, Michele: Political virtue and shopping. Individuals, consumerism, and collective action, New York 2003.

Münkler, Herfried: „Ehre, Amt und Engagement. Wie kann die knappe Ressource Bürgersinn gesichert werden?" in: Forschungsjournal Neue Soziale Bewegungen, Jg. 13, Nr. 2, 2000, S. 22-32.

Oldfield, Adrian: „Citizenship. An Unnatural Practice?“, in: Turner, Bryan S./Hamilton, Peter (Hrsg.): Citizenship. Critical Concepts, Bd. 1, London/New York 1994, S. 188-198.

Palacios, Juan José: „Corporate citizenship and social responsibility in a globalized world“, in: Citizenship Studies, Nr. 4, 2004, S. 383-402.

Pendakur, Manjunath/Harris, Roma (Hrsg.): Citizenship and Participation in the Information Age, Aurora 2002.

Pocock, John G.A.: „The Ideal of Citizenship Since Classical Time“, in: Beiner, Ronald (Hrsg.): Theorizing Citizenship, Albany, NY 1995, S. 29-52.

Priddat, Birger P.: „Moral als Kontext von Gütern. Choice and Semantics“, in: Koslowski, Peter/Priddat, Birger P. (Hrsg.): Ethik des Konsums, München 2006. S. 9-22.

Riedel, Manfred: „Bürger, Staatsbürger, Bürgertum“, in: Brunner, Otto u.a. (Hrsg.): Geschichtliche Grundbegriffe. Historisches Lexikon zur politischsozialen Sprache in Deutschland, Stuttgart 1972, S. 672-725.

Rifkin, Jeremy: Access - Das Verschwinden des Eigentums. Warum wir weniger besitzen und mehr ausgeben werden, Frankfurt a.M./New York 2000.

Rosenkrands, Jacob: „Policizing Homo economicus. Analysis of anti-corporate websites“, in: Donk, Wim van de u.a. (Hrsg.): Cyberprotest. New Media, Citizens and Social Movements, London/New York 2004, S. 57-76. 
Sennett, Richard: Verfall und Ende des öffentlichen Lebens. Die Tyrannei der Intimität, Frankfurt a.M. 2002.

Stolle, Dietlind u.a.: „Zwischen Markt und Zivilgesellschaft. politischer Konsum als bürgerliches Engagement“, in: Gosewinkel, Dieter u.a. (Hrsg.): Zivilgesellschaft - national und transnational (WZB-Jahrbuch 2003), Berlin 2004, S. 151-171.

Thompson, Grahame F.: „Global Corporate Citizenship. What Does it Mean?“،, in: Competition and Change, Jg. 9, Nr. 2, 2005, S. 131-152.

TransFair e.V./Rugmark (Hrsg.): „Jahresbericht 2006 - Ausblick 2007“, www.transfair.org/fileadmin/user_upload/_PDF_/materialien/zumdown load/download_jahresbericht0607.pdf, 06.06.2007.

Walzer, Michael: „Citizenship“, in: Ball, Terence u.a. (Hrsg.): Political Innovation and Conceptual Change, Cambridge 1989, S. 211-219.

Werner, Klaus/Weiss, Hans: Das neue Schwarzbuch Markenfirmen. Die Machenschaften der Weltkonzerne, Berlin 2006.

Werner, Klaus/Weiss, Hans: Schwarzbuch Markenfirmen. Die Machenschaften der Weltkonzerne, Wien/Frankfurt a.M. 2001.

Westebbe, Achim/Logan, David: Corporate Citizenship. Unternehmen im gesellschaftlichen Dialog, Wiesbaden 1995.

Wieland, Josef: „Corporate Citizenship“, in: Behrent, Michael/Wieland, Josef (Hrsg.): Corporate Citizenship und strategische Unternehmenskommunikation in der Praxis (DNWE-Schriftenreihe 11), München 2003, S. 13-19. 


\section{Michael Beetz}

\section{Verbraucheröffentlichkeit und Bürgerschaft}

\section{Der Wunsch nach einer Politisierung des Konsums}

Wir erleben gegenwärtig ein Zeitalter, in dem die kapitalistische Expansion der Weltmärkte durch eine radikale Globalisierung der Medienwelten nochmals in ihren kulturellen Konsequenzen verschärft und dabei zugleich in sich selbst reflektiert wird. Moderne Kommunikationsmedien wie der Mobilfunk, die Televisions-Übertragung per Satellit oder das Internet bildeten die technische Grundlage für eine weltweite Vernetzung der Informationskanäle. Dabei weitet sich gleichsam auch der öffentliche Blick auf die Welt: Selbst innerhalb der alltäglichsten Kontexte lokaler Lebenspraxis stehen uns die Wissenshorizonte einer komplexen Weltgesellschaft allgegenwärtig vor Augen. Die Effekte eines möglicherweise durch die Industrialisierung herbeigeführten Klimawandels und die Begrenztheit der fossilen Energieressourcen kommen der Öffentlichkeit damit endgültig zu Bewusstsein. Das Gefühl einer ethischen Verantwortlichkeit für die Konsequenzen des westlichen Lebensstandards lässt sich heute augenscheinlich nicht mehr nur als ideologische Distinktionsstrategie einer alternativen Szene interpretieren oder einfach als suggestiver Gestus vereinzelter moralischer Mahner abtun, welche die apokalyptische Vision eines ökologischen Endzeit-Szenarios heraufzubeschwören suchen. Die alten linken Forderungen gegenüber dem kapitalistischen Weltwirtschaftssystem - Menschenrechte global zu respektieren, die Kriterien der ökologischen Nachhaltigkeit zu beachten und die sozialen Existenzgrundlagen der weltweit eingesetzten Lohnarbeitskräfte durch faire Löhne und Arbeitsbedingungen zu gewähren - sind in Europa inzwischen weitestgehend zum Bestandteil eines politischen WerteKanons geworden.

Diese Entwicklung verschafft insbesondere den diese Werte teilenden Bürgern eine ungeahnte wirtschaftliche Definitionsmacht: Als Konsumenten könnten sie die politischen Qualitätseigenschaften der ökonomischen Warenproduktion grundsätzlich in dem Maße beeinflussen, als sie über die Mehrheitsverhältnisse auf der Nachfrageseite bestimmen. Die Forderung nach einer Zivilisierung des Marktes angesichts ökologischer und sozialer Nebenfolgen, die aus der eindimensionalen, instrumentellen Rationalität des ökonomischen Systems erwachsen, bildet daher den gesellschaftspolitischen Hintergrund einer 
aktuellen Debatte über den Zusammenhang von Konsum und Bürgerschaft. ${ }^{1}$ Gesellschaftstheoretischer Klärungsbedarf besteht dabei vor allem bezüglich der Frage, wie man sich die vielfach beschworene Macht des Consumer Citizen überhaupt vorstellen sollte. ${ }^{2}$

Die Besonderheit einer bürgerschaftlich geprägten Politisierung des Konsums lässt sich anhand einer theoretischen Vorüberlegung verdeutlichen. Bezüglich der Gestaltung gesellschaftlicher Zusammenhänge gibt es im Allgemeinen zwei paradigmatische Modelle, durch die insbesondere auch die gesellschaftliche Wirksamkeit sozialwissenschaftlicher Erkenntnisse erklärt werden kann. Diese lassen sich als Steuerung von oben bzw. Steuerung von unten bezeichnen. $^{3}$

Die jeweiligen Vor- und Nachteile beider Paradigmen liegen auf der Hand: Das Modell einer administrativen Steuerung von oben bezieht sich auf eine handlungsfähige Instanz. Im Alltagsverständnis identifiziert man mit der Politik. gemeinhin den Staat als eine historische Errungenschaft, die sich durch Wahlen demokratisch legitimieren muss und die nötige administrative Macht hat, um verbindliche Entscheidungen durchzusetzen. Das Vorhaben einer staatlichen Steuerung der Wirtschaft ist in diesem Zusammenhang allerdings immer schon äußerst strittig gewesen. Markt und Staat erscheinen aus dieser Perspektive als zwei autonome Koordinationsmechanismen. Politik und Wirtschaft sind institutionell klar voneinander zu unterscheiden. Die vorgebrachten Bedenken betreffen daher sowohl die Legitimität von Eingriffen in die marktwirtschaftliche Selbstorganisation als auch deren Effektivität. ${ }^{4}$ Gesellschaftliche Subsysteme wie die Ökonomie sind schlicht zu komplex, um sich in ihren grundlegenden Strukturen durch externe Impulse steuern zu lassen.

Das Modell einer Steuerung von unten trägt dagegen stärker der gesellschaftlichen Eigendynamik Rechnung. Demokratietheoretische Überlegungen führen häufig zu dem Ergebnis, dass eine staatszentrierte Auffassung politischer Koordination keineswegs ausreicht. Zu einer funktionsfähigen Demokratie gehören auch eine kritische Öffentlichkeit, eine politische Kultur und

1 Vgl. z.B. Micheletti u.a.: Politics, Products, and Markets; Lamla/Neckel: Politisierter Konsum - konsumierte Politik.

2 Vgl. auch Lamla in diesem Band.

3 In der Soziologiegeschichte nennt man das erste Modell häufig etwas abfällig Sozialtechnologie, das zweite dagegen Aufklärung. Vgl. auch Kneip und Niesyto in diesem Band für eine Diskussion von Kampagnenpolitik und politischem Konsum als weiche Steuerungsinstrumente des Staates im Kontext von Governancekonzepten.

4 Für eine steuerungspessimistische Position stehen in der Soziologie Autoren wie Herbert Spencer oder Niklas Luhmann. 
eine aktive Zivilgesellschaft. Von einem solchen Standpunkt aus gelangt man daher in der Regel zu einem weiter gefassten Begriff von Politik. Soziale Praxis kann dann per se als politisch erscheinen, sodass letztlich auch die Grenzen zwischen Öffentlichkeit und Privatsphäre unscharf werden und sich die politischen und ökonomischen Aspekte der Gesellschaft miteinander verzahnen. Im Hinblick auf eine interne bürgerschaftliche Selbstorganisation der Gesellschaft besteht allerdings das grundlegende Problem, dass es in der Regel nicht gelingt, die einzelnen Individuen so zu vereinen, dass sie tatsächlich eine Öffentlichkeit im Sinne einer kollektiven Instanz bilden. ${ }^{5}$

Um zu verstehen, wieso man sich mit dem Thema einer bürgerschaftlich engagierten Verbraucheröffentlichkeit beschäftigt, welches sich offensichtlich auf das zweite Modell einer Steuerung von unten bezieht, wäre zunächst zu erklären, warum sich bestimmte unerwünschte Folgen der Marktwirtschaft nicht durch politische Interventionen von oben korrigieren lassen. Mit anderen Worten: Kann man Umweltverschmutzung und Sozialdumping nicht einfach verbieten? Hierzu seien drei Eckpunkte angedeutet: Der Ruf nach einer politisch aktiven Verbraucheröffentlichkeit resultiert nicht selten aus der Feststellung, dass in einem globalisierten Wirtschaftssystem die rechtsstaatlichen Mittel zur Regulierung unerwünschter Markteffekte begrenzt sind. Oftmals mag es auch so erscheinen, als ob die staatliche Regierungspolitik durch das Konkurrieren um die Wählergunst quasi blockiert ist und die Bürger die Probleme deshalb selbst in die Hand zu nehmen hätten. Der Verweis auf solche Formen des Fehlens bzw. faktischen Versagens administrativer Institutionen genügt jedoch nicht. Bestimmte soziale Praktiken bedürfen vielmehr per se einer kulturellen Selbstregulierung. Die Ideale und Werte einer Kultur müssen durch die kollektive Lebenspraxis selbst gefunden und begründet werden.

Im Folgenden soll nun die theoretische Stringenz möglicher Modelle einer politischen Beeinflussung der Wirtschaft diskutiert werden, die auf der sanften Macbt der Verbraucheröffentlichkeit beruhen. Dazu gilt es einerseits genauer zu bestimmen, auf welche spezifische Weise sich hierbei politische und ökonomische Aspekte überlagern, und andererseits, in welcher Form sich dabei tatsächlich eine Öffentlichkeit konstituiert. Anhand solcher Analysen lassen sich dann insbesondere die zentralen Konsequenzen aufzeigen, welche die entsprechenden impliziten Problemdeutungen für die Einschätzung von fak-

5 Die Mehrdeutigkeit der Formulierung ist beabsichtigt, denn die Konstitution einer Öffentlichkeit bereitet sowohl empirische (praktische) als auch konzeptionelle (theoretische) Schwierigkeiten. Insbesondere die an Strukturwandel der Öffentlichkeit (Habermas) anschließende historische Diskussion zeigt, dass die von Habermas untersuchte bürgerliche Öffentlichkeit selbst für das 18. Jahrhundert letztlich nur eine idealtypische Konstruktion darstellt. 
tischen Konsumvorgängen und politischen Kampagnen haben. Das Postulieren von politischen Motiven auf Seiten der Verbraucher legt beispielsweise ein dem Paradigma der politischen Wahl entsprechendes Modell nahe, bei dem es um die demokratische Steuerung der Wirtschaft durch Konsumentscheidungen geht. Die Leitvorstellung einer Interpretation individueller Bedürfnisse vor dem Hintergrund eines kulturell verankerten Selbstverständnisses des guten Lebens führt dagegen zu einem alternativen Modell. Die Verbraucheröffentlichkeit wird dann als eine Instanz begriffen, welche die für entsprechende Konsumpraktiken maßgeblichen Produktimages prägt. Während im ersten Falle Vorstellungen einer positiven politischen Steuerung dominieren, welche durch moralisch verantwortliches Verhalten ermöglicht wird, lässt sich der zweite Fall eher mit einer fundamentalen Kulturkritik des Kapitalismus verbinden, die sich vorrangig auf die gesellschaftliche Definition grundlegender Werte, Ideologien und Lebensentwürfe bezieht. Innerhalb der Diskussion über die Möglichkeiten einer politischen Steuerung des Marktes durch die Verbraucher lassen sich entsprechend eine handlungstheoretische und eine kulturtheoretische Lesart identifizieren. Obgleich sich beide Aspekte in der politischen wie in der sozialwissenschaftlichen Kommunikation in der Regel überlagern, ist es aus analytischer Sicht sinnvoll, sie als idealtypische Modelle strikt voneinander zu unterscheiden.

\section{Zum innergesellschaftlichen Verhältnis von Politik und Ökonomie}

Phänomene der ökonomischen oder politischen Durchdringung gesellschaftlicher Lebenszusammenhänge bilden häufig den Kern kritischer Zeitdiagnosen $^{6}$, wobei Ökonomisierungserscheinungen typischerweise als Bedrohung empfunden und daher negativ bewertet werden, Tendenzen der Politisierung sich dagegen vielfach als rationale oder gar notwendige Reaktion interpretieren lassen und daher eher als wünschenswert gelten. Es mag hier zunächst ausreichen, sich mit dieser recht pauschalen Feststellung zu begnügen und auf eine differenziertere Analyse der entsprechenden soziologischen Ansätze zu verzichten. Worauf es an dieser Stelle ankommt, ist der schroffe Kontrast, in dem solche Beobachtungen zu gesellschaftstheoretischen Konzepten der funktiona-

6 Es sei nur stichwortartig auf Begriffe wie Kulturindustrie (Horkheimer/Adorno), Kulturkonsum bzw. Kolonialisierung der Lebenswelt (Habermas), Zivilgesellschaft (Gramcsi), life politics (Giddens), usw. verwiesen. Für eine Diagnose in Richtung Ökonomisierung vgl. beispielsweise Neckel: „,Leistung“ und ,Erfolg““, für eine politisierende Perspektive vgl. Stäheli: Sinnzusammenbrüche. 
len Differen₹ierung stehen. Zwar halten Differenzierungstheorien eigene Gegenbegriffe zur systematischen Erfassung von Durchdringungsphänomenen bereit. ${ }^{7}$ Dennoch beinhaltet der begriffliche Gegensatz von Differenzierung und Diffusion eine grundsätzliche Problematik, die sich insbesondere in der Systemtheorie Niklas Luhmanns aufgrund der paradigmatischen Annahmen über die Geschlossenheit sozialer Systeme nach Ansicht zahlreicher theorieexterner Beobachter zu einer unrealistischen Dogmatik verschärft. Theoretische Konsequenz scheint hier empirische Inadäquanz zur Folge zur haben, d.h. logische Präzision und diagnostische Schärfe würden sich dann wechselseitig ausschließen. ${ }^{8}$ Wie sich gerade am Thema des politisierten Konsums zeigen lässt, kann jedoch das Konzept der funktionalen Differenzierung für eine kritische Gesellschaftsdiagnose sehr wohl von Wert sein, wenn es als erkenntniserweiternde Heuristik ernst genommen und dann durch souveräne Interpretationen ergänzt wird.

Wirtschaft und Politik sind zweifellos zwei unterschiedliche gesellschaftliche Felder. Nicht, dass es keine Überlappungen gäbe. Nicht, dass eine klare Arbeitsteilung zwischen politischer Soziologie auf der einen und Wirtschaftssoziologie auf der anderen Seite die gesellschaftlichen Gegenstandsfragmente restlos zuzuteilen vermöge. Die Phänomene der gegenseitigen Durchdringung beider Sphären bilden jedoch für die Gesellschaftstheorie in besonderem Maße eine analytische Herausforderung, weil sich hier begriffliche Differenzierung und lebenspraktische Diffusion multipler Kontexte diametral gegenüberstehen, wobei Theorie und Praxis gewissermaßen in der Sache selbst miteinander konfrontiert werden. Dies gilt zumal dort, wo sich die Verschränkung von Ökonomie und Politik jenseits der formal organisierten Expertensysteme vollzieht, denn in der Peripherie des Publikums (der Zivilgesellschaft, des Volkes) konvergieren die durch spezielle Institutionen betreuten unterschiedlichen gesellschaftlichen Sinnzusammenhänge ohnehin. Bürger, Verbraucher, Gemeindemitglieder, Patienten, Leser und Zuschauer werden letztlich in Personalunion durch einen alten Bekannten der Soziologie verkörpert: das Individuum. Wie also lässt sich das innergesellschaftliche Verhältnis von Politik und Ökonomie

7 So unter anderem Interpenetration (vgl. Münch: Dialektik der Kommunikationsgesellschaft), Integration (vgl. Parsons: Das System moderner Gesellschaften) oder strukturelle Kopplung (vgl. Luhmann: Die Gesellschaft der Gesellschaft). Die hier anschließende Diskussion ist breit gefächert. In jedem Falle erlauben solche Begriffe eine Immunisierung gegenüber externer Kritik, da sie eine empirische Widerlegung der Differenzierungshypothesen weitestgehend ausschließen.

8 Vgl. zu der diesbezüglichen Problemlage Teubner, der aus historischen Gründen für das Rechtssystem eine Gradualisierung des Autopoesisbegriffs vorschlägt. Vgl. Teubner: Recht als autopoietisches System. 
analytisch so präzisieren, dass es die empirischen Wechselwirkungen zwischen beiden Bereichen in angemessener Weise zu berücksichtigen gestattet?

Obgleich Verwaltungsbürokratie und Betriebswirtschaft ähnliche Strukturen formaler Organisation aufweisen, ergießen sich ökonomische bzw. politische Operationen doch in jeweils deutlich voneinander verschiedene organisatorische Kanäle. Heften ökonomische Sinnbezüge sich an Banken und Unternehmen, so beziehen sich politische Erwartungen auf Regierungen und Parteien. Geht es im ökonomischen Kalkül primär um Kategorien wie Arbeit, Verwertung und Vermarktung, so in der politischen Logik um Gemeinwohl, Herrschaft und demokratische Legitimation. Beide Bereiche unterscheiden sich signifikant in Karrierewegen und spezifischem Habitus. Folgt man der systemtheoretischen Sichtweise, so operiert die Wirtschaft in der Form von Zahlungen im Medium des Geldes und richtet sich dabei nach dem Markt, die Politik orientiert sich an der öffentlichen Meinung und manifestiert sich im Medium der Macht.

Bis hierhin dürfte sich die differenzierungstheoretische Lesart von Gesellschaft weitestgehend mit dem soziologischen common sense decken. Heikler wird es bei der Frage nach der Stellung des Bürgers bzw. Verbrauchers. Gilt der Konsum üblicherweise als Privatangelegenheit, so ist die Rolle des Bürgers an die Konstitution einer zivilgesellschaftlichen Öffentlichkeit gebunden. Mit anderen Worten: Privat tritt man der Gesellschaft als Konsument, in der Öffentlichkeit tritt man ihr als Bürger gegenüber. Die Unterscheidung zwischen privaten Wirtschaftsakteuren auf der einen und politischer Öffentlichkeit auf der anderen Seite bleibt jedoch zu einfach. Ein Grund hierfür ist, dass auch die Verbraucher in einem spezifisch ökonomischen Sinne eine Öffentlichkeit bilden. ${ }^{9}$ Für die Vermarktung ihrer Produkte muss die Wirtschaft eine gewisse öffentliche Transparenz herstellen, in die insbesondere auch die Konsumenten mit einbezogen sind. Hersteller und Verbraucher treten sich - vermittelt über den Handel - am Markt gegenüber, wo Preise, Qualitätsstandards und die Bedürfnisse der Verbraucher wechselseitig gegeneinander abgeglichen werden. Die Produzenten müssen dazu ihre Abnehmer in ihren typischen Gewohnheiten und Erwartungen kennen.

Auch die Verbraucher orientieren sich an ihresgleichen, und der eine schaut dem anderen schon mal in den Warenkorb. Dass die Werbung versucht, die Bedürfnisse zu manipulieren, ist kaum zu bestreiten. Produkte werden als kulturelle Bedeutungsträger ${ }^{10}$ vermarktet und wirken dabei auf die

9 Vgl. unter Gender-Gesichtspunkten Bernold/Ellmeier: „Konsum, Politik und Geschlecht".

10 Vgl. Heubach: „Produkte als Bedeutungsträger“. 
repräsentierten Lebensstile zurück. ${ }^{11}$ Auch wenn der Verbraucher seine Bedürfnisse nur vor dem Hintergrund des verfügbaren Angebots bestimmen kann ${ }^{12}$ und die Werbung erzieherische Funktionen beinhaltet ${ }^{13}$, vermag sie doch die Orientierungen des Konsumenten niemals kausal zu determinieren. Das Verhältnis zwischen Kultur und Produktimage ist vielmehr zirkulär zu verstehen ${ }^{14}$, und die Kaufentscheidung trifft letztendlich nach wie vor der Käufer. Der Verbraucher gewinnt aus dieser Konstellation eine nicht zu unterschätzende Macht. Er verfügt über diese Macht aber nicht als privater Einzelner, sondern allein als generalisierter Anderer des Wirtschaftssystems. Die Herausbildung ökonomischer Lebensstandards und kulturell verankerter Qualitätszuschreibungen an unterschiedliche Produktarten, auch der Ruf einer Marke oder einer ganzen Sparte obliegt somit der Verbraucheröffentlichkeit.

Diese Verbraucheröffentlichkeit ist aber nicht kurzschlüssig mit der zivilgesellschaftlichen Öffentlichkeit der Politik gleichzusetzen. Da die Ökonomie die Verknüpfung von materiellem Genuss und Lebensstil geradezu fordert, indem sie die distinguierenden Eigenschaften der Marke hervorkehrt, kann die Berücksichtigung sozialer und ökologischer Produktionsbedingungen und der regionalen Herkunft eines Produktes von Seiten des Konsumenten noch nicht per se als politischer Akt gelten. Ein mit sozialen Bezügen aufgeladenes Produktimage bedeutet nicht unbedingt eine Politisierung des Konsums an sich, selbst wenn es sich bei dem Produkt beispielsweise um ein politisches Buch oder ein Che-Guevara-Poster handelt. Anders verhält es sich womöglich, wenn Konsumentscheidungen als politisch zelebriert werden und explizit durch kollektive Ambitionen der Wirtschaftssteuerung von unten motiviert sind, etwa bei moralisch hochgradig aufgeladenen Boykottaktionen. ${ }^{15}$ Die Grenzen sind allerdings wie so oft fließend, und es fällt daher nicht leicht zu entscheiden, ob es sich im Einzelfall um ökonomisch vermittelte Distinktion oder um eine politisch motivierte Aktion handelt, zumal die Motive der Konsumenten nur schwer zu dechiffrieren sind.

Wirtschaft und Politik sind ökonomisch gesehen vor allem über Steuergelder, aus politischer Sicht über den Zusammenhang von Wirtschaftspolitik

11 Vgl. Hölscher: Lebensstile durch Werbung.

12 Eine zentrale Vermittlerrolle bei der Etablierung neuer Produkte am Markt spielt auch der Einzelhandel, der die Produkte schließlich in die Regale stellen muss. Da die verschiedenen Händler aber um Kunden konkurrieren müssen, richtet sich die Angebotspalette gleichwohl an der anvisierten Konsumentengruppe aus.

13 Vgl. Hellmann: Soziologie der Marke, S. 365ff.; Luhmann: Die Realität der Massenmedien.

14 Vgl. Hellmann/Schrage: Konsum der Werbung.

15 Vgl. Friedman: Consumer Boycotts. 
und politischer Machterhaltung miteinander verzahnt. Die jüngste Debatte über die Offenlegung der Nebenverdienste von Politikern zeigt einmal mehr die massiven politischen Kontakte der ökonomischen Lobby. Auch vom sozialen Alltagsleben aus gesehen liegt der Zusammenhang von Politik und Wirtschaft klar vor Augen. Da berufliche Ausbildung und Arbeitsleben im Zentrum der biographischen Entwicklung stehen, rangiert deren gemeinwohlorientierte Regulierung, was die inhaltliche Rangordnung der öffentlichen Belange betrifft, an Nummer eins, wenn man die Sicherung des staatlichen Gewaltmonopols und der rechtsstaatlichen Verfolgung von Verbrechen einmal als Voraussetzung politischer Gestaltung überhaupt unterstellt. Die Programme der Wirtschafts- und Sozialpolitik sind unter anderem zur Kompensation ökonomischer Mechanismen der Differenzverstärkung notwendig, da diese soziale Ungleichheiten erzeugen, die nicht einmal mehr durch Leistungskriterien gerechtfertigt werden können. An dieser Problemstelle greifen vor allem die groBen Sozialversicherungssysteme ein und gewähren soziale Sicherheit in Form von medizinischer Versorgung, Arbeitslosengeld und Altersrente. Bestimmte, grundsätzlich ökonomisch verfasste Leistungen sind darüber hinaus offenbar nicht effektiv marktwirtschaftlich auf die Leistungsabnehmer zuzurechnen, sondern bleiben an gemeinwohlorientierte Kalküle gebunden. Traditionell gehören hierzu Bereiche wie Kultur, Bildung und Landwirtschaft, sowie Verkehrs- und Kommunikationsnetze. Die in den letzten beiden Jahrzehnten sich vollziehende Privatisierungstendenz staatlicher Großunternehmen gibt nicht ohne Grund vielerorts Anlass zur Sorge, da die inhaltlichen Leistungen von der Änderung der äußeren Form berührt werden (man denke nur an die viel gescholtenen Inhalte des Privatfernsehens). Diese konkreten Probleme stehen hier nicht zur Diskussion. Vom Standpunkt der Gesellschaftstheorie ist in diesem Zusammenhang vielmehr die eher abstrakte Frage nach den Funktionen und Strukturen der politischen Selbstorganisation einer Gesellschaft relevant.

Üblicherweise wird die zweifellos notwendige politische Einflussnahme auf die wertblinde Verwertungslogik des Wirtschaftssystems als politische Steuerung in der Form von hierarchischen Entscheidungen gedacht. Im Falle sozialistischer Planwirtschaften war der Grenznutzen solcher Maßnahmen offenbar bei Weitem überschritten. Zu viel Paternalismus hat - wie man inzwischen wei $3^{16}$ - massive dysfunktionale Folgen. Wenn man nicht viel Theorie investieren möchte, liegt es nahe, dieses Spannungsverhältnis auf die Frage zuzuspitzen: Wie viel Staat - wie viel Markt? Aber politische Abstimmung muss nicht unbedingt hierarchisch verlaufen. Eine der augenfälligsten organisatorischen Schnittstellen von Politik und Wirtschaft sind beispielsweise die Zentralbanken, die in der Regel politisch unabhängig agieren. Auch das aktuelle

16 Vgl. Giddens: Jenseits von Links und Rechts. 
Interesse der Politikwissenschaft an so genannten Governance-Ansätzen unterstreicht die Bedeutung dezentralisierender Strategien zur Lösung wirtschaftspolitischer Probleme. Eine rechtliche Fixierung erweist sich hier in vielen Fällen als kontraproduktiv.

Dezentralisierung könnte auch im Hinblick auf eine verbraucherorientierte Wirtschaftspolitik eine zeitgemäße Antwort auf die in Zeiten der Globalisierung stattfindende Entmachtung staats- oder gewerkschaftszentrierter Regulierungspotenziale darstellen. Indem man dem aufgeklärten Verbraucher die Wahl lässt, kann eine in vielen Hinsichten ineffektive hierarchische Steuerung der Wirtschaft über das Rechtsmedium vermieden werden. Die zugehörige politische Vision besagt, dass im Zuge der kulturellen Etablierung eines politisch sensibilisierten Verbraucherbewusstseins die sanfte Macht autonomer Konsumenten als wirkungsvolles ideelles Korrektiv für die instrumentell-eindimensionalen Engführungen der ökonomischen Geldlogik fungieren kann. ${ }^{17}$ Es handelt sich also bei den entsprechenden politischen Programmen, wie beispielsweise der im Anschluss an die BSE-Krise kommunizierten Agrarwende, um weiche Reformen, bei der die professionelle Politik lediglich als Moderator fungiert, indem sie den gesellschaftlichen Diskurs institutionell stützt und die notwendige Transparenz garantiert. Wer als Bürger eine bestimmte kollektive Identität teilt, wird auch als Konsument seine Bedürfnisse entsprechend zu interpretieren wissen. Spielräume hierfür ergeben sich allerdings nur in dem Maße, wie die Konsumgewohnheiten von traditionell vorgegebenen Verrichtungen oder durch soziale Umstände auferlegten Sachzwängen entkoppelt und zum Gegenstand einer autonomen Lebensgestaltung werden. Die kulturelle Bedeutungsschicht von individuellen Bedürfnissen sollte dabei nicht unterschätzt werden. ${ }^{18}$

17 Vgl. Lamla: „Zivilität und Konsum“.

18 Vgl. Berger: „Das bedürftige Subjekt“; Douglas: „In Defence of Shopping“; Bourdieu: Die feinen Unterschiede. Spielräume gibt es daher auch unter widrigsten Umständen. Marx beschreibt beispielsweise im Kapital die in England Mitte des 19. Jahrhunderts übliche Praxis der Brotverfälschung, bei der das zum Backen verwendete Mehl zu großen Teilen mit Sägemehl u.ä. gestreckt wurde, sodass das Brot dann unter dem Normalpreis verkauft werden konnte. Obgleich der entsprechend geringe Nährwert des Brotes bekannt war, fand dieses dennoch seine Abnehmer. Die entsprechende Konsumentscheidung hatte demnach weniger etwas mit den physischen Notwendigkeiten, als vielmehr mit dem Wunsch nach einem vollen Magen zu tun. Die Interpretation der individuell empfundenen Bedürfnisse hängt dabei in hohem Maße von kulturellen Kontextbedingungen ab. Diese aber können sich mit der Zeit ändern. So kommt es dann vielleicht, dass Tofu auf einmal als wohlschmeckend empfunden wird und Bockwürste als geschmacklos gelten. Auch der vermeintlich rein physiologisch bedingte plötzliche Appetit auf Schokolade etwa ist nur vor dem Hintergrund einer weit reichenden 


\section{Die handlungstheoretische Deutung: Verbraucheröffentlichkeit als moralische Kontrollinstanz}

Wie bereits angedeutet, lassen sich im Hinblick auf eine konsumbasierte Steuerung der Wirtschaft von unten eine handlungstheoretische und eine kulturtheoretische Lesart unterscheiden. Die handlungstheoretische Deutung richtet ihren Fokus auf die individuelle Konsumentscheidung. Wenn man gemäß der klassisch-liberalistischen Gesellschaftsauffassung Politik durchweg unter dem Aspekt der kollektiven Bündelung individueller Interessen und des zivilisierten Ausgleichs zwischen unterschiedlichen materiellen Interessenlagen betrachtet, dann konstituiert sich eine Öffentlichkeit grundsätzlich nur in der Form der Aggregation einzelner Entscheidungen. Demokratie wäre demnach als ein gewaltfreier Prozess zu verstehen, im Zuge dessen sich individuelle Interessen auf eigentümliche und geheimnisvolle Weise zu kollektiven Interessen bündeln. Diese werden dann auf eine Alternative von zwei Optionen reduziert und können somit letztlich durch Abstimmung per Mehrheitsregel entschieden werden. Der Mark.t wäre auf der Gegenseite eine gesellschaftliche Instanz, die grundsätzlich als Spiegel einer heterogenen Bedürfnislage zu verstehen wäre. Im Gegensatz zur Demokratie aggregieren sich die individuellen Entscheidungen hier nicht zu einer kollektiv verbindlichen Gesamtentscheidung. Der Markt passt sich stattdessen an die Nachfrage in der Form einer Segmentierung von Produktsparten an. In diesem Sinne kann es unter anderem genauso Nischen für nachhaltigen oder sozial gerechten Konsum geben, wie es Nischen für Wegwerfprodukte oder HightechArtikel gibt. Einem solchen materialistischen Marktmodell zufolge führt beispielsweise der Konsum von Biolebensmitteln niemals zu einer wirklich nachhaltigeren Weltwirtschaft, da er immer nur ein relativ kleines Ökomilieu bedient. ${ }^{19}$ Dieses lässt sich soziologisch exakt identifizieren und dürfte auch langfristig lediglich ca. zwei bis acht Prozent des europäischen Lebensmittelmarktes umfassen.

Wenn es eine politische Dimension des Marktes gibt, dann aus dieser Perspektive nur dahingehend, dass der Markt auch ein Abdruck unterschiedlicher politischer Positionen ist. Die meisten Bedürfnisse sind kulturell konstruiert und somit nicht - wie etwa der Bedarf nach Trinkwasser - durch physiologische oder anthropologische Parameter vorgegeben. Jedes Produkt, jede Marke ist Träger sozialer Botschaften, symbolisiert eine gesellschaftliche Stellung, eine be-

kulturgeschichtlichen Entwicklung des Kakaos möglich geworden, im Zuge derer dem exotischen Produkt eine quasierotische Bedeutung zugeschrieben werden konnte. Vgl. Coe/Coe: Die wahre Geschichte der Schokolade.

19 Vgl. hierzu Mach in diesem Band, der ökonomische Profitstrategien in Bezug auf nachhaltige Wirtschaftsweisen diskutiert. 
stimmte Haltung oder Lebenslage. Der individuelle Konsum bringt insofern oftmals unbewusst - zum Ausdruck, an welchem gesellschaftlichen Ort und in welcher sozialen Situation wir uns befinden. Dieses Entsprechungsverhältnis von politischer Position und Konsum-Gewohnheiten kann freilich kaum als Form einer politischen Steuerung gelten.

Ein weiter Begriff von Politik beinhaltet indes immer auch eine moralische Dimension. Moralische Urteile besitzen im Unterschied zu politischen Präferenzen prinzipiell eine universelle Gültigkeit. Es gibt zahlreiche Phänomene, bei denen Menschen von großem Enthusiasmus ergriffen werden oder sich kollektiv empören. Dies gilt insbesondere auch für konsumrelevante Kampagnen und Boykott-Aktionen. Liegt in dieser allgemeinen Verbindlichkeit der Moral eventuell der Schlüssel zur Konstitution einer politisch geschlossen agierenden Verbraucheröffentlichkeit? ${ }^{20}$ Oder handelt es sich bei solchen symbolträchtigen Fällen einer moralisch aufgeladenen Mobilisierung der Verbraucheröffentlichkeit lediglich um plakativen politischen Aktionismus? Worin genau bestehen die langfristigen ökonomischen Steuerungseffekte?

Als Kommunikationsform ist Moral zunächst etwas Negatives: Moralische Kommunikation ist immer dann empirisch zu beobachten, wenn gegen moralische Erwartungen verstoßen wird. Wenn es im Konsumbereich zu expliziter Moralisierung kommt, geht es entsprechend darum, bestimmte unmoralische Praktiken zu enthüllen und öffentlich anzuprangern. Solche Mechanismen der moralischen Empörung, die zur Ächtung bestimmter Akteure führen können, erfüllen - nicht nur in der Wirtschaft, sondern auch in der Politik oder der Wissenschaft - zum einen eine wichtige Alarmierungsfunktion. Zum anderen disziplinieren sie im Hinblick auf sittliches Verbalten, denn die Wirtschaftsunternehmen müssen solche Reaktionen, die sich im Konsumverhalten niederschlagen, antizipieren und entsprechend eine eigene Imagepflege betreiben. Der Nachteil dieser moralischen Immunreaktionen ist allerdings, dass sie nur bei eklatanten Missständen greifen, wenn nämlich die Diskrepanz von ökonomischer Praxis und moralischen Werten offensichtlich geworden ist. Skandale zeigen in diesem Sinne letztlich eher administrativen Handlungsbedarf, denn hier sind mittelfristig zumeist auch Maßnahmen der Steuerung von oben, sprich: Verbote, möglich.

Wenn man einmal von solchen Verbraucherkampagnen absieht, die sich von vornherein an die politische Öffentlichkeit richten, um die Aufmerksamkeit der Medien auf bestimmte Probleme zu lenken, dann basiert das Steuerungsprinzip einer politisch aktiven Verbraucheröffentlichkeit auf dem moralischen Appell an die Konsumentscheidung der Verbraucher. Der auf die kritisierten

20 Zur Diskussion des Zusammenhangs von Wirtschaft und Moral vgl. Corsten: „Sind wirtschaftliche Handlungsnormen immer schon moralisch konstituiert?“. 
Unternehmen ausgeübte Druck ergibt sich schließlich aus den im Falle erfolgreicher Kampagnen drohenden Umsatzeinbußen. Ein solches handlungstheoretisches Verständnis der Verbraucheröffentlichkeit als moralischer Instan₹ offenbart nun allerdings erhebliche Schwächen. Das Modell der moralischen Kontrolle durch die Öffentlichkeit wäre ohnehin nur dann effektiv, wenn man unterstellen könnte, dass die Normalität prinzipiell moralisch einwandfrei funktioniert. Deviante Praktiken und schwarze Schafe müssten die Ausnahme bilden. Dies ist aber eher unrealistisch. Insofern trifft die moralische Empörung immer nur die sprichwörtliche Spitze des Eisberges. Man muss sogar befürchten, dass durch die willkürliche Abstrafung einzelner Sündenböcke lediglich Symptome bekämpft werden und dies sogar von den zugrundeliegenden strukturellen Problemen eher ablenkt: Man boykottiert eine Tankstelle und fährt stattdessen zur nächsten. Da dies in der Logik der materialistischen Kultur des Kapitalismus liegt, wird es Umweltverschmutzung und Ausbeutung trotzdem immer geben. Jede Diskussion über bürgerschaftliche Verantwortung provoziert daher die These, dass diese destruktiven Effekte durch den kritischen Anschein der Moralisierung lediglich kaschiert werden, indem gleichsam immer wieder eine moralische Fassade errichtet wird, die dann systematisch einer schleichenden Korrosion unterliegt.

Moralische Appelle können sicher in Ausnahmefällen sogar im positiven Sinne zur Lösung konkreter Probleme beitragen. Wenn etwa ein gewisser Bruchteil der Einnahmen pro verkauftem Produkt für einen guten Zweck abgezweigt wird, kann unter Umständen die für eine gewünschte Maßnahme erforderliche Summe tatsächlich aufgebracht werden. Wie bei Spendenaktionen schwindet jedoch die altruistische Motivation zwangsläufig, sobald es sich nicht mehr lediglich um Einzelfälle handelt. Das Modell des moralischen Verbrauchers, demzufolge der Markt nach dem Paradigma der politischen Wahl von unten gesteuert wird, taugt daher nicht ohne Weiteres für den Alltagskonsum. ${ }^{21}$ Politischer Konsum ist letztlich nur als demonstrativer Akt sinnvoll: Er muss selbst öffentlich vollzogen werden. Wie bereits der Gang zur Wahlurne beinhaltet auch der Konsumvorgang eine symbolisch-rituelle Komponente. Diese symbolische Dimension des Konsums, die sich bereits oben angedeutet hatte, führt direkt zu einer kulturtheoretischen Interpretation der Verbraucheröffentlichkeit.

21 Permanent einen freiwilligen Moralaufschlag zu zahlen, wäre selbst für den moralisch gutwilligen Verbraucher irrational, zumal man sich vor Augen halten kann: Auf mich kommt es nicht an! 


\section{Die kulturtheoretische Deutung: Politisierter Konsum als diskursive Verschiebung}

Aus handlungstheoretischer Perspektive erscheint auch die Öffentlichkeit vorzugsweise als kollektiver Akteur, der sich primär in Ausnahmefällen konstituiert. Öffentlichkeit lässt sich jedoch grundsätzlich auch als ein kulturell wirksames Prinzip der Beobachtung zweiter Ordnung verstehen, mit dem die Gesellschaft sich gleichsam permanent selbst beobachtet. Innerhalb eines jeden sozialen Feldes beobachten sich sämtliche Mitspieler durchweg gegenseitig. Man nimmt dabei insbesondere sich selbst virtuell durch die Augen der Öffentlichkeit wahr. Innerhalb dieses durch und durch reflexiven Vorgangs können sich gleichwohl bestimmte Strukturen stabilisieren, etwa Modetrends oder eine öffentliche Meinung.

Auf den speziellen Fall des Konsums bezogen bedeutet dies, dass auch alle individuellen Bedürfnisse immer erst Ergebnis eines Interpretationsvorgangs sind, der vor einem konkreten sozialen Hintergrund stattfindet. Da der damit gegebene Kontext des Konsums unter anderem kollektive Identitäten berührt, lässt sich das jeweilige kulturell verankerte Selbstverständnis des guten Lebens als eine politische Dimension des Konsums begreifen. Die individuellen Bedürfnisse werden dadurch zwar nicht determiniert, sie werden jedoch definiert und kanalisiert und sind damit letztlich Ausdruck einer spezifischen sozialen Lage.

Formulierungen dieser Art mögen den alten Verdacht erneuern, die Soziologie würde den freien Willen der Individuen leugnen. Wann man welches Bedürfnis hat, bestimmt natürlich jeder selbst. Aber man kann nur auf etwas Appetit haben, was es tatsächlich gibt. In diesem Sinne eines Abgleichs der privaten Sinngebungen mit der sozialen Umwelt sind die Möglichkeiten, ein diffuses Gefühl als Bedürfnis nach etwas Konkretem zu interpretieren, letztlich sehr begrenzt.

Die sozialen Felder Wirtschaft und Politik generieren - wie oben bereits dargelegt - je eigene Öffentlichkeiten: Die Verbraucheröffentlichkeit wäre somit als ein Feld konstitutiver Differenzen zu verstehen, das sich anhand von Produktimages bildet und die den Konsumpraktiken zugeschriebenen Bedürnisse und Gebrauchswerte betrifft. Es ist bekannt, dass die gesellschaftliche Produktpalette trotz eines kulturell bedingten Drangs zur Individualität, zur Distinktion und zum Exotischen recht homogen bleibt. Wenn auch nicht alles sich äußerlich gleicht, so gibt es doch überall feste Standards für klar definierte Bedürfnislagen. Die Verbraucheröffentlichkeit, welche nach dieser Lesart einfach den Horizont für die Interpretation der privaten Bedürfnisse bildet, korreliert insofern mit dem Markt als einem System von Waren, die wechselseitig aufeinander verweisen: die Welt dessen, was sich produzieren und verkaufen lässt.

Davon zu unterscheiden ist folglich eine zivilgesellschaftliche Öffentlichkeit. Diese politische Öffentlichkeit betrifft die Interpretation individueller Lebensent- 
würfe im Kontext kollektiver Werte und Praktiken. Auch hier gibt es bekanntlich eine Tendenz zu alternativen Lebensentwürfen, die dann wiederum massenweise nachgeahmt werden. In materieller Hinsicht korreliert diese lebenspolitische Öffentlichkeit daher wiederum mit der Welt dessen, was sich politisch verwalten lässt: die gesamte Infrastruktur des kollektiven Lebens, die von Autobahnen über Spielplätze bis zu Biergärten reichen kann.

Wenn man vom Standpunkt der damit skizzierten kulturtheoretischen Deutung des Öffentlichkeitsbegriffs aus noch einmal die Frage nach dem Verhältnis von Politik und Wirtschaft stellt, wäre nun zu überlegen, auf welche Weise sich diese beiden Felder praktisch übereinander schieben. Die politische Steuerung des Marktes durch die Konsumenten ist dann grundsätzlich nur als eine durch politische Kommunikationsprozesse bzw. Lebenspraktiken bewirkte diskursive Verschiebung des Feldes der Produktimages im Ganzen zu verstehen. Der Markt passt sich sozusagen an die veränderte kollektive Bedürfnislage an.

Wie kann man sich eine solche diskursive Verschiebung der Ökonomie konkret vorstellen? Genannt seien stellvertretend drei Dimensionen. Die Veränderungen können sich zunächst ganz oberflächlich auf die Etikettierung beziehen: Eine Kneipe heißt dann nicht mehr Zum Reichsadler sondern Zur Sonnenblume, bleibt aber eine Kneipe. Der Wandlungsprozess kann zweitens auch die Leitgesichtspunkte betreffen, an denen Produkte gemessen werden. Wenn Handys beispielsweise primär anhand ihrer Pixelauflösung beurteilt werden, hat man es schwer, wenn man die Angebote anhand der Emissionswerte vergleichen möchte. Die kulturellen Dimensionen, welche die Attraktivität der Produkte ausmachen, verändern sich mit der Zeit. Statt auf das Kriterium technischen Fortschritt zu setzen, wäre daher vielleicht zu hoffen, dass irgendwann einmal Ökologie, die sozialen Produktionsbedingungen oder die Qualität von Handarbeit im Mittelpunkt stehen. Tiefergehende Transformationen könnten drittens bis in die innere Struktur der Wirtschaftslandschaft selbst hineingehen, wenn beispielsweise neue Branchen wie die Umwelttechnik entstehen. Ob etwa die Produktsparten der Autoindustrie, der Haushaltselektronik und der Pharmaindustrie boomen oder aber jene des Verlagswesens, der Landwirtschaft und des Dienstleistungssektors, ist nicht zuletzt auch eine kulturabhängige Frage.

Die ökonomische Adaption kultureller Kontexte lässt sich ihrerseits auf zweierlei Weise konzipieren: entweder als Marktsegmentierung oder nach dem Muster des Modetrends. Im ersten Modell reagiert die Wirtschaft auf politische Kritik durch die Bereitstellung von Nischenprodukten für moralisch anspruchsvolle Verbraucher. Da im Gegenzug auch Produkte für den politisch ansprucbslosen Verbraucher angeboten werden, wäre für politisch rationale Effekte wiederum die individuelle Entscheidung zugunsten eines moralischen Konsums ausschlaggebend $(=$ handlungstheoretisches Modell der politischen 
Wabl). Wenn es auf dem Markt solche und solche Produkte/Produzenten gibt, liegt die Verantwortung für die politische Korrektheit der Produktion beim Verbraucher. Da es aber auch solche und solche Verbraucher gibt, droht der durch die wenigen gesellschaftsbewussten Verbraucher generierte politische Impuls im Zuge seiner ökonomischen Adaption ineffektiv zu bleiben. Im Falle einer Marktsegmentierung, die immer auch eine Segmentierung von Zielgruppen ist, kann der kulturelle Hintergrund der Produkte nicht als Ausdruck einer übergreifenden kollektiven Identität, sondern eben nur als Ausdruck einer Identität der jeweiligen Zielgruppe gelten (auch wenn diese mit universalisierten Ansprüchen auftritt). Die Segmentierung des Marktes wäre dann lediglich die Folge einer vorausgehenden politischen Segmentierung.

Dem zweiten Modell zufolge - welches schwächer, aber gleichzeitig robuster ist - kann die ökonomische Adaption auch nach dem Muster eines von der Verbraucheröffentlichkeit (inklusive diverser Trendsetter) abhängigen Modetrends begriffen werden. Die gesellschaftliche Bedeutung der einzelnen Produkte bemisst sich damit per se an der Instanz einer allgemeinen Verbraucheröffentlichkeit. Der persönliche Sinn, der einen Käufer mit einem bestimmten Produkt verbindet, kann dabei durch die Logik der Distinktion vermittelt sein. Aus Ächtung kann Abenteuerwert erwachsen (Zigaretten, Waffen, Motorräder), der Erwerb bzw. der Konsum kann als Provokation motiviert werden (Heavy Metal, Kampfhunde, Gartenzwerge), kann zur gesellschaftlichen Positionierung subkultureller Gruppen dienen usw. Dies alles wäre gleichwohl noch Teil eines über den Konsum vermittelten Prozesses des individuellen Ausbildens und kollektiven Abgleichens politischer Identitäten. Bei aller (durchaus erwünschten) Pluralität bleibt dabei die Einheit der Öffentlichkeit als implizit mitgeführter Weltbezug erhalten. Wenn es also ein Defizit an Öffentlichkeit gibt, dann allenfalls ein qualitatives. Was aber, wenn die Öffentlichkeit bloß eine dumpfe Masse ist?

\section{Qualitätsdefizite einer massenkulturell geprägten Öffentlichkeit}

Das Phänomen der Massenkultur kann historisch mit der Ausweitung von Inklusionsansprüchen - in Richtung auf die unteren Bevölkerungsschichten, aber auch im Hinblick auf die globale Ausbreitung des westlichen Gesellschaftsmodells - in Zusammenhang gebracht werden. Im Gegenzug etablieren sich die modernen Massenmedien, und es ergibt sich - etwas formelhaft umschrieben - mit der quantitativen Erweiterung der Öffentlichkeit ein qualitatives Problem der die Öffentlichkeit dominierenden Kultur. Diese strukturell bedingte Ten- 
denz zur Vermassung hat zu einer fatalen Verbindung von Konsumismus und instrumenteller Vernunft geführt. ${ }^{22}$

Die Erweiterung der Inklusionschancen hat ihren Preis. Die Masse verfügt über keine Bildungsgeschichte. Eine komplexe Verankerung der vermittelten Deutungsmuster im Kontext lokaler Kulturen ist nicht mehr möglich. Sinnangebote müssen daher wie Discomusik quasi als Instantprodukt greifen. Das Aufschnappen von Sinnmustern erfolgt - ohne reflektierten Bezug zum Ganzen - in der Form eines imitierenden, intuitiven Mitschwingens. Das gesamte Sozialleben wird damit zu einem improvisierten Tanz der Sinnscherben und Ideenfragmente. Gleichzeitig wird die voraussetzungsarme Anschlussfähigkeit der Sinnangebote über eine Öffentlichkeitsstruktur gewährleistet, die auf einem Maximum an Redundanz und massiver Wiederholung basiert und so eine weitestgehende Homogenisierung der Kultur nach sich zieht. Im Gegenzug wird die Bewährung von Person und Werk in Kunst, Wissenschaft, Politik, Wirtschaft usw. immer stärker an das Kriterium des Massenerfolgs gebunden. Eine tyrannische Mehrheit mit schlechtem Geschmack bestimmt über den in der Öffentlichkeit als erwartbare Erwartungen etablierten Standard. Die Folge ist eine Welt der Superstars, Hits, Fertiggerichte und Skandalschlagzeilen.

Die Expansion der Öffentlichkeitshorizonte bewirkt in allen charakteristischen Bereichen der modernen Gesellschaft durchweg eine drastische Verflachung des kulturellen Niveaus. Die technischen Revolutionen, welche eine ungeheure Ausweitung der Medien zur kommunikativen Informationsverbreitung ermöglicht haben, sind gleichzeitig für den Wandel der ehemals feudal bzw. bürgerlich geprägten Kulturlandschaft hin zur Massenkommunikation und kommerziellen Unterhaltungskunst mitverantwortlich. ${ }^{23}$ Die staatliche Garantie vergleichbarer Bildungschancen unabhängig von der sozialen Herkunft hat die Universitäten zu Masseninstitutionen verkommen lassen, die biografisch vor allem als Ort für soziale Moratorien taugen. Durch die Ausweitung politischer Partizipationschancen auf sämtliche Bevölkerungsgruppen wurde politischer Erfolg an eine gelingende Mobilisierung von Wählermassen gebunden, die oft nur über eine unzureichende politische Bildung verfügen. Die Steigerung der Kaufkraft in den unteren Gesellschaftsschichten schließlich hat der Umstellung der Industrie auf billige Massenproduktion Vorschub geleistet.

Wenn die Konsum- und Unterbaltungsangebote gleichsam für sich stehen müssen, sinkt beispielsweise das Niveau von Literatur oder Musik beträchtlich. Die kulturellen Bedeutungen verkümmern zu plumpen Klischees und Stereotypen,

22 Vgl. Horkheimer: Zur Kritik der instrumentellen Vernunft; Marcuse: Der eindimensionale Mensch.

23 Vgl. Habermas: Strukturwandel der Öffentlichkeit. 
die überall in der Welt und quer durch alle Schichten verstanden werden. Das Resultat sind standardisierte Produkte wie Chinesisches Hubn süßsauer aus der Tiefkühltruhe. Auch die Lebensentwürfe und die politischen Identitäten haben keine Geschichte mehr; es gibt nur noch eine zentrale Verwaltungsstruktur und abstrakte institutionelle Standards, die den lokalen politischen Kulturen übergestülpt werden. Dies alles führt insgesamt zu einer tendenziell materialistischen Orientierung. Für die Konsumkultur bedeutet dies einen Trend zu Massenprodukten, zum Wegwerfkonsum, zum Leichten und Schnellen: viel Müll, Plastik und Elektronik. Für die politische Kultur setzen sich Leitwerte wie Wohlstand, Hedonismus und das Streben nach simplen Statussymbolen durch. Der soziale Status wird dabei primär an materiellen Reichtum und an Karrieren innerhalb formaler Organisationshierarchien (eine Männerdomäne!) gebunden. Das diesbezügliche Weltbild wird vor allem durch eine Medienöffentlichkeit getragen, welche die entsprechenden materialistischen Deutungsmuster durchweg als Selbstverständlichkeiten suggeriert.

Die in dieser Weise zu charakterisierende allgemeine Aushöhlung sozialer Sinnqualitäten ist indirekt auf die Umstellung auf oben beschriebene Techniken der Beobacbtung zweiter Ordnung ${ }^{24}$ zurückzuführen. Angesichts der außerordentlichen Komplexität funktionsspezifischer Sinnstrukturen verfügen individuelle Akteure heute in der Regel weder über materielle Kriterien zur objektiven Evaluation der verfügbaren Sinngehalte, noch gibt es verbindliche Vorgaben von oben. Stattdessen ist man gehalten, sich in generalisierter Form an dem $\mathrm{zu}$ orientieren, was andere Beobachter beobachten. ${ }^{25}$ Oft lässt sich beispielsweise die Gebrauchsqualität von Produkten nur schwer prüfen. Man hält sich als Konsument daher an die etablierten Marken und an die über die Werbung transportierten Suggestionen. Da Politik auch für die Politiker selbst weitestgehend undurchsichtig bleibt, erscheint ihr Bild allein im Zauberspiegel der öffentlichen Meinung. Wissenschaftler wiederum wissen zwar nicht wirklich die Wabrbeit, können sich aber in ihren Urteilen an die einschlägigen Publikationen halten und sich so des aktuellen Forschungsstands vergewissern. Und wenn im Fußball Unsicherheit darüber besteht, wer der bessere deutsche Torhüter sei, hält man sich an die Ergebnisse der Wahl zum Welttorhüter des Jahres.

Die Beobachtung der Öffentlichkeit bildet in diesem Sinne ein unentbehrliches Prinzip der gesellschaftlichen Koordination. Die daraus resultierende Kontingenz, die kognitive Ungewissheit und der Mangel an substanziellen Bewährungskriterien verführen dazu, sich ausschließlich an dem zu orientieren,

24 Vgl. Luhmann: Die Politik der Gesellschaft, S. $283 \mathrm{ff}$.

25 Vgl. Beetz: Rationalität der Öffentlichkeit. 
was faktisch Erfolg bedeutet ${ }^{26}$ : die Wiederwahl, der gesteigerte Absatz, die hohe Zitierquote. Die Tyrannei der Mehrheit führt zu Effekten der Popularisierung. Eine Folge sind die bekannten Phänomene der Kulturindustrie, der McDonaldisierung und der Reduktion des Allgemeinwissens auf das Format von Quizshows. Die zum Erfolg Erwählten lassen es sich gefallen, und der Protest der Erfolglosen verhallt als schierer Neid.

Vielleicht ermöglicht gerade die aus dieser Tautologie des Erfolges resultierende Schwächung des Niveaus das Eindringen ökonomischer Logiken in originär autonome gesellschaftliche Sinnsphären, denn die Vermassung führt zur Orientierung an grobschlächtigen materiellen Kriterien wie Marktwerte, Einschalt- oder Drittmittelquoten und Auflagenhöhen. Ob im Bildungssektor, in der Unterhaltungskunst oder in der Wissenschaft: Die Phänomene der Kommerzialisierung sind nur schwer zu leugnen.

Gegen diese Tendenzen zur Popularisierung und zur kommerziell ausbeutbaren Vermassung gibt es aber immer auch eine Bewegung der elitären Distinktion, die ihre eigenen Insider-Kriterien für Qualität hervorbringt. Das Missverhältnis von Popularität und Qualität wird also stets beobachtet, und dies nicht nur von den gesellschaftlichen Eliten, sondern auch von den Unterscbicbten selbst. Distinktion ist nicht nur eine Strategie der jeweils Statushöheren. Als Resultat eines öffentlichen Selbstverstärkungseffektes scheint sich vermittelt über Themen wie PIS A, Parallelgesellschaften oder Hartz IV in jüngster Zeit in Deutschland gar ein neues Unterschichtenbewusstsein zu etablieren.

Gegen die These einer allgemeinen Ökonomisierung spricht auch, dass die Wirtschaft von der Vermassung selbst betroffen ist, und zwar im Hinblick auf die (Lebens-)Qualität ihrer Produkte. ${ }^{27}$ Die besagten Qualitätsdefizite der Öffentlichkeit wären demnach keineswegs durch eine Politisierung der Wirtschaft zu kompensieren. Vielmehr sollte eine Revitalisierung des Bürgers vorrangig zu einer Politisierung der Politik selbst führen. Analog dazu käme eine Sensibilisierung des Verbrauchers lediglich einer Ökonomisierung der Ökonomie gleich, indem diese sich von passiven Endabnehmern der Massenproduktion zu lebensstilbewussten Kennern qualifizierten. ${ }^{28}$ Der Effekt wäre eine Verschiebung des für den Konsum konstitutiven kulturellen Hintergrundes von Kategorien wie Wohlstand, technischer Kontrolle oder instrumenteller Bedürfnisbefriedigung

26 Neckel verbindet die These der Umstellung von Leistung auf Erfolg mit einer Diagnose der modernen Gesellschaft als Marktgesellschaft. Vgl. Neckel: „,Leistung' und ,Erfolg““. Beide Thesen lassen sich aber auch auseinander ziehen, indem man an die Stelle des Marktes den Begriff der Öffentlichkeit bzw. der Beobachtung zweiter Ordnung setzt und die Frage der Ökonomisierung getrennt verhandelt.

27 Vgl. Bachmair: „Was ist Qualität, wenn Lifestyle dominiert?““.

28 Vgl. Hansen: „Haushalte im Markt“. 
hin zu Lebensstil, sozialer Identität und Zukunftsoffenheit. Gewisse Indizien für eine solche Entwicklung gibt es durchaus ${ }^{29}$. So lässt sich in der Tat eine Schwerpunktverschiebung der Produktimages hin zu Lifestyle-Produkten beobachten. ${ }^{30}$ In mancherlei Hinsicht mag die Lage allerdings hoffnungslos erscheinen, denn ein Sättigungseffekt bezüglich der Massenangebote in Bereichen wie Heimelektronik, Autos oder Unterhaltungskunst scheint kaum gegeben zu sein.

\section{Die Frage nach den Potenzialen einer bürger(schaft)lichen Konsumkultur}

Die implizierte Steuerungsdramaturgie des politisierten Konsums lässt also zwei gegensätzliche Deutungen zu, bezüglich derer im Kontext der hier dargestellten Überlegungen die Favorisierung der letzteren nicht schwer fällt. Entweder die einzelne Kaufentscheidung wird nach dem Muster politischer Wahlen als moralisch aufgeladenes Steuerungsritual verstanden oder aber die Transformation des Marktes wird auf eine allgemeine diskursive Verschiebung der Produktimages zurückgeführt.

Nach dem ersten (handlungstheoretischen) Modell werden die Motive des Konsumenten in Augenschein genommen. Dem souveränen Verbraucher wird zugemutet, sich eigenständig über die im Angebot stehenden Waren zu informieren und bei der Kaufentscheidung dann gegebenenfalls bei gleicher Qualität einen höheren Preis in Kauf zu nehmen oder sogar freiwillig zusätzlichen Aufwand (z.B. Rückgabe von Pfandflaschen) zu investieren. Ähnlich wie bei politischen Wahlen ist der individuell erzielte (hier: ökonomische) Effekt äußerst gering. Die eigene Stimme hat unter Millionen anderer Wähler selbst bei knappem Wahlausgang nur ein nahezu infinitesimales Gewicht. Und auch über den ökologischen Nutzen des Verzehrs einer Bio-Nussecke braucht man sich nicht viel einzubilden. Daher würde es sich - aber Rational-Choice-Modelle sind flexibel - vom individuellen Standpunkt aus womöglich selbst dann um eine irrationale Entscheidung handeln, zur Wahlurne zu gehen bzw. ein politisch korrektes Produkt zu kaufen, wenn man überhaupt ein eigenes Interesse am Gewinn der Wahl durch eine bestimmte politische Partei oder an ökologischer Nachhaltigkeit hätte. Sinnvoll wird die individuelle Entscheidung in beiden Fällen erst durch den demonstrativen Charakter, durch den das moralisches Handeln rituelle Züge erhält.

29 Vgl. Szallies/Wieswede: Wertewandel und Konsum.

30 Vgl. Haudenschild: Konsum als Mittel der Lebensweltstilisierung. 
Das zweite (kulturtheoretische) Konzept ist bedeutend einfacher: Wir leben so, wie wir leben wollen, und die Wirtschaft muss sich anpassen, indem sie die geeigneten Angebote bereithält. Der politische Impuls greift somit gleichsam an der äußersten Peripherie der Ökonomie an, nämlich bei der Bedürfnisinterpretation. Je nach Beobachterperspektive ist diese bereits der Umwelt der Wirtschaft zuzurechen; es wird also ein Perturbationseffekt erzielt. Verändern sich im Zuge politisch motivierter Diskurse die kulturellen Hintergründe und Kontexte der unterschiedlichen Bedürfnisse, dann kommt es in der Folge auch zu einer Verschiebung der dazugehörigen Produktimages. Dies führt schließlich zu einer ökonomischen Neubewertung des Marktes und induziert mithin eine Anpassungsbewegung der Wirtschaft an die veränderte politischöffentliche Lage. Die Bürger müssen, damit dies gelingen kann, an diesem zivilgesellschaftlichen Prozess aktiv teilhaben und ihre Lebenspraxis an einer politisch verfassten kollektiven Identität (kritisch) ausrichten. Als Konsumenten jedoch brauchen sie nur noch ihre Bedürfnisse richtig zu interpretieren. Die im politisch eingefärbten Konsum vermeintlich zugrundeliegende persönliche Intention der Wirtschaftssteuerung von unten (mit politischer Zielvorgabe) entpuppt sich dann lediglich als eine spezifisch politische Interpretation dieses Geschehens, ist also lediglich ein von außen zugeschriebenes Motiv. Es ist weder möglich noch erforderlich, die Wirtschaft individuell aktiv mitzusteuern. Allenfalls kann es gelingen, die natürliche Adaptionsfähigkeit der Ökonomie geschickt zur Geltung zu bringen. Dazu müssen wir unsere individuellen Bedürfnisse nur im kollektiven Kontext identifizieren - und die Wirtschaft ist gefordert, sich anzupassen.

Das handlungstheoretische Modell, welches sich stärker an Problemen der sozialen Gerechtigkeit und moralischer Bürgertugenden orientiert, muss dabei keineswegs gänzlich verworfen werden. Die Frage nach dem Stellenwert und dem Verhältnis der beiden Modelle soll hier bewusst offen bleiben. Wenn man das Thema Verbraucheröffentlichkeit und Bürgerschaft jedoch auf die oben beschriebene Weise gleichsam kulturalistisch verfremdet, kommt man letztlich zu der Auffassung, dass wir es hier keineswegs lediglich mit einem politisch zu lösenden ökonomischen Problem zu tun haben. Vielmehr erscheint uns die gesamte Kultur - vom Konsum über die Massenmedien bis zu den politischen Werten - zutiefst fragwürdig. Damit ist freilich noch nicht entschieden, inwieweit das gesellschaftliche Gesamtsystem sich auf Basis seiner institutionellen Strukturen bereits endgültig stabilisiert hat (wie das aus einer marxistischen Perspektive auf den Kapitalismus behauptet wurde), oder ob die Öffentlichkeit durch bestimmte politische Strömungen und Konsumdynamiken tatsächlich eine bessere Qualität gewinnen könnte.

Die forschungspraktischen Konsequenzen dieser Überlegungen liegen in jedem Falle auf der Hand. Wenn wir unsere Aufmerksamkeit stärker auf die 
historische Transformation von Produktimages richten, dann brauchen wir neben einer motivorientierten Konsumentenforschung auch verstärkt eine Forschung, die den langfristigen Wandel jener kulturell verankerten Stereotypen untersucht, auf welche die Vermarktungsstrategien der ökonomischen Produkte sich beziehen. Bereits eine kursorische Betrachtung typischer Verpackungsdesigns zeigt, dass Produktwerbung sich lange Zeit auf die Evidenz wissenschaftlich-technischer Deutungsmuster stützen konnte, sodass die Grenzen zwischen Werbeaufdrucken und gesetzlich vorgeschriebenen Inhaltsangaben verschwimmen konnten. Die zu beobachtende Politisierung des Konsums könnte daher als Gegenbewegung - aus ökonomischer Sicht gar als funktionales Äquivalent - zur zurückliegenden Phase der Verwissenschaftlichung des Konsums interpretiert werden: Auf der Verpackung steht nun der Aufdruck aus den neuen Bundesländern, wo früher geprïfte Qualität gestanden hätte. Das Vertrauen in die professionelle Organisation des gesellschaftlichen Wohlstands durch Fachleute scheint gesunken zu sein. Eine reflexiv gewordenen Moderne reflektiert auch in Konsumangelegenheiten den gesellschaftlichen Kontext der Produkte mit. Konsum wird im Gegenzug zu einer öffentlichen Operation und damit um den Preis kleiner materieller Opfer in einem spezifischen Sinne sozial aufgewertet. Anstelle von technokratischen Expertensystemen mit ihren Labortests und Gütesiegeln fungiert in Zukunft vielleicht die politische Öffentlichkeit als Legitimationsinstanz der Produkte. Der Konsum wird also resozialisiert, der Bürger politisiert und die wissenschaftliche Produktforschung - soziologisiert. Hätte irgendjemand etwas dagegen einzuwenden?

\section{Literaturverzeichnis}

Bachmair, Ben: „,Was ist Qualität, wenn Lifestyle dominiert? Maßstäbe in einer individualisierten Kinderkultur", in: Flach, Sabine/Grisko, Michael (Hrsg.): Fernsehperspektiven. Aspekte zeitgenössischer Medienkultur, München 2000, S. 95-113.

Beetz, Michael: Die Rationalität der Öffentlichkeit, Konstanz 2005.

Berger, Wilhelm: „Das bedürftige Subjekt. Psychoanalyse, Bedürfnis und Ökonomie“, in: Eisendle, Reinhard/Miklautz, Elfie (Hrsg.): Produktkulturen. Dynamik und Bedeutungswandel des Konsums, Frankfurt a.M./New York 1992, S. 51-66.

Bernold, Monika/Ellemeier, Andrea: „Konsum, Politik und Geschlecht. Zur „Feminisierung" von Öffentlichkeit als Strategie und Paradoxie“, in: Siegrist, Hannes u.a.: Europäische Konsumgeschichte. Zur Gesellschafts- 
und Kulturgeschichte des Konsums (18. bis 20. Jahrhundert), Frankfurt a.M. 1997, S. 441-466.

Bourdieu, Pierre: Die feinen Unterschiede, Frankfurt a.M. 1982.

Coe, Sophie/Coe, Michael: Die wahre Geschichte der Schokolade, Frankfurt a.M. 1997.

Corsten, Michael: „Sind wirtschaftliche Handlungsnormen immer schon moralisch konstituiert?“, in: Lange, Elmar (Hrsg.): Der Wandel der Wirtschaft, Berlin 1994, S. 121-142.

Douglas, Mary: „In Defence of Shopping“, in: Eisendle, Reinhard/Miklautz, Elfie (Hrsg.): Produktkulturen. Dynamik und Bedeutungswandel des Konsums, Frankfurt a.M./New York 1992, S. 95-116.

Friedman, Monroe: Consumer Boycotts. Effecting Change through the Marketplace and the Media, New York/London 1999.

Giddens, Anthony: Jenseits von Links und Rechts, Frankfurt a.M. 1997.

Habermas, Jürgen: Strukturwandel der Öffentlichkei, Frankfurt a.M. 1990.

Hansen, Ursula: „Haushalte im Markt: Partner oder Konsumäffchen. Rollenanalyse am Beispiel der Produktentwicklung", in: Tornieporth, Gerda Haudenschild, Christoph: Konsum als Mittel der Lebensweltstilisierung, Bern 1989.

Hellmann, Kai-Uwe/Schrage, Dominik (Hrsg.): Konsum der Werbung. Zur Produktion und Rezeption von Sinn in der kommerziellen Kultur, Wiesbaden 2004.

Hellmann, Kai-Uwe: Soziologie der Marke, Frankfurt a.M. 2003.

Heubach, Friedrich: „Produkte als Bedeutungsträger. Die heraldische Funktion von Waren. Psychologische Bemerkungen über den kommunikativen und imaginativen Gebrauchswert industrieller Produkte“, in: Eisendle, Reinhard/Miklautz, Elfie (Hrsg.): Produktkulturen. Dynamik und Bedeutungswandel des Konsums, Frankfurt a.M./New York 1992, S. 177-198.

Hölscher, Barbara: Lebensstile durch Werbung. Zur Soziologie der lifestyleWerbung, Opladen 1998.

Horkheimer, Max: Zur Kritik der instrumentellen Vernunft, Frankfurt a.M. 1985.

Lamla, Jörn/Neckel, Sighard (Hrsg.): Politisierter Konsum - konsumierte Politik, Wiesbaden 2006. 
Lamla, Jörn: „Zivilität und Konsum. Die Bürgerkultur im Prozess gesellschaftlicher Vermarktlichung“, in: Corsten, Michael u.a. (Hrsg.): Die Gerechtigkeit der Gesellschaft, Wiesbaden 2005, S. 281-308.

Luhmann, Niklas: Die Politik der Gesellschaft, Frankfurt a.M. 2000.

Luhmann, Niklas: Die Gesellschaft der Gesellschaft, Frankfurt a.M. 1997.

Luhmann, Niklas: Die Realität der Massenmedien, Opladen 1996.

Marcuse, Herbert: Der eindimensionale Mensch. Studien zur Ideologie der fortgeschrittenen Industriegesellschaft, Neuwied 1967.

Micheletti, Michele u.a.: Politics, Products, and Markets. Exploring Political Consumerism Past and Present. New Brunswick/London 2004.

Münch, Richard: Dialektik der Kommunikationsgesellschaft, Frankfurt a.M. 1991.

Neckel, Sighard: „Leistung ${ }^{6}$ und ,Erfolgc. Die symbolische Ordnung der Marktgesellschaft"،, in: Barlösius, Eva u.a. (Hrsg.): Gesellschaftsbilder im Umbruch. Soziologische Perspektiven in Deutschland, Opladen 2001, S. 245-265.

Parsons, Talcott: Das System moderner Gesellschaften, München 1972.

Stäheli, Urs: Sinnzusammenbrüche. Eine dekonstruktive Lektüre von Niklas Luhmanns Systemtheorie, Weilerswist 2000.

Szallis, Rüdiger/Wieswede, Günther: Wertewandel und Konsum. Fakten, Perspektiven und Szenarien für Markt und Marketing, Landsberg 1990.

Teubner, Gunther: Recht als autopoietisches System, Frankfurt a.M. 1989. 



\section{Jörn Lamla}

\section{Die Autonomie des Verbrauchers und ihre politischen Formen. Bausteine einer Kulturtheorie des Consumer Citizen}

Im vorliegenden Beitrag möchte ich der schwierigen Frage nach der Autonomie des Verbrauchers nachgehen. Diese Figur betrachte ich dazu nicht als rein privaten Marktakteur, dessen Autonomie sich in Wahl- und Entscheidungsfreiheiten gegenüber Anbietern erschöpft. Vielmehr beziehe ich auch die politischen Aspekte der Staatsbürgerin ein, die mit ihren Verbrauchereigenschaften hybride Verbindungen eingehen. ${ }^{1}$ Eine solche Perspektivenerweiterung lässt sich heuristisch durch das Konzept des Consumer Citizen bezeichnen. Allerdings ergeben sich Probleme bereits dadurch, dass die Verknüpfungen zwischen Consumer und Citizen keineswegs eindeutig sind und auf ganz unterschiedliche Weise konzipiert werden: ${ }^{2}$ Zum einen kann darauf abgestellt werden, dass Konsumpraktiken und -gewohnheiten selbst gewisse politische Qualitäten zukommen, zum anderen kann aber auch gemeint sein, dass die Bürgerin gegenüber dem politischen Gemeinwesen und der staatlichen Politik zunehmend konsumistische Haltungen einnimmt. ${ }^{3}$ Drittens schließlich ist das Begriffspaar von Consumer und Citizen auch dahingehend zu hinterfragen, inwiefern die so verknüpften idealtypischen Handlungs- und Autonomieformen der hybriden Lebenspraxis und den diffusen Selbstkonzepten überhaupt gerecht werden und als adäquate Vergleichsfolie dienen können. Sie bilden deshalb weniger den Ausgangspunkt der nachfolgenden Überlegungen als vielmehr ihren Fragenhorizont oder Suchauftrag: Untersucht werden soll, ob und inwiefern wir davon sprechen können, dass Verbrauchereigenschaften für (heutige) Muster der Lebensführung charakteristisch sind und entlang welcher Dimensionen sich darin typische Autonomieprobleme konstituieren und artikulieren. Ich vermute, dass die Dimensionen der Bürgerin und des Verbrauchers hierfür tragend und erhellend sind, auch wenn das kulturelle Leben sich darin sicher nicht erschöpft.

Die Klammer für die folgende Bearbeitung dieser Fragestellung wird durch die Konzentration und Beschränkung auf kultursoziologische Zugänge ge-

1 Ich benutze hier entgegen verbreiteten Klischees die männliche Form für die konsumorientierten und die weibliche Form für nicht-häusliche Akteurskategorien. Gemeint sind in aller Regel beide Geschlechter.

2 Vgl. Schudson: „The Troubling Equivalence of Citizen and Consumer“.

3 Vgl. Lamla/Neckel: Politisierter Konsum - konsumierte Politik. 
bildet, die mit einer holistischen Perspektive auf die Lebenspraxis starten und darin spezifische Züge und Probleme eines Verbraucher- und Bürgerdaseins entziffern und erhellen. Die drei Vertreter, deren Arbeiten als Bausteine für ein solches Vorhaben aufgegriffen werden, sind darüber vergleichbar, auch wenn sie sich der Problematik aus unterschiedlichen Richtungen nähern: Sie fragen nach dem elementar Politischen im Konsumalltag (Michel de Certeau) oder arbeiten umgekehrt die alle Lebensbereiche durchdringenden Verbrauchereigenschaften auch am politischen Verhalten heraus (David Riesman mit seinen Mitarbeitern). Während die Unterschiede zwischen Konsument und Bürgerin hier zu verschwimmen beginnen, liefern diese der dritten Theorie gerade das zentrale Erklärungsproblem, wie nämlich ein Wechsel der Engagementformen endogen motiviert ist (Albert O. Hirschman). Zusammen betrachtet stellen diese drei Zugänge weniger alternative, als sich ergänzende Sichtweisen auf die Autonomieprobleme der Lebenspraxis dar. In gewisser Hinsicht handelt es sich um Stufen einer Theorie des Consumer Citizen, die im Folgenden vom Allgemeinen zum Besonderen abgeschritten werden sollen.

\section{Die Taktiken des Verbrauchers - Michel de Certeaus Theorie der Konsumpraktiken}

Eine abstrakte, dadurch aber auch sehr weitreichende Fassung von Verbraucherautonomie lässt sich aus Michel de Certeaus sozialtheoretischen Überlegungen zur Kunst des Handelns ${ }^{4}$ gewinnen. Zwar spricht de Certeau nicht vom Consumer Citizen. Seine Theorie rückt aber eine politische Qualität des Verbraucherhandelns in den Blick, die als grundlegendes Eigenschaftsbündel in sämtlichen Praktiken des Alltags zum Tragen kommt. Sein Zugang ist ungewohnt, weil Konsum weder ökonomisch über Warentausch, Geldverwendung, Haushalt, Knappheit oder Überfluss noch sozialpsychologisch anhand von Kategorien des Bedürfnisses, des Statuskampfes, der Neugier o.ä. bestimmt wird. Vielmehr orientiert sich sein Begriff von Konsumpraktiken an Wittgensteins Philosophie der normalen Sprache. Es ist das Modell des alltäglichen Gebrauchens von Sprache, des Sprechaktes und der Sprachspiele, das dem Verbraucherhandeln bei de Certeau ganz elementare politische Züge verleiht. ${ }^{5}$ Denn durch diesen gebrauchstheoretischen Ansatz wird dem Konsum ein Moment von Aktivität zugesprochen, wo ihm in herkömmlichen Gegenüberstellungen zur Produktion oder Investition immer das Stigma des Passiven und Vernichtenden anhaftet. Im Ergebnis führt dies zur Revision gewohnter Einteilungen, inso-

4 Vgl. Certeau: Kunst des Handelns

5 Vgl. ebd., S. 46-51. 
fern auch der arbeitende Mensch als Verbraucher betrachtet werden kann, der sich zu den vorgegebenen Bedingungen seines Arbeitslebens, den Wahlmöglichkeiten, Einschränkungen, Arbeitsmitteln usw. verhalten, sich diese also gebrauchend aneignen muss. Zugleich erscheinen die herkömmlich dem Konsumalltag subsumierten Praktiken nicht mehr als einheitlicher Block, insofern sie in unterschiedlicher Weise politisch oder kommerziell aufgeladen sein können.

Der Gegenstand des Gebrauchens ist immer etwas Vorgegebenes, das allerdings erst durch seine Verwendung sozial wirksam wird. Das Vorgegebene und sein Gebrauch stehen in einem wechselseitigen Bedingungs- oder Konstitutionsverhältnis. Überlegungen zu diesem Zusammenhang finden sich bekanntlich schon bei Karl Marx im acbtzebnten Brumaire des Louis Bonaparte: „Die Menschen machen ihre eigene Geschichte, aber sie machen sie nicht aus freien Stücken, nicht unter selbstgewählten, sondern unter unmittelbar vorgefundenen, gegebenen und überlieferten Umständen." "6 Obgleich diese Stelle in der soziologischen Tradition häufig zitiert wurde, hat man darin zumeist wenig Anlass gesehen, die Dominanz des Arbeits- oder Produktionsparadigmas in Zweifel zu ziehen. Mit de Certeau ließe sich jedoch behaupten, dass die Menschen in erster Instanz immer Nutzer oder Verbraucher sind, insofern sie in allen Lebensbereichen stets auf vorgefundene Möglichkeiten verwiesen sind und nur im Gebrauch dieses Angebotes gestaltend tätig werden können. Es gilt also zu klären, wie und in welchen Bereichen diese Verbraucher zu autonomen Gestaltern ihrer Lebensverhältnisse werden können, ohne den Gegensatz von Arbeit, Politik und Konsum vorab festzuschreiben.

An der Theorie der Sprache lässt sich der Gedanke präzisieren. Sprechen, schreiben oder lesen sind Praktiken des Sprachgebrauchs (parole), die nur möglich sind, weil es die Sprache als komplexes Gefüge von Zeichen und Regeln (langue) bereits gibt. Aber dieses strukturelle Sprachgefüge bleibt virtuell existent, solange es nicht durch Gebrauch zu praktischer Wirksamkeit in Raum und Zeit gebracht worden ist. Dieser rekursive Zusammenhang bildet auch den Ausgangspunkt in Anthony Giddens Strukturierungstheorie, ${ }^{7}$ die ebenfalls an die Philosophie von Wittgenstein anschließt. ${ }^{8}$ Im Zentrum steht dessen Begriff einer Regel, die in grundlegender Weise vom Anwendungs-Know-how der Handelnden abhängt. Diese müssen ein praktisches Wissen davon haben, wie Regeln kontextspezifisch, also je nach Situation zu gebrauchen sind, da die Regeln unmöglich alle Aspekte ihrer Anwendung vorab regeln können. Denn

6 Marx/Engels: Ausgewählte Werke, S. 308.

7 Vgl. Giddens: Die Konstitution der Gesellschaft.

$8 \mathrm{Zu}$ den hier ansetzenden Theoriedebatten um Strukturalismus und Poststrukturalismus sowie die Theoreme der Praxis bzw. Praktiken vgl. auch Schatzki (1996) und Reckwitz (2003). Einen Bezug zum Konsum stellt u.a. Warde (2005) her. 
gegen das notwendig verallgemeinernde Strukturmoment jeglicher Regel (sonst wäre es keine) steht die Singularität von Raum-Zeit-Stellen, durch die hindurch sich eine Praxis vollzieht. Auch Garfinkels Ethnomethodologie betont diese aktiven und kreativen Anpassungsleistungen der Handelnden im Regelgebrauch, die im Regelgefüge stets auch Modifikationen, Verschiebungen oder Grenzverletzungen bewirken. Es gibt keine Strukturreproduktion ohne Strukturtransformation. Genau darin wurzelt eine Machtquelle jedes Handelnden, ein Vermögen, das bis in die alltäglichsten Routinevollzüge hineinreicht. Verglichen mit der Theorie von Giddens liegt die besondere Leistung de Certeaus darin, dass er diesen Handelnden provokativ Verbraucher nennt und damit eine neue Sicht auf Konsumpraktiken einleitet.

Gewisse Unterschiede werden sichtbar, wenn man die jeweilige Behandlung der Machtproblematik genauer betrachtet: Macht ist für Giddens ein Vermögen zur Umgestaltung von Objekten oder materiellen Phänomenen (allokative Macht) bzw. ein Vermögen, den Entscheidungsspielraum anderer Akteure zu modifizieren (autoritative Macht). Die transformativen Kapazitäten, die hierbei zum Tragen kommen, sind aber keineswegs allein als Eigenschaft der Akteure aufzufassen. Vielmehr gehen sie maßgeblich auf die Verteilung von Ressourcen zurück, die wiederum ein Moment institutionalisierter Strukturen sind. ${ }^{9}$ Das sieht de Certeau kaum anders. Er setzt aber andere Akzente und unterscheidet solche (machtpolitischen) Praktiken, die in Strukturen angelegte oder ausgewiesene Ressourcen gebrauchen, von solchen, die sich auf Quellen der Autonomie stützen, die in den Institutionen nicht vorgesehen sind. ${ }^{10}$

So stellt er z.B. unter den Praktiken des Sprachgebrauchs dem Scbreiben das Lesen gegenüber, das als typische Konsumpraktik gelten kann, die scheinbar nichts Eigenes produziert, sondern nur Vorgegebenes benutzt, also im Vergleich zur Tätigkeit des Autors das Bild vom passiven Verbraucher zu bestätigen scheint:

Das gesellschaftliche und technische Funktionieren der gegenwärtigen Kultur hierarchisiert diese beiden Tätigkeiten. Schreiben bedeutet, den Text zu produzieren; lesen bedeutet, den Text des Anderen zu rezipieren, ohne ihm einen eigenen Stempel aufzudrücken, ohne ihn neu

9 Vgl. Lamla: Anthony Giddens, S. 45-62.

10 Auch Giddens betont freilich, dass Macht keine Einbahnstraße ist und die Handelnden sich auch unter restriktiven Bedingungen einen Rest an Autonomie bewahren. Vgl. Giddens: Die Konstitution der Gesellschaft, S. 199-213. Ebenso wie de Certeau distanziert er sich vom Machtverständnis der Überwachung und Disziplinierung bei Michel Foucault (1976). Vgl. Certeau: Kunst des Handelns, S. 105112. Alternativ dazu greift Giddens insbesondere Erving Goffmans (1973) Analysen zur totalen Institution auf. 
zu gestalten. [...] Was man in Frage stellen muß, ist leider nicht diese Arbeitsteilung (sie ist nur zu real), sondern die Gleichsetzung von Lektüre und Passivität. ${ }^{11}$

Denn nach de Certeau verhält es sich eher umgekehrt: Das Schreiben unterliege, indem es sich zunächst von der Außenwelt absondere, auf die es ausgehend von einer leeren Seite konstruierend einwirken will, einer Ökonomie der Schrift, die als mythische Praktik die moderne, technokratische Herrschaftsordnung reproduziert: ${ }^{12}$

Selbst die Revolution, diese ,moderne“ Idee, stellt ein Schreib-Projekt auf der Ebene einer ganzen Gesellschaft dar, die die Absicht hat, sich gegenüber der Vergangenheit als unbeschriebenes Blatt zu konstituieren $[\ldots] \cdot{ }^{13}$

Gegen Formen des Politischen, die sich in den Codes verfangen, aus denen sie ihre Macht und Wirksamkeit schöpfen, bringt de Certeau die Praktiken des Lesens ins Spiel, die im Text wildern können, weil sie nichts erschaffen müssen.

Gegen das strukturalistische Denken wird hier also eine Autonomie der Praxis betont, die sich in Raum und Zeit vollzieht und sich nicht vollständig kontrollieren oder disziplinieren lässt. ${ }^{14}$ De Certeau unterscheidet Praktiken dahingehend, wie sie zur Ordnung der Strukturen, Codes und Sprachsysteme stehen. Die Differenz von Raum und Zeit ist hierfür wesentlich, denn Kennzeichen institutioneller Machtpraktiken sei eine Dominanz des Ortes über die Zeit, wohingegen Konsumpraktiken die Zeit dem Ort vorziehen müssten. Der Ort steht bei de Certeau für das Planerische, für eine Heimatbasis, von der aus strategisch agiert werden und in die man sich zurückziehen kann, um in Ruhe zu kalkulieren, die Beziehungen zu ordnen usw. Wichtig für die ortsbezogenen Praktiken ist daher die Abgrenzung gegenüber anderen, fremden Territorien. Die Vorbereitungen des Handelns benötigen allerdings Disponibilität in der Zeit, weshalb deren Fließen und Vergehen als natürlicher Feind dieser Form von Machtpraktiken erscheint. Umgekehrt haben die Konsumpraktiken gar keine solche Basis, keinen Ort, von dem aus sich die Handelnden als Subjekte entwerfen könnten. Weil sie vollständig auf das Gebrauchen von Vorgegebe-

11 Certeau: Kunst des Handelns, S. 299.

12 Vgl. ebd., S. $245 f$.

13 Vgl. ebd., S. 248, Hervorhebung weggelassen.

14 Kritisch setzt sich de Certeau auch mit dem Habitus-Konzept von Pierre Bourdieu auseinander, dessen Entwurf zu einer Theorie der Praxis (1979) er als brillanten Text bezeichnet, der aber dem strukturalistischen Denken letztlich verhaftet bleibe. Vgl. ebd., S.112-129. 
nem beschränkt sind, können sie sich eine gewisse Autonomie nur durch die Ausnutzung der sich in der Zeit bietenden günstigen Gelegenheiten bewahren. Genau diese Form von Autonomie sei aber eine in Praktiken des Gebrauchens notwendig enthaltene Qualität, die gegen alle Versuche ihrer Kolonialisierung durch ordnende Prinzipien bewahrt bleibt: „Die Konsumpraktiken sind die Phantome einer Gesellschaft, die ibren Namen trägt. Wie früher die ,Geister' postulieren sie die vielförmige und geheime produktive Tätigkeit."15

Diese Überlegungen münden in eine Unterscheidung von politischen Formen, die für die weitere Beschäftigung mit dem Autonomieproblem des Consumer Citizen hohen Anregungsgehalt besitzt. De Certeau unterscheidet zwischen Taktiken und Strategien, um das spezifisch Politische der Alltagspraktiken von Verbrauchern auf den Begriff zu bringen. Betrachten wir zunächst die Definition von Strategien:

Als Strategie bezeichne ich die Berechnung (oder Manipulation) von Kräfteverhältnissen, die in dem Moment möglich wird, wenn ein mit Willen und Macht versehenes Subjekt (ein Unternehmen, eine Armee, eine Stadt oder eine wissenschaftliche Institution) ausmachbar ist. Sie setzt einen Ort voraus, der als etwas Eigenes beschrieben werden kann und somit als Basis für die Organisierung von Beziehungen zu einer Exteriorität dienen kann, seien dies Stoßrichtungen oder Bedrohungen (Kunden oder Konkurrenten, Feinde, das Umland der Stadt, Forschungsziele und -gegenstände etc.). ${ }^{16}$

Eine strategische Analyse kann in der modernen Konsumgesellschaft z.B. am Marketing und an der Trendforschung durchgeführt werden, sofern diese von einem sicheren Ort aus versuchen, durch Ordnung und Einteilung des Raumes der Zeit vorauszueilen. Grundlegend für die strategischen Praktiken ist die Typisierung und Beobachtung der Anderen, der panoptische Blick auf die Objekte, deren Einteilung und Klassifizierung eine mit der Ordnung ihres Wissens verbundene Macht mobilisieren. Auch wenn sie immer tiefer in die Sphäre der privaten Erfahrungen und Erzählungen vordringen, müssen sie die narrativen Zusammenhänge doch ab einem bestimmten Punkt abschneiden und in die Sprache einer Mode ${ }^{17}$ kleiden, die sich dann wie ein Gerücht (Werbung) verselbständigen und verbreiten kann. Durch die sprachlichen Ordnungs- und Darstellungszwänge, die sich der ökonomischen Produktionslogik verdanken, reproduzieren die Strategien des Marketing dabei laufend eine Dis-

15 Ebd., S. 86, H.d.A.

16 Ebd., S. 87, H.i.O.

17 Vgl. Barthes: Die Sprache der Mode. 
krepanz zwischen den konstruierten Gescbichten, die dem Körper ihren modischen Code aufdrücken wollen, ${ }^{18}$ und den Spuren existenziell gelebter Geschicbtlichkeit, die sich wie ein störendes Geräusch in den körperlichen Praktiken bemerkbar machen. Indem das Marketing diese unverfügbare Eigenaktivität der Verbraucher leugnet, diszipliniert oder auszutreiben versucht, repräsentiert es die modernen „Informations'-Techniker [...], die immer weniger von den Konsumenten wissen“. 19

Im Gegensatz zu den Strategien [...] bezeichne ich als Taktike ein Handeln aus Berechnung, das durch das Fehlen von etwas Eigenem bestimmt ist. Keine Abgrenzung einer Exteriorität liefert ihr also die Bedingung einer Autonomie. Die Taktik hat nur den Ort des Anderen. [...] Sie hat also nicht die Möglichkeit, sich einen Gesamtüberblick zu verschaffen und den Gegner in einem abgetrennten, überschaubaren und objektivierbaren Raum zu erfassen. Sie macht einen Schritt nach dem anderen. Sie profitiert von ,Gelegenheiten' und ist von ihnen abhängig; sie hat keine Basis, wo sie ihre Gewinne lagern, etwas Eigenes vermehren und Ergebnisse vorhersehen könnte. Was sie gewinnt, kann nicht gehortet werden. Dieser Nicht-Ort ermöglicht ihr zweifellos die Mobilität - aber immer in Abhängigkeit von den Zeitumständen -, um im Fluge die Möglichkeiten zu ergreifen, die der Augenblick bietet. ${ }^{20}$

Nicht in den dichotomen Praktiken des Auswäblens, sondern in den fließenden Praktiken des Anwendens und Umfunktionierens lägen demnach die taktischen Autonomiepotenziale des Consumer Citizen. Eine Politisierung dieser Formen hätte weitreichende Konsequenzen für das demokratietheoretische Verständnis von Zivilgesellschaft oder bürgerschaftlichem Engagement, das mit einer Aktivierung der Verbraucherschaft verbunden wäre. Denn die populären Taktiken verankern de Certeau zufolge eine sozio-politische Ethik im ökonomischen System, die sich von der Illusion bereits verabschiedet hat, „dass sich in Kürze etwas ändern wird“. ${ }^{21}$ Sie gehen kein strategisches Bündnis mit den Mächtigen ein, und weit davon entfernt, eine ganze Gegenkultur entwerfen und durchsetzen zu wollen, geht es den Taktiken um die Erhaltung von Räumen, in denen sich Praktiken entfalten können, die nicht den Regeln des Marktes oder des Gesetzes folgen. So kann etwa in der Weigerung von Verbrauchern, für digitale Waren zu zahlen, die sich über Internet-Tauschbörsen auch kostenlos

18 Vgl. Certeau: Kunst des Handelns, S. 265-270.

19 Ebd., S. 296.

20 Ebd., S. 89, H.i.O.

21 Ebd., S. 73. 
downloaden lassen, ein politischer Akt erblickt werden. Für de Certeau wäre dies sicher ein Beispiel dafür, wie der Potlatch als Hinweis auf eine andere Ökonomie im fortgeschrittenen Liberalismus überlebt - wenn auch in illegitimer Form:
Aus diesem Grunde wird auch die Politik der, Gabe` zu einer Taktik der Umfunktionierung. Ebenso verwandelt sich der Verlust, der in ei- ner Ökonomie der Gabe freiwillig war, in einer Ökonomie des Profits in Überschreitung: sie zeigt sich hier als Exzeß (Verschwendung), Protest (Ablehnung des Profits) oder Vergehen (Angriff auf das Ei- gentum). ${ }^{22}$

Es stellt sich allerdings die Frage, ob die Autonomie der Verbraucher in dieser politischen Form ausreichend gesichert werden kann. Sind Taktiken und Strategien nur als prinzipielle Alternativen oder auch als Kombinationen denkbar? ${ }^{23}$ Einerseits weisen neuere Zeitdiagnosen darauf hin, dass strategische Optionen der Zivilgesellschaft schwinden und der flexiblen Bewegung in locker geknüpften sozialräumlichen Netzwerkstrukturen unseres Zeitalters die Zukunft gehört. ${ }^{24}$ Andererseits ist völlig unklar, ob sich „herdenmäßige“ 25 Taktiken im Falle einer fragmentarischen Verbraucherschaft zu einem politischen Projekt bündeln (lassen), das in irgendeiner Form mit bürgerschaftlichen Ideen einer demokratischen Autonomiesicherung verknüpft ist. Auch de Certeau ist sich hier unsicher: Waren die Taktiken unter traditionalen Bedingungen noch in Rituale des Alltags eingebunden, so tauchen die Konsumpraktiken in der atomisierten Großstadt des heutigen Liberalismus wild verstreut auf. Sie irren darin als „Immigranten“26 umher und es ist unklar, ob sie in diesem Zustand eine nennenswerte Wirkung erlangen können. Diese Einschränkungen werfen nicht zuletzt deshalb die Frage nach erweiterten strategischen Optionen und Res-

22 Ebd., S. 74, Hervorhebung weggelassen.

23 Vgl. Parmiggiani/Musarò: „Tactics and strategies of consumption“.

24 Vgl. Castells: Die Macht der Identität; Boltanski/Chiapello: Der neue Geist des Kapitalismus; dazu: Lamla: „Kontexte der Politisierung des Konsums“.

25 Certeau: Kunst des Handelns, S. 353.

26 Es habe „den Anschein, daß die Verallgemeinerung und die Expansion der technokratischen Rationalität im Rahmen der gegenwärtigen Geschichte zu einem Losbröckeln und Auswuchern dieser Praktiken, die früher durch stabile lokale Einheiten reguliert wurden, zwischen den Maschen des Systems geführt hat. Immer mehr geraten die Taktiken aus der Bahn. Losgelöst von den traditionalen Gemeinschaften, die ihr Funktionieren festlegten, beginnen sie in einem sich homogenisierenden und sich ausdehnenden Raum überall aufzutauchen. Die Konsumenten verwandeln sich in Immigranten.“ Ebd., S. 94. 
sourcen der Consumer Citizens auf, weil die Taktiken durch intelligente Veränderungen im (politischen) Marketing ihrerseits vereinnahmt zu werden drohen: Indem es die Verbraucher mit medial produzierten Trugbildern der Glaubwürdigkeit versorgt, ersetzt es das traditionale Moment religiöser Rituale und bietet den Taktiken neue, ambivalente Heimaten. ${ }^{27}$

\section{Shifting Involvements - Albert O. Hirschmans Zyklustheorie des Consumer Citizen}

Die Ambivalenz, die aufgrund dieser ungewissen Dynamik von Taktiken und Strategien stehen bleibt, könnte sich in dem Scbwanken der Consumer Citizens zwischen Privatwobl und Gemeinwobl wiederholen, das Albert O. Hirschman zum Gegenstand einer theoretischen Reflexion gemacht hat. Dabei geht Hirschman allerdings anders als de Certeau davon aus, dass die zyklisch und phasenweise sich ablösenden Engagementformen des Verbrauchers bzw. der Bürgerin entsprechend differenzierte Handlungsarenen des Konsums und der Politik vorfinden. Seine These, wonach es die in diesen Arenen angelegten Enttäuschungserfahrungen sind, die den Wechsel der Engagementform motivieren, setzt voraus,

daß wir es mit Verbrauchern zu tun haben, die sich außerdem auch ihrer Rolle als Staatsbürger bewußt sind und in einer Gesellschaft leben, in welcher der Gegensatz von privatem und öffentlichem Leben Gewicht hat, so daß beide Sphären dauernd um die Aufmerksamkeit und die Zeit des Konsumenten-Bürgers konkurrieren. ${ }^{28}$

Hirschman vergleicht und konfrontiert unterschiedliche Handlungsoptionen des Verbrauchers bzw. der Bürgerin miteinander. Am geläufigsten ist das Begriffspaar Abwanderung und Widerspruch (exit/voice), dem als dritte Option die Loyalität gegenübersteht, die etwa einer Marke, einem Unternehmen oder einer Partei entgegengebracht werden kann. ${ }^{29}$ Es handelt sich um strukturell in die Ordnungen des Marktes bzw. demokratischen Staates eingelassene strategische Optionen, auf wahrgenommenen Leistungsabfall zu reagieren. Hirschman kritisiert marktliberale Theorien der Wohlfahrtsproduktion, indem er zeigt, dass die freie Konkurrenz um Kunden keineswegs zwingend den Output optimiert und unter Umständen sogar der planwirtschaftlichen Steuerung

27 Vgl. ebd., S. 311-333.

28 Hirschman: Engagement und Enttäuschung, S. 70.

29 Vgl. Hirschman: Abwanderung und Widerspruch. 
in autoritären Staaten unterlegen sein kann. Auch wenn die Abwanderungsoption der Verbraucher gesichert ist, also keine Monopole auf dem Markt bestehen, können sich bei Verzicht auf vernehmbaren Protest (voice) Verhältnisse einspielen, die zur allgemeinen Senkung der Qualität marktseitig angebotener Produkte führen. Es sei daher zur Hebung des allgemeinen Wohlstands notwendig, eine Balance zu finden zwischen dem Markt und demokratischen Institutionen, die Feedback ermöglichen.

Exit, Voice, and Loyalty bewegt sich noch ganz auf dem Gebiet einer institutionellen Analyse von strategischen Handlungsoptionen und deren Wohlfahrtseffekten, da die Handlungen in den institutionellen Ordnungen des Marktes oder der Politik vorgesehen sind. Hirschman interessieren jedoch auch die Motivlagen. Dabei rechnet er mit widersprüchlichen Dispositionen der Handelnden, die in einer ökonomischen Theorie des rational kalkulierenden Akteurs nicht adäquat erfasst werden. ${ }^{30}$ Im Anschluss an Tibor Scitovsky ${ }^{31}$ sucht er nach einer triftigen Erklärung für Abstufungen im persönlichen Engagement und findet diese in einer Zyklustheorie emotionaler Wandlungen: In der modernen Gesellschaft korrigieren sich Hirschman zufolge die verschiedenen Motivlagen und Orientierungen der Consumer Citizens nach einiger Zeit von selbst. Das Schwanken zwischen Privatwohl und Gemeinwohl kann durchaus stark in die eine oder andere Richtung ausschlagen. Aufgrund der spezifischen Enttäuschungserfahrungen, die der eigeninteressierte Verbraucher oder die politisch engagierte Bürgerin in ihren Handlungsfeldern jeweils machen, setzt jedoch ein Präferenzwandel ein. Dessen endogene Logik will Hirschman ausgehend von den Erfahrungen im privaten Konsumbereich über die Verlagerung des Engagements in die politische Arena bis zur erneuten Hinwendung zu den privaten Interessen herausarbeiten. Die Konzentration auf endogene Faktoren geschieht nicht gegen die Einsicht, dass änßere Ereignisse (z.B. Kriege oder ökonomische Krisen) für kollektive Verhaltensänderungen häufig sehr erklärungskräftig sind. Vielmehr geht es ihm darum,

die Aufmerksamkeit auf sonst eher vernachlässigte Faktoren zu lenken, auf die inneren Triebkräfte, die hinter den genannten Verhaltensänderungen stehen könnten. Es handelt sich dabei um eben jene Faktoren, die für das massenhafte Auftreten eines Präferenzwandels

30 Schon in seiner ideengeschichtlichen Abhandlung zum Gegensatz von Leidenschaften und Interessen befasst sich Hirschman (1980) mit der Vielschichtigkeit von Handlungsantrieben, allerdings nur aus Sicht politischer Theorien, die den Kapitalismus in Frühphasen seiner Entstehung zu legitimieren versuchten.

31 Vgl. Scitovsky: Psychologie des Wohlstandes. 
bei Konsumenten bzw. Bürgern verantwortlich sind, wenn sie sich eine Zeitlang entweder in der Sphäre des privaten oder des öffentlichen Lebens bewegt haben und dann ihre dabei gemachten Erfahrungen einer wertenden Prüfung unterziehen. ${ }^{32}$

Zunächst tritt auch Hirschman dem Vorurteil entgegen, dass einem aktiven politischen Handeln das passive Verbraucherdasein gegenübersteht. Vielmehr handele es sich um zwei Formen eines aktiven, engagierten Lebens:

(Die) eine ist die traditionelle vita activa, die ganz der politischen Arbeit gewidmet ist, die andere ist darauf gerichtet, sich selbst und der eigenen Familie ein besseres Leben verschaffen zu wollen, wobei mit, besser $^{5}$ hier vor allem vermehrter materieller Wohlstand gemeint ist. ${ }^{33}$

Die zweite Engagementform impliziert keine produktivistische Haltung, die das Lebensglück vollständig in Geldäquivalenten misst und auf Erwerbsarbeit fixiert ist, da die Zufriedenheit mit einzelnen Tätigkeitsbereichen Hirschman zufolge stärker von der Zufriedenheit mit der gesamten Lebenssituation abhängt als umgekehrt. Gegen den abstrakten Maßstab des Geldes führt er auBerdem das praktische Gebrauchen von Gütern an, währenddessen sich vielfältige Überraschungen positiver oder negativer Art einstellen. ${ }^{34}$ So werden auch hier die komplexen Alltagsvollzüge zum eigentlichen Untersuchungsgegenstand, wobei die Enttäuschung im Konsumbereich ähnlich wie im Fall positionaler Gü$\operatorname{ter}^{35}$ zunächst an formalen Kriterien verschiedener Güterklassen festgemacht wird. Hirschman unterscheidet kurzlebige Verbrauchsgüter wie Nahrungsmittel, deren Konsum ein verhältnismäßig geringes Enttäuschungspotenzial aufweise, von verschiedenen Arten langlebiger Gebrauchsgüter sowie Dienstleistungen, die für das allmähliche Einsetzen des Präferenzwandels bedeutsamer seien. Die Enttäuschungen basieren auf der Erfahrung einer Diskrepanz zu den Erwartungen, die mit bestimmten Gütern verbunden sind, und die sich im Falle langlebiger Begleiter des Alltags oder sozialer Dienstleistungsbeziehungen nicht so leicht durch exit-Strategien oder Verdrängung (i.S. der Theorie kognitiver Dissonanz) aus der Welt schaffen lässt.

Diese Diskrepanzerfahrung und das resultierende Enttäuschungsgefühl basieren auf einem Zurechnungsproblem: In den Konsumalltag spielt mehr hinein als die instrumentelle Beziehung zu einem Gut oder einem Dienstleistungsan-

32 Hirschman: Engagement und Enttäuschung, S. 11, H.i.O.

33 Ebd., S. 13, H.i.O.

34 Vgl. ebd., S. 33f.

35 Vgl. Hirsch: Die sozialen Grenzen des Wachstums. 
bieter. So zeigt Hirschmans Analyse der Dienstleistungsbeziehung (etwa zu Ärztinnen, Therapeutinnen oder Bildungseinrichtungen), dass die Zurechnung der Enttäuschung auf die verkaufte Leistung nicht zweifelsfrei möglich ist. In gelingender Weise von Dienstleistungsangeboten Gebrauch zu machen, erfordert nämlich häufig aktive Eigenleistungen der Klienten, deren Fehlgehen ebenso für die Unzufriedenheit mit einem Resultat verantwortlich sein kann wie das Angebot. Ebenso ist bei langlebigen Gebrauchsgütern häufig nicht die Qualität des Produkts, sondern die vor dem Kauf projizierte Glückserwartung verantwortlich dafür, dass sich in der alltäglichen Nutzung anschließend ein Diskrepanzgefühl einstellt. ${ }^{36}$ Auch dieses hängt von Arten der Lebensführung und ihren weiteren Bedingungskonstellationen ab, seien es nun Erschöpfungszustände angesichts des Alltagstrotts oder der Stress aufgrund von Termindruck oder vollen Autobahnen, die zur Einschätzung beitragen, dass das Leben vom Glückszustand, der mit einzelnen Anschaffungen assoziiert war, weit entfernt ist. ${ }^{37}$

Das entscheidende Problem für Hirschman ist nun, den Wechsel in die politische Arena zu erklären, ohne auf externe Faktoren und Ereignisse zu rekurrieren. Er geht davon aus, dass dieser Wechsel eine Veränderung im gesamten Lebensstil dokumentiert. Mit dem Konzept der Willensäußerungen zweiter Ordnung bzw. Meta-Präferenzen von Harry G. Frankfurt bzw. Amartya Sen sucht Hirschman nach Erklärungen, wie es zur kritischen Neueinschätzung des gesamten Systems der ,in Kaufentscheidungen und sonstigen Handlungsweisen ,zutagetretenden' Präferenzen im Blick auf andere mögliche Präferenzordnungen“38 kommt. Inwiefern liegen diesem Wandel exit-/voice-Strategien, d.h. eine strategische Kalkulation alternativer Handlungsoptionen zu Grunde? Und welche Rolle spielt die Evaluation von Enttäuschungen im privaten Konsum unter dem Gesichtspunkt, dass mit Alltagstaktiken in der privaten Lebensführung nur sehr begrenzte Autonomiegewinne möglich sind? Eine Klärung dieser Fragen kann Aufschluss darüber geben, wie Politisierungsprozesse als Bildungsprozesse des Consumer Citizen vonstatten gehen und auf welche Weise unterschiedliche Quellen der Autonomie darin ineinandergreifen.

36 Vgl. Hirschman: Engagement und Enttäuschung, S. 50-52.

37 Diese zwei Seiten der Enttäuschungszurechnung lassen sich mit de Certeaus Unterscheidung von Taktiken und Strategien als Formen der Autonomiegewinnung in Verbindung bringen: Während die Taktiken darauf abstellen, aus vorgegebenen Bedingungen durch kreativen Gebrauch Gewinne zu erzielen, neigen Strategien zu einer instrumentellen Haltung, die durch gezielte Eingriffe - Tapetenwechsel, neue Möbel, ein anderes Auto etc. - die Situation neu ordnen will.

38 Ebd., S. 76. 
Sicherlich führt nicht ein einziger Weg in die politische Arena. Ein wiederkehrendes Muster in den verschiedenen Politisierungspfaden, die Hirsch$\operatorname{man}^{39}$ an aufkommenden Konsumkritiken entziffert, scheint aber ein Missverhältnis zwischen spezifischen institutionellen Marktoptionen und diffuseren alltagskulturellen Erwartungen - also eine Art Konflikt zwischen System und Lebenswelt ${ }^{40}-\mathrm{zu}$ sein: Dies trifft auf die traditionale Kritik am Konsumismus, die dessen kulturelle Zersetzungstendenzen anprangert, ebenso zu wie auf eine Kritik ungleicher Lebenschancen, die aus starken Einkommensunterschieden resultieren, oder auf eine existenzialistische Argumentation, die im Konsum eine völlig unzureichende Kompensation tieferer Sinnfragen erblickt, sowie schließlich auf die Mobilisierung von Zukunftsängsten, die mit der rastlosen Innovationsdynamik der Konsumgüterindustrie verbunden werden können. Immer werden Autonomieansprüche thematisiert, die im Wechsel in die Politik nicht einfach die Verfolgung marktstrategischer Zwecke mit neuen Mitteln sehen. Die im Konsumalltag angelegten Enttäuschungen führen demnach nicht auf direktem Wege zur Politisierung des Engagements. Vielmehr können sie sehr lange zur Beibehaltung oder sogar Steigerung eines marktkonformen strategischen Konsummusters beitragen, dessen laufende Erneuerung gerade auf permanente Entwertung angewiesen ist. Eine weitere denkbare Folge wäre, dass die Akteure in depressive Stimmungslagen verfallen, wenn die ins konsumkulturell durchzogene Alltagsgeschehen eingelassenen taktischen Fähigkeiten zur Bewahrung von Distanz und Unabhängigkeit versagen. Erforderlich ist daher die Aktivierung von Interpretationsquellen, die das Diskrepanzgefühl des enttäuschten Verbrauchers mit anderen, die systemischen Codes des Marktes überschreitenden Sinn- und Lebensbezügen in Verbindung bringt und eine Neubewertung unter veränderten Meta-Präferenzen einleitet:

Am plausibelsten kann man es sich vielleicht so vorstellen, daß sich erfahrene Enttäuschungen mit der Zeit in konsumkritischen Bedürfnissen zweiter Ordnung niederschlagen und dann ein äußeres Ereignis (der Vietnamkrieg oder eine individuelle Neurose) den tatsächlichen Wechsel zum politischen Engagement auslöst. Umgekehrt könnte auch die Enttäuschung die Rolle des auslösenden Ereignisses übernehmen, wobei dann die Bedürfnisse zweiter Ordnung ihre Ursache nicht in Konsumerfahrungen haben würden, sondern z.B. in jugendlichen Geistern eingepflanzten Ideologien davon, wie wichtig es sei,

39 Vgl. ebd., S. 53-66.

40 Vgl. Habermas: Theorie des kommunikativen Handelns. 
sich für eine gute Sache einzusetzen und so dem Gemeinwohl zu dienen. ${ }^{41}$

Für das politische Engagement der vom privaten Verbraucherdasein enttäuschten Bürgerin zählt dementsprechend nicht so sehr der strategische Erfolg, sondern vor allem die Praktizierung einer veränderten Lebensform. Angesichts der Befriedigungen, die aus dem gemeinwohlorientierten Handeln selbst gezogen werden, können die damit verbundenen politischen Zielvorstellungen verhältnismäßig unbestimmt bleiben und frei fluktuieren. Die Illusion oder das Gefühl, an einer Verbesserung der Gesellschaft aktiv teilzuhaben, ist zunächst wichtiger, als der tatsächlich erreichte oder erreichbare Fortschritt in der Sache. ${ }^{42}$ Enttäuschungen in der politischen Arena resultieren dementsprechend vorwiegend aus alltagspraktischen Konflikten zwischen den Erwartungen an die Aktivitäten und eintretenden Erfahrungen, etwa hinsichtlich des erforderlichen Zeitaufwandes von gemeinwohlorientiertem Engagement, für das sich schwerlich ein angemessenes Maß finden lässt. Überengagement, Suchtbildung auf der einen und systematische Unterforderung durch die politischen Institutionen der repräsentativen Demokratie auf der anderen Seite bezeichnen daher das Spektrum an Faktoren, die eine erneute Abwendung - diesmal vom politischen Leben - vorbereiten:

Das Engagement derjenigen, die aktiv an der Gestaltung der Ereignisse mitzuwirken in der Lage sind, mag an der Gefahr der Überforderung scheitern, während andere, die nicht mehr, aber auch nicht weniger wollen, als mit Nachdruck ihre Sorge und Beunruhigung über diese oder jene Frage zu Gehör zu bringen, aufgrund der Gefahr der Unterbeanspruchung aufgeben, die sich mit der Einsicht einstellt, daß sie doch im wesentlichen auf den Gebrauch des Stimmzettels beschränkt sind. Möglich ist auch, daß ein einzelner Mensch in verschiedenen Phasen seines oder ihres Lebens beide Erfahrungen macht; interessanter noch, er könnte erkennen - und dies ist meiner Meinung nach eine keineswegs seltene Intuition -, daß sich bei einer Teilnahme am öffentlichen Leben lediglich die unbefriedigende Wahl zwischen übermäßiger und unzulänglicher Beteiligung bietet, und daß Engagement daher in jedem Falle auf Enttäuschung der einen oder der anderen Art hinauslaufen wird. ${ }^{43}$

41 Hirschman: Engagement und Enttäuschung, S. 81.

42 Vgl. ebd., S. 90-99.

43 Ebd., S. 130f., Hervorhebung weggelassen. 
Die endgültige Rückwendung auf private Interessen wird insbesondere dann vollzogen, wenn sich zu erlittenen Enttäuschungen die ernüchternde Einsicht gesellt, dass die Politik nur dem Machtkampf und der Selbstsucht von Politikerrinnen dient, die jegliche Glaubwürdigkeit in ihre guten Absichten verspielen. Da Versuche, private Interessen mit dem öffentlichen Leben unter diesen Umständen zu verbinden, schnell unter Korruptionsverdacht geraten, erscheint die konsequente Abwendung plausibler und attraktiver. ${ }^{44}$

Anders als zahlreiche Zeitdiagnosen, die den Verlust einer dezidiert politischen Öffentlichkeit beklagen, ${ }^{45}$ leitet Hirschman aus seinen Analysen die Forderung ab, nach Wegen der Vermittlung und Verschränkung von privatem und politischem Engagement zu suchen. ${ }^{46}$ Nun sind Tendenzen zu einer solchen Hybridisierung der Praktiken von Consumer und Citizen längst zu verzeichnen. Schon David Riesman und seine Mitarbeiter haben diese Entwicklung konstatiert. Auch ihre klassische Charakterstudie zur einsamen Masse behandelt das Thema der Autonomie im Zusammenhang mit der Figur des Verbrauchers und Formen des politischen Handelns und Denkens. ${ }^{47}$ An diese Untersuchung lässt sich daher die Frage weiterreichen, wie die Consumer Citizens ihre Autonomie sichern können, ohne laufend den systematisch erzeugten Enttäuschungen ausdifferenzierter Ordnungen des Konsums bzw. der Politik zu erliegen. Aber droht nicht ein viel größerer Autonomieverlust, wenn das Öffentliche in den Handlungsrahmen des Konsums hineingenommen wird und die Massenmedien und Werbung alle Unterschiede zwischen politischen und ästhetisch-expressiven Wertfragen zum Schwinden bringen?

44 Vgl. ebd., S. 136-142.

45 Vgl. Arendt: Vita Activa; Habermas: Strukturwandel der Öffentlichkeit; Sennett: Verfall und Ende des öffentlichen Lebens; Bauman: Flüchtige Moderne.

46 Vgl. Hirschman: Engagement und Enttäuschung, S. 146f.

47 Hirschman und Riesman interessieren sich beide für Entwicklungen, die in Folge der Wohlstandssteigerungen und Konsumrevolutionen auftreten, wie sie insbesondere für die 1950er Jahre typisch waren, die aber schon früher begannen. Dabei geht Hirschman von Beobachtungen aus, die Riesman noch nicht machen konnte: Seine Zyklustheorie steht unter dem Eindruck der Politisierungen von 1968 sowie deren Abflauen im Laufe der 1970er Jahre, in denen „der ungestörte wirtschaftliche Aufschwung der vorausgegangenen Jahre von einer Periode der Instabilität und der Krisen abgelöst wurde“. Ebd., S. 9. 


\section{Die Autonomie des Außen-Geleiteten - David Riesmans typologische Rekonstruktionen}

Der Consumer Citizen erscheint bei Riesman als typische Gestalt der entwickelten Moderne, die mit historisch früheren Typen kontrastiert wird, wodurch sich die Frage nach Autonomiepotenzialen und Bildungsprozessen zielgenauer stellen lässt. Seine Unterscheidung von drei Charakter-Typen - dem traditions-geleiteten, dem innen-geleiteten und dem außen-geleiteten Charakter - erfolgt in der Absicht einer empirischen Generalisierung von Charaktermerkmalen, die zu bestimmten historischen Zeiten dominant in der amerikanischen Gesellschaft auftreten, wobei stets betont wird, dass sie kaum in der Reinheit ihrer idealtypischen Abstraktionen vorkommen, sondern in mannigfaltigen Abstufungen und Mischungsverhältnissen. ${ }^{48}$ Der typologische Ansatz trägt also stärker den Differenzierungslinien zwischen einzelnen Fällen Rechnung, rechnet mit der Koexistenz verschiedener Charaktere, Engagementformen und Zeitgeister in einer Epoche und begreift es als sein Hauptproblem, jeweils empirisch angemessene Ebenen der Verallgemeinerung von Merkmalen zu identifizieren, auf der die Mannigfaltigkeit konkreter Einzelfälle zu überschaubaren und theoretisch aussagekräftigen Typologien gruppiert und angeordnet werden kann.

Hierbei tritt der Verbraucher in Gestalt des außen-geleiteten Charakters auf den Plan. Dieser unterscheidet sich signifikant von jenem prinzipienfesten, an Idealen ausgerichteten Typus des Innen-Geleiteten, den Riesman - wie viele nach ihm - in Anlehnung an Max Webers Rekonstruktion von Spuren der protestantischen Ethik im Geist des modernen Kapitalismus bestimmt. ${ }^{49}$ Eine wesentliche Eigenschaft dieses überzeugten Berufsmenschen, dessen asketische Züge, Entschlossenheit und Rastlosigkeit Weber auf seelische Bedürfnisse zurückführte, die aus dem Glauben an die calvinistische Lehre der Gnadenwahl resultierten, ist ein inneres Richtungsbewusstsein, das sein Handeln weitgehend unabhängig von den geäußerten und wechselnden Meinungen und Ansichten seiner Mitmenschen macht. Im Kontrast zu diesem Handeln nach einem inneren Kreiselkompass kennzeichnet Riesman den außen-geleiteten Typus durch das nautische Bild einer Radar-Anlage, die ausgelegt ist, sämtliche Signale

48 Vgl. etwa Riesman u.a.: Die einsame Masse, S. 47.

49 Bekanntlich wollte Weber (1996) klären, wie sich der moderne ökonomische Habitus gegen die vorherrschende traditionsgeleitete Lebensweise durchsetzen konnte. Die Fortsetzungen von David Riesman, Daniel Bell (1991), Colin Campbell (1987) bis hin zu Luc Boltanski und Ève Chiapello (2003) interessieren sich vor allem für jene Schwellen oder Brüche, die nach oder mit der vollen Entfaltung des Kapitalismus entstehen. 
aus der Umwelt einzufangen, um auswerten zu können, wie das Handeln am günstigsten an diese Umwelt anzupassen ist. ${ }^{50}$ Günstig verweist hierbei vor allem auf die Gunst der Anderen und nicht unbedingt auf ein ökonomisches Kalkül: Der Außen-Geleitete braucht laufend die Anerkennung und Bestätigung seiner verschiedenen Bezugsgruppen.

Das für die Ausbildung dieser Charakterzüge maßgebliche soziale Feld ist nicht die Produktion, der innere Zusammenhang von Beruf und Berufung, sondern angesichts des Ressourcenüberschusses in Wohlstandsgesellschaften zunehmend die Freizeit, das harmonische Zusammenleben und die fluktuierenden Welten des Konsums. Die Erziehung zum Verbraucher, die nach Riesman bei einsetzender gesellschaftlicher Bevölkerungsschrumpfung funktional wird $^{51}$ und den außen-geleiteten Charaktertypus hervorbringt, beginnt bei der frühen Sozialisation durch verständnisvolle Eltern und Lehrer - deren Einfluss allerdings im Laufe der Kindheit und Jugend zugunsten der Peer-Group, also der Gruppe der Altersgenossen, zurücktritt - und reicht bis zur veröffentlichten Meinung durch moderne Massenunterhaltungsmittel und kundenorientierte Marktakteure. Das Individuum lernt, sich flexibel auf die äußeren Erwartungen einzustellen, d.h. seine Meinungen und seinen Geschmack entsprechend zu wechseln, und spezialisiert sich auf die zwischenmenschliche Kommunikation in Freizeit und Beruf, indem es seine Persönlichkeit durch kleine Stilbesonderheiten (marginal differentiations) ausformt und auf diese Weise für die antagonistischen Kooperationen in diesen Feldern fit macht.

Sein außenorientiertes Konsumverhalten schlägt auch auf andere Handlungsbereiche durch und prägt nicht zuletzt die politischen Haltungen. Anders als Hirschman nimmt Riesman hier keine Pendelbewegung an, sondern rekonstruiert zunächst die zu den Charaktertypen und ihren Untertypen passenden politischen Engagementformen. Unter den Außen-Geleiteten nähmen zwar viele die Haltung einer neuen Gleichgültigkeit an. Eine nicht unerhebliche Minderheit zelebriere jedoch ein ausgiebiges politisches Interesse. Dies sind die Informationssammler (inside-dopester), die das außen-geleitete Konsumverhalten auf die Politik übertragen:

Wir können uns unter dem Informationssammler einen Menschen vorstellen, der (aus guten Gründen) zu dem Schluß gekommen ist,

50 Vgl. Riesman u.a.: Die einsame Masse, S. 32-41.

51 „In der Tat ist in der Phase der beginnenden Bevölkerungsschrumpfung die Bevölkerungskurve stark mit unproduktiven Verbrauchern besetzt, also der wachsenden Anzahl von alten Menschen und der rückläufigen Anzahl von jungen, noch unausgebildeten, und diesen muß einerseits wirtschaftlich Gelegenheit gegeben werden, an dem Überfluß teilzunehmen, andererseits müssen sie die hierfür erforderliche Charakterstruktur besitzen." Ebd., S. 35. 
daß er, unfähig den Verlauf des politischen Geschehens zu ändern, diesem nur noch Verständnis, aber keinen Handlungsimpuls entgegenbringen kann. ${ }^{52}$

Diese konsumierende Bürgerin bemüht sich, stets gut informiert zu erscheinen, nimmt Anderen gegenüber eine abgeklärte, tolerante Haltung ein und beschränkt sich darauf, sich selbst zu manipulieren. Durch ihr Konsuminteresse stützt sie das massenmedial verbreitete, illusionäre Bild einer von Persönlichkeiten gemachten Politik, die tatsächlich bloß inszeniert ist. Mit der Zeit kann sie gegenüber der öffentlichen Meinung keine klare Position mehr beziehen, weil sie Zusammenhänge zwischen der Politik und ihren persönlichen Erfahrungen nicht mehr interpretieren kann:

Der außen-geleitete Informationssammler ist unfähig, irgendein Werturteil auf eine vorgefaßte und auf einem einheitlichen Gefühlszusammenhang beruhende Überzeugung zu stützen. ${ }^{53}$

Es ist die hybride Gestalt eines Consumer Citizen, dem die Quellen der Autonomie weitgehend abhanden gekommen sind. Die Verschmelzung von politischen und Konsum-Orientierungen und der Wunsch, stets alle Optionen offen zu halten, disponieren ihn zum „Drifter“54, der seine Entscheidungsfähigkeit weitgehend eingebüßt hat. ${ }^{55}$

Mit dieser Schlussfolgerung gibt sich Riesman jedoch keineswegs zufrieden, weshalb er im dritten Hauptteil seines Buches systematisch nach den Reserven fragt, die insbesondere von den Außen-Geleiteten, aber auch von den anderen Charaktertypen gegen Konformitätszwänge in Anschlag gebracht werden können. Denn eine einfache Gleichsetzung des Innen-Geleiteten mit der autonomen Bürgerin und des Außen-Geleiteten mit dem hilflos den Modeströmungen ausgelieferten Verbraucher verbietet sich für Riesman. Auf ihre Weise repräsentieren alle Charaktertypen ein konformistisches Handlungsmuster:

Die ,Angepaßten' (adjusted) [...] sind die typischen Traditions-Geleiteten, Innen-Geleiteten und Außen-Geleiteten - jene, die ihrer charakterlichen Struktur nach den Forderungen der Gesellschaft oder

52 Ebd., S. 193.

53 Ebd., S. 239.

54 Sennett: Der flexible Mensch.

55 Vgl. zusammenfassend: Rosa: Beschleunigung, S. 381-390. 
Klasse in den jeweiligen Stadien der Bevölkerungsbewegung entsprechen. ${ }^{56}$

Neben die Angepassten und Autonomen stellt Riesman die Anomalen. So praktiziert jene innen-geleitete Bürgerin, die ihre Maximen unter gegenwärtigen Bedingungen noch gesinnungsethisch vertritt (Hier stehe ich, ich kann nicht anders), eine womöglich auch für sie selbst schädliche Form von Anpassungsverweigerung. Die Lösung des Problems kann demnach kaum in der Neuauflage von Charaktermerkmalen des alten Bildungsbürgertums bestehen, auch wenn in der innen-geleiteten Epoche die Autonomiereserven größer waren. ${ }^{57}$ Riesman sucht daher nach unentdeckten Reserven, die den Verbrauchern im Zeitalter des außen-geleiteten Charakters zur Autonomie verhelfen können. Auch wenn er hauptsächlich Hindernisse dieser Autonomie identifiziert, also das Problem mit den Mitteln der bestimmten Negation angeht, liefern seine Bemühungen doch eine herausragende Quelle für jede zeitgemäße Theorie des Consumer Citizen.

Das Haupthindernis für die Herausbildung autonomer Consumer Citizens sieht Riesman in der falschen Zentrierung aller Anstrengungen auf das Feld der Arbeit. Der zwanghafte Produktivismus, der fest in die Institutionen der modernen Wohlfahrtsgesellschaft eingeschrieben ist, hindert sie daran, sich auf die Vorteile und Möglichkeiten der Freizeitgestaltung wirklich einzulassen. Stattdessen wird das Berufsleben mit Ansprüchen der Selbstverwirklichung überzogen, die darin oftmals nur unzulänglich realisiert werden können. So tritt dort massenhaft die gespielte Freundlichkeit oder inszenierte Aufrichtigkeit in Erscheinung, die das Erfolgskalkül des Marktkontextes nicht abzuschütteln vermögen, in dem sie hervorgebracht wurden. Das demonstrative Konsumieren, das Siegfried Kracauer an Angestellten beobachtet hat, ${ }^{58}$ ihr zwanghaftes Distinktionsgebaren gegenüber der alten Arbeiterklasse, deren „Widerstand gegenüber jedem persönlichen Engagement bei der Arbeit ${ }^{\star 59}$ sie im Grunde beneiden, das Gefühl, Urlaub stets als produktive Investition rechtfertigen zu müssen u.v.m. lässt Riesman zu dem Schluss kommen, dass sich Autonomie nur durch eine deutlichere Abgrenzung zur Sphäre der Erwerbsarbeit gewinnen lässt. Aber wenn diese negative Freiheit - etwa durch ein bedingungsloses Grundeinkommen - hergestellt ist, stellt sich die Autonomie noch nicht von selbst ein. Dieses Problem sieht Riesman sehr klar, was ihn aber

56 Riesman u.a.: Die einsame Masse. S. 253, Hervorhebung weggelassen.

57 Vgl. ebd., S. 263.

58 Vgl. Kracauer, Siegfried: Die Angestellten

59 Riesman u.a.: Die einsame Masse, S. 281. 
nicht davon abhält, „,die Möglichkeit einer organischen Entwicklung der Autonomie aus der Außen-Lenkung “60 ernsthaft zu eruieren:

[Genauso] wie meines Erachtens die Mannigfaltigkeit des Freizeitverhaltens im heutigen Amerika größer ist, als man an der Oberfläche wahrnimmt, so könnten auch die Quellen für utopisches politisches Denken verborgen bleiben, sich dauernd wandeln und ständig selbst verstecken. Obgleich die Neugier und Aufgeschlossenheit dem offiziellen Bereich des politischen Geschehens gegenüber durch das dauernde ,Krisengerede der Presse und der verantwortlichen Kreise des öffentlichen Lebens verdrängt worden sind, könnten die Menschen in dem Bereich, der noch von ihrem Privatleben übriggeblieben ist, neue kritische und schöpferische Maßstäbe entwickeln. Wenn diese Menschen nicht schon in Zwangsjacken gesteckt werden, ehe sie überhaupt den Anfang dazu machen [...], so lernen sie vielleicht eines Tages, nicht nur mit Verbrauchsgütern wie Lebensmitteln oder Büchern, sondern auch mit den ,größeren Gütern' richtig umzugehen: einer Nachbarschaft, einer Gesellschaft und einer Lebensweise. ${ }^{61}$

Charakterliche Reserven, die in der Freizeit zu entfalten wären, liegen in der gesteigerten Sensibilität und Reaktionsfähigkeit, die mit der Außen-Lenkung einhergeht. Doch müssten diese Reserven mobilisiert werden, um die Selbstinterpretation zu verfeinern, d.h. „die eigenen Gefühlsbewegungen, Entfaltungsmöglichkeiten und Grenzen zu erkennen und zu achten“, 62 anstatt sie laufend an externe Anforderungen auszuliefern. Riesman weiß ebenso wie de Certeau, welche Bedeutung hierfür der narrativen Aktualisierung des lebensgescbichtlichen Erfabrungsschatzes zukommt, der sich als wichtigste Quelle für die Kultivierung von Lebenskunst und Verbraucherdasein erweisen kann. Allerdings lässt sich dieser Prozess weder nach Bildungsidealen denken, die vom innengeleiteten Charakter ausgehen oder das Überwechseln in die politische Arena empfehlen, noch kann er sich in beliebigen alltäglichen Konsumpraktiken entfalten. Vielmehr erfordert er ein geeignetes Setting, Ressourcen und Freiräume, für dessen Gestaltung Riesman kluge Anhaltspunkte liefert. Sie lassen sich systematisch in vier Kategorien zusammenfassen und mit neueren Theorieansätzen verknüpfen:

a) Die Autonomie des Verbrauchers wird nicht unabhängig von den Bedingungen sozialer Anerkennung zu gewinnen sein, sondern bedarf der
60 Ebd., S. 272.
61 Ebd., S. 319.
62 Ebd., S. 272. 
Unterstützung durch Freunde, die ihn bei der Interpretation seines lebensgeschichtlichen Zusammenhangs begleiten, „die Lebhaftigkeit und die Aufdeckung jener verborgenen Anlagen des Selbst fördern und anerkennen, zumindest aber nicht bestrafen". ${ }^{63}$ Hierbei handelt es sich um eine Form der sozialen Wertschätzung der Authentizität einer Persönlichkeit, die an der Künstlerbiographie ein Modell finden kann ${ }^{64}$, jedoch nur, sofern diese Abstand zu den verstümmelten marktförmigen und massenmedialen Inszenierungen von Aufrichtigkeit hält, die das Unterscheidungsvermögen des Verbrauchers allenthalben zu unterminieren drohen. Riesman ${ }^{65}$ sucht nach Wegen der Geschmacksverfeinerung durch egalitären, demokratischen Austausch innerhalb der Verbraucherschaft, die ohne Bevormundung auskommen. Hierbei stellt sich allerdings die Frage, ob sich die Anerkennung ästhetisch-expressiver Werte einem deliberativen Austausch und dadurch angestoßenen Lernprozessen überhaupt fügen kann. Die Antwort muss aber nicht negativ ausfallen, sofern angenommen werden darf, dass der moderne Mythos der Authentizität einen Geltungsüberhang aufweist, an dem sich die Consumer Citizens in ihrem „Kampf um Anerkennung “66 kritisch abarbeiten, reiben und über den sie auch politische Bildungsprozesse einleiten können. ${ }^{67}$

b) Eine zweite Voraussetzung für die Autonomie des Außen-Geleiteten sieht Riesman in Tätigkeiten, die einer seelischen Verarmung der Verbraucher in ihrer Privatsphäre entgegenwirken. Am Beispiel des ehrenamtlichen, heute würde man sagen: freiwilligen bürgerschaftlichen Engagements von Frauen an der Heimatfront, aber auch an Formen der Geselligkeit in

63 Ebd., S. 290.

64 Vgl. ebd., S. 304.

65 Vgl. ebd., S. 311-313.

66 Honneth: Kampf um Anerkennung.

67 Dieser Mythos kennzeichnet eine tiefgreifende Ambivalenz im heutigen kulturellen Kapitalismus: Einerseits ist er darin bevorzugtes Objekt kulturindustrieller Übergriffe auf die gesamte Lebensführung durch kommerzielle Lifestyle-Schablonen, andererseits bleibt er Quelle der Kritik, da er die Aufmerksamkeit auf Diskrepanzen zwischen symbolischem Schein und praktischer Lebenswirklichkeit lenkt und dadurch stets aufs Neue taktische Finessen der Verbraucher aktivieren kann, die das ökonomische Sprachspiel durchkreuzen. Vgl. Lamla: „Authentizität im kuturellen Kapitalismus“. Aus diesem Grund lässt sich die Figur eines Kampfes um Anerkennung, also einer empirisch offenen Auseinandersetzung über den Sinngehalt normativer Geltungsansprüche, auf Fragen und Probleme der Authentizität gut übertragen. Die Frage ist, unter welchen Bedingungen diese Dynamik dem AußenGeleiteten hilft, aus der Abhängigkeit von konsumistisch und massenmedial codierter Wertschätzung des Selbst auszubrechen. 
Clubs oder Vereinigungen verdeutlicht er, dass ihm eine gewisse politische Partizipation am Gemeinwesen hierfür unverzichtbar erscheint. ${ }^{68}$ Die Autonomie kann demnach gerade nicht im ganz privaten Konsumalltag gesichert werden. Vielmehr laufen die Konsumgewohnheiten darin in hohem Maße Gefahr, zur seelischen Verarmung ${ }^{69}$ beizutragen, insofern sie häufig zur bloßen Kompensation jener Leerstellen in der Freizeit dienen, die unter anderen Umständen den nötigen Freiraum für die Entfaltung der Persönlichkeit bieten würden. Allerdings bedarf es auch für diese politische Form der Geselligkeit und Partizipation am öffentlichen Leben eines Rahmens, der Lernoffenheit sichert und den Beiträgen einer noch unbekannten, neuen oder fremden Kultur nicht mit desinteressierter Toleranz, aber auch nicht mit Vorurteilen und Klischees begegnet. ${ }^{70}$

c) Als ein wesentliches Element der Autonomiekonstitution ist sodann komplementär zu den öffentlichen Seiten der Consumer Citizens die unverbrüchliche Zusicherung der Privatsphäre anzusehen. ${ }^{71}$ Die Privatsphäre ist ein Ort des Rückzugs von den Anstrengungen des zwischenmenschlichen Austausches und bietet dem Einzelnen zudem die Möglichkeit, in „Spielen, bei denen er allein seinen Träumen nachhängen kann und die seine Phantasie anregen“72 seine persönlichen Neigungen und Interessen besser kennen und einschätzen zu lernen. Die Institutionalisierung solcher Grenzwälle um das Private ist auch gegenüber der Erwerbsarbeitssphäre wichtig. Am Beispiel der Hobbies diskutiert Riesman etwa die Schwierigkeiten, private Selbsterkundungen im Rahmen handwerklicher Tätigkeiten zu vollführen, da sich diese stets mit den entsprechenden beruflichen Tätigkeiten messen müssten. ${ }^{73}$ Dies kann aus heutiger Sicht als warnender Hinweis gelesen werden, dass die Praktiken, die der privaten Selbstexploration in der Freizeit gewidmet sind, immer Gefahr laufen,

68 Vgl. Riesman u.a.: Die einsame Masse, S. 293-298.

69 Heute spricht man von der Volkskrankheit Depression. Vgl. Ehrenberg: Das erschöpfte Selbst.

70 Das Internet könnte einer solchen Öffentlichkeit, in der gemeinwohlbezogene Kriterien für bürgerschaftliches Engagement ebenso wie (ästhetische) Kriterien der sozialen Wertschätzung authentischer Individualität in lernoffener und egalitärer Atmosphäre verhandelt werden, eine geeignete technische Infrastruktur bieten. Neben innovativen Ansätzen der Verbrauchervernetzung setzen sich im digitalen Kulturraum allerdings auch eingespielte kommerzielle und politische Muster fort. Vgl. Bieber/Lamla: „Das Netz der Konsumenten“.

71 Vgl. auch Rössler: Der Wert des Privaten.

72 Riesman u.a.: Die einsame Masse, S. 301.

73 Vgl. ebd., S. 307f. 
durch marktförmige Schablonen - etwa seitens der Beratungsliteratur vorgeformt zu werden. Hier kommt es auf taktische Fertigkeiten der Verbraucher an, sich von den Offerten des Marktes, von denen sie unvermeidlich Gebrauch machen müssen, im Alltag nicht vollständig vereinnahmen zu lassen, wofür Räume des privaten Rückzugs eine wichtige Stütze bilden können.

d) Diese private Autonomie der Verbraucher ist nun paradoxerweise kaum zu sichern, ohne die Hilfe von Freizeitberatern, also von vermittelnden oder stellvertretend für die Verbraucher entscheidenden Akteuren in Anspruch zu nehmen. Riesman benennt das Folgeproblem sehr klar: „Allerdings bleibt der Einwand, daß die Abhängigkeit des außen-geleiteten Menschen nur noch erhöht werden wird, wenn man ihn dem Freizeitberater anvertraut, damit dieser seine Freizeitbeschäftigungen kultiviere, denn er ist ja gerade auf Grund seiner Abhängigkeit außen-geleitet und

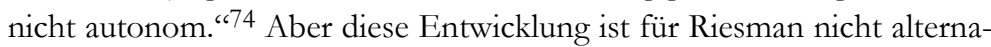
tivlos. Vielmehr kommt es auf die Form des Zusammenwirkens zwischen Berater und Klient an: Für die Verbraucherbildung von kleinen Kindern entwirft er z.B. ein Experiment, in dem sich ein von Werbung und anderen Geschmacksmaßstäben unbeeindruckter Verbrauchernachwuchs ausgerüstet mit Gutscheinen in ,einer Art ständig geöffneter Weltausstellung ${ }^{\text {c675 }}$ frei bewegen kann. Der Marktforschung soll so die Chance gegeben werden, ein umfassenderes Verständnis für die Praktiken des Gebrauchens und die darin angelegten Autonomiepotenziale der Consumer Citizens zu entwickeln. Auch wenn ein solches Szenario, das in der Marktforschung ,eines der wirkungsvollsten Mittel“ sieht, „um zu einer demokratischen Kontrolle unserer Wirtschaft zu gelangen " ${ }^{76}$ recht utopisch wirkt, lassen sich die Hilfestellungen verschiedener Akteure doch danach unterscheiden, ob sie die Autonomie der Verbraucher eher stärken oder schwächen. ${ }^{77}$ Die beratenden, verführenden, unterstützen-

74 Ebd., S. $314 f$.

75 Ebd., S. 315.

76 Ebd., S. 316.

77 Für Anbieter konstatiert Riesman: „Natürlich besteht die Freizeitberatung [...] oft allein in dem Versuch, eine Ware oder einen Dienst abzusetzen, anstatt darin, dem einzelnen zu dem zu verhelfen, was er gerade braucht oder brauchen könnte.“ Ebd., S. 314. Marktforschern dagegen attestiert er, dass sie „sehr wohl [wissen], daß sich die Anwendungsmöglichkeiten ihrer Methoden nicht darin erschöpfen, die Menschen so zu manipulieren, daß sie irgendwelche Artikel oder bereits bestehende kulturelle Anschauungen kaufen, oder sich mit kleinen Besonderheiten [...] ausstaffieren, sondern daß sie durchaus auch dazu benutzt werden können, um zu 
den oder mobilisierenden Aktivitäten von Designerinnen, Verkäuferinnen, PR-Managerinnen, Werbetragenden, Marktforscherinnen, Verbraucheranwältinnen, Schuldnerberatungsstellen, Bewegungsaktivistinnen, Produkttesterinnen und anderen intermediären Instanzen sind mit dem Modell eines professionellen Arbeitsbündnisses ${ }^{78}$ zu konfrontieren, das dem Klientenbezug in therapeutischen Berufen als Norm zu Grunde liegt: Deren Fokus ist die Wiederherstellung oder Kräftigung der beschädigten oder gefährdeten Autonomie und Integrität einer Person - was kaum bedeuten kann, dass sich das Leben noch mehr um die Existenz als auswählender Verbraucher und kompetenter Marktteilnehmer dreht.

\section{$4 \quad$ Fazit}

Ausgehend von drei kultursoziologischen Perspektiven auf die alltägliche Lebensführung hat dieser Beitrag die Frage verfolgt, welche Autonomieprobleme, aber auch -potenziale aus den Handlungskonstellationen von Verbrauchern erwachsen und inwiefern darin Überschreitungen angelegt oder motiviert sind, die politische Formen annehmen. Die hybride Gestalt des Consumer Citizen und deren typische Praktiken kulturtheoretisch zu durchleuchten ist nicht zuletzt deshalb wichtig, weil diese Gestalt wachsende Aufmerksamkeit in einem gesellschaftspolitischen Diskurs erfährt, der die bürgerschaftliche Autonomie der Verbraucher aktivieren und in den Dienst der Zivilisierung einer globalen Marktgesellschaft stellen will, für deren politische Gestaltung andere Mittel abhanden gekommen oder zumindest deutlich geschwächt worden sind. Dies kann - muss aber nicht zwingend - zur Konsequenz haben, dass solche Ambivalenzen, Konflikte, Probleme oder Spannungen ausgeblendet bleiben, die aus der Lebens- und Alltagsperspektive der Consumer Citizens selbst für Gewinne oder Einbußen an Autonomie vordringlich sind. Unter dem ideologischen Deckmantel der Aktivierung, Förderung und Forderung von Verbraucherautonomie würde dann eine Politik betrieben, die Entschei-

erfahren, welche Wünsche die Menschen nicht nur augenblicklich, sondern - mit der Befreiung ihrer Phantasie - auch in Zukunft haben könnten“. Ebd., S. 316; vgl. auch Koppetsch: „Die Werbebranche im Wandel“. Zu bedenken ist freilich (und skeptisch macht), dass das Feld der individuellen Freizeitberatung inzwischen als entscheidender Wachstumsmarkt im kulturellen Dienstleistungskapitalismus ausgemacht worden ist und somit das Ziel der Autonomiegewinnung wiederum unter ökonomische Prämissen zu geraten droht. Vgl. etwa Zuboff/Maxmin: The Support Economy.

78 Vgl. Oevermann: „Theoretische Skizze einer revidierten Theorie professionellen Handelns". 
dungslasten und moralische Zumutungen auf die individuellen Konsumsubjekte bloß abwälzt und in der Konsequenz deren Autonomieprobleme noch verschärft. ${ }^{79}$ Gegen solche Instrumentalisierungen macht die Kultursoziologie Gesichtspunkte der Autonomiegewinnung stark, die an der alltäglichen und biographischen Lebensführung ansetzen, aber gleichwohl in der Wiederaneignung eines politischen Handlungsraumes durch die Verbraucher münden können und wohl auch müssen.

Die Theorie der Konsumpraktiken von Michel de Certeau hat den Blick auf Formen der Autonomiegewinnung oder -sicherung gelenkt, die Überschreitungen von Regeln und Konventionen geordneter Marktteilnahme primär über subversive Taktiken realisieren. Dadurch sind weitergehende Politisierungen des Verbraucheralltags, wie sie von Albert O. Hirschman als Reaktion auf Enttäuschungen, Elemente eines Präferenzwandels und Motive des Wechsels in die politische Handlungsarena untersucht worden sind, freilich nicht ausgeschlossen. Denn die Shifting Involvements zwischen Verbraucher und Bürgerin lassen sich nicht einfach als strategisches Hin- und Herwechseln zwischen exit- und voice-Optionen interpretieren, sondern bezeichnen viel eher verschachtelte Bildungsprozesse, die angetrieben durch Probleme der Autonomiesicherung oder -erweiterung nach geeigneten praktischen Formen der Lebensführung suchen. Diese scheitern aber nicht zuletzt an den institutionellen Rahmenbedingungen der ausdifferenzierten politischen und ökonomischen Ordnungen, weil diese ein ausgeglichenes Engagement sowohl für das Privatals auch das Gemeinwohl systematisch erschweren. Die dadurch gewonnene Perspektive auf die institutionellen und kulturellen Rabmenbedingungen der Autonomiegewinnung über (politische) Bildungsprozesse wird vollends bedeutsam, wenn die typische Lebenskonstellation heutiger Verbraucher mit David Riesman und seinen Mitarbeitern durch die Eigenschaften des Außen-Geleiteten charakterisiert werden, für den der Wechsel von Engagementformen erschwert ist, weil er sich tief in Abhängigkeiten von äußeren Meinungsmoden verstrickt hat und zu deren Spielball geworden ist. An den Schwierigkeiten, diese Abhängigkeiten ein Stück weit zu überwinden und die Konformitätsregeln der Anerkennung und der marginalen Differenzen in Richtung einer gesteigerten Autonomie der Verbraucherpersönlichkeit zu überschreiten, lassen sich einige der Kriterien ablesen, denen die politische Form der Realisierung und Förderung dieser Autonomie heute genügen müsste.

79 Vgl. Lamla: „Sozialpolitische Verbraucheraktivierung“. 
Jörn Lamla | Die Autonomie des Verbrauchers und ihre politischen Formen

\section{Literaturverzeichnis}

Arendt, Hannah: Vita activa oder vom tätigen Leben, München/Zürich 1981.

Barthes, Roland: Die Sprache der Mode, Frankfurt a.M 1985.

Bauman, Zygmunt: Flüchtige Moderne, Frankfurt a.M. 2003.

Bell, Daniel: Die kulturellen Widersprüche des Kapitalismus, Frankfurt a.M./New York 1991.

Bieber, Christoph/Lamla, Jörn: „Das Netz der Konsumenten. Innovationschancen der Verbraucherbewegung im Internet", Forschungsjournal Neue Soziale Bewegungen, Jg. 18, Nr. 4, 2005, S. 65-77.

Boltanski, Luc/Chiapello, Ève: Der neue Geist des Kapitalismus, Konstanz 2003.

Bourdieu, Pierre: Entwurf einer Theorie der Praxis (auf der ethnologischen Grundlage der kabylischen Gesellschaft), Frankfurt a.M. 1979.

Campbell, Colin: The Romantic Ethic and the Spirit of Modern Consumerism, Oxford 1987.

Castells, Manuel: Die Macht der Identität. Das Informationszeitalter, Bd. 2, Opladen 2002.

Certeau, Michel de: Kunst des Handelns, Berlin 1988.

Ehrenberg, Alain: Das erschöpfte Selbst. Depression und Gesellschaft in der Gegenwart, Frankfurt a.M./New York 2004.

Giddens, Anthony: Die Konstitution der Gesellschaft. Grundzüge einer Theorie der Strukturierung. Frankfurt a.M./New York 1992.

Habermas, Jürgen: Theorie des kommunikativen Handelns, Frankfurt a.M. 1981.

Habermas, Jürgen: Strukturwandel der Öffentlichkeit. Untersuchungen zu einer Kategorie der bürgerlichen Gesellschaft, Frankfurt a.M. 1990.

Hirsch, Fred: Die sozialen Grenzen des Wachstums. Eine ökonomische Analyse der Wachstumskrise, Reinbek 1980.

Hirschman, Albert O.: Engagement und Enttäuschung. Über das Schwanken der Bürger zwischen Privatwohl und Gemeinwohl, Frankfurt a.M. 1984.

Hirschman, Albert O.: Leidenschaften und Interessen. Politische Begründungen des Kapitalismus vor seinem Sieg, Frankfurt a.M. 1980.

Hirschman, Albert O.: Abwanderung und Widerspruch. Reaktionen auf Leistungsabfall bei Unternehmungen, Organisationen und Staaten, Tübingen 1974. 
Honneth, Axel: Kampf um Anerkennung. Zur moralischen Grammatik sozialer Konflikte, Frankfurt a.M. 1992.

Koppetsch, Cornelia: „Die Werbebranche im Wandel. Zur Neujustierung von Ökonomie und Kultur im neuen Kapitalismus“, in: Hellmann, KaiUwe/Schrage, Dominik (Hrsg.): Konsum der Werbung. Zur Produktion und Rezeption von Sinn in der kommerziellen Kultur, Wiesbaden 2004, S. 147-161.

Kracauer, Siegfried: Die Angestellten. Aus dem neuesten Deutschland, in: ders.: Schriften, Bd. 1, Frankfurt a.M. 1971.

Lamla, Jörn: „Authentizität im kulturellen Kapitalismus. Gedanken zur ,konsumistischen' Subjektformation der Gegenwart", in: Amrein, Ursula (Hrsg.): Das Authentische. Zur Konstruktion von Wahrheit in der Moderne, Zürich 2007 (im Erscheinen).

Lamla, Jörn: „Sozialpolitische Verbraucheraktivierung. Konsumsubjekt und Bürgergemeinschaft in der Marktgesellschaft", in: Evers, Adalbert/ Heinze, Rolf G. (Hrsg.): Sozialpolitik: Ökonomisierung und Entgrenzung, Wiesbaden 2007 (im Erscheinen).

Lamla, Jörn: „Kontexte der Politisierung des Konsums. Die Zivilgesellschaft in der gegenwärtigen Krisenkonstellation von Politik, Ökonomie und Kultur", in: Adloff, Frank u.a. (Hrsg.): Wirtschaft und Zivilgesellschaft. Theoretische und empirische Perspektiven, Wiesbaden 2005, S. 127-153.

Lamla, Jörn: Anthony Giddens, Frankfurt a.M. 2003.

Lamla, Jörn/Neckel, Sighard (Hrsg.): Politisierter Konsum - konsumierte Politik, Wiesbaden 2006.

Marx, Karl/Engels, Friedrich: Ausgewählte Werke in sechs Bänden, Bd. 2, Berlin 1972.

Oevermann, Ulrich: „Theoretische Skizze einer revidierten Theorie professionellen Handelns", in: Combe, Arno/Helsper, Werner (Hrsg.): Pädagogische Professionalität. Untersuchungen zum Typus pädagogischen Handelns, Frankfurt a.M. 1997, S. 70-182.

Parmiggiani, Paola/Musarò, Pierluigi: „Tactics and strategies of consumption: new way of creative resistance between global and local", Paper zur Online-Diskussion im Rahmen der Tagung „Politisierter Konsum konsumierte Politik“", Gießen, 03.-04.06.2005, www.politik-konsum.de/ pdf/tacticandstrategytotal.pdf, 28.07.2007.

Riesman, David u.a.: Die einsame Masse. Eine Untersuchung der Wandlungen des amerikanischen Charakters, Reinbek 1958. 
Rosa, Hartmut: Beschleunigung. Die Veränderung der Zeitstrukturen in der Moderne, Frankfurt a.M. 2005.

Rössler, Beate: Der Wert des Privaten. Frankfurt a. M. 2001.

Schudson, Michael: „The Troubling Equivalence of Citizen and Consumer“, The ANNALS of the American Academy of Political and Social Science 2006, Nr. 608, 2006, S. 193-204.

Scitovsky, Tibor: Psychologie des Wohlstands. Die Bedürfnisse des Menschen und der Bedarf des Verbrauchers, Frankfurt a.M./New York 1977.

Sennett, Richard: Der flexible Mensch. Die Kultur des neuen Kapitalismus. Berlin 1998.

Sennett, Richard: Verfall und Ende des öffentlichen Lebens. Die Tyrannei der Intimität, Frankfurt a.M. 1986.

Warde, Alan: „Consumption and Theories of Practice“, in: Journal of Consumer Culture, Jg. 5, Nr. 2, 2005, S. 131-153.

Weber, Max: Die protestantische Ethik und der „Geist“ des Kapitalismus, Weinheim 1996.

Zuboff, Shoshana/Maxmin, James: The Support Economy. Why corporations are failing individuals and the next episode of capitalism, New York 2002. 


\title{
Sigrid Baringhorst
}

\section{Konsumenten als Netizens. Das Internet als ambivalentes Medium für ein Empowerment von Verbrauchern}

\author{
Denn die Macht der Konzerne \\ ist nur von den Konsumenten und \\ Konsumentinnen geborgt. ${ }^{1}$
}

\section{Peretti versus Nike - ein Cybermythos des politischen Konsumerismus?}

Am 5. Januar 2001 schrieb Jonah Peretti, damals Assistant Adjunct Professor an der New York University, eine E-Mail an den Sportartikelhersteller Nike. Das Unternehmen hatte angeboten, Designanregungen von Verbrauchern aufzunehmen, die ihren persönlichen Lebensstil durch ein individuell geprägtes Markenprodukt ausdrücken wollten. „[...][A]ll they were really doing was sending instructions to cheap labour in developing countries", 2 dachte Peretti und versuchte, das Unternehmen mit seinen eigenen PR-Waffen zu schlagen. Er nahm die Unternehmensofferte kritisch auf, um ein Paar Turnschuhe mit der Aufschrift sweatshop zu bestellen. Seine E-Mail-Anfrage löste einen längeren E-Mail-Austausch mit dem Online-Verbraucherservice des Unternehmens aus; beendet wurde der Dialog mit der spöttischen Aufforderung Perettis: „Could you please send me a colour snapshot of the ten-year-old Vietnamese girl who makes my shoes?" Der junge Professor mailte die in der protestkulturellen Tradition des Culture Jamming, d.h. der parodistischen Verfremdung, stehende elektronische Diskussion an ca. zwölf Freunde, die sie wiederum weiter an ihre Freunde mailten, und so wurde im elektronischen Schneeballsystem die EMail in kurzer Zeit millionenfach repliziert. ${ }^{3}$ Ende Januar 2001 veröffentlichte die regionale San Jose Mercury News die Geschichte, kurze Zeit später griffen nationale Zeitungen und Zeitschriften wie Time, Village Voice und Wall Street Journal and sogar einige europäische Zeitungen wie The Guardian, La Repubblica und die französische Liberation die Story auf. Gekrönt wurde der Medienerfolg der parodistischen Protestaktion durch einen Auftritt Perettis in der NBC Today Show - er wurde eingeladen, um dort mit einem Vertreter des

1 Werner/Weiss: Das neue Schwarzbuch Markenfirmen, S. 14.

2 Peretti/Micheletti: „The Nike Sweatshop Email“, S. 128.

3 Ebd., S. 129. 
skandalisierten Unternehmens über soziale Unternehmensverantwortung zu sprechen. ${ }^{4}$

Der symbolische Angriff des Culture Jammers und Konsumentenbürgers im Netz auf die sich selbst in ihrer Unternehmens-PR als Unternehmensbürger (Corporate Citizen) inszenierende Nike Corporation hat nicht nur bemerkenswert viel Medienresonanz erfahren. Auch in der wissenschaftlichen Literatur wird Perettis erfolgreiche Konfrontation mit dem internationalen Großunternehmen häufig angeführt, wenn es darum geht, das Potenzial des Internets für die Mobilisierung einer transnationalen Bewegung von Konsumenten zu veranschaulichen.

In diesem Beitrag möchte ich einerseits argumentieren, dass die provokante Aktion Perettis zu Recht so häufig zitiert wird, zumal sie zahlreiche Aspekte einer neuen politischen Protestform, der Politisierung der Konsumsphäre im Rahmen der transnationalen Global-Justice-Bewegung, exemplarisch verdeutlicht. Andererseits wende ich mich jedoch dagegen, dem geschilderten Einzelfall repräsentative Geltung für die Macht von Cyberaktivismus und die Konnektivität zwischen Mikro-, Meso- und Makromedien ${ }^{5}$ im Allgemeinen zuzusprechen, da dadurch die faktische Einlösung der Potenziale computervermittelter Kommunikation im Rahmen von Verbraucherprotesten mystifiziert würde. Erste Auswertungen von Anti-Corporate Campaigns im deutschen Sprachraum führen zu einer weit weniger euphorischen Einschätzung der interaktiven Möglichkeiten der Netztechnologie.

Der Beitrag ist in zwei Teile gegliedert: Im ersten Teil werden aufbauend auf die Aktion von Jonah Peretti einige allgemeine Merkmale der auch als "politischer Konsumerismus" ${ }^{\prime 6}$ bezeichneten transnationalen Verbraucherbewegung dargestellt. Im zweiten Teil wird das Internet als neue und ambivalente Gelegenheitsstruktur für ein politisches Empowerment von Konsumenten gedeutet. Auf der einen Seite hat das Internet zur ökonomischen Globalisierung beigetragen und den Unternehmen neue Mittel und Wege zur interaktiven, netzgestützen Markenbildung offeriert, die potenziellen Kunden - wie das Online-Service-Angebot von Nike zeigt - eine Illusion von Empowerment und Teilhabe vermitteln. Auf der anderen Seite bieten die digitalen Informations- und Kommunikationstechnologien innovative und effiziente Mittel für die kollektive Produktion und Vermittlung alternativen Wissens, das für die Stärkung der Marktposition von Verbrauchern wie für die Stärkung ihrer Rolle als gemeinwohlorientierte Bürger genutzt werden kann. Im Gegensatz zu tra-

4 Ebd., S. 136.

5 Vgl. ebd.

6 Lamla/Neckel: Politisierter Konsum - konsumierte Politik. 
ditionellen Massenmedien ermöglicht das Internet Many-to-Many-Kommunikation und stellt dadurch eine bedeutsame mediale Infrastruktur für netzwerkartige Formen partizipatorischer Politik dar. Jedoch steht der umfassenden Einlösung der technischen Möglichkeiten eine Kampagnenlogik der Protestkommunikation entgegen, die noch immer primär bestimmt ist durch die Notwendigkeit, massenmediale Aufmerksamkeit zu erzeugen. Bürgerkonsumenten im Netz, Netizen Consumers, sind weitaus weniger an deliberativen, diskursiven kulturellen Praxen beteiligt, als es die kommunikative Struktur der neuen Medien ermöglicht. Zudem spielen Nichtregierungsorganisationen (NGOs) in der politischen Mobilisierung von Verbrauchern noch immer eine zentrale Rolle. $^{7}$

\section{Charakteristische Merkmale des politischen Konsumerismus}

Perettis E-Mail-Austausch mit Nike ist aus verschiedenen Gründen charakteristisch für unternehmenskritische Proteste im Rahmen eines transnationalen politischen Konsumerismus, d.h. einer nationale Grenzen überschreitenden Politisierung der Konsumsphäre zur Durchsetzung übergeordneter politischer und sozialer Protestziele. Merkmale dieser konsumeristischen Protestpolitik sind:

\subsection{Entideologisierung}

Appelle an die Macht von Verbrauchern zur Durchsetzung politischer Ziele wie etwa humane Arbeitsbedingungen oder die Einhaltung ökologischer Normen ist in der Regel nicht in umfassende Grand Narratives eingebunden. ${ }^{8}$ Die Anti-Sweatshop-Bewegung, der Perettis Aktion zuzuordnen ist, wie auch Kampagnen zur Skandalisierung gewerkschaftsfeindlicher Arbeitnehmerpolitik in Discountern wie Walmart in den USA, Tesco in Großbritannien bzw. Lidl in Deutschland oder Proteste gegen genveränderte Nahrungsmittel beziehen ihre Legitimation weniger aus komplexen Weltanschauungen als aus der Referenz auf recht allgemeine Diskurse über die Verletzung globaler Menschenrechte. In der Bewegungsforschung gelten die Deutungsmuster konsumeristischer Protestkampagnen als ideologisch „relaxed“ (Bennett) und als auf

7 Zu NGO-zentrierten Anti-Corporate Campaigns vgl. auch Niesyto: „Networking Campaigns".

8 Vgl. Bennett: „Branded Political Comunication“; Micheletti: „Just Clothes?“. 
„flexible identities“ (Tarrow und della Porta) basierend. ${ }^{9}$ Ein breites Spektrum von Forderungen alter und neuer sozialer Bewegungen, von klassischen Arbeitnehmerrechten, Menschenrechten, Frauenrechten oder Normen nachhaltiger Entwicklung, werden lose verknüpft. Im Gegensatz zu alten wie neuen sozialen Bewegungen der 1960er und 1970er Jahre sind gegenwärtige konsumeristische Protestkampagnen in Europa weder schlicht antikapitalistisch noch konsumfeindlich, weder eindeutig auf die Mittelschicht noch allein auf Arbeitnehmer als Träger der Aktionen gerichtet. Unabhängig von ideologischem Hintergrund und sozialem Status der Akteure haben konsumeristische Aktionen eines gemeinsam: Sie zielen auf die Mobilisierung eines neuen Agenten des sozialen und politischen Wandels. Angesprochen werden die Bürger als ethische Konsumenten, ${ }^{10}$ als Bürger, die die Chance nutzen sollen, ihre Konsumpräferenzen zu reflektieren und zu artikulieren, um Unternehmen unter Druck zu setzen, entsprechend den eigenen Präferenzen zu agieren.

\subsection{Medien- statt Marktorientierung}

Gegenwärtige Appelle an die Verbraucher, durch ihr Konsumverhalten Veränderungen einer skandalisierten Unternehmenspolitik zu erwirken, unterscheiden sich von vergleichbaren Aktionen im 19. und frühen 20. Jahrhundert dadurch, dass sie primär auf mediale Resonanz zielen und weniger auf direkte Handlungsfolgen in Form direkter Protestaktionen in örtlichen Konsumzentren. ${ }^{11}$ Während eine erfolgreiche marketplace-oriented action die Mobilisierung einer großen Zahl von „foot soldiers to staff the boycott picket lines at the entrances to retail stores"12 voraussetzt, stellen media-oriented actions weitaus geringere Anforderungen an die politische Beteiligung von Bürgerkonsumenten. ${ }^{13}$ Sofern Campaigner wissen, wie man die Aufmerksamkeit der Journalisten auf Protestaktionen und -ziele richtet, bedarf die Inszenierung von Protest nur noch eines reduzierten Personals; zuweilen reicht, wie die mediale An-

9 Tarrow und della Porta definieren „flexible identities“ als „,...] identities characterised by inclusiveness and a positive emphasis upon diversity and cross-fertilization, with limited identifications that develop especially around common campaigns on objects perceived as ,concrete and nurtured by search for dialogue." Tarrow/Porta: „Conclusion“, S. 236, H.i.O.

10 Vgl. Beetz in diesem Band zur Diskussion von allgemein- und eigenwohlorientierten Aspekten von Consumer Citizenship.

11 Vgl. Friedman: Consumer Boycott, S. 45-62.

12 Ebd., S. 51.

13 Zur Kontinuität massenmedialer Ausrichtung politischen Protests vgl. auch Baringhorst/Kneip/Niesyto in diesem Band. 
schlusskommunikation der Provokation Jonah Perettis zeigt, die kreative Initiative eines Einzelnen.

\subsection{Transnationale Markenfirmen als Protestziele}

No logo - der Titel des Bestsellers von Naomi Klein bringt die besonders markenfeindliche Haltung des gegenwärtigen politischen Konsumerismus auf den Punkt. Transnational operierende Markenunternehmen bilden die häufigsten Angriffsziele transnationaler Verbrauchermobilisierung. ${ }^{14}$ Marken sind

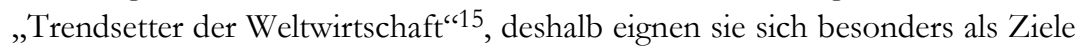
konsumeristischen Protests. Transnationale Unternehmen werden für die meisten Ungerechtigkeiten verantwortlich gemacht, die der ökonomischen Globalisierung zugeschrieben werden. Da die Marktverhältnisse jedoch aufgrund der Vielfalt von Produkten und der Komplexität von Eignerstrukturen der Unternehmenswelt immer weniger durchschaubar geworden sind und dadurch new cognitive burdens für rein marktorientierte Protestakteure erzeugt werden, greifen Protestakteure im Sinne des brand bashing bekannte Dachmarken an. Große transnationale Unternehmen haben oft eine Vielzahl von Zulieferern und Teilhabern, die ihre eigenen Produkte unter verschiedenen Markennamen verkaufen. Der Boykott gegen Nestlé in den 1970er Jahren verdeutlichte die Schwierigkeiten, die entstehen, wenn ein skandalisiertes Unternehmen seine Produkte und Dienstleistungen unter vielen verschiedenen Markennamen anbietet. Insofern ist es einfacher, in einer weitgehend symbolisch bleibenden Aktion eine Dachmarke anzugreifen, als alle Waren und Dienstleistungen einer Firma zu boykottieren.

\subsection{Culture Jamming als protestkulturelle Ausdrucksform}

Mit der Fokussierung auf medienorientierte Protestaktionen gegen bekannte Markenprodukte und -firmen geht eine in der Regel binär codierte kommunikative Rahmung konsumeristischer Kampagnen einher. Die ökonomische Macht der als ruchlos und übermächtig konstruierten Unternehmen wird in oft simplen David-versus-Goliath-Strukturen mit der moralischen Überlegenheit, Kreativität, Einsatzbereitschaft und dem Mut der als machtlos und ressourcenarm konstruierten Advokaten einer humanen Weltethik konfrontiert. Die außergewöhnliche Aufmerksamkeit, die das in Kanada herausgegebene $A d$ -

14 Vgl. Evans: Fighting Marginalization with Transnational Networks, S. 231.

15 Werner/Weiss: Das neue Schwarzbuch Markenfirmen, S. 47. 
busters Magazine oder auch andere Akte des Culture Jamming wie etwa die Nikeground-Kampagne der Wiener Netzkulturinitiative Public Netbase aus dem Jahr 2003 erzielen, resultiert aus der Kombination avangardistischer humorvoller Praxen des so genannten uncooling cooler Markenimages verbunden mit hochmoralischen Forderungen nach einer Befreiung öffentlicher Räume von der Dominanz kommerzieller Zeichen:

We will take on the archetypal mind polluters - Marlboro, Budweiser, Benetton, Coke, McDonald's, Calvin Klein - and beat them at their own game. [...] On the rubble of the old media culture, we will build a new one with a non commercial heart and soul ${ }^{16}$

so die selbstgesetzten Ziele der Bewegung im Adbusters Media Manifesto.

\subsection{Veralltäglichung des Protests}

Wie der Fall Jonah Peretti illustriert, sind die Protestaktionen des gegenwärtigen politischen Konsumerismus weitaus weniger kollektivistisch als Protestmobilisierungen früherer sozialer Bewegungen. Unterstützungshandlungen wie das Schreiben standardisierter elektronischer Protestbriefe an skandalisierte Unternehmen oder der Boykott bestimmter Produkte und Firmen sind einfach in die alltägliche Einkaufspraxis zu integrieren. Sie folgen einem allgemeinen Trend zur Veralltäglichung politischen Protests, der nach Dieter Rucht charakteristisch ist für den Wandel von Protestkulturen in den letzten Jahrzehnten. Die geringen Kosten und Hemmschwellen der politischen Beteiligung an einer Politik mit dem Einkaufswagen helfen Free-Rider-Aktionen wie aber auch ein Burn-Out unter den Aktivisten zu verhindern. Die Kopplung der Bürgerrolle an den Konsumentenstatus spiegelt zudem den für die Entwicklung politischer Partizipation allgemein gültigen Trend des Rückzugs vom öffentlichen ins private Leben wider. Lebensstilfragen werden politisch aufgeladen - Bennett spricht in dem Zusammenhang mit Bezug auf Anthony Giddens und Ulrich Beck zu Recht von lifesytle politics - damit verschwimmt die Trennlinie zwischen öffentlicher und privater Sphäre. ${ }^{17}$

16 Zitiert nach Danesi: Brands, S. 133.

17 Vgl. Micheletti: „Just Clothes?“, S. 24. 


\subsection{Schwache Gemeinschaftsbindungen}

Protestkulturelle Politisierungen der Konsumsphäre setzen keine klar umrissenen, dauerhaften kollektiven Identitäten unter den Unterstützern voraus. Fallbezogene Gemeinschaftsbildungen basierend auf schwachen, lockeren Bindungen unter den Protestakteuren reichen für eine erfolgreiche Protestmobilisierung durchaus aus. Unterstützer von Protestnetzwerken und -kampagnen müssen sich nicht unbedingt in der Offline-Welt treffen, um intensive emotionale Bindungen aufzubauen oder Gemeinschaftsgefühle zu entwickeln. Die Alteritätskonstruktionen, die Erzeugung von Negativ-Images skandalisierter Markenfirmen, bieten abgesehen von moralisch positiv aufgeladenen Selbstkonstruktionen skandalisierender NGOs oder Protestnetzwerken in der Regel eine ausreichende symbolische Grundlage zur individuellen und kollektiven Orientierung unter den Protestakteuren. ${ }^{18}$

\subsection{Protestnetzwerke als vorherrschende Organisationsformen}

Ein weiteres Merkmal unternehmenskritischer, konsumeristischer Protestaktionen besteht - wie auch das Fallbeispiel von Jonah Peretti erkennen lässt - in den netzwerkähnlichen Sozialbeziehungen unter den Protestakteuren. Idealerweise spiegeln die Strukturen der Protestnetzwerke die transnationale Dimension der Netzwerkstruktur der angegriffenen Großunternehmen wider. $\mathrm{Zu}$ unterscheiden sind in dem Zusammenhang zwei Typen transnationaler Netzwerke. ${ }^{19}$ Erstens: transnational advocacy networks. ${ }^{20}$ Sie zielen darauf, Akteure von Entwicklungsländern mit Protestakteuren der so genannten Ersten Welt zu verknüpfen, in der Annahme, dass letztere einen größeren Einfluss auf die globale Ökonomie besitzen. Die organisatorischen Koalitionen verbinden unterschiedliche gewerkschaftliche Organisationen und Berufsverbände, wie etwa Bauernverbände, mit zivilgesellschaftlichen Organisationen, wie EntwicklungsNGOs, Menschenrechts-NGOs oder Kirchen. Diese NGO-zentrierten Netzwerke zeichnen sich durch einen geteilten strategischen Handlungsrahmen aus und zentrieren ihr Aktionsbündnis in der Regel auf ein einziges, gemeinsam festgelegtes Protestissue. Entscheidungsstrukturen innerhalb der Protestnetzwerke sind top-down ausgerichtet, d.h. strategische Absprachen erfolgen unter den jeweiligen Repräsentanten der beteiligten NGOs, nicht aber unter den einfachen Organisationsmitgliedern. Zweitens: lose gekoppelte, polyzentrische

18 Vgl. auch März in diesem Band.

19 Vgl. Bennett: „Social Movement beyond Borders“, S. 213-216.

20 Vgl. Keck/Sikkink: Activists beyond Borders. 
Aktivistennetzwerke. Diese auf direkte, nicht durch NGOs vermittelte Aktionen ausgerichteten Netzwerke sind in der Regel durch schwache Bindungen unter den Mitgliedern gekennzeichnet. Sie beruhen, wie das Peretti-Beispiel veranschaulicht, vor allem auf den neuen ortsungebundenen Kommunikationsmöglichkeiten computergestützer Medien für die politische Selbstorganisation. Zahlreiche Autoren gehen davon aus, dass dieser Netzwerktyp charakteristisch für die Global Social Justice Bewegung und deren globalisierungskritische Protestkampagnen gegen große internationale Regierungsorganisationen wie WTO oder IMF oder transnationale Konzerne ist. Ein dritter Netzwerktyp kombiniert Elemente aus beiden anderen Typen: So z.B. die Kampagne gegen Coca Cola, in der ein von Greenpeace zentriertes Protestnetzwerk mit einem auf direkte Aktionen zielenden Handlungsnetzwerk, in diesem Fall den kreativen Culture-Jamming-Aktivisten von Adbusters, kooperiert.

\section{Empowerment der Verbraucher durch das Internet?}

Die Politisierung des Konsums im Sinne einer allgemeinen Stärkung politischethischer Konsumpräferenzen wie im Sinne spezifischer, auf die Dekonstruktion skandalisierter Marken gerichteter Kampagnen hat vielfältige strukturelle und kulturelle Gründe. ${ }^{21}$ Strukturell ist vor allem auf den mit der ökonomischen Globalisierung einhergehenden Machtzuwachs transnationaler Unternehmen hinzuweisen. Mit ihrer Exit-Option setzen sie nationale Regierungen unter Druck, steuerliche Belastungen zu reduzieren; zugleich verlieren nationale Gewerkschaften durch eine zunehmende Flexibilisierung der Arbeitsbedingungen an Einfluss auf die Arbeitsbeziehungen. Während Arbeitnehmer nur im Ausnahmefall von ihrer Exit-Option Gebrauch machen können, um Unternehmen zu Verhaltensänderungen zu zwingen, scheinen Verbraucher angesichts der Fülle des Angebots von in der Regel gleichwertigen Waren und Dienstleistungen eher in der Lage zu sein, soziales und politisches Gegenmachtpotenzial zu entfalten. Kulturelle Erklärungen einer zunehmenden Mobilisierung von Verbrauchermacht rekurrieren auf Veränderungen in der Lebenswelt der Konsumenten. Prozesse der Enttraditionalisierung und Individualisierung lösen tradierte Gruppenbindungen auf. Bedürfnisse nach Orientierung und Gemeinschaftsbindung werden zunehmend durch Lebensstil- und damit verbundene Konsumpräferenzen ausgedrückt.

Neben den strukturellen und lebensweltbezogenen Erklärungen für die Mobilisierung der sozialen und politischen Gestaltungsmacht von Verbrau-

21 Vgl. dazu ausführlicher Baringhorst: „Keine Reizwäsche aus Burma“; dies.: „Political Empowerment of Consumer Citizens“. 
chern ist auch die Veränderung medialer Infrastrukturen für die Veränderung des Konsumverhaltens wie für die Entstehung und den Mobilisierungserfolg transnationaler unternehmenskritischer Kampagnen bedeutsam.

Die Kernfrage, die im Folgenden diskutiert werden soll, lautet: In welchem Ausmaß hat das Internet die Agency von Verbrauchern im Sinne eines Empowerment von Konsumenten geschwächt oder gefördert? Die Antwort wird ambivalent ausfallen: Einerseits bietet eine digitalisierte Medienkultur eine effektive Gelegenheitsstruktur für die Schaffung von brandspaces, von Räumen der Markenentfaltung, die tief in die Lebenswelt der Kunden hineinreichen. Andererseits können Protestakteure die digitalen Medien nutzen, um die kommerzielle Markenkommunikation zu dekonstruieren und die kommerzielle wie symbolische Macht von Markenfirmen anzugreifen.

\subsection{Markenkommunikation im Netz - Verbrauchermacht als Illusion}

Euphorische Stimmen betrachteten die neuen digitalen Medien in den 1990er Jahren als technologische Verkörperung und Einlösung der in den 1960er und 1970er Jahren eingeforderten Kulturen der Freiheit und individuellen Autonomie. Insbesondere das Internet galt als Medium der Generierung neuer nicht hierarchischer Formen der politischen Partizipation und der Stärkung insbesondere ressourcenarmer politischer Akteure. Das Internet vermag, wie weiter unten näher erläutert wird, zwar all dies zu leisten, doch ist es aufgrund seiner inhaltlichen Offenheit und Plastizität ${ }^{22}$ zugleich ein Medium der sozialen, politischen und kulturellen Meinungsbeeinflussung durch das Marketing und die PR etablierter ressourcenstarker Akteure, seien es große politische Parteien oder kommerzielle Großunternehmen. Computerspiele und Online-DatingAgenturen sind nur zwei Beispiele der neuen Dimensionen der Intimität, die netzgestützte Kommunikation erlaubt und die zunehmend von privaten Unternehmen erzeugt wird, um Produkte zu vermarkten und Netzuser in vorstrukturierte virtuelle Räume der Markenkommunikation einzubinden. Das Internet kann nach Arvidsson kommerzielle Umwelten schaffen, die alle menschlichen Sinne ansprechen und alle Handlungen nach spezifischen Markenprogrammen steuern. In der kommerziell gesteuerten Kolonialisierung individueller Lebenswelten im Netz lösen sich die Differenzen zwischen einer persönlichen Entfaltung der Subjekte und einer unternehmerischen Gewinnorientierung auf. „ICTs have the technological potential to complete the real

22 Vgl. Manchovic: The Language of the New Media, S. 27. 
subsumption of life under capital, to the extent that the becoming of subjectivity and the becoming of value coincide. “23

Die Markenkommunikation im Netz ist zu einem wichtigen Element des Markenmanagements geworden. Ziel ist die Verbesserung der Wettbewerbsposition von Markenfirmen durch Förderung einer gemeinschaftsähnlichen Interaktion unter Verbrauchern. Mitglieder der Gemeinschaft von Buchliebhabern werden von Amazon ermutigt, Rezensionen zu schreiben, um ihre Buchempfehlungen mit anderen Konsumenten zu teilen. eBay-Nutzer bewerten sich gegenseitig und erzeugen so gegenseitiges Vertrauen wie aber auch Vertrauen in das Unternehmen selbst. Innovative Modi des Online-Marketings bieten, wie auch das oben angeführte Nike-Beispiel zeigt, Konsumenten neue Möglichkeiten, am Prozess der Produktion teilzunehmen und selbst Vorschläge zu Produktentwicklung und -design zu äußern, um somit affektive und interaktive Beziehungen zu Markenfirmen zu stärken. ${ }^{24}$ Den interaktiven Beteiligungspotenzialen sind jedoch klare Grenzen gesetzt: Diese impliziten Grenzen werden, wie nicht nur das Beispiel der provokanten Herausforderung von Nike durch den Konsumentenbürger Jonah Peretti demonstriert, immer dann explizit, wenn die interaktiven Angebote von Unternehmen parodiert und der angebotene Kommunikationsraum genutzt wird, um Markenimages zu dekonstruieren und die hinter den interaktiven Angeboten liegenden Machtverhältnisse bloßzustellen. Als das Aktionsnetzwerk Attac versuchte, das AntiProdukt N.I.X. Version 11.04 am Kauf-Nix-Tag (Buy-Nothing-Day) im Auktionsunternehmen eBay anzubieten, stoppte eBay die Versteigerung als die Angebote 150,- Euro erreichten. Während Attac Deutschland seine parodistische A(u)ktion als künstlerische Handlung und N.I.X. Version 11.04 als Kunstprodukt verstanden wissen wollte, begründete eBay Community Watch sein Auktionsverbot damit, dass es seine Verantwortung für die Seriosität der Online-Geschäfte wahrnehmen müsse.

Hallo! Angebote sind nicht der richtige Ort für Spendengesuche und eBay ist es darüber hinaus auch nicht möglich die Seriosität derartiger Aufrufe zu überprüfen und einzuschätzen. Der Inhalt von Angebotsbeschreibungen sollte auf eine Beschreibung des angebotenen Artikels beschränkt sein. Mit freundlichen Grüßen, eBay Community Watch. ${ }^{25}$

23 Arvidsson: Brands, S. 96.

24 Weitere Beispiele sind die Autohersteller Audi, Volvo und Peugeot, die potenzielle Kunden auffordern, dem Unternehmen Ideen zur Entwicklung zukünftiger Modelle mitzuteilen.

25 Zitiert nach Vogelbusch: „eBay versteht N.I.X. Spaß!!!“. 


\subsection{Stärkung der Marktmacht von Konsumenten im Netz}

Die genannten Beispiele illustrieren die gewachsenen Möglichkeiten, durch Online-Marketing Konsumenten zu erreichen und sie dazu anzuregen mit anderen Konsumenten wie mit dem Markenunternehmen direkt in gemeinschaftsähnlichen Formen zu interagieren. Abgesehen von durch die Unternehmen kontrollierten Modi der Konsumenteninteraktion stärkt das Internet die Wirtschaftmacht von Verbrauchern durch den erleichterten Zugang zu marktbezogenen Informationen ganz erheblich.

Das Netz ist ein äußerst effizientes Medium für die kollektive Wissensproduktion und ortsungebundene Gemeinschaftsbildung wie vor allem aber auch für die Suche nach aller Art von Informationen. Die geringen Transaktionskosten verbunden mit der Ortsungebundenheit und dem freien Zugang haben die soziale Stellung von Verbrauchern in ihrem Verhältnis zu Waren- und Dienstleistungsanbietern deutlich verbessert. ${ }^{26}$ Hagel und Armstrong, zwei Unternehmensberater von McKinsey, schildern diesen Wandel geradezu als Umkehrung der herrschenden Marktbeziehungen und -dynamik:

In their relationships with customers, vendors have long held the upper hand. This has to do with information. Access to information is a key determinant of bargaining power in any commercial transaction. If one party gains access to more information, that party tends to be able to extract more value from transactions than a party with access to less information. In most markets today, vendors are armed with comparatively more information than their customers. [...] Virtual communities are likely to turn these market dynamics upside down by creating ,reverse markets' ${ }^{6}$ - markets in which the customer armed with a growing amount of information, uses that information to search out vendors offering the best combination of quality and price tailored to his or her individual need. ${ }^{27}$

Waren- und Dienstleistungsanbieter verlieren durch die Informationsmöglichkeiten im Netz ihr Informationsmonopol und sind deshalb gezwungen, ihre Preise zu senken und die Qualität ihrer Angebote zu verbessern. In einer ähnlich gerichteten Argumentation hat die britische Expertin für politische Kommunikation Margaret Scammell die Auswirkungen des Internets auf die Entstehung des politischen Konsumerismus als re-writing the rules of the marketplace bezeichnet:

26 Vgl. Arvidsson: Brands, S. 103.

27 Hagel/Armstrong: Net.gain, S. 17. 
It is democratising the information environment, transforming what Kotler calls the ,asymmetry ${ }^{6}$ between sellers and customers. Sellers typically have had greater access to and better control of market information and could effectively set the terms, while consumers mostly relied on shortcuts such as brand recognition, reputation and consumer advice media. The Internet allows buyers to compare prices and product attributes in minutes, facilitated by consumer information websites. ${ }^{28}$

Gleichzeitig, so ihre Argumentation, werden dem Verbraucher erheblich mehr Auswahlmöglichkeiten geboten. „Digital deregulated markets lower the costs of entry for new producers and substantially reduce, or make irrelevant, barriers of time and space." 29

Eine einseitige Hervorhebung der Vorteile von Verbraucherinformation und interaktiven Möglichkeiten der Verbraucherkommunikation verkennt jedoch, dass ein Großteil der Informationen, die Konsumenten im Netz nachfragen, in einer hochgradig kommerzialisierten Umwelt generiert und angeboten werden. ${ }^{30}$ Kommerzielle Portale wie www.dooyoo.de, www.ciao.de, www.yopi.de, die stark nachgefragte Verbraucher-Ratings und -meinungen offerieren, sind keineswegs günstige Netzumwelten für die Stärkung einer kritischen Bürgerrolle von Verbrauchern und einer damit verbundenen öffentlichen Deliberation über Aspekte der Entstehung und Distribution von Produkten. In diesen Portalen kommentieren Netzuser Waren und Dienstleistungen, die sie schon erworben haben. Insofern ist es, wie Bieber und Lamla zu Recht einwenden, wenig wahrscheinlich, dass sie dort Fragen der Arbeitsbedingungen oder der Umweltbeeinträchtigung thematisieren. ${ }^{31}$ Zudem ist die Glaubwürdigkeit von Konsumenten-Postings nur schwer zu kontrollieren. Wie können Netzuser sicher sein, dass diese Portale nicht von Händlern genutzt werden, um Wettbewerbern zu schaden und um die eigene Marktposition zu optimieren?

Verbraucherschutz ist ein weiteres Element eines wirtschaftlichen Empowerment von Verbrauchern. Entsprechend der neokorporatistischen Struktur des Verbraucherschutzes in Deutschland wird Verbraucherschutz primär von unabhängigen, aber staatlich finanzierten Organisationen wie vor allem dem Bundesverband der Verbraucherzentralen angeboten. Deren Websites

28 Scammell: „Citizen Consumers“, S. 122.

29 Ebd.

30 Vgl. Arvidsson: Brands, S. 104.

31 Vgl. Bieber/Lamla: „Das Netz der Konsumenten“. 
bieten vielfältige Markt- und Produktinformationen, doch geben sie nur selten Chancen zur Verbraucherpartizipation.

Vor allem unter der Rot-Grün-Regierung haben Vorstellungen eines nachhaltigen und sozial gerechten Konsums die Gestaltung der staatlichen Verbraucherpolitik beeinflusst und sowohl die ministerielle PR wie die Kommunikationspolitik von Verbraucherschutzorganisationen verändert. Kommuniziert wurde das Bekenntnis zum ethischen Konsum in Kampagnen, die das Verbraucherschutzministerium in Kooperation mit Verbraucherorganisationen wie Umwelt-, Menschenrechts- und Entwicklungs-NGOs unter den Slogans Echt gerecht - clever kaufen und fair feels good lancierte. ${ }^{32}$ Wie die Websites der traditionellen Verbraucherschutzorganisationen so sind auch die Informationsangebote des Ministeriums in der Regel top-down und nach dem Muster der One-to-Many-Kommunikation strukturiert. In Multiple-Choice-Tests sollen Verbraucher ihr eigenes Konsumverhalten reflektieren; virtuelle Bibliotheken offerieren umfassende Archive für den wissenshungrigen Konsumenten, vor allem aber auch für Multiplikatoren wie Journalisten, Politiker und Wissenschaftler. $^{33}$

\subsection{Der Konsument als Netzbürger - zum politischen Empowerment von Verbrauchern}

„Wie habt ihr das alles recherchiert?“, zitieren die Autoren des bekannten Schwarzbuch Markenfirmen eine häufig gestellte Leserfrage. „Vor allem mithilfe des Internet" so ihre Antwort. ${ }^{34}$ Das Internet dient nicht nur der Beschleunigung ökonomischer Globalisierungsprozesse und der weitreichenden Kolonialisierung der Lebenswelt und Unterordnung zwischenmenschlicher Interaktion unter den Primat unternehmerischer Gewinnmaximierung. Es ist zugleich die stärkste Waffe des Widerstands gegen skandalisierte Unternehmenspraktiken. Jedoch wird die Asymmetrie zwischen Verkäufer und Käufer im Netz keineswegs einfach umgekehrt. Angesichts des enormen Umfangs und des häufig ungesicherten Quellenstatus dieser Informationen sind Konsumenten auf die Prüf- und Filterleistungen von Nichtregierungsorganisationen angewiesen. ${ }^{35}$ Politisches Empowerment von Verbrauchern ist ohne die Watchdog- und Gatekeeper-Funktion vertrauenswürdiger zivilgesellschaftlicher Organisationen nicht denkbar.

32 Vgl. Kneip/Niesyto in diesem Band.

33 Vgl. Bieber/Lamla: „Das Netz der Konsumenten“.

34 Vgl. Werner/Weiss: Das neue Schwarzbuch Markenfirmen, S. 12.

35 Vgl. Bieber/Lamla: „Das Netz der Konsumenten“. 
Nur Nichtregierungsorganisationen oder zivilgesellschaftliche Aktionsbündnisse haben die Ressourcen und die Expertise, um diese Funktionen zuverlässig und kontinuierlich wahrnehmen zu können. Annahmen einer radikalen Individualisierung von Protest in der Global Social Justice Bewegung übersehen häufig die unverändert große Bedeutung von NGOs in konsumeristischen Aktionen, sei es als handlungsbestimmende Einzelorganisationen oder als Teil einer Koalition unterschiedlicher NGOs. Selbst wenn sie Informationen, wie etwa wissenschaftliche Gutachten oder Erfahrungsberichte von Unternehmensmitarbeitern, nicht eigenständig generieren, so sind NGOs doch für die Bewertung, Deutung und Kommunikation dieser Informationen unverzichtbar. Wichtige Informationslieferanten sind die Websites transnationaler NGOs und NGO-Netzwerke wie

- www.corpwatch.org;

- www.sweatshopwatch.org;

- www.globalwitness.org;

- www.prwatch.org;

- www.endgame.org;

- www.multinationalmonitor.org;

- www.ethicalconsumer.org;

- www.oeko.investvest.com;

- www.transnationale.org;

- www.maketradefair.com.

Die Mission Statements einiger dieser Organisationsbündnisse verdeutlichen die breite Koalitionsbasis und das weite Problemspektrum, das auf diesen Websites angesprochen und abgedeckt wird:

\section{www.corpwatch.org}

CorpWatch investigates and exposes corporate violations of human rights, environmental crimes, fraud and corruption around the world. We work to foster global justice, independent media activism and democratic control over corporations. ${ }^{36}$

36 Corpwatch: „About CorpWatch“. 
Sweatshop Watch is a coalition of labor, community, civil rights, immigrant rights, women's, religious and student organizations, and individuals, committed to eliminating the exploitation that occurs in and the illegal and inhumane conditions that characterize sweatshops.

Sweatshop Watch serves low wage workers, with a focus on garment workers, primarily in the state of California, but also nationally and globally. While recognizing that most of our work must be local and driven by the unique needs of the communities in which we work, we are also aware that the existence of sweatshops raises fundamental issues of injustice, unfairness, inhumanity, racism, and lack of accountability that collaborative efforts are best suited to confront. [...] Because we aim to affect both grassroots action and public policy at every level - local, regional, national and international - Sweatshop Watch will support each member organization in a wide range of activities, including educating workers, consumers, the media, and one another; speaking out to affect public opinion on sweatshop conditions; organizing workers through community organizations, union boycotts, large scale campaigns, and street actions; advocating for policies that protect workers; monitoring state and federal agencies charged with enforcing laws that protect workers; bringing lawsuits against, as well as defending lawsuits brought by, retailers, manufacturers, contractors, and government institutions; training judges and labor commissioners to be aware of sweatshop conditions; and demanding corporate accountability through dialogue with contractors, manufacturers, and retailers, and worker, consumer and shareholder campaigns.

As a central part of our mission, we will remember that the workers who labor in sweatshops are our driving force. Our decisions, projects, and organizing efforts will be informed by their voices, their needs, and their life experiences. ${ }^{37}$

\section{www.globalwitness.org}

Global Witness campaigns to achieve real change by challenging established thinking on seemingly intractable global issues. We work to highlight the link between the exploitation of natural resources and human rights abuses, particularly where the resources such as timber, diamonds and oil are used to fund and perpetuate conflict and corruption. ${ }^{38}$

37 Sweatshop Watch: „Mission“.

38 GlobalWitness: „Resources, Conflict and Corruption“. 


\section{www.prwatch.org}

[Is published by the Center for Media and Democracy, which is] a non-profit, non-partisan, public interest organization that strengthens participatory democracy by investigating and exposing public relations spin and propaganda, and by promoting media literacy and citizen journalism. [...] The Center serves journalists, researchers, policymakers and citizens at large in the following ways:

- Countering propaganda by investigating and reporting on behindthe-scenes public relations campaigns by corporations, industries, governments and other powerful institutions.

- Informing and assisting grassroots citizen activism that promotes public health, economic justice, ecological sustainability and human rights.

- Promoting media literacy to help the public recognize the forces shaping the information they receive about issues that affect their lives.

- Sponsoring open content media that enable citizens from all walks of life to be the media and to participate in creating media content. ${ }^{39}$

Der Adressatenkreis dieser Websites wird allgemein als global definiert. Untersucht man jedoch ihre Bedeutung für transnationale unternehmenskritische Kampagnen im deutschsprachigen Raum, so erweist sich ihr Einflussradius als recht beschränkt. Häufiger finden sich Referenzen auf Hintergrundinformationen national einflussreicher Umweltorganisationen wie Greenpeace, des globalisierungskritischen Aktionsbündnisses Attac, der kritischen Verbraucherorganisation foodwatch sowie die Website www.markenfirmen.com von Klaus Werner und Hans Weiss, den Autoren von Das neue Schwarzbuch Markenfirmen sowie die Website www.kritischeaktionaere.de. Eine Untersuchung von 109 Anti-Corporate Campaigns, die zwischen 1995 und 2005 im deutschsprachigen Raum lanciert wurden, zeigt, dass fast 80 Prozent von ihnen eine eigene Website betrieben haben, um regelmäßig über den Fortgang der Kampagne zu berichten und Informationen zum angegriffenen Unternehmen oder der angegriffenen Branche zu aktualisieren. Die Websites werden entweder mit einem eigenen Domain Name oder als Subdomain von Websites beteiligter NGOs veröffentlicht.

Um die funktionale Bedeutung computergestützter Kommunikationsmedien für unternehmenskritische Kampagnen zu analysieren und zu bewerten, ist es sinnvoll, ihren Beitrag zur Erfüllung allgemeiner funktionaler Handlungs-

39 PR Watch: „About CMD“. 
notwendigkeiten erfolgreicher transnationaler Kampagnen zu untersuchen. Konzeptionell ist davon auszugehen, dass transnationale kampagnenförmige Mobilisierungen von Verbrauchermacht, wie transnationale Protestkampagnen generell, eine sehr komplexe multidimensionale Struktur aufweisen, die vertikal unterschiedliche Handlungsebenen und horizontal unterschiedliche Handlungsfelder integriert. Transnationale Protestkampagnen haben nach Christian Lahusen folgende Aufgaben zu erfüllen: ${ }^{40}$

1. die Entwicklung organisierter Handlungsprogramme, die auf einer strategischen Planung von Interaktionsprozessen zwischen beteiligten Konfliktakteuren und der Koordination kollektiver Aktionen basieren,

2. die thematische Fokussierung auf bestimmte Themen oder Issues,

3. die Erzeugung öffentlicher Aufmerksamkeit und öffentlichen Drucks in der Regel durch moralische Aufladung der Themen bzw. Issues und mediengerechte, ästhetische Formen der Protestinszenierung,

4. die Erzeugung und Stabilisierung von Netzwerken bzw. die Stabilisierung der eigenen Organisation durch Ressourcenmobilisierung, politische Partizipationsangebote und die Mobilisierung kollektiver Identitäten und Gemeinschaftsgefühle,

5. die Koordination und Verknüpfung unterschiedlicher räumlicher Handlungsebenen vor allem durch Integration lokaler, regionaler und nationaler sowie im Falle transnationaler Kampagnen auch transnationaler Akteure und Arenen,

6. die Kooperation mit Akteuren in unterschiedlichen gesellschaftlichen Subsystemen wie Massenmedien, Politik, Wirtschaft oder Wissenschaft.

Aufgrund der erheblichen empirischen Defizite, die derzeit noch hinsichtlich der Untersuchung der Rolle von computergestützten Kommunikationsmedien für Protestakteure im Allgemeinen und NGOs im Besonderen bestehen, möchte ich im Folgenden hinsichtlich der genannten Funktionen nur einige Aspekte, die mit dem Beitrag des Internets für die Erfüllung dieser Funktionen verbunden sind, problematisieren. Dabei soll ein Schwerpunkt auf die spezifische Spannung gelegt werden, die durch die funktional notwendige Orientierung an gegensätzlichen Medienlogiken entsteht. Diese Logiken bestehen zum einen aus der Aufmerksamkeitslogik der traditionellen Massenmedien, die eine Tendenz zur Professionalisierung von Medienarbeit und organisatorischen Zentralisierung von Protestakteuren begünstigt, zum anderen aus der Netz-

40 Vgl. Lahusen: „Internationale Kampagnen“. 
werklogik des Internets, die eher Tendenzen der Dezentralisierung und der Bildung weniger hierarchischer Protestkoalitionen fördert. Das Spannungsverhältnis zwischen diesen beiden Medienlogiken unterliegt, so die These, allen transnationalen Protestkampagnen, die von demokratischen zivilgesellschaftlichen Akteuren initiiert werden. Einerseits beziehen zivilgesellschaftliche Akteure ihre Legitimität aus öffentlicher Zustimmung für ihre Anliegen und wollen ihre Problemdeutungen und Forderungen deshalb möglichst vielen Bürgern vermitteln. Zugleich müssen sie möglichst großen Druck auf politische Entscheidungsträger oder angegriffene Unternehmen ausüben. Eine Verwirklichung dieser beiden Ziele ist nur durch die Erzeugung massenmedialer Aufmerksamkeit zu erreichen. Andererseits beziehen zivilgesellschaftliche Protestakteure ihre Legitimität auch aus ihrer demokratischen Organisationsstruktur und prinzipiellen Offenheit für die Beteiligung möglichst vieler interessierter Bürger. Während das Internet neue Möglichkeiten für eine Stärkung interner demokratischer bottom-up-Strukturen eröffnet, hängt die erfolgreiche Ansprache eines massenmedialen Publikums noch immer primär von einem topdown-strukturierten Kommunikationsmanagement ab.

Was nun leisten netzgestützte Kommunikationsmedien konkret für die oben genannten Funktionen? Es ist offensichtlich, dass die Erfüllung der ersten Funktion, d.h. der Entwicklung organisierter Handlungsprogramme basierend auf der strategischen Interaktionsplanung zwischen Konfliktpartnern und der Koordination kollektiver Aktionen, eher zentralistische Formen der Protestorganisation verlangt. Internet, Intranet und E-Mail tragen wesentlich zur Reduzierung von Transaktionskosten bei und offerieren ressourcenarmen Akteuren wichtige logistische Vorteile: Netzbasierte Kommunikation ist schnell und billig. Zeiten, Orte und Modi kollektiver Protestaktionen können, sofern alle Unterstützer am Netz angeschlossen sind, in kürzester Zeit topdown bekannt gemacht und zirkuliert werden. Die Beschleunigung der Kommunikation im Netz verschafft Protestakteuren auch strategische Vorteile in der Konfliktdramatisierung. In ihrem Handlungsrepertoire spielen Formen zivilen Ungehorsams eine wichtige Rolle. Zahlreiche Beispiele belegen, dass Online-Medien von Cyberaktivisten auch als strategische Plattformen, als Waffe und Zielscheibe transnationalen elektronischen Widerstands, genutzt werden. ${ }^{41}$ Dabei zeigt das Repertoire virtueller Protestaktionen eine Mischung altbekannter Aktionen des zivilen Ungehorsams mit erst durch die Technizität des Netzes ermöglichten rekombinaten Formen. ${ }^{42}$ Zuerst umgesetzt und häufig genutzt ist die klassische Artikulationsform der Petition in Form elektronischer

41 Vgl. Jordan: Activism!

42 Vgl. Schönberger: Persistenz und Rekombination. 
Unterschriftensammlungen. Online-Petitionen sind nach einer Befragung von Teilnehmern auf großen globalisierungskritischen Events die am meisten bekannte Form des Netzaktivismus. ${ }^{43}$ Kostengünstige standardisierte Protestformen wie elektronische Petitionen sind jedoch für den Adressaten des Protests wie für journalistische Gatekeeper weniger eindrucksvoll als Aktionen, die ein hohes persönliches Engagement erfordern. ${ }^{44}$ Low cost but low impact, könnte man gegen die high impact on little resources-These von Street und $\mathrm{Scott}^{45}$ einwenden.

Weniger bekannt und genutzt ist der virtuelle Protest in Form von Netzstreiks oder so genannte Denial-of-Service-Attacks. Dabei sollen viele User zu einer bestimmten Zeit eine als symbolisches Ziel festgelegte Website aufrufen, um sie dadurch stillzulegen. Die Mobilisierung dazu erfolgt über Chats und Mailing-Lists. In der Regel wird der Besitzer der Website zuvor informiert. Kreativer, aufwendiger und deshalb weniger verbreitet, ist das Klonen oder defacement von Websites, d.h. die Schaffung so genannter fake web sites, wobei unter dem Domain Name bekannter klassischer Institutionen (wie www.gatt.org) oder parodistischen Verfremdungen von Domain Names wie www.world bunk.org oder www.whirledbank.org organisationskritische Inhalte verbreitet werden und die Reputation der angegriffenen Organisation angegriffen wird.

Gegner konsumeristischer Protestaktionen sind, wie oben erwähnt, häufig einflussreiche Großunternehmen. Um sie unter Druck zu setzen und um deren ausgefeilte PR-Maschine auszumanövrieren, müssen Protestaktionen möglichst geheim geplant werden und sollten nicht in Netzforen, Mailinglisten und auf Weblogs breit und offen diskutiert werden, zumal deren Beobachtung ein integrierter Teil der Öffentlichkeitsarbeit großer Unternehmen geworden ist.

Ein oft zitiertes Beispiel der taktischen Netznutzung als Waffe im Sinne der Denial-of-Service-Attack ist die Blockade der Lufthansa Website im Rahmen der transnationalen Deportation Class Campaign. Organisiert wurde der Tag für den Kranich von dem Aktionsnetzwerk Kein Mensch ist illegal, bestehend aus antirassistischen Gruppen und der Gefangenenhilfsorganisation Libertad, um öffentliche Aufmerksamkeit für die Beteiligung von Fluggesellschaften an der Deportation von abgelehnten Asylbewerbern zu erzeugen. Die virtuelle Protestaktion war insofern erfolgreich, als sie von 150 zivilgesellschaftlichen Organisationen wie z.B. Gewerkschaften unterstützt wurde. 13.000 Teilnehmer blockierten am 20. Juni 2001 für zwei Stunden während der gleichzeitig stattfindenden Aktionärsversammlung teilweise die Möglichkeit, im Netz

43 Vgl. Porta: „Transnational Social Movements“, S. 102.

44 Vgl. Rucht: „The quadruple ,A““, S. 51.

45 Vgl. Street/Scott: „From media politics to e-protest?““. 
Flugtickets der Lufthansa zu bestellen. Da die Aktion vorher öffentlich angekündigt wurde, wurde darüber in vielen Nachrichtenorganen berichtet. Dadurch wurde zwar viel massenmediale Aufmerksamkeit erzeugt, zugleich konnte sich das angegriffene Unternehmen jedoch gründlich auf den Angriff vorbereiten und dadurch schlimmere Schäden vermeiden.

Unternehmen lernen schnell und passen sich den Veränderungen kollektiver Handlungsrepertoires an. Viele von ihnen haben inzwischen Websites in ihren virtuellen Schubladen, auf denen sie antizipierter Kritik unverzüglich entgegentreten können. ${ }^{46}$ Sie werden blitzschnell aktiviert, wenn es darum geht, von Angriffen abzulenken oder Skandalisierungen mit Gegenbehauptungen zu begegnen. Aus der zunehmenden Netzbeobachtung und Anpassung der Unternehmens-PR an die Kritik netzaktiver Konsumbürger folgt, dass erfolgreiche Protestkampagnen stets eine Güterabwägung treffen müssen, in der sie zwischen der Nutzung des demokratischen, deliberativen Netzpotenzials oder der Nutzung des Geheimhaltungspotenzials anonymer Kommunikation im Netz zu entscheiden haben.

Die zweite Funktion, die Fokussierung der öffentlichen Aufmerksamkeit auf ausgewählte Issues und die Generierung öffentlichen Drucks durch eine an den Nachrichtenfiltern der massenmedialen Kommunikation ausgerichtete Moralisierung und Protestdramatisierung, läuft einer stärker dezentralisierten und egalitären Netzwerkstruktur des Internets entgegen. Unabhängige Nachrichtenportale wie Indymedia sowie die oben genannten Websites konsumeristischer Aktionsbündnisse sind zwar inzwischen wichtige Ressourcen der Informationsbeschaffung von Journalisten geworden. Doch greifen journalistische Gatekeeper nur dann auf diese alternativen Nachrichtenquellen zurück, wenn ein Aktionsbündnis oder eine bekannte NGO schon durch die eigene PR oder öffentliche Protestaktionen vor oder in Geschäften bzw. Unternehmensstandorten ihre Aufmerksamkeit geweckt hat. Dabei zeigt eine exemplarische Analyse der Medienresonanz auf die Kampagnen gegen den Discounter Lidl, dass die Massenmedien die Heterogenität der Akteure eines unternehmenskritischen Protestnetzwerks (das Protestnetzwerk der Kampagnen reicht von ver.di, Attac, WEED, der Arbeitsgemeinschaft bäuerliche Landwirtschaft, e.V., BanaFair bis zur Aktion Selbstbesteuerung e.V.) keineswegs angemessen widerspiegeln, sondern die größten und bekanntesten Organisationen überproportional häufig erwähnen. Obwohl das Internet die Kooperation in ausgedehnten Netzwerkorganisationen erleichtert, erfordert ein erfolgreiches IssueFraming in der Regel eine Fokussierung auf einen oder einige wenige Sprecher der Netzwerke. ${ }^{47}$

46 Vgl. hierzu Köhler in diesem Band.

47 Vgl. Baringhorst/Kneip/Niesyto in diesem Band. 
Anti-Corporate Campaigns zielen nicht nur auf die öffentliche Bloßstellung angegriffener Unternehmen. Ihre Sprecher versuchen häufig, direkten Kontakt mit verantwortlichen Managern aufzubauen, um diese zu einem Dia$\log$ mit politisierten Verbrauchergruppen über Aspekte der Produktions- und Distributionspraxen zu motivieren. So Bernhard Mark-Ungericht in seiner Habilitationsschrift:

Der Gestaltungswille zivilgesellschaftlicher Akteure bedingt, dass sie nicht ausschließlich auf politische Kritik ausgerichtet sind, sondern Proteste vornehmlich als Instrument betrachten, politische und ökonomische Entscheidungsträger zu einem Problemlösungsdialog zu verpflichten. ${ }^{48}$

In welcher Hinsicht das Internet diesen direkten Unternehmenskontakten förderlich ist, ist noch unklar. Einerseits nutzen Protestakteure Kampagnenwebsites und Weblogs, wie etwa den Lidl-Weblog von ver.di, um kritische Informationen über skandalisierte Unternehmen zu verbreiten oder um in standardisierten E-Mails Unternehmen direkt ihr Missfallen auszudrücken. Während massenmediale Kommunikation binäre Strukturen der Kommunikation fördert und dadurch auch binär strukturierte Protestformen wie Konsumentenboykott oder -buykott begünstigt, sind diskursivere Formen der Konfliktinteraktion nur schwerlich in einer kommerzialisierten massenmedialen Landschaft zu kommunizieren. Demgegenüber erlaubt das Netz die Veröffentlichung umfangreicher Informationen und Gegeninformationen und eine interaktivere dialogorientiertere Kommunikation zwischen Skandalisierer und Skandalisierten. Wenn es jedoch um direkte Kommunikation zwischen Protestakteuren und Unternehmen geht, scheint das persönliche Gespräch, die Face-to-FaceKommunikation nicht zuletzt aufgrund der von beiden Konfliktpartnern häufig unterstellten mangelnden Glaubwürdigkeit der Gegenseite noch immer sehr bedeutsam zu sein.

Während die ersten Funktionen eher für Zentralisierung und Professionalisierung von Kampagnenorganisationen sprechen, erfordert eine erfolgreiche Erfüllung der weiteren oben genannten Kampagnenfunktionen eine stärker partizipative Protestkultur, die durch die spezifische Technizität computergestützter Kommunikationsmedien durchaus begünstigt werden könnte. Dabei ist davon auszugehen, dass Organisationen - und auch Aktionsnetzwerke -, die stärker auf professional resources angewiesen und hierarchisch organisiert sind ${ }^{49}$ diese Partizipationschancen anders nutzen als basisdemokratisch

48 Mark-Ungericht: Betriebliche Schließungs- und Öffnungsprozesse.

49 Vgl. Diani: „Social Movement Networks“, S. 122f. 
strukturierte Organisationen und Netzwerke. ${ }^{50}$ So sind Organisationen wie Greenpeace oder Friends of the Earth, die von ihren Mitgliedern kaum mehr als Mitgliedsbeiträge und Spenden einfordern, weniger geneigt, ihre Handlungsprogramme intern wie extern mit einer Vielzahl von Akteuren abzustimmen.

Wie die Analyse der Websites von Anti-Corporate Campaigns im deutschsprachigen Raum zeigt, bieten sie Interessierten eine Vielzahl von Partizipationsmöglichkeiten. Sie offerieren den Download von Campaign-Kits, OnlineHandbüchern und Mobilisierungsratgebern sowie eine regelmäßige Aktualisierung von Informationen über Protestevents. Konsumbürger werden aufgefordert, Informationen abzurufen, Flyer zu erstellen, Newsletter zu abonnieren, Petitionen zu unterzeichnen oder standardisierte Protestmails zu schreiben. Während all diese Aktionsformen eine asymmetrische Beziehung zwischen Organisatoren und Unterstützern von Protestkampagnen reproduzieren, finden sich auch einige Interaktionsofferten, die eine eher symmetrische Struktur aufweisen. Zu nennen sind in dem Zusammenhang Aufforderungen, durch eigene Informationsinputs zur kollektiven Wissensproduktion von Protestinitiativen beizutragen. So können Cyberaktivisten als Gendetektive fungieren und Greenpeace über Funde genmanipulierter Nahrungsmittel informieren. Auch die Verbraucherorganisation foodwatch appelliert an die aktive Unterstützung durch politisierte Verbraucher und fordert sie auf, ihre Beobachtungen über Normverletzungen in Supermärkten und Discountern unter Regalpatrouille@foodwatch.de der Organisation mitzuteilen. Dabei sind Cyberaktivisten im Rahmen von unternehmenskritischen Kampagnen nicht unbedingt immer Marktaktivisten oder politisierte Konsumbürger. Häufig werden wichtige Informationen über unternehmerische Normverletzungen auch von Unternehmensmitarbeitern oder früheren Mitarbeitern kommuniziert. Insbesondere die aufgrund ihrer finanziellen Unternehmensabhängigkeit sehr verwundbare Position kritischer unternehmensangehöriger Arbeitnehmer wird durch die Anonymität der Netzkommunikation strukturell gestärkt. Sie werden ermutigt, Unternehmensgeheimnisse über produktionsbezogene Umwelt- und Gesundheitsrisiken, drohende Betriebsschließungen oder umstrittene ausländische Investitionen zu veröffentlichen. Ein illustratives Beispiel bietet der von ver.di eingerichtete Lidl-Weblog (www.verdi-blog.de/lidl), auf dem Beschäftigte ihre Erfahrungen mit dem Unternehmen austauschen oder die Möglichkeit nutzen sollen, per E-Mail Berichte an die Dienstleistungsgewerkschaft zu schicken, die dann die Grundlage einer Aktualisierung des Lidl-Schwarzbuchs bilden sollen. Unter einer Aktion mit dem Titel Lidl live werden auch Arbeitnehmer aus Lidl-Filialen in anderen Ländern zum Erzählen ihrer Lidl-Ge-

50 Vgl. Pickerill: „Rethinking political participation“. 
schichten gebeten. Ein weiteres anschauliches Beispiel bildet die Website der Alliance@IBM, die offizielle nationale Website der IBM-Mitarbeitergewerkschaft in den USA, IBM Employees' Union CWA Local 1701, AFL-CIO, www.allianceibm.org.

In der Analyse unternehmenskritischer Kampagnen zeigt sich eine zunehmende Bedeutung der visuellen, ästhetischen Dimension der Netzkommunikation: $\mathrm{Zu}$ nennen sind in dem Zusammenhang insbesondere die parodistischen Verfremdungen kommerzieller Werbung. So werden in Anti-Corporate Campaigns im deutschen Sprachraum Elemente der künstlerischen CultureJamming-Bewegung aufgenommen und im Netz kommuniziert. Eine andere Form der Aufwertung der ästhetischen Dimension des Protests findet sich in Verweisen auf inzwischen zahlreiche Dokumentarfilme, die sich mit konsumeristischen und unternehmenskritischen Themen befassen wie etwa Super Size Me oder Wal Mart. Der Hohe Preis der Niedrigpreise.

Weniger ästhetisch anspruchsvoll, aber für die kollektive Identitätsbildung unter Protestakteuren vielleicht noch bedeutsamer, sind die auf den Kampagnenwebsites zahlreich zu findenden digitalen Fotogalerien lokaler Protestevents. Selbst wenn man mit Bennett davon ausgeht, dass erfolgreiche Kampagnenpolitik gegenwärtig weniger kollektive Bindungen unter Unterstützern voraussetzt als vergleichbare Kampagnen der 1960 und 1970er Jahre, so lässt sich doch hinsichtlich der zahlreichen visuellen Protestdokumentationen feststellen, dass dadurch nicht nur die Archivfunktion des Internets erweitert wird, sondern vor allem auch kollektive Bindungen unter den Akteuren erzeugt und verfestigt werden. Konsumeristische Kampagnen sind gegenwärtig, wie oben erwähnt, nicht zuletzt aufgrund gesunkener politischer Partizipationsbereitschaft weniger markt- als medienbezogen. Dies zeigt sich auch im Umfang der zahlenmäßigen Unterstützung von lokalen Aktionen gegen einzelne skandalisierte Unternehmen bzw. Geschäfte. Auf den meisten Fotos sind nicht mehr als eine Hand voll Aktivisten zu sehen. Betrachtet man jedoch die Bildergalerie im Netz insgesamt, erweckt sie einen für das prognostische Framing, d.h. die Vermittlung von Erfolgsaussichten der Kampagne, nicht unwichtigen Wir-sindviele-Eindruck. 


\section{$4 \quad$ Ausblick}

Die große Mehrheit unternehmenskritischer Kampagnen im deutschsprachigen Raum wird von NGO-gestützten Netzwerken organisiert. Insofern zeigt die häufig zitierte Schneeballaktion von Jonah Peretti eher das Potenzial eines netzbasierten individualisierten Aktivismus als dessen reale Einlösung; sie ist eher Ausnahme als Regel. Massenmediale Aufmerksamkeit kann durch die Kopplung von Mikro- (z.B. E-Mail), Meso- (z.B. alternative Nachrichtenportale) und Makromedien (z.B. TV; nationale Presse) erzeugt werden. Dennoch sind NGOs aufgrund ihrer fachlichen Expertise und ihrer Kompetenzen im Bereich eines professionellen Medienmanagements noch immer die zentralen Katalysatoren für politische Protestkampagnen im Allgemeinen wie unternehmenskritische Mobilisierung einer Protestpolitik mit dem Einkaufskorb im Besonderen.

Große Hoffnungen auf eine Demokratisierung der Politik durch die Netzkommunikation sind inzwischen ernüchternden Bilanzen gewichen. Auch die Analyse transnationaler Anti-Corporate Campaigns im deutschsprachigen Raum bestätigt den nur geringen Anteil interaktiver, Partizipation und Deliberation fördernder Kommunikationsangebote im Netz. Konsumeristische Aktionen bedürfen jedoch der deliberativen Praxis, um Konsumpräferenzen und Unternehmenskritik zu legitimieren und zu einer lebendigen zivilgesellschaftlichen Thematisierung der Rolle des Konsums als Vehikel und Sphäre sozialen und politischen Wandels beizutragen.

Vor allem aufgrund des aufgezeigten Spannungsverhältnisses zwischen (inter)netzwerk- und massenmedienbezogenen Medienlogiken sind die Asymmetrien zwischen Protestorganisationen und individuellen Protestunterstützern durch die Einführung computergestützer Kommunikationsmedien nicht umfassend gemindert worden: Individuelle Aktivitäten von netizen consumers werden unvermindert zumeist von organisatorischen Zentren initiiert und gesteuert. ${ }^{51}$ Insofern ist das eingangs geschilderte Erfolgsbeispiel von Peretti eher als Cybermythos und nicht als repräsentatives Beispiel für die erfolgreiche Politisierung des Konsums zu betrachten.

Die Stärke gegenwärtiger konsumeristischer Aktionen liegt in der organisatorischen und individuellen Zusammenarbeit von Akteuren alter und neuer sozialer Bewegungen wie auch in der Überschreitung nationaler territorialer Grenzziehungen. Die dadurch entstehende Heterogenität resultiert in neuen Problemen der Erzeugung öffentlicher Sichtbarkeit und der damit verbundenen Generierung politischen Einflusses. Die aktuell in der Weltsozialforumsbewegung geführte Debatte um eine Beibehaltung dezentralisierter Aktions-

51 Vgl. Bieber/Lamla: „Das Netz der Konsumenten“, S. 70. 
formen oder Schaffung repräsentativer Sprecherrollen für die Außendarstellung, vor allem die Kommunikation mit Journalisten ${ }^{52}$, zeigt sich somit auch im Zusammenhang transnationaler konsumeristischer Initiativen.

Wer spricht für wen in der entstehenden Bewegung des politischen Konsumerismus? Was sind die geteilten Ziele und Konsummodelle jenseits des wenig konturierten Deutungstahmens globaler sozialer Rechte? Diese Fragen sind nicht nur von strategischer Bedeutung. Die Frage, ob Kampagnenpolitik eher dezentrale Netzwerk- oder zentralisierte Massenmedienorientierung bedeutet, ist auch für die politische Legitimation des politischen Konsumerismus von zentraler Bedeutung. NGO-basierte Kampagnenpolitik gründet ihre Legitimation auf das Expertenwissen, die Erfahrung und Glaubwürdigkeit von NGOs sowie deren Rechenschaftspflicht gegenüber Mitgliedern und Sponsoren. Direkter Aktivismus in horizontalen Netzwerken bietet den Vorteil umfassenderer politischer Beteiligung. Jedoch lässt er jede Form der Rechenschaftspflicht gegenüber einer breiten Öffentlichkeit vermissen. In beiden Fällen bleibt die für liberale Demokratien zentrale Frage der Legitimation ungelöst. Eine Antwort auf diese komplexe Frage kann im Rahmen dieses Beitrags nicht geleistet werden. Jedoch scheint das aufgezeigte Spannungsverhältnis zwischen zentralisierenden und dezentralisierenden Medienlogiken ein sinnvoller Ausgangspunkt für die Analyse der skizzierten Legitimationsproblematik zu sein.

\section{Literaturverzeichnis}

Arvidsson, Adam: Brands. Meaning and value in media culture, London/New York, 2006.

Baringhorst: „Political Empowerment of Consumer Citizens - Chances and Problems of Anti-corporate Campaigning on the Net", in: Calenda, Davide u.a. (Hrsg.): Net working/Networking: Politics on the Internet, Tampere 2007 (im Erscheinen).

Baringhorst, Sigrid: „Keine Reizwäsche aus Burma. Menschenrechte durch politisierten Konsum?"“, in: Lamla, Jörn/Neckel, Sighard (Hrsg.): Politisierter Konsum - konsumierte Politik, Wiesbaden 2006, S. 233-258.

Bennett, Lance W.: „Social Movements beyond Borders: Understanding Two Eras of Transnational Activism", in: Tarrow, Sydney/Porta, Donatella della (Hrsg.): Transnational Protest and Global Activism, Oxford 2005, S. 203-226.

52 Vgl. Glasius u.a.: Global Civil Society 2005/6. 
Bennett, Lance W.: „Branded Political Communication: Lifestyle Politics, Logo Campaigns, and the Rise of Global Citizenship“, in: Micheletti, Michele u.a. (Hrsg.): Politics, Products and Markets. Exploring Political Consumerism Past and Present, New Brunswick/London 2004, S. 101-126.

Bieber, Christoph/Lamla, Jörn: „Das Netz der Konsumenten. Innovationschancen der Verbraucherbewegung im Internet", in: Forschungsjournal Neue Soziale Bewegung, Jg. 18, Nr. 4, 2005, S. 65-77.

CorpWatch: „About CorpWatch“, www.corpwatch.org/article.php?id=11314, 15.08.2007.

Danesi, Marcel: Brands, New York u.a. 2006.

Diani, Mario: „Social Movement Networks. Virtual and Real“, in: Webster, Frank (Hrsg.): Culture and Politics in the Information Age. A new politics? London/New York 2001, S. 117-128.

Evans, Peter: „Fighting Marginalization with Transnational Networks. Counter-hegemonic Globalization“, in: Contemporary Sociology, Jg. 29, Nr. 1, 2000, S. 230-241.

Friedman, Monroe: Consumer Boycott. Effecting Change through the Marketplace and the Media, London 1999.

Glasius, Marlies u.a. (Hrsg.): Global Civil Society 2005/6, London 2005.

GlobalWitness: „Resources, Conflict and Corruption“, www.globalwitness.org/ media_library_get.php/149/Global\%20Witness\%20profile.pdf, 15.08.2007.

Hagel, John/Armstrong Arthur G.: Net.gain. Expanding Markets through Virtual Communities, Boston, MA 1997.

Jordan, Tim: Activism! Direct action, hacktivism and the future of society, London 2002.

Keck, Margaret E./Sikkink, Kathryn: Activists beyond Borders. Advocacy Networks in International Politics, Ithaca/London 1998.

Lahusen, Christian: „Internationale Kampagnen. Grundmuster und Kontextfaktoren globalen kollektiven Handelns", in: Forschungsjournal Neue Soziale Bewegungen, Jg. 9, Nr. 2, 1996, S. 42-50.

Lamla, Jörn/Neckel, Sighard (Hrsg.): Politisierter Konsum - konsumierte Politik, Wiesbaden 2006.

Manchovic, Lev: The Language of the New Media, Cambridge 2001.

Mark-Ungericht, Bernhard: Betriebliche Schließungs- und Öffnungsprozesse gegenüber gesellschaftlichen Anliegen und zivilgesellschaftlichen An- 
spruchsgruppen vor dem Hintergrund der Transformation gesellschaftlicher Rahmenbedingungen, Graz 2002 (Habil.).

Micheletti, Michele: „Just Clothes? Discursive Political Consumerism and Political Participation", Paper presented at the European Consortium for Political Research, Workshop „Emerging Repertoires of Political Action“, Uppsala, 14.-18.04.2004.

Niesyto, Johanna: „Networking campaigns - towards a transnational civil society?“, Vortrag gehalten auf dem Workshop „European Protest Movements since the Cold War. The Rise of a (Trans-)national Civil Society and the Transformation of the Public Sphere", Zürich, 07.10.03.2007

Peretti, Jonah/Micheletti, Michele: „The Nike Sweatshop Email. Political Consumerism, Internet, and Culture Jamming“, in: Micheletti, Michele u.a. (Hrsg.): Politics, Products and Markets. Exploring Political Consumerism Past and Present, New Brunswick/London 2004, S. 127-142.

Pickerill, Jenny: „Rethinking political participation: experiments in Internet activism in Australia and Britain“, in: Gibson, Rachel u.a. (Hrsg.): Electronic Democracy. Mobilisation, Organisation and Participation via New ICTs, MiltonPark/New York 2004, S. 170-193.

Porta, Donatella della: „Transnational Social Movements. A Challenge for Social Movement Theory?", Vortrag gehalten auf der Konferenz „Crossing Borders. On the Road Toward Transnational Social Movement Analysis“, Berlin, 05.-07.10.2006.

PR Watch: „About CMD“, www.prwatch.org/cmd/index.html, 15.08.2007.

Rucht, Dieter: „The quadruple ,A'. Media strategies of protest movements since the 1960s", in: Donk, Wim van de u.a. (Hrsg.): Cyberprotest. New Media, Citizens and Social Movements, London/New York, S. 29-56.

Scammell, Margaret: „Citizen consumers: towards a new marketing of politics“, in: Corner, John/Pels, Díck (Hrsg.): Media and the restyling of politics - consumerism, celebrity and cynicism. London 2003, S. 117-136.

Schönberger, Klaus: Persistenz und Rekombination. NGOs und zivilgesellschaftliche Organisationen zwischen traditionalen und weiterentwickelten Praktiken politischen Handelns in netzbasierter Kommunikation, Tübingen 2004.

Street, John/Scott, Alan: „From media politics to e-protest? The use of popular culture and new media in parties and social movements", in: Webster, Frank (Hrsg.): Culture and Politics in the Information Age. A new politics?, London/New York 2001, 32-52. 
Sweatshop Watch: „Mission“, www.sweatshopwatch.org/index.php?s=52, 15.08.2007.

Tarrow, Sydney/Porta, Donatella della: „Conclusion. ,Globalization', Complex Internationalism, and Transnational Contention", in: dies. (Hrsg.): Transnational Protest and Global Activism, Oxford 2005, S. 227-246.

Vogelbusch, Josua: „eBay versteht N.I.X. Spaß!!!“, 2004, de.indymedia.org/ 2004/11/100121.shtml, 30.07.2007.

Werner, Klaus/Weiss, Hans: Das neue Schwarzbuch Markenfirmen. Die Machenschaften der Konzerne, Wien/Frankfurt a.M. 2004. 


\section{Sigrid Baringhorst/Veronika Kneip/Johanna Niesyto}

\section{Wandel und Kontinuität von Protestkulturen seit den 1960er Jahren: Eine Analyse ausgewählter Anti-Corporate Campaigns ${ }^{1}$}

\section{$1 \quad$ Wandel oder Kontinuität?}

Während noch in den 1990er Jahren zahlreiche Arbeiten angesichts der Einführung neuer Informations- und Kommunikationstechnologien von einem grundlegenden Wandel politischer Protestkulturen sprachen, sind die Einschätzungen inzwischen nüchterner und moderater geworden. Alter Wein in neuen Schläuchen, so etwa die kritische Einschätzung von Street und Scott der durch die Netzkommunikation bedingten Erneuerungspotenziale. Die angeblich neuen Inhalte der globalisierungskritischen Bewegung seien, so ihre These, eher schlichte Varianten eines alten anti-kapitalistischen und anti-imperialistischen Master Frame. Zudem sei die karnevaleske Spaß- und Erlebnisorientierung der Akteure grundsätzlich nicht neu, sondern inspiriert vom Situationismus und einer schon in der Studentenbewegung zu findenden Orientierung von Handlungsrepertoires an Aktionsformen künstlerischer Avantgarden. ${ }^{2}$ Auch Dieter Rucht sieht in seiner Übersicht zum $W$ andel politischen Protests in der Bundesrepublik seit 1950 eher kontinuierlich sich entfaltende Trends als einschneidende Brüche oder Neuorientierungen. ${ }^{3}$ Die Entwicklung von Protestkulturen in Deutschland, so seine These, zeichnet sich vor allem aus durch: eine Ausdifferenzierung der symbolischen Formensprache zugunsten der Einbeziehung unterhaltsamer Repertoires, eine fortschreitende Professionalisierung von Protestplanung und Inszenierung, eine zunehmende Abkopplung von soziokulturellen Milieus und allgemeine Dekontextualisierung sowie, da-

1 Bei diesem Beitrag handelt es sich um die Überarbeitung eines Vortrags, der am 19.10.2006 im Rahmen der Tagung Bürgergesellschaft - Wunsch und Wirklichkeit des Wissenschaftszentrums Berlin gehalten wurde.

2 „Wir vertreten die These, dass die ,neue Politik“ dieser Protestformen zwar viel von der popular culture, also der Alltagskultur, besonders der Popkultur und den dort praktizieren medialen Methoden entlehnt (Hart 1994), jedoch diese neuen Methoden eigentlich nur eine bloße Verfeinerung des Instrumentariums im politischen Konflikt darstellen, in dem die Kultur sowohl als manipulatives wie auch als expressives Element genutzt wird.“ Street/Scott: „E-Protest“, S. 64.

3 Vgl. Rucht: „Zum Wandel politischen Protests in der Bundesrepublik“, S. 8ff. 
mit verbunden, eine programmatische Entideologisierung und Veralltäglichung des Protests.

Dieser Beitrag greift einige der von Street und Scott wie Rucht vertretenen Einschätzungen des - so könnte man vielleicht zusammenfassen - kontinuierlichen Wandels von Protestkulturen auf und erhärtet bzw. illustriert diese am Beispiel ausgewählter Protestkampagnen gegen privatwirtschaftliche Unternehmen, modifiziert sie aber in gewisser Hinsicht auch. Während das Bild des kontinuierlichen Wandels eher die evolutionäre Dimension von Veränderungsprozessen betont, zeigt der Beitrag am Beispiel dreier Kampagnen - neben sich eher kontinuierlich entfaltenden Elementen der Kampagnenpolitik wie z.B. strategischer Zielorientierung, zentraler Handlungsplanung und -koordination, Ausrichtung an massenmedialer Resonanz und damit verbundenen Aspekten wie Symbolhaftigkeit und Körperlichkeit - auch die grundlegenden Veränderungen kampagnenförmigen Protesthandelns auf. Protestkulturen, so die These, entfalten sich in mancher Hinsicht zwar kontinuierlich, in anderer Hinsicht aber auch diskontinuierlich und eher im Sinne der Entfaltung dialektischer Gegensätze und diese Gegensätze in sich aufnehmender und partiell überwindender Synthesen. Ziel des Beitrages ist es, die Gleichzeitigkeit von Kontinuitäten und Diskontinuitäten beispielhaft an der Entwicklung strategischer Deutungsmuster zur Legitimation von Unternehmenskritik sowie an der einhergehenden veränderten Interpretation der Rolle von Konsumenten als Protestakteure und der damit verbundenen unterschiedlichen Nutzung von Protestrepertoires zu illustrieren.

Bei den ausgewählten Protestkampagnen handelt es sich um die Kampagne Enteignet Springer (1967), die Brent-Spar-Kampagne (1995) und die Kampagne Lidl ist nicht $2 u$ billigen (2005-06). Die umfangreiche Literatur zu den beiden älteren Kampagnen ermöglicht eine fundierte sekundäranalytische Betrachtung dieses Zeitraums. ${ }^{4}$ Aussagen zu aktuellen Protestformen werden durch Ergebnisse des im Rahmen des Forschungsprojektes Protest- und Medienkulturen im Umbruch entstandenen Samples von über 100 deutschsprachigen Anti-Corporate Campaigns (1995-2005) untermauert. $^{5}$

4 An dieser Stelle sei herzlichst Vincent da Silva für seine Recherche und Kommentare zur Springer-Kampagne gedankt.

5 Informationen zum Forschungsprojekt finden sich unter www.protest-cultures. uni-siegen.de. 


\section{Strategisches Framing - Legitimation von Unternehmenskritik}

Im Folgenden werden diejenigen Kontinuitäten und Diskontinuitäten herausgearbeitet, die speziell unternehmenskritische Protestkampagnen prägen. Dabei wird zunächst auf veränderte Deutungsrahmen (Frames) zur Begründung der Auswahl von Unternehmen als Zielscheibe zivilgesellschaftlichen Protests eingegangen.

\subsection{Enteignet Springer - Unternehmen als Verursacher von Ausbeutung und Manipulation}

Unternehmenskritik hat nicht nur eine lange Tradition in der Arbeiter- und Gewerkschaftsbewegung, sie bildet seit der Studentenbewegung auch einen festen Bestandteil der programmatischen Ausrichtung neuer sozialer Bewegungsakteure in Deutschland. Mit der Integration der Gewerkschaften in das korporatistische Verhandlungssystem der Nachkriegsgesellschaft und der Verabschiedung des Godesberger Programms der SPD wird die Arbeiterbewegung gewissermaßen politisch entschärft und verliert ihre grundsätzlich sozialistische Perspektive der Systemtransformation. Die Analyse der Rahmung der Protestmobilisierung gegen den Springer-Konzern verdeutlicht, dass die vor allem von der Studentenbewegung getragene APO $^{6}$ der 1960er Jahre das von der Arbeiterbewegung weitgehend aufgegebene Ziel revolutionärer Systemveränderung aufnimmt. Der antiautoritäre Protestdiskurs ist charakterisiert durch einen grundlegenden Antikapitalismus, verbunden mit einem die Verknüpfung von Kapitalismus und NS-Vergangenheit skandalisierenden Anti-Faschismus, in dem sich vor allem der starke Generationenbezug der studentischen Gesellschaftskritik ausdrückt: „Mörder?“ so die Überschrift über den im Wanted-Stil abgedruckten Konterfeis von Julius Streicher und Axel C. Springer auf einem der Flugblätter der Kampagne. „JULIUS STREICHER“, so der Subtext,

6 Der Begriff der APO (außerparlamentarische Opposition) wird in der Literatur uneinheitlich verwendet, da diese ein offenes und hohen Dynamiken unterliegendes Netzwerk darstellt: „Diese zum Eigenbegriff gewordene ,außerparlamentarische Opposition“ oder ,APO‘ war der Sammelname für eine Vielzahl außerparlamentarischer Kampagnen und Aktionen vor allem gegen die atomare Rüstung, die Notstandsgesetzgebung, den Vietnamkrieg, gegen die Manipulationsmacht des Springer-Konzerns, für Hochschulreform, Abrüstung und partiell - vor allem mit der Hinwendung der Studentenbewegung zu marxistischer Theorie und antiautoritärer Praxis - für radikale sozialistische Strukturreform. Die der APO zugerechneten Gruppen, Verbände, Bewegungen und Wählerbündnisse lagen in ihrem Selbstverständnis innerhalb einer politischen Bandbreite von ,linksliberal' bis linksradikal“." Otto: APO, S. 13. 
„hetzte in seiner Zeitung ,Der Stürmer' zum Judenmord. Er wurde dafür zum Tode verurteilt. AXEL C. SPRINGER hetzt zum Studentenmord. Er wurde bisher nicht verurteilt und hetzt und hetzt und hetzt..."

Kennzeichnend ist darüber hinaus ein anti-imperialistischer Deutungsrahmen, in dem die Solidarität der Studentenbewegung mit Befreiungsbewegungen in der zweiten und dritten Welt legitimiert wird. Entsprechend des marxistischen bzw. neo-marxistischen Weltbildes und basierend auf der Konzeptionalisierung der Kulturindustrie in der Gesellschaftskritik der Kritischen Theorie wird die ungebrochene Massenloyalität der Deutschen zum als ausbeuterisch diagnostizierten kapitalistischen Wirtschaftssystem wesentlich auf die Manipulation der öffentlichen Meinung durch Boulevardzeitungen wie die BILD-Zeitung zurückgeführt:
Zögert nicht! Die Vernichtung des Springerkonzerns hat schon be- gonnen[.] Weder die internationale Konterrevolution noch ihre Läufer und Springer können gerettet werden. Brecht die Macht der Manipu- lateure! Worauf wartet ihr? Feinfühligkeit gegenüber dem Feind be- deutet Brutalität gegenüber der Revolution. Enteignet Springer. ${ }^{8}$

Der Inhalt des zitierten Flugblattes des Springertribunals: Berlin dokumentiert die für die Gesellschafts- und Politikdeutung der APO typische Interpretation des Kampagnenziels - die Enteignung Springers - im Rahmen einer umfassenden revolutionären Umwälzung. Während die Enteignung erst durch das Fernziel der revolutionären Transformation von Staat und Wirtschaftsordnung umgesetzt werden kann, werden der Boykott der Springer-Presse und Demonstrationen vor dem Konzerngebäude als alternative, zeitnahe und realisierbare Mobilisierungsziele propagiert. Der Warenkonsum wird in den Begründungstexten generell aus der Perspektive der Kritik des Warenfetischismus (Mark; Haug) gedeutet und steht deshalb allgemein unter dem Verdacht, kapitalistische Macht- und Ausbeutungsverhältnisse zu stabilisieren. Dem antikonsumistischen Grundgedanken folgend thematisiert der Aufruf gegen die Springer-Presse nicht - wie in den späteren Kampagnen - den Konsumenten als Regulationsinstanz des Marktes. Auch die Verhinderung der Zeitungsauslieferung durch Blockadeaktionen vor dem Verlagshaus ist vielmehr Ausdruck eines Bürgerprotestes, der sich gegen die bestehenden herrschaftlichen Macht-

7 Flugblatt zitiert in Miermeister/Staadt: Provokationen, S. 144.

8 Ebd., S. 147. 
strukturen wendet. Ein unmittelbarer Zusammenhang zwischen Produktionsund Distributionsprozess wird hier nicht hergestellt. ${ }^{9}$

\subsection{Brent Spar - Unternehmen als Produzenten technisch bedingter Modernisierungsrisiken}

Vergleicht man die Flugblatt-Rhetorik der Springer-Kampagne mit der Skandalisierung von Shell im Kontext der Greenpeace-Kampagne, so zeigen sich stichwortartig verkürzt folgende inhaltliche Gemeinsamkeiten und Differenzen: Wie die Springer-Kampagne so richtet sich auch die vor allem von Greenpeace in den Medien artikulierte Kritik an Shell gezielt gegen ein in der Öffentlichkeit allgemein bekanntes Markenunternehmen. Die Skandalisierung von Shell erfolgt - entsprechend einer auf inhaltliche Eingängigkeit und Eindeutigkeit zielenden Kampagnenlogik - in einer simplen und moralisch hoch aufgeladenen Binärcodierung von Freund und Feind. Die Kritik an Shell setzt jedoch nicht an der herrschaftslegitimierenden oder Ausbeutungsfunktion des Konzerns in der kapitalistischen Wirtschaftsordnung oder seiner etwaigen schuldhaften Verstrickung in der Vergangenheit an. Die skandalisierte Versenkung einer Bohrinsel in der Nordsee gilt nicht als Ausdruck einer strukturellen und prinzipiell mit der Kapitalverwertungslogik unvereinbaren Unternehmenspolitik, sondern als Ausdruck einer vermeidbaren, moralisch von der Unternehmensleitung zu verantwortenden Normverletzung. Statt auf eine Enteignung des Konzerns zielt der Protest auf eine Verpflichtung des ÖlMultis auf eine Ethik der ökologischen Nachhaltigkeit.

Wenn in Bezug auf die Mobilisierung zum Shell-Boykott überhaupt von einem Master Frame, einem umfassenden weltanschaulichen Deutungsrahmen zur Interpretation eines gesellschaftlichen Problems, gesprochen werden kann, dann im Sinne der seit den 1970er Jahren zunehmenden „Moralisierung der Industrieproduktion“ (Beck) und der kritischen Bewertung der mit der technologischen Modernisierung verbundenen Risiken. Als Folge der öffentlichen Skandalisierung von häufig nicht abschätzbaren Risiken technologischer Innovationen für die Gesundheit der Bürger oder den Erhalt des ökologischen Gleichgewichts sehen sich Unternehmen wachsenden gesellschaftlichen Ansprüchen und Wertkonflikten zwischen ethischen und ökonomischen Hand-

9 Noch deutlicher als im unmittelbaren Zusammenhang der Springer-Kampagne tritt die konsumkritische Haltung im weiteren Kontext der Studentenproteste hervor. Hier kann beispielhaft die vom AStA und SDS Berlin organisierte Demonstration gegen die großen Konsumtempel im Zentrum Berlins am 26. August 1967 anlässlich des ersten langen Sonnabends genannt werden. Vgl. Lönnendonker u.a.: Die antiautoritäre Revolte, S. 485. 
lungszielen ausgesetzt. Die Shell-Kampagne konzentriert sich im Rahmen dieser Thematisierung von Modernisierungsrisiken vor allem auf das in schlichten Slogans wie Save our Seas formulierte Ziel des normativen Primats des Umweltschutzes vor ökonomischen Kosten-Nutzen-Erwägungen einzelner Unternehmen. Dabei wird Umweltschutz als prinzipiell mit der kapitalistischen Ordnung vereinbar gedeutet und auch Massenkonsum nicht mehr - wie noch in der von Marcuse inspirierten Kritik der 1968er - als Ausdruck eines Massenloyalität generierenden falschen Bewusstseins gegeißelt. ${ }^{10}$

Die im Shell-Boykott erstmals (sieht man einmal ab von der rassistischen Kauft-nicht-bei-Juden-Kampagne der Nazis) massenhaft in Deutschland unterstützte Politisierung des Konsums kann mit Rucht als ein Ausdruck der „Veralltäglichung“ oder „Trivialisierung“ politischen Protests betrachtet werden. Indem Protesthandeln in das alltägliche Konsumhandeln integriert wird, wird es nicht nur von spezifischen Protestmilieus abgekoppelt, ${ }^{11}$ sondern auch in einer zuvor ungewohnten Weise individualisiert. Mit der im Shell-Boykott ausgedrückten massenhaften Unterstützung der Skandalisierung eines schwarzen Unternehmerschafes gerät nicht das ressourcenvernichtende und umweltschädliche Konsumverhalten der Bürger in Misskredit. Die kollektive und rituelle Abstrafung des Einzelunternehmens bestätigt geradezu die Moralität der Gesamtgesellschaft inklusive ihrer kapitalistischen Wirtschaftsordnung.

Die Brent-Spar-Kampagne indiziert den Höhepunkt einer politischen Entschärfung und systemischen Anpassung von Protestkommunikation und -kulturen auf unterschiedlichen Ebenen:

- $\quad$ Sie markiert einen sich schon seit den 1970er Jahren vollziehenden Abschied von politisch revolutionären Zielvorstellungen einer sozialistischen Systemalternative.

- $\quad$ Sie steht beispielhaft für eine zunehmende Zahl von Kampagnen, in denen Unternehmen aufgrund nicht kalkulierbarer technologischer Modernisierungsfolgen skandalisiert werden.

- Sie verdeutlicht zugleich die Abkehr einer in großen Bewegungsorganisationen institutionalisierten Protestbewegung von einer gegenkulturellen Kritik an einer „Kolonialisierung der Lebenswelt“ (Habermas) und von

10 Dies belegt u. a. auch die in der Folge (Ende 1999) von Greenpeace gegründete Greenpeace energy e.G., durch die Verbraucher alternativen, d.h. nicht durch Atom- oder Kohlekraftwerke erzeugten Strom beziehen können.

11 Während der Boykott Springers eher eine Sache studentischer Zirkel blieb, wurde der Boykott von Shell-Tankstellen im September 1995 von weiten Teilen der Bevölkerung unterstützt. 
einer programmatischen Durchbrechung ökonomischer Handlungsrationalitäten durch die Aktivierung des Eigensinns kommunikativer Alltagspraxis.

- $\quad$ Sie steht beispielhaft für eine Anpassung politischen Protests an eine primär auf die Selektionsprinzipien massenmedialer Kommunikation ausgerichtete Kampagnenlogik,

- $\quad$ sowie für eine Adaption von Protesthandeln an die Konsumpraxis einer individualisierten Wohlstandsgesellschaft.

Protest gegen Unternehmen wird mehrheitsfähig, indem die Ziele und Handlungsformen des Protests der Handlungslogik individualisierter Kosten-Nutzen-Maximierung angepasst werden. Die Greenpeace-Kampagne markiert einen gewissen Höhepunkt in der Orientierung politischen Protests in Deutschland an Systemrationalitäten, die in die 1960er Jahren noch heftig kritisiert wurden. Zugleich steht sie aber auch am Beginn einer neuen systemkritischen Protestbewegung, in der alte antikapitalistische Ideologeme in einem globalisierungskritischen Master Frame eine neuartige Verbindung mit Elementen einer systemkonformen Unternehmensethik eingehen. Dabei wird die Politisierung des Konsumverhaltens zu einem zentralen Vehikel einer sozial und ökologisch fundierten Unternehmenskritik.

\subsection{Lidl ist nicht zu billigen - Unternehmen als Produzenten globaler Ausbeutung und ökologischer Modernisierungsfolgen}

Beispielhaft für die Synthese kapitalismuskritischer und unternehmensethischer Deutungsrahmen ist die Unternehmenskritik in der vom Aktionsnetzwerk Attac initiierten Kampagne Lidl ist nicht $z u$ billigen. ${ }^{12}$ Eingebettet sind die Kampagnenaufrufe in eine Deutung von Globalisierungsprozessen aus der Perspektive globaler Gerechtigkeit. Selbsterklärtes Ziel ist die Durchsetzung von Globalen Sozialen Recbten. Während die Brent-Spar-Kampagne die Unternehmenskritik weitgehend von globalen Produktions- und Verwertungszusammenhängen dekontextualisiert, wird mit der Lidl-Kampagne von Attac Unternehmenskritik rekontextualisiert und - darin vergleichbar mit der Unternehmenskritik der Kampagne Enteignet-Springer - in einen internationalen Protestkontext unterschiedlicher sozialer Widerstandkämpfe eingebettet:

Attac kritisiert mit seiner Kampagne die Ursachen und verhängnisvollen Folgen dieser Form der Globalisierung im Einkaufswagen. Wir agieren konzernkritisch, weil es uns wichtig ist, ganz konkrete, im

12 Vgl. auch Löding/Schulze/Sundermann in diesem Band. 


\begin{abstract}
Alltag erfahrbare Phänomene aufzugreifen. Mit unserer Kampagne üben wir Globalisierungs- und Konsumkritik, die von den VerbraucherInnen - so unsere Erfahrung - auch verstanden wird. [...] Die Kritik an der Unternehmenspolitik von Discountern verweist auf den Teufelskreis von Sozialabbau und ökonomischen Kostensenkungsstrategien. ${ }^{13}$
\end{abstract}

Die Veralltäglichung des Protests im politisierten Einkaufswagen ist nicht wie bei der Shell-Kampagne Ausdruck einer systemkonformen Umweltschutzorientierung sondern Indikator für eine Verknüpfung von Konzernkritik mit umfassender Systemkritik. Der attackierte Discounter wird aus pädagogischen und mobilisierungspraktischen Gründen skandalisiert. Lidl soll mehr sein als nur das Extrembeispiel einer Branche, in der das „,billig, billig, billig - auf Kosten von ganz, ganz vielen"14 geht. Das skandalisierte Unternehmen soll für die gesamte strukturelle Dynamik der ökonomischen Globalisierung und das mit dem ungezügelten Wettbewerb verbundene Preis-, Umwelt- und Sozialdumping in Deutschland wie in den Ländern der ausgelagerten Produktion stehen. Ohne auf einen konkreten Protestanlass rekurrieren zu können, knüpft der Angriff auf den Schwarz-Konzern - im Sinne eines mehrdimensionalen Frame-Bridging - an unterschiedliche Deutungsrahmen westlicher sozialer Bewegungen der letzten fünfzig Jahre an:

Mit aggressivem Preisdumping pressen Sie die Lieferanten aus, so dass Bauern in der Folge immer wieder gezwungen sind, ihre Milch unterhalb der Produktionskosten zu verkaufen. Auch auf dem Weltmarkt macht Lidl Druck und sorgt für mieseste Arbeitsbedingungen bei Bananenpflückern in Ecuador, Näherinnen in Vietnam oder LKW-Fahrern aus Lettland. Sie stellen sich mit Ihrem Konzern dem Umweltschutz entgegen. Durch Ihr Preisdumping erzwingen Sie Massenproduktion und weite Transportwege. Ihr Billigwahn geht auf Kosten der Natur und unserer Zukunft.

In ihren Filialen beuten Sie VerkäuferInnen durch niedrige Löhne Arbeitsbedingungen aus.

Ich werde Preis-, Umwelt- und Sozialdumping bei Lidl nicht hinnehmen.

So will ich nicht einkaufen und fordere deshalb:

- Faire Preise für Milch und Bananen!

- Soziale Rechte weltweit achten!

13 Attac Lidl-Kampagnengruppe: „Vorstellung Attac Lidl-Kampagne“, S. 2f.

14 Attac zitiert in Deutschlandfunk: , Attac startet Lidl-Kampagne in Göttingen“. 
- Demokratische Kontrolle zulassen!

- Karten auf den Tisch! Produktgeschichten offen legen!

Stehen Sie zu Ihrer Verantwortung!

Denn heute gilt leider: Lidl ist nicht zu billigen! ${ }^{15}$

Der Einsatz für die Rechte der überwiegend weiblichen Beschäftigten (ca. 85 Prozent) erlaubt den Anschluss an die Ziele der Frauenbewegung; die Forderung nach fairen Preisen und globalen sozialen Rechten formuliert den programmatischen Anschluss an die Menschenrechts- und Dritte-Welt-Bewegung; die Kritik an „weiten Transportwegen“ und „Billigwahn“ (Attac) ermöglicht die ideologische Brücke zur Umweltbewegung; schließlich indiziert die Skandalisierung der Ausbeutung der Beschäftigten den Schulterschluss mit der parallel laufenden ver.di-Kampagne, die sich speziell gegen die Einschränkung von Arbeitsrechten beim Discounter Lidl richtet.

Die Lidl-Kampagne verbindet auf der inhaltlichen Ebene Elemente einer sozialtheoretisch fundierten, grundlegenden Systemkritik, wie sie für die Studentenbewegung charakteristisch war, mit Elementen einer strategisch und professionell durchgeplanten Aktionskampagne, wie sie beispielhaft von Greenpeace entwickelt wurde. Die intendierte Synthese von Theorie und Praxis gelingt aber nur partiell. Die Aufhebung der seit den 1980er Jahren fortschreitenden protestkulturellen Tendenz zur ideologischen Verflachung ist eher Programm als gelebte Kampagnenpraxis. Angesichts des Erfolgsdrucks moderner Kampagnenpolitik ist die im Zuge der Professionalisierung von Bewegungsorganisationen gewachsene organisationsinterne Ausdifferenzierung in unterschiedliche funktionale Handlungsbereiche und die damit verbundene Trennung zwischen zentralisierter, professioneller Kampagnenplanung und organisation auf der einen und basisnaher Kampagnenumsetzung auf der anderen Seite kaum rückgängig zu machen.

\section{$3 \quad$ Konsum und Protest}

Spiegeln sich die aufgezeigten Entwicklungen des strategischen Framing auch in der Ansprache der Konsumenten wider? Können wir einen Trend zum Empowerment des Consumer Citizen beobachten? Welche Auswirkungen haben deutungskulturelle Veränderungen auf die ästhetische Inszenierung von Protestkampagnen? Finden sich - wie eingangs angenommen - auch in der symbolischen Formensprache Tendenzen zugunsten einer Einbeziehung unter-

15 Attac: „Mailomat“. (Elektronischer Protestbrief an Lidl.) 
haltsamer Repertoires Kontinuitäten und Diskontinuitäten? Inwieweit nehmen ästhetische Protestartefakte die Politisierung des Konsums in ihrer Bildsprache auf?

\subsection{Empowerment von Verbrauchern als Consumer Citizens}

Brüche und diskontinuierlichen Wandel gibt es nicht nur in den geschilderten unterschiedlichen dominanten Deutungen der Rolle von Unternehmen in der modernen Gesellschaft, sondern auch hinsichtlich der Politisierung des Konsums und der damit verbundenen Ansprache potenzieller Unterstützer als Bürgerkonsumenten. Während die Kampagne Enteignet Springer nicht auf das Empowerment von Konsumenten setzt und der SDS Verbraucher primär als von der Verführungsmacht der so genannten herrschenden Klasse manipuliert betrachtet, rückt mit der Brent-Spar-Kampagne das einflussreiche Gegenmachtpotenzial eines kollektiv abgestimmten Verbraucherverhaltens in den Blickpunkt der Suche nach den Subjekten gesellschaftspolitischer Veränderung. In der Kampagne Lidl ist nicht zu billigen scheint die Reflexion des gesellschaftlichen Einflusses mobilisierter Bürgerkonsumenten weitaus differenzierter als in der schlichten, zwar nicht von Greenpeace selbst geforderten, aber im Kontext der Bohrinselbesetzung propagierten Shell-Tank-Verweigerung. In Kenntnis der Erfahrung der Shell-Kampagne und sicherlich auch in Reaktion auf die vielfältigen Anpassungsleistungen, die Unternehmen im Laufe der Zeit aufgrund der gewachsenen gesellschaftlichen normativen Ansprüche entwickelt haben, plädieren die Organisatoren von Attac nicht für eine Exit-, sondern die Voice-Variante politischen Protests. Zum Boykott wird nicht aufgerufen. Stattdessen geht es darum, Kaufentscheidungen öffentlich zu thematisieren und - dem Leitbild des verantwortungsbewussten Verbrauchers folgend die kritische Reflexivität der Konsumenten zu fördern. Ziel ist die Sensibilisierung der Verbraucher für die Produktgeschichten der von ihnen gekauften Waren, das Empowerment der Kunden als politische Subjekte gegenüber den finanzstarken Handelsunternehmen. Damit ändert sich der Inhalt politischer Protestkampagnen in Deutschland insofern, als

- $\quad$ erstens die Politik großer Markenfirmen zunehmend zum Angriffspunkt politischen Protests geworden ist,

- $\quad$ zweitens Fragen von Produktion und Konsumption enger miteinander verkoppelt werden,

- $\quad$ und drittens die Distributionssphäre zu einer entscheidenden Dimension der Kritik ökonomischer Verhältnisse avanciert. 
Dies scheint aus einer historischen Sicht auf die letzten fünfzig Jahre politischen Protests in Deutschland ein Novum zu sein. So gibt es zwar vereinzelte Vorläufer in den Jahrzehnten zuvor, doch ist das Ausmaß der Politisierung des Konsums im Zeitraum 1995 bis 2005 erstaunlich hoch. Neben der Lidl-Kampagne von Attac gibt es in dieser Dekade ungefähr 80 weitere Anti-Corporate Campaigns, in denen Aspekte der Warenzirkulation mit Aspekten der Warenproduktion ebenso miteinander verknüpft werden wie Forderungen nach weltweit geltenden sozialen und ökologischen Rechten.

\subsection{Symbolik des Konsumentenprotests}

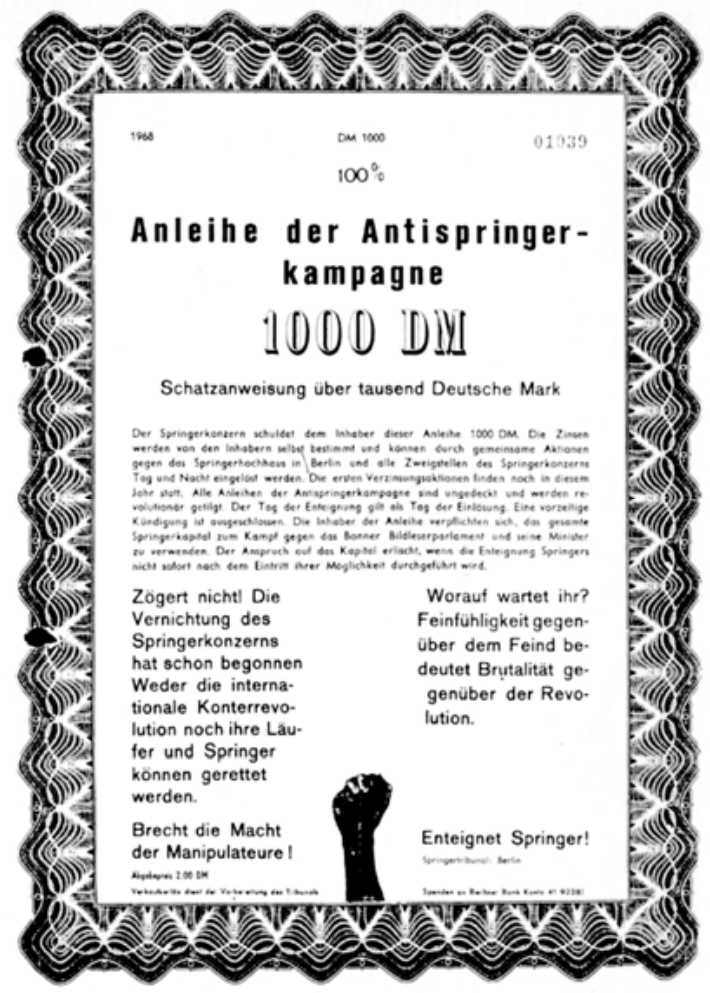

Abb. 1: Anleihe der Anti-Springer-Kampagne. ${ }^{16}$

16 Quelle: Miermeister/Staadt: Provokationen, S. 147. 
Dieser diskontinuierliche Wandel in den verschiedenen Dimensionen zeigt sich schließlich auch in der Ästhetik des Konsumentenprotests. Vergleicht man die Ästhetik der Protestaufrufe der drei untersuchten Kampagnen, so präsentiert sich der APO-Protest in klassischen Kampfsymbolen und Revolutionsgesten wie zum Beispiel der geballten Faust - die Protestästhetik unterstreicht die im öffentlichen Tribunal begründete und auf bleischweren Flugblättern zirkulierte kompromisslose Umsturz- und Enteignungsrhetorik.

Insbesondere die Brent-Spar-Kampagne ist Sinnbild für „Entertainisierung“ (Rucht) und „Erlebnisorientierung“ (Baringhorst), die mit der zunehmenden Ausrichtung an massenmedialen Selektionslogiken verbunden ist. Wie kaum eine andere Kampagne der Nachkriegsgeschichte dokumentiert die ShellKampagne die symbolische Verdichtung der Kampagnenaussage auf Teleaufmerksamkeit generierende, riskante Schlauchbootinszenierungen vor einem Furcht einflößenden Stahlkoloss und massiver Gegenwehr des angegriffenen Konzerns. Im Reality-Protest-TV können Zuschauer den Thrill der Konfrontation hautnah und risikolos verfolgen; die Transaktionskosten der Teilnahme tendieren gegen Null. In der ästhetischen Veralltäglichung des Protests fügen sich die Bilder des Konfliktgeschehens auf hoher See bruchlos in die bildreicher gewordene Nachrichtenkommunikation der kommerzialisierten Fernsehmedien.

Attac gelingt es zwar weitaus weniger als Greenpeace, die Sensationslust der Medien durch expressive Bilder für sich zu instrumentalisieren. Dennoch kann auch diese Kampagne durch den hohen Symbolwert des attackierten Unternehmens eine relativ hohe Medienresonanz erzeugen. Ähnlich wie Greenpeace greift Attac dabei auf unterhaltsame Repertoires zurück, so bietet die Attac-Kampagne beispielsweise Einkaufswagenchips an, welche Kampagnenslogan und -logo transportieren. In beiden Kampagnen werden Unternehmensimages auch visuell dekonstruiert. Adbusting ${ }^{17}$ (vgl. untenstehende Abbildungen ${ }^{18}$ ) bildet eine beliebte ästhetische Strategie der visualisierten Unternehmenskritik. Dabei werden Logos, Slogans oder andere Elemente der Produktund Unternehmenswerbung symbolisch verfremdet, um gewohnte Wahrnehmungsmuster zu durchbrechen und kommerzielle Werbebotschaften politisch und moralisch aufzuladen. Allerdings wird die von Attac im Rahmen der

17 Adbusting wird in den Beiträgen von Hubbertz und März in diesem Band thematisiert.

18 Neben den dargestellten verfremdeten Logos bilden die Kampagnenslogans Lidl ist nicht zu billigen und Shell: Wir kümmern uns um mehr als Autos. Wir versenken Ölplattformen im Meer, belasten die Umwelt, verseuchen Lebensräume, gefährden das Ökosystem und ignorieren Alternativen. GREENPEACE: Das werden wir ändern weitere Adbusting-Beispiele. 
Kampagne generell geübte Systemkritik nicht auf die symbolische Ebene übertragen.
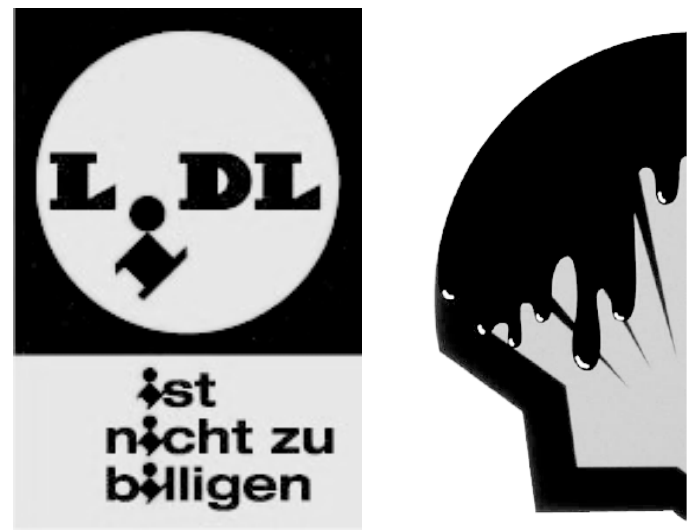

Abb. 2: Kampagnenlogos Attac, Lidl-Kampagne und Greenpeace, Shell-Kampagne. ${ }^{19}$

\section{Binnenstruktur: Netzwerklogik vs. Kampagnenlogik}

Politischer Protest gewinnt über die symbolische Attackierung von Markenunternehmen einen Wiedererkennungswert, der nicht nur für die Protestwahrnehmung von außen, sondern vor allem auch für die Stärkung der schwächer gewordenen Sozialbindungen innerhalb der Protestnetzwerke bedeutsam ist. Die parodistische Dekonstruktion des Unternehmensimages als subkulturelle Ausdrucksform dient zugleich der eigenen Imageaufwertung, der Inszenierung der moralischen Überlegenheit, der Glaubwürdigkeit des skandalisierenden Protestakteurs sowie der bildlichen Darstellung des Konsumthemas.

Unterschiedliche Inszenierungsstrategien stehen im Zusammenhang mit der Binnenstruktur der Kampagnen sowie den verfolgten Öffentlichkeitsstrategien. Zentral ist die Frage, ob Kontinuitäten und Diskontinuitäten von Protestkulturen auch mit veränderten organisatorischen Kampagnenstrukturen einhergehen. Wird in der kampagnenförmig organisierten Protestpolitik mit dem Einkaufswagen die seit den 1980er Jahren zunehmende Tendenz zur Professionalisierung, Institutionalisierung massenmedialen Ausrichtung von Protest zugunsten dezentraler, basisnaher Organisationsformen gebrochen?

19 Quellen: Attac: „Lidl ist nicht zu BILLIGen“; Greenpeace: Brent Spar und seine Folgen, S. 30. 
Während Kampagnenplanung und -arbeit eingängige Slogans und Visualisierungen verlangen, welche sich für die Lebenswelten der zu Mobilisierenden als anschlussfähige Komplexitätsreduktionen erweisen müssen und zudem Prozesse der Selbstvergewisserung der Protestakteure unterstützen sollen, zeichnen sich Netzwerke durch die Betonung der horizontalen Struktur der Beziehungen zwischen den Protestakteuren aus. Die Verbindung von Netzwerk und Kampagne birgt zwei gegenläufige Logiken, welche sowohl auf der strukturellen als auch auf der inhaltlichen Ebene aufeinander treffen. Auf der strukturellen Ebene stellt sich dabei die Frage, wie Kampagneninhalte und -organisation, welche Konsensleistungen und schnelle Entscheidungsprozesse erfordern, in Netzwerken ausgehandelt und durchgeführt werden können. Auf der inhaltlichen Ebene stehen soziale Bewegungen und Nichtregierungsorganisationen mit demokratischem Selbstverständnis vor der Herausforderung, demokratische Legitimität durch dezentralisierte, horizontale Strukturen der internen Meinungsbildung und Entscheidungsfindung zu erzeugen und gleichzeitig dem Anspruch einer auf Populärkultur und Sensation ausgerichteten Kampagnenkommunikation gerecht zu werden.

In den drei analysierten Kampagnen findet sich jeweils ein unterschiedliches Verhältnis von Netzwerk- ${ }^{20}$ und Kampagnenlogik, welches stark mit dem eigenen Selbstverständnis und den jeweiligen Organisationsformen der Hauptträger der Kampagnen korrespondiert. So handelt es sich bei der durch Teile der Studentenbewegung getragenen Springer-Kampagne um ein Aktionsnetzwerk, welches sich erst nach einer ersten Phase der symbolisch-expressiven Demonstration von emotionalen Befindlichkeiten wie Trauer und Empörung im Rahmen von Deeskalationsbemühungen stärker strategisch ausrichtet. Das Netzwerk ist zunächst vor allem durch Spontaneität, informelle Beziehungen und eher horizontale Strukturen gekennzeichnet. Später stellen beispielsweise die auf der 22. Delegiertenkonferenz des zentralen Akteurs SDS $^{21}$ verabschiedete Resolution zum Kampf gegen Manipulation und für die Demo-

20 Mit dem Begriff der Netzwerklogik sind im Folgenden die netzwerkinhärenten multi-dependenten (Austausch-)Prinzipen gemeint, die auf der Zugänglichkeit von Ressourcen, der Gleichberechtigung von Akteuren und Verantwortlichkeit der Handlungsträger und einer damit einhergehenden eher dezentralen Struktur beruhen.

21 Nach der Erschießung Benno Ohnesorgs am 2. Juni 1967 kann insbesondere der SDS das organisatorische Netz verschiedener Hochschulorganisationen an den Universitäten für sich gewinnen, um die sprunghaft angewachsene Protestbasis zu koordinieren und zu verbreiten. Dagegen fehlt der Kommune das organisatorische Netz von Bündnissen. Sie agiert viel isolierter und ist daher primär darauf angewiesen, dass die unterschiedlichen Medien über sie berichten. Zudem steht sie aufgrund früherer Aktionen zunehmend unter dem Druck der Justiz. Vgl. Lönnendonker u.a.: Die antiautoritäre Revolte, S. 481. Auch ältere Protestbewegungen wie 
kratisierung der Öffentlichkeit oder die im Oktober 1967 geschlossene Vereinbarung der gemeinsamen APO-Kampagne gegen Springer zwischen Vertretern verschiedener Studentenverbände (LSD, SHB, SDS), den ASten verschiedener Universitäten, der Kampagne für Abrüstung (KfA) des Republikanischen Clubs (RC) und des Publikationsorgans Berliner Extra-Dienst strategische Elemente der Kampagne dar. Dennoch ist die Springer-Kampagne - im Gegensatz zu den von Attac und Greenpeace initiierten Kampagnen - weniger zeitlich und strategisch geplant und setzt eher auf interne Verhandlungsprozesse als auf Mobilisierung durch Komplexitätsreduktion. Die weitgehende Dezentralität und so entstehende (Eigen-)Dynamik der Netzwerklogik eröffnet den studentischen Akteuren einen großen Gestaltungsspielraum, ist jedoch gleichzeitig eine Ursache für die fehlende Umsetzung geplanter Maßnahmen so wurde das Springer-Hearing als zentrales Kampagnenereignis abgebrochen, die Kampagne löste sich letztlich selbst auf.

Im Vergleich zur Springer-Kampagne kann die Shell-Kampagne als ein eher geschlossenes Netzwerk von Greenpeace-Kampagneninitiatoren und aktivisten beschrieben werden, welches sich jedoch aufgrund seiner SingleIssue-Orientierung als anschlussfähig für verschiedene gesellschaftliche Gruppen (Kirchen, Organisationen/Verbände), Politiker und einzelne Bürger erweist. Hier verbinden sich alte und neue soziale Bewegungsakteure in lockerer Weise zu einem Aktionsnetzwerk, wobei Greenpeace als eigentlicher Träger der Kampagne gilt. Dabei ist die Shell-Kampagne im Gegensatz zur SpringerKampagne stark durch hierarchisierte Entscheidungsprozesse geprägt. Diese Top-Down-Strukturen sind laut des damaligen Geschäftsführers Thilo Bode bewusst im Sinne der Kampagnenlogik gewählt:

Mit einer Kampagne, die aus Mehrheitsentscheidungen entsteht, kann man nun mal nicht erfolgreich sein, da werden Risiken minimiert und niemand trägt die Verantwortung. Und es gibt ohne Risiko keinen Erfolg. ${ }^{22}$

Die Lidl-Kampagne versucht schließlich Netzwerk- und Kampagnenlogik zu vereinen, indem sie eine Kampagnenstruktur aufbaut, die sich durch die Integration verschiedener Netzwerkakteure einerseits und durch die Erreichung

die von christlichen, pazifistischen und sozialistischen Gruppierungen getragenen Ostermärsche der Atomwaffengegner, die zwar aufgrund der Ereignisse wieder erstarken, können dem organisatorisch besser eingebetteten und argumentativ überzeugenderen SDS die Führer- und öffentliche Sprecherschaft nicht streitig machen. Vgl. Sösemann: „Die 68er Bewegung und die Massenmedien“, S. 679.

22 Bode in Transit: „Das Auftreten der NGOs spiegelt nur das Versagen der offiziellen Politik“, S. 136. 
massenmedialer Aufmerksamkeit andererseits auszeichnen soll. So gelingt es der Attac-Kampagne, verschiedene NGOs in das Netzwerk zu integrieren. Neben der Abgrenzung zum Gegner verbindet alle Akteure die zentrale universalistisch-orientierte Forderung der Kampagne nach globalen sozialen Rechten, welche weltanschaulichen Pluralismus zulässt. Mit den verschiedenen konkreteren Forderungen der Kampagne wie z.B. Faire Preise für Bananen, Milch und Wasser können sich einzelne Kooperationspartner ${ }^{23}$ wie z.B. BanaFair e.V. identifizieren. ${ }^{24}$ Im Sinne einer Druckkampagne sollen die Kooperationen weiteren Druck auf Lidl von mehreren Seiten erzeugen. Der gemeinsame Gegner bewirkt neben solchen Synergieeffekten jedoch auch Schwierigkeiten: Wie ist beispielsweise eine Abgrenzung zwischen der Kampagne Lidl ist nicht zu billigen und der Parallelkampagne von ver.di möglich? Attac versucht dies durch weiterreichende Forderungen, welche allerdings in manchen Presseberichten verkürzt dargestellt werden, indem ausschließlich auf die ver.di-Forderung nach Betriebsräten eingegangen wird. Auch werden in Medienberichten zur Kampagne Lidl ist nicht zu billigen nicht immer alle Akteure des Netzwerks namentlich genannt, sodass nicht gewährleistet ist, dass alle Netzwerkmitglieder dieselbe Medienaufmerksamkeit erfahren. ${ }^{25}$ Hier zeigt sich einmal mehr der strukturell angelegte Widerspruch von Kampagne und Netzwerk.

Ein Merkmal, das allen Kampagnen mehr oder weniger gemeinsam ist, stellt die lange Dauer des Protests dar. ${ }^{26}$ Bei allen Kampagnen zeigt sich, dass die Dauerhaftigkeit der Kampagnen ${ }^{27}$ an die Einbindung in relativ dauerhafte Akteursnetzwerke (Studentenbewegung) bzw. an stabile Organisationsstruktu-

23 So werden die weiteren Netzwerkmitglieder auf der Kampagnenwebsite bezeichnet.

24 Unter Bezugnahme auf die Selbstdarstellung der verschiedenen Akteure können die Kooperationspartner wie folgt den einzelnen Unterforderungen zugeordnet werden: Faire Preise für Bananen, Milch und Wasser (Arbeitsgemeinschaft bäuerliche Landwirtschaft e.V., BanaFair e.V.), Demokratische Kontrolle zulassen (Kampagne für Saubere Kleidung, ver.di), Karten auf den Tisch - Produktgeschichte offen legen (Kampagne für Saubere Kleidung).

25 Vgl. Attac: „Kampagnenarbeit bei Attac“, S. 3.

26 Nachdem die Kampagne Lidl ist nicht zu billigen erst ausschließlich als Druckkampagne angelegt war, wird ihr Erfolgspotenzial nun in einer Dauerkampagne höher eingeschätzt. Vgl. Attac: „Kampagnenarbeit bei Attac“, S. 3. Die Kampagnenwebsite verkündet zwar das Ende der bundesweit koordinierten Kampagne im letzten Newsletter vom 04. April 2006, auf der Startseite der Website wird jedoch zugleich zur dezentralen Weiterführung der Kampagne aufgerufen.

27 Ca. die Hälfte der im Rahmen unseres Forschungsprojektes erhobenen 109 Kampagnen können als Permanent Campaigns bezeichnet werden. Zudem dominieren netzwerkförmig organisierte Kampagnen in der Zusammenschau. 
ren (Greenpeace, Attac, Hochschulverbände etc.) und damit einhergehende Ressourcenausstattungen gekoppelt ist, die eine gewisse Kontinuität der Kampagne gewährleisten können. Auch wenn sich Akteurskonstellationen mit der Zeit verändern, wie beispielsweise in der Springer-Kampagne, so ist doch entscheidend, dass einzelne Akteure sich in einer Kampagne über die gesamte Laufzeit hinweg engagieren. Insgesamt bestätigt auch unsere erste Bestandsaufnahme von Anti-Corporate Campaigns, dass netzwerkförmige Kampagnen in der Regel von professionellen NGOs getragen werden und dadurch eine gewisse Dauerhaftigkeit in der Kampagnenarbeit ermöglicht wird. Durch die Zentralität bestimmter Akteure in einem Netzwerk können die Spannungen zwischen dezentraler, flexibler, diskursorientierter und die Autonomie der beteiligten Akteure gewährleistender Struktur und dem Anspruch kampagnenförmigen Protests auf gemeinsame Formeln und schnelle, einheitliche (Re-)Aktionen zu einem gewissen Grad ausgehalten, wenn auch nicht aufgelöst werden. Allerdings erweist sich dies als ein schwieriges Unterfangen, wie insbesondere das Beispiel der Attac-Kampagne verdeutlicht: Dem Selbstverständnis der Initiatoren und Verantwortlichen nach zielt die Lidl-Kampagne darauf, die Eindimensionalität einer allein an strategischen Gesichtspunkten ausgerichteten und top-down-durchorganisierten Kampagnenpolitik zu vermeiden und die Ausdifferenzierung von Bewegungskommunikation in PR und Diskurs sowie die dialektische Trennung von Praxis und Theorie (wieder) aufzuheben. Lässt sich aber die Kampagnenlogik aufheben, organisatorische Schlagkraft mit diskursiver Kommunikation verbinden, ohne Verluste in der massenmedialen Resonanz, der Mobilisierung von Unterstützern und der Einschüchterung des unternehmerischen Gegners hinnehmen zu müssen? Sind die angestrebten Synthesen in der gegenwärtigen Protestkultur tatsächlich umsetzbar und die Veralltäglichung von Protest zu einer Politik des Einkaufswagens in ein umfassendes, mehrdimensionales Kampagnenkonzept integrierbar? Inwiefern sind die normativen Postulate der Kampagnenaufrufe mehr als griffige Slogans und tatsächlich begriffliche Kondensate einer umfassenden theoretischen Ausarbeitung einer politischen Ökonomie der Globalisierung? Die Campaigner von Attac ziehen nach einem Jahr Kampagnenarbeit eine ernüchternde Bilanz:

Anfangs gab es einen schönen Plan: Der Kampf für Globale und Soziale Rechte sollte unser inhaltlicher Rahmen sein, der weiter diskutiert wird und aus dem heraus immer wieder Kampagnen stattfinden. Mit der Lidl-Kampagne fangen wir an, derweil wird der Begriff weiter mit Inhalt gefüllt und stark gemacht.

Die ,Theoriegruppe‘ begann jedoch nie so richtig zu arbeiten. Die Kampagnengruppe sah sich nicht imstande, neben ihrer praktischen Arbeit auch noch die theoretische zu übernehmen. 
So wurde der Begriff eher ein ,Überschwamm` [...] und unser Umgang mit ihm eher schwierig. Als Slogan ist er sehr sperrig und blieb stets erklärungsbedürftig. Zudem sollte der Diskussions-Kontext dazu dienen, gut aus der Lidl-Kampagne raus zu kommen' - denn es würde ja weitere Kampagnen geben und der Diskurs innerhalb Attacs wäre auch ohne uns fortgeschritten. So gab es jedoch weit mehr kritische Fragen: ,warum hört Ihr jetzt mit Lidl auf?

Gelernt haben wir, uns nicht auf eine ,Müsste-Sollte-Gruppe außerhalb der Kampagne zu verlassen. Es ist gut, wenn sich eine Kampagnengruppe auf die Mobilisierungs- und Öffentlichkeitsarbeit konzentrieren kann und es daneben eine Reihe Menschen gibt, die sich eher der Theorie und Strategie widmen. Aber jene müssen sich auch im selben Maße für die Kampagne verantwortlich fühlen. ${ }^{28}$

Diskursivität als Grundlage für Gemeinschaftsbildung und Aktivismus zeigt sich am deutlichsten bei der Springer-Kampagne, welche dort allerdings mit weitreichenden Beschränkungen für die strategischen Elemente der Kampagne korrespondiert. Dennoch scheint die Verbindung von einer auf massenmediale Resonanz ausgerichteten Kampagnenlogik mit einer organisatorischen Netzwerkstruktur für viele Anti-Corporate Campaigns erfolgversprechend, da mit dieser Verbindung eine Anpassung an erhöhte Umweltkomplexität und eine Flexibilisierung von Protestkampagnen einhergehen kann.

\section{$5 \quad$ Wandel von Öffentlichkeitsstrategien und Leitmedien des Protests}

Die drei Kampagnen sind neben den bereits erwähnten Aspekten durch unterschiedliche Öffentlichkeitsstrategien und damit verbundene unterschiedliche Schwerpunkte in der Mediennutzung gekennzeichnet.

\subsection{Enteignet Springer - Abgrenzung von massenmedialer Manipulation?}

Die Proteste gegen den Springer-Konzern sind eingebettet in den Kontext der Studentenbewegung, die ab Mitte der 1960er Jahre mit ihren Go-Ins und Sit-Ins den straßenöffentlichen Raum prägt. So findet auch der zentrale Mobilisierungsschub der Kampagne seinen Ausgangspunkt im Straßenprotest. Der

28 Attac: „Kampagnenarbeit bei Attac“. 
massive Polizeieinsatz gegen demonstrierende Studenten am zweiten Juni 1967, der schließlich zum Tod Benno Ohnesorgs führt, sowie die anschließenden studentenkritischen bis -feindlichen Zuschreibungen in der SpringerPresse mobilisieren erstmals über den Berliner Raum hinaus. Allerdings spielen im Rahmen der Springer-Kampagne die für die Studentenbewegung typischen unkonventionell provozierenden Formen der „Begrenzten Regelverletzung ${ }^{‘ 29}$ nur eine untergeordnete Rolle. Vielmehr führen die gewaltsamen Reaktionen der Polizei auf studentische Provokationen ${ }^{30}$ bereits im Vorfeld der eigentlichen Kampagne zu einer Radikalisierung des Straßenprotests. Ihren Höhepunkt findet diese Radikalisierung in der Reaktion auf den Anschlag auf Rudi Dutschke im April 1968.

Demgegenüber steht das Bedürfnis eines Großteils der Kampagnenakteure, Eskalationen zu verhindern und der Stigmatisierung von Presse und Politik auf der kommunikativen Ebene durch eine ,aufklärende Gegenöffentlichkeit $^{\star 331} \mathrm{zu}$ begegnen. Im Sinne einer Versammlungsöffentlichkeit dient zunächst der universitäre Raum als kommunikative Plattform dazu, entsprechende Konzepte zu entwickeln und zu diskutieren. Die Ausweitung des Kommunikationsraums erfolgt über verschiedene Medien, wobei dem Flugblatt vor allem in den frühen Phasen der Kampagne eine Doppelfunktion zukommt: Es dient gleichzeitig zur Ansprache einer breiteren Öffentlichkeit ${ }^{32}$ und zur kommunikativen Verständigung innerhalb des Protestnetzwerks. Darüber hinaus bemühen sich die Kampagnenakteure um die Etablierung eigener Publikationsorgane. Besonders hervorzuheben ist dabei das Extra-Blatt, eine in Eigenregie verschiedener Redakteure geführte Wochenzeitung, in der erstmals die Enteignung des Springer-Konžerns als spätere Mobilisierungsformel der Kampagne

29 Stamm: Alternative Öffentlichkeit, S. 25f; Oy: Die Gemeinschaft der Lüge, S. 118.

30 So wurde im Februar 1966 eine Vietnam-Demonstration in Berlin von der Polizei gewaltsam aufgelöst, nachdem die Studenten im Anschluss an die genehmigte Protestveranstaltung vor das Amerika-Haus gezogen waren, um dort das amerikanische Sternenbanner auf Halbmast zu setzen und das Gebäude mit Eiern zu bewerfen. Im April 1967 nahm die Polizei bereits im Vorfeld einer Demonstration gezielt Aktivisten in Untersuchungshaft, um einen, verschwörerischen' Bombenanschlag auf den US-Vizepräsidenten Humphrey zu vereiteln, der sich letztlich als relativ harmlose Provokation in Form von mit Farbstoff, Pudding und Mehl gefüllten Plastikbeuteln herausstellte. Miermeister/Staadt: Provokationen, S. 86.

31 Aus der Resolution zum Kampf gegen Manipulation und für die Demokratisierung der Öffentlichkeit, zitiert in: Miermeister/Staadt: Provokationen, S. 141.

32 Die Bedeutung des Mediums Flugblatt für die Ansprache einer breiten Öffentlichkeit verdeutlicht die ungeheure Auflage von bis zu 100000 Exemplaren. Vgl. Stamm: Alternative Öffentlichkeit, S. 31. 
durch studentische Autoren genannt wird. ${ }^{33}$ Ebenfalls erwähnenswert sind Versuche von Ad-hoc-Gruppen, über die lokale Alternativpresse an die jeweilige Bevölkerung heranzutreten, ${ }^{34}$ sowie die Gründung des Instituts für Presseanalyse und Öffentlichkeitsforschung (später bekannt als Gegenöffentlichkeitsinstitut) mit dem Ziel der Etablierung einer linken Tageszeitung. ${ }^{35}$

Daneben kommt jedoch den theoretisch kritisierten Massenmedien eine nicht unerhebliche Bedeutung für die Außenkommunikation der Kampagne zu. Stamm hebt die Bedeutung von Massenmedien als wichtige Informationsquelle und Forum für die Vermittlung von Aktionszielen hervor. ${ }^{36}$ Lönnendonker u.a. bezeichnen den ,antiautoritären Aktionismus“ auch als eine Methode, um die Revolte für die Medien attraktiv zu gestalten und damit breitere öffentliche Aufmerksamkeit zu erhalten. ${ }^{37}$ Diese Tendenzen stehen in scharfem Kontrast zu der rigiden Ablehnung des massenmedialen Systems als Manipulationsinstan₹, welche die gesamte Argumentationsstruktur und den theoretischen Anspruch der Kampagne prägt, sodass das Verhältnis zu den Massenmedien insgesamt äußerst ambivalent erscheint. Betrachtet man zusammenfassend die Öffentlichkeitsstrategie der Springer-Kampagne, steht trotz der erwähnten Ausrichtung von Protestaktionen an massenmediale Resonanz die Abgrenzung vom Meinungsmonopol etablierter Massenmedien und die Schaffung von Gegenöffentlichkeit mittels eigener Publikationsorgane im Mittelpunkt der Kampagne, wobei die Protestakteure letztlich an der Etablierung einer übergreifenden publizistischen Plattform scheitern und weitgehend im studentischen Milieu verhaftet bleiben.

\subsection{Brent Spar - Anpassung an massenmediale Selektionsmechanismen}

Im Gegensatz zur Kampagne Enteignet Springer räumt die Brent-Spar-Kampagne der Mobilisierung einer massenmedialen Öffentlichkeit - insbesondere durch die Orientierung an den Logiken des Mediums Fernsehen - bewusst den entscheidenden Raum ein. Durch spektakuläre Aktionen wie die Besetzung der Ölplattform oder die Blockade der Shell-Zentrale in Den Haag wird massenmediale Aufmerksamkeit und damit die Aufmerksamkeit eines Massenpubli-

33 Vgl. Melchert: Meinungsfreiheit in Gefahr? S. 292.

34 Vgl. Lönnendonker u.a.: Die antiautoritäre Revolte, S. 465.

35 Vgl. Oy: Die Gemeinschaft der Lüge, S. $126 f$.

36 Vgl. Stamm: Alternative Öffentlichkeit, S. 33.

37 Vgl. Lönnendonker u.a.: Die antiautoritäre Revolte, S. 427. 
kums erzeugt. ${ }^{38}$ In einem Dreischritt - Aktion, Medienresonanz, Mobilisierung - sorgt die massenmediale Berichterstattung nicht nur für die Aufmerksamkeit des Publikums, sondern verstärkt gleichzeitig den Mobilisierungserfolg der Kampagne. ${ }^{39}$ Gegenöffentlichkeit spielt im Kontext der Greenpeace-Kampagne „,weder zur Verbreitung ,unterdrückter Wirklichkeiten' noch zur Selbstkonstituierung einer betroffenen Öffentlichkeit oder ihrer Standortbestimmung ${ }^{‘ 40}$ eine Rolle. Anstelle der Konzentration auf alternative Publikationsorgane wie in der Springer-Kampagne erfolgt eine professionelle Zusammenarbeit mit bestimmten Journalisten und Medien. Die Dominanz der massenmedialen Öffentlichkeitsstrategie wird schließlich auch dadurch nicht gebrochen, dass Greenpeace in einem recht frühen Stadium der Verbreitung des Internets auf das neue Medium zurückgreift. Vielmehr wird massenmediale Resonanz als Voraussetzung für einen erfolgreichen Internetauftritt betrachtet:

The Brent Spar page was also interesting as it showed the strong link with traditional media. The number of people logging into the Brent Spar page was directly related to when the story was covered in newspapers and on TV. ${ }^{41}$

Insgesamt kommt es in der Shell-Kampagne zu einer mehrstufigen Unterteilung relevanter Öffentlichkeiten der Kampagne, wobei insbesondere das massenmediale Publikum mit einem Platz in der Galerie vorlieb nehmen muss.

\subsection{Lidl ist nicht zu billigen - Protestkommunikation in Massenmedien und Internet}

Weniger als der Kampagne Enteignet Springer und der Brent-Spar-Kampagne lässt sich der Kampagne Lidl ist nicht zu billigen eine dominante Öffentlichkeitsstrategie zuordnen. Weder konzentriert sich die Kampagne fast ausschließlich auf

38 Berens identifiziert allein an 17 Tagen im Kampagnenzeitraum 93 Beiträge in den Abendnachrichtensendungen von ARD, ZDF, RTL, SAT1 und Pro7. Vgl. Berens: Prozesse der Thematisierung in publizistischen Konflikten, S. 15.

39 Berens weist vor allem der Berichterstattung über Boykott-Aktionen eine Mobilisierungsleistung zu: „Die Forsa-Umfragen belegen [...] ziemlich eindeutig, daß vor dem 12. Juni höchstens drei Prozent der Bevölkerung ein Interesse an einer Auseinandersetzung hatte. Unter diesen Bedingungen scheint die Boykottberichterstattung einem tatsächlichem Boykott vorausgelaufen zu sein. [...] Der zunächst in den Medien konstruierte Boykott manifestiert sich schließlich als faktischer Boykott in der Berichterstattung selbst." Ebd., S. 148.

40 Vandamme: Basisdemokratie als zivile Intervention, S. 161.

41 Keys: „Environmental Internet Campaigning of NGOs“. 
massenmediale Aufmerksamkeitserzeugung und Mobilisierung, noch wird das massenmediale System als überwiegend feindselig und manipulativ abgelehnt. Massenmedialer Resonanz kommt im Rahmen der Kampagne ein wichtiger Stellenwert zu. So werden geplante Veranstaltungen durch umfangreiche Pressemitteilungen angekündigt und Kampagnenaktionen gezielt auf Medienwirksamkeit angelegt. ${ }^{42}$ Attac will jedoch mehr als nur die Instantaufmerksamkeit der Fernsehkameras und nutzt dazu vor allem die Möglichkeiten der Netzkommunikation: Factsheets und andere Hintergrundmaterialien unterfüttern für Presseexperten, Aktivisten und adressierte Unternehmen die symbolisch verdichteten Kampagnenbotschaften. Darüber hinaus werden im Rahmen der Kampagne virtueller und physischer Protestraum verknüpft. Auf der Kampagnen-Website wird detailliert von Aktionen verschiedener Ortsgruppen in mehr als 30 deutschen Städten berichtet, wodurch die dezentralen Einzelaktionen zusammengeführt werden. War das Flugblatt das dominante Medium der APO, das Fernsehen das Leitmedium der Greenpeace-Kampagne, so ist die Website das zentrale Medium der Attac-Kampagne.

Die Öffentlichkeitsstrategien der untersuchten Kampagnen verdeutlichen insgesamt Diskontinuitäten in der Entwicklung zivilgesellschaftlichen Protests. Während die Springer-Kampagne die „Qualifizierung der demokratischen Öffentlichkeit" in den Mittelpunkt stellt, fordert die Greenpeace-Kampagne lediglich „quantifizierbare Voten“43 von Konsumenten. Die Kampagne gegen Lidl versucht schließlich über die Kampagnen-Website Qualifizierung und Quantifizierung von Öffentlichkeit miteinander zu verbinden. Neben umfassenden Hintergrundinformationen bietet die Website verschiedene standardisierte Protestformen wie Unterschriftenlisten oder teilformulierte Protest-E-Mails an.

Demgegenüber prägen verschiedene Konstanten die Generierung von Öffentlichkeit durch unternehmenskritische Kampagnen. Neben effektiven Strukturen und schnellen Entscheidungswegen, die Kampagnenerfolg sichern, aber Diskursivität einschränken, kann hier vor allem die Bedeutung massenmedialer Resonanz als Konstante von Kampagnenpolitik genannt werden: Sei es vorwiegend zur Definition von Außengrenzen des Protestnetzwerks wie im Fall der Springer-Kampagne, als maßgebliche Projektionsfläche der Kampagne wie bei der Shell-Kampagne oder als ein Instrument, um Druck zu erzeugen und sich über den eigenen Kampagnenerfolg zu vergewissern wie im Fall von Lidl ist nicht zu billigen. Eng verbunden mit der Bedeutung massenmedialer Berichterstattung ist der Inszenierungsbedarf von Kampagnen, der sich in den

42 Vgl. Attac Lidl-Kampagnengruppe: „Vorstellung der Attac Lidl-Kampagne“, S. 4.

43 Oy: Die Gemeinschaft der Lüge, S. 170. 
exemplarisch untersuchten Beispielen in der ungebrochenen Bedeutung von Körperlichkeit als starkem symbolischen Mittel zeigt. Sowohl der Massenkörper des Straßenprotests gegen Springer als auch spektakuläre Einzelaktionen der Shell-Kampagne und schließlich die Vielzahl dezentraler Aktionen vor Lidl-Filialen, die sich mit Hilfe der Kampagnen-Website zu einem Massenkörper formen, sind Ausdruck einer konstanten Kampagnenlogik, die zivilgesellschaftlichen Protest ebenso prägt wie die genannten Diskontinuitäten.

\section{Kontinuierlicher und diskontinuierlicher Wandel - Ausdruck zunehmender Komplexität}

Protestkulturen, so die eingangs formulierte These, entfalten sich sowohl kontinuierlich als auch diskontinuierlich. Dies konnte exemplarisch entlang der drei ausgewählten Beispiele nachgezeichnet werden. Aktuelle internetbasierte Anti-Corporate Campaigns zeichnen sich, wie am Beispiel der Lidl-Kampagne exemplarisch erläutert wurde, durch eine Verknüpfung von Elementen der stärker basisnah und gegenkulturell ausgerichteten Protestkultur der 1960er Jahre und der professionalisierten zentralisierten Kampagnenpolitik der 1990er Jahre aus. Ursachen für den kontinuierlichen und durch Brüche geprägten diskontinuierlichen Wandel in Deutungsmustern, Organisationsstrukturen und Öffentlichkeitsstrategien unternehmenskritischer Anti-Corporate Campaigns liegen vor allem in den veränderten Kontextbedingungen für unternehmenskritischen Protest.

Hier sind zum einen exogene Faktoren in den Umwelten von Protestakteuren relevant:

- Die zunehmende Komplexität und Verflechtung globaler Problemlagen prägt die Themen- und Diskursvielfalt von Anti-Corporate Campaigns. Themen wie Menschenrechte, Arbeitsbedingungen, Handelsbedingungen oder Umweltschutz sind angesichts komplexer Produktionsprozesse unmittelbar miteinander verknüpft und werden dementsprechend als interdependent aufgegriffen.

- Veränderte mediale Infrastrukturen ermöglichen eine Vereinfachung und Erweiterung von Protestkommunikation. Geringe Transaktionskosten für die Binnenkommunikation, die Bündelung dezentraler (lokaler) Diskurse und Initiativen sowie lockere Verknüpfungen mit ähnlich gelagerten Initiativen und Kampagnen sind Voraussetzung für tragfähige Netzwerke, die ein dauerhaftes Drohpotenzial für Unternehmen aufbauen können. Umfassende Hintergrundinformationen im Netz wirken darüber hinaus der Unterkomplexität von Kampagnenslogans entgegen und bil- 
den so den Ausgangspunkt für eine aufgeklärte - wenn auch nur bedingt diskursive - (Gegen-)Öffentlichkeit von Consumer Citizens.

- Formen unternehmenskritischen Protests passen sich als ,lifestyle politics“44 den Individualisierungsprozessen westlicher Gesellschaften an. Sie appellieren in der Regel an die Verantwortung des einzelnen Verbrauchers und bieten individualisierte Partizipationsmöglichkeiten wie Boy- oder Buykott sowie dementsprechende in der Lebenswelt verankerte ästhetische Angebote (z.B. Adbusting). Die Relevanz individualisierter konsumorientierter Protestformen zeigt sich unter anderem daran, dass sowohl Greenpeace als auch Attac mit dem „EinkaufsNetz“ (Greenpeace) bzw. dem „Konsumnetz“ (Attac) Verbraucherplattformen gegründet haben, die eigene konzernkritische Aktionen und Kampagnen durchführen.

- $\quad$ Daneben sind es häufig die Zielscheiben des Protests selbst, welche Umwelten und damit einhergehende Anpassungsnotwendigkeiten der Kampagnen darstellen. Insbesondere das veränderte Kommunikationsverhalten von Unternehmen zeugt von Lernprozessen auf mehreren Ebenen. Zum einen nutzen Unternehmen und Branchen im Kontext von Konzepten wie Corporate Citizenship und Corporate Social Responsibility normativ-moralisch aufgeladene Kommunikation, um gesellschaftliches Verantwortungsbewusstsein und Engagement zu verdeutlichen. ${ }^{45}$ Dabei spielt auch für die Unternehmen das Internet eine herausragende Rolle, da das gesellschaftspolitische Engagement hier im Kontext genereller Unternehmensinformation dargestellt werden kann und somit weniger Gefahr läuft als kommunikatives Feigenblatt oder Greenwashing wahrgenommen zu werden. Zum anderen verdeutlichen Konzepte wie Krisen$\mathrm{PR}^{46}$ eine Professionalisierung im medialen Umgang mit verschiedenen Anspruchsgruppen sowie eine Differenzierung der eigenen Kommunikationsstrategie, die es Protestakteuren erschwert, mit binärcodierten Schuldzuweisungen $\mathrm{zu}$ arbeiten. Zudem greifen Unternehmen mit aggressiven Werbestrategien zum Teil die subkulturellen Resonanzen auf, um damit Guerillamarketing im eigenen Interesse zu betreiben. Beispiel hierfür ist eine von der Werbeagentur Jung von Matt entwickelte Kampagne für die Bild-Zeitung im Jahr 2005, welche Bezüge zur Springer-Kampagne herstellt. Unter dem Slogan Schluss mit Bild wendet

44 Bennett: „Communicating global activism“.

45 Vgl. die Beiträge von Curbach und Kneip in diesem Band.

46 Vgl. Köhler in diesem Band. 
sich der vermeintliche Bund der Sozial-Schmarotzer mit einem amateurhaft gestalteten Aufruf gegen den Medienkonzern. ${ }^{47}$

- Darüber hinaus gehen transnationale Wertschöpfungsketten mit einer Verquickung von Produktions- und Konsumptionssphäre einher, die einerseits die Verantwortung von Ungerechtigkeiten auch auf Seiten von Konsumenten verortet und andererseits ein langfristiges Engagement zur Lösung tiefenstruktureller Probleme erfordert. So können einige AntiCorporate Campaigns bereits als Policy Communities bezeichnet werden, da sie Labelprogramme implementieren und/oder aktiv an Richtlinien und Codes of Conduct für Unternehmen mitarbeiten (z.B. Kampagne für Saubere Kleidung).

Zum anderen lassen sich endogene Faktoren als Ursachen diskontinuierlichen Wandels erkennen. Ebenso wie auf Unternehmensseite zeigen sich auf der Seite der Protestakteure Veränderungen interner Prozesse vor dem Hintergrund kollektiven Lernens. So kann die zunehmende Professionalisierung und Zentralisierung zivilgesellschaftlichen Protests, wie sie vor allem mit Greenpeace verbunden wird, auch als Reaktion auf das Scheitern der Studentenbewegung verstanden werden, ihre Protestanliegen über das eigene Bewegungsmilieu hinauszutragen. Dass jedoch spontaneistische dezentrale Elemente wichtige Pfeiler zivilgesellschaftlicher Protestkultur sind, wurde insbesondere sichtbar, als die Auseinandersetzung über hierarchische Organisationsstrukturen innerhalb von Greenpeace 1982 zur Abspaltung einiger ehrenamtlicher Aktivisten und zur Gründung von Robin Wood führte. In diesem Spannungsfeld zwischen Zentralität und Dezentralität verortet sich Attac, indem die Organisation mit der Lidl-Kampagne die Synthese von dezentralisierten Aktionsnetzwerken und professioneller Kampagnenplanung versucht.

Es lässt sich der Schluss ziehen, dass Anti-Corporate Campaigns heute vor der Herausforderung stehen, die Balance zwischen individueller und kollektiver Partizipation, stabilen dauerhaften und flexiblen Strukturen sowie demokratisch erlangten und hierarchisch bestimmten Deutungsrahmen in der Kampagnenkommunikation und -organisation auszutarieren, um zum einen internen und demokratischen Anforderungen der Mit- und Selbstbestimmung gerecht zu werden und zum anderen auf externe Veränderungen - beispielsweise in den Verhaltensweisen von Unternehmen - eingehen zu können. ${ }^{48}$

47 Eine Abbildung des Plakates findet sich in Nowak: „Schluss mit Bild“.

48 Vgl. Baringhorst in diesem Band. 
Sigrid Baringhorst u.a. | Wandel und Kontinuität von Protestkulturen

\section{Literaturverzeichnis}

Attac: „Mailomat“, www.attac.de/lidl-kampagne/content/mailomat/index.php, 05.09.2006.

Attac: „Lidl ist nicht zu BILLIGen“, www.attac.de/lidl-kampagne/?id=107, 05.09.2006.

Attac: „Kampagnenarbeit bei Attac: Lessons Learned“, www.attac.de/lidlkampagne/content/campaign/Lidl-Kampagne_Erfolge_und_Erfahrungen.pdf, 01.09.2006.

Attac Lidl-Kampagnengruppe (Hrsg.): „Vorstellung Attac Lidl-Kampagne“, www.attac.de/lidl-kampagne/content/campaign/internat/dt/vorstellung_lidlkampagne_komplett.pdf, 05.09.2006.

Baringhorst, Sigrid: Politik als Kampagne. Zur medialen Erzeugung von Solidarität, Opladen/Wiesbaden 1998.

Berens, Harald: Prozesse der Thematisierung in publizistischen Konflikten. Ereignismanagement, Medienresonanz und Mobilisierung der Öffentlichkeit am Beispiel der Öffentlichkeit von Castor und Brent Spar, Wiesbaden 2001.

Bennett, Lance W.: „Communicating global activism. Strenghts and vulnerablities of networked politics“, in: Donk, Wim van de u.a. (Hrsg.): Cyberprotest. New Media, Citizens and Social Movements, London/New York 2004, S. 123-146.

Deutschlandfunk: „Attac startet Lidl Kampagne in Göttingen“, 13.08.2005, www.attac.de/lidl-kampagne/content/reader/6_radiobeitrag.rtf, 26.08.2006.

Greenpeace: Brent Spar und seine Folgen. Zehn Jahre danach, Flensburg 2005.

Keys, Jane: „Environmental Internet Campaigning of NGOs“, www.isep.at/ internet_ws/keys.html\#6, 16.11.2005.

Lönnendonker, Siegward u.a. (Hrsg.): Die antiautoritäre Revolte. Der Sozialistische Deutsche Studentenbund nach der Trennung von der SPD. Bd. 1: 1960-1967, Wiesbaden 2002.

Melchert, Florian: Meinungsfreiheit in Gefahr? Die medienpolitische Debatte in der Bundesrepublik vom Fernsehstreit bis zur Anti-Springer-Kampagne (1961-1969), Bochum 2003.

Miermeister, Jürgen/Staadt, Jochen (Hrsg.): Provokationen. Die Studentenund Jugendrevolte in ihren Flugblättern 1965-1971, Darmstadt u.a. 1980.

Nowak, Peter: „Schluss mit Bild“, Telepolis 25.11.2005, www.heise.de/tp/ r4/artikel/21/21427/1.html, 24.07.2007. 
Otto, Karl, A.: APO: Außerparlamentarische Opposition in Quellen und Dokumenten (1960-1970), Frankfurt a.M. 1989.

Oy, Gottfried: Die Gemeinschaft der Lüge. Medien- und Öffentlichkeitskritik sozialer Bewegungen in der Bundesrepublik, Münster 2001.

Rucht, Dieter: „Zum Wandel politischen Protests in der Bundesrepublik“, in: Vorgänge 164, Jg. 42, 2003, S. 4-21.

Sösemann, Bernd: „Die 68er Bewegung und die Massenmedien“, in: Wilke, Jürgen (Hrsg.): Mediengeschichte der Bundesrepublik Deutschland, Bonn 1999, S. 672-697.

Stamm, Karl-Heinz: Alternative Öffentlichkeit. Die Erfahrungsproduktion neuer sozialer Bewegungen, Frankfurt a.M./New York 1988.

Scott, Alan/Street, John: „E-Protest: neue Formen politischer Agitation - neue Politik? Das Internet als Instrument des Globalisierungsprotests, in: SOWI, Jg. 31, Nr. 2, 2002, S. 63-73.

Transit: „Das Auftreten der NGOs spiegelt nur das Versagen der offiziellen Politik“": Interview mit Thilo Bode, in: Transit, Nr. 24, 2002/2003, S. 125139.

Vandamme, Ralf: Basisdemokratie als zivile Intervention. Der Partizipationsanspruch der Neuen sozialen Bewegungen, Opladen 2002. 



\section{Annegret März}

\section{Protestnetzwerke im Internet - Kollektive Identitätskonstruktion in konzernkritischen Kampagnen?}

Bewegungseigene Medienprodukte wie Websites dienen nicht nur zur (Gegen)information, sondern auch zur ,[...] kollektiven Selbstvergewisserung der Bewegungsakteur/-innen, sie sind Foren des Austauschs und der Diskussion und offerieren Elemente zur Herausbildung kollektiver Identität."1

Am Beispiel konzernkritischer Kampagnen geht dieser Beitrag der Frage nach, inwiefern in netzgestützter Kommunikation verschiedene Elemente zur Identitätskonstruktion angeboten werden. Dabei wird auf die Gesamterhebung des Projekts Protest- und Medienkulturen im Umbruch zurückgegriffen, in deren Rahmen 109 transnationale Anti-Corporate Campaigns im deutschsprachigen Raum identifiziert wurden. Des Weiteren werden die Analysen zweier bereits abgeschlossener Case Studies (Lidl ist nicht zu billigen von Attac und die LidlKampagne von ver.di) ${ }^{2}$ herangezogen, um tiefergehend zu illustrieren, ob und wie netzgestützte Protestkampagnen versuchen, online gegenseitiges Verständnis und Sinn darüber zu erzeugen, was kollektiv durch Handlungen erreicht werden soll und warum. Abschließend wird unter Rückgriff auf bisherige emprirische Studien zur Identitätskonstruktruktion im Internet diskutiert, inwieweit diese Angebote tatsächlich zur Herausbildung einer kollektiven Identität beitragen können. Konzernkritische, netzgestützte Kampagnen bieten sich als Analysegegenstand in besonderem Maße an, da sie vor einer doppelten Herausforderung stehen: Zum einen wird konzernkritischen Kampagnen, welche sich einem konsumeristischen Repertoire bedienen, nachgesagt, dass sie sich aus eher schwach strukturierten, heterogenen Netzwerken speisen, in welchen so genannte flexible Identitäten ${ }^{3}$ erzeugt werden. ${ }^{4}$ Zum anderen stehen sie vor der in

1 Haunss: Identität in Bewegung, S. 376.

2 Aus der Gesamterhebung werden im Rahmen des Forschungsprojekts in einer zweiten Phase ausgewählte Beispiele einer Tiefenanalyse unterzogen. Vorläufige Ergebnisse finden sich als Arbeitspapiere auf der Website www.protest-cultures.uni-siegen.de.

3 Als flexible Identitäten werden Identitäten bezeichnet, welche charakterisiert sind durch: ,[...]inclusiveness and a positive emphasis upon diversity and cross-fertilization, with limited identfications that develop especially around common campaigns on objects perceived as ,concrete and nurtured by search for dialogue“. Tarrow/Porta: „Conclusion“, S. 236.

4 Vgl. ebd. 
diesem Beitrag zu thematisierenden Herausforderung, kollektive Identität im Internet zu stiften, ohne für ihre Gefüblsarbeit auf physische Präsenz der Aktivisten zurückgreifen zu können. ${ }^{5}$

\section{$1 \quad$ Kollektive Identität}

Während bestimmte Ansätze der Bewegungsforschung ${ }^{6}$ wie der RessourcenMobilisierungsansatz das Wie kollektiver Handlungen erklären wollen, widmen sich Ansätze kollektiver Identität dem Warum: Warum handeln Protestakteure kollektiv? Warum partizipieren Einzelne in einer sozialen Bewegung oder schließen sich einer Protestkampagne an? Mit Ansätzen der kollektiven Identität versuchen Sozial- und Kulturwissenschaftler das Phänomen zu untersuchen, das sich als „ „Kitt" ${ }^{\text {“7 }}$ sozialer Bewegungen beschreiben lässt. Theoretische Ansätze zur kollektiven Identität betonen besonders die Existenz kollektiver Entitäten und sozial konstruierter Bedeutungszuschreibungen als zentrale Bedingungen für kollektive und indviduelle Entscheidungen und Handlungen, welche sich auch auf emotionale, affektive Faktoren stützen. ${ }^{8}$ Kollektive Identität wird als sozialpsychologischer Prozess beschrieben, welcher Individuuen mit einer Gruppe verbindet. In einer kulturwissenschaftlich orientierten Perspektive definiert Melucci diesen Prozess als

$[\ldots]$ an interactive and shared definition produced by several individuals (or groups at a more complex level) and concerned with the orientations of action and field of opportunities and constraints in which action takes place. ${ }^{?}$

5 Für Hunt und Benford geht Gefühlarbeit Hand in Hand mit der Konstruktion kollektiver Identität. Vgl. dies.: „Collective Identity, Solidarity, and Commitment“, S. 446f.

6 Für eine Darstellung sämtlicher Ansätze der Bewegungsforschung vgl. van de Donk u.a.: „Introduction“, S. 14; Hellmann: Paradigmen der Bewegungsforschung.

7 Rucht: „Kollektive Identität“, S. 9.

8 Dennoch bleibt wie beim Ressourcen-Mobilisierungsansatz die Frage nach der Interdependenz von strukturellen Variablen, sozial konstruierten Bedeutungen/ Werten und kollektiver Handlung offen. Strukturelle Bedingungen können sowohl Vorbedingungen als auch Produkt kollektiver Handlungen sein, geteilte Bedeutungszuschreibungen können kollektive Handlungen hervorrufen als auch aus ihnen resultieren. Kollektive Handlung ist also beides, abhängige und unabhängige Variable zugleich. Vgl. Klandermans: „The social construction of protest and multiorganizational fields".

9 Melucci: Challenging Codes, S. 44. 
Melucci betont hier insbesondere die durch Interaktion hergestellten geteilten Definitionen. Geteilte Definitionen können als Wirklichkeitsdefinitionen aufgefasst werden: Was definiert ein Protestnetzwerk als richtig, was als falsch? Zu diesem Prozess des Zustandekommens geteilter Definitionen tragen koginitive Elemente bei, welche Überzeugungen individueller Akteure mit den Überzeugungen des übergreifenden Protestnetzwerks in Verbindung bringen. Aufbauend auf der Annahme, dass geteilte Definitionen zum Prozess kollektiver Identitätsbildung beitragen, erweitern Taylor und Whittier das Konzept kollektiver Identität und schlagen einen Analyserahmen vor, welcher in der folgenden Untersuchung konzerkritischer Kampagnen genutzt wird und folgende drei Ebenen umfasst: ${ }^{10}$

- Grenzen verweist auf einen eher diffusen Prozess der Grenzziehung, welcher ideologisch aufgeladen ist und sich auf soziale, psychologische und physische Strukturen des Aufbaus von Unterschieden zwischen so genannten herausfordernden und dominanten Gruppen bezieht. Dabei wird ein kollektives Wir und Sie konstruiert.

- Bewusstsein umfasst den Interpretationsrahmen, welcher aus den Auseinandersetzungen über die Definition gemeinsamer Interessen entsteht. Bisherige Forschungen weisen darauf hin, dass Gruppenbewusstsein ,$[\ldots]$ is constructed through a variety of mechanisms including talk, narratives, framing processes, emotion work, and interaction with antagonists among others. “11

- Verhandlung beschreibt schließlich die Anstrengungen von Aktivisten, Außenstehende zu einer positiven Bewertung der eigenen Ziele und Politikentwürfe zu bewegen und umfasst „[...] the symbols and everyday actions subordinate groups use to resist and restructure existing systems of domination"12 und beinhaltet somit Dimensionen kultureller Repräsentation.

Um alle drei Ebenen berücksichtigen zu können, ist es des Weiteren notwendig, verschiedene Diskurse, auf die Identitätskonstruktionen sich beziehen, in die Analyse zu integrieren, indem für die Protestnetzwerke zentrale politische und kulturelle Auseinandersetzungen rekonstruiert werden.

Anknüpfend an die Erläuterung des Konzepts kollektiver Identität stellt sich die Frage nach dem Begriff der Online-Identität. Hiermit werden Prozesse

10 Vgl. Taylor/Whittier: „Collective Identity in Social Movement Communities“.

11 Hunt/Benford: „Collective Identity, Solidarity, and Commitment“, S. 445.

12 Taylor/Whittier: „Collective Identity in Social Movement Communities“, S. 111. 
der Identitätskonstruktion bezeichnet, welche auf virtueller, digitaler Interaktion und Kommunikation basieren:

Online identity is largely determined by social interaction and what individuals deliberately expose - texts, pictures, symbols, their work and other digital objects they share with other. ${ }^{13}$

Die folgende Untersuchung erfolgt entlang des vorgeschlagenen Analyseschemas von Taylor und Whittier und nimmt Kampagnenwebsites sowie die dort offerierten Anwendungen und digitalen Artefakte als Datengrundlage. Zudem werden Ergebnisse qualitativer Interviews mit Kampagnenakteuren sowie der Online-Befragungen von Aktivisten im Rahmen der Case Studies unterstützend herangezogen. ${ }^{14} \mathrm{Da}$ in den Befragungen vor allem kognitive Elemente abgefragt wurden und die Kampagnenwebsite als primäre Quelle dient, bezieht sich die Analyse insbesondere auf die Außenkommunikation der Kampagnen und auf die in diesem Kontext unterbreiteten Angebote zur kollektiven Identitätskonstruktion. Aussagen, welche sich auf sozialpsychologische Prozesse beziehen, sind aus diesem Grund als vorsichtige Deutungen zu verstehen.

\section{Identitätsangebote in netzbasierten Anti-Corporate Campaigns}

\subsection{Grenzen}

Den meisten konzernkritischen Kampagnen ist gemein, dass ihnen kein konkreter, personifizierter Gegner gegenübersteht, der adressiert und attackiert werden könnte - vielmehr verschleiern die komplexen und oft intransparenten Konzernstrukturen die Zuständigkeiten und Ansprechpartner, mit der Folge, dass Unternehmen bzw. ihre Marken als sichtbarstes Element und nicht Per-

13 Hemetsberger: „Understanding consumers” collective action on the Internet“, S. 8.

14 An die ca. 700 Mitglieder der Mailing-Liste der Kampagne Lidl ist nicht zu billigen von Attac wurde der Link zu einem Fragebogen versandt. Die genannten Ergebnisse beziehen sich auf den erhaltenen Rücklauf von 76 ausgefüllten Fragebögen im Zeitraum 4. bis 25. August 2006. Ebenso wurde an ca. 250 Mitglieder verschiedener Mailing-Listen der Lidl-Kampagne von ver.di der Link zu einem Fragebogen versandt. Die genannten Ergebnisse beziehen sich auf den erhaltenen Rücklauf von 38 ausgefüllten Fragebögen im Zeitraum 3. August 2006 bis 8. November 2006. 
sonen angegriffen werden. Eine Ausnahme stellen die Lidl-kritischen Kampagnen von Attac und ver.di dar, die den Gründer des Unternehmens, Dieter Schwarz, in unterschiedlicher Weise moralisch codieren und zum Opponenten einer Grenzziehung des Innen- und Außenraums stilisieren: Während ver.di den Namen im Schwarz̧buch Lidl und im Magazin Schwarzmarkt präsent hält, spricht Attac Herrn Schwarz in Informationsbroschüren und auf der Kampagnenwebsite konkret an und stellt Forderungen direkt an ihn. Der Einfluss der Internettechnologie lässt sich in diesen Fällen auf zwei Ebenen beobachten: Zum einen bietet die Website eine Plattform zur pointierten Darstellung und Diffamierung des Gegners, zum anderen stellt die Kommunikation per selbstoder vorformulierter E-Mails einen einfachen und direkten Weg zur Ansprache des Gegners dar. Des Weiteren nutzen verschiedene Kampagnen prominente Personen zur positiven Identifikation und Stärkung des Innenraums. Diese werden als Mitstreiter präsentiert und kommen auf der Kampagnenwebsite, in Offline-Publikationen oder bei Aktionen vor Ort als Fürsprecher oder Pate zu Wort. So wirbt die Kampagne Gendreck weg! Freiwillige Feldbefreiung ${ }^{15}$ mit Weltweiten Stimmen. Unter anderem sind dort die Trägerin des Alternativen Nobelpreises, Vandana Shivam, und der äthiopische Umweltminister mit Bild und Zitat aufgeführt; die Organisation PETA kann gar hochkarätige Hollywoodstars abbilden, die lieber nack. sind als Pelze zu tragen. ${ }^{16}$ Auch ver.di lässt prominente deutsche Politiker, Künstler und Kirchenvertreter im Schwarzmarkt zu Wort kommen. Durch Personalisierungen werden Grenzen etabliert, in dem die jeweils moralisch aufgeladenen Personen zu Referenztypen der Ein- und Ausgrenzung als Idealtyp stilisiert werden: als diffamierter Gegner, der alles Übel in sich vereint, oder als Held, der exemplarisch für die Werte und Ziele der Innengruppe steht.

Daneben betonen Symbole und Rituale die Grenzen zwischen der Gruppe derjenigen, die kulturelle Codes ungefragt deuten können, und der Gruppe der Außenstehenden, die (noch) nicht zum Kreis der Eingeweihten gehören. Vor allem die Durchführung lokaler Aktionen, etwa Demonstrationen oder Informationsveranstaltungen lassen sich als Rituale zur Homogenisierung und Bestätigung des Innenraums verstehen. ${ }^{17}$ Sie können nicht nur der Außenwirkung, der „Missionierung “'18 neuer Anhänger dienen, sondern mit der Bestäti-

15 Die Kampagne setzt sich gegen den Anbau genmanipulierter Organismen ein und organisiert so genannte freiwillige Feldbefreiungen: „Wir gehen nach öffentlichen Ankündigungen auf Gentech-Maisfelder und reißen die gefährlichen Pflanzen aus“. Gendreck weg: „Kleiner Flyer Feldbefreier“, S. 1.

16 Informationen zu dieser Kampagne unter www.pelzinfo.de/c_lieber_nackt.html.

17 Vgl. Giesen: Kollektive Identität, S. 57f.

18 Ebd., S. 56. 
gung der kollektiven Meinung auch zu einer Stärkung der Innengrenze des Protestnetzwerks beitragen. Neu ist die teilweise Verlagerung dieser Rituale in den virtuellen Raum: Kollektivierungsprozesse finden etwa innerhalb der Kampagne Lidl ist nicht zu billigen nur selten im physischen Raum statt und auch dort in der Regel nur mit wenigen Personen. Vor diesem Hintergrund kommt der medialen Dokumentation physischer Protestaktionen eine zentrale Bedeutung zu, da diese „zur Repräsentation einer über das Ereignis hinausweisenden sozialen Erfahrung “ ${ }^{\text {19 }}$ beiträgt:

Für die Leute, die an diesen Aktionen beteiligt waren, ist es immer noch schön, sich daran zurück zu erinnern, weil man gemeinsam was gemacht hat und auch am Anfang nicht wusste, wie es ausgehen würde. ${ }^{20}$

Auf diese Weise können Kampagnen, die eher mit kleineren Aktionen arbeiten, zumindest ansatzweise die fehlende Körperlichkeit kompensieren, welche bei Massenveranstaltungen die Definition des Wir prägt. Identitätsangebote basieren somit nach wie vor maßgeblich auf physischer Protestinszenierung, ${ }^{21}$ werden jedoch durch die mediale Inszenierung der Proteste auf der Kampagnenwebsite ergänzt.

\subsection{Bewusstsein}

Die Erzeugung kollektiven Bewusstseins und die Herausbildung eines gemeinsamen Interpretationsrahmens sind in vielen Anti-Corporate Campaigns an das Handlungsmuster des Konsums gebunden. Konsum wird vielfach als politische Handlung konturiert und politische Probleme werden als durch individuelles und kollektives Konsumverhalten beeinflussbar vermittelt. Die Rolle der Kampagnenunterstützer als Consumer Citizens ${ }^{22}$ spielt sogar im Rahmen prinzipiell globalisierungs- und kapitalismuskritisch ausgerichteter Kampagnen wie Lidl ist nicht $z^{u}$ billigen eine zentrale Rolle bei der Definition gemeinsamer Interessen. Die Orientierung der Bewusstseinsbildung an der Rolle des politischen Konsumenten ermöglicht den Kampagneninitiatoren, an verschiedene universale Wertzusammenhänge anzuschließen und bietet somit die Gelegen-

19 Baringhorst: Politik als Kampagne, S. 142.

20 Interview mit Thomas Schulz, Basisakteur der Kampagne Lidl ist nicht zu billigen.

21 Alle untersuchten Kampagnen machen ihren Unterstützern Beteiligungsangebote im physischen Raum etwa in Form von Demonstrationen.

22 Vgl. dazu Baringhorst, Beetz, Lamla in diesem Band. 
heit flexibler Identitätsangebote. Appelliert wird an das Bewusstsein des Consumer Citizen sowohl in einer Advokatenfunktion im Kontext von Menschenrechtsverletzungen (z.B. Boycott made in China), Umweltverschmutzung (z.B. StopEsso) oder ungerechten Handelsbedingungen (z.B. Make Trade Fair) als auch vor dem Hintergrund seines individuellen Interesses, beispielsweise was Gesundheitsaspekte betrifft (z.B. Gift im Essen). Nicht zuletzt wird die Konstruktion eines gemeinsamen Bewusstseins durch die Ansprache des Konsumenten von der Bewusstseinsbildung innerhalb der Trägerorganisation der Kampagnen entkoppelt. Identitätsangebote können infolgedessen an einen breiteren Unterstützerkreis adressiert werden. Internettechnologie wird in diesem Zusammenhang beispielsweise eingesetzt, um Boykott- oder Buykottaufrufe $^{23}$ zu verbreiten, über Produktionsprozesse zu informieren oder dem Konsumenten weitere Handlungsoptionen (z.B. Einfordern des Rechts auf Information) nahezulegen.

Auch unabhängig von der Ansprache des Konsumenten spielen universalistische Diskursstrategien bei der Konstruktion eines gemeinsamen Bewusstseins im Rahmen von Anti-Corporate Campaigns eine wichtige Rolle. So entfalten über der Hälfte aller 109 untersuchten Kampagnen humanitär-universalistische Diskurse, wobei vielfach die Themen Menschenrechte, Arbeitsbedingungen und Umweltschutz miteinander verknüpft werden und so der Interpretationsrahmen gemeinsamer Interessen weit gesteckt wird. Dies ermöglicht neben der Ansprache eines breiten Spektrums individueller politischer Akteure Kampagnenkoalitionen von Organisationen unterschiedlicher Provenienz. So sind in etwa einem Drittel der untersuchten Kampagnen sowohl Akteure alter als auch neuer sozialer Bewegungen beteiligt. Aktivisten beider Kampagnen gegen Lidl antworten auf die Frage, warum sie sich in der Kampagne engagieren, ähnlich und verweisen auf übergreifende geteilte frames wie z.B. menschenwürdige Arbeitsbedingungen:

- „Weil Arbeit menschenwürdig seien muss“ (Aktivist der ver.di-Kampagne)

- $\quad$ „um den Angestellten einen menschenwürdigen Arbeitsplatz zu erhalten, von dessen Entlohnung sie auch leben können. Das gleiche gilt für die Warenlieferanten, egal ob In- oder Ausland.“ (Aktivist der Attac-Kampagne)

23 Während Boykott den bewussten Nichtkauf bestimmter Produkte oder Produktgruppen bezeichnet, werden mit dem Begriff Buykott Kaufhandlungen aus ethischen, moralischen oder politischen Motiven gefasst. 
Hier stellt sich die Frage, inwieweit Kampagneninitiatoren das Netz nutzen, um die kollektive Bewusstseinsbildung innerhalb dieser Koalitionen bzw. der losen Netzwerke individueller Unterstützer zu fördern. Zunächst kann in diesem Kontext die Bedeutung der Kampagnenwebsite genannt werden. Diese ermöglicht eine unkomplizierte Dokumentation des Kampagnenverlaufs: Interne Entscheidungen, Berichte von Veranstaltungen oder Fotos von Demonstrationen können zeitnah zugänglich gemacht und Kampagnenmaterialien wie Flyer oder Informationsbroschüren, Expertisen oder Presseberichte für bereits Beteiligte und potenziell Interessierte bereitgestellt werden. Der $\mathrm{Zu}-$ gang zu Informationen wird darüber hinaus über die Vernetzung durch Hyperlinks erleichtert, das Angebot an weiterführenden Informationen kann so von den Kampagneninitiatoren vorstrukturiert und nach Relevanz sortiert werden.

Im Hinblick auf die interne Auseinandersetzung über die Definition gemeinsamer Interessen zwischen beteiligten Individuen und Akteursgruppen ist beispielsweise die Nutzung von Weblogs hervorzuheben. Diese digitalen Journale präsentieren aktuelle Meldungen, Kommentare und Statements so genannter Blogger und bieten in der Regel die Möglichkeit, diese Beiträge zu kommentieren und zu diskutieren. Ein illustratives Beispiel kampagneninterner Weblog-Kommunikation stellt das 2006 eingerichtete Schwarzbuch-Weblog der ver.di-Kampagne gegen Lidl dar. Ein Redaktionsteam erstellt in unregelmäBigen Abständen Beiträge zu aktuellen Fragen und Ereignissen rund um die Lidl-Kampagne. Diese Beiträge werden von den Lesern in unterschiedlichem Maße kommentiert: Während manche Beiträge unkommentiert bleiben, entwickeln sich bei anderen rege Diskussionen mit mehreren Hundert Kommentaren. Agnes Schreieder, Initiatorin der Kampagne, hebt dabei hervor, dass das Weblog unter anderem dazu dient, „Nicht-Mitglieder, aber Interessierte, die bislang keine Funktionen in ver.di haben“ zu integrieren: „Wir möchten nicht nur Beteiligung von Menschen, die eine engere Funktion einnehmen, sondern eben eine breite Beteiligung. “24 Allerdings bieten insgesamt nur ein Fünftel der untersuchten Kampagnen dialogorientierte Online-Kommunikationsangebote wie Weblogs, Chats oder Foren an. Als Gründe dafür lassen sich z.B. die hohen Anforderungen an die Schreibgeschwindigkeit beim Chatten oder die komplizierte Thread-Struktur von Diskussionen in Foren anführen. ${ }^{25}$ Die Kommunikation via E-Mail erfährt dagegen in den durchgeführten Case Studies eine konstant hohe Beliebtheit. So stellt beispielsweise die AttacKampagne gegen Lidl weder Chat, Forum noch Weblog zur Verfügung,

24 Interview mit Agnes Schreieder, Kampagnenleiterin der Ver.di Lidl-Kampagne.

25 Vgl. Rogg: Demokratie und Internet, S. 153f., 161. 
dennoch geben mehr als 20 Prozent der im Rahmen dieser Case Study Befragten an, mit mindestens 90 Prozent ihrer Mitstreiter ausschließlich über das Internet zu kommunizieren, sodass auch hier der Integration von Unterstützern über das Internet Bedeutung beigemessen werden kann. ${ }^{26}$

Insgesamt kann festgehalten werden, dass Netzkommunikation vor allem dann eine wesentliche Rolle in der Etablierung von Netzwerken und der Konstruktion eines gemeinsamen Bewusstseins bildet, wenn Kampagnen nicht mehr aus einem Personenkreis bestehen, der sich regelmäßig trifft und vor Ort kommunizieren kann, sondern maßgeblich durch virtuelle Gruppen getragen werden, die diskutieren, organisieren und Entscheidungen treffen müssen. Die Bedeutung des Internets für Identitätsangebote konzernkritischer Kampagnen muss deshalb im Kontext der Kampagnen- und Trägerstruktur betrachtet werden. Dies zeigt sich etwa in den Ergebnissen der Online-Befragung von Basisakteuren der beiden Kampagnen gegen Lidl: Während die Befragten der AttacKampagne vor allem E-Mails und Mailing-Listen zur Diskussion über Kampagneninhalte nutzen, findet diese Diskussion im Rahmen der ver.di-Kampagne vor allem als Face-to-Face-Kommunikation innerhalb der Gruppentreffen statt. Hier bleibt die Bewusstseinsbildung somit deutlich an die interne Ordnung und Struktur der Gewerkschaft sowie deren lokale Verankerung gebunden. Im Fall der Attac-Kampagne geht die Bedeutung des Internets für die Herausbildung eines gemeinsamen Bewusstseins zudem mit einer Betonung der kognitiven Ebene von Identifikationsprozessen einher:

[...] ich denke, die wenigsten Leute, die hier mitmachen, haben irgendwie diese Verbundenheit, OK wir gehören alle zu einer großen Familie, sondern eher so im Sinne von: Wir arbeiten alle zusammen und haben etwa ähnliche Interessen $[\ldots] .{ }^{27}$

\subsection{Verhandlung}

Um die rational-kognitiven Momente der Kampagne, also gemeinsame Ziele und Forderungen, ansprechender medial zu transportieren und auch für AuBenstehende anschlussfähig zu machen, werden diese durch die Einbettung in Symbole und Rituale affektiv unterfüttert. Die einzelnen Kampagnen nutzen

26 Dieses Ergebnis ist allerdings vor dem Hintergrund der Tatsache, dass den Teilnehmenden einer Online-Befragung tendenziell eine höhere Affinität zum Medium Internet unterstellt werden kann, als Tendenz zu werten.

27 Interview mit Kay Oliver Schulze, zuständig für die Koordination der Kampagne Lidl ist nicht zu billigen, H.i.O. 
diese „symbolische Verdichtung“28 in Form von Logos, Slogans oder Personifizierungen in unterschiedlicher Weise, um ihre Forderungen pointiert und greifbar zu gestalten.

Ein Großteil der untersuchten Kampagnen bedient sich dabei Formen des Culture Jamming. Kalle Lasn definiert Culture Jamming als „Rebranding“, also als „eine Strategie, eine Marke umzucodieren, als eine soziale Kampagne der Entmarkierung “29. Konkret nutzen Anti-Corporate Campaigns Techniken des Ad-Busting ${ }^{30}$, d.h. die gezielte Verfremdung von Werbeelementen wie Slogans oder Logos. Auf diese Weise wird die Bekanntheit einer Marke aufgegriffen, um hinter der bekannten Fassade neue, kritische Botschaften zu verbreiten. Anti-Corporate Campaigns finden in der Ästhetik der anvisierten Unternehmen oft ideale Vorlagen zur Verfremdung und Umgestaltung. So sieht Kay Schulze von Attac den Vorteil der Ad-Busting darin, ,[...] dass sie denselben Kanal nutzen wie die eigentliche Konzernwerbung auch, also sie setzen sozusagen auf einen gängigen Kommunikationskanal auf und bringen dann unterschührig [unterschwellig] eine andere Botschaft rein “31. Die Attac-Kampagne Lidl ist nicht zu billigen nahm eine Abwandlung des damaligen Werbespruches Lidl ist billig zum Ausgangspunkt und verwandte zudem eine Verfremdung des Lidl-Logos im Protestkontext. Das $i$ dieses Logos ist nach unten versetzt und erinnert so an eine stilisierte fallende Person (vgl. Abbildung 1).

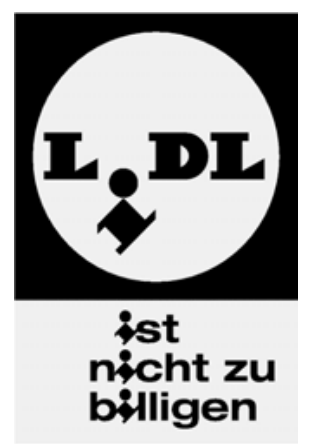

Abb. 1: Logo der Kampagne Lidl ist nicht zu billigen. ${ }^{32}$

Die Kampagne nutzte diese Ad-Bustings sowohl als Designgrundlage für die in den Lidl-Farben blau, rot und gelb gestaltete Protestwebsite als auch in ih-

28 Fahlenbrach: Protest-Inszenierungen, S. $117 \mathrm{ff}$.

29 Lasn: Culture Jamming, S. 15.

30 Siehe dazu auch Hubbertz in diesem Band.

31 Interview mit Schulze.

32 Attac: „Lidl-Kampagnen-Logos“. 
ren Publikationen und Aktionen. Die Abbildungen bot die Kampagne in verschiedenen Formaten zum Download an und ermöglichte Basisaktivisten, die kulturelle Repräsentation der Kampagne selbst voranzutreiben, etwa indem sie im Rahmen lokaler Aktionen vor Lidl-Filialen Flyer im Stil der Lidl-Werbeprospekte mit Informationen zu Dumpingpreisen und schlechten Beschäftigungsverhältnissen verteilten. Die eigenen Ziele und Politikentwürfe mit den Mitteln des Gegners zu transportieren, stellt dabei hohe Anforderungen an den Verhandlungsprozess kollektiver Identiät, da Passanten und Konsumenten binnen Sekunden die Essenz der Forderungen auf Plakaten und Flyern aufnehmen müssen. ${ }^{33}$ Die Ähnlichkeit zur Unternehmenskommunikation birgt die Gefahr der Verwechslung: Ein im Rahmen der Case Study zur Attac-Kampagne befragter Aktivist betonte beispielsweise die zu starke Ähnlichkeit des Werbe-Plagiats mit dem Original, die dazu geführt habe, dass er das Papier ungelesen weggeworfen habe, da er es für die echte Werbung gehalten habe.

Allerdings nutzen einige konzernkritische Kampagnen unternehmerische Werbeelemente, um gezielt auf eine derartige Verwechslung hinzuarbeiten. Die Kampagne Nikeground ${ }^{34}$ etwa basiert auf einer gefälschten Website des Unternehmens, welche die Umbenennung des Wiener Karlsplatzes in Nikeplatz und den Bau eines Nikemonumentes in Form des Nikelogos, dem so genannten Swoosh, ankündigte. Diese Kampagne instrumentalisierte das weltweit bekannte Nike-Logo, um mit dem Mythos der Nike-Identität die Omnipräsenz von Marken im öffentlichen Raum zu kritisieren: „[...] the Swoosh, is probably the most ,viewed' brand on earth, more than any political or religious symbol.“35 Auch hier ist die Verwendung des unternehmerischen Zeichenrepertoires zur Vermittlung der eigenen Ziele und Politikentwürfe nicht unproblematisch. Die Kritik an der dominanten kulturellen Präsenz multinationaler Unternehmen wird subversiv geäußert, die positive Bewertung des Protestnetzwerks ist somit abhängig von der Reflexionsleistung der Außenstehenden.

Neben der Verwendung und Umdeutung werblicher Kommunikation entwickeln Anti-Corporate Campaigns eigene Symbole und Alltagspraxen kultureller Repräsentation, deren Vermittlung an Außenstehende unter anderem

33 Vgl. autonome a.f.r.i.k.a.-Gruppe u.a.: Kommunikationsguerilla, S. 65ff.

34 Unter dem Titel Rethinking Space startete das Künstlerpaar Eva und Franco Mattes in Zusammenarbeit mit Public Netbase, dem Institut for New Culture Technologies 2003 eine vermeintliche Kampagne des Unternehmens Nike zur Umbenennung des Wiener Karlsplatzes in Nikeground. Nachdem die Wiener Kronenzeitung das Gerücht der Umbenennung aufnahm und zahlreiche Einwohhner Wiens gegen das Vorgehen des Unternehmens protestierten, stellte Nike in einem Dementi klar, dass es keinerlei Pläne zur Umbenennung des Karlsplatzes gebe und die Aktion einen Schwindel darstelle. 
internetbasiert erfolgt. Auf der Website der Kampagne Lidl ist nicht zu billigen findet sich etwa eine multimediale Online-Sammlung von Protestliedern, Slogans und Vorlagen für Theaterstücke und Verkleidungen, die interessierten Aktivisten als Inspiration und Vorbild für ihre lokalen Aktionen dienten. Andere Kampagnen, wie beispielsweise die Butterfinger-Kampagne von Greenpeace arbeiten mit Bildergalerien und bringen das lose Netzwerk ihrer Unterstützer somit zumindest visuell zusammen. Auch die bereits thematisierte Dokumentation von physischen Aktionen im Internet kann zur Selbstvergewisserung der Kampagnenunterstützer und zur Repräsentation des Protestnetzwerks beitragen.

Symbole und Alltagspraxen stellen die emotionale, affektive Dimension der Identitätsangebote von Kampagnen dar und zielen vor allem auf die Herstellung eines Zugehörigkeitsgefühls. Internetbasierte Identitätsangebote können zwar, wie beschrieben, in einem gewissen Maße zur kulturellen Repräsentation des Protestnetzwerks beitragen. Inwieweit die über das Netz vermittelten Symbole und Praxen tatsächlich zur Identitätskonstruktion und einer erfolgreichen Verhandlung mit Außenstehenden beitragen, bleibt jedoch fraglich.

\section{$3 \quad$ Fazit und Ausblick}

In der Zusammenschau der Identitätsangebote auf den verschiedenen Ebenen kann festgehalten werden, dass der affektive Charakter gemeinschaftlicher Protestinszenierung bei Online-Protestkampagnen auf den ersten Blick in den Hintergrund tritt, während kognitive Elemente durch die Bereitstellung von Information, Dokumentation und Kommunikation im Netz gefördert werden. Die Kampagnen entwickeln jedoch neue Strategien der Ansprache emotionaler kollektiver Identitätsangebote und passen etablierte Strategien an das digitale Medium an. Der Einsatz der Internettechnologie bedeutet für Anti-Corporate Campaigns damit mehr als nur eine veränderte Kommunikationsstruktur: Er greift in unterschiedlicher Weise in die Muster kognitiver und affektiver Dimensionen der Identitätskonstruktion ein. Zum einen zielen Online-Praxen von Kampagnen auf die kognitiven Aspekte der Einbindung in das Protestnetzwerk, indem sie Kommunikation, Dokumentation und Weitergabe von Wissen vereinfachen und so positiven Einfluss auf den gemeinsamen Diskurs ausüben wollen. Zum anderen muss das fehlende körperliche Erleben gemeinsamer Rituale und Zusammentreffen kompensiert, die emotionale Dimension der Gemeinschaftlichkeit ${ }^{36}$ neu konstruiert und an das Medium Internet ange-

36 Inwiefern tatsächlich von einer Protestgemeinschaft ausgegangen werden kann, vgl. die folgenden Ausführungen. 
passt werden. Die untersuchten Kampagnen nutzen dazu z.B. neue Formen des politischen Protests wie Online-Demonstrationen und greifen on- wie offline auf Symbole und Slogans in Form von Ad-Bustings oder prominente Personen als Feindbilder bzw. Leitfiguren zurück. Dabei werden Angebote zur medialen Ansprache affektiver Dimensionen durch die Dokumentation des gemeinsamen Erlebens auf der Straße unterfüttert. Identitätsangebote internetgestützter Protestbewegungen erfolgen somit in einem Spannungsfeld zwischen dem virtuellen Raum des Internets und dem lokalen Agieren einzelner Akteure und kleinerer Gruppen, zwischen Deterritorialisierung und Lokalisierung ${ }^{37}$, wobei Identitätsangebote sowohl im Hinblick auf die Integration individueller Unterstützer, als auch was die organisationale Integration verschiedener Akteure betrifft, universal formuliert werden und somit Potenziale für die Herausbildung flexibler Identitäten eröffnen.

Unter Rückgriff auf bisherige emprirische Studien zur Identitätskonstruktruktion im Internet wird abschließend diskutiert, inwiefern diese Angebote tatsächlich zur Herausbildung einer kollektiven Identität beitragen können. Ayers vergleichende Studie zur Entwicklung kollektiver Identität in der Frauenbewegung, welche auf qualitativen Interviews mit Aktivistinnen einer Online- und einer Offlinegruppe basiert, kommt zu dem Schluss, dass kollektive Identitäten eher im Offline- als im Onlineraum konstruiert werden:

I showed that participants in an online group do not feel close to one another as a result of their group participation. Even though people are ,together in cyberspace, this research indicates that they might not feel together. ${ }^{38}$

Hinsichtlich Granovetters Unterscheidung in strong und weak ties lässt sich hier vermuten, ${ }^{39}$ dass Beziehungen im Netz insbesondere dem Typus schwächerer Bindungen angehören. Ausgehend von der Annahme, dass im virtuellen Raum der Grad der Verbindlichkeit variieren kann sowie multiplexe Beziehungsmuster entwickelt werden können, schlägt von Kardoff vor, den Begriff virtueller Netzwerke anstelle von virtuellen Gemeinschaften zu verwenden. ${ }^{40}$

37 Vgl. Hepp: „Deterritorialisierung und die Aneignung von Medienidentität“, S.109ff.

38 Ayers: „CollectiveIdentity.org“, S. 56.

39 Vgl. Granovetter: „The strength of weak ties“.

40 „Der [...] in der englischsprachigen Literatur eingeführte Begriff der ,Community (,Gemeinschaft') bietet Anlass zu Missverständnissen, weil er in unterschiedlichen kulturellen und soziologischen Verweisungszusammenhängen steht. [...] Subjektive Gefühle der Verbundenheit, sozialer Einbettung (,belongingness) und des Vertrauens (Siegert/Pühringer 2004) können sich auch ohne Ortsbezug und Face- 
Noch weiter geht Wellman, welcher insgesamt den Begriff der community durch den Netzwerk-Begriff ersetzt. ${ }^{41}$

Für Protestkampagnen im Netz stellt sich, dieser Überlegung folgend, zum einen die Herausforderung, Angebote zur kollektiven Identitätsstiftung für eine heterogene Teilnehmerschaft mit unterschiedlich engen bzw. schwachen Beziehungen zu unterbreiten und zum anderen Internetanwendungen bereitzustellen, welche die Beteiligung Einzelner an der Verständigung auf eine „shared definition“ (Melucci) sowie an kollektiven Handlungen ermöglichen. Die dargestellten Beispiele sowie die Studie von Ayers lassen allerdings vermuten, dass Protestkampagnen nur sehr bedingt kollektive Identität ausschließlich im Cyberspace stiften können, vielmehr sind diese auf kollektive Erfahrungen im lokalen konkreten Sozialraum angewiesen, aus welchen Zugehörigkeitsgefühle und ein gemeinsame, übergreifende kollektive Identität erwachsen können. Während mittlerweile die Aufeinanderbezogenheit von physischem und virtuellem sozialem Raum als wissenschaftlicher Allgemeinplatz gelten kann, gibt es bisher nur wenige Erkenntnisse darüber, wie die Netznutzung individueller Protestakteure sich auf Formen kollektiver Identitätskonstruktion auswirkt. Hier besteht erheblicher Forschungsbedarf, der insbesondere durch qualitative Längsschnittstudien zur Sinnkonstruktion in virtuellen Protestnetzwerken aufzugreifen wäre, da bisherige Studien über Cyberculture weniger Prozesse kollektiver Identitätsstiftung als vielmehr die Konstruktion individueller Identitäten im Netz in den Blick nehmen. ${ }^{42}$

to-face-Kontakte durch eine stabile Kommunikation mit anderen im Netz einstellen. [...] Anstelle von, virtuellen Gemeinschaften' folge ich daher einer operationalen Minimaldefinition für virtuelle Netzwerke: Es handelt sich dabei um ,Gruppen von Personen, die [...] über elektronische Medien kommunizieren und interagieren' (Fremuth/Tasch 2002: 5). Das Konzept der Netzwerke umfasst die heterogene Teilnehmerschaft und die zeitlich unterschiedlichen stabilen und verschieden engen Beziehungen am besten (vgl. Stegbauer 2001: 92).“ Kardoff: „Virtuelle Netzwerke“, S. 74f., H.i.O.

41 Vgl. Wellman: „Physical Place and Cyber Place“, S. 228. Aus seinen empirischen Studien zu virtuellen Netzwerken von Nachbarschaftsbeziehungen zieht Wellman den Schluss eines vernetzten Individualismus (networked individualism), durch den „each person is becoming an individualized switchboard, linking a unique set of ties and networks.“ Wellman: „Connecting Community“, S. 7. Castells begreift den vernetzten Individualismus bereits als gesamtgesellschaftliches Muster, welches durch das Internet unterstützt werde. Vgl. Castells: Die Internet-Galaxie, S. 144f. In ähnlicher Weise verweisen Münch und Schmidt darauf, dass das mit der Etablierung des Internet ein Strukturwandel der sozialen Integration von engen, räumlich definierten Gemeinschaften hin zu sozialen Netzwerken erfolge. Vgl. Münch/Schmidt: „Medien und Sozialer Wandel“, S. 213.

42 Vgl. z.B. Turkle: „Cyberspace and Identity“; Döring: Sozialpsychologie des Internet. 


\section{Literaturverzeichnis}

0100101110101101.org: „Interview“, in: rebel:art \#1: how to provoke today? Spring/Summer 2004, S. 52.

Attac (Hrsg.): „LiDL-Kampagnen-Logos“, www.attac.de/lidl-kampagne/ index.php?id=100, 17.07.2007.

autonome a.f.r.i.k.a gruppe u.a.: Handbuch der Kommunikationsguerilla, Berlin 2001.

Ayers, Michael D.: „CollectiveIdentity.org: Collective Identity in Online and Offline Feminist Activist Groups“ (MA), scholar.lib.vt.edu/theses/ available/etd-06112001-151759/unrestricted/thesis_final.pdf, 2001.

Baringhorst, Sigrid: Politik als Kampagne. Zur medialen Erzeugung von Solidarität, Opladen 1998.

Castells, Manuel: Die Internet-Galaxie. Internet, Wirtschaft und Gesellschaft, Wiesbaden 2005.

Döring, Nicole: Sozialpsychologie des Internet. Die Bedeutung des Internet für Kommunikationsprozesse, Identitäten, soziale Beziehungen und Gruppen, Göttingen 2003.

Fahlenbrach, Kathrin: Protest-Inszenierungen. Visuelle Kommunikation und kollektive Identitäten in Protestbewegungen, Wiesbaden 2001.

Gendreck weg: „Kleiner Flyer Feldbefreier“, www.gendreck-weg.de/content/ downloads/kampagnenmaterial/Kleiner_Flyer_Feldbefreier.pdf, 29.05.2007.

Giesen, Bernhard: Kollektive Identität. Der Intellektuelle und die Nation, Frankfurt a.M. 1998

Granovetter, Mark: „The strenght of weak ties“, in: American J. Sociology, Jg. 78, 1973, S. 1360-1380.

Haunss, Sebastian: Identität in Bewegung. Prozesse kollektiver Identität bei den Autonomen und in der Schwulenbewegung, Wiesbaden, 2004.

Hellmann, Kai-Uwe. „Paradigmen der Bewegungsforschung“ , in: Klein, Ansgar u.a. (Hrsg.): Neue Soziale Bewegungen. Impulse, Bilanzen und Perspektiven, Opladen 1999, S. 91-113.

Hemetsberger, Andrea: „Understanding consumers’ collective action on the Internet - a definition and discussion of relevant concepts for research", Paper präsentiert auf der Jahreskonferenz der ACR (Association for Consumer Research) 2002 in Atlanta, Georgia, opensource.mit/edu/papers/ hemetsberger3.pdf, 16.07.2007. 
Hepp, Andreas: „Deterritorialisierung und die Aneignung von Medienidentitäten“, in: Winter, Carsten u.a. (Hrsg.): Medienidentitäten. Identität im Kontext von Globalisierung und Medienkultur, Köln 2003, S. 94-119.

Hunt, Scott A./Benford, Robert D.: „Collective Identity, Solidarity, and Commitment", in: Snow, David A. u.a.: The Blackwell Companion to Social Movements, Malden MA 2004 u.a., S. 433-457.

Kardoff, Ernst von: „Virtuelle Netzwerke - eine neue Form der Vergesellschaftung?‘, in: Hollstein, Bettina/Straus, Florian (Hrsg.): Qualitative Netzwerkanaylse. Konzepte, Methoden, Anwendungen, Wiesbaden 2006, S. 63-97.

Klandermans, Pieter G.: „The social construction of protest and multiorganizational fields“, in: Morris, Aldon D./McClurgh Mueller, Carol (Hrsg.): Frontiers in Social Movement Theory, New Haven 1992, S. 77-103.

Lasn, Kalle: Culture Jamming, Freiburg 2005.

Melucci, Alberto: Challenging Codes - Collective Action in the Information Age. Cambridge 1996.

Münch, Richard/Schmidt, Jan: „Medien und sozialer Wandel“, in: Jäckel, Michael (Hrsg.): Mediensoziologie. Grundfragen und Forschungsfelder, Wiesbaden 2005, S. 201-218.

Rogg, Arne: Demokratie und Internet. Der Einfluss von computervermittelter Kommunikation auf Macht, Repräsentation, Legitimation und Öffentlichkeit, Opladen 2003.

Rucht, Dieter: „Kollektive Identität. Konzeptionelle Überlegungen zu einem Desiderat der Bewegungsforschung“, in: Forschungsjournal NSB, Jg. 8, Nr 1, 1995, S. 9-23.

Schreieder, Agnes: Interview vom 23.10.2006.

Schulz, Thomas: Interview vom 11.12.2006.

Schulze, Kay O.: Interview vom 11.10.2006.

Tarrow, Sydney/Porta, Donnatella della: „Conclusion: ,Globalization“, Complex Internationalism, and Transnational Contention“, in: dies. (Hrsg.): Transnational Protest and Global Activism, Oxford 2005, S. 227-246.

Taylor, Verta/Whittier, Nancy: „Collective Identity in Social Movement Communities: Lesbian Feminist Mobilization“, in: Morris, Aldon D./ McClurgh Mueller, Carol (Hrsg.): Frontiers in Social Movement Theory, New Haven, 1992, S. 53-76. 
Turkle, Sherry: „Cyberspace and Identity“, in: Contemporary Sociology, Jg.28, Nr.6, 1999, S. 643-647.

Wellman, Barry: Connecting Community. On- and Offline. www.chass. utoronto.ca/ wellman/publications/index.html, 17.07.2007.

Wellman, Barry: „Physical Place and Cyber Place: The Rise of Personalized Networking", in: International Journal of Urban and Regional Research, Jg. 25, Nr. 2, 2001, S. 227-252. www.chass.utoronto.ca/ $\sim$ wellman/ publications/index.html, 17.07.2007. 



\title{
Veronika Kneip/Johanna Niesyto
}

\section{Politischer Konsum und Kampagnenpolitik als nationalstaatliche Steuerungsinstrumente? Das Beispiel der Kampagne Echt gerecht. Clever kaufen ${ }^{1}$}

\author{
Mit klaren Kennzeichnungen finden wir die \\ clevere Kaufalternative. So kommen Lifestyle \\ und Verantwortung mit höchstem Genuss im \\ Alltag zusammen. Denn Nachhaltigkeit ist \\ auch eine Frage der Gerechtigkeit. Und \\ gerecht lebt es sich besser. ${ }^{2}$
}

Insbesondere Prozesse der ökonomischen Globalisierung erschweren es $\mathrm{Na}$ tionalstaaten, politische Rahmenbedingungen für wirtschaftliches Handeln festzulegen. Weltwirtschaftliche Ordnung ist immer weniger an territoriale Grenzen und nationalstaatliche Regelungsinstanzen gebunden. Welche neuen Möglichkeiten sehen westliche Staaten, der Meta-Macht der Global Players gegenüber zu treten? Die Kampagne der deutschen Bundesregierung Echt gerecht. Clever kaufen kann als Beispiel einer Reaktion auf nationalstaatliche Steuerungsverluste bzw. als Ausdruck neuer Formen politischer Steuerung verstanden werden. Verbraucherpolitik erhebt hier den Anspruch, neben der Produktqualität auch die Nachhaltigkeit des (transnationalen) Produktionsprozesses indirekt über die Verbrauchermacht politischer Konsumenten zu beeinflussen. In dieser Aktivierung des Bürgerkonsumenten zeigt sich, so unsere These, eine neue Form der Ansprache des Bürgers durch den Staat. Der Staatsbürger wird aufgefordert, gewisse politische Steuerungsfunktionen zu übernehmen bzw. zu unterstützen. In diesem Kontext ist die Kampagne Ausdruck eines weiter gefassten Verständnisses von Governance, das neben staatlicher Lenkung und kooperativen Formen der Verhandlung auch gesellschaftliche Selbststeuerung einschließt. ${ }^{3}$ Der in der Kampagne angesprochene Bürgerkonsument soll Produktionsprozesse und Produktqualitäten indirekt durch Verbrauchermacht beeinflussen. Diese Verschränkung der Bürger- und Konsumentenrolle birgt neben neuen Chancen politischer Steuerung auch Risiken: Kann der Staat durch den Aufruf zum politischen Konsum seinem Steuerungsverlust partiell entge-

1 Der Beitrag stellt eine überarbeitete und veränderte Version des auf der Nachwuchstagung des SFB 597 Wandel des Staates - Transformation von Herrschaft? (31.03.02.04.2006) in Bremen präsentierten Papers dar.

2 Künast zitiert in: Echt Gerecht. Clever kaufen: „Presse“.

3 Vgl. Blumenthal: „Governance - eine kritische Zwischenbilanz“, S. 1154. 
genwirken oder kommt persuasiven Aktionen wie der oben genannten verbraucherpolitischen Kampagne nur eine symbolpolitische Alibifunktion zu? Fraglich ist auch, ob dadurch politische Partizipation aktiviert wird oder ob sich (Verbraucher-)Politik auf passiven Konsumismus als Ausdruck des individuellen Lebensstils beschränkt. Kommen „Lifestyle und Verantwortung“ (Künast) wirklich zusammen?

Als Analysebeispiel wird die Kampagne Echt gerecht. Clever kaufen gewählt, da an ihr zum einen die Ambivalenz von politischem Konsum und Kampagnenpolitik verdeutlicht werden kann. Zum anderen wird sie von einem Bundesministerium selbst getragen und nicht nur - wie im Falle der Kampagne Fair Feels Good ${ }^{4}$ - finanziell gefördert. In einem ersten Schritt der Analyse werden Kampagnenpolitik und politischer Konsum als mögliche alternative Steuerungsmaßnahmen im Bereich der Regulierung von Unternehmensmacht dargestellt. Darauf aufbauend werden insbesondere der Einsatz von Kampagnenpolitik und politischem Konsum als Alternativen, welche auf gesellschaftliche Selbststeuerung zielen, am Beispiel der Kampagne illustriert. Dabei greift die Analyse der Kampagne Echt gerecht. Clever kaufen auf sozialwissenschaftliche Framing-Konzepte zurück, mittels welcher die im Rahmen der Kampagne symbolisch vermittelten Deutungsmuster analysiert werden. Hierbei wird zwischen der Deutungsrahmung der identifizierten Probleme (Diagnostic Framing), der Rahmung von Handlungs- und Lösungsmöglichkeiten (Prognostic Framing) und der Rahmung von Anreizen (Motivational Framing) unterschieden. ${ }^{5}$

In einem weiteren Schritt werden politischer Konsum und Kampagnenpolitik in den steuerungstheoretischen Kontext eingeordnet, wobei eine Bewertung der analysierten Kampagne unter dem Aspekt der Ermöglichung gesellschaftlicher Selbststeuerung erfolgt. Zudem werden Forschungsergebnisse des Projekts Protest- und Medienkulturen im Umbruch an der Universität Siegen vorgestellt, ${ }^{6}$ welche die Einschätzung gesellschaftlicher Selbststeuerung aus zivilgesellschaftlicher Sicht ergänzen.

4 Die Kampagne, welche vom Oktober 2003 bis Ende Dezember 2006 lief, wurde von der Verbraucher Initiative e.V. in Kooperation mit TransFair e.V. und dem Weltladen-Dachverband e.V. getragen und ist Teil des Aktionsprogramms 2015 der Bundesregierung.

5 Vgl. Snow/Benford: „Ideology, Frame Resonance and Participant Mobilization“.

6 Informationen zu diesem Projekt finden sich unter www.protest-cultures.unisiegen.de. 


\section{Alternative Steuerungsinstrumente}

Die weltwirtschaftliche Ordnung ist kaum noch an territoriale Grenzen und nationalstaatliche Regelungsinstanzen gebunden: „Die Meta-Macht der Weltwirtschaft gegenüber den Nationalstaaten beruht auf der Exit-Option (Hirschman), die das Kapital sich im digitalen Raum erobert hat. ${ }^{\text {"7 }}$ Dezentrale Organisationsstrukturen und wenig transparente Produktionsprozesse transnationaler Unternehmen komplizieren zudem die Einrichtung und unabhängige Kontrolle allgemein gültiger Standards in verschiedensten Bereichen, wie z.B. dem Umweltschutz. „Die Krise des Regierens"8 ist dadurch charakterisiert, dass nationale Maßnahmen bei vielen Problemen nicht greifen. Dies gilt auch hinsichtlich der Steuerung von Konsumverhalten durch staatliche Verbraucherpolitik. Weltweite Trends zur Deregulierung von Märkten erhöhen die Komplexität von Marktbeziehungen und stellen verbraucherpolitische Akteure vor die neuen Herausforderungen, die Verbraucher als Nachfrager auf dem Markt zu unterstützen sowie ihre Konsumkompetenzen zu fördern. ${ }^{9}$ Dabei ist solch eine neue Verbraucherpolitik nicht nur am Leitbild der Konsumentensouveränität sondern auch am Leitbild der Nachhaltigkeit ${ }^{10}$ orientiert. ${ }^{11}$ Die traditionelle defensive Verbraucherpolitik bildet hier die erste Säule einer neuen proaktiven Verbraucherpolitik, ${ }^{12}$ welche die Bedeutung des Schutzes von individuellen

7 Beck: Macht und Gegenmacht im globalen Zeitalter, S. 99.

8 Zürn: Regieren jenseits des Nationalstaats, S. 11.

9 Vgl. Reisch: „Strategische Grundsätze und Leitbilder einer neuen Verbraucherpolitik“, S. 11; Müller: „Grundlinien einer modernen Verbraucherpolitik“, S. 14f.; dies.: „Vom Verbraucherschutz zur Verbraucherpolitik“, S. 3.

10 Nachhaltige Verbraucherpolitik versteht sich als Querschnittspolitik, die in wirtschafts-, gesellschafts- und nachhaltigkeitspolitische Politikbereiche hineinreicht. Im Koalitionsvertrag der ehemaligen rot-grünen Regierung wurde dies erstmals verankert.

11 Vgl. z.B. Belz/Bilharz: Nachhaltiger Konsum; Reisch: „Neuer Wein oder nur neue Schläuche?"; Müller: „Vom Verbraucherschutz zur Verbraucherpolitik“.

12 Insbesondere die Verbraucherpolitik der ehemaligen Bundesregierung unter der Bundesministerin Künast orientierte sich unter anderem an dem Grundsatz der Stärkung der Eigenverantwortung der Verbraucher und ist damit Ausdruck einer modernen Verbraucherpolitik. Vgl. Bundesministerium für Verbraucherschutz, Ernährung und Landwirtschaft 2003: Aktionsplan Verbraucherschutz der Bundesregierung, S. 1. Dagegen besinnt sich ihr Nachfolger Seehofer eher auf den reinen Verbraucherschutz und konzentriert sich verstärkt auf den Bereich der Landwirtschaft. Vgl. Seehofer: „Rede des Bundesministers für Ernährung, Landwirtschaft und Verbraucherschutz". Damit zeichnet sich ein Rückschritt hin zur klassischen Verbraucherpolitik ab, was auch Ausdruck im neuen Namen des Ministeriums findet. Auf der Grundlage des Kabinettsbeschlusses vom 22. November 2005 wurde 
Verbraucherinteressen nicht in Frage stellt. Im Folgenden sind die beiden Säulen dargestellt:

\begin{tabular}{|c|c|c|}
\hline $\begin{array}{c}\text { 1. Säule } \\
\text { (Klassische Verbraucherpolitik) }\end{array}$ & & 2. Säule \\
\hline $\begin{array}{l}\text { Leitbild } \\
\text { Konsumentensouveränität }\end{array}$ & $\leftarrow$ Legitimation $\rightarrow$ & $\begin{array}{c}\text { Leitbild } \\
\text { Nachhaltigkeit }\end{array}$ \\
\hline Marktordnungsfunktion & $\leftarrow$ Ziel $\rightarrow$ & $\begin{array}{l}\text { Innovationsfunktion } \\
\text { (proaktive Gestaltung) }\end{array}$ \\
\hline $\begin{array}{c}\text { Mikroebene des individuellen } \\
\text { Verbraucherschutzes }\end{array}$ & $\leftarrow$ Gegenstand $\rightarrow$ & $\begin{array}{l}\text { Makroebene der Nach- } \\
\text { frage auf Märkten } \\
\text { (Realisierung kollektiver } \\
\text { Ziele) }\end{array}$ \\
\hline Rechtliche Regelungen & $\leftarrow$ Instrumente $\rightarrow$ & Kooperative Instrumente \\
\hline Sektoralpolitik & $\leftarrow \underset{\text { Verankerung }}{\text { institutionelle }} \rightarrow$ & Querschnittspolitik \\
\hline
\end{tabular}

Tab. 1: Moderne Verbraucherpolitik. ${ }^{13}$

Mit der Erweiterung der klassischen Verbraucherpolitik um die Dimension der Nachhaltigkeit sieht sich eine moderne Verbraucherpolitik erhöhten Anforderungen ausgesetzt. Während sich traditionelle Verbraucherpolitik aus ihrem Verhältnis zur Wettbewerbstheorie definiert und den Schutz individueller Verbraucherinteressen in den Vordergrund stellt, will moderne Verbraucherpolitik diese um die Einbeziehung einer kollektiven Dimension erweitern und proaktiv wirken. Dies bedeutet, dass Verbraucherpolitik sich nicht auf ihren marktkomplementären und -kompensatorischen Charakter beschränkt, sondern sich als politische Steuerung unter wachsender gesellschaftlicher Mitgestaltung der Bürger versteht. Zentral für eine moderne Verbraucherpolitik ist zudem der Einsatz von kooperativen Instrumenten, sprich die Einbeziehung

das Bundesministerium für Verbraucherschutz, Ernährung und Landwirtschaft nochmals umbenannt in Bundesministerium für Ernährung, Landwirtschaft und Verbraucherschutz.

13 Quelle: Belz/Bilharz: Nachhaltiger Konsum, S. 20. 
nicht-staatlicher Akteure wie Nichtregierungsorganisationen - z.B. foodwatch - und Unternehmen in den Politikprozess. ${ }^{14}$

Neben der Zusammenarbeit von wirtschaftlichen, zivilgesellschaftlichen und (trans)staatlichen Akteuren - z.B. im Rahmen von Codes of Conduct ${ }^{15}$ stellt die Zusammenarbeit zivilgesellschaftlicher und (trans)staatlicher Akteure mit Bürgern als Konsumenten, so unsere These, ein weiteres alternatives Steuerungsinstrument dar, welches auf die Ermächtigung des Verbrauchers im Sinne gesellschaftlicher Selbststeuerung zielt. Dabei versuchen staatliche Akteure, den Markt nicht über ordnungspolitische Instrumente, sondern über die Marktmacht der Konsumenten zu steuern. Politischer Konsum zeichnet sich dabei insbesondere dadurch aus, dass individuelle Kaufentscheidungen auch an gemeinwohlorientierten Gesichtspunkten ausrichtet sind:

Political consumers respond to corporate politics and products as reflecting, expressing, and promoting political, social, and normative values beyond those of consumer price, taste, and quality of goods. ${ }^{16}$

Autoren wie Scammell oder Gabriel/Lang sprechen in diesem Zusammenhang vom Consumer Citizen, welcher sein politisches Handeln in der Sphäre des Konsums entfaltet und so die Rollen von Citoyen und Bourgeois verbindet. ${ }^{17}$

Orientierungshilfen für das politische Handeln in der Konsumsphäre stellen dabei unter anderem Labeling-Initiativen dar. Diese eignen sich zur Kontrolle von Produktionsbedingungen und Herstellungsprozessen, auf die der Nationalstaat allein keine unmittelbaren Einflussmöglichkeiten (mehr) hat. ${ }^{18}$ So bieten Labeling-Systeme die Möglichkeit, Bereiche zu steuern, deren Regel-

14 Vgl. Reisch: „Neuer Wein oder nur neue Schläuche?“, S. 295; Müller: „Vom Verbraucherschutz zur Verbraucherpolitik“, S. 10.

15 Die im Beitrag vorgenommene Fokussierung auf Kampagnenpolitik und politischen Konsum geschieht vor dem Hintergrund, dass es zu Verhaltenskodizes bereits eine breite Diskussion gibt, während Kampagnenpolitik und politischer Konsum im Zusammenhang mit politischer und staatlicher Steuerung bisher kaum in der wissenschaftlichen Diskussion aufgegriffen wurden. Vgl. z.B. Jenkins u.a.: Corporate Responsibility and Ethical Trade; Adloff u.a.: Wirtschaft und Zivilgesellschaft.

16 Micheletti u.a.: Political virtue and shopping, S. ix.

17 Vgl. Scammell: „The Internet and Civic Engagement“, S. 351; Gabriel/Lang: The unmanageable consumer, S. 185.

18 Die wissenschaftliche Diskussion konzentriert sich dabei vor allem auf Steuerungsmöglichkeiten im Bereich der Umweltpolitik, so sprechen Jordan u.a. beispielsweise von Labeln als einem New Environmental Policy Instrument. Vgl. Jordan u.a.: „Consumer Responsibility-Taking and Eco-Labeling Schemes in Europe“, S. 162. 
ungskompetenz bereits an supranationale Institutionen übergeben wurde. Die Prinzipien der Welthandelsorganisation (WTO) untersagen zum Beispiel Einfuhrbeschränkungen aufgrund bestimmter Produktionsbedingungen in Herstellungsländern. Positive - und freiwillige - Kennzeichnungen von Produkten, die unter den gewünschten Bedingungen produziert wurden, widersprechen den Vorgaben der WTO jedoch nicht und bieten dabei ein eigenständiges Steuerungselement. Noch effektiver können Labeling-Systeme als Steuerungselement eingesetzt werden, wenn zur Kennzeichnung so genannte „Multilevel Label Systems“19 genutzt werden. Diese Systeme, wie beispielsweise das EU-Energielabel, ordnen die zertifizierten Produkte in verschiedene Klassen ein und weisen somit nicht nur auf positive, sondern auch auf negative Produkteigenschaften hin (z.B. Energieeffizienzklasse A = niedriger Energieverbrauch, Energieeffizienzklasse $G=$ hoher Energieverbrauch ${ }^{20}$ ). Eine Studie von Grankvist u.a. zu Umwelt-Labeln zeigt, dass gerade Konsumenten ohne ausgeprägtes Umweltbewusstsein stärker auf negative als auf positive Label reagieren. Mehrstufige Labeling-Systeme sind jedoch in der Regel nur in Verbindung mit einer Kennzeichnungspflicht realisierbar (z.B. EU-Haushaltsgeräterichtlinie und ihre Umsetzung in der Energieverbrauchskennzeichnungsverordnung). Hier sind nationalstaatliche Alleingänge kaum möglich und angesichts der weitreichenden Produktionsprozesse, auf die mithilfe von Labeln Einfluss genommen werden soll, auch wenig sinnvoll. Transnationale Governance-Strukturen aus Regierungen, internationalen Institutionen, Nichtregierungsorganisationen und Bürgern bzw. Konsumenten könnten dagegen grenzüberschreitende Auszeichnungssysteme entwickeln und durchsetzen. ${ }^{21}$

Insgesamt ist politischer Konsum als alternatives Steuerungsinstrument ambivalent zu werten, denn wenn Konsumenten den „Kaufakt als direkten Stimmzettel“22 benutzen, wandert die Politik gewissermaßen in die Sphäre des „Subpolitischen“ (Beck) ab, in der sich individuelle mit kollektiven und private mit öffentlichen Handlungen vermischen. Handlungen von politischen Konsu-

19 Grankvist u.a.: „The Impact of Environmental Labelling on Consumer Preference“, S. 216.

20 Eine Verfälschung der Aussagekraft des Energielabels ergibt sich jedoch dadurch, dass die meisten Elektrogeräte inzwischen in den höheren Energieeffizienzklassen $\mathrm{A}+$ und $\mathrm{A}++$ erhältlich sind. Eine generelle Überarbeitung dieses Labeling-Schemas wäre also notwendig, damit die Energieeffizienzklasse A nicht länger den höchstmöglichen Standard suggeriert.

21 Bis auf wenige Ausnahmen wie z.B. dem bereits genannten Energieeffizienzsiegel existieren solche Initiativen kaum. Politische Institutionen engagieren sich zurzeit überwiegend durch finanzielle Projektförderung bzw. durch den eigenen Kauf zertifizierter Produkte.

22 Beck: Was ist Globalisierung?, S. 124. 
menten können nicht nur an kollektiven Zielen ausgerichtet sein, wie es die moderne Verbraucherpolitik idealtypisch annimmt, sondern können sich auch an individuellen Werten wie Geschmack, Preis, Qualität etc. orientieren. ${ }^{23}$ Dies bedeutet, dass politischer Konsum zu einer Entgrenzung des Politischen beitragen kann. Will Verbraucherpolitik politischen Konsum als Steuerungsinstrument einsetzen, so ist es deswegen entscheidend, dass ein staatlicher Rahmen sichtbar wird, welcher die Gemeinwohlorientierung unterstreicht. Im Sinne eines kooperativen Instruments sollte darüber hinaus nicht nur die Eigenverantwortung der Konsumenten, sondern auch die Verantwortung des Staates und transstaatlicher Institutionen betont werden. Die Integration neuer marktund konsumentenorientierter Steuerungsinstrumente und klassischer Regulierungsbemühungen ist unabdingbar, da Konsumentenbewusstsein allein weder globale Umwelt-, noch Handels- oder Menschenrechtsprobleme lösen kann. Zentral für die Effektivität dieses neuen Steuerungsinstruments ist also die Verbindung der Marktmacht aufgeklärter Konsumenten mit der regulativen Macht staatlicher bzw. transstaatlicher Institutionen. ${ }^{24}$ Hierbei brauchen die Zivilgesellschaft und der einzelne politische Konsument die Macbtleibe der Politik, um in gleicher Augenhöhe mit der Angebotsseite verhandeln zu können. Ein Beispiel für eine solche Machtleihe bildet das in den Jahren 2006/7 in der Diskussion stehende Verbraucherinformationsgesetz, ${ }^{25}$ welches zu einer besseren Verbraucherinformation und einer höheren Markttransparenz beitragen soll. Entscheidend ist also, politischen Konsumenten nicht den schwarzen

23 Vgl. die Einführung von Baringhorst/Kneip/März/Niesyto in diesem Band.

24 Dabei ist es jedoch schwer abzuschätzen, wie bereits aktivierte politische Konsumenten den Einsatz von politischem Konsum als staatliches Steuerungsinstrument werten, da eine Studie über schwedische politische Konsumenten zeigt, dass diese nationalen Institutionen oft misstrauisch gegenüberstehen. Vgl. Stolle u.a.: „Zwischen Markt und Zivilgesellschaft", S. 165f.

25 Das deutsche Verbraucherinformationsgesetz, welches die Verbraucherrechte stärken und verbessern soll, wurde ursprünglich von Verbraucherministerin Künast vorgelegt. Der Koalitionsvertrag der neuen Bundesregierung enthält die Absicht, ein solches Gesetz zu verabschieden. Das Verfahren wurde inzwischen vom Bundesministerium für Ernährung, Landwirtschaft und Verbraucherschutz erneut angestoßen; ein Gesetzesentwurf wurde im Mai 2006 zur ersten Lesung in den Bundestag eingebracht. Im Juni 2006 wurde das Gesetz durch den Deutschen Bundestag beschlossen, im September 2006 stimmte der Bundesrat dem Gesetz zu. Nachdem Bundespräsident Horst Köhler im Dezember 2006 entschieden hatte, das Gesetz zur Neuregelung des Rechts der Verbraucherinformation nicht auszufertigen, wurde vom Bundeskabinett im April 2007 ein überarbeiteter Entwurf des Gesetzes beschlossen. Am 5. Juli 2007 wurde das Gesetz durch den Bundestag verabschiedet. 
Peter zuzuspielen, sondern für „Waffengleichheit“"26 zwischen Wirtschafts- und Verbraucherpolitik zu sorgen. Der gezielte Aufbau von Policy-Netzwerken und vor allem die Einbeziehung und Ansprache von Konsumenten als Bürgern sind dann nicht nur Ausdruck nationalstaatlicher Steuerungsverluste, sondern können ebenso als neue Steuerungsstrategien angesehen werden, um der „Nationalitätsfalle“ ${ }^{\text {27 }} \mathrm{zu}$ entgehen:

Vielmehr kann aus gutem Grund der Wandel vom korporativen zum kooperativen Staat gerade im Zuge der Globalisierung als eine Notwendigkeit gedeutet werden, um die bestehenden Herrschaftsverhältnisse im Inneren des Staates wie nach außen trotz sozialer und ökologischer Krisen zu sichern. ${ }^{28}$

Schließlich können Kampagnen als appellative und persuasive Antwort auf politische Steuerungsprobleme im Bereich der Regulierung von Unternehmensmacht betrachtet werden. Persuasion und Gefühle werden im Rahmen des von Beyerle entwickelten Konzepts der kulturellen Steuerung als zentrale Ressourcen zur Steuerung von Individuen dargestellt. ${ }^{29}$ Kernfrage der kulturellen Steuerung bildet die Frage nach der Herstellung einer gemeinsamen Wertorientierung der beteiligten Akteure, welche im Sinne eines reflexiven Kontexts für alle Systeme als Grundlage zur Lösung gesellschaftlicher Probleme fungieren kann. Kulturelle Steuerung unterstützt, so Beyerle, politische Steuerung und gesellschaftliche Selbststeuerung normativ und fördert deren Akzeptanz. Ziel staatlicher Steuerung durch Kampagnen ist es also, Überzeugung für solidarisches Handeln auf individueller Ebene hervorzurufen. Das individuelle Verhalten muss dabei nicht die einzige Stoßrichtung von Kampagnen sein. Vielmehr kann versucht werden, über die Einflussnahme auf individuelle Verhaltensweisen - wie beispielsweise den umweltbewussten Konsum - kollektive Verhaltensmuster zu entwickeln und damit strukturelle Veränderungen - wie beispielsweise ressourcenschonende Produktionsweisen - herbeizuführen. Beetz thematisiert diese Form der Steuerung für den Bereich politischen Konsums und bezeichnet die Bemühungen professioneller Politik, über die Etablierung politisch sensibilisierten Verbraucherbewusstseins indirekte Steuerungskompetenzen aufzubauen, als weiche Reformen. 30

26 Müller: „Vom Verbraucherschutz zur Verbraucherpolitik“, S. 11, 20.

27 Beck: Macht und Gegenmacht im globalen Zeitalter, S. 142.

28 Dienel u.a.: Politische Regulierungsformen, S. 44.

29 Vgl. Beyerle: Staatstheorie und Autopoiesis.

30 Vgl. Beetz: „Leben zwischen Politik und Wirtschaft“", S. 4; dazu auch ders. in diesem Band. 
Politische Kampagnen als Instrumente persuasiver Steuerung sind Teil politischer Öffentlichkeitsarbeit, welche in einem demokratischen System als interessengeleitete Kommunikation politischer Institutionen und Akteure verstanden werden kann. Dabei wollen politische Public Relations Öffentlichkeit herstellen, um Handlungen und/oder Anschlusskommunikation hervorzurufen. Politische Öffentlichkeitsarbeit zielt darüber hinaus auf Konsens oder Akzeptanz für politisches Agieren und politische Entscheidungen. Bentele schreibt den politischen PR die Basisfunktionen „Information über etwas anderes“ (Darstellungsfunktion), „Selbstdarstellung“ (Ausdrucksfunktion) und „Persuasion“ (Appellfunktion) zu. ${ }^{31}$ Kampagnen nehmen im Rahmen der Persuasionsfunktion eine zentrale Rolle ein, da sie eine ,geplante und vorbereitete Reihe von Kommunikationsaktivitäten“ zur „Erzielung oder Verhinderung eines Wandels von Einstellungen, Verhaltensweisen oder Entscheidungen “32 sind, welche sich an den einzelnen Bürger richten. Dadurch, dass Kampagnen ausschließlich mit dem Mittel der Kommunikation arbeiten, sind sie eine relativ schwache Form politischer Intervention. Sie zielen beispielsweise weder darauf, das individuelle Verhalten durch finanzielle Anreize zu steuern, noch strukturelle Veränderungen durch rechtliche Regulierungen herbeizuführen. Die Wirksamkeit dieses Steuerungsinstruments ist in besonderem Maße auf die freiwillige Mitwirkung des Bürgers angewiesen und entzieht sich so einer gezielten Steuerung. Darüber hinaus laufen solche kampagnenförmigen alternativen Steuerungsmaßnahmen Gefahr, durch fehlende Rückkoppelung an die politische Entscheidungsebene auf die symbolische Ebene beschränkt zu bleiben und Eigeninteressen verschiedener Akteure auszublenden. Der Erfolg staatlich initiierter Kampagnen wird zudem dadurch erschwert, dass sich die Kampagnen auf dem Aufmerksamkeitsmarkt gegen freie Informationsanbieter durchsetzen müssen. Hinzu kommt, dass sich diese Kampagnen gegenüber sämtlichen Werbeanstrengungen und Werbeversprechen verschiedener Industriezweige (wie z.B. der Textilindustrie) behaupten müssen. Auch können sie ihre Chance auf Aufmerksamkeitserreichung in der Regel nicht durch eine passgenaue Zielgruppenausrichtung erhöhen, da z.B. im Fall der Kampagne Echt gerecht. Clever kaufen die Gesamtheit der Bürger den Adressatenkreis bilden. Die Bewertung der Wirksamkeit staatlich initiierter Kampagnen und einer damit verbundenen gezielten Steuerung ist vor diesen Hintergründen und auch aufgrund der schlechten Einschätzbarkeit von Medienwirkungen nur schwer möglich. Deswegen sollten Kampagnen als persuasive Instrumente mit anderen Interventionsinstrumenten wie z.B. Kennzeichnungspflichten kombiniert

31 Vgl. Bentele: Politische Öffentlichkeitsarbeit.

32 Lahusen: „Transnationale Kampagnen sozialer Bewegungen“, S. 43, 49. 
werden, welche Verbraucher bei der gesellschaftlichen Selbststeuerung unterstützen können. Auf der anderen Seite bieten kampagnenförmige Maßnahmen - verglichen mit dem finanziellen und organisatorischen Aufwand institutioneller Anreiz- und Sanktionssysteme - ein relativ kostengünstiges und zudem flexibel einsetzbares Steuerungsinstrument, welches die Stabilität sozialer Systeme erhöhen kann. Im Falle erfolgreicher Kommunikation können sie ein wirksames Instrument darstellen, da Verhaltens- und Einstellungsänderungen aus dem freiwilligen Commitment der adressierten Akteure resultieren und als Unterstützung gesellschaftlicher Selbststeuerung legitimierend auf die institutionelle Politik zurückwirken können. ${ }^{33}$

Erfolgsmessungen von Kampagnen sind generell mit Vorsicht zu genießen, da Bewusstseins- und Verhaltensänderungen kaum ausschließlich und eindeutig auf die Kampagnenkommunikation zurückzuführen sind. Dennoch geben Erfolgsevaluierungen Hinweise darauf, dass Kampagnen Wirkungen entfalten können: So führte beispielsweise die Kampagne Fair Feels Good ${ }^{34}$ zweimalig (2004 und 2007) Erfolgsmessungen durch und kann auf der Grundlage von Marktforschungsdaten nach Abschluss der Kampagne belegen, dass während der Laufzeit der Kampagne ein Zuwachs um insgesamt 6,2 Millionen Käufern bei der Gruppe der regelmäßigen, gelegentlichen oder seltenen Käufer von Fair-Trade-Produkten verzeichnet werden kann. ${ }^{35}$ Trotz der Ambivalenz dieses Instruments schreiben Lange und Braun ihm eine wachsende Bedeutung zu: „Insgesamt wird das Instrument der Persuasion zunehmend wichtiger und tritt neben Geld und Recht. ${ }^{\text {‘36 }}$ Die Autoren sehen die wachsende Bedeutung insbesondere durch ein wandelndes Staatsverständnis bedingt: „, [A]us dem aktiven Wohlfahrtsstaat, der dem Bürger Last und Unsicherheit abnahm, entwickelt sich heute das Bild einer sich selbst bestimmenden Gesellschaft, in der der Staat zurücktritt [...].“37 Zudem versprechen sich die Autoren nachhaltigere Verhaltensänderungen als beim Einsatz harter Steuerungsinstrumente wie Geld und Recht, da über moralische und normative Ressourcen bei der individuellen Motivation und kulturell eingebetteten Lebenswelten angesetzt werde und nicht bei der Begrenzung vorhandener Verhaltensmuster. ${ }^{38}$

33 Vgl. Dahme/Grunow: „Implementation persuasiver Programme“.

34 Bezüglich der Kampagne Echt gerecht. Clever kaufen liegen keine zugänglichen Daten vor.

35 Vgl. Verbraucher Initiative e.V.: „Fairer Handel. Stetiges Wachstum“.

36 Lange/Braun: Politische Steuerung zwischen System und Akteur, S. 164.

37 Ebd., S. 171.

38 Vgl. ebd., S. 163. 
Die dargestellten Beispiele zeigen in der Zusammenschau, dass sich alternative Steuerungsinstrumente in der Regel durch geringere Verbindlichkeit auszeichnen und ihr Erfolg in weiten Teilen von der Kooperation bzw. Mitwirkung der beteiligten Akteure abhängt. Im Folgenden wird anhand der Kampagne Echt gerecht. Clever kaufen die Verknüpfung von politischem Konsum und Kampagnenpolitik im Sinne eines alternativen Steuerungsversuchs staatlicher Akteure exemplarisch analysiert.

\section{Echt gerecht. Clever kaufen 39}

Im Dezember 2004 wurde die Kampagne Echt gerecht. Clever kaufen unter der damaligen Verbraucherministerin Künast gestartet und bis Ende des Jahres 2006 unter Minister Seehofer fortgeführt. Die Kampagne wurde von einem externen Akteur, der Agentur neues handeln, im Auftrag des Bundesministeriums für Ernährung, Landwirtschaft und Verbraucherschutz durchgeführt. Konkret versuchte die Kampagne durch so genannte Einkaufshilfen Einfluss auf Konsum- und Einkaufentscheidungen zu nehmen. Dazu bot sie unterschiedliche Labe ${ }^{40}$ in den vier Bereichen Lebensmittel und Emäbrung, Textilien, Bekleidung und Spielzeng, Reisen, Mobilität und Geldanlagen und Bauen, Wobnen, Haushalt und Energie an. Ziel war es, Verbraucher so über nachhaltigen Konsum aufzuklären und zu informieren. Die Kampagne war eingebettet in die nationale Nachhaltigkeitsstrategie der Bundesregierung und in die Empfehlungen des Rates für nachhaltige Entwicklung. Damit war die Kampagne zwar auf Deutschland ausgerichtet, ordnete sich aber in ihrem humanitär-universalistischen, ökologischen Diskus der internationalen Forderung nach der Ausbildung nachhaltiger Konsum- und Produktionsmuster unter. Im Sinne eines kooperativen Staates wurde die Kampagne von verschiedenen zivilgesellschaftlichen und wirtschaftlichen Akteuren unterstützt. ${ }^{41}$ Die einzelnen Akteure führten eigene Projekte

39 Die Website der Kampagne dient bei der folgenden Darstellung als Informationsgrundlage.

40 In der Kampagne selbst wird in diesem Zusammenhang von Siegeln gesprochen. Im Folgenden werden die Begriffe Siegel und Label synonym verwendet.

41 Folgende nicht-staatliche Akteure sind unter anderem an der Kampagne beteiligt: Deutscher Verband der Spielwaren-Industrie e.V., Hauptverband des Deutschen Einzelhandels, International Council of Toy Industries Europe, Agentur für Nachhaltigkeit $\mathrm{GmbH}$, Bundesweite Servicestelle Lokale Agenda 21, Aktion fair spielt. Für faire Regeln in der Spielzengproduktion, Bundesverband für Umweltberatung (bfub) e.V., BUND Freunde der Erde, Forum Nachhaltige Geldanlagen e.V., Forum Waschen und Reinigen, Grüne Liga Thüringen, Kontaktstelle für Umwelt und Entwicklung e.V. Berlin, NaturFreunde Deutschlands, Ökumenische Initiative Eine Welt, TransFair, Transfer-21, Verkehrsclub Deutschland (VCD) e.V. - für 
im Rahmen der Kampagne durch; so setzte sich zum Beispiel der BUND Göttingen für die Aufklärung über die Folgen des Papierkonsums ein; das Projekt Papier - Global gesehen richtete sich mit der Zielsetzung, dass Schulmaterialien aus Recyclingpapier verstärkt genutzt werden, an Kinder und Jugendliche. Laut Auskunft des im Bundesministerium beauftragten Referats Koordination der Angelegenheiten der Abteilung $2^{42}$ verstand sich die Kampagne demnach als akteurszentrierte Kampagne, welche zu einer Vernetzung der Einzelaktivitäten der gesellschaftlichen Akteure beitragen sollte. ${ }^{43}$

Neben Verbrauchern wurden auch die produzierenden Unternehmen adressiert. Im Kontext des thematischen Bereichs Textilien, Bekleidung und Spielzeng wandte sich die damalige Verbraucherministerin Künast mit der Forderung nach einer klaren Kennzeichnung der Produkte auch an die Spielzeugindustrie im Besonderen und an die gesamte Industrie im Allgemeinen:

Ich fordere deshalb die Wirtschaft auf, mit einer klaren Kennzeichnung uns Verbraucherinnen und Verbrauchern den Weg durch die Regale zu erleichtern. Wir wollen Gerechtigkeit auch kaufen können! ${ }^{44}$

Diese Aussage verdeutlicht beispielhaft den Anspruch der Kampagne, indirekt über die Verbrauchermacht politischer Konsumenten neben der Produktqualität auch die Nachhaltigkeit des (transnationalen) Produktionsprozesses zu beeinflussen.

\subsection{Warum Echt gerecht. Clever kaufen?}

Im Rahmen der Kampagne nahm die Ebene des Diagnostic Framing - also der Problemselektion, -identifikation sowie der Benennung der Problemursachen einen relativ geringen Stellenwert ein. So wurde zwar das Ziel der Nachhaltigkeit eingeführt, die diesem Ziel zu Grunde liegenden Probleme bzw. Missstände wurden jedoch nur implizit bzw. punktuell thematisiert. Dr. Klaus Piepel, Experte des kirchlichen Hilfswerks Misereor, sprach beispielsweise das Problem fragwürdiger Arbeitsbedingungen in der Spielzeugindustrie an und

eine zukunftsfähige Verkehrspolitik, Verbraucherzentrale Bundesverband, Viabono.

42 Die Abteilung 2 nennt sich auch Abteilung Verbraucherschutz, Ernäbrung, Bio- und Gentechnik.

43 Vgl. Bundesministerium für Verbraucherschutz, Ernährung und Landwirtschaft: Verbraucherpolitischer Bericht der Bundesregierung 2004.

44 Künast in Echt Gerecht. Clever kaufen: „Presse“. 
nannte in diesem Zusammenhang das Beispiel China. ${ }^{45} \mathrm{Im}$ Bereich Reisen, Mobilität und Geldanlagen wurde die Schadstoffbelastung von Luft, Wasser und Böden thematisiert. ${ }^{46}$ Vielfach konnte allerdings nur aufgrund des genannten Lösungsansatzes - z.B. Umweltschutz oder faire Löhne - auf das dahinter liegende Problem geschlossen werden. Darüber hinaus wurde den angesprochenen Bürgern nur wenig Kontextwissen vermittelt. Lediglich kurze Anmerkungen wie: „Auch in der Textil- und Spielzeugproduktion kommt es auch auf die Bedingungen der Herstellung an: Faire Löhne, menschenwürdige Arbeitsbedingungen und soziale Standards sollten überall eingehalten werden “47 verwiesen auf den breiteren Kontext der Nachhaltigkeitsdebatte. Hintergründe des fehlenden Arbeitsschutzes in Produktionsländern oder globaler Umweltbelastung wurden dabei allerdings nicht diskutiert.

Ebenso wenig wurde im Zusammenhang der Problemidentifikation auf nationale und internationale institutionelle politische Reformbemühungen verwiesen, in die die Kampagne eingebettet war. So hätte beispielsweise die Konferenz der Vereinten Nationen für Umwelt und Entwicklung von 1992 erwähnt werden können, deren Agenda 21 den Grundstein für nationale Bemühungen um Nachhaltigkeit gelegt hat. Das Kapitel 4 der Agenda 21 beschäftigt sich explizit mit der Veränderung von Konsumgewohnheiten und umfasst folgende zwei Programmbereiche: (a) die gezielte Auseinandersetzung mit nicht nachhaltigen Produktionsweisen und Konsumgewohnheiten sowie (b) die Entwicklung von einzelstaatlichen Politiken und Strategien zur Förderung von Veränderungen bei nicht nachhaltigen Konsumgewohnheiten. ${ }^{48}$ Auch wurde die Kampagne Echt gerecht. Clever kaufen nicht mit der nationalen Nachhaltigkeitsstrategie im Rahmen der Folgekonferenz von Rio de Janeiro aus dem Jahr 2002 verknüpft, um den breiteren Problemkontext der Kampagne zu thematisieren. In diesem Sinne wäre auch die Vernetzung der Kampagne mit weiteren Bemühungen der Bundesregierung im Bereich der Nachhaltigkeitsförderung, wie der Durchsetzung von Umwelt- und Sozialstandards auf internationaler institutioneller Ebene, ${ }^{49}$ sowie mit Bemühungen im Bereich der Verbraucherpolitik, z.B. der Planung des Verbraucherinformationsgesetzes, möglich gewesen.

45 Vgl. Echt Gerecht. Clever kaufen: „Mitmachen“.

46 Vgl. dies.: „Reisen, Mobilität und Geldanlagen“.

47 Dies.: „Textilien, Bekleidung und Spielzeug“.

48 Vgl. Konferenz der Vereinten Nationen für Umwelt und Entwicklung: „Agenda 21 “.

49 Auf EU-Ebene sind hier beispielhaft Bemühungen um die Durchsetzung erneuerbarer Energien zu nennen, bei denen das deutsche Erneuerbare-Energien-Gesetz eine Vorreiterrolle einnimmt. 
Des Weiteren wurde nicht auf die direkte Anknüpfung an die übergeordnete Informationskampagne zur Förderung nachhaltiger Konsummuster hingewiesen. Mit dieser sollen Verbrauchern Handlungsmöglichkeiten aufgezeigt werden, wie sie ihre täglichen Kaufentscheidungen nach Kriterien der Nachhaltigkeit ausrichten können. Hierfür hat der Rat für nachhaltige Entwicklung einen Nachbaltigen Warenkorb entwickelt, welcher sich als Wegweiser und Einkaufsführer zum zukunftsfähigen Konsum versteht. ${ }^{50}$ Wie die Kampagne Echt gerecht. Clever kaufen ruft der Nachbaltige Warenkorb zum nachhaltigen Einkauf und Konsum auf und bietet Einkaufs- und Konsumhilfen - in der Regel in Form von Labels - an, welche sich an den individuellen Verbraucher richten. Insgesamt zeigen die aufgeführten Beispiele, dass es die Kampagne verpasst, Rückkopplungen zur Verbraucherpolitik und zu übergreifenden Politikprogrammen wie der Nachhaltigkeitsstrategie herzustellen.

\subsection{Lösungsansatz: Clever kaufen}

Im Gegensatz zum Diagnostic Framing wurde dem Prognostic Framing im Rahmen der Kampagne ein zentraler Stellenwert eingeräumt. Neben kurzen Hinweisen auf mögliche Verhaltensänderungen im Alltag wie der Nutzung öffentlicher Verkehrsmittel oder Energiesparmaßnahmen im Haushalt bezogen sich Lösungsstrategien und Handlungsvorschläge dabei vorwiegend auf das individuelle Konsumverhalten. Angesprochen wurde der Bürger als Konsument, der über die Nachhaltigkeit seiner individuellen Kaufentscheidungen Einfluss auf Markt- und Produktionsmechanismen nehmen soll:

Ihre Kaufentscheidungen haben Auswirkungen auf Umwelt und Ge-
sellschaft und auf die Lebensqualität der nachfolgenden Generatio-
nen. Sie entscheiden also mit, ob Waren und Dienstleistungen, die
nachhaltig produziert oder erbracht wurden, auf dem Markt eine
Chance haben. Nachhaltigkeit wird damit auch zum Motor erfolg-
reicher Unternehmen und Volkswirtschaften.

Auf der Handlungsebene sollte die Nachhaltigkeit des Konsums vor allem mit dem bereits als Steuerungsinstrument beschriebenen Labeling gefördert werden. Dazu wurden Einkaufshilfen in Form von insgesamt 33 Produkt- und Organisationssiegeln vorgestellt. Jedes Siegel war mit einer knappen Beschreibung versehen und wurde zum jeweiligen Anbieter bzw. Träger verlinkt. Die Label

50 Vgl. Bundesministerium für Verbraucherschutz, Ernährung und Landwirtschaft : Aktionsplan Verbraucherschutz der Bundesregierung, S. $35 \mathrm{f}$.

51 Echt Gerecht. Clever kaufen: „Die Einladung“. 
sollten als Orientierungshilfe dienen und Aufschluss über den Herstellungsprozess des jeweiligen Produkts geben. Generell können Label aufgrund ihrer Vielfalt ${ }^{52}$ und der häufig unklaren Trägerstrukturen und Vergaberichtlinien allerdings teilweise sogar für Unsicherheit statt für Orientierung sorgen:

The recognition of a label is, however, not the same as understanding even the approximate meaning of it. Several studies have found that consumers often have a hard time in understanding what labels are intended to communicate, and uncertainty about what a label means could be associated with mistrust. ${ }^{53}$

Das Bundesministerium wies zwar selbst darauf hin, dass es bisher noch kein Nachhaltigkeits-Siegel gebe, welches ökologische, soziale und ökonomische Aspekte gleichermaßen berücksichtige und die empfohlenen Siegel jeweils nur Einzelaspekte der Nachhaltigkeit kennzeichneten. Unverständlich ist vor diesem Hintergrund jedoch, warum die ausgewählten Siegel nahezu kommentarlos nebeneinander gestellt wurden und weder eine Differenzierung hinsichtlich der Art und Reichweite noch eine tiefergehende Bewertung erfolgte. Die Kampagneninformationen vermittelten nicht, warum gerade die ausgewählten 33 Siegel in besonderem Maße als Einkaufshilfen dienen sollen. So wurde beispielsweise nicht zwischen regional begrenzten Labeln wie dem Siegel des ökologischen Landbauverbands in Mecklenburg-Vorpommern Biopark und Siegeln wie Bioland oder Naturland, die über eine deutschlandweite Struktur aus Landes- und Regionalverbänden verfügen, differenziert. Auch wurden international tätige Zertifizierungsorganisationen wie der Marine Stewardship Council oder der Forest Stewardship Council nicht gesondert aufgeführt. Darüber hinaus wurden kaum Angaben zu den Initiatoren der Zertifizierungsschemata und Label gemacht, obwohl diese vielfach Aufschluss über den Hintergrund der Zertifizierung geben können. Einige Siegel wie Der Blaue Engel oder das Bio Siegel sind etwa von Bundesministerien selbst ins Leben gerufen worden; die Blume - das europäische Umweltzeichen - und das europäische Energielabel gehen auf Initiativen bzw. Richtlinien der Europäischen Union zurück. Andere Zertifizierungen wie das Flower Label Programm oder das Grüner Strom Label

52 So zählt beispielsweise das Bundesministerium für Verbraucherschutz, Ernährung und Landwirtschaft 2001 über 100 Siegel und Gütezeichen für Lebensmittel aus kontrolliert biologischem Anbau. Vgl. Schrader: „Überwindung von Marktversagen durch Öko-Label“, S. 198. Der Arbeitskreis Naturtextil beziffert die Zahl der Umweltsiegel auf dem deutschen Textilmarkt auf rund 70. Vgl. Balzer: Gerechte Kleidung, S. 369.

53 Grankvist u.a.: „The Impact of Environmental Labelling on Consumer Preference", S. 215. 
werden dagegen von Nichtregierungsorganisationen getragen. Zahlreiche weitere Zertifizierungsinitiativen gehen direkt von Herstellern bzw. Herstellerverbänden aus, so beispielsweise Naturtextil oder das Goldene $M-$ das Label der Deutschen Gütegemeinschaft Möbel e.V. Schließlich sind bestimmte Label wie Neuland, VLABONO oder ok Power in Kooperation zwischen staatlichen, wirtschaftlichen bzw. zivilgesellschaftlichen Organisationen entwickelt worden. Gravierend ist jedoch vor allem, dass im Rahmen der Kampagne Echt gerecht. Clever kaufen keine Bewertung hinsichtlich der Zertifizierungsrichtlinien und der Überprüfung der Einhaltung aufgestellter Richtlinien erfolgte. Ein Vergleich von Richtlinien der genannten Label in den Bereichen Lebensmittel/Ernährung bzw. Bauen/Wohnen könnte beispielsweise Aufschluss über unterschiedliche Grenzwerte und Standards bei Landbau und Tierhaltung bzw. Forstwirtschaft geben. Generell hätte die Überprüfung der Transparenz von Vergabegrundlagen der einzelnen Siegel den angesprochenen Konsumenten eine deutlich bessere Informationsbasis geboten als die äußerst knapp gehaltenen Tabellen. Vor allem die Art des Monitoring, also die Überprüfung der Einhaltung aufgestellter Richtlinien, kann dabei als Indikator für die Glaubwürdigkeit von Zertifizierungssystemen dienen. Entscheidend für die Differenzierung von Labeling-Schemata ist dabei die Art und Weise, wie Zertifizierungen vergeben und überwacht werden. ${ }^{54}$ Echt gerecht. Clever kaufen unterschied allerdings nicht danach, ob es sich bei den Zertifizierungen und den damit verbundenen Richtlinien um reine Selbstverpflichtungen handelt oder ob die Vergabe und die Überprüfung der Einhaltung von Richtlinien durch unabhängige Einrichtungen erfolgen.

Die im Rahmen der Kampagne genannten Empfehlungen boten aus den dargestellten Gründen insgesamt keine ausreichende Grundlage, den Konsumenten mit zusätzlichen Kompetenzen auszustatten, um im Konsum nachbaltig zu handeln. ${ }^{55}$ Im Mittelpunkt stand weniger die tatsächliche Informationsfunktion der Label als vielmehr ihre Funktion als „,moralische Gütesiegel“56 und als Orientierungspfeiler in einer pluralisierten, unsicheren Welt. Diese Kritik

54 Vgl. Micheletti: Political virtue and shopping; Musiolek: „Die Debatte um Verhaltenskodex und unabhängiges Monitoring".

55 Eine breitere Informationsgrundlage bietet beispielsweise die Label-Datenbank der Verbraucher Initiative e.V. (www.label-online.de), die von der Bundesregierung finanziell unterstützt wird. Die Label-Datenbank enthält Informationen zu mehr als 300 Labeln, die unter anderem hinsichtlich ihrer Vergabekriterien und -verfahren bewertet werden. Auf den Seiten der Label-Datenbank fand man an zentraler Stelle einen Link zur Kampagne Echt gerecht. Clever kaufen. Die Kampagne verlinkte jedoch nur auf der Unterseite des Kooperationspartners Verbraucher Initiative e.V. zur Datenbank und nicht im Kontext der eigenen Label-Vorschläge.

56 Baringhorst: „Öffentlichkeit als Marktplatz“, S. 55. 
zeichnete sich in ähnlicher Form im Rahmen einer Studie zum Projekt Nachhaltiger Warenkorb ab. Die befragten Testhaushalte, welche nach den Empfehlungen des Nachbaltigen Warenkorbs eingekauft und gelebt hatten, kritisierten vor allem das unzureichende Angebot an Hintergrundinformationen. ${ }^{57}$

\subsection{Echt gerecht mobilisiert}

Echt gerecht. Clever kaufen definierte unter der Überschrift „Was heißt hier nachhaltig?" für die vier Themenbereiche jeweils Grundlagen nachhaltiger Ernährung und Kleidungswahl bzw. nachhaltigen Reisens und Wohnens, wobei Nachhaltigkeit fast ausschließlich im Zusammenhang mit dem individuellen Kaufverhalten verstanden wurde. Nachhaltiger Konsum wurde dabei als ein besonderer Typus von Konsum vermittelt und unmittelbar mit dem Gerechtigkeitsbegriff verbunden. So sollten beispielsweise nachhaltige Geldanlagen „insbesondere ethische, soziale und ökologische Kriterien“"58 berücksichtigen und mit dem Kauf fair gehandelter Produkte „gerechte Arbeits-, Handels- und Lebensbedingungen“"59 unterstützt werden. Damit wurde implizit der Gerechtigkeitsbegriff in Verbindung mit einem besseren Lebensstil als Motivation präsentiert, um die individuelle Handlungsbereitschaft zu wecken bzw. individuellen nachhaltigen Konsum zu fördern.

Generell wurde unter dem Leitbild der Nachhaltigkeit die Befriedigung menschlicher Bedürfnisse unter der Berücksichtigung intra- und intergenerationaler Gerechtigkeit verstanden. Dabei bedeutet intragenerationale Gerechtigkeit, dass die Erfüllung gegenwärtiger Bedürfnisse unter dem Gesichtspunkt der Verteilungsgerechtigkeit erfolgt. Hiermit sind Fragen verbunden, wie z.B. Wer darf wann und wo wie viel konsumieren? Intergenerationale Gerechtigkeit bezieht sich dagegen auf Konflikte zwischen verschiedenen Generationen und beinhaltet Fragen wie Für wie viele Generationen sollen die Rohstoffvorräte ausreichen? Echt gerecht. Clever kaufen betonte den Aspekt intergenerationaler Gerechtigkeit, indem zum Beispiel auf ressourcenschonenden Lebensmittel- und Energiekonsum hingewiesen wurde. Aspekte intragenerationaler Gerechtigkeit unterstrichen insbesondere Hinweise auf soziale Gerechtigkeit: „Wer selbst etwas tun will, für den gibt es viele Wege auch im globalen Maßstab aktiv den Schutz

57 Vgl. Rat für nachhaltige Entwicklung: Der nachhaltige Warenkorb, S. 7.

58 Echt Gerecht. Clever kaufen: „Reisen, Mobilität und Geldanlagen“.

59 Dies.: „Lebensmittel und Ernährung“.

60 Vgl. Belz/Bilharz: Nachhaltiger Konsum, S. 2-7. 
der Umwelt zu unterstützen und zu mehr sozialer Gerechtigkeit beizutragen." "61

Verweise der Kampagne auf die gerechte oder faire Entlohnung, beispielsweise in der Textil- und Spielzeugindustrie oder in bäuerlichen Herstellergemeinschaften, sind ebenfalls dem Bereich intragenerationaler Gerechtigkeit zuzuordnen. ${ }^{62}$ Dabei wurde jedoch nicht definiert, was unter gerechten Löhnen oder gerechtfertigtem Energieverbrauch zu verstehen ist, vielmehr diente die normative Aufladung des Konsums durch den Gerechtigkeitsbegriff als Handlungsanreiz im Sinne des Motivational Framing.

\section{Politischer Konsum und Kampagnenpolitik als nationalstaatliche Steuerungsinstrumente?}

Verhaltenskodizes, Kampagnenpolitik und politischer Konsum als alternative kooperative Steuerungsmaßnahmen von Nationalstaaten im Bereich der Regulierung von Unternehmensmacht orientieren sich eher am Verständigungsmodus des Arguing als an dem des Bargaining. Alle drei Steuerungsinstrumente können zudem als weiche Steuerungsinstrumente bezeichnet werden. Der Staat besitzt hier vor allem die Aufgabe, den Informationsfluss zwischen den relevanten am Steuerungsprozess beteiligten Akteuren zu verbessern. ${ }^{63} \mathrm{Im}$ Rahmen von Verhaltenkodizes kann er dies realisieren, indem er die verschiedenen Akteure zusammenführt und als Moderator fungiert. Führt der Staat Kampagnen durch, so optimiert er wie im Falle der analysierten Kampagne den Informationsfluss zwischen zivilgesellschaftlichen Initiativen und dem einzelnen Bürger und bündelt zugleich die zivilgesellschaftlichen Bemühungen in diesem Bereich, sodass er auch dort zu einer Vernetzung beitragen kann. Im Falle des politischen Konsums werden Labeling-Initiativen vom Staat empfohlen, unterstützt und/oder ins Leben gerufen, um zu einer Erhöhung von Transparenz in der Marktarena beizutragen.

Weiter ist allen drei Instrumenten gemeinsam, dass sie auf eine Ermöglichung gesellschaftlicher Selbststeuerung abzielen. Die steuerungstheoretische Diskussion reflektiert durch die Einbeziehung von Aspekten gesellschaftlicher Selbststeuerung soziale und politische Wandlungsprozesse, die auf eine Entwicklung weg vom aktiven Wohlfahrtsstaat hin zu einer stärker selbst organisierten und sich selbst regelnden Gesellschaft verweisen. Sich an der System-

61 Echt Gerecht. Clever kaufen: „Die Einladung“.

62 Vgl. dies.: „Reisen, Mobilität und Geldanlagen“; dies.: „Lebensmittel und Ernährung".

63 Vgl. Messner: Die Netzwerk-Gesellschaft, S. 161. 
theorie orientierende Konzepte der „Kontextsteuerung ${ }^{\text {“64 }}$ und der „medialen Steuerung ${ }^{\text {“65 }}$ gehen vom Gedanken der Autopoiesis aus und stellen dementsprechend den Gedanken der Selbststeuerung in den Mittelpunkt ihrer Überlegungen. Politische Steuerung ist hier nur durch die Beeinflussung der Kontexte und Umwelten der jeweiligen Teilsysteme in Interaktionsprozessen möglich. Voraussetzung hierfür ist die strukturelle Koppelung der Systeme, welchen die Fähigkeit zur Reflexion unterstellt wird. ${ }^{66}$ Im Rahmen der Interaktionsprozesse stellen Information und Persuasion Instrumente dieser indirekten Steuerung dar. ${ }^{67}$ Auch akteurstheoretische Positionen diskutieren Interaktionsformen von (kollektiven) Akteuren im Rahmen der Frage nach politischer Steuerung und identifizieren Selbstorganisation als eine mögliche Ausprägung. ${ }^{68}$ Allerdings wird betont, dass dabei die staatliche Regulierungsfähigkeit beibehalten werden kann und insbesondere zur Balance der Verhandlungsmacht in den gesellschaftlichen Verhandlungssystemen eingesetzt werden sollte. ${ }^{69}$ Dass auch die deutsche Bundesregierungen Formen der gesellschaftlichen Selbstorganisation eine zunehmende Bedeutung bemisst und sich in der Rolle des Ausgleichers der Balance sieht, zeigt sich in der neuen, aktivierenden Verbraucherpolitik, welche auf die Ermächtigung der Verbraucher setzt. So nehmen die Förderung von Verbraucherorganisationen und Verbraucheraufklärung in der modernen Verbraucherpolitik eine zentrale Rolle ein. Ziel ist es, den Verbraucher zu ermächtigen, sein Konsumverhalten an Kriterien der Nachhaltigkeit auszurichten. Echt gerecht. Clever kaufen und Fair Feels Good bilden hierbei zwei Beispiele für aktuelle Informations- und Aufklärungskampagnen, die von Bundesministerien durchgeführt bzw. unterstützt werden. Die Bedeutung, die die Bundesregierung Instrumenten indirekter staatlicher Steuerung wie politischem Konsum und Kampagnenpolitik zumisst, lässt sich an der Förderhöhe für die Informationskampagne Fair Feels Food erkennen: Aus den Mitteln des Aktionsprogramms 2015 der Bundesregierung werden aus dem Haushalt des Bundesministeriums für wirtschaftliche Zusammenarbeit und Entwicklung 6,5 Millionen Euro zusätzlich zur Förderung des Fairen Handels

64 Teubner/Willke: „Kontext und Autonomie“.

65 Druwe: „Rekonstruktion der ,Theorie der Autopoiese als Gesellschafts- und Steuerungsmodell“".

66 Teubner und Willke bezeichnen dies als erste Stufe von Kontextsteuerung und nennen dies „residuale Kontextsteuerung“. Teubner/Wilke: „Kontext und Autonomie“, S. 14.

67 Vgl. z.B. Görlitz/Burth: Politische Steuerung, S. 266.

68 Vgl. z.B. Scharpf: Interaktionsformen.

69 Vgl. ebd., S. 335. 
eingesetzt. Davon floss ungefähr die Hälfte - 3,3 Millionen Euro - in die Förderung der Kampagne. ${ }^{70}$

Wie ist nun die hier näher untersuchte Kampagne Echt gerecht. Clever kanfen unter dem Aspekt der Ermöglichung gesellschaftlicher Selbststeuerung zu bewerten? Mit der kampagnenförmigen Vermittlung von Normen eines politisch motivierten Konsumverhaltens versuchte das Verbraucherministerium, Selbstorganisation durch politischen Konsum anzuregen und zu fördern. Nachhaltig zu konsumieren - so die Botschaft der Kampagne - erfordert nicht viel, schließlich sind Produkte mit den empfohlenen Logos in nahezu jedem Supermarkt oder Kaufhaus, zumindest aber im Internet erhältlich. Aussagen wie „Die verschiedenen Siegel und Warenzeichen von Verbänden und Handelsketten oder zum Beispiel auch das Biosiegel bieten schnelle und sichere Orientierung ${ }^{671}$ oder „Siegel für Holz aus nachhaltiger Waldbewirtschaftung stehen dafür, dass Umwelt- wie Sozialstandards berücksichtigt werden “72 vermitteln ein beruhigendes Gefühl von Jeder kann etwas tun. Im Sinne der von Meyer formulierten „symbolischen Teilhabe“ bzw. „Partizipationsillusion“73 wurde dem Bürger ein Angebot gemacht. Tatsächliche politische Partizipation - beispielsweise in Form von Bürgerwerkstätten oder Konsumentenforen ${ }^{74}$ wurde jedoch weder gefordert noch angeboten. Aktionen wie der Infobus, welcher Verbraucher mit einer Ausstellung an das Thema des nachhaltigen Konsums heranführen sollte, beinhalteten zwar weiterreichende Informationen als die Kampagnenwebsite, jedoch keine Input-Optionen für den Verbraucher. Die Kampagne Echt gerecbt. Clever kaufen stellte also nicht den politischen Konsumenten in den Mittelpunkt ihrer Ansprache, sondern beschäftigte sich in weiten Teilen mit einem Lifestyle Konsumenten.

Im Rahmen der Kampagne vernetzte das Ministerium verschiedene zivilgesellschaftliche Aktivitäten und förderte im Sinne der kulturellen Steuerung (Beyerle) eine gemeinsame Wertorientierung, denn die Kampagne baute auf einer gemeinsamen Moral der deutschen Staatsbürger auf: Kein bewusster Verbraucher und kein verantwortungsvoller Bürger würde öffentlich gegen die hier vermittelte Botschaft der intra- und intergenerationalen Gerechtigkeit Po-

70 Vgl. Fair Feels Good: „Marktforschung“.

71 Echt Gerecht. Clever kaufen: „Lebensmittel und Ernährung“.

72 Vgl. dies.: „Bauen, Wohnen, Haushalt und Energie“.

73 Meyer: Die Inszenierung des Scheins, S. 187.

74 Unter dem Menüpunkt Mitmachen konnten sich Besucher der Website zwar dazu äußern, was für sie Nachbaltiges Konsumieren bedeutet, es bestand jedoch keine Möglichkeit zum persönlichen Erfahrungsaustausch bzw. zur Diskussion. Bieber/ Lamla sprechen in diesem Zusammenhang von „Pseudo-Aktionsmöglichkeiten“ der Kampagne. Vgl. Bieber/Lamla: Das Netz der Konsumenten, S. 68. 
sition beziehen. Problematisch im Sinne der Transparenz und der Ermächtigung des Verbrauchers ist allerdings, dass kaum Hintergrundinformationen $\mathrm{zu}$ den vorgestellten Labeln gegeben wurden und Hinweise zu relevanten staatlichen verbraucherpolitischen Maßnahmen fehlten. Auch hatte der Consumer Citizen im Rahmen der Kampagne weitgehend nur die Rolle des Informationsadressaten, nicht aber die des Dialogpartners inne. Die Kampagnenanalyse verdeutlicht, dass die zivilgesellschaftlichen Kooperationspartner sowohl im Bereich der Detailinformationen (z.B. Projekt Unfairblümt der Grünen Liga Thüringen zur Aufklärung über das Flower Label Programm) als auch im Bereich der Partizipationsmöglichkeiten (z.B. Energiesalons des Bundesverbandes für Umweltberatung zur Umsetzung umweltverträglichen Lebens) den Konsumenten stärker als politischen Bürger einbezogen als die übergeordnete Kampagnenplattform von Echt gerecht. Clever kaufen.

Kampagnenpolitik und politischer Konsum können für den Staat eine Möglichkeit sein, an den Konsumenten als Bürger heranzutreten, um dessen gesellschaftliche Selbststeuerungskräfte zu aktivieren bzw. zu stützen. Dies kann jedoch nur gelingen, wenn Konsumenten durch eine ausreichende Informationsbasis und tatsächliche Gestaltungs- und Partizipationsmöglichkeiten ermächtigt werden als politische Bürger zu handeln. Weiche Formen der Steuerung sollte der Staat darüber hinaus transparenter mit seinen - wenn auch beschränkten - regulativen Handlungsmöglichkeiten verbinden.

\section{Literaturverzeichnis}

Adloff, Frank u.a. (Hrsg.): Wirtschaft und Zivilgesellschaft, Wiesbaden 2005.

Balzer, Monika: Gerechte Kleidung: Fashion Öko Fair. Ein Handbuch für Verbraucher, Leipzig 2000.

Baringhorst, Sigrid: „Öffentlichkeit als Marktplatz. Solidarität durch Marketing?“", in: vorgänge 132, Nr. 4, 1995, S. 55-67.

Beck, Ulrich: Was ist Globalisierung? Irrtümer des Globalismus - Antworten auf Globalisierung, Frankfurt a.M. 1997.

Beck, Ulrich: Macht und Gegenmacht im globalen Zeitalter. Neue weltpolitische Ökonomie. Frankfurt a.M. 2002.

Beetz, Michael: „Leben zwischen Politik und Wirtschaft. Von der sanften Macht der Verbraucheröffentlichkeit“, Online-Paper zur Tagung „Politisierter Konsum - konsumierte Politik“, 03.-04.06.05 in Gießen, www.politik-konsum.de/pdf/verbraucheroeffentlichkeit.pdf, 21.06.2006. 
Belz, Frank-Martin/Bilharz, Michael: Nachhaltiger Konsum. Zentrale Herausforderung für moderne Verbraucherpolitik (Reihe Consumer Science, Diskussionsbeitrag Nr.1), Freising Oktober 2005.

Bentele, Günter: Politische Öffentlichkeitsarbeit, in: Sarcinelli, Ulrich (Hrsg.): Politikvermittlung und Demokratie in der Mediengesellschaft, Wiesbaden 1998, S. 124-145.

Beyerle, Matthias: Staatstheorie und Autopoiesis. Über die Auflösung der modernen Staatsidee im nachmodernen Denken durch die Theorie autopoietischer Systeme und der Entwurf eines nachmodernen Staatskonzeptes, Frankfurt a.M 1994.

Bieber, Christoph/Lamla, Jörn: „Das Netz der Konsumenten. Innovationschancen der Verbraucherbewegung im Internet", in: Forschungsjournal Neue Soziale Bewegungen, Jg. 18, Nr. 4, 2005, S. 65-77.

Blumenthal, Julia von: „Governance - eine kritische Zwischenbilanz“, in: ZPol, Jg. 15, Nr. 4, 2005, S. 1149-1180.

Bundesministerium für Verbraucherschutz, Ernährung und Landwirtschaft: Aktionsplan Verbraucherschutz der Bundesregierung, Berlin 2003.

Bundesministerium für Verbraucherschutz, Ernährung und Landwirtschaft: Verbraucherpolitischer Bericht der Bundesregierung 2004, Berlin 2004.

Dahme, Heinz-Jürgen/Grunow, Dieter: „Implementation persuasiver Programme“, in: Mayntz, Renate (Hrsg.): Implementation politischer Programme II, Opladen 1983, S. 117-141.

Dienel, Hans-Liudger u.a.: Politische Regulierungsformen. Government, Governance und Netzwerkstrukturen auf der globalen, europäischen und nationalen Ebene, Düsseldorf 2001.

Druwe, Ulrich: „Rekonstruktion der ,Theorie der Autopoiese“ als Gesellschafts- und Steuerungsmodell“", in: Görlitz, Axel (Hrsg.): Politische Steuerung sozialer Systeme, Pfaffenweiler 1989, S. 35-58.

Echt gerecht. Clever kaufen (Hrsg.): „Bauen, Wohnen, Haushalt und Energie“. www.echtgerecht.de/bauen.html, 22.02.2006.

Echt gerecht. Clever kaufen (Hrsg.): „Die Einladung“, www.echtgerecht.de/ einladung.html, 22.02.2006.

Echt gerecht. Clever kaufen (Hrsg.): „Lebensmittel und Ernährung“, www.echtgerecht.de/lebensmittel.html, 22.02.2006.

Echt gerecht. Clever kaufen (Hrsg.): „Mitmachen“, www.echtgerecht.de/ expertenrat.html, 22.02.2006. 
Echt gerecht. Clever kaufen (Hrsg.): „Presse“, www.echtgerecht.de/789.html? $\&$ tx_ttnews[tt_news] $=6 \&$ tx_ttnews[backPid] $=791 \& \mathrm{cHash}=89 \mathrm{ebcf4249}$, 22.02.2006.

Echt gerecht. Clever kaufen (Hrsg.): „Reisen, Mobilität und Geldanlagen“, www.echtgerecht.de/reisen.html, 22.02.2006.

Echt gerecht. Clever kaufen (Hrsg.): „Textilien, Bekleidung und Spielzeug“, www.echtgerecht.de/textilien.html, 22.02.2006.

Fair Feels Good (Hrsg.): „Marktforschung“, www.fair-feels-good.de/ fairfeelsgood.php/cat/49/title/Marktforschung, 02.03.2007.

Gabriel, Yiannis/Lang, Tim: The unmanageable consumer, London 2006.

Görlitz, Axel/Burth, Hans-Peter: Politische Steuerung, Opladen 1998.

Grankvist, Gunne u.a.: „The Impact of Environmental Labelling on Consumer Preference. Negative vs. Positive Labels“, in: Journal of Consumer Policy, Jg. 27, Nr. 2, 2004, S. 213-230.

Jenkins, Rhys u.a. (Hrsg.): Corporate Responsibility and Ethical Trade. Codes of Conduct in the Global Economy, London 2002.

Jordan, Andrew u.a.: „Consumer Responsibility-Taking and Eco-Labeling Schemes in Europe", in: Micheletti, Michele u.a. (Hrsg.): Politics, Products and Markets, New Brunswick/London 2004, S. 161-180.

Konferenz der Vereinten Nationen für Umwelt und Entwicklung: „Agenda 21“, Rio de Janeiro Juni 1992, www.un.org/Depts/german/conf/ agenda21/agenda_21.pdf, 21.06.06.

Lahusen, Christian: „Transnationale Kampagnen sozialer Bewegungen. Grundzüge eine Typologie“, in: Forschungsjournal Neue Soziale Bewegungen, Jg. 15, Nr. 1, 2002, S. 40-46.

Lange, Stefan/Braun, Dietmar: Politische Steuerung zwischen System und Akteur, Opladen 2000.

Messner, Dirk: Die Netzwerkgesellschaft. Wirtschaftliche Entwicklung und internationale Wettbewerbsfähigkeit als Probleme gesellschaftlicher Steuerung, Köln 1998.

Meyer, Thomas: Die Inszenierung des Scheins. Voraussetzungen und Folgen symbolischer Politik, Frankfurt a.M. 1992.

Micheletti, Michele: Political virtue and shopping. Individuals, consumerism, and collective action, New York 2003.

Micheletti, Michele u.a. (Hrsg.): Politics, Products and Markets. Exploring Political Consumerism Past and Present, New Brunswick/London 2004. 
Müller, Edda: „Grundlinien einer modernen Verbraucherpolitik“, in: APuZ, B 24, 2001, S. 6-15.

Müller, Edda: „Vom Verbraucherschutz zur Verbraucherpolitik“, März 2004, library.fes.de/pdf-files/stabsabteilung/01944.pdf, 21.06.06.

Musiolek, Bettina: „Die Debatte um Verhaltenskodex und unabhängiges Monitoring. Eine kritische Zwischenbilanz", in: dies. (Hrsg.): Gezähmte Modemultis, Frankfurt a.M./Wien 1999, S. 146-176.

Rat für nachhaltige Entwicklung: Der nachhaltige Warenkorb. Resumée zur Testphase des nachhaltigen Warenkorbs mit Empfehlungen des imugInstituts an den Rat für nachhaltige Entwicklung, Hannover/Berlin 2002.

Reisch, Lucia A.: „Strategische Grundsätze und Leitbilder einer neuen Verbraucherpolitik“. Diskussionspapier des Wissenschaftlichen Beirats für Verbraucher- und Ernährungspolitik beim BMVEL, Stuttgart-Hohenheim/Berlin 2002.

Reisch, Lucia A.: „Neuer Wein oder nur neue Schläuche? Zur Wiederentdeckung der Verbraucherpolitik“, in: Sozialer Fortschritt, Jg. 51, Nr. 11, 2002, S. 292-296.

Scammell, Margaret: The Internet and Civic Engagement. The Age of the Citizen Consumer, in: Political Communication, Jg. 17, Nr. 4, 2000, S. 351-355.

Scharpf, Fritz: Interaktionsformen. Akteurzentrierter Institutionalismus in der Politikforschung. Opladen 2000.

Schrader, Ulf: „Überwindung von Marktversagen durch Öko-Label: das Beispiel des Bio-Siegels für Lebensmittel“, in: Zeitschrift für angewandte Umweltforschung, Jg. 15/16, Nr. 2, 2003-2004, S. 198-212.

Seehofer, Horst: „Rede des Bundesministers für Ernährung, Landwirtschaft und Verbraucherschutz im Rahmen der Aussprache zur Regierungserklärung der Bundeskanzlerin vor dem Deutschen Bundestag am 1. Dezember 2005 in Berlin“, www.bundesregierung.de/Reden-Interviews/ Bulletin-,12486.929204/bulletin/Rede-des-Bundesministers-fuer-.htm, 21.06.2006.

Snow, David A./Benford, Robert D.: „Ideology, Frame Resonance and Participant Mobilization“, in: Klandermans, Bert u.a. (Hrsg.): From structure to Action: Social Movement Participation Across Cultures. Greenwich, Conn. 1988, S. 197-217.

Stolle, Dietlind u.a.: „Zwischen Markt und Zivilgesellschaft. Politischer Konsum als bürgerliches Engagement", in: Gosewinkel, Dieter u.a. 
(Hrsg.): Zivilgesellschaft - national und transnational, Berlin 2004, S. 151171.

Teubner, Gunter/Willke, Helmut: „Kontext und Autonomie. Gesellschaftliche Selbststeuerung durch reflexives Recht“, in: ZfRsoz, Jg. 5, Nr. 1, 1984, S. 4-35.

Verbraucher Initiative e.V.: „Fairer Handel: Stetiges Wachstum“. www.fairfeels-good.de/fairer-handel.php/cat/49/title/Marktforschung, 17.07.2007.

Zürn, Michael: Regieren jenseits des Nationalstaats. Globalisierung und Denationalisierung als Chance, Frankfurt a.M. 1998. 



\section{Janina V. Curbach}

\section{Unternehmen als kollektive Weltbürger}

„Businesses cannot reap the economic benefits of open global markets without acknowledging - and responding to - their social and political responsibilities. They must be global corporate citizens. "1 In diesem Appell forderte der ehemalige UN-Generalsekretär Unternehmen auf, gesellschaftliche Verantwortungsbereiche zusätzlich zu ihren ökonomischen Rechten und Pflichten anzuerkennen und eine globale Bürgerrolle anzunehmen. Unternehmen ihrerseits zeigen sich zunehmend einverstanden und erklären sich bereit, dieser Rolle als Weltbürger gerecht zu werden, wie z.B. ExxonMobil: „,We strive to be a good Corporate Citizen in all the places we operate ${ }^{\text {"2 }}$, oder auch DaimlerChrysler: „As a world Citizen we feel obliged to help solve social problems in the regions in which we live and work “3.

Die Idee, dass Unternehmen globale Bürger sein sollen und wollen, wird auf internationaler Ebene immer populärer und geradezu konsensfähig. In den wenigsten Fällen ist jedoch klar, was es eigentlich bedeutet, wenn Unternehmen als Corporate Citizens eingebürgert werden. Diese Unklarheit führt zu begrifflicher Verwirrung in den derzeitigen theoretischen und politischen Debatten um die gesellschaftliche Rolle und Verantwortung von Unternehmen. Auf der einen Seite wird dabei Corporate Citizenship mit unternehmerischem bürgerschaftlichen Engagement gleichgesetzt. Auf der anderen Seite wird mit dem Konzept eine neue, kollektive unternehmerische Weltbürgerschaft zelebriert, nach der insbesondere transnationalen Unternehmen eine postnationale politische Rolle mit umfassenden Rechten, Pflichten und globaler gesellschaftlicher Zugehörigkeit zukommt. Vor dem Hintergrund dieser Unklarheiten soll im vorliegenden Beitrag kritisch hinterfragt werden, welche Elemente des Bürgerschaftskonzepts auch jenseits von philanthropischem Engagement auf transnationale Unternehmen übertragen werden können, wenn man davon ausgeht, dass Unternehmen zugleich politische Weltbürger (Citoyen) und kollektive Weltwirtschaftsbürger (Bourgeois) sind.

Einleitend wird hierzu im vorliegenden Beitrag eine Abgrenzung von Corporate Citizenship gegenüber Corporate Social Responsibility und Corporate Sustainability getroffen. Darauf aufbauend beschäftigt sich der zweite Abschnitt mit dem Konzept Corporate Citizenship in seinen unterschiedlichen Bedeutungs- und

1 Kofi Annan in: World Economic Forum: „Corporate Citizenship“.

2 Exxonmobile: „Esso, Mobil and Exxonmobil in the UK“.

3 DaimlerChrysler: „About us“. 
Verwendungszusammenhängen. In einem dritten Abschnitt werden anschließend die normativen Verzerrungen in der Debatte um Corporate Citizenship kritisch hinterfragt und es wird eine umfassende Konzeptualisierung von Unternehmen als Weltbürger erarbeitet, nach der Unternehmen insgesamt vier unterschiedliche Rollenelemente in sich vereinen: In ihrer Hauptrolle sind sie Wirtschaftsbürger, des Weiteren Mitglieder in einer sozialen Gemeinschaft, und im politischen Prozess sowohl Regierende als auch Regierte. Die sich daraus ergebenden Rollenerwartungen konstituieren ein Spannungsfeld zwischen ethischer Gemeinwohlorientierung und ökonomischem Eigeninteresse, das sich für Unternehmen durch Globalisierungsprozesse verändert. Daraus ergeben sich Chancen und Grenzen für das Corporate-Citizenship-Konzept, die abschließend diskutiert werden.

\section{Corporate Citizenship, Corporate Social Responsibility oder Nachhaltigkeit?}

Corporate Citizenship, Corporate Social Responsibility (CSR) und unternehmerische Nachhaltigkeit werden in der theoretischen und praxisbezogenen Debatte um die gesellschaftliche Verantwortung von Unternehmen zunehmend synonym verwendet, was vor allem darauf zurückzuführen ist, dass alle drei Begriffe hochgradig unklar und auslegungsbedürftig sind. Im vorliegenden Beitrag wird deshalb folgende begriffliche Abgrenzung angenommen: Corporate Citizenship wird häufig in einer instrumentellen Variante als Bezeichnung für ein strategisches philanthropisches und bürgerschaftliches Engagement von Unternehmen verwendet. ${ }^{4}$ Über diese Bedeutung hinaus verweist Corporate Citizenship im wörtlichen Sinne jedoch auf eine erweiterte gesellschaftspolitische Rolle von Unternehmen, in der sie vor dem Hintergrund von Globalisierungsprozessen zunehmend als Weltbürger im globalen Raum gehandelt werden. Auf diese Weise wird Unternehmen formal der Mitgliedstatus als Bürger mit bestimmten Rechten und Pflichten in einer postnationalen politischen Gemeinschaft zugeschrieben. ${ }^{5}$ Die entsprechende Frage nach Corporate Citizenship lautet demzufolge: Welche Rolle schreibt eine Gesellschaft Unternehmen (im Zeitalter der Globalisierung) zu?

Davon abzugrenzen ist die Frage nach Corporate Social Responsibility, mit der die entsprechenden Verantwortungsbereiche von Unternehmen in

4 Vgl. Mutz: „Der Geist von Corporate Citizenship ist noch nicht angekommen“.

5 Die Zuschreibung eines solchen Status unterscheidet sich etwa von der Betrachtung von Unternehmen als Organisationen des Marktes, als moderne Institutionen der Wertschöpfung oder als kollektive juristische Personen. 
einer Gesellschaft expliziert werden. ${ }^{6}$ Obwohl die wörtliche Übersetzung von CSR eigentlich soziale Verantwortung von Unternehmen lautet, ist angesichts der derzeitigen Debatte um CSR die sinngemäße Übersetzung als gesellschaftliche Verantwortung treffender. Das CSR-Konzept umfasst inzwischen nämlich eine Vielzahl von Ideen, Unternehmenspraktiken, Symbolen und Ideologien, die weit über die engen, mit dem Begriff des Sozialen verbundenen Vorstellungen einer unternehmerischen Mitarbeiter- und Standortverantwortung hinausgehen. ${ }^{7}$ In seiner instrumentellen Bedeutung wird CSR zwar oft deckungsgleich mit Corporate Citizenship für strategisches Gesellschaftsengagement von Unternehmen verwendet, davon abgesehen ist der Begriff in seiner normativen Bedeutung lediglich eine Leerformel, ein Schlauch ohne Wein, weil eine Definition von gesellschaftlicher Unternehmensverantwortung zwangsläufig nur im Rückgriff auf konkrete politische und kulturelle Rollenerwartungen der Gesellschaft an Unternehmen getroffen werden kann. Verantwortung als normatives Konzept zielt also auf kulturell spezifische Vorstellungen und Soll-Erwartungen an die gesellschaftliche Rolle von Unternehmen, und CSR dient dementsprechend als moralische Leerformel zur Neuverhandlung und inhaltlichen Festlegung dieser gesellschaftlichen Erwartungen. In anderen Worten: Nach dieser Begriffslogik bezeichnet CSR also das normative, kulturelle und politische Füllmaterial, mit dem die Rolle von Unternehmen, z.B. als Corporate Citizens, in einer Gesellschaft ausbuchstabiert wird. Die Frage nach CSR lautet deshalb anders als jene nach Corporate Citizenship: Wenn Unternehmen die Rolle als eine Art kollektiver Bürger in einer Gesellschaft zukommt, wie sieht die entsprechende Rollenbeschreibung inhaltlich aus? Was macht ein guter Unternehmensbürger und was nicht? Welche (normativ und damit kulturell begründete) Verantwortung haben Unternehmen in einer Gesellschaft

6 Die Corporate Citizenship- und CSR-Debatten speisen sich größtenteils aus einem wahrgenommenen Ungleichgewicht zwischen zunehmend erweiterten Freiheiten und Rechten von Unternehmen auf der einen Seite und einer Schmälerung ihrer gesellschaftlichen Pflichten auf der anderen. Eine Auseinandersetzung mit Corporate Citizenship fokussiert vor diesem Hintergrund zwangsläufig stärker die Frage nach den unternehmerischen Pflichten - und erzeugt damit (wie weiter unten noch gezeigt wird) normative Verzerrungen und blinde Flecken, was die Gesamtheit einer Bürgerrolle von Unternehmen betrifft.

7 Deshalb scheint es sinnvoll, die - besonders im deutschen Sprachgebrauch begrifflich stark vorbesetzte soziale Verantwortung auf diese organisationsinternen Bereiche von Unternehmen zu beschränken, während die gesellschaftliche Verantwortung von Unternehmen das weitere politische und soziale Umfeld betrifft. Häufig sind in der Debatte um transnationale gesellschaftliche Unternehmensverantwortung soziale und Umweltfragen eng miteinander verwoben, sodass die Diskussion um CSR hier in weiten Teilen auch um ökologische Unternehmensverantwortung geführt wird. 
konkret? Während Corporate Citizenship Unternehmen formal einen Bürgerstatus verleiht, ist CSR also die zugehörige normative Gebrauchsanweisung, die inhaltliche Festlegung darauf, welche Verantwortungsbereiche und Rollenerwartungen mit einer solchen Einbürgerung einhergehen.

An dieser Stelle soll noch erwähnt werden, dass auch Nachhaltigkeit bzw. Corporate Sustainability zunehmend mit Corporate Citizenship und CSR gleichgesetzt wird, insbesondere in der unternehmerischen Praxis und im $\mathrm{Zu}-$ sammenhang mit transnationalen Unternehmen. ${ }^{8}$ Im Gegensatz zu Corporate Citizenship und CSR, die konzeptuell direkt mit der gesellschaftlichen Rolle und der einhergehenden Verantwortung von Unternehmen verknüpft sind, wurde Nachhaltigkeit hingegen auf sehr viel breiterer Basis zu einer weltgesellschaftlichen politischen und normativen Leitidee. Nachhaltigkeit bzw. nachhaltige Entwicklung als gesamtgesellschaftliche Zielvorgabe hat sich auf diese Weise in der letzten Dekade sukzessive zu einer (mehr oder weniger konkreten) kulturellen und politischen Rollenerwartung an verantwortliches Unternehmenshandeln entwickelt. Noch vor wenigen Jahrzehnten wäre eine Definition von CSR als „ein Unternehmensbeitrag zur nachhaltigen Entwicklung“, 9 wie durch die Europäische Kommission 2002, nicht denkbar gewesen. Damit ist Nachhaltigkeit zwangsläufig nur eine - wenngleich derzeit sehr erfolgreiche - konkrete historische Variante dessen, was Unternehmen als Soll-Erwartung und Verantwortungsbereich zugeschrieben werden kann. Nach dieser ersten Begriffsklärung werden sich die nächsten Abschnitte nun genauer mit dem Konzept Corporate Citizenship beschäftigen.

\section{Corporate Citizenship zwischen bürgerschaftlichem Engagement und unternehmerischem (Welt-)Bürgertum}

Je nach Interessenlage und Perspektive der Definierenden fallen die Definitionen von Corporate Citizenship sehr unterschiedlich aus: So hat z.B. die EU Kommission Corporate Citizenship eher bedeutungsleer als „die Gestaltung der Gesamtheit der Beziehungen zwischen einem Unternehmen und dessen lokalem, nationalem und globalem Umfeld“10 bezeichnet. Damit kann man zwar nicht auf die Qualität der Gestaltung dieser Organisation-Umwelt-Beziehung schließen, bemerkenswert ist allerdings der explizite Verweis, dass eine unternehmerische Bürgerrolle offenbar nicht ausschließlich an nationalstaat-

8 Vgl. z.B. Dunphy u.a.: Organizational Change for Corporate Sustainability.

9 Europäische Kommission: Die soziale Verantwortung der Unternehmen.

10 Europäische Kommission: Europäische Rahmenbedingungen für die soziale Verantwortung von Unternehmen, S. 28. 
liche Zugehörigkeiten gebunden ist, sondern eine Beziehungspflege von der lokalen bis zur globalen Ebene umfasst. Die Art der Beziehung zwischen Unternehmen und ihrem gesellschaftlichen Umfeld wird z.B. bei Westebbe und Logan deutlicher, die Corporate Citizenship als das gesellschaftliche Engagement von Unternehmen jenseits der ökonomischen Geschäftstätigkeit definieren, als „das Gesamte über die eigentliche Geschäftstätigkeit hinausgehende Engagement des Unternehmens zur Lösung gesellschaftlicher Probleme" "11. Unternehmen werden hier durch ihr (wie auch immer geartetes) Engagement zu gesellschaftlichen Problemlösern, und zwar unabhängig und losgelöst von ihrem Kerngeschäft. Im Gegensatz dazu schließt das World Economic Forum (WEF) die wirtschaftliche Rolle von Unternehmen in seine Definition mit ein, indem es Corporate Citizenship als „the contribution a company makes to society through its core business activities, its social investment and philanthropic programmes, and its engagement in public policy "12 bezeichnet.

Diese Uneinigkeiten in der Definition von Corporate Citizenship rühren zum Teil daher, dass der Begriff in der Debatte in zwei sehr unterschiedlichen Bedeutungen verwendet wird: Auf der einen Seite wird der Schwerpunkt auf Aspekte unternehmerischen Mäzenatentums und auf bürgerschaftliches Engagement als „The Art of Giving Back to the Community" 13 gelegt. Auf der anderen Seite verweist der Begriff auf die gesellschaftspolitische Rolle von Unternehmen als Weltbürger oder ordnungspolitische Akteure im globalen Raum. Mit diesen unterschiedlichen Perspektiven auf Corporate Citizenship beschäftigen sich die beiden nächsten Abschnitte genauer.

\subsection{Corporate Citizenship als bürgerschaftliches Engagement}

In einer ersten Variante beschreibt Corporate Citizenship die Tradition des gesellschaftlichen Engagements von Unternehmen, bei dem sie an ihren Standorten durch Unterstützung von Sportvereinen, Kulturveranstaltungen und andere Formen des Sponsorings als gute Mitbürger in ihre Nachbarschaft investieren. ${ }^{14}$ Corporate Citizenship umfasst danach vor allem die Tradition des Corpo-

11 Westebbe/Logan: Corporate Citizenship, S. 13.

12 World Economic Forum: „Corporate Citizenship“.

13 Mutz 2001: „Der Geist von Corporate Citizenship ist noch nicht angekommen“, S. 3 .

14 Diese Variante von Corporate Citizenship wird in ihrem Ursprung oft auf die USamerikanische Tradition des bürgerschaftlichen Engagements zurückgeführt, bei der Unternehmen sich um einen Ausgleich für das Fehlen einer flächendeckenden wohlfahrtsstaatlichen Versorgung bemühen (müssen). Vgl. Habisch: Corporate Citizenship, S. 42ff.; Rudolph: „Neue Kooperationsbeziehungen zwischen dem 
rate Giving, also der Spendenzahlung an Non-Profit-Unternehmen und für gemeinnützige Zwecke, und das Corporate Volunteering, bei dem gemeinnütziges Engagement von Mitarbeitern gefördert wird. ${ }^{15}$ Das Engagement kann sich z.B. durch Freiwilligenarbeit der Mitarbeiter in Suppenküchen, durch Abfallsammeln in Naherholungsgebieten oder durch den Bau eines Kinderspielplatzes manifestieren, oder Spendengelder fließen an Sprachkurse für Kinder mit Migrationshintergrund oder Computerausstattungen für benachbarte Grundschulen. Oft wird dabei auf Projektbasis mit lokalen und regionalen Non-Profit-Organisationen als Experten für bürgerschaftliches Engagement zusammengearbeitet, oder es werden von Unternehmen eigens Stiftungen gegründet. Motivation für das vielfältige Engagement ist der erwartete positive Effekt auf das Unternehmensimage und auf die Personal- und Organisationsentwicklung. ${ }^{16} \mathrm{Um}$ eine positive gesellschaftliche Außenwirkung zu erzielen, wird dazu das Motto Tue Gutes und rede darüber umgesetzt und das bürgerschaftliche Engagement von Unternehmen häufig in Form von Hochglanz-Öffentlichkeitsarbeit oder auch in Cause-Related-Marketing-Kampagnen ${ }^{17}$ zur Schau gestellt. Der Grundgedanke dahinter ist, dass das bürgerschaftliche Engagement damit sowohl der Gesellschaft als auch den Unternehmen selbst zu Gute kommt und damit eine Win-Win-Situation geschaffen bzw. genutzt wird. Backhaus-Maul beschreibt dieses Engagement von Unternehmen als gute Mitbürger als

[...] freiwillige Übernahme gesellschaftlicher Verantwortung durch private Unternehmen vor dem Hintergrund wirtschaftspolitisch günstiger Rahmenbedingungen. Die jeweiligen Vorhaben und Projekte sind verknüpft mit unternehmensstrategischen Überlegungen und beziehen sich primär auf die lokalen, regionalen und nationalen Unternehmensstandorte. Bei der Entwicklung, Durchführung und Aus-

Dritten und Ersten Sektor“. Allerdings haben Philanthropie und Sponsoring durch Unternehmen - insbesondere in den Bereichen Kultur und Sport - auch in Deutschland und anderen europäischen Ländern eine lange Tradition, ohne dass sie unter dem Begriff des Corporate Citizenship geführt wurden und werden.

15 Vgl. Backhaus-Maul/Brühl: Bürgergesellschaft und Wirtschaft; Deutscher Bundestag: Bürgerschaftliches Engagement, S. 220.

$16 \mathrm{Zu}$ möglichen Erwartungen der positiven Auswirkungen von Investitionen in das Unternehmensumfeld vgl. Rademacher in diesem Band.

17 Als Cause-Related-Marketing werden Maßnahmen bezeichnet, welche auch der Verkaufsförderung dienen sollen. 
wertung von Corporate-Citizenship-Aktivitäten arbeiten Unternehmen mit passenden Non-Profit-Organisationen zusammen. ${ }^{18}$

Spendengelder und Sachmittel fließen aber auch immer öfter an international ausgerichtete Umwelt- und Hilfsorganisationen, wodurch zwar nicht das direkte Unternehmensumfeld positiv beeinflusst wird, aber doch die unternehmerische Reputation als global agierende und verantwortungsvolle Weltbürger gestärkt werden kann. Ein Beispiel für solches weltbürgerschaftliches Engagement ist die Spendenoffensive 2006 der Brauerei Krombacher, bei der für jede verkaufte Bierflasche ein Cent an die WWF-Stiftung zum Schutz des Regenwaldes gespendet wurde. ${ }^{19}$ Ein anderes Beispiel ist die Unterstützung eines Hilfsgütertransports nach Afghanistan durch Daimler-Chrysler im Jahr 2003, für den das Unternehmen die Fahrzeuge stellte und eigene Monteure und Werksfahrer mit auf den Weg schickte. ${ }^{20}$

Corporate Citizenship ist in dieser Variante ein unternehmenspolitisches Instrument des bürgerschaftlichen Engagements und der strategischen Philanthropie. Beim Engagement steht die Investition in das direkte und (multi-)lokale gesellschaftliche Unternehmensumfeld und das Motiv der Profitsicherung durch Reputationsmanagement im Vordergrund. Diese Konzeptualisierung von Corporate Citizenship wird jedoch oft als einseitig und zu begrenzt wahrgenommen, insbesondere vor dem Hintergrund von Globalisierungsprozessen und einhergehendem Sozialabbau, staatlichen Steuerungsdefiziten und der Brisanz transnationaler Umweltprobleme. So wehrt sich z.B. Logsdon gegen die Beschränkung von Corporate Citizenship auf bürgerschaftliches Engagement und schreibt:

[...] corporate citzenship had a history in both scholarship and business usage of meaning corporate community relations, which included good-neighbor activities such as philanthropic contributions. Thus, it seemed too limited to encompass the increasing agenda of corporate social responsibility on the global scale. ${ }^{21}$

Aber auch Matten und Crane bezeichnen dieses Verständnis von Corporate Citizenship als philanthropisches Engagement am Unternehmensstandort als

18 Backhaus-Maul: „Corporate Citizenship im deutschen Sozialstaat“, S. 24.

19 Vgl. Krombacher: „Homepage“.

20 Vgl. DaimlerChrysler: „Gemeinschaft gestalten“, S. $70 \mathrm{ff}$.

21 Logsdon: „Global Business Citizenship“, S. 69. 
„Limited View“"22, im Gegensatz zu ihrer eigenen, weiter gefassten Konzeptualisierung, auf die weiter unten noch eingegangen wird.

\subsection{Corporate Citizenship als gesellschaftspolitische Bürgerrolle}

Neben der Variante des bürgerschaftlichen Engagements hat sich zusehends eine zweite Bedeutung entwickelt, nach der Corporate Citizenship Unternehmen eine erweiterte gesellschaftspolitisch-gestalterische Rolle vor dem Hintergrund von globalen Steuerungsdefiziten nationalstaatlicher Regierungen zuschreibt. Auf den ersten Blick scheint die Beschreibung von Unternehmen als politische Bürger unpassend, weil die Wirtschaftsakteure zwar Adressaten von Regulierung und Rollenerwartungen sind, aber aufgrund der angenommenen funktionalen Trennung der zivilgesellschaftlichen, politischen und Marktsphäre (zumindest theoretisch) nicht aktiv am politischen Prozess partizipieren und deshalb nicht als aktive Mitglieder einer politischen Gemeinschaft angesehen werden. Allerdings gibt es einiges gegen diese theoretisch eindeutige Rollenzuweisung einzuwenden:

Es könnte vermutet werden, dass die Citizenship-Rolle im gesellschaftlichen Gefüge am ehesten von der Zivilgesellschaft und ihren Akteuren ausgeübt wird und Regierungen die Impulse aufnehmen, um neue Rahmenbedingungen zu formulieren. Eine entsprechende funktionale Trennung verkennt jedoch, dass prinzipiell alle gesellschaftlichen Akteure, also auch Wirtschaftsunternehmen, auf die Gestaltung der Gesellschaft als Citizen direkt oder indirekt Einfluss nehmen. Die Reflexive Modernisierung beschreibt diese Einflussnahme als Subpolitik. $^{23}$

Die Frage nach Subpolitik und damit nach der gesellschaftspolitischen Bürgerrolle von Unternehmen wird vor allem vor dem Hintergrund von ökonomischer Globalisierung relevant, weil Unternehmenshandeln über nationalstaatliche Regulierungsräume hinauswächst und dadurch die steuerungspolitischen Handlungsspielräume von Staaten eingeschränkt werden. ${ }^{24}$ In anderen Worten, die Rollenerwartung und -beschreibung von Unternehmen als Weltbürger gewinnt vor allem in jenen Kontexten an Brisanz, wo Staaten im Vergleich zu NGOs und Unternehmen an Kapazität zur Regulierung und zur

22 Matten/Crane: „Corporate Citizenship“, S. 170.

23 Weiß: Unternehmensführung in der reflexiven Modernisierung, S. 149.

24 Vgl. z.B. Zürn: Regieren jenseits des Nationalstaates; Curbach: „Corporate Social Responsibility“. 
Durchsetzung und Verbreitung von ökologischen, sozialen und ethischen Standards verlieren. Diese politischen Steuerungslücken werden teilweise durch zivilgesellschaftliche und privatwirtschaftliche Akteure aufgefüllt, was nicht nur zur Folge hat, dass letztere zu „Ausfallbürgen sozialstaatlicher Politik“ ${ }^{\prime 25}$ werden, sondern es ergibt sich daraus die gesellschaftspolitische Herausforderung einer „Neurelationierung des Verhältnisses zwischen Privathaushalten (Bürgern), Staat, Drittem Sektor (Non-Profit-Organisationen) und Markt (Unternehmen)“26. Beck spricht dementsprechend vom ,und-Experiment Wirtschaft-Politik'“27, in dessen Rahmen Unternehmen zu politischen Bourgeois werden und die Differenzierung der Systeme Wirtschaft und Politik aufgehoben wird:

Der unpolitische Bourgeois des sozialstaatlich regulierten Spätkapitalismus wird zum politischen Bourgeois, der in seiner wirtschaftlichen Sphäre nach den Maßstäben legitimationsbedürftiger Politik ,regieren` muss. ${ }^{28}$

Faktisch beteiligen sich Unternehmensbürger tatsächlich immer mehr an der Gestaltung und Verbreitung von Sozial- und Umweltstandards, indem sie branchenweite Selbstverpflichtungen eingehen, Codes of Conduct übernehmen, private Regime in Form von Labeling-, Zertifizierungs- und Fair TradeSystemen ${ }^{29}$ mit aufbauen und in Public-Private-Partnerships „mitregieren“. 30 Beispiele hierfür sind die Selbstverpflichtung von Unternehmen zur Einhaltung von Sozial- und Umweltstandards im Global Compact der UN oder auch die Beteiligung am Aufbau von Zertifizierungssystemen für Branchen und Produkte wie beim Forest Stewardship Council für nachhaltige Forstwirtschaft. Unternehmen investieren auf diese Weise nicht nur in ihr direktes Umfeld in Form von Mitarbeiterengagement und Spendengeldern, sondern beeinflussen, oftmals in Zusammenarbeit mit öffentlichen Akteuren oder NGOs, die Gestaltung sozialer und politischer Ordnungen auf regionaler, nationaler und internationaler Ebene. Das ist an sich nichts Neues, denn:

25 Backhaus-Maul: „Corporate Citizenship im deutschen Sozialstaat“, S. 25.

26 Ebd., S. 26.

27 Beck: Die Erfindung des Politischen, S. 202.

28 Ebd., S. 197.

29 Zu den Themen Labeling- und Fair Trade vgl. Kneip/Niesyto und Holler in diesem Band.

30 Vgl. z.B. Börzel/Risse: „Public-Private-Partnerships“; Haufler: Public Role for the Private Sector; Pattberg: „Private-Private Partnerships als innovative Modelle zur Regel(durch)setzung?‘“. 
Corporations have of course always influenced public policy. What is new is that this influence is increasingly becoming formalized and legitimized through their involvement in partnerships with governments, international institutions and civil society organizations. This is true at the national and local levels as it is for high-profile initiatives like the Global Compact. ${ }^{31}$

Zadek macht also die neue gesellschaftspolitische Weltbürgerrolle seiner sogenannten Civil Corporation an ihrer offiziellen Beteiligung an sektorenübergreifenden Governance-Netzwerken fest, über die das steigende Ausmaß der gesellschaftspolitischen Einflussnahme durch Unternehmen institutionalisiert wird.

Euphorische Stimmen aus Theorie und Praxis plädieren in diesem Zusammenhang für eine solche Unternehmensrolle als Global Corporate Citizens zur Erhöhung der globalen gesellschaftlichen Problemlösungskapazität. ${ }^{32}$ Die gesellschaftspolitische Herausforderung an Unternehmen, ihrer Bürgerrolle gerecht zu werden, ist laut Marsdon in Entwicklungsländern mit schwächer ausgebildeten politischen und zivilgesellschaftlichen Strukturen besonders groß und außerdem abhängig vom Ausmaß des gesellschaftlichen Einflusses eines Unternehmens: ,The size and/or societal impact of these companies can force them into a quasi-governmental position regarding both the affected local communities and the official national governments“. ${ }^{33}$ Laut Marsdon wird aufgrund der zunehmenden multinationalen Unternehmenstätigkeit eine Weltbürgerrolle von Unternehmen immer wichtiger und Unternehmen fügen sich inzwischen - nach einer anfänglich ablehnenden Haltung - aktiv in diese von ihnen erwartete Bürgerrolle und übernehmen die damit verbundene gesellschaftspolitische Verantwortung. Im Idealfall arbeiten Unternehmen als globale Weltbürger mit NGOs und Regierungsorganisationen zusammen, um gemeinsam die Gestaltung und Durchsetzung weltweiter Standards zu übernehmen und politische Regulierung jenseits von Nationalstaaten zu realisieren. Ähnlich wie beim philanthropischen Engagement wird hier wieder das WinWin-Potenzial zwischen Unternehmen und Gesellschaft betont - nur eben auf ordnungspolitischer Ebene. ${ }^{34}$ „Company leaders need to be encouraged to

31 Zadek: The Civil Corporation, S. 99.

32 Vgl. Marsdon: „The New Corporate Citizenship of Big Business“. Siehe hierzu auch Logsdon in Bezug auf Global Corporate Citizenship und Scherer u.a. für eine Diskussion der Rolle von Unternehmen als politische Akteure im Global Governance. Vgl. Logsdon: „Global Business Citizenship“; Scherer u.a.: „Global Rules and Private Actors".

33 Marsdon: „The New Corporate Citizenship of Big Business“, S. 13.

34 Vgl. hierzu auch Wadell: „Complementary Resources“. 
adopt a world-statesmanlike position (e.g. in helping to establish global standard setting and accountability systems) $[\ldots]^{6335}$, so das entsprechende Plädoyer von Marsdon für die Verbreitung von Global Business Citizenship.

Mit weniger normativem Impetus als Marsdon - aber ohne den Begriff Corporate Citizenship zu benutzen - beschreibt auch Schneidewind die Rolle von Unternehmen als strukturpolitische Akteure, indem er ihre politische Gestaltungsmacht in den Mittelpunkt rückt. ${ }^{36}$ Unternehmensbezogene Strukturpolitik ist in seinen Augen „die interessengeleitete Einflussnahme von Unternehmen auf marktliche, politische und gesellschaftliche Strukturen“'37 und damit kein neues Phänomen, sondern eines, das lediglich vor dem Hintergrund globaler steuerungspolitischer Machteinbußen von Staaten eine neue Relevanz erfährt. Im Gegensatz zu Management-Theorien, die auf eine strategische Anpassung von Unternehmen an ihr (politisches) Umfeld fokussieren, wird bei Schneidewind hervorgehoben, „dass sich die Surfer ihre Wellen zu-

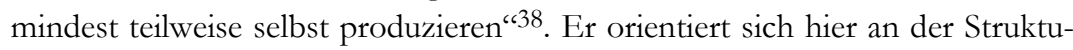
rierungstheorie von Anthony Giddens, nach der Akteure Strukturen reproduzieren und produzieren, also ihre eigenen politischen Rahmenbedingungen mitgestalten:

Vieles, was als vermeintliche, externe Rahmenbedingung' daherkommt, ist von Unternehmen und Branchenverbänden selbst mit geschaffen worden. Die Tendenz dazu wird in Zukunft noch wachsen: Globalisierungsprozesse und die steigende Regelungskomplexität vieler Sachverhalte wie z.B. des Umweltschutzes erschweren die Möglichkeiten nationalstaatlicher Rahmensetzung. Vor diesem Hintergrund entstehen gerade im internationalen Raum ganz neue Regelungsmuster, in denen staatliche Instanzen nur noch eine, und häufig nicht einmal mehr die entscheidende Rolle spielen. ${ }^{39}$

Auch wenn Schneidewind nicht wörtlich von Unternehmen als Bürger schreibt, beschreibt er Unternehmen dennoch als Träger steuerungspolitischer Verantwortung und als global orientierte, gesellschaftspolitisch-gestalterische Akteure. Im Gegensatz zu eher euphorischen Plädoyers für eine nene Bürgerrolle kann jedoch bei Schneidewind das Unternehmen durchaus auch zur Ver-

35 Marsdon: „The New Corporate Citizenship of Big Business“, S. 23.

36 Vgl. Schneidewind: „Unternehmen als strukturpolitische Akteure“; ders.: Die Unternehmung als strukturpolitischer Akteur.

37 Ders.: „Unternehmen als strukturpolitische Akteure“, S. 3.

38 Ebd., S. 2.

39 Ebd. 
folgung seiner Privatinteressen strukturpolitisch aktiv sein - ein Aspekt, auf den der Beitrag im Verlauf noch zurückkommen wird.

An dieser Stelle ist noch auf eine weitere, sehr spezielle gesellschaftspolitische Konzeptualisierung von Corporate Citizenship durch Matten und Crane hinzuweisen, die auf die Übernahme von spezifischen Staatsaufgaben durch Unternehmen abzielt, nämlich auf die ,role of the corporation in administering citizenship rights for individuals “40. Unternehmen werden demnach $\mathrm{zu}$ kollektiven Bürgern, wenn sie die sozialen, zivilen und politischen Rechte individueller Bürger verwalten, vermitteln und garantieren. Als Corporate Citizens übernehmen sie zunehmend an jenen Stellen die staatliche Aufgabe des Schutzes individueller Bürgerrechte, wo staatliche Regierungen ihren Aufgaben noch nicht, nicht mehr, oder auch nur zeitweilig nicht gewachsen sind, wie z.B. in Konflikt- und Krisensituationen. Begrifflich ist die Konzeptualisierung von Matten und Crane allerdings etwas verwirrend, weil Corporate Citizenship bei ihnen ausschließlich unternehmerisches Quasi-Staatentum beschreibt. Als Weltbürger werden Unternehmen dadurch eindeutig der öffentlich-politischen Sphäre zugeordnet und ihnen wird eigentlich eher eine Staats- und Regierungsrolle denn eine kollektive Bürgerschaft zugeschrieben.

Zusammengefasst verweist die zweite Variante von Corporate Citizenship auf eine gesellschaftspolitische Rolle von Unternehmen als struktur- oder ordnungspolitische Akteure. Wenn von Unternehmen als Corporate Citizens gesprochen wird, geht es also nicht mehr nur um nachbarschaftliches und philanthropisches Engagement, sondern außerdem um die Frage nach einer gesellschaftspolitischen Rolle von Unternehmen in einem Zeitalter, in dem nationalstaatlich-öffentliche Akteure gegenüber transnational operierenden Wirtschaftsakteuren an politischer Gestaltungsmacht eingebüßt haben. VidaverCohen und Altmann beschreiben diesen konzeptuellen Wandel sehr treffend:

The practice of corporate citizenship has moved thinking about the relationship between business and the community beyond the realm of donating ,spare change into the arena of producing ,real change ‘. ${ }^{4}$

Die zwei unterschiedlichen Bedeutungen schließen sich allerdings keinesfalls gegenseitig aus, sie werden von Habisch sogar prägnant zusammengeführt, indem er Corporate Citizenship in seiner Definition als Aktivitäten bezeichnet, „mit deren Hilfe Unternehmen selbst in ihr gesellschaftliches Umfeld investie-

40 Matten/Crane: „Corporate Citizenship“, S. 173.

41 Vidaver-Cohen/Altman: „Corporate Citizenship in the New Millenium“, S. 165. 
ren und ordnungspolitische Mitverantwortung tragen“42. Laut Habisch wird erst durch die ordnungspolitische Komponente

[...] die positive Wirkung des unternehmerischen Bürgerengagements ,auf Dauer gestellt', indem relevante gesellschaftliche Institutionen umgestaltet werden - und zwar auf regionaler, nationaler oder internationaler Ebene. Dies kann in der Formulierung oder Modifikation von Gesetzen, staatlichen Regulierungen, internationalen Verträgen oder auch Kodizes internationaler Organisationen bestehen. ${ }^{43}$

Damit umfasst die Bürgerrolle von Unternehmen eine philanthropische Dimension und eine ordnungspolitisch-gestalterische bis quasi-staatliche Dimension. Eine durchweg konsequente Übertragung des Bürgerschaftskonzepts auf Unternehmen bringt aber noch weitere Rollenelemente mit sich, ohne die das Bild vom Unternehmen als kollektiver Weltbürger zwangsläufig unvollständig bleibt: die Rollen als Wirtschaftsbürger und als Adressaten von Regulierung. Zusammen mit diesen Rollenelementen ergibt sich daraus ein Gesamtbild des Corporate Citizen als eine Art multiple Persönlichkeit, die im Folgenden vorgestellt wird.

\section{Die multiple Persönlichkeit des kollektiven Weltbürgers: Vier Rollenelemente}

Ein Bürger ist, nach der Herkunft und Entwicklung des Begriffs, zunächst nicht mehr und nicht weniger als eine Person mit einem Status als Mitglied in einer politischen Gemeinschaft. An die Bürgerschaft als gesellschaftlicher Status sind, wie an jeden Status, statusspezifische soziale Rollenerwartungen in Form von Rechten und Pflichten geknüpft. In der Debatte zu Corporate Citizenship werden jedoch zwei Rollenelemente vernachlässigt, die bei einer Verwendung von Citizenship bzw. Bürgerschaft als Begriffe berücksichtigt werden müssen: Zum einen sind Unternehmen nicht nur gemeinwohlorientierte Citizens, sondern auch, ja sogar in erster Linie, Wirtschaftsbürger. Und zum anderen sind sie nicht nur Regierende, die aktiv am politischen Prozess teilhaben oder im Extremfall sogar staatliche Aufgaben übernehmen, sondern auch Regierte, d.h. Untertanen, die sich an bestimmte gesellschaftliche Spielregeln halten müss(t)en, welche wiederum im politischen Prozess festgelegt und von außen an den Unternehmensuntertan gerichtet werden. Die Frage nach Corporate Citizenship ist ja gerade des-

42 Habisch: Corporate Citizenship, S. 58.

43 Ebd., S. 81. 
halb so aktuell, weil sich durch ökonomische Globalisierung Verschiebungen zwischen diesen zwei Teilrollen des Unternehmens als Untertan und als Wirtschaftsbürger ergeben haben. Unternehmen leben ihre Wirtschaftsbürgerrolle transnational und jenseits staatlicher Regulierung freier aus, während sie sich gleichzeitig immer mehr ihrer politischen Untertanenrolle entziehen können. Durch diese Veränderungen gewinnen sie wiederum rückwirkend an Macht, den politischen Prozess in ihrem Interesse als Regierende zu beeinflussen. Nachdem Unternehmen im Zuge von Marktöffnungs- und Globalisierungsprozessen die großzügige Freiheit zugestanden wurde, ihre ökonomischen Rechte als Wirtschaftsbürger zu erweitern, stellt die Rollenzuweisung als gute Corporate Citizens bzw. verantwortliche Weltbürger einen Versuch dar, ihre gesellschaftlichen Pflichten als politische Bürger neu zu definieren und zu stärken. Trotzdem sind Unternehmen Organisationen und kollektive Akteure, die von der Gesellschaft vorrangig als Wirtschaftsbürger geschaffen wurden. Für ein ausgewogenes theoretisches Bild der Weltbürgerrolle von Unternehmen ist es daher notwendig, die Rollenelemente von Corporate Citizenship konzeptuell zu erweitern und zusätzlich zum Philanthropen und zum gemeinwohlorientierten Teilhaber am politischen Prozess eine ökonomische Hauptrolle als Wirtschaftsbürger und eine Untertanenrolle hinzuzufügen. ${ }^{44}$ Wenn man diese Überlegungen zugrunde legt, lassen sich insgesamt vier verschiedene Rollenelemente von Unternehmensbürgern unterscheiden, die im Drei-SektorenModell von Staat, Markt und Zivilgesellschaft verortet werden können (vgl. Abbildung 1). ${ }^{45}$

44 Vgl. hierzu auch die Idee der vier Gesichter von Corporate Citizenship nach Carroll, nach denen Unternehmen nur dann gute Bürger sind, wenn sie neben den Erwartungen an philanthropisches und ethisches Unternehmenshandeln auch den rechtlichen Erwartungen an Gesetzeskonformität und Erwartungen an ökonomische Profitabilität gerecht werden. Vgl. Carroll: „,The Four Faces of Corporate Citizenship“.

45 Die unterschiedlichen Rollenelemente sind nur analytisch eindeutig trennbar, da sie sich in der Realität überlappen und miteinander im kollektiven Akteur Unternehmen verschmelzen. 


\section{STAAT (politische Sphäre)}

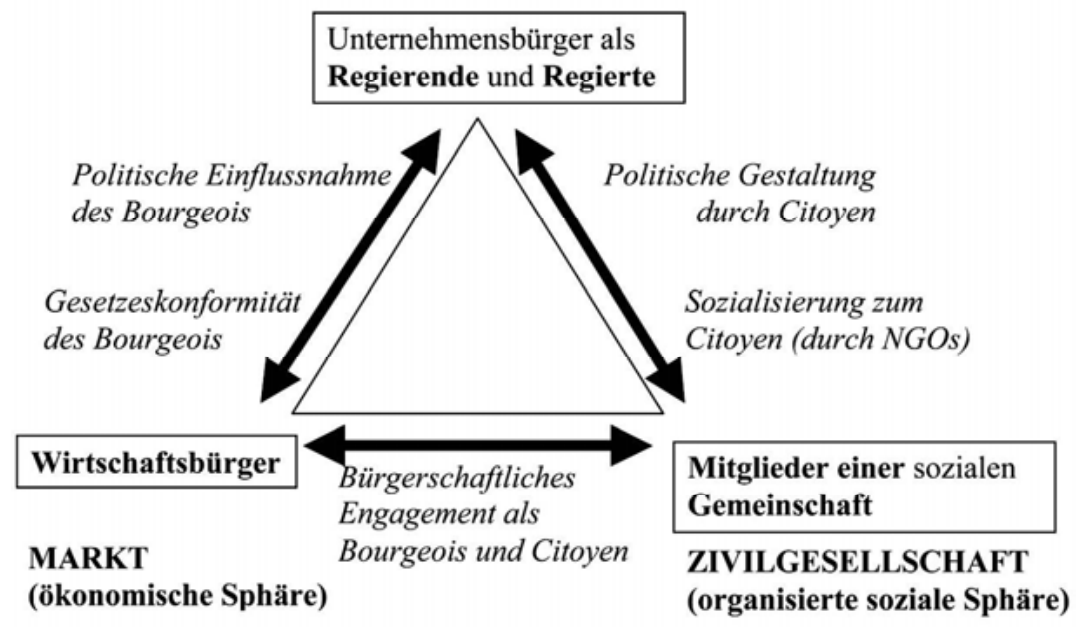

Abb. 1: Rollenelemente des unternehmerischen Weltbürgers im Drei-SektorenModell. ${ }^{46}$

In ihrer Hauptrolle sind Unternehmen Wirtschaftsbürger der Marktsphäre, in einer zweiten, peripheren Rolle Mitglieder einer sozio-politischen (Bürger-)Gemeinschaft, mit der sie sich als Philanthropen solidarisch zeigen können. Außerdem sind sie politische Bürger in zweierlei Hinsicht, und zwar als Partizipierende am politischen Prozess, d.h. als Regierende, und als Untertanen, d.h. Regierte. Die Frage, inwieweit die teilweise Ausblendung des Wirtschaftsbürgers und des Untertans zu einer normativen Verzerrung in der Debatte um Corporate Citizenship führt, ist Gegenstand der folgenden Überlegungen.

\subsection{Citoyen oder Bourgeois? Vom guten und vom bösen Bürger}

Wenn Unternehmen zu Corporate Citizens und in eine hypothetische Weltgesellschaft eingebürgert werden, wird in der Debatte häufig implizit angenommen, dass sich damit eine natürliche Synthese zwischen unternehmerischem Eigeninteresse und dem weltgesellschaftlichen Gemeinwohlinteresse als Mitglieder dieser Gemeinschaft entwickelt. Sowohl das bürgerschaftliche Engagement, als auch die strukturpolitischen Bemühungen von Unternehmen sind demnach in erster Linie Manifestationen von, aus ethischer Sicht, guter Bürgerschaft. Unternehmen als gute Corporate Citizens haben die Einsicht, dass ein Zugewinn

46 Eigene Darstellung. 
an globalem Gemeinwohl in ihrem Eigeninteresse als kollektive Weltbürger liegt, nicht zuletzt deswegen, weil sich jede Steigerung des Gemeinwohls als Reputationsgewinn oder auch in Form von faktischen gesellschaftlichen Problemlösungen positiv auf die Geschäftstätigkeit auswirkt:

Ein Unternehmen, das sich als Bürger gemeinsam mit anderen interessierten Mitbürgern ein konkretes Problem seines Standorts, seiner Branche, seines gesellschaftlichen Umfelds vornimmt und zu dessen Lösung beiträgt, tut mithin immer auch etwas für sich selbst. ${ }^{47}$

Diese Idee des gewinnbringenden Business Case, also der Profitabilität von gutem und gesellschaftlich verantwortlichem Bürgerverhalten verbreitet sich zunehmend als Glaubenssatz in der politischen Debatte und in der einschlägigen Management-Literatur. Entsprechende Glaubensbekundungen zu dieser Win-WinSituation zwischen Markt und Gesellschaft finden sich deshalb vielfach auch in den eigenen Darstellungen von Unternehmen, knapp und auf den Punkt gebracht z.B. bei Ford: „We believe that corporate citizenship creates business

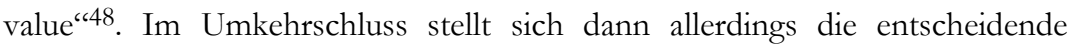
Frage: Was passiert, wenn die Interessen zwischen Gesellschaft und Unternehmen sich nicht überschneiden, und wenn Unternehmen zugleich gute politische Bürger und böse Wirtschaftsbürger sind? Dazu muss berücksichtigt werden, dass der allgemeine Bürgerbegriff zwei sehr unterschiedliche Dimensionen von Bürgerschaft vermengt: den Bürger als politischer, gemeinwohlorientierter Citoyen mit Rechten und Pflichten in einer politisch definierten Gemeinschaft einerseits, und andererseits der Bürger als privater Bourgeois der Marktsphäre, für den seine privatwirtschaftlichen Rechte im Vordergrund stehen und der seine ökonomischen Eigeninteressen durchaus - im Rahmen der vorgegebenen Spielregeln - auch auf Kosten der Gemeinschaft verfolgen darf und soll. ${ }^{49}$ Konzeptionen von Corporate Citizenship, in denen die Rolle von Unternehmen als privater Bourgeois ausgeblendet wird, greifen deshalb schlicht zu kurz, auch wenn unablässig die Synergieeffekte durch Zusammenarbeit zwischen Unternehmen und Zivilgesellschaft und die Win-WinPotenziale zwischen Unternehmensinteressen und Gesellschaft beschworen werden. Da Unternehmen in erster Linie Akteure der wirtschaftlichen Sphäre und Handlungslogik sind, läuft diese einseitige Perspektive Gefahr, Wunschdenken und normative Idealvorstellungen zum gemeinwohlorientierten Unter-

47 Habisch: Corporate Citizenship, S. 62.

48 Ford Motor Company: Connecting with Society, S. 13.

49 Zur Unterscheidung Bourgeois/Citoyen vgl. auch den Beitrag von Baringhorst/ Kneip/März/Niesyto in diesem Band. 
nehmensbürger zu befördern, während die Perspektive auf die Rollenkonflikte zwischen dem unternehmerischen Bourgeois und dem Citoyen verloren geht. Deshalb sollen nun die einzelnen Rollenelemente des Corporate Citizens, ihre Veränderung durch Globalisierungsprozesse und die darin angelegten Rollenkonflikte vorgestellt und diskutiert werden.

\subsection{Unternehmen als Bourgeois}

In ihrer Hauptrolle sind Unternehmen unumstritten Bourgeois, private Wirtschaftsbürger, für die eine freie Entfaltung ihrer ökonomischen Interessen im Vordergrund steht. Die entsprechenden Rechte und Pflichten werden in Form kollektiver Spielregeln für Marktteilnehmer und als Regeln zur Verfasstheit von Unternehmen (Corporate Governance) durch die Gesellschaft festgelegt und in Wirtschafts- und Unternehmensrecht kodifiziert (z.B. Vertrags- und Kartellrecht, Schutz von Privateigentum, internationale Handelsabkommen). Die Essenz der rollenspezifischen rights and responsibilities des unternehmerischen Bourgeois ist auf einen Punkt herunterzubrechen: Er darf und muss profitabel sein. ${ }^{50}$ In Carrolls Worten:

Profit making is not antithetical to good corporate citizenship. Indeed, it is required of good citizens. Just as private individuals are expected to work and earn an income as part of participating in society and being good citizens, business organizations are expected to generate income sufficient to pay their bills and reward their investors. ${ }^{51}$

Als Wirtschaftsbürger können Unternehmen durch globale Marktöffnungsprozesse ihre Recbte auf Profitmaximierung transnational optimieren, gleichzeitig müssen sie aber auch ihrer von der Gesellschaft erwarteten Pflicht zur Profitabilität im globalen Wettbewerb nachkommen. Diese Hauptrolle als Bourgeois zieht sich durch alle weiteren untergeordneten bzw. peripheren Bürgerrollen, die Unternehmen als Weltbürger innehaben. Wenn Unternehmen ausschließlich als gemeinwohlorientierte Bürger konzipiert werden, gibt man

50 An dieser Stelle muss zumindest in einer Fußnote der meist zitierte Satz von Milton Friedman stehen: „The business of business is to make as much money as possible $[\ldots]$ ], wobei auch Friedman einen Hinweis auf die Untertanenrolle von Unternehmen hinzugefügt hat, indem er einschränkt ,[...] while conforming to the basic rules of society, both those embodied in the law and those embodied in ethical customs“ Friedman, zitiert in Carroll: „The Four Faces of Corporate Citizenship", S. 2.

51 Ebd. 
ihnen deshalb zunächst den großen Vertrauensvorschuss, ihre Hauptrolle zugunsten von Nebenrollen zu vergessen. Kritiker der Corporate-Citizenshipund CSR-Debatte berufen sich deshalb auf eben diese Rolle des Wirtschaftsbürgers, um zu argumentieren, dass Corporate-Citizenship-Aktivitäten nicht mehr sein können als Maskerade und Täuschungsmanöver von Unternehmen, um ihre eigentlichen Interessen als Wirtschaftsbürger ungestört verfolgen und durchsetzen zu können. ${ }^{52}$ Ähnlich wie eine übertriebene Euphorie für Corporate Citizenship als universeller Problemlöser für staatliche Steuerungsdefizite ist jedoch auch diese kritische Perspektive sehr einseitig: Der Corporate Citizen, der zugleich Bourgeois mit ökonomischen Eigeninteressen und Citoyen mit politischer Gemeinwohlorientierung ist, wandert zwangsläufig und permanent auf einem schmalen Grat zwischen unterschiedlichen Rollenanforderungen, die nicht selten schizophrene Verhaltenszüge zur Folge haben. Abgesehen von einigen Win-Win-Situationen sind Unternehmen in ihrer gesellschaftlichen Rolle stets im Spannungsfeld zwischen ethischem Verhalten und oberflächlicher PR im Dienste ihrer ökonomischen Interessen hin und her gerissen. Ein Beispiel hierfür ist die Automobilbranche mit ihren Imagekampagnen und ihrer öffentlichen Demonstration von technischen Neuerungen in Sachen Umweltschutz, während sie gleichzeitig mit hartnäckigem Lobbying in der EU oder mit Klagen gegen die US-Regierung versucht, strengere Schadstoffregulierung zu verhindern.

\subsection{Unternehmen als Mitglieder in einer sozialen Gemeinschaft}

In einer zweiten, peripheren Rolle als Bürger verhalten sich Unternehmen durch philanthropisches, bürgerschaftliches Engagement als kollektive, solidarische Mitglieder einer sozialen Gemeinschaft. Diese Gemeinschaft war, zumindest in den letzten Jahrhunderten und in einigen Teilen der Welt, nationalstaatlich organisiert und wurde zur Legitimierung von Zugehörigkeiten stark mit der Idee einer imaginären kulturell-sozialen Gemeinschaft der Nation verknüpft. ${ }^{53}$ Unternehmen werden in dieser Rolle als Gemeinschaftsmitglieder mit Solidaritätserwartungen konfrontiert und aufgefordert, ihre gesellschaftlichen Zugehörigkeiten durch solidarisches Verhalten zu signalisieren. Corporate Citizens erfüllen diese Rollenerwartungen vor allem in Form von bürgerschaftlichem Engagement und philanthropischen Gesten. In einer global vernetzten Gesellschaft orientieren sich auch diese Solidaritätserwartungen in zunehmendem

52 Vgl. z.B. The Economist: „The Good Company“; Shamir: „Mind the Gap“.

53 Vgl. Anderson: Die Erfindung der Nation. 
Ausmaß global, ${ }^{54}$ und Unternehmen engagieren sich daher immer öfter weltweit bzw. multi-lokal als gute Bürger. Der unternehmerische Citoyen orientiert sich dabei am ersten Teil der Rollenvorgabe Tue Gutes..., der Bourgeois wohl eher am zweiten Teil ...und rede darüber. Symbolische Demonstrationen von gutem Corporate Citizenship werden vom unternehmerischen Bourgeois vorrangig instrumentell eingesetzt und dienen der Reputationspflege, dem Risikomanagement oder aber der Abschöpfung von Win-Win-Potenzialen. ${ }^{55}$ Der Citoyen hingegen hat eine ethische Motivation aufgrund seiner Solidarität innerhalb seiner Gemeinschaft, mit der er sich identifiziert und zu der er sich zugehörig fühlt. ${ }^{56}$

\subsection{Unternehmen als Teilhaber am politischen Prozess als Regierende}

In einer ersten politischen Rolle hat ein Bürger ein Anrecht auf Partizipation am politischen Prozess als Regierender. Diese Teilhabe kann sehr unterschiedlich ausfallen, indem er z.B. Repräsentanten wählt, sich am öffentlichen Diskurs und damit an der politischen Willensbildung beteiligt, in Interessengruppen oder Parteien politisch aktiv wird etc. Auch Unternehmen beeinflussen den politischen Prozess auf unterschiedlichste Weise, wobei wieder zwischen Bourgeois oder Citoyen unterschieden werden kann: Die gesellschaftspolitischen Partizipationsmöglichkeiten vom unternehmerischen Citoyen, die bis hin zur Übernahme von staatlichen Aufgaben reichen können, wurden weiter oben im Beitrag bereits ausführlich behandelt und sollen hier nicht weiter ausgeführt werden. Indessen beeinflusst der Bourgeois den politischen Prozess durch Teilnahme am Diskurs, Lobbying etc. mit dem Ziel, seine Eigeninteressen durchzusetzen. Zugleich bestimmt er aber auch indirekt durch Entscheidungen im Rahmen seiner Geschäftstätigkeit mit, wie z.B. durch (Androhung von) Standortverlagerung. Während eine gemeinwohlorientierte politische Mitgestaltung für den unternehmerischen Citoyen also durchaus Pflichtcharakter hat, wird sie für den Bourgeois zum Teilhaberecht oder gar zur politischen Gestaltungsmacht.

54 Vgl. Beckert u.a.: Transnationale Solidarität.

55 Zur Kommunikation von Corporate Citizenship vgl. Kneip und zur ethischen Reputation vgl. Mach in diesem Band.

56 Diese idealtypischen Motivationen des Bourgeois und Citoyen zu trennen macht offensichtlich ebenfalls nur analytisch Sinn, in der Realität wird stets eine Gemengelage zwischen den beiden vorliegen, insbesondere da Unternehmen kollektive Akteure sind. 
Der Unternehmensbürger als Regierender hat im Zuge von Globalisierungsprozessen an Macht gewonnen, den öffentlichen Willensbildungsprozess, die Politikfindung und den Politikvollzug sowie die Politik von Märkten zu beeinflussen. ${ }^{57}$ Vollkommen unklar und ungeregelt bleibt allerdings, ob dieses subpolitische Engagement als Wirtschaftsbürger oder als Citoyen stattfindet. Das Problem, das sich daraus ergibt, liegt auf der Hand, denn

[...] corporations decide on the development of a global framework and influence its general conditions without being authorized or controlled democratically. ${ }^{58}$

Wenn die strukturpolitische Rolle von Unternehmen an Bedeutung gewinnt, steigt der Legitimationsbedarf ihrer politischen Teilhabe und damit der Bedarf an Kriterien und Grundregeln für eine „verantwortungsvolle“ Strukturpolitik von Unternehmen. ${ }^{59}$ Für eine aktive politische Beteiligung von Unternehmen am Global Governance fehlt also derzeit das Unterscheidungskriterium zwischen Bourgeois und Citoyen. Ohne entsprechende Kriterien wird dem Lobbying von Unternehmen für ihre Eigeninteressen Tür und Tor geöffnet und das Machtungleichgewicht noch weiter zugunsten des unternehmerischen Bourgeois verschoben. Die Herausforderung an dieser Stelle liegt also darin, die „Gestaltungsbereitschaft und Gestaltungsmacht von Unternehmen politisch kontrollierbar zu machen". 60

\subsection{Unternehmen als Regierte und Untertanen}

Da ein Bürger nicht nur regiert, sondern auch regiert wird, kann man eine weitere gesellschaftspolitische Bürgerrolle ausmachen, in der Unternehmen Regierte bzw. Untertanen sind. Der Bürgerstatus verleiht nicht nur die Lizenz zur aktiven Teilnahme am politischen Prozess, sondern verpflichtet im Gegenzug zu Gesetzeskonformität und damit zur Einhaltung der Spielregeln, die von der Bürgergemeinschaft als Rechtsgemeinschaft im politischen Prozess festgelegt und in Rechtsnormen gegossen werden. Demnach sind Unternehmen auf dieser Ebene der Organisation-Umwelt-Beziehung Adressaten von gesellschaftlichen Spielregeln, an die sie sich als Regierte halten müssten oder sollten. Im

57 Vgl. Schneidewind: Die Unternehmung als strukturpolitischer Akteur; ders.: „Unternehmen als strukturpolitische Akteure“.

58 Scherer u.a.: „Global Rules and Private Actors“, S. 519.

59 Vgl. Schneidewind: „Unternehmen als strukturpolitische Akteure“.

60 Weiß: Unternehmensführung in der Reflexiven Modernisierung, S. 151. 
Zuge von Globalisierungsprozessen wird diese unternehmerische Untertanenrolle zugunsten der politischen Selbstbestimmung geschwächt, zum einen weil nationalstaatliche und gesetzliche Regulierung im globalen Raum nicht oder nur lückenhaft greift, zum anderen weil Unternehmen sich ihre Spielregeln zunehmend selbst gestalten. Das Unternehmen als Untertan ist allerdings nicht vollkommen freigesetzt, nicht zuletzt weil es über kodifizierte, gesetzliche Regulierung hinaus eine Vielzahl informeller Spielregeln in Form von kulturellen Institutionen und normativen Verhaltenserwartungen gibt. Es hat sich vielmehr die Art und Weise des Regiert-Werdens verändert, von einem vorrangig über Gesetze geregelten Handeln im Nationalstaat zu einem schwach regulierten globalen Umfeld, in dem sozio-kulturelle und öffentliche Erwartungen an verantwortungsvolles Unternehmenshandeln an Bedeutung gewinnen. ${ }^{61}$ In anderen Worten, auf globaler Ebene werden Unternehmen immer weniger regiert und in ihre Untertanenrolle gezwungen, sondern transnational über normative Rollenerwartungen zu Untertanen sozialisiert - wobei die Effektivität einer solchen Sozialisierung natürlich niemals an die Zwänge zur Verhaltenskonformität durch gesetzliche Regulierung heranreichen kann. Dieser Wandel vom regulierten zum sozialisierten Untertan kann durch internationale Organisationen, Regierungen, aber vor allem durch NGOs unterstützt werden, indem sie die unternehmerischen Risikokosten im gesellschaftlichen Schadensfall anheben und positive Anreize für Unternehmen setzen, sich als gute Weltbürger zu verhalten. ${ }^{62}$ Entsprechend diagnostizieren einige Autoren sogar eine Verschiebung von (zwischen-) staatlicher Regulierung hin zu Civil Regulation, in der transnationale NGOs zu Regierenden werden und Unternehmen durch öffentliche Sanktionierung von Fehlverhalten in Form von Protesten und Boykotts in eine globale Untertanenrolle sozialisieren. ${ }^{63}$

Auch in der Untertanenrolle gibt es Unterschiede zwischen dem unternehmerischen Bourgeois und Citoyen: Der Bourgeois hält sich als Untertan an das Minimum gesetzlich festgelegter Spielregeln und schöpft jedwede Freiräume aus, um seine ökonomischen Interessen zu verfolgen, wie z.B. mit der Produktionsverlagerung an schwach regulierte Standorte mit ungeregelten Dumpinglöhnen oder durch Einsatz von Kinderarbeit. Der Citoyen verpflichtet sich dagegen aus ethischen Motiven heraus zur Einhaltung von höheren sozialen, ethischen und ökologischen Standards, die über das lückenhafte globale Netz gesetzlicher Regulierung hinaus gehen: „It has often been said that

61 Vgl. Curbach: „Corporate Social Responsibility“.

62 Vgl. Marsdon: „The New Corporate Citizenship of Big Business“.

63 Vgl. z.B. Bendell/Murphy: „Towards Civil Regulation“; Newell: „Environmental NGOs and Globalization“. 
law is at the floor level of acceptable behaviour. The upright corporate citizen must go beyond mere compliance with the law". 64

\section{$4 \quad$ Fazit}

Im vorliegenden Beitrag wurde versucht, das Konzept des Corporate Citizenship über unternehmerische Philanthropie und gesellschaftliche Win-WinSituationen hinaus fruchtbar zu machen. Wie gezeigt wurde, tragen Unternehmen als Corporate Citizens Rollenelemente aus allen drei Sektoren, Markt, Staat und Zivilgesellschaft in sich. Im Zuge von Marktöffnungs- und Globalisierungsprozessen wird allerdings ihre globale Wirtschaftsbürgerrolle gestärkt. Während dadurch ihre Untertanenrolle an Bedeutung verliert, gewinnt der Unternehmensbürger an politischer und gesellschaftlicher Gestaltungsmacht. Das Problem ist jedoch, dass ungeklärt bleibt, ob er als Bourgeois oder als Citoyen am politischen Prozess partizipiert, also mit Gemeinwohlorientierung oder zur Verfolgung von Eigeninteressen. Zudem wird im globalen Raum unklar, wann Unternehmen Adressaten oder Autoren von politischer Regulierung sind. In anderen Worten: Der subpolitische Unternehmensbürger regiert und wird regiert, ist politisch und ökonomisch, partikular und gemeinwohlorientiert, engagiert sich bürgerschaftlich aus ethischen und instrumentellen Motiven heraus, ohne dass die in seiner Weltbürgerrolle angelegten Rollenkonflikte von übergeordneten politischen Strukturen vermittelt und legitimiert werden können. Eine konzeptuelle Einbürgerung von Unternehmen als gute Corporate Citizens scheint dieses Problem nur teilweise zu lösen: Es können dadurch zwar Win-Win-Potenziale zwischen Gesellschaft und Markt an einigen Stellen besser genutzt werden, als Corporate Citizens bewegen sich Unternehmen aber stets im Spannungsfeld zwischen den widersprüchlichen Rollenerwartungen an den Citoyen und den Bourgeois. Denn ein Unternehmen in seiner Wirtschaftsbürgerrolle bleibt als Philanthrop vor allem an seiner Reputation und daraus resultierenden ökonomischen Zugewinnen oder Risikominimierungen interessiert; im politischen Prozess ist es hingegen unwahrscheinlich, dass der Bourgeois Regulierungsinitiativen unterstützt, die seinen Geschäftszielen schaden könnten; und als Regierter und Untertan strebt der Bourgeois danach, politische Arrangements und normative Erwartungen zu vermeiden oder im eigenen Sinne zu beeinflussen, wenn sie seine Handlungsspielräume zur Profitmaximierung schmälern. Das ist allerdings nicht unbedingt moralisch verwerflich, sondern ist so im gesellschaftlichen Rollenskript des Bourgeois verankert. Mit einer Ausblendung der Hauptrolle von Unter-

64 Carroll: „The Four Faces of Corporate Citizenship“, S. 4. 
nehmen als Bourgeois und der Zuschreibung einer Rolle als Citoyen, mit erweiterten politischen Teilhaberechten und der Zugehörigkeit zu einem soziopolitischen Kollektiv höherer Ordnung, wird daher unter Umständen das Machtungleichgewicht noch weiter zugunsten des Wirtschaftsbürgers verschoben. Grundlegende Veränderungen in der gesellschaftlichen Rolle von Unternehmen und eine Neu-Relationierung von Markt, Staat und Gesellschaft vor dem Hintergrund von Globalisierungsprozessen sind nur dann möglich, wenn auch die Spielregeln, Rechte und Pflichten der Wirtschaftsbürger in den Blick genommen und neu formuliert werden.

\section{Literaturverzeichnis}

Anderson, Benedict: Die Erfindung der Nation, Frankfurt a.M. 1996.

Backhaus-Maul, Holger: „Corporate Citizenship im deutschen Sozialstaat“, in: Aus Politik und Zeitgeschichte, B 14, 2004, S. 23-30.

Backhaus-Maul, Holger/Brühl, Hasso: Bürgergesellschaft und Wirtschaft - zur neuen Rolle von Unternehmen, Deutsches Institut für Urbanistik (DIfU), Berlin 2003.

Beck, Ulrich: Die Erfindung des Politischen, Frankfurt a.M. 2003.

Beckert, Jens u.a.: Transnationale Solidarität. Chancen und Grenzen, Frankfurt a.M./New York 2004.

Bendell, Jem/Murphy, David F.: „Towards Civil Regulation. NGOs and the Politics of Corporate Environmentalism“, in: Utting, Peter (Hrsg.): The Greening of Business in Developing Countries, UNRISD, London/New York 2002.

Börzel, Tanja/Risse, Thomas: „Public-Privat-Partnerships: Effective and Legitimate Tools of Transnational Governance?"“, in: Grande, Edgar/Pauly, Louis: The Reconstitution of Political Authority in the 21st Century, Toronto 2005, S. 195-216.

Carroll, Archie B.: „The Four Faces of Corporate Citizenship“, in: Business and Society Review, Jg. 100, Nr. 101, 1998, S. 1-7.

Curbach, Janina V.: „Corporate Social Responsibility - Unternehmen als Adressaten und Aktivisten einer transnationalen Bewegung", in: Rehberg, Karl-Siegbert (Hrsg.): Die Natur der Gesellschaft. Verhandlungen des 33. Kongresses der Deutschen Gesellschaft für Soziologie in Kassel 2006, Frankfurt a.M./New York 2007 (Beitrag auf CD-Rom im Erscheinen). 
Curbach, Janina: Global Governance und NGOs. Transnationale Zivilgesellschaft in internationalen Politiknetzwerken, Opladen 2003.

DaimlerChrysler: „About us“, www.DaimlerChrysler.com, 11.10.2006.

DaimlerChrysler: Gemeinschaft gestalten. Brücken bauen. Dialoge führen. Bericht zur Gesellschaftlichen Verantwortung, Stuttgart 2004.

Deutscher Bundestag: Bürgerschaftliches Engagement: auf dem Weg in eine zukunftsfähige Gesellschaft, Schlußbericht der Enquete-Kommission ,Zukunft des Bürgerschaftlichen Engagements‘, Berlin 2002.

Dunphy, Dexter u.a. (Hrsg.): Organizational Change for Corporate Sustainability, London/New York 2003.

Europäische Kommission/Generaldirektion Beschäftigung und Soziales: Die soziale Verantwortung der Unternehmen. Ein Unternehmensbeitrag zur nachhaltigen Entwicklung, $\operatorname{KOM}(2002) 347,2002$.

Europäische Kommission/Generaldirektion Beschäftigung und Soziales: Europäische Rahmenbedingungen für die soziale Verantwortung der Unternehmen, Grünbuch, 2001.

Exxonmobile: „Esso, Mobil and Exxonmobil in the UK“, www.Exxon mobil.co.uk, 10.10.2006.

Ford Motor Company: Connecting with Society. Building Relationships... and Setting the Course, 2000.

Habisch, André: Corporate Citizenship. Gesellschaftliches Engagement von Unternehmen in Deutschland, Berlin u.a. 2001.

Haufler, Virginia: A Public Role for the Private Sector. Industry SelfRegulation in a Global Economy, Carnegie Endowment for International Peace, Washington D.C. 2001.

Krombacher: „Homepage“, 12.04.2006.

Logsdon, Jeanne M.: „Global Business Citizenship: Applications to Environmental Issues“, in: Business and Society Review, Jg. 109, Nr. 1, 2004, S. 67-87.

Marsdon, Chris: „The New Corporate Citizenship of Big Business: Part of the Solution to Sustainability?", in: Business and Society Review, Special Edition: Corporate Citizenship for the New Millenium, Jg. 105, Nr. 1, 2000, S. 9-26.

Matten, Dirk/Crane, Andrew: „Corporate Citizenship: Toward an Extended Theoretical Conceptualization“, in: Academy of Management Review, Jg. 30, Nr. 1, 2005, S. 166-179. 
Mutz, Gerd: „Der Geist von Corporate Citizenship ist noch nicht angekommen - In Deutschland herrscht ein einseitiges Verständnis von unternehmerischem bürgerschaftlichen Engagement", in: Maecenata Aktuell, Nr. 29, 2001, S. $2-4$.

Newell, Peter: „Environmental NGOs and Globalization. The Governance of TNCs“, in: Cohen, Robin/Rai, Shirin (Hrsg.): Global Social Movements, London 2000, S. 117-133.

Pattberg, Philipp: „Private-Private Partnerships als innovative Modelle zur Regel(durch)setzung? Möglichkeiten und Grenzen eines neuen Konzepts am Beispiel des Forest Stewardship Council (FSC)“, in: Brühl, Tanja u.a. (Hrsg.): Unternehmen in der Weltpolitik: Politiknetzwerke, Unternehmensregeln und die Zukunft des Multilateralismus, Bonn 2004, S. 143162.

Rudolph, Brigitte: „Neue Kooperationsbeziehungen zwischen dem Dritten und dem Ersten Sektor - Wege zu nachhaltigen zivilgesellschaftlichen Partnerschaften?"“, in: Birkhölzer, Karl u.a. (Hrsg.): Der Dritte Sektor. Partner für Wirtschaft und Arbeitsmarkt? Opladen 2003, S. 35-98.

Scherer, Andreas G. u.a.: „Global Rules and Private Actors: Toward a New Role of the Transnational Corporation in Global Governance", in: Business Ethics Quarterly, Jg. 16, Nr. 4, 2006, S. 505-532.

Schneidewind, Uwe: „Unternehmen als strukturpolitische Akteure“, in: Einblicke. Forschungsmagazin der Carl von Ossietzky-Universität Oldenburg, Nr. 29, 1999, S. 1-4.

Schneidewind, Uwe: Die Unternehmung als strukturpolitischer Akteur. Kooperatives Schnittmengenmanagement im ökologischen Kontext, Marburg 1998.

Shamir, Ronen: „Mind the Gap: The Commodification of Corporate Social Responsibility“, in: Symbolic Interaction, Jg. 28, Nr. 2, 2005, S. 229-253.

The Economist: „The Good Company. A Survey of Corporate Social Responsibility“, Nr. 8410, 22. Januar 2005, S. 3-18.

Vidaver-Cohen, Deborah/Altman, Barbara W.: „Corporate Citizenship in the New Millenium: Foundation for an Architecture of Excellence“, in: Business and Society Review, Special Edition: Corporate Citizenship for the New Millenium, Jg. 105, Nr. 1, 2000, S. 145-168.

Waddell, Steve: „Complementary Resources. The Win-Win Rationale for Partnership with NGOs“", in: Bendell, Jem/Murphy, David F. (Hrsg.): Terms of Endearment. Business, NGOs, and Sustainable Development, Sheffield/Bristol 2000, S. 193-206. 
Weiß, Ralf: Unternehmensführung in der Reflexiven Modernisierung. Global Corporate Citizenship, Gesellschaftsstrategie und Unternehmenskommunikation, Marburg 2002.

Westebbe, Achim/Logan, David: Corporate Citizenship: Unternehmen im gesellschaftlichen Dialog, Wiesbaden 1995.

World Economic Forum: „Corporate Citizenship“, weforum.org/corporate citizenship, 14.08.2006.

Zadek, Simon: The Civil Corporation, London 2001.

Zürn, Michael: Regieren jenseits des Nationalstaates. Globalisierung und Denationalisierung als Chance, Frankfurt a.M. 1998. 


\section{Karin Lukas}

\section{Menschenrechtliche Verantwortung von Unternehmen}

Menschenrechte $^{1}$ als universelle Rechte, welche weltweit Geltung besitzen, sind die angeborenen unveräußerlichen Rechte eines jeden Menschen:

Da die Anerkennung der angeborenen Würde und der gleichen und unveräußerlichen Rechte aller Mitglieder der Gemeinschaft der Menschen die Grundlage von Freiheit, Gerechtigkeit und Frieden in der Welt bildet, $[\ldots]$ verkündet die Generalversammlung diese Allgemeine Erklärung der Menschenrechte als das von allen Völkern und Nationen zu erreichende gemeinsame Ideal, damit jeder einzelne und alle Organe der Gesellschaft sich diese Erklärung stets gegenwärtig halten und sich bemühen, durch Unterricht und Erziehung die Achtung vor diesen Rechten und Freiheiten zu fördern und durch fortschreitende nationale und internationale Maßnahmen ihre allgemeine und tatsächliche Anerkennung und Einhaltung durch die Bevölkerung der Mitgliedstaaten selbst wie auch durch die Bevölkerung der ihrer Hoheitsgewalt unterstehenden Gebiete zu gewährleisten. ${ }^{2}$

In den letzten Jahren hat die Diskussion um eine mögliche menschenrechtliche Verantwortung nicht-staatlicher Akteure als Organe der Gesellschaft auch im Bereich des Rechts große Dynamik gewonnen. Ausgelöst durch die Beteiligung von Unternehmen an Menschenrechtsverletzungen ${ }^{3}$, Berichte von menschenrechtswidrigen Arbeitsbedingungen vor allem für Frauen ${ }^{4}$ und eine Reihe von

$1 \mathrm{Zu}$ den Menschenrechten gehören bürgerliche und politische Rechte (z.B. das Recht auf Leben, das Recht auf persönliche Freiheit und Sicherheit, auf Gleichheit, und das Recht auf Versammlungsfreiheit) sowie wirtschaftliche, soziale und kulturelle Rechte (z.B. das Recht auf Erwerbsmöglichkeit und gerechten Lohn). Eine Textsammlung der wichtigsten Menschenrechtsinstrumente findet sich online unter www.bpb.de/files/67JIPU.pdf.

2 Vereinte Nationen: „Die Allgemeine Erklärung der Menschenrechte“.

3 Beispielsweise im Kontext der Bohrungen von Shell im nigerianischen Ogoniland oder des Baus von Gasleitungen unter Verwendung von Zwangsarbeit mit Beteiligung von Unocal in Burma.

4 Hier wären Berichte über Arbeitsbedingungen in Fabriken von NIKE in Südostasien zu nennen, die zu einem breiten Konsumboykott von NIKE-Produkten in den Vereinigten Staaten geführt haben. NIKE hat als Reaktion darauf einen Verhaltenkodex entwickelt und versucht, einen Ruf als Corporate Citizen aufzubauen. Vgl. Williams: „The Role of Non-State Actors in Securing and Developing Human Rights“, S. 28. 
Bilanzskandalen ${ }^{5}$ ist eine heftige Diskussion darüber entstanden, ob das traditionelle Konzept des Staates als maßgeblich menschenrechtlich Verantwortlichem noch zeitgemäß sein kann. So wird beispielsweise befürchtet, dass das Völkerrecht seinen universellen Geltungsanspruch verlieren könnte, wenn multinationale Unternehmen nicht als relevante Akteure in das Völkerrecht integriert werden. ${ }^{6}$ Im derzeitigen Diskurs lassen sich dazu verschiedene Entwicklungen ausmachen.

\section{Staatliche Schutzpflicht und indirekte Verantwortung von Unternehmen}

Der Staat hat die rechtliche Verpflichtung, Menschenrechtsverletzungen durch Unternehmen zu verhindern bzw. zu ahnden. Dies ergibt sich aus seiner Schutzpflicht, die in verschiedenen Menschenrechtskonventionen verankert ist. Mit der Ausübung dieser Schutzpflicht kommt es zu einer indirekten Verantwortung von Unternehmen für die Einhaltung von Menschenrechten. Die Implementierung indirekter Verantwortung von Unternehmen kann einerseits auf Initiative von Staatengemeinschaften erreicht werden. So sehen etwa Maßnahmen der Europäischen Union (EU) zur Bekämpfung des Menschenhandels eine strafrechtliche Verantwortung von juristischen Personen (auch außerhalb des jeweiligen Mitgliedstaats) vor. Laut Artikel 4 des Rahmenbeschlusses trifft jeder Mitgliedstaat die

erforderlichen Maßnahmen, um sicherzustellen, dass eine juristische Person für eine Straftat nach den Artikeln 1 und 2 verantwortlich gemacht werden kann, die zu ihren Gunsten von einer Person begangen wurde, die entweder allein oder als Teil eines Organs der juristischen Person gehandelt hat und die eine Führungsposition innerhalb der juristischen Person innehat. ${ }^{7}$

5 Beispielhaft kann hier der Enron-Skandal angeführt werden, der zu Verurteilungen der Führungsspitze wegen Betrugs geführt hat, siehe Tagesschau: „Jury spricht Enron-Bosse schuldig“. Zu den menschenrechtlichen Verwicklungen der EnronTochter Enron Power Development Corporation vgl. Human Rights Watch: „The Enron Corporation: Corporate Complicity in Human Rights Violations".

6 Vgl. Hobe: „Die Zukunft des Völkerrechts im Zeitalter der Globalisierung“, S. $263 f$.

7 Europäischer Rat: „Rahmenbeschluss des Rates vom 19. Juli 2002 zur Bekämpfung des Menschenhandels“. Artikel 1 umfasst den Tatbestand des Menschenhandels zum Zweck der Ausbeutung der Arbeitskraft oder zum Zweck der sexuellen 
Andererseits kann auf einzelstaatlicher Ebene die Umsetzung sowohl im Strafrecht als auch im Zivilrecht erfolgen. So begründet der bislang weltweit einzigartige, im Jahre 1789 vom ersten Kongress erlassene US-amerikanische Alien Tort Claims Act (ATCA) eine zivilrechtliche Haftung von Unternehmen für Menschenrechtsverletzungen, auch wenn diese außerhalb der USA begangen werden: „, $[\mathrm{t}]$ he district courts shall have original jurisdiction of any civil action by an alien for a tort only, committed in violation of the law of nations or a treaty of the United States." ${ }^{\text {"8 }}$ Seit Mitte der 1990er Jahre werden in den USA Klagen gegen multinationale Unternehmen wegen Menschenrechtsverletzungen auf den ATCA gestützt. Im Jahr 1996 reichten z.B. burmesische Bauern beim District Court von Kalifornien Klage gegen den in Kalifornien ansässigen Ölkonzern Unocal ein. Ihr Vorwurf an Unocal lautete, dass der Konzern von schweren Menschenrechtsverletzungen, die durch burmesische Soldaten im Rahmen der Absicherung eines Pipelineprojekts von Unocal begangen wurden, wissentlich profitiert habe. Das Gericht erkannte zwar, dass Unocal wissentlich aus den Menschenrechtsverletzungen - wie z.B. von Tötungen von Gegnern des Projekts - profitierte, wies die Klage dennoch aus verschiedenen Gründen ab. Nach Diskussionen über eine Neuverhandlung, wurde der Beginn der Geschworenenverhandlung über die Mittäterschaft von Unocal an Mord, Vergewaltigung und Zwangsarbeit vom Superior Court of California für den Juni 2005 festgesetzt. Schließlich einigten sich die Kläger und Unocal im März 2005 außergerichtlich auf Vergleich.?

Maßnahmen wie der ATCA können als Versuch gewertet werden, dem Regelungsdefizit, das durch die Zersplitterung von multinational operierenden Unternehmen in zahlreiche selbständige juristische Personen des Privatrechts im In- und Ausland bedingt ist, entgegenzuwirken.

\section{Direkte Verantwortung von Unternehmen}

Neben dieser indirekten Verantwortung durch die menschenrechtliche Schutzpflicht des Staates und der Staatengemeinschaft verdichten sich erste Ansätze für eine direkte menschenrechtliche Verantwortung von Unternehmen, welche einen Paradigmenwechsel einläuten könnten. Dies bedeutet, dass vor allem transnational agierende Unternehmen (Transnational Corporations, TNCs) auf internationaler Ebene als Völkerrechtssubjekte anerkannt und dement-

Ausbeutung; Artikel 2 beinhaltet die Anstiftung, Beihilfe oder den Versuch zur Straftat.

8 Zitiert nach Schneebaum: „Human rights in the United States courts“.

9 Vgl. EarthRights International: „Doe v. Unocal Case History“. 
sprechend für Menschenrechtsverletzungen direkt, ohne Umweg über den Staat, verantwortlich gemacht werden können. Eine direkte Verantwortung von Unternehmen kann dabei unterschiedlich ausgestaltet sein. Zum einen können Unternehmen durch die Schaffung einer multilateralen Menschenrechtskonvention, der Staaten bzw. Unternehmen beitreten, direkt verantwortlich gemacht werden. Zum anderen ist ein völkerrechtlicher Vertrag zulasten Dritter (also zulasten der Unternehmen) mit Repräsentanz durch den Sitzstaat vorstellbar. In beiden Fällen könnte menschenrechtswidriges Verhalten sowohl durch die Schaffung eines internationalen Gerichtshofs als auch durch nationale Gerichte geahndet werden. Allerdings ist die Umsetzung von Ansätzen direkter menschenrechtlicher Verantwortung von Unternehmen im Vergleich zu der von Einzelstaaten sicher langwieriger. Darüber hinaus sind internationales und nationales Strafrecht wechselseitig miteinander verbunden. Die internationale ist nicht ohne die nationale Ebene denkbar, da internationales Recht davon lebt, dass es innerstaatlich umgesetzt wird. Es kommt nicht von ungefähr, dass US-amerikanische Gerichte sich auf Urteile des Internationalen Strafgerichtshofs über das ehemalige Jugoslawien stützen, um die Beteiligung von Unternehmen an schwerwiegenden Menschenrechtsverletzungen zu prüfen und zu begründen.

Direkte Formen menschenrechtlicher Verantwortung von Unternehmen stellen einen Paradigmenwechsel im menschenrechtlichen Diskurs dar und sind dementsprechend umstritten. Generell lässt sich eine gewisse Unklarheit darüber erkennen, wie weit eine solche Verantwortung gehen kann und soll. So schreibt die UNO Hochkommissarin für Menschenrechte in ihrem aktuellen Bericht zum Thema Unternehmen und Menschenrechte vom März 2005:

Es gibt noch immer eine Lücke im Verständnis darüber, was die internationale Gemeinschaft von Unternehmen im Hinblick auf die Menschenrechte erwartet [...] Die Klärung der Verantwortung von Unternehmen für Menschenrechte könnte mögliche menschenrechtliche Probleme verhindern, die Staaten dabei unterstützen, Unternehmen effektiver zu regulieren und gleichzeitig die unternehmerischen Leistungen zur Förderung der Menschenrechte stärker bündeln. ${ }^{10}$

Bisher existiert - wie auch die Aussage der Hochkommissarin zeigt - nur ein Patchwork an rechtlichen Mechanismen, um die menschenrechtliche Verantwortung von Unternehmen zu etablieren und durchzusetzen.

10 UN Economic and Social Council: „Report of the Sub-Comission on the Promotion and Protection of Human Rights“, S. 8, Übersetzung K.L. 


\subsection{Die UN Draft Norms}

Ein wichtiger Vorstoß in diese Richtung sind allerdings die so genannten „Draft Norms" 11 der UNO Unterkommission zur Förderung und zum Schutz der Menschenrechte, welche von eben dieser im August 2003 einstimmig angenommen wurden. Im Kommentar zu den Normen für die Verantwortlichkeiten transnationaler Unternehmen und anderer Wirtschaftsunternehmen im Hinblick auf die Menschenrechte heißt es:

Die Staaten tragen die Hauptverantwortung für die Förderung der im Völkerrecht wie im innerstaatlichen Recht anerkannten Menschenrechte, die Sicherung ihrer Einhaltung, ihre Achtung und die Gewährleistung ihrer Achtung sowie ihren Schutz, namentlich auch für die Gewährleistung dessen, dass transnationale Unternehmen und andere Wirtschaftsunternehmen die Menschenrechte achten. Innerhalb ihres jeweiligen Tätigkeits- und Einflussbereichs sind transnationale Unternehmen und andere Wirtschaftsunternehmen verpflichtet, die im Völkerrecht wie im innerstaatlichen Recht anerkannten Menschenrechte zu fördern, ihre Einhaltung zu sichern, sie zu achten, ihre Achtung zu gewährleisten und sie zu schützen, einschließlich der Rechte und Interessen indigener Völker und anderer schwächerer Gruppen. ${ }^{12}$

Die Draft Norms unterstreichen somit, dass die primäre Verantwortung für Menschenrechte bei den Staaten verbleiben sollte; sie nennen jedoch unternehmensrelevante Bereiche, die auch TNCs und andere Unternehmen in die menschenrechtliche Pflicht nehmen. Das sind im Einzelnen:

- das Verbot von Diskriminierung;

- das Recht auf Sicherheit (kein Engagement in und keine Vorteile aus Kriegsverbrechen, Genozid, Folter, Zwangsarbeit, außergerichtlichen Exekutionen);

- die Einhaltung der von der ILO (International Labour Organisation) festgelegten Kernarbeitsnormen;

11 Vgl. Sub-Commission on the Promotion and Protection of Human Rights: „Fiftyfifth session".

12 Wirtschafts- und Sozialrat der Vereinten Nationen: „Wirtschaftliche, Soziale und Kulturelle Rechte“, S. 4. 
- Respect for National Souvereignty and Human Rights - eine Sammlung von Regelungen wie z.B. die Einhaltung von Transparenz, Accountability oder Korruptionsbekämpfung und

- die Förderung von wirtschaftlichen, sozialen und kulturellen Rechten (WSK-Rechte) sowie des Rechts auf Entwicklung.

Nachdem die Unterkommission die Normen verabschiedet hat, wurden sie zur Menschenrechtskommission weitergeleitet, die sich im April 2004 gegen die Annahme der Normen entschied, aber beschloss, sie einer eingehenden Prüfung zu unterziehen. Im Juli 2005 ernannte UN-Generalsekretär Kofi Annan John G. Ruggie für eine Dauer von 18 Monaten als Special Representative on Human Rights and Business, welcher die folgenden Aufgaben zugeteilt bekam:

(a) To identify and clarify standards of corporate responsibility and accountability for transnational corporations and other business enterprises with regard to human rights;

(b) To elaborate on the role of States in effectively regulating and adjudicating the role of transnational corporations and other business enterprises with regard to human rights, including through international cooperation;

(c) To research and clarify the implications for transnational corporations and other business enterprises of concepts such as complicity and sphere of influence;

(d) To develop materials and methodologies for undertaking human rights impact assessments of the activities of transnational corporations and other business enterprises;

(e) To compile a compendium of best practices of States and transnational corporations and other business enterprises. ${ }^{13}$

In seinem ersten Zwischenbericht im Februar 2006 äußerte sich John G. Ruggie im Februar 2006 vorsichtig gegen den o.g. Paradigmenwechsel und betonte die Bedeutung der Kooperation zwischen Wirtschaft, Zivilgesellschaft, Regierungen und internationalen Organisationen. ${ }^{14}$ In seinem jüngsten Bericht kommt Ruggie zu folgendem eher vagen Schluss:

13 Ruggie: „Interim report of the Special Representative of the Secretary-General“, S. 3, Abschnitt 1.

14 Vgl. ebd., S. 17, Abschnitt 69. 
The extensive research and consultations conducted for this mandate demonstrate that no single silver bullet can resolve the business and human rights challenge. A broad array of measures is required, by all relevant actors. ${ }^{15}$

Auch wenn nach wie vor die Frage offen ist, ob und inwieweit die UN Draft Norms rechtlich verbindlich werden, kann bereits jetzt von einem wichtigen Schritt gesprochen werden:

Even if transnational corporations and other business enterprises are not legally bound by the Norms, there will be considerable pressure to comply with the Norms, since individual companies will be exposed to world public opinion - their customers - in the respected forum of the UN. ${ }^{16}$

So können die UN Draft Norms trotz der zum Teil berechtigten Kritik ${ }^{17}$ als „autoritativer Wegweiser" ${ }^{\text {"18 }}$ für Unternehmen und als wichtiger Schritt zur Klärung unternehmerischer Verantwortung für Menschenrechte angesehen werden. Sie fassen in sehr klarer Form die unternehmensrelevanten Bereiche Kernarbeitsnormen, Nichtdiskriminierung, Rechte auf Unversehrtheit und Sicherheit sowie WSK-Rechte aus menschenrechtlicher Sicht zusammen. Dies ist umso bedeutender in einem Aktivitätsfeld, das von unterschiedlichen Standards, Interpretationen und Sichtweisen geprägt ist. Insofern sind die Draft Norms ein sinnvoller Ansatzpunkt, um dieses wichtige Thema zu vertiefen. Des Weiteren legen sie normative Grundlagen der Einhaltung von Menschenrechten fest und spielen daher bei der Entwicklung verbindlicher menschenrechtlicher Regeln für Unternehmen eine wichtige Rolle.

15 Human Rights Council: „Report of the Special Representative of the SecretaryGeneral on the issue of human rights and transnational corporations and other business enterprises“, S. 24, Abschnitt 88.

16 Hillemanns: „UN Norms on the Responsibilities of Transnational Corporations and Other Business Enterprises with regard to Human Rights“.

17 U.a. wurde in den Normen die Gefahr einer Privatisierung des Menschenrechtsschutzes gesehen.

18 Hillemanns: „UN Norms on the Responsibilities of Transnational Corporations and Other Business Enterprises with regard to Human Rights“. 


\subsection{Die Rolle der Europäischen Union}

Wie steht die Europäische Union zu dieser in gewisser Weise revolutionären Erweiterung unternehmerischer Verantwortung, wie sie in den oben genannten Draft Norms entwickelt wurde? ${ }^{19}$ Illustrativ scheint hier die Position der Europäischen Kommission zu sein, nach der Menschenrechte keine direkte rechtliche Bindung für Unternehmen begründen, außer wenn das Unternehmen staatliche Funktionen ausübt. Unternehmensverantwortung wird vor allem Bezug nehmend auf den „Internationalen Pakt über bürgerliche und politische Rechte" thematisiert, in dessen Sinne die Kommission auf die Pflicht von Unternehmen verweist, sicherzustellen, dass sie nicht an Menschenrechtsverletzungen beteiligt sind. Auch ein Blick auf die EU-Außenpolitik zeigt, dass die Kommission politische Interventionen in Form gesetzlicher Festlegungen (bard law) scheut. Stattdessen sollen die Verbreitung des Konzepts der Corporate Social Responsibility (CSR) in den Entwicklungsländern gefördert und multinationale Unternehmen ermuntert werden, eine Rolle in der Förderung von Menschenrechten und ArbeitnehmerInnenrechten zu übernehmen - vor allem in Ländern mit einem schlechten Ruf in den genannten Bereichen. Strategisch und psychologisch gesehen hat es sicher Vorteile, einen persuasiven, weichen und ermunternden Zugang zur Unternehmensverantwortung zu wählen - diejenigen Unternehmen, die sozialer Verantwortungsübernahme prinzipiell ablehnend gegenüberstehen, fühlen sich durch einen solchen Steuerungsansatz allerdings nicht angesprochen.

Die jüngste Mitteilung der Kommission zur Umsetzung der Partnerschaft für Wachstum und Beschäftigung zeigt, dass Freiwilligkeit weiterhin das dominante Prinzip europäischer sozialer Unternehmensverantwortung bleibt:

Die Kommission möchte [...] der sozialen Verantwortung der Unternehmen eine größere politische Außenwirkung verleihen, sie möchte anerkennen, was europäische Unternehmen in diesem Bereich bereits leisten, und sie dazu ermutigen, noch mehr zu tun. Da es bei CSR im Wesentlichen um ein freiwilliges Tätigwerden der Unternehmen geht, könnte sich ein Konzept, das zusätzliche Verpflichtungen und administrative Anforderungen an die Unternehmen beinhaltet, als kontraproduktiv erweisen und würde den Grundsätzen der besseren Rechtsetzung entgegenlaufen. Da die Unternehmen die Hauptakteure im Bereich CSR sind, ist die Kommission zu dem Schluss gelangt, dass sie ihre Ziele am besten durch eine engere Zusammenarbeit mit den europäischen Unternehmen erreichen kann. Sie erklärt daher ihre

19 Zur Frage der Position der EU zu menschenrechtsrelevanter CSR siehe auch Lukas/Röhsler: „Vorwärts in die Vergangenheit?“. 
Unterstützung für die Schaffung eines Europäischen Bündnisses für CSR, ein Konzept, das auf Beiträgen von Unternehmen basiert, die aktiv die Förderung von CSR betreiben. ${ }^{20}$

In diesem Sinne werden verschiedene Aspekte genannt, auf welche die Kommission bei der weiteren Förderung von CSR den Schwerpunkt legen möchte, unter anderem die Sensibilisierung und den Austausch von vorbildlichen Verfahren, die Unterstützung von Multi-Stakeholder-Initiativen oder Verbraucherinformation und Transparenz. Es ist anzunehmen, dass die EU ihre Skepsis gegenüber der Verantwortung von Unternehmen für Menschenrechtsverletzungen nicht ändern wird. Der internationale Trend geht jedoch in Richtung einer stärkeren Unternehmensverantwortung. Die Europäische Kommission beobachtet zwar relevante internationale Prozesse und erwähnt in ihrer Mitteilung sowohl die Arbeit des o.g. UN-Sonderberichterstatters als auch die ISO-Initiative zur Erarbeitung von Richtlinien zu Sozialer Verantwortung ${ }^{21}$ oder den Kimberley-Prozess ${ }^{22}$. Fraglich bleibt allerdings, wie die Kommission vorgehen wird, wenn die von diesen Initiativen entwickelten Maßnahmen ein höheres $\mathrm{Maß}$ an Verbindlichkeit erhalten. Dass dies nicht unwahrscheinlich ist, belegt beispielsweise der Ausschluss der Demokratischen Republik Kongo aus dem Kreis der Mitgliedstaaten des Kimberley-Prozesses wegen Nichteinhaltung der Kimberley-Standards. Gerade für die Erreichung der wirtschaftlichen Ziele der EU, wie die Verbesserung der Wettbewerbsfähigkeit und Innova-

20 Europäische Kommission: „Mitteilung der Kommission an das Europäische Parlament, den Rat und den Europäischen Wirtschafts- und Sozialausschuss“, S. 3.

21 Mit der so genannten ISO 26000 wird CSR zum Thema internationaler Standardisierungsaktivitäten. Bei ihrer Tagung Ende Januar 2007 in Sydney hat die ISO beschlossen, bis Ende 2008 eine neue Richtlinie für soziale Verantwortung zu erarbeiten. Diese Richtlinie soll Standards der Social Responsibility (SR) für alle Organisationen und nicht nur exklusiv für Unternehmen festlegen. Im Mittelpunkt stehen dabei soziale und ökologische Basisstandards, etwa das Verbot der Kinderarbeit und das Recht von Beschäftigten, freie Verhandlungen über ihre Bezahlung zu führen. Der aktuelle Entwurf beinhaltet darüber hinaus, dass auch die direkten Zulieferer in den Verantwortungsbereich des Unternehmens fallen. ISO 26.000 soll weltweit gelten, wird aber keinen rechtlich verbindlichen Charakter haben. Vgl. ISO Central Secretariat: „ISO and Social Responsibility“.

22 Ziel des Kimberley-Prozesses ist es über staatliche Herkunftszertifikate den Handel mit so genannten Kriegs- oder Blutdiamanten zu unterbinden, deren Erlöse dazu genutzt wurden bzw. werden, verschiedene Kriege in Afrika zu finanzieren. Am Kimberley-Prozess beteiligen sich sowohl Staaten als auch die Diamantenindustrie und zivilgesellschaftliche Institutionen. Im November 2002 wurde das so genannte Kimberley Process Certification Scheme (KPCS) beschlossen, wonach offizielle Herkunftszertifikate des jeweiligen Ursprungslandes für den Handel mit Diamanten vorliegen müssen. Vgl. Kimberley Process: „Background“. 
tionsleistung sowie die Schaffung von Arbeitsplätzen, wäre es notwendig, Regeln zu schaffen, welche die Bedeutung menschenrechtlicher Verantwortung für Unternehmen einheitlich und klar festlegen. Nur mit einheitlichen Regelungen, die in der gesamten EU gelten, könnten Wettbewerbsverzerrungen vermieden und könnte sichergestellt werden, dass CSR-Pionierunternehmen für ihr Engagement nicht länger wirtschaftlich benachteiligt werden.

Europa soll auf dem Gebiet der sozialen Verantwortung der Unternebmen fübrend werden lautet zwar das Credo der bereits erwähnten Mitteilung der Europäischen Kommission. Um diesem selbst auferlegten Credo gerecht zu werden, wären jedoch weitergehende Maßnahmen notwendig. Die EU-Staaten haben sich zur Einhaltung der Menschenrechte verpflichtet. Dies müsste bedeuten, dass die EU Regelungen schafft, um Menschenrechtsverletzungen von Unternehmen, die in der EU tätig sind bzw. ihren Sitz in einem Mitgliedstaat haben, zu verhindern. Da der Handlungsraum transnationaler Unternehmen über einzelstaatliche Grenzen hinausgeht, wären sanktionierende Interventionen auf überstaatlicher, europäischer Ebene sinnvoll und erfolgversprechend. Eine gemeinschaftliche und damit einheitliche Regelung unternehmerischer Verantwortung für Menschenrechte würde für alle Unternehmen mit Sitz in der EU gleiche Bedingungen schaffen und damit Wettbewerbsverzerrungen zwischen Unternehmen der einzelnen Mitgliedstaaten auch bezüglich ihrer Unternehmungen außerhalb der Union verhindern. Ein Level Playing Field mit transparenten und gleichen Voraussetzungen für alle wäre möglich, und einzelstaatliches Handeln müsste sich von der Unternehmensseite die zu befürchtenden Wettbewerbsnachteile nicht vorhalten lassen. Ein verbindlicher Ansatz zur Schließung der Verantwortungslücke wäre aber durchaus auch im Interesse von Unternehmen: Einheitliche Standards würden für mehr Klarheit der Do's and Don'ts sorgen, Wettbewerbsnachteile gegenüber unethischen Konkurrenten abbauen und kostspielige, rufschädigende Prozesse vermeiden helfen.

\section{Menschenrechtliche Verantwortung von Unternehmen durch Eigeninitiative}

Unternehmen können sich schließlich selbst - unabhängig von einer direkten oder indirekten Einklagbarkeit ihrer Verantwortung - zur Einhaltung menschenrechtlicher Normen verpflichten. Beispielsweise können menschenrechtliche Standards Bestandteil der Verträge zwischen Unternehmen und Regierungen sein. So wurden vor dem Bau der Pipeline Baku-Tbilisi-Ceyhan im Jahr 2003 Abkommen (Host Government Agreements) zwischen Aserbaidschan, Georgien, der Türkei und dem Konsortium BTC Co abgeschlossen, in denen 
sich die Parteien verpflichten, die internationalen Menschenrechtsstandards, Arbeitsrechte und relevante Umweltstandards einzuhalten. Ebenfalls als Bestandteil in die Abkommen aufgenommen wurde die Verpflichtung, die Voluntary Principles on Security and Human Rights einzuhalten. Zusätzlich wurde noch ein unwiderrufbarer Vertrag geschlossen, in dem sich BTC Co verpflichtet, die Verantwortung der drei Staaten für den Schutz der Menschenrechte zu respektieren. Dieses Beispiel zeigt, dass staatliche Regulierung und freiwillige Unternehmensmaßnahmen durchaus verbunden werden können.

Die meisten Beispiele erfolgreicher CSR-Projekte sind sektor- bzw. branchenspezifische Multistakeholder-Initiativen. Es handelt sich primär um Initiativen, die eine enge Zusammenarbeit zwischen Unternehmen, Gewerkschaften, Beschäftigten und lokalen NGOs aufweisen. Diese Zusammenarbeit geht über das bloße Überwachen der unternehmensinternen Menschenrechtspolitik hinaus und integriert beispielsweise Staff-Trainings, Empowerment der Beschäftigten und eine unabhängige Monitoring-Funktion der Gewerkschaften bzw. lokalen NGOs. Ein Beispiel für eine relativ erfolgreiche Multistakeholder-Initiative im Bereich Kernarbeitsrechte ist die Zusammenarbeit zwischen dem schwedischen Möbelhersteller IKEA, der International Federation of Building and Wood Workers (IFBWW), Save the Children und UNICEF.23 Dieses Projekt führt die Überwachung der Einhaltung von Kernarbeitsnormen, insbesondere das Verbot von Kinderarbeit, unter Konsultation von Stakeholdern mit Expertise in diesen Bereichen durch. Die Überwachung weist auch einige innovative Elemente auf, wie etwa die Einrichtung eines IKEA Children's Ombudsman. Eine weitere interessante Unternehmensgruppe ist die Business Leaders Initiative on Human Rights, eine Gruppe von 13 Unternehmen, darunter The Body Shop, Barclays, GAP, und Hewlett-Packard. ${ }^{24}$ Präsidentin der Gruppe ist die ehemalige Hochkommissarin für Menschenrechte, Mary Robinson. Die Business Leaders Initiative hat einen griffigen und anwendungsfreundlichen Leitfaden zur Implementierung von Menschenrechten im Geschäftsablauf herausgegeben. Dieser Leitfaden unterstützt Schritt für Schritt die Umsetzung von Menschenrechten im Betrieb; folgende Fragen sind dabei zentral:

- Welche Menschenrechte sind für ein Unternehmen in einem bestimmten Sektor relevant?

23 Näheres unter www.ikea.com; dazu kritisch de Haan/Oldenziel: „Labour conditions in IKEA's supply chain“.

24 Vgl. Business Leaders Initiative on Human Rights: „Human Rights in the Business Sphere“. 
- Wie kann ein rights-aware approach, also ein Zugang, der Menschenrechte explizit einbezieht, entwickelt werden?

- Wie können Menschenrechte in bestehende Geschäftabläufe und Geschäftsrichtlinien integriert werden?

- Wie kann diese menschenrechtliche Leistung (performance) gemessen, überwacht, und transparent kommuniziert werden?

Unbestritten bleibt, dass nur durch politische und rechtliche Regulierungen auf supra- oder internationaler Ebene auch diejenigen Unternehmen erreicht werden können, die der Übernahme ihrer CSR ablehnend gegenüberstehen. Allerdings wird die Umsetzung von Menschenrechten von Pionierunternehmen zunehmend als Chance gesehen, sich von Konkurrenten abzuheben und sich im Aktionsfeld Menschenrechte als Good Corporate Citizen positiv zu profilieren. ${ }^{25}$

\section{$4 \quad$ Ausblick}

Zusammenfassend ist festzustellen, dass die bestehenden Mechanismen auf supra- und internationaler Ebene bisher insgesamt noch zu schwach sind, um die menschenrechtliche Verantwortung von Unternehmen durchzusetzen. Dies ist darauf zurückzuführen, dass sich zum einen die Verantwortung von Unternehmen als direkte menschenrechtliche Adressaten erst entwickelt, und zum anderen die internationalen Durchsetzungsmechanismen nicht genügend ausgeprägt sind. Solche die Grundstrukturen des internationalen Rechts ändernden Prozesse benötigen Zeit. Menschenrechtliche Standards, die nach Ende des Zweiten Weltkrieges auf internationaler Ebene geschaffen wurden, sind heute weltweit anerkannt und prinzipiell durchsetzbar. Bis zu ihrer rechtlich verbindlichen Durchsetzung im Kontext der Verantwortung von Unternehmen spielen vor allem die so genannten soft laws sowie der Druck der Öffentlichkeit eine entscheidende Rolle. ${ }^{26}$ KonsumentInnen und engagierten NGOs ist es zu verdanken, dass die soziale Verantwortung von Unternehmen sowohl die (massen-) mediale als auch die Unternehmensagenda erreicht hat. Zentral ist hierbei einerseits die Aufmerksamkeit und kritische Würdigung der Unternehmensaktivitäten im Bereich CSR bzw. Corporate Citizenship durch die öffentliche Meinung und andererseits der öffentlich ausgeübte Druck auf Regierungen, ihre Regulierungspflicht und menschenrechtliche Verantwortung

25 Zur Selbstlegitimation von Unternehmen durch Anknüpfung an Bürgerschaftskonzepte vgl. Kneip in diesem Band.

26 Zur sanften Macht der Verbraucheröffentlichkeit vgl. Beetz in diesem Band. 
wahrzunehmen. Nur durch diesen beidseitigen Druck kann die menschenrechtliche Verantwortung von Unternehmen vorangetrieben werden. Die verschiedenen Akteure müssen versuchen, die bestehende Verantwortungslücke im Rahmen ihrer Möglichkeiten und Verpflichtungen gemeinsam zu schließen. Insofern besteht eine geteilte Verantwortung von Staaten und Unternehmen, Menschenrechte in ihrer Einflusssphäre zu schützen und zu fördern. Auch der UN-Sonderberichterstatter unterstreicht den Aspekt der geteilten Verantwortung und verweist dabei auf den Ansatz geteiller Verantwortung von Iris Marion Young: 27

The soft law hybrids have made a singular contribution by acknowledging that for some purposes the most sensible solution is to base initiatives on the notion of shared responsibility from the start - a conclusion some moral philosophers have also reached with regard to global structural inequities that cannot be solved by individual liability regimes alone. ${ }^{28}$

Freiwillige Aktivitäten der Unternehmen und staatliche Regulierung sind nicht gegeneinander auszuspielen, sondern sind beide legitime Mittel, um die menschenrechtliche Verantwortung von Unternehmen zu stärken.

\section{Literaturverzeichnis}

Business Leaders Initiative on Human Rights: „Human Rights in the Business Sphere“, www.blihr.org, 24.04.2007.

EarthRights International: „Doe v. Unocal Case History“, 30.01.2006, www.earthrights.org/content/view/1/25/, 01.09.2006.

Europäische Kommission: „Mitteilung der Kommission an das Europäische Parlament, den Rat und den Europäischen Wirtschafts- und Sozialausschuss. Umsetzung der Partnerschaft für Wachstum und Beschäftigung: Europa soll auf dem Gebiet der Sozialen Verantwortung der Unternehmen führend werden“, Brüssel 2006, eur-lex.europa.eu/LexUriServ/ site/de/com/2006/com2006_0136de01.pdf, 13.05.2006.

Europäischer Rat: „Rahmenbeschluss des Rates vom 19. Juli 2002 zur Bekämpfung des Menschenhandels“, Brüssel 2002, eur-lex.europa.eu/

27 Vgl. Young: „Responsibility and Global Labor Justice“.

28 Human Rights Council: „Report of the Special Representative of the SecretaryGeneral on the issue of human rights and transnational corporations and other business enterprises“, S. 24, Abschnitt 87. 
LexUriServ/LexUriServ.do?uri=CELEX:32002F0629:DE:HTML, 13.05.2007.

Haan, Esther de/Oldenziel, Joris: „Labour conditions in IKEA’s supply chain“, www.somo.nl/html/paginas/pdf/IKEA_final_report_2003_EN.pdf, 23.04.2007.

Hillemanns, Carolin: „UN Norms on the Responsibilities of Transnational Corporations and Other Business Enterprises with regard to Human Rights“, in: German Law Journal, Jg. 4, Nr. 10, 2003, www.german lawjournal.com/print.php?id=330\#_edn1, 15.05.2007.

Hobe, Stephan: „Die Zukunft des Völkerrechts im Zeitalter der Globalisierung“, in: Archiv des Völkerrechts, Nr. 37, 1999, S. 253-282.

Human Rights Council: „,Report of the Special Representative of the SecretaryGeneral on the issue of human rights and transnational corporations and other business enterprises“, www.business-humanrights.org/Documents/ SRSG-report-Human-Rights-Council-19-Feb-2007.pdf, 28.07.2007.

Human Rights Watch: „The Enron Corporation: Corporate Complicity in Human Rights Violations“, www.hrw.org/reports/1999/enron/, 04.07. 2006.

ISO Central Secretariat: „ISO and Social Responsibility“, www.iso.org/iso/en /prods-services/otherpubs/pdf/isosr_2006-en.pdf, 23.04.2007.

Kimberley Process: „Background“, www.kimberleyprocess.com/index.php? option $=$ com_content\&task=blogcategory\&id $=14 \&$ Itemid $=26$, 23.04.2007.

Lukas, Karin/Röhsler, Maria-Theresia: „Vorwärts in die Vergangenheit? Die Europäische Union und Corporate Social Responsibility“, in: Deutsches Institut für Menschenrechte u.a. (Hrsg.): Jahrbuch Menschenrechte 2007. Privat oder Staat? Menschenrechte verwirklichen! Frankfurt a.M. 2006, S. 126-132.

Ruggie, John G.: „Interim report of the Special Representative of the Secretary-General on the issue of human rights and transnational corporations and other business enterprises“, 2006, daccessdds.un.org/ doc/UNDOC/GEN/G06/110/27/PDF/G0611027.pdf?OpenElement, 06.06.2007.

Schneebaum, Steven M.: Human rights in the United States courts: The role of lawyers, in: Washington and Lee Law Review, Summer 1998, findarticles.com/p/articles/mi_qa3655/is_199807/ai_n8788427, 23.04.2007. 
Sub-Commission on the Promotion and Protection of Human Rights: „Fiftyfifth session, Norms on the responsibilities of transnational corporations and other business enterprises with regard to human rights", 26.08.2003, www.unhchr.ch/Huridocda/Huridoca.nsf/TestFrame/64155e7e8141b38c c1256d63002c55e8?Opendocument, 28.07.2007.

Tagesschau (2006): „Jury spricht Enron-Bosse schuldig“, www.tagesschau.de/ aktuell/meldungen/0,1185,OID5563150,00.html, 25.05.2006.

UN Economic and Social Council: „Report of the Sub-Comission on the Promotion and Protection of Human Rights", daccessdds.un.org/doc/ UNDOC/GEN/G05/110/27/PDF/G0511027.pdf?OpenElement, 23.04.2007.

Vereinte Nationen: „Die Allgemeine Erklärung der Menschenrechte“, 10.12.1948, www.unhchr.ch/udhr/lang/ger.htm, 25.05.2007.

Williams, Khan: „The Role of Non-State Actors in securing and developing Human Rights from the perspective of the United Nations", in: Kirchschläger, Peter G. (Hrsg.): Menschenrechte und Wirtschaft. Im Spannungsfeld von State und Nonstate Actors, Bern 2005.

Wirtschafts- und Sozialrat der Vereinten Nationen (Hrsg.): „Wirtschaftliche, Soziale und Kulturelle Rechte. Kommentar zu den Normen für die Verantwortlichkeiten transnationaler Unternehmen und anderer Wirtschaftsunternehmen im Hinblick auf die Menschenrechte“, 2003, www.un.org/ depts/german/wiso/e-cn.4-sub.2-2003.pdf, 06.06.2007.

Young, Iris Marion: „Responsibility and Global Labor Justice“, in: Journal of Political Philosophy, Jg. 12, Nr. 4, 2004. 



\title{
Veronika Kneip
}

\section{Legitimationsfaktor Bürgerschaft. Die kommunikative Vermittlung von Corporate Citizenship}

\author{
Again and again it emerges with some clarity \\ that it is not because people are equal \\ that they are granted citizen rights; it is \\ because people demand and obtain citizen rights \\ that they become equal persons. ${ }^{1}$
}

Die Frage nach den Leistungen und der Reichweite des Bürgerbegriffs wurde und wird angesichts sich verändernder ökonomischer, sozialer und politischer Bedingungen gestellt. So ist die Entstehung liberaler individualistischer Vorstellungen von Bürgerschaft eng mit dem sich im Zuge der industriellen Revolution entwickelnden modernen Kapitalismus verbunden, ${ }^{2}$ unterschiedliche Stränge des Gender-Diskurses spiegeln sich in verschiedenen Forderungen nach Ausweitung bzw. Umgestaltung von Bürgerschaftskonzepten wider ${ }^{3}$ und die Diskussion um die Erosion nationalstaatlicher Regierungsformen zieht eine Auseinandersetzung um postnationale, multikulturelle oder globale Bürgerschaft mit sich. ${ }^{4}$ Mit dem Ansatz der Unternehmensbürgerschaft erfährt der Bürgerbegriff eine erneute Ausdehnung, mit der Ideen und Vorstellungen verbunden sind, die an die historisch-philosophischen Begründungslinien klassischer Bürgerschaftskonzepte anknüpfen, jedoch eigene Schwerpunkte setzen und Dimensionen von Bürgerschaft einführen, die vor dem Hintergrund politikwissenschaftlicher Fragestellungen kritisch betrachtet werden müssen. Hier stellt sich insbesondere die Frage, wie die zentrale Bedeutung der kommunikativen Vermittlung des eigenen Bürgerstatus durch Unternehmen zu bewerten ist. Im Folgenden wird deshalb zunächst auf die Hintergründe der Verwendung des Bürgerbegriffs im Unternehmenskontext und die Grenzen der Übertragung historischer Vorstellungen von Bürgerschaft eingegangen, um darauf aufbauend den Stellenwert kommunikativer Vermittlung von Corporate Citizenship herauszuarbeiten. Diese Dimension der Unternehmensbürger-

1 Clarke: Citizenship, S. 19.

2 Vgl. Mackert/Müller: „Der soziologische Gehalt moderner Staatsbürgerschaft“, S. 14; Mouffe: „Citizenship“, S. 218; Nauta: „Changing Conceptions of Citizenship“, S. 20.

3 Vgl. Heater: What is citizenship? S. $91 \mathrm{ff}$.

4 Vgl. Dower: „Situating Global Citizenship“; Weinbach: „Staatsbürgerschaft und nationale Zugehörigkeit heute: multikulturell und de-ethnisiert?“. 
schaft wird abschließend in Bezug zu unternehmenskritischen Kampagnen gesetzt, die den Bürgerstatus von Unternehmen in Frage stellen, und in dem entstehenden Spannungsfeld demokratie- bzw. öffentlichkeitstheoretisch verortet.

\section{Der gesellschaftliche Legitimationsbedarf wirtschaftlicher Macht}

Transnational operierende Unternehmen können als treibende Kraft ökonomischer Globalisierung betrachtet werden, welche die Agenda der fortschreitenden strukturellen Entgrenzungs- und neuen entterritorialisierten Abhängigkeitsverhältnisse dominiert. Durch ihre finanzielle Verhandlungsmacht ${ }^{5}$ gepaart mit den Möglichkeiten moderner Informations-, Kommunikations- und Verkehrstechnologien, die eine Entkopplung von Produktions- und Verwaltungsstandorten erlauben, haben sich Unternehmen dabei zu politischen Verhandlungspartnern entwickelt, die insbesondere gegenüber schwachen Volkswirtschaften maßgeblichen Einfluss auf die finanziellen, technischen oder ökologischen Rahmenbedingungen ihres ökonomischen Handelns nehmen können. ${ }^{6}$ Darüber hinaus wird die Relevanz transnationaler Unternehmen als politische Verhandlungspartner im Rahmen internationaler Politik deutlich. So verweist beispielsweise Müller für den europäischen Kontext auf die Dominanz der energieintensiven Wirtschaft in der High Level Group on Competitiveness, Energy and the Environment, die Ansätze für das Funktionieren der Energiemärkte, zum Klimawandel und Emissionshandel sowie zum Better-RegulationAnsatz in der Energiepolitik entwickeln soll. ${ }^{7}$ Tony Clarke, Direktor des kanadischen Polaris Institute, ${ }^{8}$ thematisiert den Machtgewinn transnationaler

5 Die 200 größten Unternehmen der Welt erwirtschaften insgesamt ein Viertel des weltweiten Bruttoinlandsprodukts. Vgl. Werner/Weiß: Schwarzbuch Markenfirmen, S. 43. Beispielhaft können hier die Ölfirmen BP, Exxon Mobil und Royal Dutch/Shell genannt werden, deren Umsätze 2006 jeweils fast das Dreifache des Bruttoinlandsprodukts von Nigeria - Afrikas führendem Ölexporteur - betrugen. Vgl. CNNMoney.com: „Fortune Global 500“; The World Bank: „Total GDP 2006 ".

6 In diesem Zusammenhang muss auf so genannte negative externe Effekte (Externalitäten) oder soziale Kosten verwiesen werden, die sich beispielsweise für die Felder des Umwelt- oder Arbeitsschutzes ergeben können.

7 Vgl. Müller: „Privilegiert und umstritten“, S. 19.

8 Das Polaris Institute Canada hat es sich zur Aufgabe gemacht, zivilgesellschaftliche Handlungsrepertoires gegenüber dominanten Marktkräften zu unterstützen (www.polarisinstitute.org). 
Unternehmen gegenüber Regierungen und Nationalstaaten angesichts von Freihandelsabkommen wie der NAFTA und ähnlichen Institutionen:

Through these new institutional mechanisms, the power wielded by corporations in determining public policy directions has become much more pervasive, systemic and decisive. In short, we are now living in a political era of corporate rule. ${ }^{9}$

Ihrer gestiegenen politischen Macht stehen allerdings Legitimationsdefizite gegenüber, da sich Unternehmen ihrer Rolle als Regierte in einem nicht oder nur fragmentarisch gesetzlich regulierten globalen Raum weitgehend entziehen können und sich in ihrer Rolle als Regierende nicht wie politische Mandatsträger regelmäßig durch Wahlen legitimieren müssen. ${ }^{10}$ Sowohl individuell als auch kollektiv formulierte normative Verhaltenserwartungen an Unternehmen thematisieren diese Legitimationsdefizite und fordern Unternehmen auf, ihr Legitimationsvakuum zu füllen. Erfüllte oder nicht erfüllte normative Verhaltenserwartungen werden von Konsumenten beispielsweise mit dem Kauf oder Nichtkauf bestimmter Produkte beantwortet. In diesem Sinne hebt der jüngste Ethical Consumerism Report der britischen Co-operative Bank für 2004 den Anstieg des Umsatzes für ethische Produkte und Dienstleistungen von über 15 Prozent auf 25,8 Milliarden britische Pfund hervor und weist auf den Anteil von 28 Prozent der britischen Konsumenten hin, die mindestens ein Produkt aus ethischen Gründen boykottiert haben. ${ }^{11} \mathrm{Zu}$ ähnlichen Ergebnissen kommt eine Studie für den schwedischen Raum in Anlehnung an den European Social Survey 2002, derzufolge 33 Prozent der schwedischen Konsumenten in den letzten zwölf Monaten mindestens ein Produkt boykottiert und 55 Prozent mindestens ein Produkt aus politischen, ethischen oder ökologischen Gründen gekauft haben. ${ }^{12}$ Für den deutschen Raum lassen sich Ergebnisse einer repräsentativen Haushaltsbefragung des Instituts für Markt-Umwelt-Gesellschaft Hannover für das Jahr 2006 nennen, nach der mehr als 80 Prozent der Befragten Präferenz- und Boykottbereitschaft ${ }^{13}$ für bestimmte Unternehmen auf Grund von Informationen über deren gesellschaftliche Verantwortungsübernahme

9 Clarke: Silent Coup, S. 5.

10 Zum Spannungsverhältnis von Unternehmen als Regierte und Regierende vgl. Curbach in diesem Band.

11 Vgl. The Co-operative Bank: „The Ethical Consumerism Report 2005“, S. 4, 9.

12 Vgl. Stolle u.a.: „Politics in the Supermarket“, S. 248.

13 Die Präferenz- und Boykottbereitschaft wird dabei für den gleichen Preis und die gleiche Qualität des Alternativkaufs erhoben. Vgl. Institut für Markt-Umwelt-Gesellschaft e.V.: „CSR-Informationsbedarf von Verbrauchern“, S. 43. 
äußern. Die Studie Good Brand 2006 der gleichnamigen Agentur konstatiert für mehr als ein Drittel der im Rahmen dieser Studie befragten Bundesbürger gesellschaftliches oder ökologisches Engagement von Unternehmen als kaufentscheidenden Faktor. ${ }^{14}$

In so genannten Anti-Corporate Campaigns formulieren zivilgesellschaftliche Akteure darüber hinaus kollektiv normative Verhaltenserwartungen an Unternehmen - beispielsweise im Hinblick auf menschenrechtliche, ökologische oder gewerkschaftliche Fragestellungen. Sowohl auf der Ebene des individuellen Verbraucherverhaltens als auch auf der Ebene kollektiver Proteste spielen dabei neue Medien, insbesondere das Internet, eine entscheidende Rolle. Digitale Informations- und Kommunikationstechnologien erleichtern den Zugang zu produktions- und konsumrelevantem Wissen und ermöglichen es, dieses Wissen sowie damit verknüpfte Forderungen an die Legitimationserzeugung von Unternehmen effizient aufzubereiten und weiterzugeben. ${ }^{15}$

\section{Legitimation durch Bürgerschaft?}

\subsection{Nutzung des Bürgerbegriffs im Unternehmenskontext}

Warum nun nutzen Unternehmen den Bürgerbegriff, um auf die zuvor dargestellten Legitimitätsanforderungen zu reagieren? Als das „Recht, Rechte zu haben“16 ist Bürgerschaft Ausdruck der legitimen Stellung des Einzelnen innerhalb einer Gemeinschaft. Dahrendorf verweist in diesem Zusammenhang auf die Dynamik der Figur des Bürgers, die verschiedenen gesellschaftlichen Gruppen - von der Bourgeoisie der feudalen Städte bis zu Leibeigenen - als Leitbild ihres politischen Statusgewinns diente. ${ }^{17}$ In diesem Sinne dient auch ein Anspruch auf Unternehmensbürgerschaft der Legitimation der eigenen Stellung und des eigenen Handelns. Die Ansprüche des Unternehmens auf ordnungspolitische Mitgestaltung aber auch auf die gewinnorientierte Gestaltung der eigenen Geschäftstätigkeit werden infolgedessen als legitime Bürgerrechte angesehen:

14 Vgl. Blumberg/Conrad: Good Brand 2006. Zu den Ergebnissen der Studie vgl. auch Conrad/Diehl in diesem Band.

15 Zum politischen Empowerment von Konsumenten durch das Internet vgl. Baringhorst in diesem Band.

16 Kymlicka/Norman zitieren hier mit „the right to have rights“ den US Supreme Court. Kymlicka/Norman: „Return of the Citizen“, S. 355.

17 Vgl. Dahrendorf: „Zu viel des Guten“, S. 133. 
Dabei zeichnet sich ein Wandel von einem gemeinwohlorientierten Unternehmensengagement, das von den Vorstellungen sozialer Verantwortung getragen ist, zu einem unternehmensstrategisch ausgerichteten Verständnis von Corporate Citizenship ab. Unternehmerische Engagementförderung wird nicht mehr mit sozialen Verpflichtungen im Sinne einer diffusen Corporate Social Responsibility, sondern mit dem Recht von Unternehmen zur Verfolgung unternehmerischer Interessen und zur Mitgestaltung gesellschaftlicher Verhältnisse begründet. $^{18}$

In der Tradition liberaler Denkmodelle wird die Ausübung des individuellen Rechts der Gewinnerwirtschaftung als unabdingbar und zuträglich für die Verwirklichung gesamtgesellschaftlicher Interessen gedeutet. So verweist beispielsweise der Präsident des BDA, Dieter Hundt, auf die Bedeutung des wirtschaftlichen Erfolgs für ein funktionierendes Gemeinwesen; Matthias Kleinert von Daimler-Chrysler sieht Profitabilität und gesellschaftliches Engagement als sich wechselseitig bedingende Größen an. ${ }^{19}$ Ebenso verbindet der Pharmakonzern Novartis die eigene Bürgerrolle mit dem wirtschaftlichen Erfolg des Unternehmens:

Corporate citizenship at Novartis begins with the success of our core business. The more successful we are in discovering, developing, manufacturing and marketing new medicines, the greater the benefits we can offer to society. ${ }^{20}$

Anknüpfend an republikanische Ansätze von Bürgerschaft wird Corporate Citizenship gleichzeitig an Vorstellungen von Gemeinschaft gebunden. Der Unternehmensbürger erscheint als aktiver Teil einer politischen Gemeinschaft mit dem Recht, diese gemäß den eigenen Vorstellungen und Ideen mitzugestalten und entsprechend den eigenen Potenzialen zur Lösung gesellschaftlicher Probleme in verschiedenen Bereichen beizutragen. In diesem Kontext werden die Pflichten des Unternehmens thematisiert, sich gesetzeskonform zu verhalten und darüber hinaus im Hinblick auf die Gemeinschaft ökonomisch, sozial und ökologisch verantwortlich zu handeln. ${ }^{21}$ Das Chemieunternehmen Degussa versteht sich in diesem Sinne als:

18 Backhaus-Maul: „Corporate Citizenship“, S. 239.

19 Vgl. Hundt: „Corporate Social Responsibility“, S. 2; Kleinert: „Politisches Marketing in der globalen Wirtschaft", S. 492.

20 Novartis: „Corporate Citizenship“.

21 Vgl. McIntosh u.a.: Corporate Citizenship, S. 40f.; Marsden/Andriof: „Towards an Understanding of Corporate Citizenship and How to Influence It“, S. 332f. 
[...] Teil der Gesellschaft mit Rechten, aber auch mit allen Pflichten, wie ein guter Bürger. [...] Als guter Corporate Citizen nimmt Degussa so ihre Verantwortung wahr und wirkt an der Weiterentwicklung der Gesellschaft mit. ${ }^{22}$

Ebenso werden Kooperationen mit anderen (individuellen oder kollektiven) Bürgerinnen und Bürgern herausgestellt, in denen das Unternehmen als Mitbürger agiert und so die Erfüllung gesellschaftlicher Erfordernisse und Ansprüche ermöglicht. Durch die Verbindung unterschiedlicher Elemente der verschiedenen Theoriestränge historisch-philosophischer Bürgerschaftstheorien verweist der Bürgerbegriff im Unternehmenskontext einerseits auf die Einbindung des Unternehmens in eine politische Gemeinschaft und demonstriert so dessen Verbundenheit mit dem sozialen und ökologischen Umfeld. Investitionen in die Gestaltung dieses Umfelds - beispielsweise was die Einflussnahme auf ordnungspolitische Maßnahmen wie die Festlegung bestimmter Grenzwerte betrifft - werden durch den Bürgerstatus des Unternehmens als legitime politische Partizipation konturiert. Gleichzeitig erscheint die Verfolgung individueller Gewinnziele unter der Prämisse des Bürgerstatus als angemessene Wahrnehmung ökonomischer Freiheitsrechte, die als konstitutiv für liberale Ansätze von Bürgerschaft verstanden werden können.

\subsection{Grenzen der Übertragbarkeit}

Die Anknüpfung an historische Begründungstraditionen von Bürgerschaft im Kontext von Corporate Citizenship wirft Fragen nach den Grenzen der Übertragbarkeit dieser Konzepte auf. So ist der Bürgerstatus nicht nur mit einem bestimmten Bündel an Rechten und Pflichten verknüpft, sondern zeichnet ein Individuum als Mitglied einer politischen Gemeinschaft freier und gleicher Bürger aus, die ihren Bezugspunkt ursprünglich in der griechischen Polis und im Zuge der Französischen Revolution im modernen Nationalstaat findet:

First, citizenship is a legal concept which refers to the legal status of a natural person in respect to a state or nation, and is gained by meeting the legal requirements of a national, state, or local government. ${ }^{23}$

Hier ergibt sich bei der Übertragung von Bürgerschaftskonzepten auf Unternehmen zunächst das Problem, dass der eigentlich Individuen - natürlichen

22 Degussa: „Corporate Citizenship Report 2005“, S. 53.

23 Anheier/List: A dictionary of civil society, philanthropy and the non-profit sector, S. $49 \mathrm{f}$. 
Personen - vorbehaltene Bürgerstatus nun auf die allenfalls juristische Person des Unternehmens als Kollektivbürger übertragen wird. Zwar existieren durchaus Ansätze, die bürgerliche Rechte und Pflichten sowohl für die individuelle als auch die organisationale und gesamtgesellschaftliche Ebene definieren und sich in diesem Zuge beispielsweise mit der Bürgerschaft von Unternehmen oder Religionsgemeinschaften auseinandersetzen, ${ }^{24}$ allerdings wird in diesem Fall auf organisationaler Ebene vor allem auf die Bürgerrechte und -pflichten von Gruppen rekurriert, sodass eine unmittelbare Übertragung auf Unternehmen insbesondere angesichts geteilter und verschachtelter Verantwortungsketten in Aktiengesellschaften und ähnlichen Unternehmenskonstellationen problematisch ist. Diesen historisch entstandenen Trennungsprozess des Unternehmens vom Individuum hat Gonin exemplarisch herausgearbeitet: ${ }^{25}$ Ist das Unternehmen ursprünglich als konkrete Handlung des Unternehmers untrennbar an dessen Person gebunden, wandelt sich das Unternehmensverständnis um das 17. Jahrhundert von konkreten Handlungen zu selbstständigen Organisationen - vor allem in Form von unbefristeten, nicht projektgebundenen Aktiengesellschaften, die ab dem 19. Jahrhundert auch als juristische Personen bezeichnet werden. Hinzu kommt ab Ende des 19. Jahrhunderts die Ermöglichung des Aktienkaufs durch juristische Personen. Die sich daraus ergebende Kapitalverschachtelung führt zur Entstehung großer und unübersichtlicher Konzerne mit weitgehend anonymer Eigentümerschaft. Verstärkt wird dieser Trend der Trennung von Eigentum und Unternehmertum durch eine Vervielfachung der Anzahl von Aktionären in der ersten Hälfte des 20. Jahrhunderts, woraus eine verminderte Identifikation der Aktionäre mit dem Unternehmen sowie Informationsdefizite und so eine Abschwächung der Verantwortung resultieren. Der anonymen Masse der Eigentümer stehen professionell agierende Manager gegenüber, die weniger als autonome Personen sondern vielmehr als Agenten ihrer Aktionäre nach einer internen Profitmaximierungslogik agieren. Unternehmen können demnach kaum als Entität betrachtet werden, da nicht nur Management und Vorstand, sondern auch die übrigen Mitarbeiter und Aktionäre unternehmensrelevante Entscheidungen treffen, sodass häufig unklar bleibt, wer letztlich als Unternehmensbürger agiert.

Ebenso schwierig gestaltet sich die Frage nach dem Bezugspunkt der Unternehmensbürgerschaft. Bürgerschaft als Stellung des Einzelnen in einer politischen Gemeinschaft ist seit der Antike an eine konkrete, herrschaftlich organisierte Einheit gebunden, was vor allem im Begriff des Staatsbürgers zum Ausdruck kommt:

24 Janoski/Gran sprechen hier in Anlehnung an Daniel Hoffmann (1986) von „quasi-humans“. Vgl. Janoski/Gran: „Political Citizenship“, S. 14, 35.

25 Vgl. Gonin: „Die Trennung des Unternehmens vom Bürger“, S. $42 \mathrm{ff}$. 
Bürgersein qua Staatsangehörigkeit begründet nur eine dem Menschen äußerliche Identität. Aber diese ist unter den Bedingungen der modernen Welt der Nationalstaaten immer noch eine conditio sine qua non $[\ldots] .^{26}$

Insbesondere für transnational agierende Unternehmen stellt sich somit die Frage nach dem Bezugsrahmen ihrer Bürgerschaft. Ist der Unternehmensbürger allein an den Standort seiner Konzernzentrale gebunden und kann so als Bürger einer bestimmten Nation (oder gar nur einer bestimmten Region) betrachtet werden? Oder ist das Unternehmen im Sinne einer multiplen oder multikulturellen Bürgerschaft Bürger all jener Länder, in denen es Standorte besitzt bzw. kann sogar als Weltbürger verstanden werden, da die Produktionsund Distributionszyklen globale Wirksamkeit entfalten und das Unternehmen zudem Einfluss auf globale ökologische Entwicklungen nimmt?

Eng verbunden mit einer herrschaftlich organisierten Einheit als Bezugsgröße von Bürgerschaft ist der Einfluss des Bürgers auf die Konstitution derselben. Die von Aristoteles geforderte Wechselseitigkeit des Regierens und Regiert-Werdens findet ihren Ausdruck im aktiven und passiven Wahlrecht ${ }^{27}$ des Bürgers. Hier ergibt sich für das Unternehmen nicht nur die Frage, wie diese unmittelbare Teilhabe am politischen Entscheidungsprozess in einen möglichen globalen Bezugsrahmen von Bürgerschaft übertragen werden soll, ${ }^{28}$ sondern bereits ob und inwieweit dieses zentrale Bürgerrecht auf der Ebene des Nationalstaats für Unternehmen umgesetzt werden kann. Zwar können Unternehmen wie bereits erwähnt durch ihre Standortentscheidungen und Lobbyingbemühungen durchaus Einfluss auf die politische Willensbildung und Rahmensetzung nehmen, der direkte Einfluss auf die Herrschaftssicherung durch Wahl steht Unternehmen allerdings nicht zu, wodurch ihr Bürgerstatus in Frage gestellt werden kann. Schließlich ergeben sich in diesem Kontext Übertragungsprobleme von Bürgerschaftskonzepten auf Unternehmen durch den Anspruch dieser Konzepte, die Mitgliedschaft in einer Gemeinschaft von „formal Gleichen“29 zu regeln. Zwar ist die formale Gleichheit der Bürger immer mit realer Ungleichheit verknüpft - beispielsweise was die marginalisierte Stellung bestimmter gesellschaftlicher Gruppen im Prozess der politischen In-

26 Gebhardt: „Die Idee des Bürgers“, S. 353, H.i.O.

27 Abhängig vom Nationalstaat muss allerdings von einer aktiven Wahlpflicht gesprochen werden.

28 Dies ist eine Frage, die sich nicht nur für Kollektivbürger stellt, sondern mit der sich auch die auf Individuen bezogenen Konzepte globaler Bürgerschaft im Hinblick auf weltweit gültige Repräsentationsverfahren auseinandersetzen müssen.

29 Mackert/Müller: „Der soziologische Gehalt moderner Staatsbürgerschaft“, S. 14. 
teressenvertretung betrifft -, allerdings ergibt sich für den Unternehmensbürger ein besonderes Spannungsfeld der formalen Exklusion und des faktischen Einflusses auf kollektiv verbindliche Entscheidungen.

Angesichts der Grenzen der unmittelbaren Übertragbarkeit klassischer Bürgerschaftskonzepte kann Corporate Citizenship vor allem als Selbstdefinition von Unternehmen verstanden werden, durch die die Legitimation der eigenen Position in der Gesellschaft vorangetrieben wird und in deren Rahmen bestimmte Aspekte der historischen Begründungslinien betont und neu vernetzt werden, wohingegen andere Aspekte ausgeklammert werden. Ein Kernpunkt der Bürgerrolle des Unternehmens liegt somit in der öffentlichen Vermittlung und Konturierung dieser Rolle durch das Unternehmen selbst, wobei die Gestaltung dieser öffentlichen Vermittlung einer genaueren Analyse bedarf.

\section{3 Öffentlichkeit und Corporate Citizenship}

\subsection{Die kommunikative Vermittlung der Unternehmensbürgerschaft}

Generell sind Konzepte von Bürgerschaft eng mit der Erzeugung von Öffentlichkeit verknüpft. Die politische Forderung nach Öffentlichkeit hängt unmittelbar mit der Durchsetzung von Bürgerrechten zusammen. Im Prozess der Meinungs- und Willensbildung soll Öffentlichkeit die Interessen aller Bürger eines Gemeinwesens zur Geltung bringen und eine Sphäre konstituieren, in der Fragen von allgemeinem Interesse diskutiert werden. ${ }^{30}$ Wie nun kommt das Prinzip der Erzeugung von Öffentlichkeit in Vorstellungen der Unternehmensbürgerschaft zum Tragen? In der in weiten Teilen wirtschaftswissenschaftlich geprägten Forschungsliteratur zu Corporate Citizenship steht hier vor allem die Gestaltung der sozialen Beziehungen des Unternehmens durch Reputationsaufbau im Mittelpunkt. Die Reputation als Good Corporate Citizen soll die gesellschaftsgestaltende Rolle des Unternehmens legitimieren bzw. seine „licence to operate“"31 sichern. Es geht somit nicht nur darum, den Status des Unternehmensbürgers als solchen zu festigen, sondern ihn als wertvollen Teil der Gemeinschaft zu etablieren. Hemphill spricht hier vom Aufbau eines „reputational capital“32 und Marsden/Andriof stellen Unternehmensbürger-

30 Vgl. Schulz: Politische Kommunikation, S. 87.

31 Hemphill: „Corporate Citizenship“, S. 354.

32 Ebd., S. 341. 
schaft in den Kontext eines ,reputation market place“33. Die gezielte Kommunikation des Engagements, durch das ein Unternehmen seine Bürgerrolle ausfüllen möchte, wird infolgedessen als ebenso zentral betrachtet wie das Engagement selbst: „Wesentliches Element von Corporate Citizenship ist die bewußte und gezielte Kommunikation des gesellschaftlichen Engagements gegenüber möglichst vielen Zielgruppen. “34 Weiter noch als Westebbe/Logan geht beispielsweise Behrent, der Corporate Citizenship als Bestandteil des Corporate Branding und als Ergebnis kommunikationsstrategischer Überlegungen versteht. ${ }^{35}$ Ähnlich ordnet Willmott die Unternehmensbürgerschaft als ,branding issue ${ }^{\text {36 }}$ ein. Auch wenn die Autoren diese Einordnung in ihren Ausführungen teilweise relativieren und auf die Beiträge der Unternehmensbürger für die Gemeinschaft hinweisen, welche die notwendige Grundlage des Vermittlungserfolgs der Bürgerrolle des Unternehmens seien, so bleibt die kommunikative Vermittlung ein zentraler Aspekt des Corporate Citizenship. Diese Schwerpunktsetzung in Vorstellungen von Unternehmensbürgerschaft spiegelt sich auch in der Reflexion und Umsetzung durch Unternehmen selbst wider. So verweisen Lang/Solms auf eine Studie des britischen Meinungsforschungsinstituts MORI, derzufolge die „PR-opportunity“ von einem großen Teil britischer Klein- und Mittelunternehme(r)n als entscheidende Triebkraft für ihr bürgerschaftliches Engagement genannt wird. ${ }^{37}$ Strategische Aspekte der Unternehmensbürgerschaft in Form erhoffter Reputationsgewinne heben ebenso verschiedene transnationale Konzerne hervor. Beispielhaft können hier Stellungnahmen von Siemens oder Procter \& Gamble genannt werden:

- „Unsere Corporate-Citzenship-Programme stärken die Reputation von Siemens und tragen damit zur langfristigen Sicherung unseres Geschäfts bei. “ 38

- „We build sustainable, strategic partnerships that not only contribute to our society but also provide tangible business benefits and help strength-

33 Marsden/Andriof: „Towards an Understanding of Corporate Citizenship and How to Influence It", S. 338.

34 Westebbe/Logan: Corporate Citizenship.

35 Vgl. Behrent: „Citizens in der Weltarena“, S. 23.

36 Willmott: „Citizen brands“, S. 367.

37 Vgl. Lang/Solms: „Geschäftsstrategie Verantwortung“, S. 5.

38 Siemens AG: „Geschäftsbericht 2006 - Corporate Responsibility“. 
en $P \& G$ 's reputation as a proactive corporate citizen in the UK \& Ireland.“39

Bezeichnend ist in diesem Kontext auch, dass Planung und Durchführung derartiger Initiativen häufig in der PR- oder Marketing-Abteilung von Unternehmen angesiedelt sind. ${ }^{40}$

Aus diesen Einschätzungen und Schwerpunktsetzungen einer Bürgerrolle von Unternehmen ergibt sich die Frage, inwieweit Corporate Citizenship insgesamt weniger eine relevante Erweiterung des Bürgerbegriffs als vielmehr eine Facette eines professionellen Social Marketing darstellt, in dessen Rahmen soziale Ideen und Entwürfe als Tauschobjekte zur Absatzförderung genutzt werden, und die Legitimationsbemühungen des Unternehmens somit auf einer symbolpolitischen Ebene verbleiben. Inwieweit ist der Bürgerbegriff ein Instrument im Repertoire der Öffentlichkeitsarbeit von Unternehmen und dient der Thematisierung freiwillig initiierter sozialer Projekte mit hohem Nachrichtenwert sowie der Dethematisierung problematischer Verantwortungsketten entlang des Produktionszyklus? Die Ausrichtung einer Vielzahl bestehender Entwürfe von Corporate Citizenship sowie die Interpretation durch Unternehmen machen deutlich, dass der Bürgerbegriff im Unternehmenskontext durchaus strategisch genutzt wird, um die Unterstützung bestimmter (umsatz-)relevanter Teilöffentlichkeiten zu erlangen. Die Kommunikation der Bürgerrolle von Unternehmen hat in diesem Zusammenhang weniger den Charakter eines öffentlichen Diskurses über die Position des Unternehmens in der Gesellschaft, sondern dient der Sicherung von Autorität und Deutungsmacht, wobei der Erzeugung von Glaubwürdigkeit und Vertrauen entscheidender Stellenwert zukommt. Vor diesem Hintergrund wird Unternehmensbürgerschaft außerdem vor allem für diejenigen Unternehmen relevant, die unmittelbar an der Schnittstelle zum Endverbraucher arbeiten bzw. diejenigen, die entweder homogene Produkte anbieten und sich deshalb durch andere - vor allem kommunikationsorientierte - Differenzierungsmerkmale abgrenzen müssen oder diejenigen, die in besonders heiklen Produktbereichen tätig sind und sich so einem erhöhten Legitimationsbedarf ausgesetzt sehen. Habisch ${ }^{41}$ und Backhaus-Maul identifizieren in diesem Sinne bestimmte Branchen, die vorwiegend mit dem Begriff der Unternehmensbürgerschaft arbeiten. Backhaus-Maul nennt konkret für Deutschland „die Auto-, die Konsumgüter- und auch die Pharmaindustrie, Finanzdienstleistungen und Unternehmensbera-

39 The Procter \& Gamble Company: „P\&G ,Community Matters` Programme UK and Ireland".

40 Vgl. Backhaus-Maul: „Corporate Citizenship im deutschen Sozialstaat“, S. 27.

41 Vgl. Habisch: Corporate Citizenship, S. 89. 
tungen sowie vor allem das Handwerk“ als „Corporate-Citizenship-intensive Branchen“"42. Auch wenn die Relevanz des Konzepts somit für eine Vielzahl von Branchen sowie für kleine bzw. mittelständische Unternehmen und Großkonzerne gleichermaßen gegeben ist, besteht die Gefahr, dass durch die Vermittlung des Bürgerstatus bestimmter Unternehmen und Branchen die öffentliche Auseinandersetzung über die gesellschaftliche Rolle anderer wirtschaftlicher Akteure geschwächt wird.

\subsection{Transparenz und Kontrolle}

Neben ihrer strategischen Ausrichtung auf Glaubwürdigkeitserzeugung und ihrer Konzentration auf bestimmte Unternehmen und Branchen kann der Unternehmensbürgerschaft jedoch auch in der Form eines kommunikativ vermittelten Konzepts eine Funktion zukommen, die über ihre instrumentelle, symbolpolitische Anwendung hinausreicht. Durch die Kommunikation des (angestrebten) Bürgerstatus bekennen sich Unternehmen zu ihrem Legitimationsdefizit und führen ihr eigenes Handeln demonstrativ aus der Sphäre des Privaten hinaus. Auch wenn Unternehmen in ihrer Selbstdefinition als Bürger das eigene Handeln eventuell sehr selektiv kommunizieren, so kann auch diese Kommunikation zur Entfaltung einer kritischen Öffentlichkeit beitragen. In der wirtschaftswissenschaftlichen Literatur wird dies in der Regel zunächst als Kommunikationsrisiko gedeutet. Der Legitimationsversuch über die Kommunikation des Bürgerstatus kann Ansprüche und Fragen der adressierten Mitbürger wecken, sodass der Legitimationsbedarf des Unternehmens letztlich erweitert statt erfüllt wird. Im Sinne der Öffentlichkeitserzeugung kann ein solcher Prozess als Beitrag zur Transparenz und Validierung von Themen und Meinungen betrachtet werden. Dieser Ansatz wird teilweise auch in der bestehenden Corporate-Citizenship-Literatur verfolgt und schließt Unternehmensbürgerschaft damit nicht nur auf der Ebene der Begrifflichkeiten an den politikwissenschaftlichen Kontext an. So nennt beispielsweise Behrent mit dem „Glaubwürdigkeits-Dilemma“, „Aufmerksamkeits-Dilemma“ und „Leadership-Dilemma" Risiken der Corporate-Citizenship-Kommunikation. ${ }^{43}$ Diese Dilemmata rekurrieren auf ein generelles Misstrauen gegenüber der Betonung guter Absichten, auf eine erhöhte Skandalisierungsgefahr bzw. auf kaum zu erfüllende Erwartungen der Öffentlichkeit. Daraus leitet Behrent die Notwendigkeit $a b$, unternehmensinterne Vorgänge öffentlich transparent zu machen und sich aktiv mit anderen gesellschaftlichen Akteuren auseinanderzusetzen.

42 Backhaus-Maul: „Corporate Citizenship im deutschen Sozialstaat“, S. 28.

43 Vgl. Behrent: „Citizens in der Weltarena“, S. 34. 
Habisch benennt darüber hinaus die demokratische Öffentlichkeit als wichtige Kontrollinstanz des Unternehmensbürgers. ${ }^{44}$

Eine wichtige Vermittlungs- bzw. Scharnierfunktion kommt in diesem Zusammenhang wiederum zivilgesellschaftlichen Organisationen und den durch sie angestoßenen Kampagnen zu. Sie thematisieren nicht nur den Machtgewinn von Unternehmen oder deren Legitimationsvakuum und formulieren konkrete Verhaltenserwartungen oder allgemein das Recht der Öffentlichkeit auf Information. Vielmehr hinterfragen sie kritisch die Legitimationsbemühungen von Unternehmen und fungieren so als Korrektiv im Meinungsbildungsprozess. Beispielhaft kann hier der Bericht von Christian Aid, einer kirchlich getragenen Nichtregierungsorganisation in Großbritannien und Irland, genannt werden, in dem unter dem Titel Behind the mask das soziale oder ökologische Fehlverhalten bestimmter Unternehmen thematisiert und ihrem offiziellen Bekenntnis zu gesellschaftlicher Verantwortungsübernahme gegenübergestellt wird. ${ }^{45}$ Darüber hinaus haben sich mit zivilgesellschaftlichen Akteuren wie CorpWatch, Germanwatch, dem CorA Netzwerk für Unternehmensverantwortung ${ }^{46}$ oder dem Dachverband der Kritischen Aktionärinnen und Aktionäre Organisationen und Plattformen herausgebildet, die ihren Schwerpunkt auf die Kontrolle unternehmerischen Handelns und unternehmerischer Kommunikation legen. In diesem Sinne hinterfragt ein auf der Internetseite von CorpWatch veröffentlichter Artikel die Auszeichnung des Magazins Business Ethics für die 100 Best Corporate Citizens:

[...] examples of companies with ethical lapses can be found on this list of supposedly exemplary corporate citizens. Johnson \& Johnson

44 Vgl. Habisch: „,Corporate Citizenship“ - unternehmerisches Bürgerengagement im Gemeinwesen des 21. Jahrhunderts“, S. 6.

45 Konkret setzt sich der Bericht mit den Aktivitäten von Shell im Niger Delta, von British American Tobacco in Kenia und von Coca-Cola in Indien auseinander. Vgl. Christian Aid: „Behind the mask“. Dabei wird nicht nur auf die Selbstdarstellung von Unternehmen als Corporate Citizens rekurriert sondern auch auf deren Darstellung ihrer Corporate Social Responsibility. Ebenso wie diese beiden Konzepte selbst verknüpft sind, wird auch in der unternehmerischen Kommunikation häufig auf beide Konzepte Bezug genommen.

46 CorA steht dabei für Corporate Accountability. In diesem Netzwerk haben sich zivilgesellschaftliche Organisationen zusammengeschlossen, um Unternehmen für die Auswirkungen ihres Handelns auf Mensch und Umwelt zur Rechenschaft zu ziehen und sie zur Einhaltung der Menschenrechte sowie internationaler Sozialund Umweltstandards zu verpflichten. Dem Koordinationskreis gehören derzeit Mitglieder folgender Organisationen an: Germanwatch, Greenpeace, WEED, Verbraucher Initiative, Global Policy Forum, ver.di Vgl. CorA - Netzwerk für Unternehmensverantwortung: „Koordinationskreis“. 
(No. 12) refuses to join the 300 other companies that have signed the Campaign for Safe Cosmetics pledge not to use toxic ingredients. NIKE Inc. (No. 13) has adopted some reforms in response to years of criticism over labor practices at its overseas suppliers, but activist groups continue to cite abuses. General Mills (No. 14) sells food products with unlabeled genetically modified ingredients. ${ }^{47}$

Auch verschiedene der im Rahmen des Forschungsprojekts Protest- und Medienkulturen im Umbruch ${ }^{48}$ an der Universität Siegen untersuchten Kampagnen benennen die Kontrolle der Selbstpositionierung und Verantwortungskommunikation von Unternehmen als eine wichtige Aufgabe. So hinterfragt beispielsweise die BUKO Pharma-Kampagne die öffentlichkeitswirksame Spendentätigkeit von Arzneimittelproduzenten; im Rahmen der Bananen-Kampagne wird nicht nur die gesellschaftliche Verantwortungsübernahme von Unternehmen durch die Etablierung von Codes of Conduct gefordert, sondern es werden gleichzeitig Strategien angedacht, die ein rein kommunikatives Bekenntnis zu unternehmerischer Selbstverpflichtung entlarven können. ${ }^{49}$ In den bisher durchgeführten qualitativen Interviews mit Initiatoren verschiedener unternehmenskritischer Kampagnen lässt sich weitgehend Skepsis gegenüber der Selbstdefinitionen von Unternehmen als verantwortliche Bürger ablesen. Entsprechende Legitimationsversuche werden beispielsweise als „problematisches Feigenblatt“ oder „Greenwashing“ bezeichnet. ${ }^{50}$ Hier wird deutlich, dass Kampagneninitiatoren vor allem die Kontroll- bzw. Watchdog-Funktion der im Rahmen von Anti-Corporate Campaigns erzeugten Öffentlichkeit sehen. Diese Funktion von Öffentlichkeit als kritische Instanz und Gegengewicht zur Dominanz bestimmter Akteure wird beispielsweise von Meyer und Norris als eine Anforderung an massenmedial vermittelte Öffentlichkeit formuliert. ${ }^{51} \mathrm{Un}$ ternehmenskritische Kampagnen können in diesen Prozess nicht nur relevantes Expertenwissen einbringen, sondern selbst als Intermediäre agieren, also Prüf- und Filterleistungen übernehmen. Dabei bietet vor allem die Kampagnen-Website die Möglichkeit, der ressourcenstarken Unternehmenskom-

47 Mattera: „US: The 100 Worst Corporate Citizens“.

48 Informationen zum Projekt: www.protest-cultures.uni-siegen.de.

49 Vgl. Smith: „Campaigning for Codes of Conduct“; BUKO Pharma-Kampagne: „Pharma Brief Nr. 6“.

50 Interviews im Rahmen der Kampagnen Lidl ist nicht zu billigen mit Kay O. Schulze (Attac, Deutschland) und Nikeground mit Konrad Becker (Public Netbase, Österreich). Diese Skepsis spiegelt ebenfalls der Beitrag von Löding/Schulze/Sundermann in diesem Band wider.

51 Vgl. Meyer: Europäische Öffentlichkeit als Kontrollsphäre, S. 68ff.; Norris: A Virtuous Circle, S. 24ff. 
munikation - die beispielsweise in der Möglichkeit Fernsehspots zu schalten oder in der Bedeutung als Anzeigenkunde für die Finanzierung von Tageszeitungen zum Ausdruck kommt - eine eigene Informationsplattform entgegenzusetzen.

Insgesamt bietet das Spannungsfeld unternehmerischer Selbstlegitimation durch Corporate-Citizenship-Kommunikation und zivilgesellschaftlicher AntiCorporate Campaigns Raum für die Entstehung einer öffentlichen Diskussion über die gesellschaftliche Rolle von Unternehmen. Die in unternehmenskritischen Kampagnen öffentlich formulierten Problemstellungen und Forderungen machen den Legitimationsbedarf von Unternehmen deutlich und kontrollieren gleichzeitig deren Legitimationsbestrebungen. Auch wenn die Konfliktdynamik unternehmenskritischer Skandalisierung und strategischer Unternehmenskommunikation ${ }^{52}$ normativen Anforderungen einer diskursiven Öffentlichkeit im Sinne des Austauschs vernünftiger, rationaler Argumente nicht zwangsläufig gerecht wird, so kann sie doch im Sinne eines Arenamodells von Öffentlichkeit zwischen verschiedenen Handlungssystemen vermitteln und Transparenz schaffen - insbesondere, was die Meinungsbildung in der Galerie der verschiedenen Anspruchsgruppen wie Konsumenten, Mitarbeitern oder Aktionären betrifft, die in ihren jeweiligen Rollen entweder auf Unternehmensseite oder auf Seiten der Protestkampagnen zu Akteuren der Arena werden können. Die im Rahmen von Unternehmens- und Protestkommunikation erzeugten Transparenzschleifen übernehmen eine Irritations- und Korrekturfunktion, sie zwingen sowohl Unternehmen als auch deren Kritiker zur Begründung und Rechtfertigung ihrer Position und können in einem weiteren Verständnis demokratischer Öffentlichkeit, das Rationalität nicht normativ voraussetzt, sondern auch expressive oder visuelle Kommunikationselemente als konstitutiv anerkennt, als ein Beitrag zur Herausbildung einer solchen verstanden werden.

\section{$4 \quad$ Ausblick}

Abschließend betrachtet sind der Übertragbarkeit historisch-philosophischer Bürgerschaftskonzepte auf Unternehmen deutliche Grenzen gesetzt. Unternehmen handeln als kollektive und privatwirtschaftliche Akteure, deren Logiken nur bedingt in klassische Vorstellungen von Bürgerschaft integrierbar sind. Dennoch eröffnet die Verwendung des Konzepts durch Unternehmen

52 Die Tendenz von Unternehmens- bzw. Protestkommunikation zu extrem positiven bzw. extrem negativen Aussagen zeigt sich auch in den Ergebnissen des Ethical Quotation System der Agentur Covalence. Vgl. Mach in diesem Band. 
analytisches Potenzial, verdeutlicht sie doch das gestiegene Legitimationsbedürfnis unternehmerischen Handelns in der Gesellschaft und damit die Entgrenzung öffentlicher und privater Sphären. Wirtschaftliche Entscheidungen und Transaktionen nehmen Einfluss auf gesamtgesellschaftliche Entwicklungen, sodass sich Unternehmen normativen und moralischen Verhaltenserwartungen ausgesetzt sehen, die ihren Einbezug in die Gesellschaft sowohl fordern als auch hinterfragen. Die Selbstdefinition als Unternehmensbürger dient in diesem Zusammenhang nicht nur der Statussicherung des Unternehmens als Mitglied einer Gemeinschaft - in dessen Rolle als Mitbürger und Regierter - sondern auch der Legitimation von unternehmerischen Entscheidungen gesamtgesellschaftlichen Ausmaßes, also einer Art Bestätigung des Unternehmensbürgers in einem politischen Amt - in dessen Rolle als Regierender.

Darüber hinaus ist der zentrale Stellenwert des Vermittlungsaspekts im Kontext der Unternehmensbürgerschaft Ausdruck der generellen Bedeutung von Öffentlichkeit als Legitimationsressource und Regulationsmechanismus in politischen Kräftefeldern. So ist die Legitimationserzeugung durch (nichtwirtschaftliche) Nichtregierungsorganisationen ebenfalls in hohem Maße an öffentliche Zustimmung gebunden, wie etwa Altvater/Brunnengräber angesichts des fehlenden demokratischen Mandats dieser Organisationen hervorheben. ${ }^{53}$ Auch in transstaatlichen Politikprozessen wie dem europäischen Mehrebenensystem spielt Öffentlichkeit als Legitimationsquelle eine entscheidende Rolle: Das Demokratiedefizit der EU wird unter anderem auf eine fehlende europäische Kommunikationsgemeinschaft zurückgeführt, während gleichzeitig große Hoffnungen in die Potenziale politischer öffentlicher Diskurse als Forum für den politischen Gestaltungswillen von Bürgern gesetzt werden. ${ }^{54}$

In der Verwendung des Bürgerbegriffs im Unternehmenskontext wird die Dynamik der mit diesem Begriff verbundenen Konzepte deutlich, die von verschiedenen Akteuren und in verschiedenen historischen Konstellationen genutzt wurden und werden, um gesellschaftliche Anerkennung zu sichern und politische Handlungsspielräume zu erobern. Die in diesem Beitrag angedeuteten Grenzen der Übertragbarkeit von Bürgerschaftskonzepten auf Unternehmen bieten einen ersten Einblick in die theoretischen und analytischen Herausforderungen, die mit einer derartigen Ausdehnung des Bürgerbegriffs verbunden sind, erfordern jedoch weitere Differenzierungen und Systematisierun-

53 Vgl. Altvater/Brunnengräber: „NGOs im Spannungsfeld von Lobbyarbeit und öffentlichem Protest", S. 12.

54 Vgl. Dienel u.a.: Politische Regulierungsformen, Government, Governance und Netzwerkstrukturen auf der globalen, europäischen und nationalen Ebene, S. 23; Meyer: Europäische Öffentlichkeit als Kontrollsphäre, S. 51f. 
gen. Vor dem Hintergrund, dass Neukonfigurationen von Bürgerschaft immer auch als „ongoing products of intense political contests" ${ }^{\text {" } 55}$ verstanden werden können, erscheint dabei insbesondere eine Analyse der Auseinandersetzung zwischen Unternehmen und verschiedenen gesellschaftlichen Akteuren um die Akzeptanz von Unternehmen als Bürger vielversprechend.

\section{Literaturverzeichnis}

Altvater, Elmar/Brunnengräber, Achim: „NGOs im Spannungsfeld von Lobbyarbeit und öffentlichem Protest", in: Aus Politik und Zeitgeschichte, B 6-7, 2002, S. 6-14.

Anheier, Helmut K./List, Regina A.: A dictionary of civil society, philanthropy and the non-profit sector, London 2005.

Backhaus-Maul, Holger: „Corporate Citizenship. Liberale Gesellschaftspolitik als Unternehmensstrategie in den USA“, in: Adloff, Frank u.a. (Hrsg.): Wirtschaft und Zivilgesellschaft. Theoretische und empirische Perspektiven, Wiesbaden 2005, S. 225-243.

Backhaus-Maul, Holger: „Corporate Citizenship im deutschen Sozialstaat“, in: Aus Politik und Zeitgeschichte, B 14, 2004, S. 23-30.

Becker, Konrad: Interview vom 26.02.2007.

Behrent, Michael: „Citizens in der Weltarena“, in: Behrent, Michael/Wieland, Josef (Hrsg.): Corporate Citizenship und strategische Unternehmenskommunikation in der Praxis, (DNWE-Schriftenreihe Folge 11), München/Mering 2003, S. 21-35.

Blumberg, Martin/Conrad, Christian: Good Brand 2006. Gutes tun und davon profitieren? Ethisches Verbraucherverhalten und Cause Related Marketing in Deutschland, Bremen 2006.

BUKO Pharma-Kampagne (Hrsg.): „Pharma Brief Nr. 6“, Oktober 2006, www.bukopharma.de/Pharma-Brief/PB-Archiv/2006/Phbf2006_06.pdf, 02.04.2007.

Christian Aid (Hrsg.): „Behind the mask: The real face of corporate social responsibility“, 2004, www.christian-aid.org.uk/indepth/0401csr/csr_ behindthemask.pdf, 02.04.2007.

Clarke, Paul Barry: Citizenship, London/Boulder CO, 1994.

55 Smith: „Modern Citizenship“, S. 114. 
Clarke, Tony: Silent Coup. Confronting the Big Business Takeover of Canada, Ottawa 1997.

CNNMoney.com: „Fortune Global 500“, money.cnn.com/magazines/ fortune/global500/2006/full_list/, 06.08.2007.

CorA - Netzwerk für Unternehmensverantwortung: „Koordinationskreis“, www.cora-netz.de/?page_id=9, 02.04.2007.

Dahrendorf, Ralf: „Zu viel des Guten. Über die soziale Dynamik von Staatsbürgerschaft“", in: Mackert, Jürgen/Müller, Hans-Peter (Hrsg): Citizenship - Soziologie der Staatsbürgerschaft, Wiesbaden 2000, S. 133-155.

Degussa AG: „Corporate Citizenship Report 2005“, www.econsense.de/ _PUBLIKATIONEN/_PUBLIKATIONEN_MITGLIEDER/images/ Degussa/Degussa_CC-Bericht_2005_dt.pdf, 02.04.2007.

Dienel, Hans-Liudger u.a.: Politische Regulierungsformen, Government, Governance und Netzwerkstrukturen auf der globalen, europäischen und nationalen Ebene, Düsseldorf 2001.

Dower, Nigel: „Situating Global Citizenship“, in: Germain, Randall D./Kenny, Michael (Hrsg.): The Idea of Global Civil Society. Politics and Ethics in a Globalizing Era, London/New York 2005, S. 100-118.

Gebhardt, Jürgen: „Die Idee des Bürgers“, in: Beyme, Klaus von/Offe, Claus (Hrsg.): Politische Theorien in der Ära der Transformation, (Politische Vierteljahresschrift, Sonderheft 26), Opladen 1996, S. 349-361.

Gonin, Michaël: „Die Trennung des Unternehmens vom Bürger - eine historisch-kritische Perspektive“, in: Patry, Eric/Ulrich, Peter (Hrsg.): Marktwirtschaft als Teil einer bürgergesellschaftlichen Gesamtordnung, St. Gallen 2006, S. 41-56.

Habisch, André: Corporate Citizenship. Gesellschaftliches Engagement von Unternehmen in Deutschland, Berlin u. a. 2003.

Habisch, André: „,Corporate Citizenship“ - unternehmerisches Bürgerengagement im Gemeinwesen des 21. Jahrhunderts“, in: Litzel, Susanne u.a. (Hrsg.): Handbuch Wirtschaft und Kultur. Formen und Fakten unternehmerischer Kulturförderung, Berlin u.a. 2003, S. 4-13.

Heater, Derek: What is citizenship? Cambridge 1999.

Hemphill, Thomas A.: „Corporate Citizenship. The Case for a New Corporate Governance Model“", in: Business and Society Review, Jg. 109, Nr. 3, 2004, S. 339-361.

Hundt, Dieter: „Corporate Social Responsibility. Das gesellschaftliche Engagement von Unternehmen“, (Papier des Arbeitskreises Bürger- 
gesellschaft und Aktivierender Staat der Friedrich-Ebert-Stiftung), Bonn 2005, library.fes.de/pdf-files/kug/02914.pdf, 02.04.2007.

Institut für Markt-Umwelt-Gesellschaft e.V. (Hrsg): „CSR-Informationsbedarf von Verbrauchern. Informations- und Einkaufsverhalten im Kontext von CSR“, imug1.de/pdfs/verbraucher/hp_imug_CSR_Verbraucher_Reprae sentativbefragung_2006_03_16.pdf, 02.04.2007.

Janoski, Thomas/Gran, Brian: „Political Citizenship: Foundations of Rights“, in: Isin, Engin F./Turner, Bryan S. (Hrsg.): Handbook of Citizenship Studies, London u.a. 2000, S. 13-52.

Kleinert, Matthias: „Politisches Marketing in der globalen Wirtschaft. Interessenvertretung und Good Corporate Citizenship“, in: Kreyer, Volker J. (Hrsg.): Handbuch politisches Marketing. Impulse und Strategien für Politik, Wirtschaft und Gesellschaft, Baden-Baden 2004, S. 489-497.

Kymlicka, Will/Norman, Wayne: „Return of the Citizen. A Survey of Recent Work on Citizenship Theory“, in: Ethics, Jg. 104, Nr. 2, 1994, S. 352-381.

Lang, Susanne/Solms Nebelung, Frank: „Geschäftsstrategie Verantwortung. Corporate Citizenship als Business Case“, (Papier des Arbeitskreises Bürgergesellschaft und Aktivierender Staat der Friedrich-Ebert-Stiftung), Bonn 2005, library.fes.de/pdf-files/kug/03892.pdf, 02.04.2007.

Mackert, Jürgen/Müller, Hans-Peter: „Der soziologische Gehalt moderner Staatsbürgerschaft. Probleme und Perspektiven eines umkämpften Konzepts“, in: dies. (Hrsg.): Citizenship - Soziologie der Staatsbürgerschaft, Wiesbaden 2000, S. 9-42.

Marsden, Chris/Andriof, Jörg: „Towards an Understanding of Corporate Citizenship and How to Influence It", in: Citizenship Studies, Jg. 2, Nr. 2, 1998, S. 329-352.

Mattera, Phil: „US: The 100 Worst Corporate Citizens“, www.corpwatch.org/ article.php?id=13849, 02.04.2007.

McIntosh, Malcolm u.a.: Corporate Citizenship. Successful Strategies for Responsible Companies, New York 1998.

Meyer, Christoph O.: Europäische Öffentlichkeit als Kontrollsphäre. Die Europäische Kommission, die Medien und politische Verantwortung, Berlin 2002.

Mouffe, Chantal: „Citizenship“, in: Lipset, Seymor Martin (Hrsg.): The Encyclopedia of Democracy, London 1995, S. 217-221.

Müller, Ulrich: „Privilegiert und umstritten. Der Einfluss der Konzerne in Europa“, in: Inkota Brief 136, 2006, S. 19-20. 
Nauta, Lolle: „Changing Conceptions of Citizenship“, in: Praxis International, Jg. 12, Nr.1, 1992, S. 20-34.

Norris, Pippa: A Virtuous Circle. Political Communications in Postindustrial Societies, Cambridge 2000.

Novartis International AG: „Corporate Citizenship“, www.novartis.com/ about-novartis/corporate-citizenship/index.shtml, 02.04.2007.

Schulz, Winfried: Politische Kommunikation. Theoretische Ansätze und Ergebnisse empirischer Forschung zur Rolle der Massenmedien in der Politik, Opladen 1997.

Schulze, Kay O.: Interview vom 11.10.2006.

Siemens AG: „Geschäftsbericht 2006 - Corporate Responsibility“, www. siemens.com/index.jsp?sdc_p=i1420432z3i141947610mo1419461pGB06c fs3t55u20z2\&sdc_bcpath=1415713.s_0,\&sdc_sid=9315900500\&, 02.04.2007.

Smith, Alister: „Campaigning for Codes of Conduct“, www.banafair.de/ $\mathrm{publ} / \mathrm{report} / \mathrm{eng} / \mathrm{coc} . \mathrm{htm}$, 02.04.2007.

Smith, Rogers M.: „Modern Citizenship“, in: Isin, Engin F./Turner, Bryan S. (Hrsg.): Handbook of Citizenship Studies, London u.a. 2002, S. 105-115.

Stolle, Dietlind u.a.: „Politics in the Supermarket. Political Consumerism as a Form of Political Participation“, in: International Political Science Review, Jg. 26, Nr. 3, 2005, S. 245-269.

The Co-operative Bank (Hrsg.): „The Ethical Consumerism Report 2005“, www.cooperativebank.co.uk/images/pdf/coopEthicalConsumerismReport2005.pdf, 02.04.2007.

The Procter \& Gamble Company: „P\&G ,Community Matters‘ Programme UK and Ireland“, www.uk.pg.com/downloads/communityMatters Guide.pdf, 02.04.2007.

The World Bank (Hrsg.): „Total GDP 2006“, siteresources.worldbank.org/ DATASTATISTICS/Resources/GDP.pdf, 06.08.2007.

Weinbach, Christine: „Staatsbürgerschaft und nationale Zugehörigkeit heute: multikulturell und de-ethnisiert?“ in: Gusy, Christoph/Haupt, HeinzGerhard (Hrsg.): Inklusion und Partizipation. Politische Kommunikation im historischen Wandel, Frankfurt a.M./New York 2005, S. 187-211.

Werner, Klaus/Weiss, Hans: Schwarzbuch Markenfirmen. Die Machenschaften der Weltkonzerne, Wien/Frankfurt a.M. 2001. 
Westebbe, Achim/Logan, David: Corporate Citizenship. Unternehmen im gesellschaftlichen Dialog, Wiesbaden 1995.

Willmott, Michael: „Citizen brands: Corporate citizenship, trust and branding“", in: Brand Management, Jg. 10, Nr. 4-5, 2003, S. 362-369. 



\section{Tanja Köhler}

\section{Netzaktivismus. Herausforderung für die Unternehmenskommunikation}

Unternehmen agieren in einer differenzierten und sensibilisierten Gesellschaft und stehen in einem immer komplexer werdenden Beziehungsgeflecht mit unterschiedlichen Anspruchsgruppen. Da sich die wirtschaftlichen Aktivitäten von Unternehmen auch auf gesellschaftliche Verhältnisse auswirken, reichen Unternehmensentscheidungen oftmals über das wirtschaftliche Unternehmensumfeld hinaus und tangieren verschiedene gesellschaftliche Bereiche, die von öffentlichem Interesse sind. ${ }^{1}$ Unternehmerisches Handeln wird daher auch von der Öffentlichkeit erörtert und von dieser in Frage gestellt, wodurch konfligierende Wertvorstellungen und Interessen zwischen Unternehmen und den unterschiedlichen Interessengruppen einer Gesellschaft deutlich werden. Die damit verbundenen öffentlichen unternehmens- und branchenkritischen Auseinandersetzungen können die unternehmerische Handlungsautonomie stark einschränken und zum Teil zu existenzbedrohenden Unternehmenskrisen führen. Die Stellung von Unternehmen in der Gesellschaft kann infol-

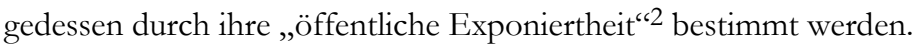

Unternehmensentscheidungen nachhaltig zu beeinflussen und Unternehmen mitunter sogar zu zwingen, ihr Handeln zu rechtfertigen sowie ihre gesellschaftliche Verantwortung zu thematisieren, gelingt strategiekritischen Anspruchgruppen $^{3}$ in der Regel erst durch die öffentliche, oft (massen)medial vermittelte Artikulation marktkritischer Anliegen. Diese Kritik erreicht Unternehmen vermehrt über das Internet; mitunter fungiert das Netz sogar als Ausgangsort von Unternehmenskrisen. In den vergangenen Jahren hat netzspezifischer Protest erheblich dazu beigetragen, dass Konzerne krisenanfälliger geworden sind und unter einem erhöhten gesellschaftlichen Legitimationsdruck stehen. Durch das gestiegene Protestvolumen im Internet sind Unternehmen gezwungen, sich mit kommunikativen Handlungsstrategien auseinanderzusetzen, die sie dabei unterstützen, netzbasierten Protest abfedern und bewältigen zu können. Dabei wird das Internet auch für Unternehmen zum maßgeblichen Instrument der Unternehmenskommunikation im Krisenkontext, da

1 Vgl. Dyllick: Management der Umweltbeziehungen, S. 13.

2 Ebd., S. 15.

3 Als strategiekritisch gelten im Folgenden diejenigen Anspruchsgruppen, die sich durch Unternehmensaktivitäten betroffen und/oder bedroht fühlen und die die Zielerreichung eines Unternehmens beeinflussen können. 
es ein breit gefächertes Spektrum an Kommunikationsmöglichkeiten zur Verfügung stellt. Dieser Beitrag erörtert, welche (unternehmenskritischen) Protestformen das Internet ermöglicht und wie sich Netzaktivismus gegen privatwirtschaftliche Unternehmen richten kann. Darauf aufbauend werden onlinegestützte Handlungsstrategien für den kommunikativen Umgang mit Netzaktivismus und digitalem Protest entwickelt.

\section{Machtverschiebungen im Cyberspace}

In der Vermittlung gesellschaftlicher Anliegen und der Etablierung von (krisenhaltigen) Themen kommt den traditionellen Massenmedien nach wie vor eine Schlüsselrolle zu. Der Zugang zu dieser relevanten Ebene der Öffentlichkeit ist jedoch aufgrund spezifischer Selektionskriterien beschränkt, sodass Zugangs- und Partizipationschancen nicht in gleichem Maße verteilt sind. Im Gegensatz zu tradierten Massenmedien ermöglicht das Internet als frei zugänglicher Kommunikationsraum praktisch jedem Nutzer, kritische Anliegen ungefiltert zu äußern. Unternehmen werden daher in zunehmendem Maße über das Internet von verschiedenen Akteuren attackiert, die im Netz ihre Kritik, ihren Unmut und ihren Protest frei formulieren können. Ausgehend von prinzipiellen Charakteristika des Netzaktivismus werden im Folgenden Ausdrucksformen von onlinebasiertem Protest gegen privatwirtschaftliche Unternehmen näher erläutert.

\subsection{Protestmöglichkeiten und Partizipationschancen}

Bereits in seinen Anfängen wurde das Internet durch den freien Zugriff auf Ressourcen und die beinahe grenzenlosen Partizipationsmöglichkeiten der Nutzer neben dem Militär und der Wissenschaft schnell für eine weitere Nutzergruppe attraktiv: die libertäre Protestkultur, die das Netz als Instrument für ihre Kampagnen gegen Staaten und/oder Großunternehmen einsetzte. ${ }^{4}$ Digitaler Protest ist beinahe so alt wie das Netz selbst und keine sich plötzlich entwickelnde neue Nutzungsform. Noch bevor das Internet flächendeckend kommerziell genutzt und von Unternehmen als Kommunikationskanal entdeckt wurde, gestalteten Protestbewegungen und kritische Akteure das Netz aktiv mit. $^{5}$

4 Vgl. Castells: „Internet, Netzgesellschaft“, S. 38-39.

$5 \mathrm{Zu}$ den frühen Protesten im Netz gehört der virtuelle Sit-In der italienischen Initiative strano.net, mit dem 1995 gegen französische Atomtests auf dem Pazifikatoll Mururoa demonstriert wurde. Vgl. Morell: „Online-Aktivismus“. 
Zugangsbarrieren, wie sie den klassischen Massenmedien immanent sind, existieren im Internet (vordergründig) nicht, sodass die Stärken des Internets insbesondere in der Verbesserung der Informations- und Artikulationsfunktion sowie der Interessenorganisation zu finden sind. Insofern bietet das Internet gesellschaftlichen Akteuren verbesserte Partizipations- und Kommunikationsmöglichkeiten, indem gesellschaftliche Fehlentwicklungen und/oder unternehmenskritische Sachverhalte thematisiert werden können, die von den traditionellen Massenmedien aus unterschiedlichen Gründen (Selektionskriterien, Angst vor Verlust von Anzeigenkunden, usw.) nicht aufgegriffen und erörtert werden. Kritik und eigene Anliegen können im Netz daher ungefiltert öffentlich und darüber hinaus einer breiten Nutzerschicht zugänglich gemacht werden.

Als Plattform für Protest und Kritik gesellschaftlicher Akteure ermöglicht das Internet daneben eine Ausweitung des Protestpotenzials sowie ein $\mathrm{Zu}$ sammenschließen von Betroffenen, da Gleichgesinnte über das Internet leichter zu finden und zu erreichen sind. ${ }^{6}$ Durch die vergleichsweise einfache Handhabung von Online-Kommunikation (z.B. E-Mail-Versand) sinkt zudem die Aktivitätsschwelle, weshalb auch Personen für Proteste mobilisiert werden können, die sich bisher nicht an Protesten außerhalb des Internets beteiligt haben. ${ }^{7}$ Castells sieht im Internet die Verbindung des Globalen mit dem Lokalen und damit eine neue Form der Kontrolle und der sozialen Mobilisierung unserer Gesellschaft. ${ }^{8} \mathrm{Da}$ gesellschaftliche Akteure das Internet auch als Instrument ihrer Selbstorganisation nutzen, übernimmt das Netz neben der Informations-, Artikulations- und Mobilisierungsfunktion auch eine Organisationsund Koordinationsfunktion. Für Castells ist das Internet eine Organisationsstruktur und ein Kommunikationsinstrument, das eine flexible und temporäre Mobilisierung ermöglicht, gleichzeitig aber diese Mobilisierung koordinieren und fokussieren kann. ${ }^{9}$ Insbesondere für Personen bzw. gesellschaftliche Minderheiten, die über keine klassischen Organisationsformen verfügen und von den traditionellen Massenmedien unbeachtet bleiben, bieten sich damit entscheidende Vorteile in der Organisation und Kommunikation ihrer Anliegen. ${ }^{10}$

6 Zu Protestnetzwerken im Internet vgl. März in diesem Band.

7 Vgl. Gräf: „Locker verknüpft im Cyberspace“, S.120.

8 Vgl. Castells: „Internet, Netzgesellschaft“, S 43.

9 Vgl. ebd.

10 Vgl. Scherer: „Partizipation für alle?“, S. 184. 


\subsection{Protestformen im Internet}

Durch die frühe Herausbildung einer netzbasierten libertären Protestkultur hat sich im Laufe der Entwicklung des Internets ein Netzaktivismus etabliert, der eine breite Palette an Protestformen hervorgebracht hat. Verschiedene Autoren machen darauf aufmerksam, dass Protestbewegungen mittlerweile mit Hilfe des Internets weltweite Netzwerke bilden, die schnell und flexibel auf etablierte Akteure (netz)öffentlichen Druck ausüben können. ${ }^{11}$ Die Protestformen von Akteuren im Internet unterscheiden sich dabei nicht wesentlich von denjenigen außerhalb des digitalen Datenraumes.

\begin{tabular}{|c|c|}
\hline \multicolumn{2}{|c|}{ WWW } \\
\hline Protestform & Beschreibung \\
\hline Netstrike & $\begin{array}{l}\text { Virtuelle Sitzblockade, in der zu einer verabredeten } \\
\text { Zeit möglichst viele Nutzer gleichzeitig eine }\end{array}$ \\
\hline (auch: virtuelle Sit-Ins bzw. & Website anklicken, um mit der Masse ihrer \\
\hline Denial-of-Service-Attacke $=$ & Anfragen eine Überlastung und schließlich den \\
\hline Angriff zur Verweigerung des Dienstes) & Ausfall des Angebots zu erreichen. \\
\hline Enthüllungs-Site & $\begin{array}{l}\text { Website, die auf ein tatsächliches oder angebliches } \\
\text { Fehlverhalten einer Person oder eines }\end{array}$ \\
\hline (auch: Anti-Sites) & Unternehmens aufmerksam macht. \\
\hline Protest-Site & $\begin{array}{l}\text { Website, die als inhaltlicher Knotenpunkt einer } \\
\text { Protestaktion Informationen bereitstellt sowie die } \\
\text { Kommunikation zwischen den Teilnehmern } \\
\text { unterstützt und die Mobilisierung der Aktionsbasis } \\
\text { verfolgt. }\end{array}$ \\
\hline $\begin{array}{l}\text { Web-Hack } \\
\text { (auch Web-Graffiti) }\end{array}$ & $\begin{array}{l}\text { Eingriff in die Quelldatei einer Website, um den } \\
\text { ursprünglichen Inhalt zu verändern bzw. zu } \\
\text { manipulieren. }\end{array}$ \\
\hline Streik-Links & $\begin{array}{l}\text { Querverweise auf einer Website, die auf andere } \\
\text { Web-Sites mit ähnlichem oder gleichem Anliegen } \\
\text { verweist, um die Aktionsbasis zu vergrößern. }\end{array}$ \\
\hline
\end{tabular}

11 Vgl. u.a. ebd., S. 183-184; Bieber: Politische Projekte im Internet; Dembowski: „Wenn Zernán Toledo die internationale Cyber-Solidarität mobilisiert“; Castells: „Internet, Netzgesellschaft“; Burger: „Der Angriff via Internet wird immer einfacher“; Ehrenberg: „Absturzgefahr für den Kranich“. 


\section{E-Mail}

\section{Protestform}

Elektronische Kettenbriefe

(auch: elektronische Protestschreiben)

Mailing-Listen

E-Zines, Newsletter

News

Protestform

Newsgroup-Postings

Einrichtung interessenspezifischer

Newsgroups

Einrichtung interessenspezifischer Chats

News

\section{Beschreibung}

Digitale Unterschriftensammlung als digitaler Protestbrief, der an den Adressaten der Protestaktion geschickt und an Bekannte zwecks VergröBerung der Aktionsbasis weitergeleitet wird.

Information und Koordination der Teilnehmer, ggf. auch Protestaufruf.

Digitale Protest- bzw. Streikzeitungen.

\begin{tabular}{|c|c|}
\hline Newsgroup-Postings & $\begin{array}{l}\text { Informationen werden in Newsgroups verbreitet. } \\
\text { Sie dienen der Vergrößerung/Mobilisierung der } \\
\text { Aktionsbasis. }\end{array}$ \\
\hline $\begin{array}{l}\text { Einrichtung interessenspezifischer } \\
\text { Newsgroups }\end{array}$ & $\begin{array}{l}\text { Informationsverbreitung und -austausch über die } \\
\text { Protestaktion in eigens für den Protest } \\
\text { eingerichteten Newsgroups, ggf. Aufruf zum } \\
\text { Protest. }\end{array}$ \\
\hline \multicolumn{2}{|c|}{ Chat } \\
\hline Protestform & Beschreibung \\
\hline Chat-Nachrichten & $\begin{array}{l}\text { Informationen werden in Chats verbreitet. Sie } \\
\text { dienen der Vergrößerung/Mobilisierung der } \\
\text { Aktionsbasis. }\end{array}$ \\
\hline Einrichtung interessenspezifischer Chats & $\begin{array}{l}\text { Informationsverbreitung und -austausch über die } \\
\text { Protestaktion in eigens für den Protest } \\
\text { eingerichteten Chats, ggf. Aufruf zum Protest. }\end{array}$ \\
\hline
\end{tabular}

Tab. 1: Protestformen im Internet. ${ }^{12}$

Die Aufführung der Artikulations- bzw. Protestformen in Tabelle 1 verdeutlicht die Komplexität der Online-Instrumente, derer sich gesellschaftliche Akteure zur Durchsetzung ihrer Anliegen bedienen. In der Regel setzen Protestakteure dabei sowohl informations- als auch kommunikations- und mobilisierungsorientierte Instrumente ein. Dabei gewährleisten die digitalen Protestformen eine Positionierung der Kampagne im Internet, die gleichzeitig infor-

12 Eigene Darstellung. 
mierend auf die Teilnehmer sowie mobilisierend auf neue Unterstützerkreise wirken kann. ${ }^{13}$

Gegenöffentlichkeit im Netz kann jedoch nur dann erfolgreich sein, wenn die digitalen Protestformen mit Protesten im realen Raum verknüpft werden. Bieber beobachtet daher den Trend, dass digitale Protestaktionen zunehmend mit klassischen Formen der Protestkommunikation verbunden werden und somit eine Verknüpfung alter und neuer Protestformen stattfindet. ${ }^{14}$ Die Verknüpfung digitalen Protests mit Protestaktionen im realen Raum zielt auf größtmögliche Aufmerksamkeit und ein höheres Durchsetzungspotenzial. ${ }^{15}$ Digitale Proteststrategien verdrängen oder ersetzen traditionelle Proteststrategien allerdings nicht, vielmehr kann die Verbindung beider Protestformen zu einer wirkungsvollen und verstärkten Selbstartikulation der entsprechenden Akteure führen. ${ }^{16}$

Auch die traditionellen Massenmedien spielen in diesem Zusammenhang eine entscheidende Rolle, da sie nicht zuletzt Online-Proteste aufgrund des (noch) hohen Nachrichtenwertes thematisieren und so den öffentlichen Druck im realen bzw. physischen Raum mobilisieren. Die in der Literatur aufgeführten Beispiele von Online-Protesten und Netzaktivismus weisen zudem in der Regel erst dann Erfolge auf, wenn dem virtuellen Protest eine Thematisierung in den traditionellen Massenmedien folgt. ${ }^{17}$ Insofern unterstützt das Internet relevante Anspruchsgruppen bei der Gewinnung öffentlicher Aufmerksamkeit bzw. Zustimmung zu ihren Anliegen und mobilisiert öffentlichen Druck, indem es spezifische (krisenhaltige) Themen in unterschiedliche Öffentlichkeitsarenen trägt, wobei der massenmedialen Arena nach wie vor eine zentrale Bedeutung zukommt.

\subsection{Netzaktivismus gegen privatwirtschaftliche Unternehmen}

Adressaten digitaler Protestkampagnen sind in zunehmendem Maße privatwirtschaftliche Unternehmen, die von Akteuren im Netz auf unterschiedliche Art angegangen und kritisiert werden (können). Klenk konstatiert in Anbetracht der steigenden Proteste von unternehmensrelevanten Anspruchsgruppen im Internet,

13 Vgl. Bieber: „Politische Projekte im Internet“, S. 170, 182.

14 Vgl. ebd., S. 171.

15 Vgl. ebd.

16 Vgl. Bieber/Hebecker: „Internet und soziale Bewegungen“, S. 176.

17 Vgl. Roselieb: „New Crisis Communications?“. 
dass Unternehmen noch nie so verwundbar [waren] wie heute und faktisch $[\ldots]$ jederzeit neue kleine und große Krisenherde entstehen [können]. Immer neue Akteure und Stakeholder kommunizieren mit und über Unternehmen. ${ }^{18}$

Für Coombs vergrößert das Internet die Macht gesellschaftlicher Anspruchsgruppen gegenüber Unternehmen:

The Internet offers a low cost, direct, controllable communication channel for activists. [...] the Internet has the potential to increase the power of activist groups and make their concerns more salient to organizations. The reason for the power increase is the Internet's potential to alter organizational stakeholder networks so that an activist group's power to influence is increased while an organization's ability to resist is reduced. ${ }^{19}$

Roselieb, der an der Universität Kiel Fälle von Unternehmenskrisen deutscher und internationaler Unternehmen dokumentiert, stellt entsprechend fest, dass seit Mitte der 1990er Jahre fast jeder vierte erfasste Krisenfall in direkter oder indirekter Art mit dem Internet verbunden ist. ${ }^{20}$ Der Protest der Akteure gestaltet sich durchaus differenziert und kann sich gegen einzelne Produkte und Dienstleistungen ebenso richten wie gegen einzelne Unternehmen oder gegen ganze Branchen. ${ }^{21}$ In der Literatur findet sich eine Vielzahl dokumentierter Online-Kampagnen und digitaler Proteste, die sich für das jeweils betroffene Unternehmen zu einer mehr oder weniger schweren und ernsthaften Unternehmenskrise entwickelten. ${ }^{22}$ Eines der bekanntesten, weil oft publizierten Beispiele betrifft die Rückrufaktion des Intel Pentium Prozessors im Jahr 1994. Die zunächst beim Hersteller des Prozessors vorgetragene Beschwerde durch einen Mathematik-Professor über einen Rundungsfehler des Chips wurde vom Unternehmen ignoriert und als Insider-Problem abgetan. Der Kunde wandte sich nun an Newsgroups und thematisierte den Fehler des Prozessors sowie das kundenunfreundliche Verhalten des Herstellers. Er traf

18 Klenk: „Der ignorierte Kontrollverlust der Corporate Communications“, S. 110111.

19 Coombs: „The Internet as Potential Equalizer“, S. 299-300.

20 Vgl. Roselieb: „New Crisis Communications?“, S. 32.

21 Unterschiedliche Ansatzpunkte konzernkritischer Kampagnen beleuchten Löding/Schulze/Sundermann in diesem Band.

22 Vgl. Dembowski: „Wenn Zernán Toledo die internationale Cyber-Solidarität mobilisiert“; Ehrenberg: „Absturzgefahr für den Kranich“; Roselieb: „New Crisis Communications?". 
dort auf zahlreiche Gleichgesinnte, sodass sich der Protest gegenüber dem Unternehmen im Internet schnell ausbreitete und sich zu einer Unternehmenskrise für Intel entwickelte. Als das Thema schließlich auch von den Massenmedien außerhalb des Internets aufgegriffen wurde, sah sich das Unternehmen zum Einlenken gezwungen. ${ }^{23}$

Beispiele dieser und ähnlicher Art verdeutlichen, dass das Internet zum einen die Krisenanfälligkeit von Unternehmen steigert und zum anderen unternehmerisches Handeln unter einen erhöhten gesellschaftlichen Legitimationsdruck setzt. Die Zahl der Proteste im Internet gegenüber Unternehmen wächst stetig. So liegt beispielsweise die Anzahl deutschsprachiger Newsgroups, die zum Boykott von Produkten oder Unternehmen aufrufen, im oberen fünfstelligen Bereich. ${ }^{24}$ Unternehmenskritische Web-Sites wachsen in einem Ausmaß, dass das Internet-Portal Yahoo bereits eine eigene Kategorie (Consumer Opinion) für sie eingerichtet hat. Und in Verbraucherportalen (z.B. www.dooyoo.de, www.ciao.com) geben Konsumenten ihre subjektive Meinung über nahezu jedes Produkt und jede Dienstleistung ab. Diese Kritik sollte von Unternehmen nicht unterschätzt werden: Die Aussagen erreichen aufgrund des Wegfalls räumlicher und zeitlicher Restriktionen eine große Anzahl von Konsumenten, die im Internet zudem gezielt nach derartigen Informationen suchen. Außerdem wird der Kritik von Kunden gemeinhin ein neutraler(er) Status unterstellt, wodurch sie meist eine höhere Glaubwürdigkeit als die scheinbar interessengebundene Aussage eines Unternehmens besitzt. ${ }^{25}$

\section{Onlinegestützte Handlungsstrategien für die Unternehmenskommunikation}

Paradoxerweise ist die Kritik im Internet nicht nur verantwortlich für eine gesteigerte Krisenanfälligkeit des Unternehmens, sondern bietet Unternehmen gleichzeitig bessere Möglichkeiten der Krisenprävention: Denn diese sind durch das Internet zwar einem weitaus höheren öffentlichen Druck ausgesetzt, können ihn allerdings - im Gegensatz zur direkten Mund-zu-Mund-Propaganda - selbst mitverfolgen. Hierdurch können Erwartungen von Anspruchs-

23 Vgl. Hilse/Hoewner: „Die Kommunikationskrise im Internet - und was man dagegen tun kann“, S. 144; Roselieb: „New Crisis Communications?“, S.113.

24 Vgl. z.B. Schatz: „Dem Externen auf der Spur“, S. 291. Eine Anfrage bei der Suchmaschine Google ergibt für den Begriff „,boycott“ 13.400.000 und auf deutsche Sites beschränkt („Boykott“) 1.550.000 Treffer (Stand: Juli 2007).

25 Zum Empowerment von Konsumenten im Internet vgl. Baringhorst in diesem Band. 
gruppen sowie krisenhaltige Sachverhalte weitaus schneller antizipiert werden. Insofern bergen Online-Proteste nicht nur Gefahren, sondern auch eine verbesserte Chance zur Früherkennung möglicher Konfliktthemen und Protestgruppen. Durch die Nutzung der unterschiedlichen Kommunikationsmodi des Internets können die Instrumente der Unternehmenskommunikation in Qualität wie Quantität erheblich ausgeweitet werden. Der Einsatz des Internets birgt dabei mehrere Vorteile:

- Sowohl die Mehrheit der deutschen Bevölkerung als auch die Mehrheit der Journalisten nutzt mittlerweile das Internet und kann darüber angesprochen werden. ${ }^{26}$ Angesichts des wissenschaftlichen Ursprungs des Internets nutzen darüber hinaus immer noch viele höher Gebildete das Internet, ergo auch Experten aus Wissenschaft und Forschung. Gemäß Dyllicks Lebenszyklusmodell ${ }^{27}$ öffentlicher Anliegen besitzt die Kommunikation mit diesen Anspruchsgruppen eine besondere Relevanz, da sie es sind, die als Erste Interesse an einem Thema zeigen und die Entwicklung des Anliegens weiter verfolgen. Das Internet kann vor diesem Hintergrund einen besseren Zugang zu diesen im Krisenkontext strategisch wichtigen Gruppen und ihren Anliegen bieten.

- $\quad$ Durch die globale Netzwerkstruktur werden die Dimensionen von Zeit und Raum im Internet nahezu aufgehoben, was zu einer immensen Beschleunigung des medialen Kommunikationsprozesses führt. Angesichts der Dringlichkeit zur schnellen Reaktion und Kommunikation in Krisensituationen stellt das Internet eine Kommunikationsplattform zur Verfügung, auf der im Vergleich zu anderen Medien Fakten schneller und direkter zirkulieren.

- Die Etablierung des Internets führt zwangsläufig zu Veränderungen im Kommunikationssystem. So weisen Studien ein erhebliches Wachstum des Medienzeitbudgets zugunsten des Internets und zuungunsten klassischer Medien nach. ${ }^{28}$ Zudem hat sich das Internet als wichtiges Medium für tagesaktuelle Informationen etabliert. ${ }^{29}$ Empirischen Befunden zufolge könnte in Unternehmen die E-Mail-Kommunikation sogar an-

26 Vgl. van Eimeren u.a.: „Internetverbreitung in Deutschland“, S. 352; Breunig: „Internet: Auf dem Weg zu einem kommerziellen Medium?“, S. 385; news aktuell: media studie 2002.

27 Vgl. Dyllick: Management der Umweltbeziehungen.

28 Vgl. Oehmichen/Schröter: „Funktionswandel der Massenmedien durch das Internet?", S. 382.

29 Vgl. van Eimeren u.a.: „Internetverbreitung in Deutschland“, S. 356. 
dere Kommunikationskanäle wie Post oder Fax bald vollständig substituieren und sich zum wichtigsten oder gar einzigen Distributionskanal in der Informationsübermittlung an Journalisten entwickeln. ${ }^{30}$ Insofern hängt die erfolgreiche Verteilung relevanter Fakten in der jeweiligen Krisensituation auch von der Berücksichtigung der zunehmenden Basis-Informationsfunktion des Internets und der gestiegenen Bedeutung der EMail-Kommunikation ab. Mit dem adäquaten Einsatz der Kommunikationsmittel könnten (potenzielle) Krisensituationen daher zielführender abgefedert werden.

Angesichts eines zunehmenden Netzaktivismus, hierdurch entstehender potenziell krisenauslösender Tendenzen sowie der Vorteile, die sich für Unternehmen durch die Nutzung des Internets ergeben, sollte das Netz im Krisenkontext als zentrales Instrument in die strategische Unternehmenskommunikation integriert werden, um für unternehmenseigene Problemdefinitionen Aufmerksamkeit zu erreichen. Hierfür stellt das Internet ein breitgefächertes Anwendungsspektrum an Kommunikationsmöglichkeiten zur Verfügung, die sowohl zur Krisenprävention ${ }^{31}$ als auch zur Krisenbewältigung ${ }^{32}$ eingesetzt werden können. Diese onlinegestützten Handlungsfelder finden sich zusammengefasst dargestellt in Abbildung 1 und werden im Folgenden näher vorgestellt.

30 So gibt der PR-Akteur eines DAX-Unternehmens während des teilstandardisierten Leitfadengesprächs im Rahmen der empirischen Untersuchung von Köhler (2006) beispielsweise an, mittelfristig den schriftlichen Versand komplett einstellen und alle Informationen an Journalisten nur noch über E-Mail versenden zu wollen: „[...] Also bei [Fach]Journalisten [...] werden auch noch Sachen per Fax geschickt $[\ldots]$. Aber es sind nur noch wirklich wenige. Es dauert noch ein, zwei, drei Jahre dann stellen wir das ganz ein und machen das nur noch per E-Mail, weil die Vorteile sind einfach riesengroß. Ich kann da direkt einen Link reinmachen, dann schicke ich die Leute auf bestimmte Seiten, die werden auf die Fotoseiten geführt, wo sie die aktuellsten Bilder-Downloads bekommen, man kann sie richtig in virtuelle Welten reinbringen, was weiß ich, auf ein Glossar stoßen oder sonst irgendwas. Das kann ich alles mit Fax und so 'nem Unsinn nicht sicherstellen." Vgl. Köhler: Krisen-PR im Internet, S. 354.

31 Vgl.ebd.; dies.: „Online-gestützte Krisen-PR“.

32 Vgl. hierzu insbesondere dies.: „Gefahrenzone Internet““. 


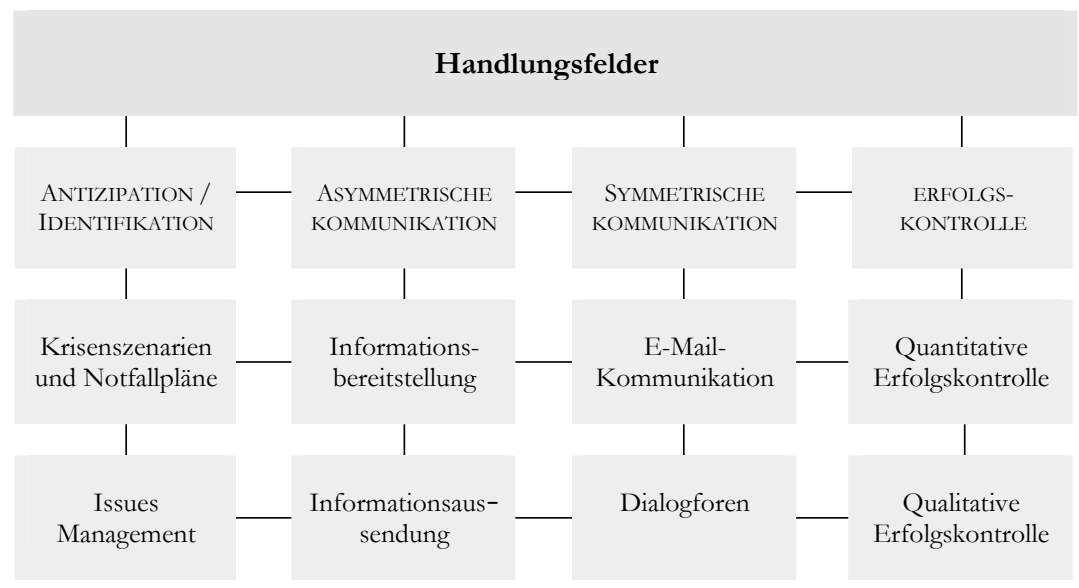

Abb. 1: Onlinegestützte Handlungsfelder. ${ }^{33}$

\subsection{Antizipation und Identifikation}

Unternehmenskrisen treten zwar häufig überraschend auf, dennoch sollten sie ein Unternehmen nicht unvorbereitet treffen. Um in einer Krisensituation schnell und adäquat reagieren zu können, sollten Krisen- bzw. Notfallpläne angelegt werden, die unterschiedliche Krisenszenarien antizipieren und entsprechende Handlungs- und Maßnahmerichtlinien festlegen. Derartige Notfallpläne sollten grundsätzlich auch als Internet-Krisenhandbücher vorliegen und im unternehmenseigenen Intranet den entsprechenden Mitarbeitern zur Verfügung stehen, um im konkreten Problemfall Maßnahmen direkt einleiten sowie einen schnellen Zugriff in allen Krisensituationen gewährleisten zu können. ${ }^{34}$

Im Vorfeld können außerdem so genannte Darksites für den Krisenfall erstellt werden, welche erst bei einem eintretenden Problemfall freigeschaltet werden. Darksites enthalten i.d.R. diejenigen Informationen, die für die jeweils relevanten Anspruchsgruppen in der unterstellten Krise und dem potenziellen Krisenverlauf relevant sind. ${ }^{35}$ Derartige Informationen können vielfältig sein und beinhalten je nach Krisenszenario aufbereitete Textbausteine zu unterschiedlichen Kommunikationsschwerpunkten, beispielsweise zu Maßnahmen, die das Unternehmen für Sicherheit und Umweltschutz trifft, zu Verhaltensregeln für Szenarien, die Gefahren für die Gesundheit von Verbrauchern bergen,

33 Eigene Darstellung.

34 Vgl. Schäfer: „Unberechenbar und Anarchisch“, S. 90; Roselieb: „New Crisis Communications?", S. 118.

35 Vgl. ebd.; Hasse: „Krisenraum Internet“, S. 172. 
oder Kontaktadressen, Hotline-Nummern etc. ${ }^{36}$ Die Informationen können sich dabei auch an Protestkampagnen orientieren, um den dort geäußerten kritischen Sachverhalten und Argumentationen unternehmenseigene Problemdefinitionen gegenüberzustellen. Darksites beschleunigen in der entsprechenden Krise den Kommunikationsprozess, sie können relevante Fakten schnell und direkt zugänglich machen. Darüber hinaus entlasten sie andere, im Krisenfall stark belastete Kommunikationskanäle wie beispielsweise die Pressestelle.

Gemäß Dyllicks Lebenszyklusmodell öffentlicher Anliegen treten krisenhaltige Issues in ihrer Latenzphase und Emergenzphase vermehrt im Internet auf, sodass dem Netz neben der Antizipationsfunktion ein wichtiger Stellenwert in der Identifikation von krisenhaften und konfliktträchtigen Themen zukommt. Im Internet sind auch schwache Krisensignale frühzeitig erkennbar, sodass krisen- und konflikthaltige Themen noch zu Beginn ihres Entstehungsprozesses identifiziert werden können. Internetrecherche stellt somit ein wichtiges Standbein des so genannten Issues Management dar, in dessen Rahmen kritische Themen und Ansprüche von Stakeholdern frühzeitig erkannt werden sollen, um Organisationen so in der Bewältigung von Ungewissheit und Risiko $\mathrm{zu}$ unterstützen. ${ }^{37}$ Liebl unterscheidet für die Identifizierung unternehmensrelevanter Informationen zwischen Sekundär- und Primärdaten im Netz. ${ }^{38}$ Während Sekundärdaten vom Unternehmen selbst geortet werden müssen, werden Primärdaten an das Unternehmen herangetragen. Sekundärdaten stehen im Internet in vielfältiger Weise zur Verfügung und können sowohl auf Websites als auch innerhalb der unterschiedlichen Dialogforen (News, Mailinglisten, Chats) gesucht werden. Besondere Bedeutung bei der Suche und Identifikation strategiekritischer Issues ${ }^{39}$ kommt Meinungs- und Verbraucherportalen - wie z.B. www.dooyoo.de, www.ciao.com - sowie WebAngeboten unternehmenskritischer Anspruchsgruppen - wie z.B. www.boykott.de, www.essential.org - zu, da die dort veröffentlichte Kritik gegenüber Unternehmen, ihren Produkten, Dienstleistungen oder Handlungen in der Regel wegen möglicher Interessenkollisionen mit Anzeigenkunden oder Geschäftspartnern zunächst nicht von traditionellen Massenmedien aufgegrif-

36 Vgl. Hoffmann: „Krisenprävention“, S. 130-131.

37 Vgl. Röttger: „Issues Management“; Lütgens: Potentiellen Krisen rechtzeitig begegnen.

38 Vgl. Liebl: Der Schock des Neuen, S. 143.

39 Analog zu strategiekritischen Anspruchgruppen werden unter strategiekritischen Issues diejenigen Themen verstanden, die Unternehmensaktivitäten betreffen bzw. bedrohen können und somit die Zielerreichung eines Unternehmens beeinflussen können. 
fen wird. ${ }^{40}$ Grundsätzlich ist die individuelle Suche nach und die Identifikation von strategiekritischen Issues im Netz angesichts der Informationsfülle mit einem erheblichen Zeit- und Personalaufwand verbunden, der von Unternehmen nicht immer bewältigt werden kann. In solchen Fällen sollte die Informationsrecherche an externe Dienstleister delegiert werden. Obwohl Sekundärdaten im Internet eine wichtige Informationsquelle für die Umweltanalyse darstellen, besitzen Primärdaten für Unternehmen eine noch größere Relevanz, da sie direkt an das Unternehmen herangetragen werden und insofern unmittelbar unternehmensrelevante Problembereiche betreffen. Die Auswertung der unternehmensgerichteten Kommunikation kritischer Akteuren kann deshalb wichtige Anhaltspunkte über deren Anliegen liefern.

\subsection{Asymmetrische Kommunikation}

Problemorientierte asymmetrische Kommunikationsstrategien stellen einen wichtigen Baustein im Rahmen der Unternehmenskommunikation im Krisenkontext dar. Durch sie kann die unternehmenseigene Position optimiert bzw. eine anzustrebende Verständigung mit strategiekritischen Anspruchsgruppen im Sinne der Krisenbewältigung vorbereitet werden. Diese Kommunikationsprozesse lassen sich im Netz auf zwei Ebenen einleiten: Einerseits können Informationen für Anspruchgruppen bereitgestellt und andererseits direkt an sie gesendet werden.

Die Informationsbereitstellung erfolgt über das unternehmenseigene Webangebot, welches als strategisches Informationssystem sowie als dialoginitiierendes Instrument (z.B. Bereitstellung von Kontaktdaten) im Krisenkontext betrachtet werden kann. Eine proaktive Informationspolitik setzt allerdings voraus, dass die Informationen, die für den potenziellen Krisenverlauf relevant sind, auch umgehend im Netz bereitgestellt werden. Denn nur so erhält das Unternehmen die Möglichkeit, eigene Problemdefinitionen einzubringen, noch bevor sich die traditionellen Medien der Thematik annehmen. Durch eine umgehende und umfassende Darstellung relevanter Informationen kann somit auch der Entstehung oder Etablierung einseitiger Problemdefinitionen zuungunsten des jeweiligen Unternehmens in der Öffentlichkeit vorgebeugt werden. Um die Transparenz und Glaubwürdigkeit des Unternehmens im Krisenkontext zu erhöhen, plädieren einige Autoren sogar dafür, auch kommentierte Linklisten zu produkt- oder unternehmenskritischen Websites - ergo zu digitalen Protestkampagnen, Protestgruppen und Netzaktivisten, die sich gegen das Unternehmen richten - in das unternehmenseigene Angebot zu integrie-

40 Vgl. Neuberger: „Online Journalismus“, S. 133. 
ren. ${ }^{41}$ Hinsichtlich der Selbstdarstellung im Internet muss jedoch einschränkend darauf hingewiesen werden, dass Unternehmensnachrichten eine höhere Glaubwürdigkeit beim Rezipienten besitzen, wenn sie über die klassischen Massenmedien verbreitet werden, als wenn sie im unternehmenseigenen WebAngebot präsentiert werden. ${ }^{42}$ Anspruchsgruppen könnten daher an der Vollständigkeit der Informationen zweifeln sowie die Informationen fehlinterpretieren, was zu einer Konfliktverhärtung führen kann. Dennoch bietet das WWW für eine glaubwürdige Kommunikation mit relevanten Protestgruppen und Netzaktivisten günstige Voraussetzungen, denn durch die Abwesenheit journalistischer Gatekeeper erhalten Unternehmen die Möglichkeit, strategiekritischen Akteuren ungekürzte Primärinformationen zu vermitteln und somit auch negative Tendenzen, welche meist durch die massenmediale Berichterstattung im Krisenkontext evoziert werden, im Internet zu relativieren. Durch die Darstellung von Sachverhalten auf Unternehmensseiten können Anspruchsgruppen insofern auch die Aussagen und Argumentationen von Netzaktivisten mit denjenigen des Unternehmens vergleichen und in Beziehung setzen.

Neben der Informationsbereitstellung kann die Informationsaussendung als weiteres Instrument asymmetrischer Kommunikation im Krisenkontext eingesetzt werden. ${ }^{43}$ Dabei werden Informationen mittels E-Mail über so genannte Newsletter versendet, die, Rundbriefen gleich, anlassbezogen bzw. periodisch und kostenlos an relevante Anspruchsgruppen gesandt und vom jeweiligen Unternehmen selbst erstellt werden. Während der anlassbezogene Versand Nutzer über bestimmte unternehmensrelevante Ereignisse informiert und nicht in regelmäßigen Abständen erfolgt, informieren periodische E-MailNewsletter regelmäßig über spezielle Themen. Hinsichtlich einer krisenpräventiven Kommunikationsstrategie stehen bei einer solchen zielgruppenspezifischen Informationsaussendung die problemorientierten Hintergrundinformationen und strittigen Sachverhalte im Vordergrund, um so das Wissen strategiekritischer Anspruchsgruppen über unternehmenseigene Problemdefinitionen zu vertiefen. Unternehmen erhalten so die Möglichkeit, über strittige Sach-

41 Vgl. Kent/Taylor: „Building Dialogic Relationships Through the World Wide Web“, S. 328; Mickeleit: „Wer gewinnt die Online-Schlacht?“, S. 117.

42 Vgl. Rössler/Ognianova: „Die journalistische Identität als Qualitätskriterium im World Wide Web“, S. 121; Schweiger: „Medienglaubwürdigkeit - Nutzungserfahrung oder Medienimage?“", S. 105, 108; Köhler: Krisen-PR im Internet, S. 220-224.

43 Neben dieser monodirektionalen Nutzung kann Informationsaussendung im Rahmen der Initiierung bzw. Vorbereitung eines Dialogs mit relevanten Anspruchsund Protestgruppen eingesetzt werden, indem Kontaktmöglichkeiten und Ansprechpartner angegeben werden. 
verhalte proaktiv zu informieren und die unternehmenseigene Positionierung zu verbessern. Als nachteilig erweist sich jedoch, dass die unternehmenseigenen Aussagen von Anspruchsgruppen immer in Verbindung mit dem Absender interpretiert werden und eventuell auftretende Zweifel an der Vollständigkeit der Informationen daher nicht völlig ausgeschlossen werden können. Auf der anderen Seite müssen Newsletter von den jeweiligen Anspruchsgruppen abonniert werden, sodass im Vergleich mit der Informationsdarstellung im WWW mit geringeren Streuverlusten sowie mit höherer Aufmerksamkeit und größerem Interesse auf Nutzerseite gerechnet werden kann.

\subsection{Symmetrische Kommunikation}

Das vorherrschende Kommunikationsverständnis in der Wissenschaft wie in der Praxis geht davon aus, dass zur Lösung krisenhafter Sachverhalte ein symmetrischer Kommunikationsprozess geeignet ist. Insbesondere das Internet bietet die Möglichkeit medialer, symmetrischer Kommunikationsbeziehungen, die auf Einzelebene (E-Mail-Kommunikation) und Gruppenebene (Dialogforen) erfolgen können.

Anders als bei der Informationsaussendung steht beim herkömmlichen EMail-Versand der symmetrische Kommunikationsprozess im Vordergrund der kommunikativen Beziehungen. Aufgrund dieser Möglichkeit zur dialogorientierten Kommunikation stellt E-Mail im Krisenkontext eine wichtige Alternative zu tradierten symmetrischen Kommunikationsformen dar, da sie eine erheblich höhere Reichweite als herkömmliche symmetrische Kommunikationsprozesse erzielen kann, die bisher fast ausschließlich auf Face-to-Face-Kommunikation beschränkt waren. Die besondere strategische Bedeutung der EMail-Kommunikation im Krisenkontext erwächst jedoch nicht zuletzt aus dem Wegfall bestimmter verbaler und nonverbaler Ausdrucksmöglichkeiten dieser direkten sozialen Interaktion. Während bei Face-to-Face-Gesprächen schon die Wahrnehmung kategorisierender sozialer Hinweise das Erkennen von Gemeinsamkeiten beeinflussen und mitunter erschweren kann, sind in der EMail-Kommunikation derartige (Stör-)Größen nicht vorhanden, sodass der Austausch von Sachargumenten und die Erarbeitung eines Interessenausgleichs bzw. einer Verständigung zwischen Unternehmen und relevanten Anspruchs- und Protestgruppen unter Umständen vereinfacht und so die Basis für eine sachlich-neutrale Konfliktaustragung geschaffen werden kann.

Dennoch scheinen Unternehmen die Möglichkeiten des E-Mail-Versands im Krisenkontext nicht wesentlich zu nutzen. Dabei liegt das Problem vieler Unternehmen nicht darin, Anfragen zu spät oder unzureichend zu beantworten, sondern vielmehr darin, überhaupt nicht zu antworten. Gründe hierfür 
sind oft ungeklärte oder fehlende Zuständigkeitsregelungen, Kompetenzverteilungen und fehlende Qualitätskriterien im Umgang mit den Anliegen strategiekritischer Anspruchgruppen innerhalb des Unternehmens und seiner einzelnen Abteilungen ${ }^{44}$, die im schlimmsten Fall zu neuen Krisenpotenzialen führen. So warnt beispielsweise Marschall vor der Erzeugung einer Dialogillusion, welche dem Nutzer nur die Möglichkeit zum Austausch suggeriere und bei einer Desillusionierung zu einem drastischen Schwund an Glaubwürdigkeit und zu einem vollständigen Verlust an Transparenz - im Sinne der Schaffung und Etablierung einer dialogischen Struktur - führe. ${ }^{45}$ Unternehmen werden durch eine mangelhafte Nutzung des Kommunikationskanals E-Mail (z.B. durch fehlende Medienkompetenz oder fehlende organisationsstrukturelle Steuerungssysteme) somit selbst zum Risiko- und Krisenproduzenten. Den fahrlässigen Umgang mit strategiekritischen Anspruchsgruppen bestätigen auch empirische Untersuchungen: Meyer stellt in ihrer Untersuchung die Beantwortung von E-Mail-Anfragen an Unternehmen als unzuverlässig und langwierig dar ${ }^{46}$ und Köhler weist in einer E-Mail-Response-Analyse eine geringe Dialogbereitschaft der 30 DAX-Unternehmen bei der Beantwortung von kritischen E-Mail-Anfragen nach. ${ }^{47}$

Im Krisenkontext sind Unternehmen aber nicht nur gefordert, schnell und adäquat auf problemorientierte E-Mail-Anfragen zu reagieren, sie sollten auch aktiv in den Kontakt und den Dialog mit strategiekritischen Protestgruppen und Netzaktivisten treten. Denn oftmals stehen hinter der im Internet geäußerten Kritik Personen, die sich vom Unternehmen oder einzelnen Mitarbeitern schlecht behandelt fühlen und die durch ein proaktives und verständigungsorientiertes Kommunikationsverhalten des Unternehmens (beispielsweise Wiedergutmachungsangebote oder ernsthafte Entschuldigungen) bisweilen schnell zufrieden zu stellen sind. ${ }^{48}$ Durch aktive Kontaktaufnahme und die damit verbundene Initiierung eines Dialogs können Krisenverläufe positiv beeinflusst, wenn nicht gar völlig gestoppt werden. ${ }^{49}$

Den strategischen Vorteilen, die sich durch die Nutzung von E-Mail im Krisenkontext ergeben, stehen jedoch auch Nachteile gegenüber, die aufgrund medienspezifischer Restriktionen entstehen: Durch die ausschließlich ver-

44 Vgl. Wiegran/Harter: Kundenfeedback im Internet, S. 132-147; Wiegran: „Warten auf Antwort", S. 30-31.

45 Vgl. Marschall: „Politischer Prozess und Internet“, S. 168.

46 Vgl. Meyer: Internet und strategisches Management, S. 186.

47 Vgl. Köhler: „E-mail ohne Antwort“.

48 Vgl. Roselieb: „New Crisis Communications?“, S. 125-126.

49 Vgl. Schäfer: „Unberechenbar und Anarchisch“, S. 92. 
schriftlichte und technisch vermittelte Kommunikation wird die Gesprächssituation mitunter flüchtiger, unverbindlicher sowie störanfälliger und die Gefahr von Fehlinterpretation der Aussagen wächst. Unternehmen müssen darüber hinaus spezifische Anforderungen (z.B. organisationsstrukturelle Steuerungssysteme, adäquate Reaktionszeit, Medienkompetenz der Mitarbeiter) berücksichtigen, wenn sich die Kommunikation nicht negativ auf die Krisensituation auswirken soll.

Während E-Mail-Kommunikation den symmetrischen Austausch auf der individuellen Ebene unterstützen kann, ermöglichen Dialogforen symmetrische Kommunikationsprozesse auf Gruppen- und Massenebene und erlangen hierdurch aufgrund mehrerer Faktoren besondere Relevanz im Umgang mit Netzaktivismus und digitalem Protest: Sie stellen aufgrund ihrer erheblich höheren Reichweite sowie ihrer zeit- und kostengünstigeren Organisation eine wichtige Alternative zu den entsprechenden herkömmlichen Kommunikationsprozessen im Rahmen organisierter Veranstaltungen dar, die nur wenige Betroffene und aktive Teilöffentlichkeiten erreichten. ${ }^{50}$ Der Vorteil von Dialogforen im Krisenkontext ergibt sich auch hier durch den Wegfall verschiedener Ausdrucksmöglichkeiten direkter zwischenmenschlicher Interaktion sowie durch die Anonymität der Diskussionsteilnehmer. Die anonyme Gesprächsituation kann dazu führen, dass Teilnehmer ihre Meinung offener und unbefangener aber auch vehementer äußern, weshalb in Dialogforen strategiekritische Issues frühzeitig identifiziert werden können. Insbesondere in Konflikt- und Krisensituationen kann die anonyme Gesprächssituation zudem zu einer offeneren und objektiveren Debatte führen und zur Optimierung einer gemeinsamen Lösungsfindung beitragen. ${ }^{51}$ Dennoch sind Dialogforen

50 Vgl. Hribal: „Risikokommunikation“, S. 453.

51 Der Konformitätsdruck, der in traditionellen Dialogveranstaltungen dazu führt, dass sich Diskussionsteilnehmer der herrschenden Meinung der Gruppenmitglieder bzw. eines dominanten oder hierarchisch ranghohen Mitglieds unterordnen und sich dessen Positionen anschließen, wird in digitalen Dialogforen durch die Anonymität der Teilnehmer weitgehend aufgehoben. Teilnehmer an digitalen Dialogforen haben angesichts der anonymen Gesprächssituation im Grunde keine Restriktionen zu befürchten und äußern sich freier und bereitwilliger. Vgl. Hiltz/Turoff: The Network Nation, S. 95, 106; Naderer/Wendpap: „Online-Gruppendiskussionen“, S. 7; Wiegran: „Warten auf Antwort“, S. 18. Wie Connolly u.a. in ihrer Untersuchung zum Kommunikationsverhalten in computervermittelten Gruppendiskussionen nachweisen, sorgt die Anonymität dafür, dass mehr Aspekte eines Themas diskutiert und mehr Ideen generiert werden. Vgl. Connolly u.a.: „Effects of Anonymity and Evaluative Tone on Idea Generation in Computer Mediated Groups“. Hinzu kommt, dass sich in digitalen Dialogforen der Unterschied zwischen Teilnehmern mit starkem Kommunikationsverhalten und Beteiligten mit geringem Mitteilungsbedürfnis ausgleicht, wodurch die Diskus- 
durch die gleichen medienspezifischen Restriktionen beeinträchtigt wie die EMail-Kommunikation (s.o.). Erschwerend kommt für Unternehmen hinzu, dass die anonyme Gesprächssituation und die hierdurch nicht zu erkennende Identität der Gesprächspartner die Überprüfung der Informationsrelevanz und -authentizität beeinträchtigt. Die Ein- und Austrittskosten in und aus derartigen Diskussionen sind angesichts einer meist unpersönlichen, rein verschriftlichten Online-Kommunikation deutlich herabgesetzt, sodass der Diskurs bisweilen schwer aufrecht zu halten ist.

Grundsätzlich können Unternehmen Dialogforen im eigenen Kommunikationsangebot integrieren, oder aber sie beteiligen sich an externen, bereits bestehenden Diskussionsgruppen. Da Protestgruppen und Netzaktivisten nicht zwangsläufig eigens vom Unternehmen eingerichtete Diskussionsgruppen ansteuern, sondern ebenso andere Kommunikationsangebote nutzen, bietet sich für Unternehmen ein Engagement auch außerhalb des eigenen Kommunikationsbereichs an. Unternehmen können sich insofern an bereits existierenden Diskussionsgruppen von Netzaktivisten und strategiekritischen Anspruchsgruppen beteiligen. Eine solche aktive Beteiligung in bestehenden Dialogforen ermöglicht es Unternehmen, Diskussionsverläufe, die sich gegen das Unternehmen, seine Produkte, Dienstleistungen, Handlungen oder gegen die ganze Branche richten, durch Einbringung eigener Sichtweisen und Problemdefinitionen aktiv zu steuern, um so krisenhemmend auf den Kommunikationsverlauf einzuwirken.

\subsection{Erfolgskontrolle}

Erfolgskontrollen stellen ein zentrales Handlungsfeld im Krisenkontext dar, um den Erfolg und die Effizienz der Unternehmenskommunikation zu sichern. Sie sollten daher integraler Bestandteil des gesamten onlinegestützten Kommunikationsprozesses sein. Um die Effektivität der onlinegestützten kommunikativen Aktivitäten im Krisenkontext zu sichern, bedarf es einer PREvaluation. Die einfachste Form der Erfolgskontrolle besteht in der quantitativen Erfassung der Nutzeranzahl mittels serverzentrierter Reichweitenmes-

sion nicht einseitig beeinflusst wird. Vgl. Wiegran: „Warten auf Antwort“, S. 18. Teilnehmer in computervermittelten Diskussionsgruppen kommen weitaus gleichmäßiger zu Wort als in herkömmlichen Gesprächsrunden, in denen zumeist die hierarchisch Ranghöchsten oder Vielredner die Sprechzeit dominieren. Vgl. Stegbauer: Electronic Mail und Organisation. Zudem führt die Anonymität im Internet zu einer tiefergehenden inhaltlichen Auseinandersetzung im Vergleich zu traditionellen Gruppen. Vgl. Naderer/Wendpap: „Online-Gruppendiskussionen“, S. 9 . 
sungen und der quantitativen Erfassung eingegangener E-Mails; sie lässt jedoch keine gesicherten Schlussfolgerungen über die Wirkung auf strategiekritische Anspruchsgruppen zu. Über die rein quantitative Evaluation hinaus geht der Einsatz von Feedback-Instrumenten, wie Online-Befragungen der Nutzer und die systematische inhaltliche Auswertung der Nutzeranfragen aus E-Mails, Dialogforen oder Gästebüchern. Hiermit können Erkenntnisse über die Meinungen von relevanten Netzaktivisten und Protestgruppen gewonnen werden. Darüber hinaus können mit diesen Instrumenten krisenhaltige Sachverhalte noch innerhalb der Latenz- oder Emergenzphase identifiziert werden.

\section{$3 \quad$ Fazit}

Netzaktivismus, so meine Einschätzung, wird auch in Zukunft die Krisenanfälligkeit von Unternehmen weiter steigern. Gleichzeitig können Unternehmen durch die Nutzung unterschiedlicher Kommunikationsmodi im Internet ihre Unternehmenskommunikationsinstrumente qualitativ wie quantitativ erheblich ausweiten. Angesichts der wachsenden gesellschaftlichen Bedeutung und der potenziell krisenauslösenden Tendenzen des Internets wird dieses Medium für Unternehmen weiter an Relevanz gewinnen. Es ist deswegen davon auszugehen, dass der Einsatz des Internets im Rahmen der unternehmerischen Kommunikationsaktivitäten sukzessive zunehmen und dass sich das Netz mittelfristig als Standardinstrument der Unternehmenskommunikation im Krisenkontext etablieren wird.

Gegenwärtig greifen Unternehmen allerdings noch bevorzugt auf tradierte Kanäle wie Telefon oder Face-To-Face-Begegnungen zurück - insbesondere bei der Umsetzung symmetrischer Kommunikationsmaßnahmen. Empirische Befunde weisen einen geringen konzeptionell-strategischen Einsatz des Internets insbesondere im Bereich krisenpräventiver Kommunikationsmöglichkeiten, dialogischer Kommunikationsoptionen und der Erfolgskontrolle nach. Dabei gestaltet sich die Nutzung des Internets in der Praxis in der Regel umso reduzierter und weniger professionell, je komplexer die Anforderungen bei der Umsetzung der Kommunikationsaufgaben werden. ${ }^{52}$

52 Zwar haben alle in der empirischen Untersuchung befragten Unternehmen das Verfahren des Issues Management bzw. der Umweltanalyse implementiert, das Internet wird aber sowohl für die Ortung von Sekundärdaten als auch für die Analyse von Primärdaten in den Unternehmen mehrheitlich nicht regelmäßig und systematisch genutzt. Es zeigt sich zudem, dass die PR-Akteure symmetrische Kommunikationsabsichten mit traditionellen Kommunikationskanälen (z.B. Telefon/Face-to-Face-Gespräche) zu erfüllen suchen, während sie hinsichtlich der 
Um die Handlungs- und Eingriffsmöglichkeiten im Umgang mit Netzaktivismus nicht einzuschränken, ist ein adäquater Einsatz der Kommunikationsmittel und -medien unverzichtbar. Unternehmen sind gefordert, netzspezifische Instrumente bei der strategischen Ausrichtung ihrer Kommunikation zu berücksichtigen, um mit strategiekritischen Akteuren anspruchsgruppengerechter in Kontakt treten und somit auch Krisen und Kritik erfolgreicher abfedern zu können.

\section{Literaturverzeichnis}

Bieber, Christoph: Politische Projekte im Internet. Online-Kommunikation und politische Öffentlichkeit, Frankfurt a.M./New York 1999.

Bieber, Christoph/Hebecker, Eike: „Internet und soziale Bewegungen. Der Studentenstreik als Fallbeispiel“", in: Gellner, Winand/Korff, Fritz von (Hrsg.): Demokratie und Internet, Baden-Baden 1998, S. 171-177.

Breunig, Christian: „Internet: Auf dem Weg zu einem kommerziellen Medium? Inhaltliche Entwicklungen und Finanzierungsformen von Onlineangeboten“, in: Media Perspektiven, Nr. 8, 2003, S. 385-393.

Burger, Reiner: „Der Angriff via Internet wird immer einfacher. Potentielle Ziele für ,Cyberterroristen' gibt es nicht nur in Amerika. Bislang nur Aktivisten, nicht Terroristen“, in: Frankfurter Allgemeine Zeitung, 14.08.2001, S. 4.

Castells, Manuel: „Internet, Netzgesellschaft. Das World Wide Web als neues technisch-soziales Paradigma“, in: Lettre International, Nr. 54, 2001, S. 38-44.

Connolly, Terry u.a.: „Effects of Anonymity and Evaluative Tone on Idea Generation in Computer-Mediated Groups", in: Management Science, Jg. 36, Nr. 6, 1990, S. 689-703.

Coombs, Timothy W.: „The Internet as Potential Equalizer: New Leverage for Confronting Social Irresponsibility“, in: Public Relations Review, Jg. 24, Nr. 3, 1998, S. 289-303.

Dembowski, Hans: „Wenn Zernán Toledo die internationale Cyber-Solidarität mobilisiert. Im Internet setzen Gewerkschaften und Initiativen Multis unter Druck“, in: Frankfurter Rundschau, 09.06.1999, S. 15.

asymmetrischen Kommunikation bevorzugt auf das Internet zurückgreifen. Vgl.

Köhler: Krisen-PR im Internet, S. 364-371. 
Dyllick, Thomas: Management der Umweltbeziehungen. Öffentliche Auseinandersetzungen als Herausforderung, Wiesbaden 1992.

Ehrenberg, Markus: „Absturzgefahr für den Kranich. Weil die Lufthansa abgeschobene Asylbewerber transportiert, wollen Aktivisten ihre Homepage lahm legen“, in: Die Zeit, 13.06.2001, S. 36.

Eimeren, Birgit van u.a.: „Internetverbreitung in Deutschland: Potenzial ausgeschöpft? ARD-ZDF-Online-Studie 2004“, in: Media Perspektiven, Nr. 8, 2004, S. 350-370.

Gräf, Lorenz: „Locker verknüpft im Cyberspace. Einige Thesen zur Änderung sozialer Netzwerke durch die Nutzung des Internet“, in: Gräf, Lorenz/Krajewski, Markus (Hrsg.): Soziologie des Internet. Handeln im elektronischen Web-Werk, Frankfurt a.M./New York 1997, S. 99-124.

Hasse, Malte: „Krisenraum Internet. Online-gestützte Handlungsstrategien und Instrumente zur Krisenbewältigung“, in: Möhrle, Hartwin (Hrsg.): Krisen-PR. Krisen erkennen, meistern und vorbeugen. Ein Handbuch für Profis, Frankfurt a.M. 2004, S. 167-182.

Hilse, Markus/Hoewner, Jörg: „Die Kommunikationskrise im Internet - und was man dagegen tun kann", in: Krzeminski, Michael/Zerfaß, Ansgar (Hrsg): Interaktive Unternehmenskommunikation. Internet, Intranet, Datenbanken, Online Dienste und Business-TV als Bausteine erfolgreicher Öffentlichkeitsarbeit, Frankfurt a.M. 1998, S. 137-154.

Hiltz, Starr Roxanne/Turoff, Murray: The Network Nation. Human Communication via Computer, London u.a. 1978.

Hoffmann, Petra: „Krisenprävention. Gefahren erkennen und Chancen ergreifen“, in: Möhrle, Hartwin (Hrsg.): Krisen-PR. Krisen erkennen, meistern und vorbeugen. Ein Handbuch für Profis, Frankfurt a.M. 2004, S. 122140.

Hribal, Lucie: „Risikokommunikation“, in: Jarren, Otfried/Bonfadelli, Heinz (Hrsg.): Einführung in die Publizistikwissenschaft, Bern 2001, S. 439-460.

Kent, Michael L./Taylor, Maureen: „Building Dialogic Relationships Through the World Wide Web“, in: Public Relations Review, Jg. 24, Nr. 3, 1998, S. 321-334.

Klenk, Volker: „Der ignorierte Kontrollverlust der Corporate Communications“, in: Köhler, Tanja/Schaffranietz, Adrian (Hrsg.): Public Relations. Perspektiven und Potenziale im 21. Jahrhundert, Wiesbaden 2004, S. 109120. 
Köhler, Tanja: „Gefahrenzone Internet - Die Rolle der Online-Kommunikation bei der Krisenbewältigung“, in: Holz, Katrin u.a. (Hrsg.): Krisenmanagement in der Mediengesellschaft, Wiesbaden 2007 (im Erscheinen).

Köhler, Tanja: Krisen-PR im Internet. Nutzungsmöglichkeiten, Einflussfaktoren und Problemfelder, Wiesbaden 2006.

Köhler, Tanja: „Onlinegestützte Krisen-PR. Ein integrativer Ansatz zur Prävention und Bewältigung von Unternehmenskrisen“, in: prmagazin, Nr. 5, 2006, S. 55-62.

Köhler, Tanja: „E-Mail ohne Antwort“, in: Harvard Business Manager, Nr. 10, 2005, S. 12-13.

Liebl, Franz: Der Schock des Neuen. Entstehung und Management von Issues, München 2000.

Lütgens, Stefan: Potentiellen Krisen rechtzeitig begegnen - Themen aktiv gestalten. Strategische Unternehmenskommunikation durch Issues Management, Schifferstadt 2002.

Marschall, Stefan: „Politischer Prozeß und Internet. Neue Einflußpotentiale für organisierte und nichtorganisierte Interessen?“, in: Politische Bildung, Jg. 32, Nr. 1, 1999, S. 40-51.

Meyer, Kirsten: Internet und strategisches Management. Krisenabwehr durch Stakeholder-orientierte Kommunikation, Wiesbaden 1997.

Mickeleit, Thomas: „,Wer gewinnt die Online-Schlacht? Krisenkommunikation in Zeiten des Internet", in: Möhrle, Hartwin (Hrsg.): Krisen-PR. Krisen erkennen, meistern und vorbeugen. Ein Handbuch von Profis für Profis, Frankfurt a.M. 2004, S. 115-119.

Morell, Anne: „Online-Aktivismus: Vom virtuellen Sit-In bis zur digitalen Sabotage", in: com.une.farce, Nr. 5, 2001, www.copyriot.com/unefarce/ no5/oaktivismus.html, 16.07.2007.

Naderer, Gabriele/Wendpap, Marion: „Online-Gruppendiskussionen. Möglichkeiten und Grenzen“, Vortrag auf dem BVM-Kongress 2000 in Basel, www.ifm-mannheim.de/veroeffentlichungen/gruppendiskussionen.html, 27.04.2003.

Neuberger, Christoph: „Onlinejournalismus. Veränderungen - Glaubwürdigkeit - Technisierung“, in: Media Perspektiven, Nr. 3, 2003, S. 131- 138.

news aktuell: media studie 2002. Journalisten online - die Folgestudie, Hamburg 2002. 
Oehmichen, Ekkehardt/Schröter, Christian: „Funktionswandel der Massenmedien durch das Internet? Veränderungen des Mediennutzungsverhaltens bei Onlinenutzern“, in: Media Perspektiven, Nr. 8, 2003, S. 374-384.

Roselieb, Frank: „New Crisis Communications? - Krisenkommunikation und Issues Management in der New Economy“, in: Roselieb, Frank (Hrsg.): Die Krise managen, Frankfurt a.M. 2002, S. 104-146.

Rössler, Patrick/Ognianova, Ekaterina: „Die journalistische Identität als Qualitätskriterium im World Wide Web. Ein Experiment zur Glaubwürdigkeit des Markenartikels Journalismus“, in: Rössler, Patrick/Wirth, Werner (Hrsg.): Glaubwürdigkeit im Internet. Fragestellungen, Modelle, empirische Befunde, München 1999, S. 111-122.

Röttger, Ulrike: „Issues Management. Mode, Mythos oder Managementfunktion? Begriffsklärungen und Forschungsfragen. Eine Einleitung“, in: dies. (Hrsg.): Issues Management. Theoretische Konzepte und praktische Umsetzung. Eine Bestandsaufnahme, Wiesbaden 2001, S. 11-39.

Schatz, Roland: „Dem Externen auf der Spur: Wenn aus Gegnern Partner werden“, in: Henckel von Donnersmarck, Marie/Schatz, Roland (Hrsg.): Frühwarnsysteme, Bonn u.a. 1999, S. 285-324.

Schäfer, Annette: „Unberechenbar und Anarchisch. Gerüchte verbreiten sich im Internet in Echtzeit. Das macht eine neue Unternehmenskommunikation nötig“, in: Wirtschaftswoche, Nr. 18, 26.04.2001, S. 89-92.

Scherer, Helmut: „Partizipation für alle? Die Veränderungen des Politikprozesses durch das Internet“, in: Rössler, Patrick (Hrsg.): Online-Kommunikation, Opladen 1998, S. 171-188.

Schweiger, Wolfgang: „Medienglaubwürdigkeit - Nutzunsgerfahrung oder Medienimage? Eine Befragung zur Glaubwürdigkeit des World Wide Web im Vergleich mit anderen Medien“, in: Rössler, Patrick/Wirth, Werner (Hrsg.): Glaubwürdigkeit im Internet. Fragestellungen, Modelle, empirische Befunde, München 1999, S. 89-110.

Stegbauer, Christian: Electronic Mail und Organisation. Partizipation, Mikropolitik und soziale Integration von Kommunikationsmedien, Göttingen 1999.

Wiegran, Gaby: „Warten auf Antwort“, in: IS-Report, Jg. 7, Nr. 11, 2003, S. 30-31.

Wiegran, Gaby/Harter Georg: Kundenfeedback im Internet. Strukturiert erfassen, schnell beantworten, systematisch auswerten, Wiesbaden 2002. 



\section{Christian Conrad/Benjamin Diehl}

\section{Unternehmenskommunikation als Stakeholder-Dialog}

\section{Unternehmens- und Markenkommunikation}

Kommunikation von Unternehmen und Marken hat die Aufgabe, Informationen und Bedeutungsinhalte an spezifische Adressaten zu vermitteln, um Einstellungen, Meinungen, Erwartungen und Verhalten gegenüber Organisationen, Themen, Produkten und/oder Dienstleistungen zu beeinflussen und zu steuern. ${ }^{1}$ Marken sind dabei ein Spiegel der Wahrnehmung dieser Kommunikation durch die Adressaten oder Zielgruppen.

Unter Unternehmenskommunikation wird im Allgemeinen die Gesamtheit aller Kommunikationsinstrumente und -maßnahmen eines Unternehmens verstanden, mit denen das Unternehmen sich und seine Leistungen gegenüber relevanten Anspruchsgruppen darstellt, d.h. „alle kommunikativen Handlungen von Organisationsmitgliedern, mit denen ein Beitrag zur Aufgabendefinition und -erfüllung in gewinnorientierten Wirtschaftseinheiten geleistet wird“. ${ }^{2}$ Entsprechend bezeichnet Markenkommunikation die Vermittlung der Leistungen und Identität einer Marke gegenüber ihren Zielgruppen.

Anhand dieser Definitionen werden die Überschneidungen aber auch die Unterschiede zwischen beiden Kommunikationsformen deutlich. Die Unterschiede liegen vor allem im a) inhaltlichen Fokus, b) dem Kommunikationsumfeld bzw. den primären Rezipienten und c) den zu verwendenden Kommunikationsinstrumenten. Bei der Unternehmenskommunikation steht das Unternehmen als Ganzes im Vordergrund, d.h. die Kommunikation des Unternehmens mit seinem Umfeld. Die Markenkommunikation dagegen bezieht sich konkret auf ein spezifisches Produkt oder eine Dienstleistung. Des Weiteren unterscheiden sich die Zielgruppen, mit denen kommuniziert werden soll. Das Unternehmen vertritt im Rahmen der Unternehmenskommunikation seine Position gegenüber allen internen und externen Anspruchsgruppen ${ }^{3}$, während die Markenkommunikation auf klar definierte Nutzergruppen und Marktsegmente abzielt. Als wesentliches Instrument der Markenkommunikation wird die Werbung in ihren verschiedenen Formen und Ausprägungen an-

1 Vgl. Bruhn u.a.: „Integrierte Kommunikation in Theorie und Praxis“.

2 Zerfaß: Unternehmensführung und Öffentlichkeitsarbeit, S. 287.

3 Im Folgenden werden die Begriffe Anspruchsgruppen und Stakeholder synonym verwendet. 
gesehen, während der Unternehmenskommunikation vor allem die Öffentlichkeitsarbeit (Public Relations, PR) zugeordnet wird. ${ }^{4}$ Gemeinsam haben beide Kommunikationsformen, dass sie die Meinung und das Verhalten der Zielpersonen beeinflussen wollen. Dabei strebt PR eher nach der Gewinnung öffentlichen Vertrauens und einer allgemein positiven Einstellung gegenüber dem Unternehmen, während Werbung auf die gezielte Beeinflussung und Überzeugung des Konsumenten von konkreten Angeboten bzw. Leistungen ausgerichtet ist. ${ }^{5}$

\subsection{Unternehmens- und Produktmarken}

Das Verhältnis von Unternehmens- und Produktmarken hängt stark von der zugrundeliegenden Marketingstrategie ab und in diesem Kontext insbesondere von der Markenarchitektur. Das Spektrum reicht von einer vollen Übereinstimmung zwischen Unternehmens- und Produktmarken (z.B. IKEA, NIKE oder eBay) über Unternehmensmarken, die als Dach- oder Absendermarken fungieren (z.B. Danone, Kellogg's) und Unternehmensmarken, die einer von mehreren Produktmarken entsprechen (z.B. Mars, Kraft) bis hin zu Unternehmensmarken, die wenig oder keine Verbindung zu den Produktmarken aufweisen (z.B. Procter\&Gamble, General Motors). Unternehmensmarken können dann als Botschafter zwischen Unternehmen und Stakeholdern fungieren, wenn jene in ihrer Wahrnehmung eine Verbindung zwischen beiden herstellen können. Wird die Unternehmensmarke zudem positiv wahrgenommen, kann dies zu positiven Abstrahleffekten von Unternehmens- auf Produktmarken führen. Beispielsweise positioniert die Firma Henkel ihre Unternehmensmarke aktiv ( $A$ brand like a friend) und bringt diese in Verbindung mit ihren Produktmarken. ${ }^{6}$

Im Verhältnis von Unternehmens- und Produktmarken lassen sich folgende Veränderungen feststellen: Zum einen wächst das Interesse von Verbrauchern an den Unternehmen binter den Marken, was im Wesentlichen auf die bessere Verfügbarkeit von Informationen zurückzuführen ist. Zum anderen rückt die Frage nach der gesellschaftlichen Verantwortung von Unternehmen stärker ins Blickfeld relevanter Stakeholdergruppen und wird zu einer bedeutsamen Bestimmungsgröße für Marken. Das steigende Interesse von Stakeholdern - und im Fall von Konsumgüterunternehmen besonders von Verbrauchern - am Unternehmen hinter der Marke hat Einfluss auf das Ver-

4 Vgl. Grunig/Hunt: Managing Public Relations.

5 Vgl. Pepels: Marketing-Lexikon.

6 Vgl. Bargen: „Make an Impact on Tomorrow“. 
trauen in, aber auch auf die Potenziale von Produktmarken, sich von ähnlich aufgestellten Marken abzugrenzen. Das Vertrauen in Produktmarken wird damit zunehmend abhängig von der Wahrnehmung der Unternehmensidentiät oder -persönlichkeit durch die Stakeholder. Ist diese Wahrnehmung positiv, bestehen deshalb Chancen, durch eine stärkere Verlinkung von Unternehmens- mit Produktmarken Markenvertrauen und Markendifferenzierung zu stärken.

Als Beispiel für eine stärkere Verknüpfung von Unternehmens- und Produktmarken kann Unilever genannt werden. Die Marke und das Unternehmen Unilever waren bis vor wenigen Jahren weitgehend unbekannt; eine Zuordnung der zahlreichen bekannten Marken zum niederländisch-britischen Konsumgüterkonzern war nur wenigen Stakeholdern, vor allem aber wenigen Verbrauchern möglich. Unilever hat sich entschieden, die Unternehmensmarke nun auch an Endverbraucher aktiver zu kommunizieren - beispielsweise als Absendermarke auf Produktverpackungen. Die Marke wurde im Rahmen einer strategischen Neuausrichtung des Unternehmens (Vitality Mission) positioniert. Parallel fand eine tiefgreifende Reorganisation und stärkere Zentralisierung des Unternehmens statt. Auf der Homepage von Unilever wird dies folgendermaßen zusammengefasst:

Die Verbraucher beziehen ihre Ansichten als mündige Bürger zunehmend in ihre Kaufentscheidungen ein und verlangen mehr von den Unternehmen, die hinter den Marken stehen. Sie wünschen sich Unternehmen und Marken, denen sie vertrauen können. ${ }^{7}$

Das Thema der gesellschaftlichen Rolle und Verantwortung von Unternehmen (Corporate Social Responsibility, CSR) wird zunehmend bedeutsam für verschiedene unternehmensrelevante Stakeholdergruppen. Neben Investoren und Finanzkreisen, für die die CSR-Performance von Unternehmen immer stärker zu einem Kriterium für Investitionsentscheidungen wird (nicht zuletzt aus Gründen der Risikoabwägung), ${ }^{8}$ interessiert sich mittlerweile eine breitere Öffentlichkeit für das gesellschaftliche Selbstverständnis und das konkrete Engagement von Unternehmen für soziale und Umweltthemen. ${ }^{9}$ Dass auch die

7 Vgl. Unilever Deutschland GmbH: „Vitality“.

8 Mit der Bedeutung der ethischen Reputation für Investitionsentscheidungen setzt sich der Beitrag von Mach in diesem Band auseinander.

9 Beispiele für dieses Interesse bietet die stark zugenommene Präsenz von Begriffen wie CSR, Corporate Citizenship oder Nachhaltigkeit in Breitenmedien. So stellte das Manager Magazin 2006 und 2007 ein so genanntes Good Company Ranking auf; die Financial Times Deutschland und das Handelsblatt veröffentlichten CSR-Beilagen. Eine zusätzliche Verstärkung der Anfragen an Unternehmen hat die Anfang 
Verbraucherrelevanz des unternehmerischen Engagements steigt, zeigen aktuelle Studien wie z.B. „Good Brand 2006“10. Diese Studie verdeutlicht eine neue Werteorientierung bei Verbrauchern und weist darauf hin, dass diese in Zeiten von Globalisierung und Staatsabbau eine größere Verantwortung von Unternehmen für das Gemeinwohl erwarten. So äußert jeder zweite Konsument, an Informationen darüber interessiert zu sein, unter welchen sozialen und ökologischen Bedingungen Unternehmen produzieren (vgl. Abbildung 1). Die Kaufbereitschaft wird durch negative Schlagzeilen über Unternehmen negativ, durch proaktives soziales und ökologisches Engagement positiv beeinflusst (vgl. Abbildungen 2 und 3).

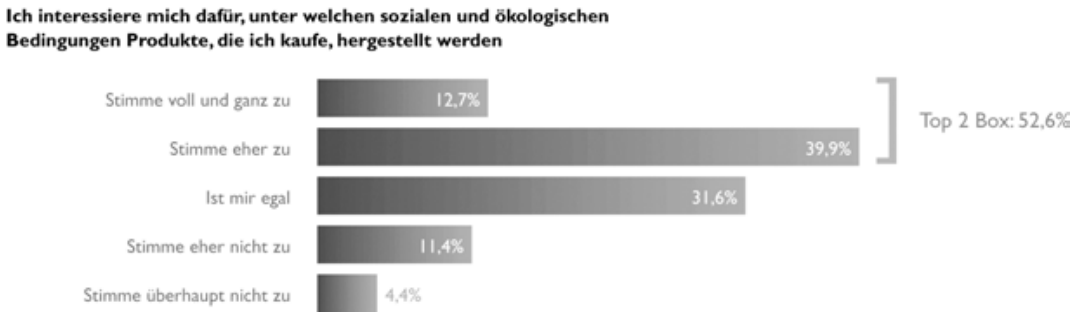

Abb. 1: Werteorientierung bei Verbrauchern. ${ }^{11}$

\section{Wenn ich die Wahl habe, kaufe ich lieber Produkte}

von Unternehmen, die sich für die Lösung sozialer und/oder ökologischer Probleme einsetzen

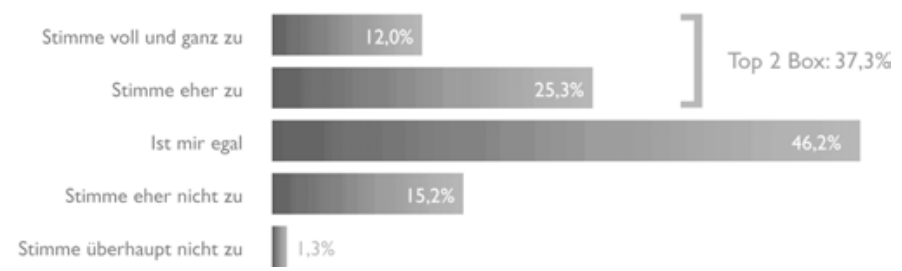

Abb. 2: Kaufverhalten und unternehmerisches Engagement. ${ }^{12}$

2007 enorm an Dynamik gewinnende Klimaschutzdiskussion ausgelöst. Zu den Begriffen Corporate Citizenship, CSR und Nachhaltigkeit vgl. auch Curbach in diesem Band.

10 Blumberg/Conrad: Good Brand 2006.

11 Quelle: ebd.

12 Quelle: ebd. 
Kritische Presse, wie zum Beispiel schlechte Arbeitsbedingungen,

beeinflussen mein Kaufverhalten

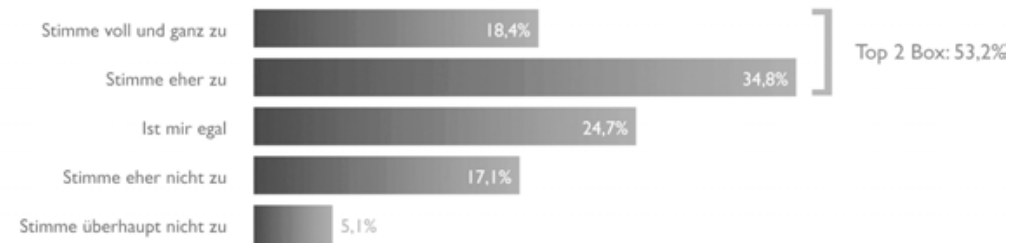

Abb. 3: Kaufverhalten und negative Berichterstattung. ${ }^{13}$

Eine weitere Studie, das „Moralbarometer“"14, kommt zu dem Schluss, dass Verbraucher sogar bereit sind, einen Aufpreis für solche Produkte und Marken zu bezahlen, die sich aktiv für gesellschaftliche Belange einsetzen. Die Erhebung des Good Brand Social Equity Index ${ }^{\circledR}$ in Großbritannien und Polen hat darüber hinaus gezeigt, dass die gesellschaftliche Dimension von Marken - der so genannte gesellschaftliche Markenwert (Social Equity) - einen signifikanten Einfluss auf wesentliche Markenparameter besitzt und die Präferenz von Marken im Wettbewerb und damit die Kaufentscheidung positiv beeinflusst. Die Ergebnisse lassen darauf schließen, dass der gesellschaftliche Markenwert bereits heute eine bedeutende Rolle in der Beurteilung sowohl von Unternehmens- als auch von Produktmarken einnimmt und Unternehmen Potenziale zur Imagebildung, Wettbewerbsdifferenzierung und Wachstum eröffnet. Sie deuten zudem darauf hin, dass durchaus ein Imagetransfer zwischen Unternehmensund Produktmarken möglich ist. ${ }^{15}$

Vor diesem Hintergrund wird CSR zu einem relevanten Feld für Unternehmens- und Markenkommunikation, die sich hier zudem wechselseitig beeinflussen. Das gesellschaftliche Engagement betrifft immer weniger nur die Imagepflege, sondern die Positionierung von Unternehmen und Marken im Wettbewerb und somit das Kerngeschäft: Trendforscher Matthias Horx formuliert dies pointiert in seinem Trendreport 2007 unter der Überschrift Die neue Moral: „Vor uns liegt ein hypermoralisches Zeitalter, in dem Marketing, Ökonomie und moralisches Engagement zunehmend konvergieren." 16

\footnotetext{
13 Quelle: ebd.

14 Puls Marktforschung: Moralbarometer 2006.

15 Vgl. Blumberg/Conrad: Good Brand 2006.

16 Horx: Trend-Report 2007, S. 6.
} 


\subsection{Medialer Kontext und Kommunikationsumfeld}

Veränderungen im Verhältnis von Unternehmens- und Markenkommunikation sind nicht zuletzt auf Veränderungen des medialen Kontexts und Kommunikationsumfelds zurückzuführen. Dies gilt für das Interesse am Unternehmen hinter der Marke ebenso wie für die zunehmenden Anfragen zur gesellschaftlichen Rolle von Unternehmen.

Der externe Einfluss auf Unternehmens- und Produktmarken hat zugenommen. Markenbotschaften können nicht mehr zwangsläufig an die jeweiligen Zielgruppen vermittelt werden, ohne dabei Gefahr zu laufen, von störenden, die Markenbotschaft beeinflussenden Faktoren konterkariert zu werden. Dies ist insbesondere auf die Potenziale zurückzuführen, die mit der Verbreitung des Internets verbunden sind. Das Internet hat sich inzwischen zum zentralen Kommunikations- und Informationsmedium unserer Zeit entwickelt und gewinnt permanent weiter an Einfluss, vor allem aufgrund steigender Verbreitung von (breitbandigen) Internetzugängen. Laut der ARD/ZDF Online Studie 2006 stieg der Anteil der Internet-Nutzer in Deutschland in den Jahren 1997 bis 2006 von 6,5 Prozent auf 59,5 Prozent, d.h. 38,6 Millionen Erwachsene in Deutschland nutzen das Internet. ${ }^{17}$ Zugleich steigt mit der Anzahl der Nutzer auch der Umfang an Informationen, die online zugänglich sind. Damit geht die Möglichkeit einher, Informationen auszutauschen und Zusammenhänge offen zu legen. Netzwerke und Organisationen werden transparenter, was für Unternehmen konsequenterweise bedeutet, dass auch sie hinter ihren Marken erkennbar werden und sich nicht mehr hinter verschiedenen Markennamen verbergen können. Jedes Produkt, jede Marke kann einem Unternehmen zugeordnet werden und die entsprechenden Informationen können über das Internet zur Verfügung gestellt werden. ${ }^{18}$ Konsumenten können sich dadurch über jedes Unternehmen, jede Marke und jedes Produkt sowohl direkt (auf der Website des Unternehmens) als auch indirekt über Interneteinträge, Foren, Testberichte, Kampagnenseiten etc. umfassende Informationen sowie Meinungen und Erfahrungen einholen. ${ }^{19}$

17 Vgl. Eimeren/Frees: „Schnell Zugänge, neue Anwendungen, neue Nutzer?“, S. $402 f$.

18 Beispiele für Informations- und Verbraucherportale zu Marken und Markenherstellern sind www.lebensmittelmarken.de, www.markenhersteller.de und www.discountfan.de/discountermarken.php.

19 Zum Empowerment von Konsumenten im Internet vgl. Baringhorst in diesem Band. 
Ohne Zweifel verändert das Internet die Medien- bzw. Marketinglandschaft. Dementsprechend erhöht sich auch die mediale Komplexität für Unternehmens- und Produktmarken erheblich. Tim O'Reilly, Verleger und Internetpionier, hat den Begriff Web 2.0 geprägt, um das Internet der zweiten Generation auch begrifflich von einem Internet abzuheben, in dem vor allem die Technik im Vordergrund stand. Die neue Form stellt sich verstärkt anbietersowie kundengetrieben dar und befriedigt nach van Eimeren/Frees dadurch ein zentrales menschliches Mitteilungsbedürfnis. ${ }^{20}$ Die prominenten Beispiele des Web 2.0 setzen auf einen aktiven Konsumenten und Produzenten, der sich durch so genannte Social Software, d.h. Wikis, Weblogs, Podcasts, Foren, Tauschbörsen, Bildergalerien etc., einbringt und Inhalte beiträgt. Ein wichtiges Zeichen dieses Trends liefert Google, das mit über 3.000 Mitarbeitern eines der größten Medienunternehmen der Welt ist. Im Oktober 2006 übernahm Google für rund 1,65 Milliarden Dollar das Portal YouTube, das täglich von 30-40 Millionen Menschen weltweit besucht wird. Unter dem Motto Broadcast Yourself (Sende Selbst) werden täglich 70.000 neue Fernsehausschnitte, Interviews, Parodien, Musikclips und selbst gedrehte Heimvideos auf YouTube hochgeladen. ${ }^{21}$ „We are all media owners now “22 fasst UniversalMcCann diesen Trend zusammen. Jede Privatperson, aber auch Organisation kann mit geringem zeitlichen und finanziellen Aufwand weltweit kommunizieren. Ein einzelner Sender kann verschiedene Empfänger erreichen, welche die Informationen als Multiplikatoren ebenfalls weitergeben und somit Schneeballeffekte in einer vernetzten Welt auslösen können. Eine besondere Bedeutung neben der umfassenden Verbreitung von Informationen kommt dabei auf qualitativer Ebene der hohen Authentizität der Online-Kommunikation zu. Äußerungen einzelner Personen im Internet haben - trotz der häufig vorhandenen Anonymität des Netzes - große Ähnlichkeit mit der klassischen Mundpropaganda, die als besonders glaubwürdige Informationsvermittlung wahrgenommen wird. ${ }^{23}$ Verbraucherverbände, Nichtregierungsorganisationen, Meinungsbildner aus Wissenschaft, Politik und nicht zuletzt traditionellen Medien selbst nutzen das Internet, um mit verschiedenen Stakeholdergruppen in Dialog zu treten und so Meinungen zu Unternehmen und Marken zu beeinflussen. ${ }^{24}$

20 Vgl. Eimeren/Frees: „Schnelle Zugänge, neue Anwendungen, neue Nutzer?“, S. 403.

21 Als ähnliche Portale können Flickr oder MyVideo genannt werden.

22 UniversalMcCann: „We Are All Media-Owners Now“, S. 1.

23 Deutlich glaubwürdiger beispielsweise als klassische Werbung (Print, TV etc.). Vgl. Hennig-Thurau/Hansen: „Kundenartikulation im Internet“, S. 563.

24 Vgl. Blumberg/Conrad: Good Brand 2006. 


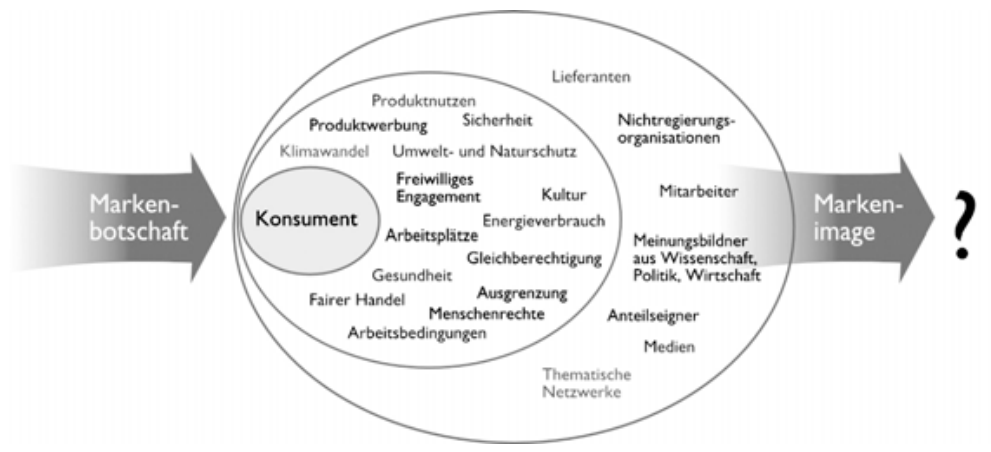

Abb. 4: Marken im Spannungsfeld zwischen Botschaft und Wahrnehmung. ${ }^{25}$

Beides, quantitative Veränderungen der Medienlandschaft und qualitative Unterschiede der auf Marken einwirkenden Botschaften, führen zu einem Kontrollverlust von Markeninhabern über das Ansehen bzw. das Image von Unternehmens- und Produktmarken. Hinzu kommt, dass die Geschwindigkeit der Verbreitung von Informationen über virale Kommunikationsformen im Internet enorm gestiegen ist und den Kontrollverlust somit weiter verschärft. Vor allem Blogs, in ihrer Gesamtheit Blogosphäre genannt, tragen dazu bei, da diese Online-Tagebücher (Blog = kurz für Weblog) in der Regel stark untereinander vernetzt sind. Diese Vernetzung innerhalb der Blogosphäre wird als „,neue, weltumspannende und interaktive Kommunikationsarena " 26 beschrieben. Den Kontrollverlust von Unternehmen und Marken können die folgenden Beispiele illustrieren:

- Kryptonite, ein Unternehmen mit dem Ruf, erstklassige Fahrradschlösser herzustellen, wurde im September 2004 in einem Internetforum beschuldigt, dass seine Schlösser mit einem einfachen Kugelschreiber in Sekundenschnelle zu knacken seien. Ein Beweis-Videoclip wurde auf einem entsprechenden Bike-Forum veröffentlicht. Das Unternehmen benötigte fünf Tage, um eine Umtauschkampagne anzukündigen, bis dahin war das Thema aber über die Blogosphäre bereits bekannt gemacht worden. Sogar renommierte Zeitungen wie die New York Times und der Boston Globe griffen das Thema auf, nachdem es etwa 1,8 Millionen negative Beiträge im Internet zu finden gab. Die Kosten der Umtauschaktion werden auf etwa 10 Millionen Dollar geschätzt, der Imageschaden lässt sich schwer abschätzen.

25 Quelle: ebd.

26 Zerfaß: „Corporate Blogs“, S. 2. 
- Jamba, Vermarkter von Klingeltönen. Im Weblog Spreeblick veröffentlichte der Autor und freie Journalist Johnny Haeusler einen Beitrag zum Thema Jamba, in dem er sich kritisch mit dem Abo-Tarifmodell des Klingeltonvermarkters auseinandersetzte. In den folgenden zwei Tagen wurde der Text in einer Vielzahl anderer Blogs verlinkt, woraufhin Mitarbeiter von Jamba versuchten, sich dort inkognito für das Unternehmen einzusetzen. Über ihre IP-Adressen konnten sie aber enttarnt werden, wodurch das Thema noch einmal an Brisanz gewann. Innerhalb einer Woche wurde es zu einem Hauptthema der Blogosphäre. Einen Monat später griff das Fernsehen dieses Thema auf, die Skandalisierten mussten sich vor laufender Kamera rechtfertigen und sogar Politiker äußerten sich öffentlich zu diesem Thema. Die Folge war eine signifikante Rufschädigung von Unternehmen und Marke.

\section{Unternehmenskommunikation: Vermittlung der Unternehmenspersönlichkeit an relevante Stakeholdergruppen}

Angesichts der beschriebenen Veränderungen im Unternehmensumfeld besteht die Rolle von Unternehmenskommunikation primär darin, die Unternehmenspersönlichkeit glaubwürdig und nachvollziehbar an relevante Stakeholdergruppen zu vermitteln. Die Unternehmenspersönlichkeit beeinflusst in starkem Maße die Glaubwürdigkeit des Unternehmens und indirekt die seiner Marken. Eine starke Identität ist die Voraussetzung für Verlässlichkeit nach außen und damit für Glaubwürdigkeit. Zudem hat die Unternehmenspersönlichkeit das Potenzial, maßgeblich zur Differenzierung und Unverwechselbarkeit von Unternehmens- und Produktmarken beizutragen. ${ }^{27}$

Der Verlust von Glaubwürdigkeit und Vertrauen von Unternehmen in den Augen der Öffentlichkeit gibt Unternehmen zu denken. Unternehmenslenker selbst äußern sich selbstkritisch: „Wir Unternehmer haben ein Glaubwürdigkeitsproblem, das akzeptiere ich", gab etwa BDI-Präsident Jürgen Thumann in der heißen Phase der Kapitalismusdebatte im Frühjahr 2005 gegenüber einer großen deutschen Tageszeitung zu Protokoll. ${ }^{28}$ Und auch die Lichtgestalt der deutschen Wirtschaft, der Vorstandsvorsitzende der Porsche

27 Vgl. Meffert u.a.: Markenmanagement. Das Verständnis des Unternehmens als Entität und Persönlichkeit spielt auch für dessen Darstellung als Corporate Citizen eine wichtige Rolle. Zu dieser Problematik vgl. Kneip in diesem Band.

28 Casdorff u.a.: „Wir müssen uns der Verantwortung stellen“. 
AG, Wendelin Wiedeking, schrieb sich und seinen Kollegen im September 2006 ins Stammbuch:

Es ist nicht nachzuvollziehen, wenn Konzerne Rekordgewinne melden und zugleich ankündigen, dass sie Tausende von Arbeitsplätzen streichen [...] Ein möglichst hoher Gewinn kann doch nicht das einzige Ziel eines Unternehmens sein [...] Es muss zu denken geben, wenn Menschen vielen Wirtschaftsführern und Politikern keinerlei Glaubwürdigkeit mehr zubilligen. ${ }^{29}$

Wie wichtig den Verantwortlichen der Wert Vertrauen ist, zeigt das Ergebnis einer aktuellen Führungskräftebefragung: Hinter „Verantwortung“ nahm „Vertrauen“ den zweiten Platz ein. ${ }^{30}$ Diese Sorge verwundert nicht, ist doch Glaubwürdigkeit die Basis für Vertrauen und Vertrauen neben dem Kostenfaktor ein wesentlicher Faktor für das Funktionieren von Geschäftsbeziehungen jeder Art. Zunehmend belegen wissenschaftliche Untersuchungen, dass Vertrauen die Transaktionskosten senkt, die Wettbewerbs-fähigkeit steigert $^{31}$ und Kundenloyalität erhöht. ${ }^{32}$ Glaubwürdigkeit ist damit ein Aspekt der Wahrnehmung des Unternehmens durch seine internen und externen Stakeholder, die wiederum in nicht zu unterschätzendem Maße von der Unternehmenspersönlichkeit oder auch Corporate Identity (CI ${ }^{33}$ abhängt. Verantwortlich für die Wahrnehmung der Unternehmenspersönlichkeit ist die Unternehmenskommunikation. An dieser Stelle sei noch einmal darauf hingewiesen, dass darauf indirekt auch das Vertrauen in Produktmarken einen Einfluss hat, auch wenn die Produktmarken nur mittelbar der Unternehmensmarke/dem Unternehmen zugeordnet werden.

29 Spiegel Online: „Unternehmenskultur: Porsche-Boss kritisiert Managerkollegen“.

30 Vgl. Bucksteeg/Hattendorf 2007: „Führungskräftebefragung 2007“.

31 Vgl. Bahlmann u.a.: „Vertrauen als Governance Instrument in der Supply Chain“.

32 Vgl. Morgan/Hunt: „The Commitment-Trust Theory of Relationship Marketing“, S. 22f; Garbarino/Johnson: „The Different Roles of Satisfaction, Trust, and Commitment in Customer Relationships“, S. 71; Chadhuri/Holbrook: „Chain of Effects from Brand Trust and Brand Effect to Brand Performance", S. 81.

33 Vgl. Wiedmann: „Corporate Identity (CI) und Markenpolitik“, S. 1415. Unternehmenspersönlichkeit wird hier verstanden als „Gesamtheit der für ein Unternehmen typischen und als typisch wahrgenommenen Werthaltungen, Ziele, Denk- und Handlungsweisen, Verhaltensroutinen, Fähigkeiten und Fertigkeiten, strukturellen Regelungen und Erscheinungsbildern“. Ebd. Birkigt u.a. definieren Corporate Identity als schlüssigen Zusammenhang von Erscheinung, Worten und Taten eines Unternehmens und dessen Wesen. Vgl. Birkigt u.a.: Corporate Identity. 
Persönlichkeit ist die Summe der individuellen Eigenschaften eines Menschen und damit das, was ihn ausmacht und von anderen unterscheidet. Entsprechend drückt die Unternehmenspersönlichkeit die Unverwechselbarkeit des jeweiligen Unternehmens aus. Die wesentlichen Elemente einer starken Unternehmenspersönlichkeit sind Profil, Charakter, Authentizität, Gestaltung und Beziehungen. Das Profil soll das Unternehmen unverwechselbar und erkennbar machen, sodass es Stakeholdern aus der Vielzahl von Unternehmen und Marken in Erinnerung bleibt. Der Charakter entwickelt sich auf der Basis längerfristigen konsequenten Handelns, das sich an bestimmten Werten orientiert. Wenn dieses Handeln von relevanten Stakeholdergruppen als echt und wahrhaftig wahrgenommen wird, spricht man von einer authentischen Unternehmenspersönlichkeit. Authentizität schafft Glaubwürdigkeit und Vertrauen. Die Gestaltung ist dagegen weniger Inhalt als vielmehr ein Mittel der Kommunikation. Corporate Design soll gestalterischer, visueller Ausdruck der Unternehmenspersönlichkeit sein und bestimmt den Auftritt des Unternehmens gegenüber seinen Stakeholdern. Corporate Design ist die Kunst, der Unternehmenspersönlichkeit ein Gesicht zu geben, und beschreibt damit die materielle Konkretisierung des Profils und des Charakters eines Unternehmens. Um authentisch zu wirken, müssen Inhalte und visuelle Gestaltung aus Sicht der Stakeholder intuitiv konsistent sein. Was die Persönlichkeit eines Unternehmens mit Leben erfüllt, sind jedoch die Beziehungen zu seinen Stakeholdern. ${ }^{34}$ Die Stärke einer Unternehmenspersönlichkeit erkennt man an der Qualität der Beziehungen zu den wesentlichen Stakeholdergruppen. Diese setzten sich in erster Linie aus Mitarbeitern, Kunden und Lieferanten zusammen. Es sind aber auch die kritischen Beobachter, wie Medien, Meinungsbilder und Nichtregierungsorganisationen sowie staatliche Stellen und die breite Öffentlichkeit. Die Intaktheit der wesentlichen Beziehungen und die Integrität der Beziehungsgestaltung mit den postulierten Werten des Unternehmens(-Charakters) zeigt, in welchem Maße das Unternehmen seine Unternehmenspersönlichkeit tatsächlich lebt. Die Wahrnehmung der Beziehungen durch die Stakeholder entscheidet darüber, ob und inwiefern die CI als authentisch und glaubwürdig gelten kann.

Eine positive und glaubwürdige Vermittlung der Unternehmenspersönlichkeit an die Stakeholdergruppen beruht deshalb im Wesentlichen auf der Realisierung von Beziehungen nach innen und außen. Im Rahmen der Unternehmenskommunikation muss die inhaltliche und emotionale Integration der Stakeholder in das Unternehmensgeschehen im Vordergrund stehen: „[T]ell them, and they will forget. Demonstrate to them, and they will perhaps re-

34 Vgl. Conrad: „Welche Mittel nutzen Handels- und Dienstleistungsunternehmen, um Corporate Identity mit Leben zu erfüllen?“" 
member. Integrate them, and they will understand. “35 In diesem Sinne ist eine enge Abstimmung und Integration mit der Markenkommunikation, die vor allem an die Kunden oder Verbraucher (im Falle von Konsumgüterunternehmen) kommuniziert, unerlässlich, um Konsistenz und Integrität sicher zu stellen.

Der Gewinn einer Unternehmenskommunikation, die primär die Aufgabe der Vermittlung der Unternehmenspersönlichkeit hat, liegt für das Unternehmen vor allem darin, dass sie zu einem wichtigen Differenzierungs-merkmal in wettbewerbsintensiven und zunehmend homogenen Produktmärkten wird und damit Produktmarken in ihren Profilierungs- und Positionierungsbemühungen maßgeblich unterstützen kann. ${ }^{36}$ Dadurch, dass sie über die Stärkung der Unternehmenspersönlichkeit die Markenidentität fördern und differenzieren kann, leistet die Unternehmenskommunikation einen wichtigen Beitrag zur Wertschöpfung, denn zum einen führt eine relevante Differenzierung beispielsweise durch höheres Kundenvertrauen zu höherer Kundenpräferenz und damit zu einer Umsatzsteigerung, zum anderen wird durch die Differenzierung und Verbesserung des Ansehens der Markenwert gesteigert und damit indirekt der Wert des Unternehmens erhöht. ${ }^{37}$

\section{Stakeholder-Dialog als Instrument der Unternehmenskommunikation}

Funktionierende Beziehungen zu Stakeholdern sind die Grundlage einer starken, wettbewerbsfähigen und differenzierenden Unternehmenspersönlichkeit. Kommunikation ist dabei der Schlüssel funktionierender Beziehungen. Dialog als Zwei-Wege-Kommunikation stellt die Beziehungen des Unternehmens zu relevanten Stakeholdern in den Mittelpunkt. Im Folgenden sollen die Vorteile und Möglichkeiten des Stakeholder-Dialogs für die Unternehmenskommunikation aufgezeigt werden.

35 Wiedmann: „Corporate Identity (CI) und Markenpolitik“, S. 1433.

36 „How can brands differentiate themselves and maintain an advantage? One answer is to base the brand identity in part on the organization behind the brand [...] These organizational characteristics can provide a basis for differentiation, a value proposition, and a customer relationship“. Aaker: Building Strong Brands, S. 115.

37 Nach dem Markenansatz des Y\&R Brand Asset Valuator ${ }^{\circledR}$ (BAV), der größten Markendatenbank der Welt, werden Marken durch vier Dimensionen beschrieben: Differenzierungsfähigkeit (verfügt die Marke über Merkmale, die sie im Wettbewerb einzigartig machen?), Relevanz (stiftet die Marke einen für mich relevanten Nutzen?), Ansehen (fühle ich mich der Marke emotional verbunden?), Vertrautheit (ist mir die Marke bekannt?). Vgl. Blumberg/Conrad: Good Brand 2006. 
Mit dem Wechsel im Marketing vom Transaktions- hin zum Beziehungsmanagement hat sich auch der Kommunikationsprozess gewandelt. Im Rahmen dieses Paradigmenwechsels schlagen Bruhn u.a. ein neues Kommunikationsmodell vor, das sich von einem einseitigen hin zu einem „zweiseitigen Kommunikationsprozess bzw. Dialog zwischen gleichberechtigten Kommunikationspartnern“"38 wandelt. Dabei müssen spätestens seit der Verbreitung des Internets die verschiedenen Modelle der integrierten Kommunikation um das Element der Interaktivität ergänzt werden, ${ }^{39}$ welches als Grundvoraussetzung eines Dialogs gilt und als solches aktiv genutzt werden kann. Von immer größerer Bedeutung wird dabei der Dialog als Mittel der Beziehungsentwicklung zwischen voneinander abhängigen Partnern.

Auch wenn an verschiedenen Stellen diese Form der dialogischen Kommunikation gefordert wurde und wird, z.B. im Dialogmarketing, so findet man sie in der Praxis bisher eher selten. Ein Großteil der Kommunikation läuft weiterhin einseitig ab. Neben der wechselseitigen Richtung einer dialogischen Kommunikation spielt auch das Ziel, d.h. die „Ausgewogenheit der beabsichtigten Wirkungen auf das Unternehmen und die Umwelt ${ }^{\star 40}$, eine entscheidende Rolle. Diese bezieht sich auf die qualitative Ebene des Dialoges und auf konkrete Fragen, die sich das Unternehmen stellen muss: Welche Kommunikation des Gegenübers lassen wir als Unternehmen zu? Und wie gehen wir mit Meinungsäußerungen bzw. einem Feedback um? Hier wird also der Moment einer kommunikativen Gleichberechtigung angesprochen. Nur wenn diese als Kommunikationsgrundlage anerkannt und praktiziert wird, kann man auch von einem wirklichen Dialog sprechen, in dem sich beide Partner ernst genommen fühlen und an einer Verfestigung der Beziehung arbeiten. Im Sinne der integrierten Kommunikation macht es dabei keinen Unterschied, ob es sich um interne oder externe Partner handelt.

\subsection{Stakeholder-Dialog als Quelle von Wertschöpfung}

Die Einstellung und das Verhalten der Stakeholder sind für das Unternehmen zielrelevant und daher eine essenzielle Variable für das strategische Management. ${ }^{41}$ Dies bedeutet, dass ihre Bedürfnisse und Ansprüche wahrgenommen

38 Bruhn u.a.: Integrierte Kommunikation in Theorie und Praxis, S. 14.

39 Vgl. Mast: Unternehmenskommunikation.

40 Ebd., S. 33.

41 Vgl. Freeman: Strategic Management; ders.: „The Stakeholder Approach Revisited“; Schmid/Lyczek: „Die Rolle der Kommunikation in der Wertschöpfung der Unternehmung“, S. 67. 
und umgesetzt werden müssen. Freeman geht mit seinem Stakeholder View of Capitalism noch wesentlich weiter: Für ihn bildet Stakeholder-Management die Basis für das Funktionieren des Kapitalismus und die wesentliche Quelle der Wertschöpfung. ${ }^{42}$ Die Aufgabe des Unternehmens besteht nach Freeman in erster Linie darin, einen Interessenausgleich zwischen Stakeholdergruppen herzustellen. Aus Kommunikationssicht erfordert dies, die Bedürfnisse von Stakeholdern und ihre Einstellung gegenüber dem Unternehmen zu erkennen.

Aus dieser Perspektive bietet der Stakeholder-Dialog der Unternehmenskommunikation Chancen für einen Beitrag zur Wertschöpfung wie die Erzeugung von Vertrauen und Glaubwürdigkeit, die Identifikation von Innovationspotenzialen und Risikoreduktion. Dialog schafft potenziell Vertrauen und Glaubwürdigkeit gegenüber relevanten Stakeholdern, denn einerseits sorgt Vertrauen für Loyalität bzw. Kundenbindung und hat so einen Einfluss auf den Unternehmensumsatz. Loyale Kunden ziehen die entsprechende Marke anderen Wettbewerbern vor (Markenpräferenz), sind gegebenenfalls bereit, höhere Preise zu zahlen, bleiben der Marke treu und empfehlen die Marke sogar weiter (Multiplikatoreffekt). Andererseits schlägt sich Vertrauen in der Steigerung des Markenwerts ${ }^{43}$ und damit im Wert des Unternehmens nieder. Zudem wird in dieser Interaktion Wertschätzung für den Kunden kommuniziert, was als Grundlage einer stabilen Beziehung zu werten ist. Durch Dialog können zudem Konsumentenwünsche oder gesellschaftliche Strömungen frühzeitig entdeckt und so Innovationspotenziale erschlossen werden (z.B. Starbucks Hear Music, Toyota Hybridantrieb). Außerdem bieten User- bzw. Customer Innovations-Ansätze die Möglichkeit für Nutzer oder Endverbraucher, eigene Vorstellungen zu einem Produkt anzustoßen und umzusetzen, um auf diese Weise das Innovationspotenzial der Kunden zu nutzen. In diesem Rahmen sind sowohl produkttechnische Verbesserungen als auch geringere Ausgaben für das unternehmensinterne Innovationsmanagement zu erwarten. Drittens trägt Dialog zur Risikominimierung bei, was insofern wertschöpfend wirkt, als negative Wertschöpfungstendenzen vermieden werden können. Stakeholder-Dialog gibt dem Unternehmen Feedback und erlaubt eine Objektivierung der Außenwahrnehmung. Des Weiteren können bestimmte Issues, d.h. relevante Kommunikationsthemen, zeitnah identifiziert werden. Dies ermöglicht schnelle Reaktionen durch die rechtzeitige Abwehr reputationsschädigender Einflüsse. ${ }^{44}$

42 Vgl. Freeman: „Managing for Stakeholders as Basis for Capitalism“.

43 Vgl. Scheffler: „Kundenbindung schafft Markenwert“.

44 Zum Issues-Management im Krisenkontext vgl. Köhler in diesem Band. 


\subsection{Praktische Möglichkeiten des Stakeholder-Dialogs}

Zwar ist die Idee des Stakeholder-Dialogs nicht neu, aber die Umsetzung der meisten Unternehmen lässt viel versprechende Möglichkeiten der Beziehung zwischen Unternehmen und Stakeholder ungenutzt. Häufig werden lediglich verschiedene Informationen unterschiedlichen Stakeholdergruppen zur Verfügung gestellt, ein wirklicher Dialog kommt dadurch nicht zu Stande. Im Folgenden sollen Möglichkeiten des Stakeholder-Dialogs aus der Praxis angesprochen werden, die entweder offline oder aber online umgesetzt werden. Diese Unterscheidung basiert auf der physischen Realität des Dialogs. Während im Offline-Dialog ein realer Face-to-Face-Kontakt zumindest möglich und intendiert ist, bietet im Online-Dialog das Internet die Plattform für den Dialog.

Ein Beispiel für erfolgreichen Offline-Stakeholder-Dialog stellt der finnische Mobilfunkhersteller Nokia dar. Die unterschiedlichen Stakeholdergruppen werden auf verschiedene Weise von Nokia in einen Dialog eingebunden. Dabei engagiert sich das Unternehmen in der Kommunikation mit Konsumenten (Brand Surveys, Fokusgruppen-Diskussionen, Issue-spezifische Studien), mit Investoren (Investors days), NGOs (z.B. Partnerschaft mit WWF, UNICEF etc.), Politik (z.B. Global Compact) und im akademischen Bereich (z.B. Center for Corporate Citizenship im Boston College). In verschiedenen internen Publikationen werden auch die Mitarbeiter des Unternehmens in diese Kommunikation integriert. Nokia betont, dass eine offene Diskussion mit den Stakeholdern für den Unternehmenserfolg entscheidend sei und direkt zur Wertschöpfung des Unternehmens beitrage:

Open and effective communication is extremely important to the success of Nokia's business. Listening to employees and external parties and translating their expectations into business value is one of Nokia's highest priorities. Open communication is at the heart of our business. ${ }^{45}$

Daneben bieten Online-Dialogformen neue Möglichkeiten der Interaktion und des Meinungsaustauschs. Beispiele für diese neuen Formen des Dialogs sind Foren in Form so genannter Corporate Blogs und Community-Plattformen.

45 Nokia Corporation: „Open Communication“. Als weiteres Beispiel kann BASF genannt werden. Das Chemieunternehmen betont die Bedeutung des offenen und vertrauensvollen Dialogs mit relevanten gesellschaftlichen Gruppen. Schwerpunktthemen dieses Dialogs sind die Nanotechnologie und Sustainable Chemistry sowie so genannte Customer Advisory Panels, die standortbezogenen Dialog pflegen. Vgl. BASF-Gruppe: „Gegenseitiger Respekt und offener Dialog“; dies.: „Stakeholder Beziehungen weiterentwickeln“. 
Ein Beispiel für ein Diskussionsforum ist das Pro-Age-Forum auf der Website der Unilever Körperpflegemarke Dove, auf der seit Anfang Februar 2007 das Thema Schönheit kennt kein Alter im Rahmen der Initiative für Wabre Schönheit Deutschland diskutiert wird. ${ }^{46}$ Unter Corporate Blogs bzw. UnternehmensWeblogs werden Blogs verstanden, hinter denen ein Unternehmen oder dessen Mitarbeiter stehen. Deutschland liegt, was die Verbreitung dieser Blogs betrifft, hinter den anderen Industrienationen zurück. Laut der EuroBlog-Studie 2007 wird sich die Verbreitung jedoch deutlich verstärken und eine wichtige Kommunikationsmöglichkeit für Unternehmen werden. ${ }^{47}$ Ein Beispiel des Corporate Blogs betreibt die Frosta AG, deren Blog als „Webtagebuch von FRoSTA-Mitarbeitern“"48 geführt wird. Eine spezielle Art des Weblogs hat McDonald's ${ }^{49}$, das sich in seinem Blog mit dem Thema CSR beschäftigt und zu verschiedenen Aspekten und Beiträgen in diesem Themenbereich Stellung bezieht.

Ein weiterer Trend betrifft Community Plattformen oder virtuelle Welten, wie sie z.B. Second Life (SL) anbietet. Unternehmen, darunter einige deutsche, wie DaimlerChrysler, BMW, Pixelpark oder Bild.T-Online bemühen sich verstärkt, auch in diesen Parallelwelten zu agieren. Bitkom-Internetexperte Florian Koch sieht den Vorteil vor allem im kommunikativen Umfeld: „Die Unternehmen dringen dort mit ihrer Werbebotschaft leichter durch als in der realen Welt. “50 Mitte Februar 2007 präsentierte der Stuttgarter Automobilhersteller DaimlerChrysler auf der Mercedes-Benz Island seine Marke, umrahmt von einem abwechslungsreichen Entertainment- und Informations-Angebot. ${ }^{51}$ IBM hat sogar eine spezielle Geschäftseinheit, die Emerging Business Opportunity (EBO), gegründet, die sich mit dem Thema Virtual Worlds \& Digital Convergence beschäftigt, um die Chancen der virtuellen Welt zu testen und Unternehmen im „Wandel vom e-business zum v-business“52 zu unterstützen. Sam Palmisano, IBM-Chef, hat wohl als erster Vorstandschef eines großen Unternehmens einen Avatar, ein virtuelles alter ego, in SL platziert. Second Life wird inzwischen als eine „Erweiterung der realen Wirtschaft“ und als virtuelles Wirtschaftswunder beschrieben. ${ }^{53}$ Bereits Ende Februar wurden 3,3 Millionen

46 Vgl. Unilever Deutschland GmbH: „Dove Diskussionsforum“.

47 Vgl. Zerfaß u.a.: „Euroblog2007“.

48 FRoSTA AG: „FRoSTA Blog“.

49 Vgl. McDonald's Corporation: „McDonald's Corporate Responsibility Blog“.

50 Martell: „Auch deutsche Unternehmen entdecken Second Life“.

51 Vgl. PR-Blogger: „Mercedes-Benz setzt auf Second-Life-PR“.

52 IBM Deutschland Entwicklung GmbH: „IBM Podcast - Virtuelle Welten und 3DInternet".

53 Vgl. Hamann/Uehlecke: „Die nächste Kolonie des Kapitalismus“. 
Einwohner registriert, wobei wöchentlich rund 230.000 Neuanmeldungen dazukommen. Täglich werden knapp \$450.000 in Kleider, Autos, Grundstücke oder Immobilien investiert. ${ }^{54}$ Als Chancen für den Stakeholder-Dialog werden von der Agentur Elephant Seven (2007) unter anderem ein Life-Support für Newbies, also Neuankömmlinge, in Second Life oder auch markenspezifische Avatare angeführt.

\section{Implikationen für die Unternehmenskommunikation}

Die veränderte Rolle der Unternehmenskommunikation, bedingt durch die Entwicklung des medialen Kontexts und des damit gestiegenen Interesses von Stakeholdern an Unternehmen und ihrem Verhalten, die gestiegene Bedeutung der Unternehmenspersönlichkeit für das Vertrauen in Unternehmens- und Produktmarken und die damit verbundene Konvergenz von Unternehmensund Markenkommunikation haben drei wesentliche praktische Implikationen:

- Neudefinition der Rolle der Unternehmenskommunikation als Vermittler der Unternehmenspersönlichkeit

- Stärkere Integration von Marken- und Unternehmenskommunikation

- Entwicklung einer dialogischen Unternehmenskommunikation

\subsection{Neudefinition der Rolle der Unternehmenskommunikation}

Unternehmenskommunikation ist in den meisten Unternehmen eine dem Vorstand oder der Geschäftsführung unterstellte Stabsfunktion. Häufig ist der Leiter der Unternehmenskommunikation auch Unternehmenssprecher. Die Unternehmenskommunikation hat die Aufgabe, die Unternehmenspersönlichkeit (CI) nach innen und außen zu entwickeln und mit Leben zu erfüllen. Damit ist sie verantwortlich dafür, wie die Unternehmensmarke von internen und externen Stakeholdern wahrgenommen wird und wie diese Wahrnehmung auf das Vertrauen in das Unternehmen und seine Produktmarken abstrahlt. Diese Wahrnehmung ist das, was Autoren wie Fombrun Reputation nennen. ${ }^{55}$ Geht man ferner davon aus, dass die Unternehmensmarke einen Wert hat, der in vielen Fällen einen wesentlichen Anteil am Wert des Unternehmens darstellt, ist die erfolgreiche Führung der Unternehmensmarke eine in hohem Maße wertschöpfende Funktion. Vor diesem Hintergrund scheint eine signifikante

54 Vgl. Radler: „Virtuelles Wirtschaftswunderland“.

55 Vgl. Fombrun: „Reputation“. 
Aufwertung der Rolle der Unternehmenskommunikation angeraten. Man könnte sogar argumentieren, dass die so definierte Unternehmenskommunikation eine Linienfunktion sein sollte, zumindest, wenn der Wert der Unternehmensmarke kontinuierlich gemessen, monetär bewertet oder als non-tangible asset sogar bilanziert wird (was in den meisten Fällen allerdings noch nicht der Fall ist).

Die Verantwortung für die Unternehmenspersönlichkeit - und damit für einen wesentlichen Vertrauensfaktor sowohl in Bezug auf die Unternehmensals auch die daran gekoppelten Produktmarken - impliziert, dass die Unternehmenskommunikation sowohl den Prozess der Definition der „Soll-CI“ (Unternehmensvision, Leitbild, Werte) führt als auch den Abgleich zwischen Soll-CI und Ist-CI, also die Wahrnehmung der Unternehmenspersönlichkeit bei den internen und externen Stakeholdern. Sie ist weiterhin dafür verantwortlich, die Unternehmensmarke auf Basis der CI gegenüber den Stakeholdergruppen zu positionieren und mit den in der Regel klar positionierten und geführten Produktmarken des Unternehmens in Einklang zu bringen, um so die Integrität von Unternehmens- und Produktmarken herzustellen. Ihr obliegt ferner die Identifizierung der relevanten Stakeholdergruppen und die Definition der relevanten Dialogpartner für den Stakeholder-Dialog. Schließlich ist es Aufgabe der Unternehmenskommunikation, den Stakeholder-Dialog zu führen und die Beziehungen zu den internen wie externen Dialogpartnern so zu entwickeln, dass die Unternehmenspersönlichkeit von den Dialogpartnern als lebendig, authentisch und somit glaubwürdig wahrgenommen wird.

\subsection{Stärkere Integration von Marken- und Unternehmenskommunikation}

Verbraucher oder Medienvertreter können mittlerweile, wie oben erwähnt, über das Internet ohne weiteres Unternehmens- und Produktmarken zuordnen. Aufgrund der zunehmenden öffentlichen Diskussion über die Rolle und Verantwortung von Unternehmen in der Gesellschaft wächst das Interesse, mehr über Unternehmen zu erfahren - insbesondere über die Unternehmen hinter jenen Marken, die der Verbraucher selbst kauft oder verwendet. Aus diesem Grund wächst die Notwendigkeit, Unternehmens- und Markenkommunikation stärker abzustimmen und Unternehmensmarken ebenso strategisch und geschäftsorientiert zu führen wie Produktmarken. Entscheidend ist, dass eine absolute Integrität zwischen beiden - und damit die Bedingung für Vertrauen und Glaubwürdigkeit - gewährleistet wird. Diese These wird auch vom Ansatz des gesellschaftsorientierten Marketings gestützt, der postuliert, dass ökonomischer Erfolg nicht nur auf den Absatz- und Beschaffungsmärkten 
erreicht werden kann, sondern zunehmend auch vom gesellschaftspolitischen Umfeld des Unternehmens beeinflusst wird und daher eine Integration der Unternehmenskommunikation in die übergeordneten unternehmerischen Planungs- und Entscheidungsprozesse erfordert. ${ }^{56}$

Organisatorisch bedeutet dies für Unternehmen, dass die häufig strikte Trennung zwischen Unternehmens- und Markenkommunikation hinterfragt werden sollte. Wichtig wird eine stärkere Verzahnung beider Funktionen, die mit einem besseren Verständnis für die jeweilige Rolle beginnen muss. Den Verantwortlichen für Produktmarken (in der Regel Marketing) muss bewusst werden, welche Bedeutung sowohl die Unternehmensmarke als auch die mit der Marke eng verbundene Unternehmenspersönlichkeit (CI) auf Vertrauen und Glaubwürdigkeit, aber auch Differenziertheit der Produktmarken im Wettbewerb haben kann. Das bedeutet nicht, dass die Funktion Unternehmenskommunikation dem Marketingbereich $\mathrm{zu}$ unterstellen ist (oder umgekehrt), wohl aber, dass die Unternehmenskommunikation selbstverständlichen Zugriff auf alle Marketinginstrumente hat und diese auch einsetzt. Es kann sinnvoll sein, ein Markenführungsgremium einzurichten, in dem die für die Führung der Produkt- und der Unternehmensmarke Verantwortlichen gemeinsam mit dem Geschäftsführer bzw. dem Vorstandsvorsitzenden über die übergeordneten markenstrategischen Fragestellungen entscheiden und damit dafür Sorge tragen, dass die Synergien zwischen Unternehmens- und Markenkommunikation erschlossen und Risiken frühzeitig erkannt und integriert bearbeitet werden können. Auf Basis eines so abgestimmten und integrierten Vorgehens kann gewährleistet werden, dass die aufgezeigten Wertschöpfungspotenziale von Unternehmenskommunikation (Umsatzsteigerung durch Steigerung der Markenloyalität, Steigerung des Unternehmenswerts durch Steigerung des Unternehmensmarkenwerts, Innovationspotenziale) ausgeschöpft werden.

\subsection{Entwicklung einer dialogischen Unternehmenskommunikation}

Durch aktiven und glaubwürdigen Dialog mit internen und externen Stakeholdern soll die Unternehmenspersönlichkeit zum Leben erweckt und damit Vertrauen in die Unternehmensmarke geschaffen werden. Aus diesem Grund ist ein Paradigmenwechsel von einer stark einseitigen Unternehmenskommunikation zu einer dialogischen Zwei- oder Mehrwege-Unternehmenskommuni-

56 Vgl. Raffée/Wiedmann: „Wertewandel und gesellschaftsorientiertes Marketing“; Haedrich: „Public Relations im System des strategischen Managements“; ders.: „Die Rolle von Public Relations im System des normativen und strategischen Marketing“; Bentele/Hoepfner: „Markenführung und Public Relations“, S. 1538. 
kation notwendig. Bruhn u.a. nennen dies den Schritt „,von push zu pull Kommunikation “57. Insbesondere durch die neuen technischen Möglichkeiten, welche die Entwicklung der Online-Welt eröffnet, erwarten viele Stakeholder den Dialog stärker, als dies zuvor der Fall war. Hinzu kommt, dass die technologische Entwicklung auch die Kosten-Nutzen-Relation der klassischen Einwegkommunikation sinken lässt. ${ }^{58}$

Wie bereits erwähnt, kann die Unternehmenskommunikation als Stakeholder-Dialog in Offline- vs. Online-Dialogformen einerseits und Dialog mit internen vs. externen Stakeholdern andererseits unterteilt werden. Ferner kann der Dialog rein austauschorientiert oder aber aktionsorientiert erfolgen. Die Unterscheidung zwischen austauschorientierter und aktionsorientierter dialogischer Unternehmenskommunikation soll an zwei Beispielen erläutert werden:

- $\quad$ Ein Beispiel für austauschorientierte dialogische Unternehmenskommunikation bietet der französische Baustoffriese Lafarge. Die Erstellung des Lafarge Nachhaltigkeitsberichts erfolgt dialogisch. Dialogpartner ist ein mit externen Stakeholdern besetztes Panel, das Fragen zum Thema Nachhaltigkeit an das Unternehmen richtet. Die Antworten des Unternehmens an das Stakeholder-Panel werden von jenem beurteilt und kommentiert und bilden die Basis des Nachhaltigkeitsberichts. Darüber hinaus ist das Panel ein permanenter kritischer Beobachter des Unternehmensverhaltens. In einem zweiten, speziell eingerichteten Stakeholder-Panel geht es um die Auswirkungen des Unternehmensverhaltens auf Biodiversität. ${ }^{59}$

- Nokias Community Involvement Programm ist Herzstück des Nokia Corporate Marketing und ein Best Practice Beispiel für aktionsorientierte dialogische Unternehmenskommunikation. Dabei sind die weltweiten Jugendprogramme Make a Connection und Bridgeit Beispiele für aktionsorientierten Dialog mit externen Stakeholdern, während die globale Corporate Volunteering Initiative Nokia Helping Hands den internen Dialog mit Mitarbeitern ebenfalls aktionsorientiert zum Leben erweckt. Neben

57 Bruhn u.a.: Integrierte Kommunikation in Theorie und Praxis, S. 53.

58 Vgl. Zerfaß: Unternehmensführung und Öffentlichkeitsarbeit, S. 300.

59 „The members of our panels observe the Group critically. They serve as ,friendly challengers' to Lafarge and offer new perspectives on current issues. They bring an external point of view, give opinions on Lafarge practice and encourage it to be even more ambitious. They are chosen for their experience and knowledge. The panels, which are entirely independent, are consulted regularly and discuss strategic issues. They make recommendations, and, for the sake of good corporate governance, a consensus must always be arrived at.“ Lafarge Group: „Sustainable Development". 
der internen Dimension hat ein Corporate Volunteering Programm wie Helping Hands zugleich eine externe Dimension, da externe Stakeholder intensiv mit den freiwilligen gemeinnützigen Aktivitäten der Nokia Mitarbeiter in Berührung kommen und davon profitieren.

Insgesamt werden Online-Dialogformen immer wichtiger, da sich ein großer Teil des austauschorientierten Dialogs mit Unternehmen bzw. über Unternehmen in den neuen Kommunikationsformen des Internets abspielt, insbesondere im Rahmen des oben dargestellten Blogging. Aufgrund der enormen Geschwindigkeit, mit der sich Informationen in der Blogosphäre verbreiten können und der Verknüpfung der Online- und Offline-Medien, wird es zunehmend wichtig für die Unternehmenskommunikation, die Funktionsweise dieser Medien zu kennen und auf Entwicklungen in diesen Medien entweder reagieren zu können oder den offenen Dialog mit Stakeholdern in diesen Medien proaktiv zu suchen, um die Gesprächsagenda auch weiterhin mitbestimmen zu können. ${ }^{60}$ Blogmonitoring, d.h. die Beobachtung dessen, was in der Blogosphäre diskutiert wird und Blogspoitation, die Auswertung der Inhalte der Online-Diskussionen, gewinnen in diesem Zusammenhang an Bedeutung. Mittlerweile existieren eine Reihe von Tracking-Instrumenten für Weblogs, die diese quantitativ und qualitativ auswerten. ${ }^{61}$ Bei der aktiven Teilnahme an Online-Foren und Blogs ist es wichtig, dass Unternehmen offen agieren und nicht der Auffassung sind, sie könnten die Blogosphäre unterwandern. Im Fall des Klingeltonanbieters Jamba hatte das verdeckte Bloggen von Jamba-Mitarbeitern den Effekt, dass ihr Agieren aufgedeckt wurde und zu einem weiteren Vertrauens- und Imageverlust führte. Offenheit und Transparenz sind gerade in der zum Teil sehr kritischen Bloggergemeinde die einzige Chance für Unternehmen, Vertrauen zu erhalten oder Glaubwürdigkeit wiederzugewinnen. Dies gilt auch für unternehmenseigene Blogs, so genannte Corporate Blogs, deren Einsatz sorgfältig geplant und umgesetzt werden sollte. Vor allem ist wichtig, Ziele klar zu formulieren, diejenigen Stakeholdergruppen zu definieren, die angesprochen werden sollen und festzulegen, welchen Beitrag der Blog zur Erfüllung der Kommunikationsziele leisten sollte. Ferner sollte die Unter-

60 „Durch die Geschwindigkeit der Blogs und deren Linkdichte können diese inzwischen auch ein Agenda Setting betreiben, das Auswirkungen auf die gesamte Öffentlichkeit auch außerhalb der Blogosphäre hat. Ihr Einsatz als Multiplikatoren und Kommunikationsmittler nimmt mit der Zuwachsrate der Blogosphäre entsprechend zu.“ Fischer: „Die Entwicklung von Weblog-Issues“, S. 250.

61 Fischer nennt www.blogstats.de, www.feedster.com, www.pubsub.com, www. technorati.com auf der quantitativen Seite und www.blogdex.net, www.blogpulse. com, www.blabble.com und www.waypath.com auf der qualitativen Seite. Vgl. Fischer: „Die Entwicklung von Weblog-Issues“. 
nehmenskommunikation prüfen, welches Format geeignet ist, um die definierten Ziele zu erreichen, und welche technologischen Voraussetzungen geschaffen werden müssen. ${ }^{62}$

Entscheidend für alle Formen der dialogorientierten Unternehmenskommunikation sind die folgenden sechs Faktoren:

1. Offenbeit und Transparen₹. Im Zeitalter des Internets steigt das Risiko, dass bidden agendas aufgedeckt werden. Unternehmen, die sich auf Dialog einlassen, sollten bereit sein, ihn offen und ehrlich zu führen.

2. Lernbereitschaft. Der Dialog mit den Stakeholdern sollte auf Augenhöhe geführt werden, immer verbunden mit der Bereitschaft, zu lernen und auch Fehler einzugestehen. Wenn Lernbereitschaft vermittelt wird, entsteht Vertrauen und Glaubwürdigkeit. Dort, wo Stakeholder den Eindruck bekommen, sie und ihre Positionen werden ignoriert oder nicht ernst genommen, geht Vertrauen verloren. ${ }^{63}$

3. Zielorientierung. Strategisches Vorgehen ist aufgrund der höheren Komplexität dialogischer Unternehmenskommunikation gegenüber Einwegkommunikation entscheidend für den Erfolg. Dabei kommt der Integration von Unternehmenskommunikation mit der Markenkommunikation eine entscheidende Bedeutung zu.

4. Relevanz. Priorisierung der Stakeholdergruppen und Selektion von Themen und Ansätzen, die für die jeweiligen Stakeholdergruppen relevant sind.

62 Zerfaß unterscheidet zwischen acht unterschiedlichen Formen von Corporate Blogs (Knowledge Blogs, Service Blogs, Campaigning Blogs, CEO Blogs, Product Blogs, Collaboration Blogs, Customer Relationship Blogs und Crisis Blogs), clustert sie nach funktionalen und kommunikativen Zielen und gibt konkrete Hinweise für die Entwicklung einer Weblog Strategie. Vgl. Zerfaß: „Corporate Blogs".

63 Aktuelle Beispiele für nicht-dialogische Unternehmenskommunikation, die möglicherweise auch einen negativen Einfluss auf das Vertrauen in und das Image der entsprechenden Produktmarken haben könnten, sind die Reaktionen führender deutscher Automobilhersteller Anfang 2007 auf die Klimaschutzdebatte. Vgl. dazu das Interview mit Porsche-Chef Wendelin Wiedeking, Frankfurter Allgemeine Sonntagszeitung vom 04.03.2007 unter der Überschrift Unser Cayenne fäbrt ökologisch korrekt und VW-Chef Martin Winterkorn, der im Spiegel 10/2007 fragt: „Sollen wir alle Trabi fahren?". Positive Ausnahmen stellen BMW und - unter den ausländischen Herstellern - Toyota dar. Diese Hersteller nehmen die Diskussion glaubwürdig zur Kenntnis und versprechen klimafreundliche Autos. Vgl. Handelsblatt 07.03. 2007; Anzeige für BMW 5er mit Efficiency Dynamics, März 2007. 
5. Integrität. Entscheidend ist, dass die Kommunikation so kongruent wie möglich mit dem unternehmerischen Handeln ist. Da wo es Abweichungen gibt, müssen die Prinzipien Offenheit und Transparenz gelten.

6. Commitment. Ein begonnener Dialog lässt sich wesentlich schwieriger ohne Glaubwürdigkeits- und Reputationsverlust beenden als klassische Einwegkommunikation, weil die Involvierung der betroffenen Stakeholder höher ist und damit auch die potenzielle Enttäuschung.

Zusammenfassend bietet die zunehmende Bedeutung des Stakeholder-Dialogs der Unternehmenskommunikation Chancen, an der Wertschöpfung im Unternehmen aktiv mitzuwirken. Ihr kommt die wichtige Aufgabe zu, die Bedeutung gesellschaftlicher Themen für die Kommunikation aufzunehmen und den Diskurs um die gesellschaftliche Rolle von Unternehmen und Marken aktiv zu führen. Aufgrund des Einflusses, den gesellschaftliche Faktoren auf Markenwert und Markenpräferenz haben, kann die Integration dieser gesellschaftlichen Faktoren in Unternehmens- und Markenkommunikation einen positiven Effekt auf die Entwicklung von Marken- und Unternehmenswert haben. Aktionsorientierter Stakeholder-Dialog bewirkt dabei durch die konkrete Involvierung von internen (Mitarbeiter) und externen Stakeholdergruppen (z.B. lokale Interessengruppen oder Nichtregierungsorganisationen) eine Steigerung von Glaubwürdigkeit und Authentizität und damit eine Stärkung der wahrgenommenen Unternehmenspersönlichkeit. Erhöhte Mitarbeitermotivation und damit verbundene Produktivitätssteigerungen und erhöhte Wettbewerbsfähigkeit können die Folge sein. Durch aktiven austauschorientierten StakeholderDialog lernt das Unternehmen auf der anderen Seite die Bedürfnisse von Stakeholdern besser kennen und kann die gewonnenen Erkenntnisse, die zum Teil über die Ergebnisse traditioneller Marktforschung hinausgehen, für die Optimierung von Markenkommunikation aber auch im Innovationsbereich nutzen. Wenn ein Unternehmen durch die Gewinnung von Einsichten (social insights) seine soziale Erdung findet und einen Vertrauensschub dadurch erfährt, dass Stakeholder sich verstanden fühlen, kann dies enorme Auswirkungen auf den Geschäftserfolg haben. ${ }^{64}$

64 Dies zeigt unter anderem das Beispiel Dove (Unilever). Vgl. Barletta: „The Real Story Behind the Success of Dove's Campaign for Real Beauty“. 


\section{Literaturverzeichnis}

Aaker, David: Building Strong Brands, London 2002.

Bahlmann, Jan u.a.: „Vertrauen als Governanceinstrument in der Supply Chain am Beispiel der deutschen Fleischwirtschaft", Beitrag im Rahmen der 46. Jahrestagung der Gesellschaft für Wirtschafts- und Sozialwissenschaften des Landbaus (GeWiSoLa), Gießen 04.-06.10.2006.

Bargen, Kai von: „Make an Impact on Tomorrow - ,MIT“ at the Henkel Company“, Vortrag zu „Corporate Volunteering bei Henkel“ im Rahmen der 2. International CSR Conference an der Humboldt Universität Berlin, Oktober 2006.

Barletta, Marti: „The Real Story Behind the Success of Dove's Campaign for Real Beauty“, 20.02.2007, www.marketingprofs.com/7/Dove-Pro-AgePrime'Time-Women-barletta.asp, 15.03.2007.

BASF-Gruppe: „Gegenseitiger Respekt und offener Dialog“, www.corporate. basf.com/de/ueberuns/vision/grundwerte/respekt.htm?id=V006o6_ADUSbcp.5J, 29.03.2007.

BASF-Gruppe: „Stakeholder-Beziehungen weiterentwickeln“, www.corporate. basf.com/de/sustainability/gesellschaft/stakeholder-beziehungen.htm?id =f.RIOADJ9bss3K*, 29.03.2007.

Bentele, Günter/Hoepfner, Jörg: „Markenführung und Public Relations“, in: Bruhn, Manfred (Hrsg.): Handbuch Markenführung. Kompendium zum erfolgreichen Markenmanagement, Wiesbaden 2004, S. 1535-1564.

Birkigt, Klaus u.a.: Corporate Identity. Grundlagen, Funktionen, Fallbeispiele, Landsberg/Lech 2000.

Blumberg, Martin/Conrad, Christian: Good Brand 2006. Gutes tun und davon profitieren? Ethisches Verbraucherverhalten und Cause Related Marketing in Deutschland, Bremen 2006.

Bruhn, Manfred u.a.: Integrierte Kommunikation in Theorie und Praxis. Betriebswirtschaftliche und kommunikationswissenschaftliche Perspektiven, Wiesbaden 2000.

Bucksteeg, Mathias/Hattendorf, Kai: „Führungskräftebefragung 2007“. Eine Studie in Zusammenarbeit mit dem Institut für angewandtes Wissen e.V., www.iaw-koeln.de/uploads/wk_studie_2007.pdf, 07.05.2007.

Casdorff, Stephan-Andreas u.a.: „Wir müssen uns der Verantwortung stellen“, in: Tagesspiegel, 24.4.2005, www.tagesspiegel.de/politik/archiv/24.04. 2005/1778104.asp, 07.05.2007. 
Chadhuri, Arjun/Holbrook, Morris B.: „The Chain of Effects from Brand Trust and Brand Effect to Brand Performance. The Role of Brand Loyalty“, in: Journal of Marketing, Jg. 65, Nr. 2, 2001, S. 81-93.

Conrad, Christian: „Welche Mittel nutzen Handels- und Dienstleistungsunternehmen, um Corporate Identity mit Leben zu erfüllen?“, Forum Europrofession „Unternehmenskommunikation in Zeiten von Globalisierung und Shareholder Value - Chancen und Risiken für Unternehmen im Handel“, 2006.

Eimeren, Birgit van/Frees, Beate: „Schnelle Zugänge, neue Anwendungen, neue Nutzer?“, in: Media Perspektiven, Jg. 10, Nr. 8, 2006, S. 402-415.

Fischer, Tim: „Die Entwicklung von Weblog Issues am Beispiel des Klingeltonanbieters Jamba“, in: Picot, Arnold/Fischer, Tim (Hrsg.): Weblogs Professionell, Heidelberg 2005.

Fombrun, Charles J.: Reputation. Realizing Value from the Corporate Image, Boston, MA 1996.

Freeman, R. Edward: „Managing for Stakeholders as Basis for Capitalism“, Vortrag im Rahmen der 2nd International CSR Conference an der Humboldt Universität Berlin Oktober 2006.

Freeman, R. Edward: „The Stakeholder Approach Revisited“, in: Zeitschrift für Wirtschafts- und Unternehmensethik, Jg. 5, Nr. 3, 2004, S. 228-241.

Freeman, R. Edward: Strategic Management. A Stakeholder Approach, Boston, MA 1984.

FRoSTA AG: „FRoSTA Blog“", www.blog-frosta.de, 27.03.2007.

Garbarino, Ellen/Johnson, Mark S.: „The Different Roles of Satisfaction, Trust, and Commitment in Customer Relationships", in: Journal of Marketing, Jg. 63, Nr. 2, 1999, S. 70-87.

Grunig, James E./Hunt, Todd: Managing Public Relations, Fort Worth, TX 1984.

Haedrich, Günther: „Die Rolle von Public Relations im System des normativen und strategischen Marketing“, in: Armbrecht, Wolfgang/Zabel, Ulf (Hrsg.): Normative Aspekte der Public Relations. Grundlegende Fragen und Perspektiven. Eine Einführung, Opladen 1994, S. 91-107.

Haedrich, Günther: „Public Relations im System des strategischen Managements", in: Avenarius, Horst/Armbrecht, Wolfgang (Hrsg.): Ist Public Relations eine Wissenschaft? Eine Einführung, Opladen 1992, S. 266-278.

Hamann, Götz/Uehlecke, Jens: „Die nächste Kolonie des Kapitalismus“, in: Die Zeit, www.zeit.de/2007/02/Second-Life, 04.01.2007. 
Hennig-Thurau, Thorsten/Hansen, Ursula: „Kundenartikulation im Internet. Virtuelle Meinungsplattformen als Herausforderung für das Marketing“, in: Die Betriebswirtschaft, Jg. 61, Nr. 5, 2001, S. 561-580.

Horx, Matthias: Trend-Report 2007, Kelkheim 2006.

IBM Deutschland Entwicklung GmbH: „IBM Podcast - Virtuelle Welten und 3D-Internet", www-5.ibm.com/de/podcast/24.html, 30.03.2007.

Lafarge Group: „Sustainable Development“, www.lafarge.com/cgi-bin/ lafcom/jsp/content.do?function=1324_panel\&lang=en, 28.07.2007.

Martell, Maren: „Auch deutsche Unternehmen entdecken Second Life“, www.capital.de/unternehmen/meldungen/733857.html, 02.03.2007.

Mast, Claudia: Unternehmenskommunikation - Ein Leitfaden, Stuttgart 2002.

McDonald's Corporation: „McDonald's Corporate Responsibility Blog“, csr.blogs.mcdonalds.com, 27.03.2007.

Meffert, Heribert u.a.: Markenmanagement. Identitätsorientierte Markenführung und praktische Umsetzung, Wiesbaden 2005.

Morgan, Robert M./Hunt, Shelby D.: „The Commitment-Trust Theory of Relationship Marketing“, in: Journal of Marketing, Jg. 58, Nr. 3, 1994, S. 20-38.

Nokia Corporation: „Open Communication“, www.nokia.com/A4359282, 14.03.2007.

Pepels, Werner: Marketing-Lexikon. Über 3000 grundlegende und aktuelle Begriffe für Studium und Beruf, München 2002.

PR-Blogger: „Mercedes-Benz setzt auf Second-Life-PR“, klauseck.type pad.com/prblogger/2007/02/second_life.html, 02.05.2007.

Puls Marktforschung: Moralbarometer, Nürnberg 2006.

Radler, Christian: „Virtuelles Wirtschaftswunderland“, 26.10.2006, www.tages schau.de/aktuell/meldungen/0,OID6013938_REF1,00.html, 29.03.2007

Raffée, Hans/Wiedmann, Klaus-Peter: „Wertewandel und gesellschaftsorientiertes Marketing - Die Bewährungsprobe strategischer Unternehmensführung“, in: dies. (Hrsg.): Strategisches Marketing, Stuttgart 1989, S. 552611.

Scheffler, Hartmut: „Kundenbindung schafft Markenwert“, in: Marketingjournal, Jg. 36, Nr. 6, 2003, S. 42-47.

Schmid, Beat F./Lyszek, Boris: „Die Rolle der Kommunikation in der Wertschöpfung der Unternehmung“, in: dies. (Hrsg.): Unternehmenskommuni- 
kation - Kommunikationsmanagement aus Sicht der Unternehmensführung, Wiesbaden 2006, S. 3-148.

Spiegel Online: „Unternehmenskultur: Porsche-Boss kritisiert Managerkollegen“, 23.09.2006, www.spiegel.de/wirtschaft/0,1518, 438773,00.html, 27.03.2007

Unilever Deutschland GmbH: „Dove Diskussionsforum“, www.dove.de/ de_de/de_de/index.html, 30.03.2007

Unilever Deutschland GmbH: „Vitality“, www.unilever.de/ourcompany/ aboutunilever/vitality.asp, 25.03.2007.

UniversalMcCann: „We Are All Media Owners Now“, www.telegraph.co.uk/ news/graphics/2006/07/21/UMonblogs.pdf, 27.03.2007.

Wiedeking, Wendelin: „Unser Cayenne fährt ökologisch korrekt“, in: Frankfurter Allgemeine Sonntagszeitung, 04.03.07.

Wiedmann, Klaus-Peter: „Corporate Identity (CI) und Markenpolitik - Zentrale Bausteine eines Bezugrahmens", in: Bruhn, Manfred (Hrsg.): Handbuch Markenführung. Kompendium zum erfolgreichen Markenmanagement, Wiesbaden 2004, S. 1413-1439.

Winterkorn, Martin: Spiegel-Gespräch: „Sollen wir alle Trabi fahren?“, in: Der Spiegel, Nr. 10, 2007.

Zerfaß, Ansgar: „Corporate Blogs: Einsatzmöglichkeiten und Herausforderungen“, www.bloginitiativegermany.de, 26.03.2007.

Zerfaß, Ansgar u.a.: „Euroblog2007. Social Software - A Revolution for Communication? Implications and Challenges for Communication Management and PR“, www.euroblog2007.org, 14.03.2007.

Zerfaß, Ansgar: Unternehmensführung und Öffentlichkeitsarbeit. Grundlegung einer Theorie der Unternehmenskommunikation und Public Relations, Opladen 1996. 



\section{Antoine Mach}

\section{Ethische Reputation als Börsenwert ${ }^{1}$}

Das gesellschaftliche Engagement privater Unternehmen rückt zunehmend ins Zentrum des Interesses von Öffentlichkeit und Wissenschaft. In der Diskussion kursieren Schlagworte wie Nachhaltigkeit, Triple-Bottom-Line ${ }^{2}$, ethisches Investment und Corporate Social Responsibility. Doch inwiefern ist die systeminhärente Logik der Profitmaximierung mit ethischer Verantwortung vereinbar und wie kann eine an gesellschaftlichen Verantwortungsprinzipen orientierte Hilfe für Kapitalinvestitionen in Unternehmen aussehen? Mit diesen Fragen hat sich Covalence, eine im Jahr 2001 in Genf gegründete GmbH, intensiv auseinandergesetzt und das Instrument EthicalQuote entwickelt, welches die in Medien und zivilgesellschaftlichen Bewertungen feststellbare ethische Reputation eines Unternehmens analysiert und als Hilfsmittel für Entscheidungen ethik- und/oder profitorientierter Investoren dienen will. In Anlehnung an den Börsenwert misst EthicalQuote die historische Entwicklung der in Medien und Themenöffentlichkeiten wahrgenommenen ethischen Performance eines Unternehmens. ${ }^{3}$ Die entsprechende Kurve (vgl. Abbildung 1) ergibt sich aus der kumulativen Addition internetbasierter Quellen sowie aus der Addition von aus einem Korrespondentennetzwerk ${ }^{4}$ gewonnenen Informationen, die regelmäßig erfasst und ihrer positiven oder negativen Orientierung nach codiert werden. ${ }^{5}$ Dabei wird die Annahme zu Grunde gelegt, dass die ethische Reputation eines Unternehmens sich in Abhängigkeit von der Anzahl positiver Nachrichten verbessert bzw. in Abhängigkeit von der Anzahl negativer Nachrichten verschlechtert.

1 Übersetzung aus dem Englischen von Henrike Libal.

2 Als Triple-Bottom-Line werden die drei Säulen der Nachhaltigkeit (Ökonomie, Soziales, Ökologie) bezeichnet.

3 Zur Bedeutung der öffentlichen Kommunikation und Wahrnehmung gesellschaftlicher Verantwortungsübernahme von Unternehmen vgl. auch Kneip in diesem Band.

4 Das Netzwerk besteht vorwiegend aus Informanten aus der Medienbranche und der Zivilgesellschaft in Entwicklungsländern.

5 Eine Liste der verwendeten Quellen kann unter www.covalence.ch/index.php/ products/methodology/sources abgerufen werden. Die Quellen umfassen Newsportale und -websites in englischer, französischer, deutscher und spanischer Sprache. Vgl. auch 3.2. 
Antoine Mach | Ethische Reputation als Börsenwert

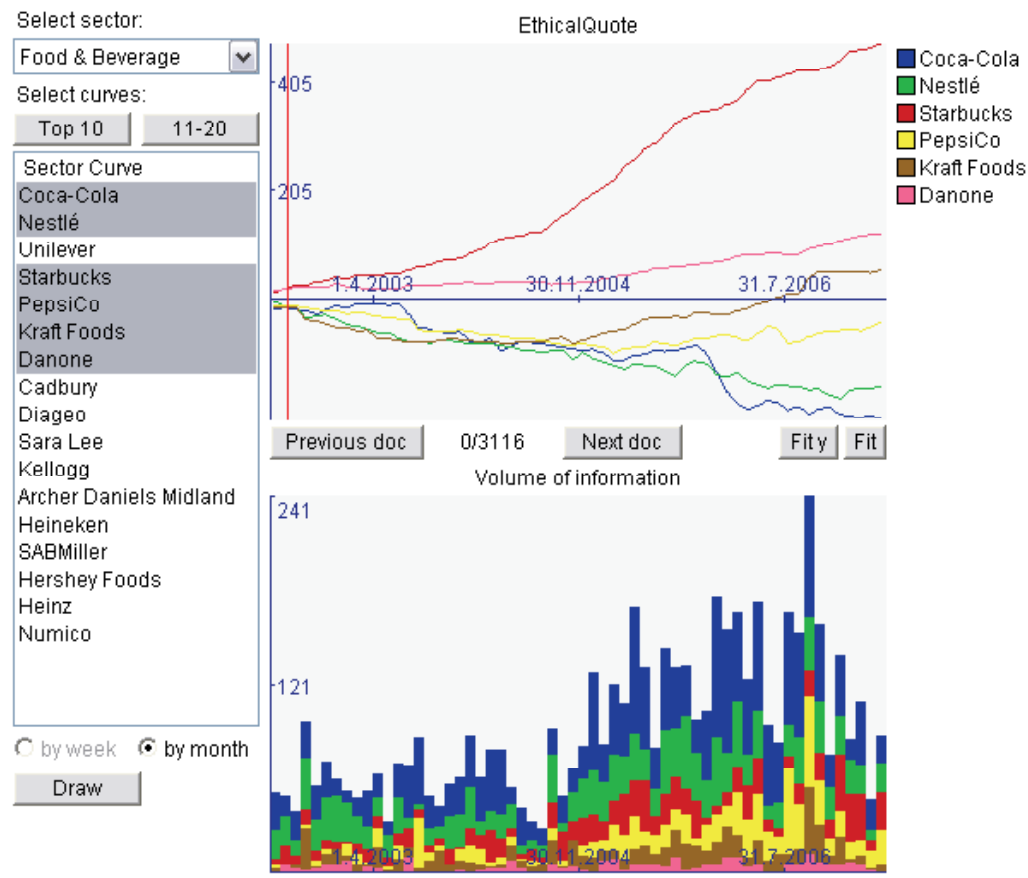

Abb. 1: Ethical Quote. ${ }^{6}$

Abbildung 1 verdeutlicht das Informationsvolumen, das durch die Berücksichtigung sämtlicher Dokumente innerhalb eines bestimmten Zeitraums entsteht, ohne jedoch die positive oder negative Bewertung bzw. Orientierung in die Berechnungen mit einzubeziehen.

Das Instrument richtet sich nicht an traditionelle ethikbewusste Investoren, die bereit sind, ganze Branchen aus dem Horizont ihrer Investitionsentscheidungen auszuschließen ${ }^{7}$, sondern ist eher für pragmatische ethikorientierte Investoren gedacht, welche Annäherungen zwischen Profit und ethischen Prinzipien aufspüren wollen. Des Weiteren wendet sich das Instrument auch an Investoren, die rein profitorientiert agieren. ${ }^{8}$ Damit geht Covalence

6 Eigene Darstellung.

7 Beispielsweise orientiert sich die in Deutschland ansässige Umweltbank ausschließlich an sozialen und ökologischen Positivkriterien. Großkraftwerke, Militärgüter, umweltschädliche und sozial unverträgliche Produkte werden von der Bank nicht unterstützt. Vgl. Umweltbank: „UmweltGarantie - die ökologische Produktgarantie der UmweltBank“.

$8 \mathrm{Zu}$ den Kunden und Nutzern zählen neben Regierungen, internationalen Organisationen und NGOs auch Medienunternehmen, multinationale Unternehmen und Investoren. 
von der Annahme aus, dass Investoren die unabhängige Einschätzung der ethischen Reputation auf der Basis verschiedener Informationsquellen bei ihrer Einflussnahme auf den Aktienkurs sowie auf die Handlungen des Unternehmens berücksichtigen. Die Unternehmensphilosophie von Covalence setzt somit darauf, dass Individuen, die daran interessiert sind, ihr Kapital zu vermehren, auch ethische Überlegungen mit einbeziehen. Hierdurch wird für Firmen ein Anreiz geschaffen, sich ethisch korrekt zu verhalten, da börsennotierte Firmen rechtlich verpflichtet sind, im Interesse ihrer Anleger zu handeln. Die ethische Reputation wird somit als Bestandteil des Börsenwertes eines Unternehmens betrachtet und mittels EthicalQuote als ethischer Börsenwert abgebildet. ${ }^{9}$

Bevor im Einzelnen das Instrument EthicalQuote dargestellt wird, wird auf das Unternehmen Covalence eingegangen, da dessen Entstehungsidee und -geschichte als Ausgangspunkt für die Entwicklung von Ethical Quote diente.

\section{Covalence - Ziele und Herausforderungen}

Covalence wurde von sechs Personen mit unterschiedlichem beruflichen Hintergrund (Politik, Wirtschaft, NGO, Recht) mit der Unterstützung des Genfer Graduate Institute of Development Studies gegründet. ${ }^{10} \mathrm{Zu}$ dieser Zeit befasste sich ein Vorläuferprojekt mit dem Aufbau eines Investmentfonds, welcher eine Umverteilung von Managergehältern zugunsten internationaler Entwicklungsprojekte anstrebte. Ein weiteres vorgelagertes Projekt bestand darin, im Auftrag von Antenna International, einer Schweizer Menschenrechtsstiftung, die Beziehungen zwischen multinationalen Konzernen und NGOs zu erforschen. Dabei wurden verschiedene Schweizer NGOs und Unternehmen bezüglich ihrer Einschätzung zu verschiedenen Themen aus den Bereichen internationale Entwicklungszusammenarbeit und Menschenrechte befragt. ${ }^{11}$ Man verständigte sich darauf, die in den vorangegangenen Projekten gewonnene Kompetenz bei der Neugründung des Unternehmens zu nutzen.

Vorrangiges Ziel von Covalence war es von Beginn an, Informationen über den unternehmerischen Beitrag zur nachhaltigen Entwicklung bereitzu-

9 Zum Zusammenhang von Börsenwert und ethischer Unternehmensverantwortung vgl. 5.3.

10 Zu den Gründungsmitgliedern von Covalence im Jahr 2001 gehörten Ngenda Kigaraba, Antoine Mach, Marc Rochat, Jean-Félix Savary, Steven Street und ein weiteres anonymes Mitglied. Im Jahr 2003 wurde der Kreis um Mélanie Clerc und Matthias Brunner erweitert. Zwei Jahre später folgten Vincent Ossipow und Beth Krasna.

11 Vgl. Mach, Antoine: „Swiss Business and Human Rights“; ders.: „Macht der NGO über die Unternehmen“. 
stellen. ${ }^{12}$ Von der Annahme ausgehend, dass ein Unternehmen für Außenstehende undurchsichtig und ethisches Verhalten nicht direkt messbar ist, betrachtet Covalence ein Unternehmen als black box, welches sich als offenes System im Austausch mit seiner Umwelt und in Wechselwirkung mit anderen Systemen entfaltetet ohne dabei die eigenen Systemstrukturen vollständig zu ändern. Dementsprechend stützt sich Covalence auf systemtheoretische Forschungsansätze und betrachtet aus dieser Perspektive den die ethische Reputation eines Unternehmens konstruierenden Informationsfluss.

Unsere Überlegungen setzen an den Herausforderungen an, die mit der Evaluation der ethischen Handlungsbereitschaft multinationaler Konzerne in der modernen Welt verbunden sind. Einige dieser Herausforderungen ergeben sich aus der Struktur großer Konzerne. Transnationale Konzerne bieten nur beschränkte Möglichkeiten der direkten Beobachtung (Wie kann man Einblicke in das Verhalten eines Unternehmens gewinnen, das in mehr als 100 Ländern tätig ist?) und begrenzten Zugang zu internen Daten (- viele Informationen, wie etwa das Steueraufkommen, fallen unter die firmeninterne Geheimhaltung). Andere Herausforderungen sind mit gesellschaftlichen Aspekten verbunden, so etwa die soziale Komplexität (Ist es möglich, Ursache-Wirkungs-Zusammenhänge zwischen den Unternehmenshandlungen und sozialen Bedürfnissen wie Gesundheit oder Bildung herzustellen?), die kulturelle Vielfalt (Wie können kulturelle Unterschiede zwischen einzelnen Ländern berücksichtigt werden?), ethischer Pluralismus (Wie sollen unterschiedliche Einstellungen gegenüber ethischen Entscheidungen gewertet werden?) und wissenschaftliche Unsicherheit (Wer ist im Recht und wer ist im Unrecht?). Neben diesen Fragen stellt sich die übergreifende Frage nach der Anwendung von Menschenrechten und nachhaltiger Entwicklung auf spezifische Fälle. Während weltweit auf diese Konzepte Bezug genommen wird und sie sich durch einen hohen Verallgemeinerungsgrad auszeichnen, erscheinen sie in ihren Interpretationen eher subjektiv als objektiv. Die Entscheidung, etwas als gut oder scblecbt einzustufen, kann Gegenstand von Meinungen, Werten und/oder Kultur sein. Auch können Ethikdefinitionen regionen-, zeit- und personenabhängig sein. Die folgenden Beispiele illustrieren die Komplexität ethischer Urteile:

- Gentechnik: Stellt sie eine Bedrohung für die Umwelt oder eine Chance für die Menschheit dar?

12 Dabei ermöglichen elektronische Medien wie Internetseiten, Blogs und Suchmaschinen, unterschiedliche und sich verändernde Wahrnehmungen greifbar zu machen, wodurch der Finanzwelt glaubwürdige Informationen über die mit ihrer ethischen Reputation verbundenen Risiken zugänglich gemacht werden können. 
- Kernenergie: Ist Nuklearenergie tödlich oder eine saubere Energiequelle?

- Medizinische Patente: Sind sie ein Hindernis für die Behandlung in Armut lebender Menschen oder dienen sie als Anreiz für Forschung und Entwicklung?

- Der Burma-Boykott: War er demokratiefördernd oder demokratiehemmend?

- Ein Unternehmen gesteht verheirateten Partnern ebenso viele Sozialleistungen zu wie ledigen Kollegen: Fördert dieses Verhalten die Vielfalt oder untergräbt es die Institution der Ehe?

- $\quad$ Ein Herausgeber pornografischen Materials hilft dabei, Pädophilie zu bekämpfen: Sollte er sich einem ethischen Investmentfond anschließen dürfen oder davon ausgeschlossen werden?

\section{Social Rating}

\subsection{Vorhandene Ansätze}

Um Ideen zur Messbarkeit ethischer Unternehmensverantwortung zu gewinnen, wurden bereits vorhandene nicht-finanzielle bzw. soziale, ethische und ökologische Rating-Ansätze analysiert. Unsere Auseinandersetzung mit den verschiedenen Ansätzen ergab, dass zum damaligen Zeitpunkt (2001) die gängigste Methode auf dem Vergleich der Selbstauskunft von Unternehmen mit externen Quellen basierte. Bei diesem Vergleich werden zunächst Untersuchungskriterien in Anlehnung an international geltende Normen, Präferenzen der Agentur oder Wünsche der Investoren festgelegt. Ein mithilfe dieser Kriterien formulierter Fragebogen wird in einem nächsten Schritt an Unternehmen mit der Bitte versandt, Auskunft darüber zu geben, inwiefern die Kriterien eingehalten werden. Die Agentur wertet die ausgefüllten Fragebögen aus und vergleicht die Antworten mit externen Informationen über das Unternehmen (von NGOs, Gewerkschaften, aus den Medien etc.). Nach Abschluss der Auswertung wird dem Unternehmen eine Note für jedes Kriterium zugewiesen (A bis E oder 1 bis 5). In einem letzten Schritt wird dann eine Durchschnittsnote aus den Noten der Einzelkriterien errechnet. 


\subsection{Der Ansatz von Covalence}

Um den oben aufgezeigten Herausforderungen gerecht zu werden, die sich aus der Struktur eines multinationalen Konzerns, den Entwicklungen der modernen Gesellschaft und den Methoden der etablierten Rating-Agenturen ergeben, hat Covalence eine eigene Vorgehensweise entwickelt.

In Zusammenarbeit mit drei verschiedenen $\mathrm{NGOs}^{13}$ wurden 45 branchenunspezifische Kriterien entwickelt, um unterschiedliche Informationen über den Beitrag multinationaler Unternehmen zur globalen nachhaltigen Entwicklung zu erfassen. Dabei standen die gegenwärtigen Probleme und Bedürfnisse der Entwicklungsländer im Vordergrund. Die Kriterien werden dabei allerdings nicht als moralische Wertungen betrachtet, sondern als Instrumente, mit deren Hilfe Informationen strukturiert und je nach Einzelfall auf einer Skala angeordnet werden können. Daneben beziehen sich die Kriterien auf internationale rechtliche Rahmen, indem ihre Prinzipien auf sechs bedeutenden internationalen Verträgen fußen. Im Einzelnen sind dies die Allgemeine Erklärung der Menschenrechte, die OECD-Leitsätze für Multinationale Unternehmen, die Dreigliedrige Grundsatzerklärung über Multinationale Unternehmen und Sozialpolitik der Internationalen Arbeitsorganisation (ILO), die Beschlüsse des Weltgipfels für Soziale Entwicklung und der Global Compact der Vereinten Nationen. Vor diesem Hintergrund basieren die Kriterien auf weitgehend anerkannten Prinzipien und nicht auf bestimmten ethisch motivierten Entscheidungen, sodass sie Vielfalt und Pluralismus berücksichtigen können. Daneben verfügen sie über die Fähigkeit, den Wandel firmeninterner Arbeitsabläufe abzubilden, und erfassen die Einflussnahme durch Stakeholder und Medienberichterstattung.

Schließlich können die Kriterien ${ }^{14}$ in folgende Gruppen eingeteilt werden:

- Arbeitsbedingungen: Orientiert sich das Unternehmen an den Normen der ILO? Hat das Unternehmen Maßnahmen implementiert, um in ausgelagerten Stufen des Wertschöpfungsprozesses (z.B. Zulieferbetrieben) Arbeitsbedingungen zu verbessern?

- Einfluss durch Produktion: Beeinflussen Investitionen des Unternehmens die lokale Wirtschaft hinsichtlich der Schaffung von Arbeits-

13 Im Prozess der Kriterienbildung wurden folgende NGOs beteiligt: Association pour le Développement des Aires Protégées, Association Geste Solidaire Immédiat, Groupe de Réalisation et d'Animation pour le développement.

14 Im Folgenden wird eine Auswahl der Kriterien genannt; eine vollständige Liste findet sich unter www.covalence.ch/docs/CovalenceCriteria.pdf. In dieser Liste findet sich auch eine Zuordnung der verschiedenen Kriterien zu den Prinzipen der oben genannten internationalen rechtlichen Rahmen. 
plätzen, Marktzugang, Wettbewerb und wirtschaftlichem Wachstum? Wurden Programme zum Schutz der lokalen Umwelt beschlossen?

- Einfluss durch Produkte: Hat das Unternehmen Produkte entwickelt oder Aktivitäten gefördert, welche auf lokale Kulturen und Traditionen zurückgehen? Spendet das Unternehmen Geld oder ist im Kontext von Social Sponsorship aktiv?

- $\quad$ Einfluss durch institutionelle Strukturen: Hat das Unternehmen Maßnahmen entwickelt, um Korruption in öffentlichen und privaten Bereichen zu verringern? Unterstützt das Unternehmen den UN Global Compact?

\section{EthicalQuote}

\subsection{Die Entwicklung der Messskala}

Analog zu den Methoden anderer Agenturen wurde die Untersuchung mit einem Fragebogen ${ }^{15}$ begonnen, der einem großen Unternehmen während der Testphase zugeschickt und von diesem beantwortet wurde. Gleichzeitig wurde Material (Jahresbericht, Nachhaltigkeitsbericht, CSR-bezogene Pressemitteilungen) aus dem Internetauftritt des befragten Unternehmens in die Analyse mit einbezogen. Da für die Analyse zudem externe Informationen über das Unternehmen von zentraler Bedeutung sind, wurden auch Dokumente aus anderen Quellen erfasst; im Einzelnen aus den Medien, von NGOs, Handelsgesellschaften, Regierungen, internationalen Organisationen oder aus wissenschaftlichen Berichten. Aus forschungspraktischen Gründen wurde die Datensammlung auf elektronisches, im Internet frei zugängliches Material begrenzt.

Nach dieser Phase lagen somit verschiedene Dokumente und Informationen vor: die Antworten des Unternehmens auf den Fragebogen, öffentlich verfügbares Material dieses Unternehmens und weiteres Material aus unterschiedlichen Quellen. Diese Einzelinformationen wurden in einem weiteren Schritt anhand der Kriterien klassifiziert. Dabei zeigten einige Einzelinformationen eine positive Bewertung des genannten Unternehmens, während andere eine negative aufwiesen. Für die erforderliche binäre Kodierung des Materials wurde ein System entwickelt, das die Unternehmensaktivität an den gesellschaftlichen Forderungen misst. Die etbische Forderung (Informationen darüber, was die Gesellschaft von dem Unternehmen verlangt) wurde folglich dem ethischen Angebot (Informationen, wie sich das Unternehmen für die Gesell-

15 Dabei wurde für jedes Kriterium eine Frage formuliert. 
schaft engagiert) gegenüber gestellt. Der ethischen Forderung sind vor allem Informationen zuzurechnen, die von Akteuren in einer am Gemeinwohl ausgerichteten Organisation verfasst wurden und die Auskunft über die sozialen oder ökologischen Konsequenzen der Unternehmensaktivität eines multinationalen Konzerns geben. Dagegen werden dem ethischen Angebot Bemühungen des Unternehmens zugeordnet, die Vorgaben der ethischen Forderung zu erfüllen. Infolge dieser Untersuchung lag eine Tabelle mit 45 Zeilen (eine Zeile für jedes Kriterium) und einigen Unterzeilen vor, die mit den betreffenden Zitaten gefüllt wurden. Die Zitate wurden entsprechend ihrer Bewertung bzw. Orientierung - ethische Forderung oder ethisches Angebot - in zwei Spalten eingefügt. Diese Spalten gaben Aufschluss darüber, inwiefern sich das Unternehmen gesellschaftlich engagierte und welches Engagement seitens der Gesellschaft gefordert wurde. Nun stellte sich die Frage, wie diese Datenfülle ausgewertet werden konnte. In einem ersten Schritt wurde für jedes einzelne Kriterium die Note 1 bis 6 vergeben. Wenn hauptsächlich positive und keine negativen Nachrichten vorhanden waren, wurde die Note 6 zugewiesen; wenn der Großteil der Nachrichten eine negative Bewertung enthielt, die Note 1 oder 2. Jedoch versagte dieses System in Fällen, in den nur wenige oder gar keine positiven und negativen Nachrichten ausfindig gemacht werden konnten. Die Vergabe von Noten stellte sich als nicht zufriedenstellend heraus, denn es wurde die Befürchtung geäußert, dass die Ergebnisse durch Subjektivität und Schätzungen verzerrt wiedergegeben werden könnten. Es erwies sich darüber hinaus als schwierig, die verschiedenen Dokumente ihrer Wichtigkeit nach zu ordnen: Sollten z.B. bestimmte Themen wie Arbeitsbedingungen stärker gewichtet werden? Sind Informationen des Konzerns glaubwürdiger als die von NGOs? Sollte die Größe der NGO eine Rolle für die Gewichtung der Information spielen? In einer Phase der Überlegung und Abwägung wurde zusammen mit externen Fachleuten aus den Bereichen BWL, Mathematik und Physik das folgende methodische Vorgehen entwickelt, das seitdem angewandt wird: $\mathrm{Zu}-$ nächst erfolgt eine Sammlung großer Datenmengen aus verschiedenen Quellen. Dabei muss die Anzahl der Daten (Dokumente, Internetseiten) festgehalten werden. In einem weiteren Schritt werden den erhobenen Daten thematisch die einzelnen Kriterien zugeordnet, wobei kürzeren, allgemeineren Informationen ein Kriterium zugeordnet wird und längeren, detaillierteren Informationen zwei Kriterien zugeordnet werden. Entsprechend wird jedes Dokument mit 1 (Zuweisung eines Kriteriums) oder 2 (Zuweisung von zwei Kriterien) codiert. Anschließend wird die Thematisierung ethisches Angebot mit +, die Thematisierung ethische Forderung mit - codiert. Zusammengefügt kann Dokumenten dann jeweils die Gewichtungen $+1,+2,-1$ oder -2 zugewiesen werden. Ausschlaggebend für die Bewertung wird somit die Detailliertheit einer Quelle: Im Falle eines bestimmten Unternehmens können zu einigen Kriterien zahl- 
reiche Dokumente vorhanden sein, während es zu anderen Kriterien keine Informationen gibt. Für unterschiedliche Unternehmen sind somit unterschiedliche Kriterien erforderlich, da einige Themen von Aktivisten, Unternehmen und Medien ausführlich thematisiert werden, während andere unterbelichtet bleiben. Auf dieser Datengrundlage wird schließlich die EthicalQuote eines Unternehmens, wie oben bereits beschrieben, durch einen Grafen sichtbar gemacht, der aus der kumulativen Addition der Werte aller codierten Dokumente entsteht. Durch die Gewichtung der Detailliertheit einer Quelle und die Unterscheidung in ethisches Angebot und ethische Forderung grenzt sich EthicalQuote von anderen Ansätzen des Social Rating ab.

Mit der neuen Methode ist es nicht mehr erforderlich, dem Unternehmen eine geschätzte Note zuzuordnen. Statt einer geschlossenen Skala mit den Noten 1 bis 6 wurde nun eine offene Skala eingeführt, mit der Werte von $+\infty$ bis - $\infty$ abgebildet werden können. Dabei wird nicht das tatsächliche ethische Engagement eines Unternehmens bewertet, sondern dessen ethische Reputation. Es ist davon auszugehen, dass die reale ethische Performanz nur bedingt messbar ist; dies gilt sowohl für die Ebene der Formulierung von Kriterien als auch für die der Beobachtung. Da kein universell anerkanntes Etbikbarometer existiert bzw. existieren kann, ist Covalence davon überzeugt, dass für den Bereich der Unternehmensethik die Messung der ethischen Reputation ein wertvolles Werkzeug zur Annäherung an die Realität ist, weil es einen Überblick über laufende Diskussionen und Auseinandersetzungen ermöglicht.

\subsection{Informationserfassung}

Covalence sammelt Informationen zu Unternehmen auf zwei Wegen: a) durch Recherche im Internet und b) durch ein offenes Netzwerk, das sich aus Korrespondenten von zivilgesellschaftlichen Organisationen, Unternehmen, Forschern, Beratern und anderen Stakeholdern zusammensetzt. ${ }^{16}$

Die Internetrecherche ist die zentrale Suchstrategie von Covalence, um relevante Informationen zu erfassen; über das Internet werden ca. 95 Prozent

16 Derzeit erfasst Covalence Informationen zu zwölf Branchen und 300 im DowJones-Aktienindex verzeichneten Unternehmen. In die Auswahl kommen die 15 bis 20 Unternehmen jeder Branche mit dem höchsten Börsenwert. Covalence betrachtet die folgenden Sektoren systematisch: Automobile \& Ersatzteile, Banken, Chemikalien, Nahrungsmittel \& Getränke, Genussmittel, Bergbau \& Metall, Öl \& Gas, Konsumgüter, Pharmaprodukte \& Biotechnologie, den Einzelhandel, elektronische Geräte, Softwareprodukte. Die vollständige Liste der erfassten Unternehmen ist unter www.covalence.ch/index.php/products/methodology/universe abrufbar. 
der Daten gesammelt. Die Internetrecherche erfolgt zunächst auf spezialisierten Internetseiten. Im Laufe der Zeit wurde eine Liste von Internetseiten erstellt, die regelmäßig themenbezogene Inhalte veröffentlichen. $\mathrm{Zu}$ diesen spezialisierten Internetseiten gehören die Internetauftritte von Unternehmen, NGOs, Beratern, Gewerkschaften, internationalen Organisationen, Regierungen und der Wissenschaft. Covalence bezieht Material von diesen Seiten entweder per E-Mail-Newsletter, durch Alerts oder durch regelmäßige Besuche der Websites. Für die Recherche von Informationen werden außerdem Suchmaschinen genutzt. So bietet Dialog Newsroom Zugang zu mehr als 10.000 Medienarchiven weltweit; diese Suchmaschine erlaubt die Erfassung der überregionalen und internationalen Finanzpresse. Google Alerts ermöglichen den $\mathrm{Zu}-$ griff auf Millionen potenzieller Informationsquellen: Die Namen der betreuten Firmen und eine Reihe thematischer Stichpunkte werden als Google Alerts abonniert, woraufhin relevante Meldungen automatisch per E-Mail zugesandt werden. Google Alerts umfassen folgende Kategorien: Google Web Alerts, Google News Alerts, Google Blogs Alerts, Google Groups Alerts. Täglich empfängt Covalence 800 Google Alerts, die den einzelnen Mitarbeitern zur Auswahl und Auswertung zugeteilt werden.

Neben der Internetrecherche hat Covalence ein offenes Korrespondentennetzwerk aufgebaut, dem Informanten aus 35 verschiedenen Ländern (überwiegend Entwicklungsländern) angehören. ${ }^{17}$ Diese Informanten lassen Covalence regelmäßig aktuelle Informationen zukommen, welche in die Datenbank aufgenommen und in die Analyse des ethischen Börsenwertes einbezogen werden. Seit 2001 wurde viel Zeit dafür aufgewandt, Covalence innerhalb der Zivilgesellschaft und in Mediennetzwerken zu etablieren: Ca. 500 direkte Kontakte wurden weltweit zu NGOs, Zeitschriften, Forschungseinrichtungen oder Gewerkschaften geknüpft. Diese Zusammenarbeit mit Informanten ermöglicht die Ergänzung des öffentlich über InternetSuchmaschinen zugänglichen Materials.

\subsection{Informationsauswertung}

Covalence folgt dem Prinzip, jede einzelne Quelle gleichwertig zu behandeln. Die Größe der Quelle (Rezipienten, Quantität der Leser/Zuschauer) spielt bei der Gewichtung ebenso wenig eine Rolle wie die Platzierung der Quelle innerhalb des Mediums. Im Folgenden sollen die Argumente für die Wahl des Gleichgewichtungs-Ansatzes näher erläutert werden:

17 Das Netzwerk lokaler Informanten in Entwicklungsländern wird von der schweizerischen Direktion für Entwicklung und Zusammenarbeit gefördert. 
- $\quad$ Die moderne Welt zeichnet sich durch Komplexität, Vielfalt, Ungewissheit und durch Pluralismus aus. Die Praxis, kleinere Quellen mit größeren gleichzusetzen, stellt eine Möglichkeit dar, diesen charakteristischen Eigenschaften gerecht zu werden.

- $\quad$ Es ist schwierig, die Größe und Beliebtheit der Quellen technisch messbar zu machen und einen Gewichtungsfaktor zu finden, der die Gesamtheit der heterogenen Quellen abbilden kann. Zu dieser Gruppe der Quellen gehören die Leitmedien ebenso wie spezialisierte NGOs, einzelne Korrespondenten und die Zentralen multinationaler Konzerne.

- Quellen aus dem angelsächsischen Raum sind in der Datenbank überrepräsentiert, da diese Quellen im Internet zahlreicher vertreten und leichter zugänglich sind als andere. Ein Gewichtungsfaktor könnte diese Tatsache zum Nachteil der Vielfalt weiter verstärken.

- $\quad$ Laut Google umfasst Google Alerts die beliebtesten Internetseiten (nach dem Page Rank): Die populärsten Seiten gelangen so automatisch in die Datenbank.

- Oft wird ein bestimmter Sachverhalt von verschiedenen Quellen thematisiert. Dies erzeugt zahlreiche Bezugspunkte in der Datenbank und begünstigt einen natürlichen Fortschritt des Gewichtungsprozesses: Das System misst die Stärke der Reaktion, das Echo, das Nachrichten bei unterschiedlichen Quellen hervorrufen. Dabei ist nicht das einzelne Dokument sondern die Zusammenschau einer Vielzahl von Dokumenten entscheidend, da so ein signifikantes Bild der Realität erzeugt werden kann.

\section{$4 \quad$ Ergebnisse der Analysen ${ }^{18}$}

Im Folgenden werden aktuelle Ergebnisse dargestellt. So zeigt Abbildung 2 die Verteilung der 50.000 positiven und negativen Informationen, die seit 2002 erfasst wurden. Es überrascht dabei nicht, dass Nachrichten, die von Unternehmen selbst veröffentlicht wurden, nahezu alle positiv sind. In der Gruppe der NGOs überwiegen dagegen die negativen Meldungen. Meldungen von Medien, die zudem im Hinblick auf das gesamte Nachrichtenvolumen die bedeutendste Gruppe darstellen, weisen eine weitgehend ausgeglichene Anzahl positiver und negativer Informationen auf.

18 Aktuelle Ergebnisse werden laufend in Newsfeeds, Artikeln und Rankings veröffentlicht. 
Antoine Mach | Ethische Reputation als Börsenwert

Positive and negative news by source groups, 10 industries, 2002-2007

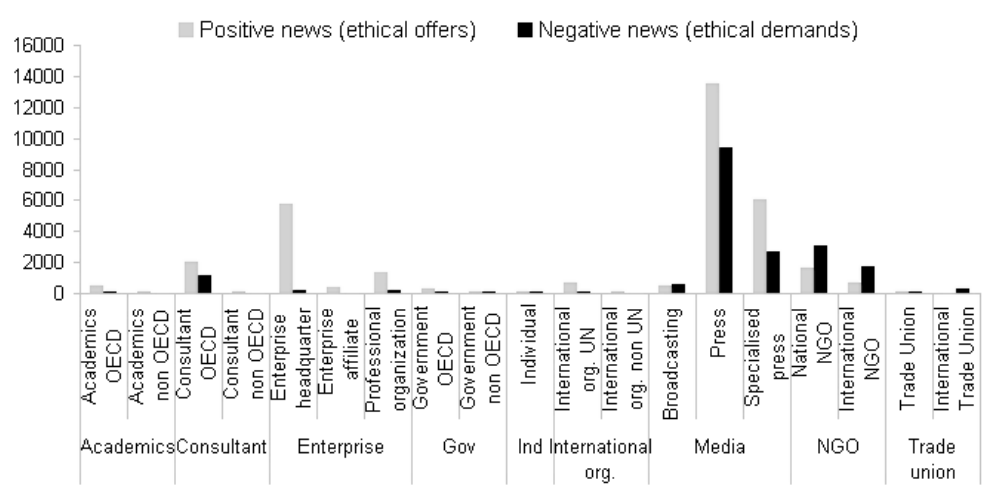

Abb. 2: Nachrichtenverteilung. ${ }^{19}$

Dass zwischen Mai 2006 und Mai 2007 sowohl in der negativen als auch in der positiven medialen und zivilgesellschaftlichen Berichterstattung verstärkt ökologische Themen behandelt wurden, verdeutlichen Abbildungen 3 und $4 .^{20}$

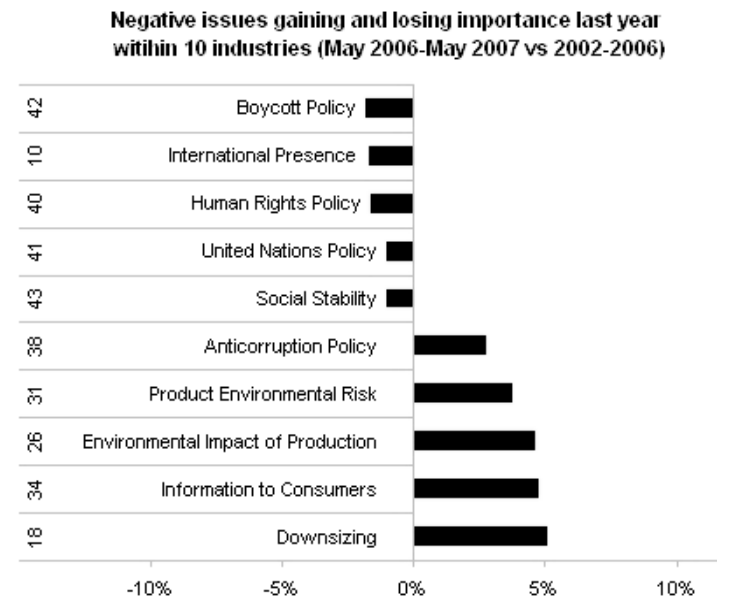

Abb. 3: Themen ethischer Forderung. ${ }^{21}$

19 Eigene Darstellung.

20 Ergebnisse für das erste Quartal 2007 finden sich unter www.covalence.ch/ docs/CovalenceEthicalRankingQ1-2007_PressRelease_26.04.2007.pdf.

21 Eigene Darstellung. Die auf der Ordinate genannten Zahlen geben die Ordnungsnummer des jeweiligen Kriteriums an. 


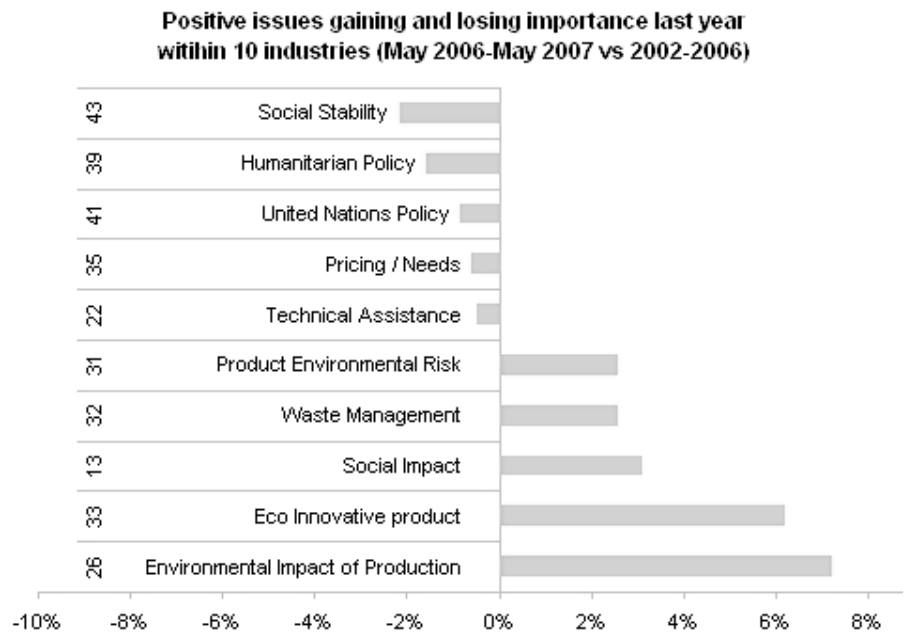

Abb. 4: Themen ethischen Angebots. ${ }^{22}$

\begin{tabular}{|cccc|}
\hline \multicolumn{4}{c|}{ Leaders across all sectors } \\
Rank & Best EthicalQuote Score & Best EthicalQuote Progress & Best Reported Performance \\
1 & Unilever & Marks \& Spencer & Wal-Mart \\
2 & Alcoa & Wal-Mart & DuPont \\
3 & Starbucks & DuPont & Alcoa \\
4 & Toyota & Alcoa & Marks \& Spencer \\
5 & BP & Dell & Toyota \\
6 & HSBC & Toyota & Starbucks \\
7 & Hewlett-Packard & Intel & Nestlé \\
8 & Intel & IBM & Dell \\
9 & GlaxoSmithKline & Cisco Systems & Alcan \\
10 & Alcan & Unilever & IBM \\
\hline
\end{tabular}

Abb. 5: Unternehmen im EthicalQuote. ${ }^{23}$

Abbildung 5 verdeutlicht, dass sich die mit EthicalQuote erfassten Unternehmen im Hinblick auf ihren Gesamtwert, den Fortschritt in der letzten Erhebungsperiode sowie ihre Selbstdarstellung unterscheiden. EthicalQuote Score und EthicalQuote Progress werden durch den Vergleich positiver und negativer Informationen über das Unternehmen ermittelt, während die Reported Performance ausschließlich auf der Anzahl positiver Selbstdarstellungen basiert. Einige Unternehmen wie z.B. Wal-Mart haben einen niedrigen EthicalQuote Score,

22 Eigene Darstellung.

23 Eigene Darstellung. 
während sie zugleich eine gute Platzierung hinsichtlich der Reported Performance erzielen. Aus diesem Grund kann man vermuten, dass die ethische Forderung (negative Informationen, z.B. in Protestkampagnen) das ethische Angebot (positive Informationen, z.B. CSR-Berichte der Unternehmen) stimuliert.

Dieses Ergebnis bestätigt sich, vergleicht man das Verhältnis positiver und negativer Berichterstattung in einzelnen Branchen (Abbildung 6). Auch hier geht ein höheres Maß negativer Berichterstattung in der Regel mit einem höheren $\mathrm{Maß}$ positiver Berichterstattung einher. Zudem überwiegt in allen Fällen die positive Berichterstattung, was auf ein Ressourcenungleichgewicht zwischen ethischen Forderern (z.B. NGOs) und ethischen Anbietern (Unternehmen) schließen lässt.

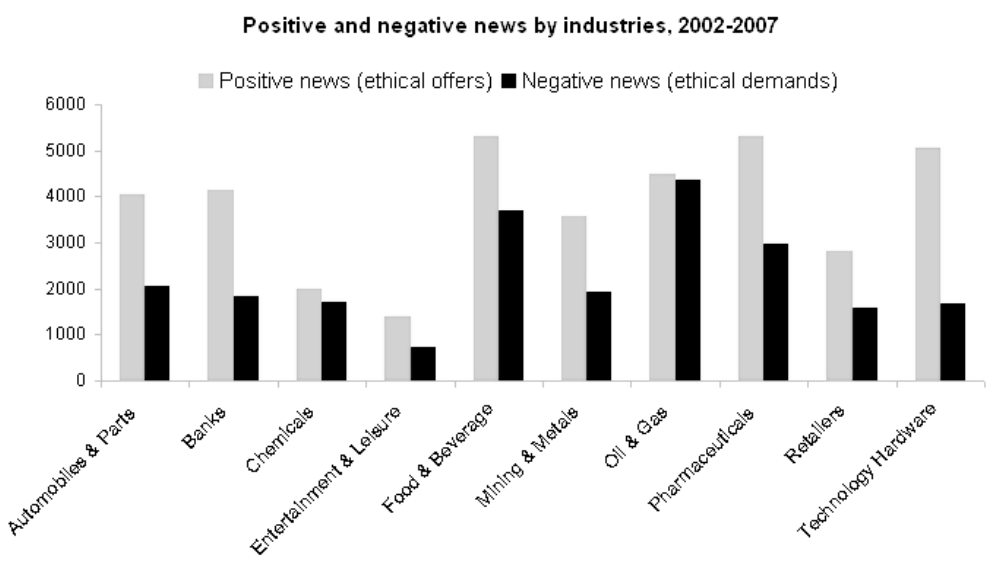

Abb. 6: Branchen. ${ }^{24}$

Abbildung 7 gibt Aufschluss darüber, wie positive und negative Einzelinformationen in den fünf bedeutenden Wirtschaftsregionen der Welt verteilt sind. Europa ist der Kontinent, aus dem die meisten Stimmen vernommen werden, dicht gefolgt von Nordamerika. Diese beiden Regionen sind damit die beiden wichtigsten Informationslieferanten und spiegeln zugleich die Dominanz der Konsumgesellschaften gegenüber den Produktionsländern in der Diskussion um ethisches Handeln von Unternehmen wider.

24 Eigene Darstellung. 
Antoine Mach | Ethische Reputation als Börsenwert

Positive and negative news by regions of source, 10 industries, 2002-2007

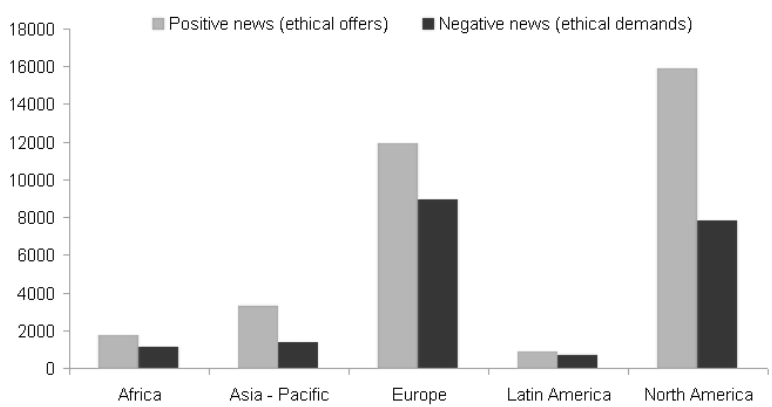

Abb. 7: Regionen. ${ }^{25}$

\section{$5 \quad$ Ausblick}

\subsection{Das Paradoxon von Gut und Böse}

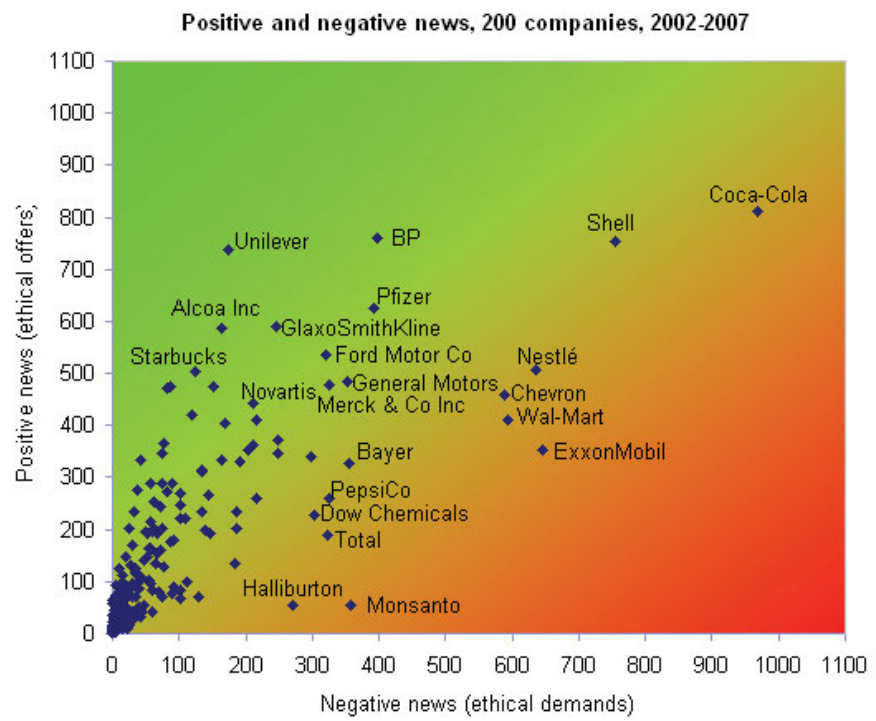

Abb. 8: Unternehmen. ${ }^{26}$

25 Eigene Darstellung.

26 Eigene Darstellung. 
Zwischen den beiden Dimensionen von Abbildung 8 - der Anzahl positiver Nachrichten (vertikale Achse) und der Anzahl negativen Meldungen (horizontale Achse) - besteht eine positive Korrelation. Dies bedeutet, dass auf die Firmen, die besonders oft Gegenstand positiver Berichte sind, auch ein hohes $\mathrm{Ma}$ an negativen Informationen entfällt. Dies bestätigt die bereits oben aufgestellte These, dass ethische Forderungen ethische Angebote stimulieren.

Dieser Zusammenhang zeigt die Bedeutung der sozialen Kontrolle als Motor für Corporate Social Responsibility und Corporate Citizenship. ${ }^{27}$ Unternehmen, die häufig Adressaten von Kritik sind, neigen dazu, als Pioniere der Selbstkritik, der Innovation und der Aktion zu agieren, während Konzerne, die seltener kritisiert werden, sich weniger engagiert zu zeigen scheinen. Dies wirft Widersprüche und Fragen auf: Welche Firmen sind tatsächlich Vorkämpfer und welche Nachzügler? Dieses Paradoxon der Union von good und bad companies, das überdies in jeder untersuchten Branche beobachtet werden kann, ist das wohl interessanteste Ergebnis.

\subsection{Ethische Messungen im globalen Zusammenhang}

Covalence hat bei der Betrachtung der ethischen Reputation multinationaler Unternehmen stets der Lebenswirklichkeit in Entwicklungsländern und deren Bedürfnissen besondere Aufmerksamkeit geschenkt. Die Aufgabe, die Wirkungskraft multinationaler Unternehmen in Entwicklungsländern zu untersuchen, birgt jedoch zahlreiche Schwierigkeiten und Probleme. Dabei ist unerheblich, ob die analysierten Unternehmen aus der nördlichen oder südlichen Hemisphäre stammen. Im Folgenden sollen einige Erfahrungen, die im Zeitraum 2001 bis 2007 gewonnen wurden, dargestellt werden:

- Technische Herausforderungen: Die Wahrscheinlichkeit, Dokumente über Entwicklungsländer im Internet zu finden, ist wesentlich geringer als an entsprechende Informationen über Industrienationen zu gelangen. Es scheint, dass potenziell verwertbare Informationen nur in Papierform vorliegen und somit ausschließlich mithilfe von Presse, NGOs, Gewerkschaften oder Forschern gefunden werden können. Selbst wenn aus Entwicklungsländern stammende Informationen im Internet veröffentlicht wurden, sind sie meist nur schwer auffindbar, da entweder die Websites keine Suchfunktion aufweisen oder aber die Seiten mit einem relativ niedrigen Google Rank bewertet werden, weswegen sie oftmals nicht erfasst und ausgewertet werden können.

27 Zum Zusammenhang von Corporate Social Responsibility und Corporate Citizenship vgl. z.B. Curbach in diesem Band. 
- Politische Herausforderungen: Möglichkeiten der Informationsbeschaffung sind zunächst abhängig vom Grad der politischen Freiheit eines Landes. In Ländern, in welchen eine aktive Zivilgesellschaft existiert, Gewerkschaftsrechte respektiert werden und die Pressefreiheit gewährleistet ist, können mehr Informationen erfasst werden als in Staaten, in denen dies nicht der Fall ist. Hinzu kommt, dass in vielen Entwicklungsländern die Unterscheidung zwischen privaten und staatlichen Sektoren nicht deutlich ist; dies wurde von einigen Covalence-Korrespondenten vor Ort wie auch von anderen Beobachtern berichtet. Folglich ist in Entwicklungsländern auch das Verständnis von Konzepten unternehmerischer Verantwortungsübernahme anders als in den OECD-Staaten. Aufgrund der Dominanz staatlicher Strukturen ist es wenig wahrscheinlich, dass private Konzerne direkt mit sozialen Forderungen konfrontiert werden, weshalb sich auch die Analysen von Covalence in diesen Kontexten mit Schwierigkeiten konfrontiert sehen.

- Kulturelle Herausforderungen: Zahlreiche Beobachter haben bereits darauf hingewiesen, dass bei der Analyse des Einflusses von Unternehmen in wirtschaftlich fortgeschrittenen Ländern andere Methoden als bei der Forschung in Entwicklungsländern angewendet werden müssen, da sich die Erwartungen an Unternehmen oftmals unterscheiden. Hinzu kommen Sprachbarrieren, da sich die Sprachkenntnisse der Analysten von Covalence auf Englisch, Französisch, Deutsch, Spanisch und Italienisch beschränken. Veröffentlichungen, die z.B. in Chinesisch oder Arabisch verfasst sind, können nicht erfasst werden, da die notwendigen Kenntnisse dieser Sprachen nicht vorhanden sind.

\subsection{Die Gralssuche: Korrelationen zwischen Aktienkurs und ethischem Kurs}

Wie viele Wissenschaftler und Experten, die in den Bereichen Corporate Social Responsibility und Socially Responsible Investing tätig sind, ist Covalence daran interessiert, die Beziehung zwischen der wirtschaftlichen und der ethischen Leistung eines Unternehmens zu erforschen. Wie bereits erwähnt, teilen die Covalence-Gründer die Annahme, dass eine solche Beziehung möglich ist. Seit 2005 wurden einige Forschungsreihen zur Korrelation von ethischen Kursen und Aktienkursen durchgeführt. An dieser Stelle sollen deren Hauptergebnisse kurz zusammengefasst werden.

Zu Beginn wurde der Versuch unternommen, Korrelationen zwischen dem ethischen Börsenwert und dem Aktienkurs von 100 Unternehmen in zehn Sektoren innerhalb eines Zeitraums von fünf Jahren aufzuzeigen. In 80 
von 100 Fällen konnte hier keine Korrelation festgestellt werden. Der ethische Wert und der Börsenwert schienen sich unabhängig voneinander zu entwickeln; in den meisten Fällen schienen Investoren finanzielle Risiken nicht mit ethischen Themen in Verbindung zu bringen. In zehn Fällen wurden positive Korrelationen beobachtet (der ethische Kurs folgte dem Aktienkurs in gleicher Richtung, steigend oder fallend). In weiteren zehn Fällen waren negative Korrelationen sichtbar: Während der ethische Kurs stieg, sank der Aktienkurs oder umgekehrt.

In einer weiteren Forschungsstufe wurden die von Covalence erfassten Daten anhand der 45 entwickelten Kriterien unterschieden, bevor sie mit dem Aktienkurs verglichen wurden. Für einige Kriterien ergaben sich keine Korrelationen. Für manche Kriterien wurde dagegen eine positive Korrelation sichtbar. Dies traf beispielsweise auf Gesundheitsgefährdungen durch pharmazeutische Produkte zu. Beschwerden bezüglich der Nebenwirkung eines Medikaments, die restriktive Informationspolitik des Unternehmens bezüglich des Themas sowie die Reaktionen der Gesundheitsbehörden haben den ethischen Börsenwert dieses Unternehmens negativ beeinflusst. Gleichzeitig fiel auch der Aktienkurs der Firma. Die Investoren befürchteten, dass solche Reaktionen eine negative Auswirkung auf die Umsätze und die Betriebslizenz des Unternehmens haben könnten.

Bei der Betrachtung anderer Kriterien wurde eine negative Korrelation sichtbar. Dies traf vor allem auf Sanierungsmaßnahmen zu: Während die Kündigung zahlreicher Mitarbeiter meist mit einer negativen Berichterstattung einhergeht, sehen Investoren dies vor dem Hintergrund der Reduktion von Produktionskosten positiv. Während Fälle von Korruption aus der ethischen Perspektive als negativ zu bewerten sind, ist dies nicht unbedingt zutreffend, wenn man sie aus einem ökonomischen Blickwinkel betrachtet. Korruption bedeutet, dass Geschäfte abgewickelt und neue Verträge geschlossen werden; dies kann von Investoren wohlwollend gebilligt werden.

Insgesamt waren die Ergebnisse allerdings enttäuschend: Nur zehn Prozent der untersuchten Fälle wiesen einen positiven Zusammenhang zwischen dem ethischen Kurs und dem Aktienkurs auf. In 90 Prozent der Fälle war eine solche Korrelation nicht vorhanden oder gar negativ. Nach wie vor scheint ein langer Weg vor dem Unternehmen Covalence zu liegen, wenn es darum geht, ethische Themen und die Interessen der Finanzwelt miteinander in Einklang zu bringen. In diesem Sinne scheint Covalence noch immer an einer Utopie festzuhalten. 


\section{Literaturverzeichnis}

Mach, Antoine: „Macht der NGO über die Unternehmen: Druck, Partnerschaft, Evaluation“, Annuaire Suisse - Tiers Monde 2002, IUED Genève, www.covalence.ch/docs/annCHTMall.pdf, 27.07.2007.

Mach, Antoine: „Swiss Business and Human Rights - Confrontations and Partnerships with NGOs", Institut Interdisciplinaire d'éthique et des droits de l'homme - Université de Fribourg, 2001, www.unifr.ch/ iiedh/publications/public-dts-iiedh/public-dt02.pdf, 27.07.2007.

Umweltbank: „UmweltGarantie - die ökologische Produktgarantie der UmweltBank“, www.umweltbank.de/umweltbank/index_produktgarantie. html, 28.07.2007. 



\section{Lars Rademacher}

\section{Bürgerschaft und Unternehmensführung. Die praktische Philosophie des Corporate Citizenship am Beispiel Bildung}

Man kann nicht sagen, dass deutsche Unternehmen der Idee des bürgerschaftlichen Engagements mit spontaner Begeisterung begegnet wären. Anders als in den USA, wo eine licence to operate als gesellschaftliche Legitimation erst als erteilt gilt, wenn ein Engagement für die Gemeinschaft feststellbar ist, sehen deutsche Unternehmen bis in die Gegenwart ihren bürgerschaftlichen Dienst in erster Linie durch die reguläre Produktion erfüllt - das Angebot hochwertiger Waren und Dienstleistungen wird als Beitrag für das Gemeinwohl betrachtet.

Andererseits haben Unternehmen schon immer aus der Mitte ihrer beruflichen Praxis heraus Maßnahmen betrieben, die auch jenseits ihrer Geschäftstätigkeit dem Wohl der Allgemeinheit dienten. Dabei lagen die Gründe für dieses Tun in der Regel im Nahbereich. Meist ging es darum, die Produktivkraft der tätigen Arbeitskräfte zu erhalten, für ihre Gesundheit zu sorgen, ihnen kulturelle oder sportliche Angebote zu offerieren, für ihre Familien und ihr Lebensumfeld einzutreten u.s.w. Aufgrund ihrer gesellschaftlichen Funktion haben Unternehmer als Einzelpersonen auf kommunaler Ebene häufig auch politische Ämter oder Verwaltungsaufgaben wahrgenommen und aus der Kenntnis um die drängenden Fragen einer Gemeinde, einer Stadt oder einer Region persönlich oder als Unternehmer Verantwortung übernommen. Wenn von Beispielen guter Mitbürgerschaft die Rede ist, steht zumeist noch der klassische Unternehmer im Blick, der selbst gegründet hat oder ein Familienunternehmen führt, das wiederum Mitarbeiterfamilien bereits seit mehreren Generation beschäftigt. Doch spätestens in Zeiten globaler Unternehmensstrukturen wird aus Corporate Citizenship ein komplexer Bestandteil der Unternehmensführung, der systematisch betrieben wird. Denn es gilt die Vielzahl der Erwartungen und Pflichten in den Ländern zu koordinieren, in denen die Unternehmung Mitarbeiter und Standorte besitzt und/oder Handel treibt. Dementsprechend ist das Engagement als guter Mitbürger in der lokalen Gemeinschaft heute in einem deutlich erweiterten korporativen Verantwortungsbereich aufgegangen. Die Rede von Corporate Citizenship bringt anders als das klassische Mäzenatentum zudem zum Ausdruck, dass es sich um ein System von Rechten und Pflichten (besser: Verpflichtungen) handelt, in das Unternehmensbürger in der Postmoderne eingebettet sind. Was Unternehmen also als Beitrag leisten, basiert nicht nur auf Freiwilligkeit, sondern entspringt auch 
der Notwendigkeit, sich als Bürger den geltenden Obliegenheiten zu unterwerfen.

In einem ersten Abschnitt werden hier kurz die Grundlagen einer global verstandenen unternehmerischen Bürgerschaft aufgegriffen und hinsichtlich der sich daraus ergebenden Anforderungen für die Unternehmensführung spezifiziert. Anschließend wird dargelegt, warum Bildung ein zentrales Handlungsfeld korporativen Engagements darstellt, um darauf aufbauend das Projekt Wissensfabrik - Unternehmen für Deutschland e.V. anhand der von Habisch entwickelten Kriterien eines effektiven unternehmerischen bürgerschaftlichen Engagements zu bewerten. Dieses Projekt setzt sich für Verbesserungen der Bildungsinfrastruktur (vor allem in der frühkindlichen Bildung) und für die Förderung von Existenzgründern und jungen Unternehmern ein und wird mittlerweile von mehr als 60 Mitgliedsunternehmen unterstützt. Abschließend werden Perspektiven der zukünftigen Rolle von Unternehmen entwickelt und in diesem Zusammenhang ein mögliches Konkurrenzverhältnis zu NGOs aufgezeigt.

\section{Die Idee des Global Corporate Citizenship}

Den Begriff des Bürgers auf Unternehmen auszuweiten - und zwar im globalen Maßstab - ist eine voraussetzungsreiche theoretische Prämisse. ${ }^{1}$ Diese Erweiterung des Bürgerbegriffs stützt sich auf Konzepte der politischen Philosophie und nimmt die Doppelrolle des Bürgers als Privatbürger (Bourgeois) und Staatsbürger (Citoyen) nun auch für Unternehmen in Anspruch, die sich ebenfalls in einem Spannungsverhältnis zwischen individuellem (hier: ökonomischem) Interesse und Gemeinwohlorientierung befinden. ${ }^{2}$ Aus Sicht der Unternehmensführung entsteht damit laut Scherer und Baumann die Herausforderung, ,dieses Konfliktverhältnis zu lösen und einen Ausgleich zwischen dem (privaten) Gewinninteresse der Unternehmung und dem öffentlichen Interesse zu finden“3. Der Anspruch von Unternehmen, als Bürger zu agieren, setzt dabei durch die Anknüpfung an einen Grundbegriff der politischen Theorie voraus, dass sie sich in ihrem Handeln sowohl von reiner Philanthro-

1 Vgl. dazu Curbach in diesem Band.

2 Vgl. Moon u.a.: „Can Corporations be Citizens?“; Pogge: „A cosmopolitan perspective on the global economic order“; Scherer u.a.: „Global Rules and Private Actors“; Scherer/Baumann: „Corporate Citizenship“.

3 Ebd., S. 861. 
pie (Corporate Giving) als auch von einer alleinigen Maßnahme zur Verkaufsförderung (Cause Related Marketing) abgrenzen. ${ }^{4}$

Für Unternehmen als Weltbürger muss diese Rollenbeschreibung sogar noch ausgeweitet werden. Sie können nicht nur selbst als Inhaber bestimmter Rechte und Pflichten ${ }^{5}$ betrachtet werden und müssen private und öffentliche Interessen vereinbaren, sondern können als Corporate Citizens nach Matten und Crane ${ }^{6}$ Bürgerrechte auch stellvertretend für Individuen ausüben - oder deren Ausübung verteidigen:

Dies gilt insbesondere dort, wo (1) der Staat sich zurückzieht oder zurückziehen muss, wo (2) der Staat noch nicht die Verwirklichung von Rechten übernommen hat oder wo (3) er prinzipiell nicht in der Lage dazu ist. ${ }^{7}$

Die beiden letztgenannten Aspekte können einerseits auf Regionen oder Flächenstaaten bezogen werden, in denen die dort ansässige Unternehmung bestimmte Regelungen treffen muss, um die Ordnung zu stützen und das Zusammenleben zu verbessern oder können neue Entwicklungsbereiche betreffen (etwa die Telekommunikation), in denen durch technischen Fortschritt Problemstellungen und neue Rechtsräume entstehen, die zunächst nur durch die verantwortliche Haltung der involvierten Unternehmen sozial geregelt werden können. Die rechtliche Regelung solcher Segmente ist der technischen Entwicklung häufig nachgelagert, da die Notwendigkeit einer rechtlich verbindlichen Regelung erst im Laufe der Zeit augenscheinlich wird. Demgegenüber kann der erste Aspekt als relativ neues Phänomen in europäischen Gesellschaften beobachtet werden. Vor dem Hintergrund demographischer und ökonomischer Entwicklungen wie etwa der sinkenden Refinanzierungsquote der Sozialkassen ${ }^{8}$ wird die „Bürgergesellschaft ${ }^{\star c 9}$ aus unterschiedlichen gesellschaftlichen Lagern propagiert. Damit verbunden ist ein Mehr an Selbstver-

4 Scherer und Baumann verweisen allerdings am Beispiel des Sportartikelherstellers Nike darauf, dass eine Integration ökonomischer Interessen und Gemeinwohlorientierung sowohl als grundsätzliche Verhaltensänderung als auch als reine Kommunikationsstrategie angelegt sein kann, wobei sich die jeweilige Strategiewahl aus Ressourcengründen an dem von Stakeholdern ausgeübten Veränderungsdruck orientiert. Vgl. ebd.

$5 \mathrm{Zu}$ den Rechten und Pflichten von Unternehmensbürgern vgl. Kneip in diesem Band.

6 Vgl. Matten/Crane: „Corporate Citizenship“.

7 Scherer/Baumann: „Corporate Citizenship“, S. 861.

8 Vgl. Kaufmann: Schrumpfende Gesellschaft, S. 63-94.

9 Vgl. z.B. Nolte: Generation Reform, S. 76-84, 124-128. 
antwortung des Staatsbürgers, aber vielfach auch ein Gestaltungsauftrag an den Unternehmensbürger. Das Konzept der Bürgergesellschaft zielt somit darauf, den Rückzug des Staates auf das minimal notwendige Verantwortungsspektrum zu legitimieren. Unbestritten bleiben das staatliche Gewaltmonopol und die Notwendigkeit staatlichen Handelns in der Judikative. In anderen Gebieten wie dem öffentlichen Transport oder der Bildung bestehen dagegen deutlich sichtbare Unsicherheiten was die Konturierung der Rolle des Staates betrifft. Während es in einigen Bundesländern z.B. völlig eindeutig zu sein scheint, dass Lehrer Staatsdiener sein sollten (wie in Bayern oder BadenWürttemberg), haben andere Länder (wie etwa Sachsen oder MecklenburgVorpommern) bereits Erfahrungen mit angestellten Lehrkräften gesammelt. Trotz der Erfolge skandinavischer Länder, die für eine ausgeprägte staatliche Förderung des Bildungswesens zu sprechen scheinen, ist die deutsche Debatte durch widerstreitende Positionen geprägt. Beim öffentlichen Transport wird die Uneinigkeit über die Funktion des Staates noch deutlicher: Hier haben Beispiele aus dem Ausland (etwa Großbritannien) und Inland (regionale Bahndienstleister) Ängste geschürt und die Privatisierungsbestrebungen der Deutschen Bahn AG zunächst ins politische Patt geführt. ${ }^{10}$ An anderen volkswirtschaftlich zentralen Stellen wie der Energieversorgung werden sogar implizite Vergesellschaftungen diskutiert (z.B. bei den Altlasten des Steinkohlebergbaus in Form einer Stiftung).

Als Quintessenz dieser divergierenden Tendenzen lässt sich festhalten, dass im „Weltinnenraum des Kapitals“"11 eine Umverteilung der Verantwortung stattfindet, die ein gestiegenes $\mathrm{Maß}$ an Selbstverantwortung propagiert. Der Rückzug des Staates ist damit als Faktor des gesellschaftlichen Umbaus definitiv (wenn auch nicht irreversibel). In den ordnungspolitisch freiwerdenden Handlungsfeldern sind korporative Akteure zunehmend gefordert. Werden etwa Fragen der allgemeinen und speziellen Bildung vernachlässigt (wie dies z.B. die Ergebnisse der PISA-Studien nahe legen), sind die Interessen der Unternehmen zutiefst tangiert. Schon aus eigenwohlorientierten Motiven werden sie die Initiative ergreifen, um einen dauerhaften Zugang zu qualifizierten Arbeitskräften zu sichern. In Ländern, in denen die Unternehmung langfristig agieren will und in denen ein verlässliches Bildungswesen noch gar nicht etabliert wurde, wird sie sogar zu dessen grundsätzlichem Aufbau beitragen wollen.

10 Erst in einer Staatssekretärsrunde am 28.06.2007 wurden Kompromisse für die umstrittenen Details der (Teil-)Privatisierung der Bahn gefunden. Das Schienennetz soll im Eigentum des Bundes bleiben, wobei die Nutzungsrechte der Bahn so übertragen werden sollen, dass sie das Netz bilanzieren und damit ihren Wert erhöhen kann. Vgl. Riedel: „Weg frei für die Bahn-Privatisierung“.

11 Sloterdijk: Im Weltinnenraum des Kapitals. 
Was damit entsteht, kann durchaus als eine neue Art von Gesellschaftsvertrag verstanden werden. Matten und Crane sprechen hier von einem „Extended View“"12 des Citizenship und verweisen zur Erläuterung auf die von Marshall ${ }^{13}$ unterschiedenen Ebenen von Bürgerrechten, die üblicherweise durch den Verfassungsstaat garantiert, nun jedoch vor dem Hintergrund staatlichen Rückzugs bzw. Staatsversagens von Unternehmen zugesichert bzw. verteidigt werden: bürgerliche Freiheitsrechte (u.a. Eigentum, Vertragsfreiheit, Meinungsfreiheit), politische Rechte (Teilhabe/Teilnahme an der kollektiven Meinungsund Willensbildung) und soziale Rechte (u.a. Bildung, medizinische Versorgung). Problematisch ist allerdings, dass die Übernahme derart umfangreicher Aufgaben durch Unternehmen mit fehlenden verbindlichen Rechtsstrukturen verbunden ist, die jedoch für das wirtschaftliche Agieren der Unternehmen selbst unabdingbar sind.

Generell kann das Auftreten von Unternehmen in der politischen Arena in Anlehnung an Ulrich Beck mit dem Begriff der Subpolitik umschrieben werden. ${ }^{14}$ Ulrich Beck betrachtet vor dem Hintergrund einer reflexiven Moderne den durch die Trennung der zivilgesellschaftlichen, politischen und wirtschaftlichen Sphäre bedingten Ausschluss von Wirtschaftsakteuren aus der politischen Gemeinschaft als hinfällig: „Der unpolitische Bourgeois des sozialstaatlich regulierten Spätkapitalismus wird zum politischen Bourgeois, der in seiner wirtschaftlichen Sphäre nach den Maßstäben legitimationsbedürftiger Politik ,regieren“ muss. “15 Was sich hier andeutet, muss dabei nicht zwangsläufig als Steuerungsdefizit des Nationalstaats bewertet werden, sondern kann auch Ausdruck der Überwindung eines überkommenen Denkens in nationalstaatlichen Kategorien hinsichtlich ausgewählter Bestandteile der globalen Wirtschaftsordnung sein - ausgelöst durch eine Evolution des Regelungskorridors. ${ }^{16}$

12 Matten/Crane: „Corporate Citizenship“, S. 172.

13 Marshall: Class, Citizenship and Social Development.

14 Vgl. z.B. Weiß: Unternehmensführung in der reflexiven Modernisierung, S. 149.

15 Beck: Die Erfindung des Politischen, S. 197.

16 In den letzten Jahren hat sich die Politische Philosophie dieser Entwicklung gestellt und bearbeitet nun intensiv das Feld des Kosmopolitischen. Dabei stehen Fragen der Vermittlung von nationalstaatlichen Ansprüchen und moralischen Verpflichtungen zu den Folgen der supranationalen Handels- und Arbeitsmobilität im Mittelpunkt. Der Kosmopolitanismus sieht uns in einer moralischen Verpflichtung auch dem Fremden gegenüber, die der Verpflichtung gegenüber Landsleuten gleich komme. Vgl. Brock/Brighouse: The Political Philosophy of Cosmopolitanism. 
Manche Autoren argumentieren bereits, global agierende Unternehmen hätten die Rolle des Weltbürgers nach anfänglichem Zögern bereitwillig übernommen. Das scheint etwas zu optimistisch. Auch ob dadurch die globale Problemlösungskompetenz ansteigt, wie immer wieder vermutet wird, ist eher in Zweifel zu ziehen. Die neuere Literatur argumentiert mit einer Trias der unternehmerischen Handlungsrollen zwischen Markt, Staat und Zivilgesellschaft, in denen sich der Unternehmensbürger mal als Wirtschaftsbürger (1), mal als Regierender und Regierter (2) und mal als Mitglied einer sozialen Gemeinschaft (3) erweist. ${ }^{17}$ Mit dieser Trias wird der Rollenkonflikt zwischen Bourgeois und Citoyen begründet, zwischen Eigeninteresse und Gemeinwohlorientierung. Doch letztlich erweist sich auch diese Aufteilung als ein Beschreibungs- oder Kategorisierungsproblem. Warum wird eine Eindeutigkeit zwischen philanthropischem Interesse und korporativem Eigeninteresse eingefordert? Weil wir so gern in dualistischen Verhältnissen denken? Ist dies nicht ein Anspruch, der nach lediglich heuristisch herstellbaren Eindeutigkeiten fahndet?

\section{Citizenship als Teil der Unternehmensführung}

Für die Systematisierung des Citizenship-Engagements als Bestandteil einer komplexen Unternehmenssteuerung muss nicht nur die Frage nach der ethischen oder politischen Motivation des Unternehmensbürgers gestellt werden. Aus Sicht des Unternehmens geht es zunächst maßgeblich um die Effektivität des unternehmerischen Handelns. Aus Perspektive der Unternehmensleitung kann das unternehmerische Engagement mehrere Aktionsfelder beeinflussen, in dem sich der Unternehmensakteur bewegt. Systematisch betrachtet, agieren Unternehmen in einem (internen) Organisationsfeld, im gesellschaftspolitischen Umfeld und im Marktumfeld. ${ }^{18}$ Schaut man zunächst auf das Organisationsfeld, so trägt das bürgerschaftliche Engagement zur Festigung und Explikation der Rollenerwartungen und Wertstrukturen der Unternehmung bei. Unternehmen haben trotz der Vielfalt der im Detail divergierenden Aufgaben übergeordnete Zielsetzungen zu erfüllen. Organisationen dienen daher immer auch der Sinnstiftung - und das in doppeltem Sinne. Die Aufgabenbewältigung, an deren Ende ein Produkt oder eine Dienstleistung steht, ist dadurch sinnerfüllt, dass durch die erstellten Produkte zur Bedürfnisbefriedigung beigetragen wird. Darüber hinaus ergibt sich auch eine individuelle Sinnstiftung für den Einzelnen, der sein Tun als Beitrag zu diesem Prozess erfährt. Alle Teilnehmer einer

17 Vgl. dazu Curbach in diesem Band.

18 Vgl. Zerfaß: Unternehmensführung und Öffentlichkeitsarbeit, S. 279f. 
Wertegemeinschaft, die an einem solchen Produktionsprozess beteiligt sind, können zusätzliche Bestätigung aus einem bürgerschaftlichen Engagement ihrer Organisation erfahren. Im Marktumfeld orientieren sich alle Handlungen an der „Durchsetzung strategischer Konzepte in Transaktions- und Wettbewerbsbeziehungen" ${ }^{\text {"19 }}$. Trotz des im globalen Maßstab zunächst unendlich anmutenden Aktionsfelds zeigen Binnendifferenzierungen, dass letztlich in einzelnen Branchen gehandelt wird, die als „strategiespezifische Arenen der Interaktion und Kommunikation“ ${ }^{20}$ gelten können. In diesen eingrenzbaren Aktionsfeldern kann die bürgerschaftliche Betätigung zur Differenzierung vom Wettbewerb beitragen. Als differenzierende Handlung kann Corporate Citizenship Beiträge zum unternehmerischen Reputationsmanagement liefern, die dann mittels Bewertung durch Externe (z.B. Rating-Agenturen ${ }^{21}$ ) in fiskalische Vorteile umgerechnet werden. Darüber hinaus können auch die direkten Umfeldbedingungen der gewöhnlichen Geschäftstätigkeit beeinflusst werden. Beispielsweise kann das bürgerschaftliche Engagement die formale Gleichstellung aller Marktteilnehmer im Sinne eines strukturpolitischen Effekts zum Ziel haben. Im gesellschaftspolitischen Umfeld ist schließlich eine Vielzahl von Sphären von Recht und Politik über Wissenschaft und Bildung bis zu Religion und Kunst - für die Unternehmung von Bedeutung. Letztlich sind all diese Felder in mehr oder weniger starker Ausprägung miteinander verknüpft und liefern füreinander Voraussetzungen und Vorbedingungen. Zerfaß spricht in diesem Kontext von einer Vielzahl regulativer Beziehungen, in die Unternehmen eingebunden sind und in denen die eigenen Handlungsspielräume stets neu gesichert und legitimiert werden müssen. ${ }^{22}$ Das Unternehmen als Corporate Citizen kann hier Initiative in den genannten Sphären ergreifen und sich so etwa in der Förderung und Durchführung wissenschaftlicher Forschungsprojekte oder der Ausrichtung kultureller Veranstaltungen engagieren. Dabei ist die öffentliche Wahrnehmung dieser Initiativen bemerkenswert und kann nicht zuletzt auf einen gewissen Überraschungseffekt zurückgeführt werden - denn bürgerschaftliches Engagement wird noch immer nicht zwingend erwartet.

Was konkret besagt nun die Einbeziehung des Citizenship-Ansatzes in die Unternehmensführung? Dies meint zunächst eine Verwurzelung in den unternehmerischen Grundwerten und Leitlinien. An ihnen orientiert sich das Handeln der Gesamtorganisation. Grundwerte werden in Führungsanweisungen und konkreten Leitlinien ausformuliert und zumeist um Compliance-Stan-

19 Ebd., S. 281.

20 Ebd.

21 Vgl. dazu Mach in diesem Band.

22 Vgl. Zerfaß: Unternehmensführung und Öffentlichkeitsarbeit, S. 282. 
dards, also unternehmensübergreifende Rechtsvorschriften und Regelsysteme, ergänzt. Das Citizenship-Engagement geht aber über die Orientierung an geltendem Recht und üblichen Gebräuchen in zwei Dimensionen hinaus: einerseits durch seine inhaltliche Ausgestaltung, indem ordnungspolitisch relevante Grundfragen adressiert werden, die gemeinhin nicht auf der Agenda der Unternehmung stehen; andererseits durch die formale Ausgestaltung, indem bürgerschaftliches Engagement mit der gleichen strukturierten Arbeitsweise betrieben wird, die auch die gewöhnliche Geschäftstätigkeit auszeichnet. Erst die Verbindung von inhaltlicher Orientierung an ordnungspolitisch relevanten Fragestellungen ${ }^{23}$ und professionalisierter Prozesshaftigkeit markiert den Übergang vom sporadischen und unsystematischen Engagement zum Unternehmen als Corporate Citizen, der seine Rechte und Pflichten offensiv annimmt und sein Verhalten in diesem Bezug auf Dauer stellt. In dem Moment, in dem ordnungspolitisch zentrale Fragen tangiert sind, handelt das Unternehmen politisch-strategisch. Dies fällt (unabhängig vom jeweiligen Handlungsträger) in den Verantwortungsbereich der Unternehmensleitung, die Entscheidungen über den Ressourceneinsatz für zentrale Aufgaben treffen und eine Professionalisierung bisher unsystematisch betriebenen Handelns anregen kann.

Insbesondere auf der transnationalen Ebene sind mit dem gesellschaftlichen Engagement von Unternehmen komplexe Steuerungsaufgaben verbunden, denn ein globaler Konzern muss sich darauf einstellen, nicht nur jeweils die in den Partnerländern geltenden Gesetzgebungen und Gebräuche zu beachten, sondern sich auch in die dort sinnvollen und nützlichen CitizenshipHandlungsfelder einzuarbeiten. Grundlage eines Global-Corporate-Citizenship-Programms kann es kaum sein, ein und dieselbe Maßnahme global einzusetzen, wie folgendes Beispiel verdeutlicht: Die Metro-Group betreibt im Jahr 2007 unter dem Slogan Gut für Dich eine Initiative Ernährung + Bewegung, dessen Testimonial Fußball-Bundestrainer Joachim Löw ist. Diese Maßnahme ist zugeschnitten auf eine reiche, westliche Industrienation mit tendenziell hohem Anteil adipöser Bevölkerung (vor allem Kinder und Jugendliche) und wäre denkbar ungeeignet in Asien oder Afrika. Ziel muss somit sein, Corporate Citizenship global auf Grundlage einer einheitlichen Haltung und Wertebasis zu betreiben, die konkreten Ausgestaltungen aber entsprechend der Länderspezifika zu variieren. Dies darf allerdings nie so weit gehen, dass die Grundwerte der Organisation zu Gunsten der Werte im Absatzland missachtet oder überdehnt werden. Wenn etwa in der Organisation die Gleichberechtigung von Mann und Frau gefördert wird, im Absatzland aber eine klare Hierarchisierung anhand des Geschlechts gelebt wird, kann die Unternehmung diesen für sie

23 Vgl. Habisch: „Unternehmergeist in der Bürgergesellschaft“, S. 17. 
zentralen Wert nicht zur Disposition stellen. Sie muss ihn so gut es geht vorleben, soweit sie dadurch nicht ihre Mitarbeiter in Gefahr bringt. Da solche Entscheidungen von großer Tragweite sind, können sie letztlich nur vom Management der Unternehmung getroffen werden.

Sowohl im Hinblick auf die Bedeutung von Corporate Citizenship für ordnungspolitische Problemlagen als auch aus einer strategischen Perspektive wird deutlich, dass Unternehmen vor allem Themen für ihre Projekte aufgreifen sollten, die gesellschaftlich nutzenstiftend und sozial anerkannt sind. Dabei sind positive Effekte für die Unternehmensreputation einkalkuliert und erwünscht. $\mathrm{Zu}$ den wichtigsten ordnungspolitisch relevanten Themenfeldern zählen - unter dem Stichwort der Nachhaltigkeit - die Themengebiete Bildung und Umwelt, wobei im Folgenden der Bereich Bildung genauer beleuchtet wird.

\section{Bildung als Handlungsfeld für Corporate Citizens}

Bildung scheint immer mehr in die Mitte der gesellschaftlichen Debatte zu rücken, wie aktuelle Debatten zur deutschen Föderalismusreform oder zu den PISA-Studien exemplarisch zeigen, und kann als Voraussetzung für gesellschaftliche Entwicklung, Wohlstand und Freiheit verstanden werden. Die nachfolgende Skizze soll illustrieren, weshalb ein Engagement für verbesserte Bildung als zentrales gesellschaftliches Anliegen - nicht zuletzt für Unternehmen - gelten kann.

Insbesondere für Deutschland stellt Bildung ein zentrales Deutungsmuster dar, welches für die kollektive Identität des Landes seit jeher von großer Bedeutung ist. ${ }^{24}$ Angeheizt wurde die Diskussion auf dieser Basis von einer Vielzahl neuer Studien und der wenig förderlichen Fixierung auf Fragen der Finanzierung von Reformvorhaben. So entstand im Bildungsbereich nach den reformfreudigen 1970er und 1980er Jahren mit vielen pädagogischen Experimenten seit den frühen 1990er Jahren ein Reformstau. Natürlich kann das Bildungssystem nicht so schnell auf Veränderungen reagieren wie andere Teile der Gesellschaft - Aktionismus ist selten ein gutes Rezept, aber die Pädagogik ist für ihre extrem langatmigen Veränderungszyklen zu Recht berüchtigt. Neu ist die massive Beteiligung von Unternehmen an der laufenden Bildungsdiskussion vor dem Hintergrund mehrerer paralleler Entwicklungen: Die Föderalismusreform hat die Rechte der Länder in Sachen Bildung weiter gestärkt. Der Bund gibt immer mehr Kompetenzen auf - bis hin zur Abschaffung des Hochschulrahmengesetzes. Dies alles geschieht, obwohl seit Jahren über bun-

24 Vgl. Bollenbeck: Bildung und Kultur. 
desweit einheitliche Bildungsstandards diskutiert wird, an denen insbesondere Unternehmen hohes Interesse zeigen, weil sie sich eine Vergleichbarkeit der Schul- und Hochschulleistungen wünschen. Prekär wird die Situation seit dem Spürbarwerden des wirtschaftlichen Aufschwungs ab 2006. Laut einer Umfrage des Instituts der deutschen Wirtschaft Köln (IW) konnten im Jahr 2006 rund 48.000 Ingenieurstellen nicht besetzt werden. ${ }^{25}$ Andere schlugen schon früher Alarm, weil den Absolventen allgemeinbildender Schulen vielfach die Ausbildungsreife fehlt. Vor allem der deutsche Mittelstand leidet unter der geringen Qualifikation vieler Bewerber. Die Unternehmen sind sich einig, dass eine gute Ausbildung früher beginnen muss, sie wollen eine bessere Qualität in der Breite. ${ }^{26}$ Stattdessen fördert der Staat Eliten mit einer Exzellenzinitiative.

\subsection{Das Beispiel Wissensfabrik - Unternehmen für Deutschland e.V.}

Katalysatoren der aktuellen Bildungsdebatte sind - neben den politischen Handlungsträgern Gewerkschaften, Standesorganisationen von Lehrern und anderem pädagogischen Personal - auch Unternehmen. Vor allem Berater wie McKinsey oder die Boston Consulting Group bemühen sich um rege Einflussnahme auf die politische Willensbildung. ${ }^{27}$ Viele Unternehmen (etwa BOSCH oder die Deutsche Telekom) sind über ihre Stiftungstätigkeiten im öffentlichen Diskurs präsent. Darüber hinaus sind Unternehmen mit konkreten Bildungsmaßnahmen aktiv geworden. Im Jahr 2005 gründeten neun Unternehmer das Netzwerk Wissensfabrik - Unternehmen für Deutschland e.V., dem mittlerweile über 60 Unternehmen angehören (Stand: Sommer 2007), darunter mehrere DAX30-Unternehmen wie BASF, Siemens, ThyssenKrupp oder The Linde Group, aber auch eine Vielzahl renommierter Familienunternehmen wie Bosch, Trumpf oder Voith. Die Wissensfabrik fördert vor allem Grundkompetenzen wie Lesen, Schreiben und Rechnen, aber auch naturwissenschaftliches, technisches und wirtschaftliches Verständnis. Dabei werden besonders Projekte im

25 Vgl. Koppel: „Ingenieurmangel in Deutschland“.

26 So stellt beispielsweise Ludolf von Wartenberg, Hauptgeschäftsführer und Mitglied des Präsidiums des Bundesverbandes der Deutschen Industrie, zur Qualifizierung im deutschen Mittelstand fest: „Die aktuelle Lehrstellensituation wird stark von der mangelnden Ausbildungsreife vieler Bewerber geprägt. Zahlreiche Unternehmen mussten leider die unzureichende Qualifikation - laut PISA rund 25 Prozent der Schulabgänger - bei den Bemühungen zur Besetzung von Ausbildungsplätzen bestätigen.“ Wartenberg: „Leistungsfähige Knowledge Industry für den deutschen Mittelstand“, S. 80.

27 Vgl. Kluge: Schluss mit der Bildungsmisere; Kilius u.a.: Die Bildung der Zukunft; dies.: Die Zukunft der Bildung. 
frühkindlichen Lernbereich hervorgehoben, die als Leuchtturmprojekte firmieren. Derzeit hat die Wissensfabrik vier solcher Leuchttürme:

- $\quad$ Sprache macht stark!,

- $\mathrm{NaWi}$ - geht das? Naturwissenschaften im Grundschulunterricht,

- KiTec - Kinder entdecken Technik und

- $\quad$ KIEWIS - Kinder entdecken Wirtschaft.

Allein im naturwissenschaftlichen Projekt NaWi - geht das? werden bereits über 250 Grundschulen und über 20.000 Kinder in Deutschland über die Mitgliedsunternehmen mit naturwissenschaftlichen Experimenten im Sachkundeunterricht versorgt. Vielfach kommen auch Schüler in die Unternehmen, besuchen auf Exkursionen Produktionsstätten oder haben Referenten der Partnerunternehmen zu Gast (Vgl. Abbildung 1).

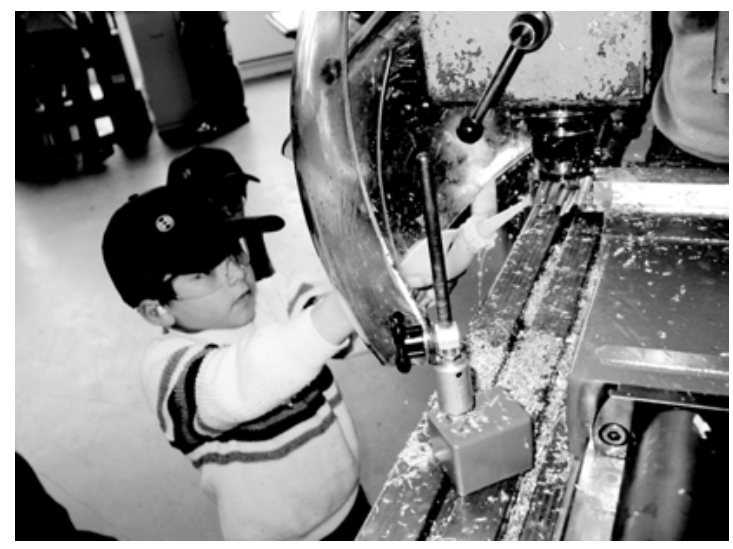

Abb. 1: Erfahrungslernen im Betrieb ${ }^{28}$

Da die Förderung bereits im zweiten oder dritten Schuljahr ansetzt, die Unternehmen selbst aber mit ihren Produkten oder Marken keinerlei Präsenz in den Bildungseinrichtungen zeigen, setzt sich das Unternehmensnetzwerk nicht dem Vorwurf aus, hier sollten die Konsumenten von morgen erzogen werden. Bei einer so frühen Förderung kann nicht einmal der Vorwurf erhoben werden, dem Unternehmen gehe es um die Rekrutierung zukünftiger Arbeitskräfte. Denn diese könnten schon innerhalb weniger Jahre die jeweilige Region verlassen und dem Unternehmen, das sie für Naturwissenschaften und Technik begeistern wollte, gar nicht mehr zur Verfügung stehen. Das Ziel ist viel-

28 Quelle: Wissensfabrik. 
mehr, insgesamt Impulse für die Bildung zu setzen. Je mehr Unternehmen sich beteiligen, so die Hoffnung der Initiatoren, umso mehr steigen Praxisbezug und Lernanreize in den Kindergärten, Schulen und für das Lehrpersonal - und damit letztlich flächendeckend die Qualität der Absolventen, was auch den Unternehmen zugute käme. Damit greifen Unternehmen mit konkreten Maßnahmen erstmals langfristig in die Bildungshoheit des Staates ein. Freilich tun sie dies noch als Partner der staatlichen Autoritäten mit dem Ziel, Konsens über Ziele und Reformbedarf herzustellen. Der Schwerpunkt auf der frühkindlichen Bildung macht dabei deutlich, wie langfristig und ernsthaft das Interesse und Engagement der beteiligten Unternehmen ist.

Ein weiteres Tätigkeitsfeld der Wissensfabrik ist der bundesweite Wettbewerb Kids in Betrieb. Mit Unternehmen praktisch lernen, der sich an Kindergärten und Grundschulen richtet. Ausgezeichnet werden im Rahmen dieser Initiative Projekte, die in den letzten beiden Jahren von Bildungseinrichtungen gemeinsam mit Unternehmen gestartet wurden, um Kindern außergewöhnliche (z.B. besonders praxisnahe) Lernerlebnisse zur ermöglichen. Sieger des ersten Durchgangs 2006/07 wurde die Gebrüder-Grimm-Grundschule aus Hannover mit dem Projekt Kids auf der Baustelle, einem fächerübergreifenden Projekt, das die benachbarte Großbaustelle der VHV Versicherungsgruppe zum Thema macht und sie in den Unterrichtsalltag integriert, statt die Baustelle als Sicherheitsrisiko zu dämonisieren (vgl. Abbildung 2). ${ }^{29}$

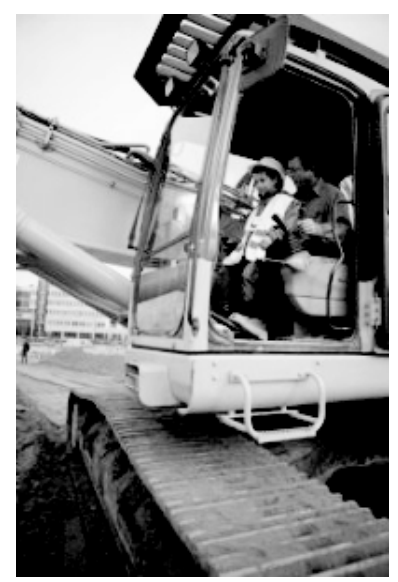

Abb. 2: Projekt Kids auf der Baustelle $\mathrm{e}^{30}$

29 Weitere Informationen und Portraits der ersten 10 Plätze unter www.kids-inbetrieb.de.

30 Quelle: Wissensfabrik. 
Um einen möglichst hohen Multiplikationseffekt zu erzielen und die frühkindliche Förderung immer wieder auf die Agenda der politischen Entscheidungsträger zu setzen, erarbeitet die Wissensfabrik darüber hinaus eigenständige Beiträge zum laufenden Diskurs. Darin soll die spezifische Perspektive von Unternehmen in Deutschland deutlich werden. Ein Beispiel ist die beim Institut der deutschen Wirtschaft Köln in Auftrag gegebene Studie Renditen der Bildung $^{31}$, mit der die Wissensfabrik belegt, dass sich Investitionen in die frühkindliche Förderung nicht nur sozial und für das Individuum rechnen, sondern auch monetär. Die Studie prognostiziert eine Rendite von 8 Prozent (volkswirtschaftlich sogar 13 Prozent) für eine Reinvestition der ab 2012 im Bildungssektor demographiebedingt frei werdenden Mittel in diesen Sektor. Diese Rendite liegt deutlich über der für langfristige Staatsanleihen. Damit wären Investitionen in die frühkindliche Bildung für den Staat attraktiver als den Schuldenabbau zu forcieren.

Insgesamt erfüllt ein solches Engagement für frühkindliche Bildung sämtliche der von Habisch ${ }^{32}$ aufgestellten Kriterien eines effektiven unternehmerischen bürgerschaftlichen Engagements:

- Das Engagement passt zu den beteiligten Unternehmen und deren Geschäftsfeldern (Technik und Naturwissenschaft), den Partnern und langfristigen Interessen.

- $\quad$ Da bei Bildung eine fast unmittelbare Betroffenheit gegeben ist, kann das Engagement von vielen Mitarbeitern mitgetragen werden.

- Da sich die Unternehmen bei den genannten Projekten immer mit eigenem Personal beteiligen und Geld und Ausstattung allenfalls hinzukommen, nutzt das Engagement die Potenziale des Unternehmens umfassend.

- $\quad$ Mit dem Thema Bildung wird ein relevantes Ordnungsproblem des 21. Jahrhunderts adressiert.

- $\quad$ Das grundlegende Prinzip der Wissensfabrik ist der Wissensaustausch im Netzwerk der Mitgliedsunternehmen, sodass Wissen und Kontakte verschiedener Partner eingebunden werden.

- Die Wissensfabrik möchte sich dauerhaft als Diskussionspartner zwischen Politik und Wirtschaft etablieren, wodurch Erfahrungen und innovative Lösungswege in die Öffentlichkeit zurückgespiegelt werden

31 Die Studie Renditen der Bildung ist als Volltext sowie als Summary unter www.wissensfabrik-deutschland.de zum Download verfügbar.

32 Vgl. Habisch: „Unternehmergeist in der Bürgergesellschaft“, S. 17. 
können (z.B. in die Bildungspolitik). So werden Anregungen gegeben und Diskussionen ausgelöst. Insgesamt können die beteiligten Unternehmen einen nachhaltigen Beitrag zur Strukturverbesserung des Wirtschaftsstandorts erbringen.

\section{Zur Zukunft des Corporate Citizen - eine Bedrohung der NGOs?}

Wenn Unternehmen ihre Rolle als Experten für spezialisierte Produkte in der hochgradig differenzierten Gesellschaft weiter vorantreiben - und davon ist auszugehen -, dann muss auch mit einer fortschreitenden Professionalisierung des bürgerschaftlichen Engagements gerechnet werden. Was das bedeutet, lässt sich gegenwärtig sicher nur zum Teil abschätzen. Es ist jedoch davon auszugehen, dass die Kombination aus professionellen Einsatzstäben, guter finanzieller Ausstattung und internationaler Vernetzung den Status multinationaler Konzerne weiter stärken wird. Schon heute treffen die Vorstände großer Aktiengesellschaften auf hochrangigen Treffen wie in Davos nicht nur auf den UN-Generalsekretär. Die politischen Ambitionen mancher Unternehmen gehen viel weiter. Informelle Netzwerke, die heute an noch peripheren, aber zentraler werdenden Themen ihre Arbeit aufnehmen, können schon morgen gewissermaßen am offenen Herzen der Gesellschaften operieren. Das ist für die staatlichen Autoritäten sicher zunächst ungewohnt. Denn ihnen wird eine ganz andere Erwartung an die kurzfristige Realisierbarkeit von Programmen und Maßnahmen von Seiten der korporativen Bürger entgegengebracht werden, die diese nicht nur einfordern, sondern mittels ihrer bis dahin aufgebauten Expertise wahrscheinlich auch selbständig umsetzen können. Nicht auszuschließen ist deshalb, dass sich der Staat in diesem Zuge aus einigen Gebieten (z.B. Wissenschaft und Forschung) noch weiter zurückzieht als bisher.

Neuen Herausforderungen dürften sich allerdings vor allem NGOs gegenübersehen. Es ist anzunehmen, dass sich Unternehmen teilweise ihrer Aufgaben annehmen werden und sie besser erfüllen als dies NGOs je konnten schon aufgrund ihrer charakteristischen Ressourcenknappheit. Unter diesem Eindruck werden einige NGOs verstärkt Kooperationen mit Unternehmen eingehen. Andere werden völlig verschwinden oder in gemeinsam mit Unternehmen gegründeten Pseudo-NGOs aufgehen. Schließlich wird es NGOs geben, die weiterhin Unternehmen und ihr quasi-staatliches Gebaren genauestens beobachten. Auf diese NGOs und die ressourcenschwachen Staaten wird die Aufgabe zukommen, die gesamte Kontrolle der korporativen Großbürger zu bewältigen und deren Handeln öffentlich transparent zu machen. In einer solchen Konstellation wird sich herausstellen, ob Unternehmen nur aus strate- 
gisch-wirtschaftlichen oder auch aus ethischen Positionen handeln, ob es ihnen stets nur um langfristige Geschäftsinteressen geht - oder um die Entwicklung einer nachhaltigen Gesellschaftsstruktur. Offen bleibt, ob das journalistische System seine Leistungsfähigkeit behält und damit die Kontrollfunktion von NGOs unterstützen kann. Ebenso bleibt abzuwarten, ob auch einzelne Bürger über ihren Konsum dauerhaft eine unterstützende Rolle und kritische Begleitung dieses Prozesses übernehmen. Zwar verfügen sie im Konsum über ökonomisches Stimmpotenzial, doch was sich ausnimmt wie eine Neuerfindung der Demokratie, sollte nicht überschätzt werden. Denn längst gibt es gegenläufige Tendenzen: Auch im Internet existiert der organisierte Verbraucherprotest nicht voraussetzungslos, manchmal wird er inszeniert und katalysiert, manchmal werden Verbraucher fast unmerklich gesteuert. Das Zentrale sind dabei nicht die wenigen Fokuspunkte (wie dereinst die Versenkung der Brent-SparÖlplattform), sondern die geläufigen Alltagssituationen. In ihnen wird Steuerung des Konsumentenwillens unterschwellig und mit langem Atem betrieben. Diesen Prozess der schleichenden Steuerung sollten Theoretiker, die auf die Macht der Verbraucher setzen, nie aus dem Auge lassen. Sonst gehen sie ihren Utopien am Ende selbst auf den Leim.

\section{Literaturverzeichnis}

Beck, Ulrich: Die Erfindung des Politischen, Frankfurt a.M. 2003.

Bollenbeck, Georg: Bildung und Kultur. Glanz und Elend eines deutschen Deutungsmusters, Frankfurt a.M. 1996.

Brock, Gillian/Brighouse, Harry: The Political Philosophy of Cosmopolitanism, Cambridge u.a. 2005.

Habisch, André: „Unternehmergeist in der Bürgergesellschaft. Verfangen in mittelalterlichen Moralvorstellungen? Zur Kritik gesellschaftlichen Engagements von Unternehmen“, in: Langenscheidt, Florian (Hrsg.): Deutsche Standards: Unternehmerische Verantwortung, Köln 2005, S. 13-23.

Kaufmann, Franz-Xaver: Schrumpfende Gesellschaft. Vom Bevölkerungsrückgang und seinen Folgen, Frankfurt a.M. 2005.

Kilius, Nelson u.a. (Hrsg.): Die Bildung der Zukunft, Frankfurt a..M. 2003.

Kilius, Nelson u.a. (Hrsg.): Die Zukunft der Bildung, Frankfurt a..M. 2002.

Kluge, Jürgen: Schluss mit der Bildungsmisere. Ein Sanierungskonzept, Frankfurt a.M. 2003. 
Koppel, Oliver: „Ingenieurmangel in Deutschland - Ausmaß und gesamtwirtschaftliche Konsequenzen“, in: IW-Trends, Nr. 2, 2007, www. presseportal.de/pm/51902/986685/institut_der_deutschen_wirtschaft_ koeln_iw_koeln, 03.07.2007.

Marshall, Thomas H.: Class, Citizenship and Social Development, New York 1965.

Matten, Dirk/Crane, Andrew: „Corporate Citizenship: Toward an Extended Theoretical Conceptualisation“, in: Aacademy of Management Review, Jg. 29, Nr. 1, 2005, S. 166-179.

Moon, Jeremy u.a.: „Can Corporations be Citizens? Corporate Citizenship as a Metaphor for Business Participation in Society“, in: Business Ethics Quarterly, Jg. 15, Nr. 3, 2005, S. 429-454.

Nolte, Paul: Generation Reform. Jenseits der blockierten Republik, München 2004.

Pogge, Thomas: „A cosmopolitan perspective on the global economic order“, in: Brock, Gillian/Brighouse, Harry (Hrsg.): The Political Philosophy of Cosmopolitanism, Cambridge u.a. 2005, S. 92-109.

Riedel, Donata (2007): „Weg frei für die Bahn-Privatisierung“, in: Handelsblatt, 28.06.2007, www.handelsblatt.com/news/_pv/_p/200040/_t/ft/ _b/1287300/default.aspx/index.html, 03.07.2007.

Scherer, Andreas Georg/Baumann, Dorothée: „Corporate Citizenship: Herausforderung für die Unternehmenskommunikation“, in: Piwinger, Manfred/Zerfaß, Ansgar (Hrsg.): Handbuch Unternehmenskommunikation, Wiesbaden 2007, S. 859-873.

Scherer, Andreas u.a.: „Global Rules and Private Actors. Towards a new role of the TNC in Global Governance“, in: Business Ethics Quaterly, Jg. 16, Nr. 4, 2006, S. 71-88.

Sloterdijk, Peter: Im Weltinnenraum des Kapitals, Frankfurt a.M. 2005.

Wartenberg, Ludolf von: „Leistungsfähige Knowledge Industry für den deutschen Mittelstand“, in: Franz, Otmar (Hrsg.): Qualifizierung im deutschen Mittelstand im Zeitalter der Globalisierung, Eschborn 2005, www.rkw.de/ 02_loesung/publikationen/Personal/1500_QualifizierungMittelstand.pdf, 03.07.2007.

Weiß, Ralf: Unternehmensführung in der Reflexiven Modernisierung. Global Corporate Citizenship, Gesellschaftsstrategie und Unternehmenskommunikation, Marburg 2002. 
Zerfaß, Ansgar: Unternehmensführung und Öffentlichkeitsarbeit. Grundlegung einer Theorie der Unternehmenskommunikation und Public Relations, Wiesbaden 2004. 



\section{Simon Holler}

\section{Fairtrade als subpolitisches Konzept. Ziele, Strukturen, Herausforderungen und Strategien}

Im Jahr 2005 verkündete der Zusammenschluss der größten Organisationen des fairen Handels, FINE ${ }^{1}$, das Ende des Nischendaseins fair gehandelter Produkte - nach jährlichen Zuwächsen von über 20 Prozent innerhalb Europas seit Beginn des 21. Jahrhundert habe der faire Handel eine neue Stufe erreicht und sei zum Mainstream avanciert. ${ }^{2}$ Eine herausragende Rolle als Wachstumsmotor kommt hierbei den gesiegelten Produkten des fairen Handels zu (auch als Fairtrade in einem Wort gegenüber anderen bzw. sämtlichen Produkten des fairen Handels als Fair Trade in zwei Worten gekennzeichnet). ${ }^{3}$ Im Jahr 2006 erreichte der weltweite Umsatz aller fair gehandelten Produkte mit rund zwei Milliarden Euro erneut eine Höchstmarke, wobei der größte Anteil mit rund 1,6 Milliarden Euro auf die gesiegelten Fairtrade-Produkte entfällt. ${ }^{4}$ Mit einem weltweiten Umsatzplus von über 40 Prozent gegenüber dem Vorjahr ist Fairtrade auch 2006 als Motor des starken Wachstums des fairen Handels insgesamt zu sehen. ${ }^{5}$ Dabei sind besonders Europa und Nordamerika als umsatzstärkste Märkte von Fairtrade-Produkten herauszustellen, angeführt von den USA, Großbritannien und der Schweiz. Neben dem Hauptprodukt Kaffee konnte vor allem der Umsatz von Bananen in den vergangenen Jahren kräftig gesteigert werden. Diese haben sich als zweitwichtigstes Fairtrade-Produkt etabliert. Nicht zuletzt die Entscheidung von Sainsbury's, einer der größten Supermarktketten Großbritanniens, das komplette Bananen-Sortiment auf Fairtrade-Produkte umzustellen, hat zu der positiven Entwicklung im Jahr 2006 beigetragen und das Ende des Schattendaseins für fair gehandelte Bananen in Großbritannien besiegelt. Auch in Deutschland haben Fairtrade-Produkte 2006 stark zugelegt: so konnte der Absatz auf 18.000 Tonnen verdoppelt werden, während der Umsatz ein Plus von 50 Prozent auf 110 Millionen Euro

1 FINE ist der Zusammenschluss folgender internationaler Organisationen des Fairen Handels: Fairtrade Labelling Organizations International (FLO), International Fair Trade Association (IFAT), Network of European Worldshops (NEWS!) und European Fair Trade Association (EFTA).

2 Vgl. Fairtrade Advocacy Office: Fair Trade in Europe.

3 Vgl. ebd., S. 7.

4 Vgl. Fairtrade Advocacy Office: „Fighting Poverty and Injustice through Fair Trade“; Fairtrade Labelling Organizations International e.V.: Annual Report 2006.

5 Vgl. ebd. 
verzeichnen konnte. ${ }^{6}$ Das starke weltweite Wachstum von Fairtrade geht neben der Konsolidierung traditioneller Fairtrade-Produkte wie Kaffee, Südfrüchten, Tee, Kakao, Zucker, Reis und Wein auch mit einer Ausweitung des Sortiments auf den Non-Food-Bereich mit Fußbällen, Baumwoll- und Kosmetikprodukten einher.

Mit seinen politischen Zielen und Werten stellt der faire Handel einen Beitrag zur internationalen Wirtschaftspolitik, genauer der internationalen Handelspolitik dar, der außerhalb der traditionellen, formalen, bürokratischen und institutionalisierten Organisationsformen des Politischen zu verorten ist. ${ }^{7}$ Ganz im Sinne Ulrich Becks verkörpert der faire Handel eine Form der Subpolitik (oder auch Subsystempolitik), verstanden als Selbstorganisation des Politischen außerhalb des offiziellen politischen oder korporatistischen Systems, die aus dem zunehmenden Aufbrechen formaler Zuständigkeiten und Hierarchien im etablierten politischen Institutionengefüge resultiert. ${ }^{8}$ Innerhalb der Subpolitik kann der faire Handel dem politisierten oder politischen Konsum, d.h. der spezifischen Gesellschaftsgestaltung durch Organisations- und Handlungsformen, die an den Akt des Konsumierens geknüpft sind, zugeordnet werden. ${ }^{9}$ Dabei wird der Konsument quasi zum Bürger, der Kassenbon zu einer Art Stimmzettel und der Kaufakt zum Wahlgang. Wendungen wie „,ote with your dollars“ oder „vote with your shopping trolley“ in Eigen- und Fremddarstellungen des fairen Handels bringen diesen Zusammenhang in der Praxis zum Ausdruck. ${ }^{10}$

Der Bereich der Subpolitik umfasst nach Becks Verständnis neben dem fairen Handel allerdings ein weites Feld unterschiedlicher Formen der Gesellschaftsgestaltung. So fällt darunter alles, was nicht der offiziellen, institutionalisierten Politik des Staates oder politischer Systeme zuzurechnen ist, aber zur Gesellschaftsgestaltung beiträgt bzw. als Teil des Politischen im Sinne der „Gestaltung und Veränderung von Lebensverhältnissen" "11 aufzufassen ist. Beck selbst macht daher auf die Notwendigkeit der näheren Differenzierung der Ziele und Inhalte, Organisationsformen, Prozesse und institutionellen Rahmenbedingungen von Subpolitik aufmerksam. ${ }^{12}$

6 Vgl. TransFair: Jahresbericht 2006, S. 7.

7 Vgl. Holzer/Sørensen: „Rethinking Subpolitics“, S. 81ff.; Beck: Die Erfindung des Politischen, S. 154ff., 206.

8 Vgl. Beck: Die Erfindung des Politischen, S. 162.

9 Vgl. Kneip/Niesyto in diesem Band.

10 Vgl. The Economist: „Voting with your Trolley“; Fair Trade: „The Story“.

11 Beck: Risikogesellschaft, S. 311.

12 Vgl. Beck: Die Erfindung des Politischen, S. 162 f. 
Vor diesem Hintergrund soll im Folgenden zunächst ein Blick auf die zentralen Ziele und Formen des fairen Handels im Allgemeinen sowie auf die Strukturen und Funktionsweisen von Fairtrade im Speziellen und die darauf gerichteten Kritikpunkte geworfen werden. Anschließend werden einige zentrale Herausforderungen, die sich für Fairtrade als Akteur auf der Bühne der Gesellschaftsgestaltung außerhalb der offiziellen, institutionalisierten Politik stellen, sowie Strategien zur Bewältigungen dieser Herausforderungen skizziert.

\section{$1 \quad$ Das Konzept Fair Trade}

\section{$1.1 \quad$ Ziele}

Hinter dem Etikett des fairen Handels verbergen sich eine Reihe unterschiedlicher Organisationen und Systeme mit durchaus unterschiedlichen strategischen Ausrichtungen. Das sie verbindende, übergeordnete Ziel bringt die folgende Definition der Dachorganisation des fairen Handels, FINE, zum Ausdruck:

Fairer Handel ist eine Handelspartnerschaft, die auf Dialog, Transparenz und Respekt beruht und nach mehr Gerechtigkeit im internationalen Handel strebt. Durch bessere Handelsbedingungen und die Sicherung sozialer Rechte für benachteiligte ProduzentInnen und ArbeiterInnen - insbesondere in den Ländern des Südens - leistet der Faire Handel einen Beitrag zu nachhaltiger Entwicklung. ${ }^{13}$

Dieses Selbstverständnis und die damit verbundene Zielsetzung beruhen im Wesentlichen auf drei zentralen Annahmen: Erstens, dass die ökonomische Globalisierung in Form einer Zunahme und Liberalisierung des Welthandels grundsätzlich das Potenzial besitzt, Motor für Entwicklung und Armutsbekämpfung zu sein - ganz im Sinne des Credos Entwicklung durch Handel der jüngeren handels- und entwicklungspolitischen Diskussion. Die zweite Annahme lautet, dass die Unvollkommenheit der Weltmarkt- und Welthandelsbedingungen in der Realität allerdings zur Folge hat, dass nicht alle Beteiligten ökonomischer Globalisierungsprozesse den gleichen Nutzen daraus ziehen und deren Potenzial ungenutzt bleibt, wenn nicht sogar umgekehrt wird. Die dritte Annahme bezieht sich auf die Unfähigkeit der internationalen Politik, zumindest unmittelbar als Korrektiv zu fungieren und die Unvollkommenhei-

13 Forum Fairer Handel: Herausforderungen des Fairen Handels durch neue Akteure wie Transnationale Unternehmen und Discounter, S. 3. 
ten des Marktes zu beheben. Diese Annahmen werden auf eine Reihe makround mikroökonomischer Bedingungen in den Entwicklungsländern zurückgeführt, welche zentralen Prämissen klassischer und neoliberaler Handelstheorien entgegenstehen und als Gründe für die ausbleibende Entwicklung und mangelnde Armutsbekämpfung im Zuge der Globalisierung aufgefasst werden. In Anlehnung an Nicholls/Opal können hierbei vier zentrale Aspekte herausgestellt werden: ${ }^{14}$

- Eingeschränkter Zugang zum Market und zu Krediten: Produzenten in Entwicklungsländern haben oftmals aufgrund mangelhafter Infrastruktur und Exportkapazitäten keinen eigenen Marktzugang und sind auf Zwischenhändler angewiesen. Dabei haben sie in der Regel nicht die Möglichkeit, langfristige Preisvereinbarungen zu treffen, die an Warenbörsen üblich sind und eine Stabilisierung und Planbarkeit des Einkommens ermöglichen würden. Auch der Zugang zu Krediten ist für Kleinbauern oft problematisch, sodass entweder gar keine Kredite verfügbar sind oder aufgrund mangelnden Wettbewerbs exorbitante Zinsen verlangt werden.

- Feblende Marktinformationen: Kleinbauern wissen oft wenig über Marktpreise und haben damit ihren Zwischenhändlern gegenüber keine Verhandlungsmacht. Ebenso können sie in der Regel keine Informationen über spezielle Qualitätsanforderungen und Nachfrageentwicklungen in den Absatzmärkten in Erfahrung bringen.

- Abbängigkeit von einer Einkommensquelle: Niedrige Einkommen und fehlende Kredite oder langfristige Preisabsprachen haben zur Folge, dass Produzenten in Entwicklungsländern vielfach nicht in der Lage sind, auf alternative Einkommensquellen umzustellen. Dadurch können sie nur schwer oder gar nicht auf Entwicklungen des Marktes wie beispielsweise einen Preisverfall reagieren.

- Mangelhafte Rechtssysteme: Arbeiter- und Umweltrechte werden in vielen Entwicklungsländern nicht eingehalten, sodass auch als race to the bottom bezeichnete Globalisierungsprozesse ungezügelt ihren Lauf nehmen können und zu unmenschlichen Arbeitsbedingungen, Ausbeutungsverhältnissen und Umweltzerstörung führen.

Die übergeordneten Zielsetzungen des fairen Handels bestehen also darin, die Lücke der politischen Gestaltung eines gerechten Welthandels zu schließen, die Unvollkommenheiten des Weltmarktes auszugleichen und das Potenzial der Globalisierung für Entwicklungsländer nutzbar zu machen. Im Sinne der

14 Vgl. Nicholls/Opal: Fair Trade, S. 33-40. 
o.g. FINE-Definition bedeutet dies auf individueller Ebene die Verbesserung der Arbeits- und Lebensbedingungen von Kleinbauern und Lohnarbeitern, wodurch die Relevanz entwicklungspolitischer und menschenrechtlicher Aspekte für den fairen Handel zum Ausdruck kommt. Konkret können folgende operationale Teilziele von Fair Trade differenziert werden:

- Größere Zugangsmöglichkeiten für Produzenten zu internationalen Märkten, vor allem zu den Industrieländern des Nordens;

- direktere und langfristigere Handelsbeziehungen;

- $\quad$ bessere Versorgung der Produzenten mit relevanten Marktinformationen sowie Management- und Marketingkenntnissen;

- angemessene und stabile Bezahlung der Produzenten, welche die Arbeits- und Lebenskosten deckt und soziale und ökonomische Entwicklung ermöglicht;

- $\quad$ Sicherung der Rechte und Stärkung der Position von ArbeiterInnen und Angestellten.

\subsection{Ansätze und strategische Ausprägungen}

Das Konzept des fairen Handels existiert bereits seit über 50 Jahren. Wie oben bereits erwähnt, haben sich im Laufe der Zeit verschiedene Ausprägungen entwickelt, die zwar das beschriebene gemeinsame übergeordnete Ziel verfolgen, aber nach wenigstens drei Aspekten differenziert werden können.

Das vielleicht wichtigste Unterscheidungsmerkmal, das auch den markantesten Einschnitt in der Geschichte des fairen Handels darstellt, ist der Grad der Separation von bzw. der Integration in den konventionellen Handel. Während die ursprüngliche Idee des fairen Handels ein eigenständiges, alternatives Handelssystem vorsieht, das vom Produzenten über alternative Handelsunternehmen bis hin zu ausgewiesenen Verkaufsstellen wie Eine-Welt-Läden in den Absatzländern reicht, bildeten sich Ende der 1980er Jahre erste Siegelinitiativen mit dem Ziel, fair gehandelten Produkten größere Absatzmöglichkeiten zu verschaffen und in konventionelle Distributionskanäle wie Supermärkte vorzudringen. ${ }^{15}$ Aufgrund ihrer unterschiedlichen Grade der Separation von bzw. Integration in den konventionellen Handel werden die Vertreter dieser beiden Ansätze des fairen Handels auch als Puristen und Pragmatiker bezeichnet.

Im Zusammenhang mit dieser Differenzierung stehen im Sinne eines zweiten Unterscheidungsmerkmales unterschiedliche politische Zielsetzungen

15 Vgl. Kleinert: „Inlandswirkungen des Fairen Handels“, S. 38. 
und Strategien. ${ }^{16}$ Das eine Ende der Skala markiert die Transformation des gesamten Welthandels als politisches Ziel, das eng mit der Strategie intensiver politischer Lobby- und Kampagnenarbeit verknüpft ist. Am anderen Ende steht das pragmatische Ziel der Maximierung der Verkaufsmengen fair gehandelter Produkte, das mit Blick auf die Handelspolitik implizit eine Regulierung des bestehenden Systems im Sinne des fairen Handels anstrebt. Beide Extreme korrelieren mit der Unterscheidung in Puristen und Pragmatiker.

Als drittes Unterscheidungsmerkmal kann die konzeptionelle Reichweite des fairen Handels gelten. Während sich die ursprüngliche Idee des fairen Handels explizit an Kleinbauern in Entwicklungsländern richtete, adressieren jüngere Ausprägungen seit den 1990er Jahren auch gezielt Lohnarbeiter in Entwicklungsländern. Gerade im Zuge der Erschließung konventioneller Distributionswege erfolgte zudem eine Ausweitung des Konzepts von ökologischen Aspekten hin zu einer umfassenderen Zielsetzung auf soziale, ökonomische und ökologische Entwicklung.

Die folgenden Überlegungen dieses Beitrags beschränken sich auf die Perspektive von Fairtrade als bedeutendste und erfolgreichste Form des fairen Handels. Mit Blick auf die unterschiedlichen Ausprägungen steht Fairtrade für die Verbreitung fair gehandelter Produkte über konventionelle Distributionswege. Konzeptionell ist Fairtrade hinsichtlich seiner politischen Zielsetzungen als gemäßigt einzustufen und integriert soziale, ökonomische und ökologische Aspekte.

\section{Kernelemente und Strukturen von Fairtrade}

\subsection{Fairtrade-Standards}

Zentrales Element im Fairtrade-System bilden Standards, in denen Handelsund Arbeitsbedingungen im Sinne der oben beschriebenen operationalen Ziele festgeschrieben sind. Fairtrade-Standards werden von der internationalen Koordinierungsstelle FLO e.V. (Fairtrade Labelling Organizations International), die 1997 von einer Reihe nationaler Fairtrade-Initiativen ins Leben gerufen wurde, festgelegt und fortlaufend weiterentwickelt. Die derzeitigen FairtradeStandards können in drei Bereiche untergliedert werden:

Erstens existieren allgemeine Standards für Kleinbauernorganisationen sowie für Plantagen und Fabriken, die ArbeiterInnen und Angestellte beschäf-

16 Vgl. Université du Québec à Montréal: „Fair Trade and the Solidarity Economy“, S. 8 . 
tigen. Zu den zentralen Anforderungen an die Organisationsform von Fairtrade-Produzenten zählt hierbei die Bedingung, dass Kleinbauern in Kooperativen organisiert sein müssen, um so ihre Marktposition zu stärken und beispielsweise den Zugang zu Marktinformationen oder die Exportkapazität zu verbessern. Sowohl Kleinbauern als auch Plantagen oder Fabriken müssen demokratisch organisiert sein, um Transparenz und Gleichberechtigung sicherzustellen. Die allgemeinen Standards schreiben zudem arbeitsrechtliche Bedingungen vor, die im Einklang mit den ILO-Konventionen (ILO: International Labour Organisation) über menschenwürdige Arbeitsbedingungen stehen. $\mathrm{Zu}$ den wichtigsten Vorschriften zählen das Verbot von Zwangs- und Kinderarbeit, das Recht auf gewerkschaftliche Organisation, Tarifabkommen, Lohnzahlungen in mindestens der Höhe regionaler bzw. gesetzlicher Mindestlöhne, ausreichende Arbeitsschutzvorkehrungen sowie Gleichberechtigung und Diskriminierungsverbot.

Zweitens bestehen produktspezifische Standards. So sind in den FairtradeStandards produktspezifische Preise festgelegt, die sich aus einem Mindestpreis und einer Sozialprämie zusammensetzen. Der Mindestpreis stellt sicher, dass die Produktions- und Lebenskosten gedeckt sind und ermöglicht ein stabiles und planbares Einkommen, während die separate Sozialprämie für Investitionen zur sozialen oder ökonomischen Entwicklung verwendet werden muss. Bei der Berechnung der Produktionskosten werden neben regionalen Gegebenheiten auch spezifische Anbauweisen berücksichtigt, sodass für biologisch angebaute Produkte ein höherer Mindestpreis festgesetzt wird. In der Regel liegt der Mindestpreis deutlich über dem Weltmarktpreis eines Produktes sollte dieser trotzdem den Mindestpreis überschreiten, passt sich der Mindestpreis dem Weltmarktpreis an. Die Sozialprämie wird als Prozentsatz der Produktionskosten auf den Mindestpreis aufgeschlagen und muss von Produzenten nach festgelegten Verfahrensweisen eingesetzt werden: Im Falle von Kleinbauernkooperativen kann so nur die Mitgliederversammlung demokratisch über die genaue Verwendung entscheiden. In Plantagen und Fabriken befindet ein Gremium, das sich aus Mitgliedern des Managements, mehrheitlich aber aus Arbeitern zusammensetzt, über die Prämienverwendung. Diese Verfahrensweise sichert Lohnarbeitern und Angestellten Entscheidungs- und Mitsprachrechte zu und bietet ihnen die Möglichkeit, ihre Arbeits- und Lebensbedingungen z.B. durch Bildungsmaßnahmen, Gesundheitsprogramme oder Investitionen in Gemeinschaftsprojekte zu verbessern. Kleinbauern können die Prämiengelder außerdem einsetzen, um ihre ökonomischen Produktionsbedingungen zu verbessern. Hierbei wird der Exportkapazität in den Fairtrade-Standards besondere Bedeutung eingeräumt, nicht zuletzt um direktere Handelswege zu fördern. Daneben können aber auch Investitionen in weiterverarbei- 
tende Maschinen erfolgen, Diversifizierungsprogramme oder die Umstellung auf biologische Anbauweisen finanziert werden. ${ }^{17}$

Schließlich können produktspezifische Handelsstandards, die in den Fairtrade-Standards angelegt sind, abgegrenzt werden. Diese schreiben vor, dass Produzenten und Händler langfristige Verträge schließen, um Produzenten eine gewisse Stabilität und Planbarkeit zu ermöglichen. Zudem müssen Händler den Produzenten eine Vorfinanzierung gewähren, sodass Investitionen für Entwicklungsmaßnahmen getätigt werden können.

Produzenten und Händler müssen die in den Fairtrade-Standards festgelegten Bedingungen erfüllen, um in das Fairtrade-System aufgenommen zu werden. Des Weiteren sind in den Standards auch Entwicklungsbedingungen festgeschrieben, die innerhalb festgelegter Zeiträume erreicht werden müssen.

\subsection{Zertifizierung}

Im Fairtrade-System dient ein umfassendes Zertifizierungssystem der Sicherstellung, dass die Produkte, die das Fairtrade-Siegel tragen, auch tatsächlich unter Produktionsbedingungen hergestellt wurden, welche die internationalen Fairtrade-Standards erfüllen. Hierzu werden alle beteiligten Produzenten und Händler regelmäßig von unabhängigen Zertifizierungsstellen überprüft. Die internationale Zertifizierungsstelle FLO-CERT GmbH ist dabei für die Zertifizierung und Inspektion der Produzenten, weiterverarbeitenden Unternehmen und Importeure zuständig. In Deutschland werden auch Lizenznehmer, die Produkte mit Fairtrade-Siegel unter ihrem Namen vertreiben, von FLO-CERT zertifiziert und kontrolliert.

\subsection{Producer Business Support}

Neben der Entwicklung der Fairtrade-Standards ist die internationale Koordinierungsstelle FLO e.V. für die Unterstützung der Produzenten verantwortlich. Dabei geht es unter anderem um die Assistenz bei der Erfüllung der

17 Neben der Förderung biologischer Anbauweisen sieht Fairtrade zudem vor, dass Produzenten die Auswirkungen ihrer Produktionstätigkeit auf die Umwelt überwachen und Pläne zur Reduktion der Umweltbeeinträchtigung entwickeln und umsetzen müssen. $\mathrm{Zu}$ den wichtigsten Bedingungen für den Umweltschutz zählen das Verbot des Anbaus in Naturschutzgebieten, die Reduktion des Einsatzes von Chemikalien, der Schutz der Bodenfruchtbarkeit und des Wassers, die Vermeidung umweltschädlicher Produktionsweisen und das Verbot genetisch modifizierter Organismen. 
Fairtrade-Bedingungen, die Unterstützung in ihrer Produktions- und Handelstätigkeit und die Bereitstellung von Informationen über Absatzmärkte sowie von Marketingkenntnissen. Daneben stellt die Produzentenunterstützung das Bindeglied zwischen Nachfrage und Angebot von Fairtrade-Produkten dar und ist für den Aufbau von direkten Handelsketten sowie für Qualitätssicherung und Produktentwicklung zuständig.

\subsection{Marketing, Öffentlichkeitsarbeit und Lizenzvergabe}

Die Siegelinitiativen sind in den Absatzmärkten der Industrieländer vor allem für die Vergabe des Siegels an Hersteller, die Fairtrade-Produkte unter ihrem Namen vertreiben, zuständig. Derzeit gibt es 20 Siegelinitiativen in 21 vorwiegend europäischen Ländern. Über die Lizenzgebühren werden die Aufgaben der Siegelinitiativen finanziert wie auch die Leistungen der Koordinierungsstelle FLO e.V., also vor allem die Entwicklung der internationalen FairtradeStandards und die Produzentenunterstützung, mitgetragen.

$\mathrm{Zu}$ den Aufgaben der nationalen Siegelinitiativen gehören neben der Vergabe des Fairtrade-Siegels vor allem Aktivitäten in den Bereichen Marketing und Öffentlichkeitsarbeit mit dem Ziel, die Bekanntheit und den Absatz von Fairtrade-Produkten zu steigern. Unter anderem geht es dabei um die Erschließung neuer Vertriebswege, die Erweiterung des Fairtrade-Produktsortiments, Pressearbeit und die Organisation öffentlichkeitswirksamer Aktionen wie der Fairen Woche, die einmal pro Jahr stattfindet und bei der Weltläden, Aktionsgruppen, Supermärkte, Kantinen und Einzelpersonen unterschiedliche Veranstaltungen zum Thema Fairtrade durchführen.

\subsection{Politische Lobbyarbeit}

Über das Fairtrade Advocacy Office im Rahmen des Zusammenschlusses mit anderen Organisationen des fairen Handels setzt sich Fairtrade auf internationaler und europäischer Ebene für eine gerechtere Handelspolitik ein, die konkret eine Berücksichtigung der benachteiligten Position von Produzenten in Entwicklungsländern, den Abbau tarifärer und nicht-tarifärer Handelshemmnisse und Entwicklungsmaßnahmen für Handelspartner in Entwicklungsländern vorsieht. ${ }^{18}$ In den konkreten Forderungen an die europäische Politik strebt Fairtrade aufgrund des Risikos einer Überregulierung nicht die Einführung

18 Vgl. Fair Trade Advocacy Office: „Fighting Poverty and Injustice through Fair Trade"; dass.: Fair Trade Rules! 
gesetzlicher Vorschriften im Sinne der Fairtrade-Standards an, sondern fordert eine Empfehlung der Europäischen Union zum fairen Handel, die unter anderem die Anerkennung der Definition und Grundsätze des fairen Handels und deren Förderung umfasst. ${ }^{19}$

\subsection{Struktur}

Die folgende Darstellung zeigt zusammenfassend in vereinfachter Form die zentralen Akteure und deren Aufgaben im Fairtrade-System (vgl. Abbildung 1):

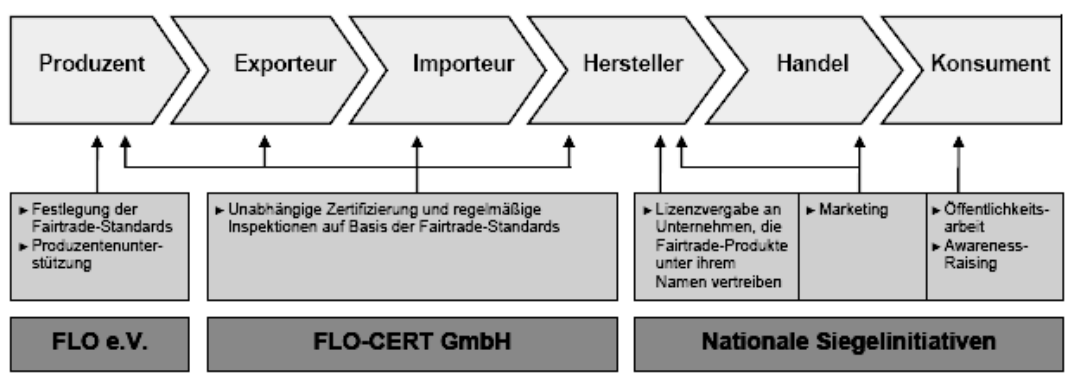

Abb. 1: Zentrale Akteure und deren Aufgaben im Fairtrade-System. ${ }^{20}$

\section{$3 \quad$ Kritik an Fairtrade}

Im Zuge des Erfolgs fair gehandelter Produkte, besonders der gesiegelten Produkte des fairen Handels, hat in den vergangenen Jahren im Rahmen einer steigenden Medienberichterstattung über Fairtrade auch die Zahl kritischer Beiträge zugenommen. In diesem Kontext können vier prominente Argumentationsebenen unterschiedlicher Provenienz herausgestellt werden, die sowohl den fairen Handel allgemein als auch das Konzept von Fairtrade gezielt kritisieren.

Kritiker des fairen Handels an sich bedienen sich in ihrer Argumentation zum einen der ökonomischen Theorie.21 Festgelegte Mindestpreise werden in diesem Zusammenhang als Subventionen begriffen, die den Preismechanismus von Angebot und Nachfrage stören und möglicherweise sogar eine Überpro-

19 Vgl. dass.: „Fighting Poverty and Injustice through Fair Trade.“

20 Eigene Darstellung.

21 Vgl. The Economist: „Voting with your Trolley“, S. 72; Nicholls/Opal: Fair Trade, S. 13. 
duktion vorantreiben. Niedrige Marktpreise, so unangemessen sie auch sein mögen, sind den Kritikern zufolge Ausdruck einer Überproduktion und können nur durch eine Reduktion des Angebots oder eine Steigerung der Nachfrage erhöht werden. Trotz geringer Nachfrage einen wesentlich höheren Mindestpreis zu zahlen, führt dieser Argumentation zufolge lediglich zu einer Stabilisierung des Angebots und kann womöglich sogar eine Steigerung der Produktion nach sich ziehen und die Überproduktion damit verschärfen. Dies könnte einen weiteren Verfall des Marktpreises bewirken und damit das Einkommen von Produzenten, die ihre Produkte zu Marktpreisen verkaufen, weiter senken. Dieser Argumentationslinie liegt das oben erwähnte Problem des Weltmarktes zu Grunde, wonach Produzenten in Entwicklungsländern nicht in der Lage sind, ohne weiteres auf Marktentwicklungen zu reagieren. Lösungsansatz kann den Kritikern zufolge nur eine Diversifikation der Produktion sein, flankiert von politischen Reformen im Sinne eines Abbaus tarifärer Handelshemmnisse der Industrieländer.

Ein zweites prominentes Argument kritisiert die mangelnde Effektivität des fairen Handels insgesamt. Umfassende Veränderungen im Sinne der strategischen Zielsetzungen des fairen Handels können dieser Sichtweise zufolge nur auf der Ebene der institutionalisierten Politik erreicht werden. ${ }^{22}$ Der faire Handel wird dabei nicht nur aufgrund seines relativ geringen Anteils am gesamten Welthandel als weitgehend wirkungslos eingestuft, sondern stellt dieser Sichtweise zufolge sogar eine Behinderung wirkungsvoller und umfassender politischer Veränderungsprozesse dar. Indem die Organisationen des fairen Handels, beteiligte Handelsunternehmen und Medien die Wirksamkeit des fairen Handels in der Öffentlichkeit maßlos hochstilisierten, mache sich der faire Handel zum „Komplizen der multinationalen Unternehmen“ und diene der „Verschleierung der wahren Probleme“ ${ }^{23}$ Dadurch nehme der Handlungsdruck seitens öffentlicher Akteure auf die internationale Politik ab und das politische Engagement der Bürger werde auf Konsumverhalten reduziert. Damit würden letztendlich infolge dieser Verschleierung wirkungsvolle politische Veränderungen verhindert.

Neben einer allgemeinen Kritik am fairen Handel richtet sich gezielte Kritik am Fairtrade-Konzept zum einen auf strukturelle und funktionale Aspekte wie die Unabhängigkeit, Transparenz und Effizienz des Zertifizierungs- und Kontrollsystems zur Einhaltung der Fairtrade-Standards sowie die Prozesse der Standardentwicklung. Zum anderen lässt sich vor dem Hintergrund der oben beschriebenen Differenzierung der gesamten Bewegung insbesondere

22 Vgl. The Economist: „Voting with your Trolley“: S. 73; Boris: Un(Fair) Trade, S. 213.

23 Ebd. 
Kritik aus dem Lager der Puristen beobachten. Im Jahr 2006 geriet diese Kritik vor allem mit der Veröffentlichung des Buches Les Coulisses du Commerce Équitable des französischen Globalisierungskritikers Christian Jacquiau in die Schlagzeilen. Ausgehend von der Annahme, dass das Konzept des fairen Handels die gesamte Handelskette abdecken müsse, wird Fairtrade vor allem wegen der Kooperation mit multinationalen Unternehmen oder auch Discountern wie LIDL als Mainstreamsystem kritisiert. Diese Zusammenarbeit diene ausschließlich kommerziellen (Eigen-)Interessen und führe zur Vernachlässigung der Bedürfnisse der Produzenten in Entwicklungsländern.

\section{Fairtrade als subpolitischer Akteur: Herausforderungen und Strategien}

Wie eingangs erwähnt, kann Fairtrade als Beitrag zur Gesellschaftsgestaltung außerhalb der offiziellen, institutionalisierten Politik betrachtet werden und steht damit exemplarisch für das Konzept der Subpolitik Ulrich Becks, das aufgrund seiner Weite und Unbestimmtheit allerdings mit Blick auf seine Erscheinungsformen weiter differenziert werden muss. Neben der Betrachtung der zentralen Zielsetzungen, Inhalte und Strukturen von Fairtrade als Subpolitik ist in diesem Zusammenhang zu fragen, welche Herausforderungen sich subpolitischen Akteuren in der Gesellschaftsgestaltung außerhalb des etablierten politischen Institutionengefüges stellen und mit einer gesellschaftlichen Selbstorganisation des Politischen einhergehen. Die Erläuterung der unterschiedlichen Ausprägungen des fairen Handels und der Kritik daran hat bereits einige Herausforderungen von Fairtrade als subpolitischem Akteur deutlich gemacht - der Blick in die Praxis lässt zudem Strategien erkennen, um diesen Herausforderungen gerecht zu werden.

\subsection{Politische Zielsetzungen, ökonomische Rahmenbedingungen und die Rolle der Medien}

Eine zentrale strukturelle Herausforderung ergibt sich für Fairtrade aus der Schnittfläche des Politischen und Ökonomischen. Die Verwirklichung der politischen Zielsetzungen und Versprechen von Fairtrade erfolgt demnach unter den ökonomischen Rahmenbedingungen einer wettbewerbsorientierten Marktwirtschaft. Statt mehrjähriger Legislaturperioden wie im Bereich der formalen Politik gilt für die Subpolitik des politisierten Konsums „der Stimmzettel 
überall und immer“24, wie Beck es ausdrückt, - jeder Tag wird damit zum Wahltag, jeden Tag überträgt der Bürger bzw. Konsument sein Vertrauen auf Fairtrade - oder eben nicht. Vor allem mit Blick auf die zunehmende Konkurrenz im näheren Umfeld von Fairtrade durch Akteure wie Rainforest Alliance, Utz. Kapeh oder auch $4 C$ haben sich die ökonomischen Rahmenbedingungen in den vergangenen Jahren deutlich verschärft. In diesem Zusammenhang kommt den Medien in ihrer Funktion als Watchdog, im Sinne eines kritischen Beobachters gesellschaftlicher und politischer Prozesse, eine wichtige Rolle zu: Aufgrund seiner politischen Zielsetzungen und Versprechen wird Fairtrade von den Medien als politischer Akteur wahrgenommen und mit denselben Maßstäben wie die Akteure des formalen politischen Systems gemessen. Jedoch sind die Akteure der institutionalisierten Politik im Vergleich zu marktabhängigen subpolitischen Akteuren wie Fairtrade mit Blick auf die Medien autonomer und weniger verwundbar. Die Akteure des etablierten politischen Systems genießen eine staatliche Risikoabsicherung (Diäten und Parteienfinanzierung) und sind nur in Wahlkampfzeiten, d.h. in der Regel alle vier bis fünf Jahre, für einige Wochen existenziell vom Medieneinfluss abhängig. Subpolitische Akteure wie Fairtrade sind demgegenüber aufgrund der harten Wettbewerbssituation im Marktsegment fair gehandelter Produkte von den tagtäglichen Kauf- bzw. Wahlentscheidungen für Fairtrade abhängig und unterliegen deshalb dem Wirkungspotenzial der Medien unmittelbarer und kontinuierlicher. Die Wahrnehmung der Watchdog-Funktion durch die Medien scheint dabei eng an den Erfolg subpolitischer Akteure wie Fairtrade gekoppelt zu sein, wie die steigende Medienberichterstattung über Fairtrade in den vergangenen Jahren nahe legt. Der Erfolg von Fairtrade und dessen Heraustreten aus dem Nischendasein kann somit als weitere Verschärfung des Spannungsfeldes aus politischen Zielsetzungen, ökonomischen Rahmenbedingungen und dem Wirkungspotenzial der Medien begriffen werden.

\subsection{Governancestrukturen}

Der Konnex des Politischen und Ökonomischen drückt sich innerhalb des Fairtrade-Systems durch einen Interessen- und Zielkonflikt unterschiedlicher Akteure aus. Als entwicklungspolitisches Instrument stehen die Bedürfnisse der Produzentenorganisationen und Lohnarbeiter in Entwicklungsländern im Mittelpunkt, zugleich müssen aber auch die Interessen der Hersteller und Handelsunternehmen in den Industrienationen berücksichtigt werden, da beide Aspekte für den Erfolg und die Zielerreichung von Fairtrade essenziell sind.

24 Beck: Was ist Globalisierung? S. 124. 
Dieser Herausforderung unterschiedlicher, oft entgegenstehender Interessen wird Fairtrade durch Governancestrukturen im Sinne eines MultistakeholderAnsatzes gerecht, die sich in den vergangenen Jahren herausgebildet haben. Zentrale Entscheidungsprozesse und -gremien im Fairtrade-System berücksichtigen das Mitspracherecht von Vertretern der unterschiedlichen Interessengruppen, um den beschriebenen trade-off erfolgreich gestalten zu können. Strategische Entscheidungen und zentrale Prozesse wie die Entwicklung der Fairtrade-Standards werden sowohl von Produzenten wie auch von Händlern (alternative Handelsorganisationen und kommerzielle Unternehmen) beeinflusst. Die folgende Darstellung veranschaulicht die MultistakeholderGovernancestrukturen im Fairtrade-System (vgl. Abbildung 2):

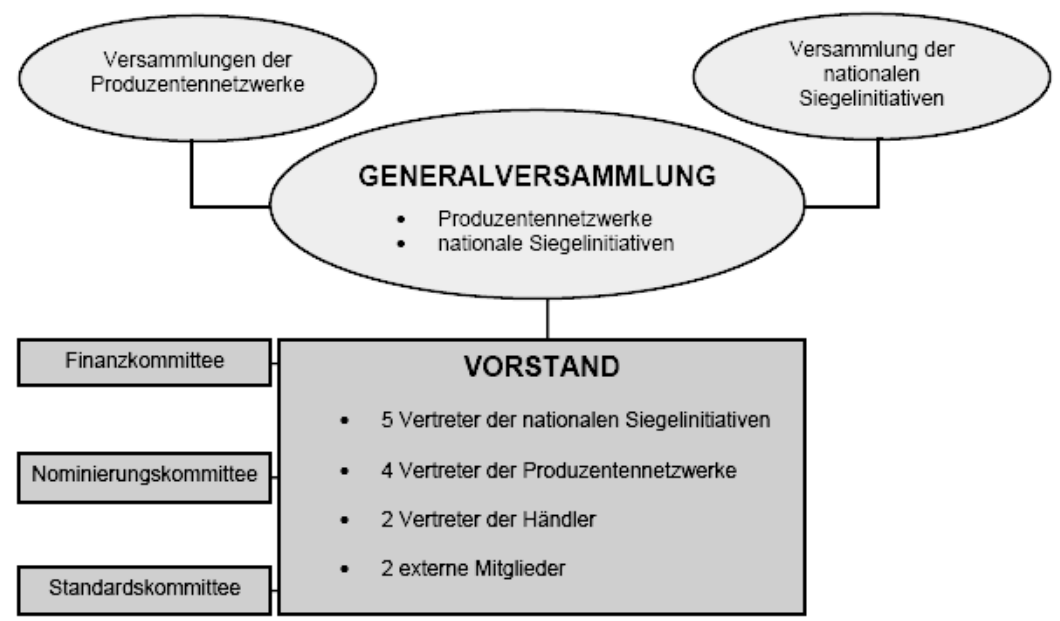

Abb. 2: Governancestrukturen von FLO e.V..$^{25}$

\subsection{Institutionelle und inhaltliche Rahmenbedingungen}

Mit Blick auf das politisch-ökonomische Spannungsfeld und das Wirkungspotenzial der Medien geht die Verwirklichung der politischen Zielsetzungen und Versprechen für Fairtrade als Akteur außerhalb der traditionellen Politik vor allem mit zwei Herausforderungen einher, die auch in der Kritik am Fairtrade-System deutlich wurden: Auf der institutionellen Ebene stellt sich die Herausforderung, einen strukturellen Rahmen zu schaffen, der Transparenz, Unabhängigkeit und Effizienz gewährleistet; auf inhaltlicher Ebene lautet die

25 Quelle: Fairtrade Labelling Organizations International e.V.: Annual Report 2006. 
Herausforderung, jederzeit die Effektivität und Wirkung von Fairtrade nachweisen zu können. In Zusammenhang mit diesem zugespitzten und dauerhaften Leistungsdruck verkörpert die Wirkungsbeobachtung und -evaluation ein entscheidendes Instrument für Fairtrade. Für viele subpolitische Akteure wie z.B. Nichtregierungsorganisationen hat die Wirkungsbeobachtung und -evaluation in den vergangenen Jahren einen enormen Bedeutungszuwachs erfahren, in dessen Zusammenhang zahlreiche Kooperationsformen zur Entwicklung adäquater Monitoring- und Evaluationssysteme zu sehen sind. ${ }^{26}$ Eine Reihe dieser auf unterschiedlichen Ebenen organisierten Zusammenschlüsse sind dabei für Fairtrade von Bedeutung: So sind auf der Ebene mit anderen entwicklungspolitischen Nichtregierungsorganisationen bzw. subpolitischen Akteuren allgemein beispielsweise die Aktivitäten des Verbandes Entwicklungspolitik deutscher Nichtregierungsorganisationen e.V. (VENRO) zu nennen. Im Rahmen der International Social and Environmental Accreditation and Labelling Alliance (ISEAL-Alliance) erfolgt daneben die spezifischere Kooperation mit anderen Sozialzertifizierern und Siegelinitiativen. Auf der Ebene der Zusammenarbeit mit anderen Organisationen des fairen Handels ist schließlich das Forum Fairer Handel von Bedeutung. ${ }^{27}$

Die Herausforderung, einen angemessenen institutionellen Rahmen zu schaffen, ist für Fairtrade gerade mit Blick auf die Verknüpfung entwicklungspolitischer und kommerzieller Interessen von besonderer Bedeutung. Die Struktur des Fairtrade-Systems trägt diesen Anforderungen allerdings durch eine strikte Trennung unterschiedlicher Interessen Rechnung: Die Entwicklung der Fairtrade-Standards und die Zertifizierung von Unternehmen auf Basis dieser Standards werden von getrennten Akteuren ausgeführt. Als strategisches Instrument zur Stärkung der Unabhängigkeit, Transparenz und Effektivität kann in diesem Zusammenhang zudem die Zertifizierung durch unabhängige und anerkannte Qualitätsmanagement-Systeme wie die International Standards Organisation (ISO) betrachtet werden. FLO-CERT hat bereits die Akkreditierungsphase des internationalen ISO Standards 65 für Produktzertifizierungsstellen durchlaufen.

\subsection{Verhältnis zur institutionalisierten Politik}

Wie die Betrachtung unterschiedlicher Ausprägungen des fairen Handels und die Aufführung zentraler Kritikpunkte bereits gezeigt haben, ist für Fairtrade

26 Vgl. Davies: „Monitoring and Evaluating NGO Achievements“, S. 523.

27 Vgl. hierzu Forum Fairer Handel: Monitoring- und Zertifizierungssysteme im Fairen Handel. 
das Verhältnis zur offiziellen, institutionalisierten Politik von zentraler Bedeutung. Die Ambivalenz dieses Verhältnisses und des damit zusammenhängenden funktionalen Selbstverständnisses von Fairtrade beinhaltet hierbei eine besondere Herausforderung.

Diese Ambivalenz zeigt sich vor allem in der Gleichzeitigkeit von Konkurrenz und Kooperation: Geht man einerseits davon aus, dass das politische Engagement der Bürger bzw. Konsumenten begrenzt ist, stehen sich Akteure der etablierten Politik und der subpolitische Akteur Fairtrade als Konkurrenten um die knappe Ressource politische Beteiligungsbereitschaft gegenüber. Geht man andererseits davon aus, dass subpolitische Akteure neben gesellschaftlicher Selbstregulierung auch politische Interventionen fordern und auf politische Entscheidungen Einfluss nehmen wollen, zeigt sich ein kooperatives Verhältnis zwischen beiden Akteurstypen. So versteht sich auch Fairtrade als Wegbereiter oder Vorbild für die formale Politik und bemüht sich um eine Einflussnahme auf politische Entscheider. Gesetzliche Regelungen im Sinne der Fairtrade-Standards wären in diesem Zusammenhang auf der einen Seite als eine Art Idealzustand mit Blick auf die Zielsetzung eines gerechteren Welthandels zu verstehen. Auf der anderen Seite würde eine Umsetzung der Fairtrade-Standards in Form gesetzlicher Regelungen allerdings für Fairtrade den Verlust der Gestaltungsmöglichkeiten und inhaltlichen Einflussnahme auf die Weiterentwicklung konkreter Regelungen und Bedingungen für einen gerechten Welthandel bedeuten. Nicht zuletzt aufgrund dieses potenziellen Interessenkonflikts ist die Positionierung zur und das Selbstverständnis gegenüber der institutionalisierten Politik für Fairtrade eine Herausforderung. Angesichts eines begrenzten politischen Engagements des Bürgers bzw. Konsumenten und des Vorwurfs der Behinderung politischer Veränderungsprozesse durch Fairtrade ist eine Positionierung jedoch unumgänglich. Als Strategie, um dieser Herausforderung gerecht zu werden, setzt sich Fairtrade nicht in erster Linie für umfassende gesetzliche Regelungen auf der Ebene der institutionalisierten Politik ein, sondern fordert eine Anerkennung und Förderung seiner Grundsätze durch die politischen Akteure.

\section{$5 \quad$ Fazit}

Zusammenfassend kann festgehalten werden, dass Fairtrade als subpolitisches Konzept im Teilbereich des politischen Konsums komplexe und vielschichtige Ziel-, Strategie- und Strukturebenen aufweist, durch die sich ein roter Faden von Differenzen und Kongruenzen, Eigeninteressen und übergeordneten Interessen sowie Kooperations- und Konkurrenzverhältnissen zieht - sowohl innerhalb des Fairtrade-Systems als auch gegenüber anderen Akteuren der Sub- 
politik sowie gegenüber der institutionalisierten Politik. Dabei sind unterschiedliche Kooperationsformen auf der Ebene des fairen Handels, im Bereich der Subpolitik sowie im Sinne eines komplementären Selbstverständnisses zur offiziellen, formalen, institutionalisierten Politik ebenso wie Konkurrenzverhältnisse zu Akteuren der Politik und Subpolitik um die Gunst des Konsumenten bzw. des (begrenzten) politischen Engagements des Bürgers deutlich geworden.

Die Darstellung der Strukturen und Funktionsweisen zeigt zudem, dass Fairtrade im Vergleich mit anderen Formen der Subpolitik bzw. des politischen Konsums, wie zum Beispiel Boykott-Aktionen, einen hohen Grad der Institutionalisierung aufweist und dadurch wiederum in einer gewissen strukturellen Nähe zur offiziellen Politik steht. Das „Außerhalb“ der formalen Politik als Kennzeichen der Subpolitik muss demnach weiter differenziert werden. In diesem Zusammenhang erscheint auch die Verbindung dieser Differenzierung mit der Unterscheidung zwischen aktiven, bewussten Formen der Subpolitik und unbewussten, zufälligen Formen interessant. ${ }^{28}$ Die weiteren Betrachtungen haben darüber hinaus gezeigt, dass viele Herausforderungen für Fairtrade als subpolitischer Akteur direkt oder indirekt mit dem vergleichsweise hohen Grad der Institutionalisierung zusammenzuhängen scheinen. Mit Blick auf das politische Engagement des Bürgers bzw. des Konsumenten stellt sich dabei die Frage, wie sich die Institutionalisierung (und die damit verbundenen Herausforderungen auch vor dem Hintergrund der Bedeutung der Medien) auf die Konkurrenz um dieses Engagement sowohl mit anderen Akteuren der Subpolitik als auch mit der offiziellen, formalen Politik auswirkt.

\section{Literaturverzeichnis}

Beck, Ulrich: Was ist Globalisierung? Frankfurt 1997.

Beck, Ulrich: Die Erfindung des Politischen, Frankfurt 1993.

Beck, Ulrich: Risikogesellschaft. Auf dem Weg in eine andere Moderne, Frankfurt 1986.

Boris, Jean-Pierre: (Un)Fair Trade, München 2006.

Davies, Rick: „Monitoring and Evaluating NGO Achievements“, in: Desai, Vandana/Potter, Robert (Hrsg.): The Companion to Development Studies, London 2002, S. 523-527.

Fair Trade Advocacy Office: Fair Trade in Europe, Brüssel 2005.

28 Vgl. Holzer/Sørensen: Rethinking Subpolitics, S. 82. 
Fair Trade Advocacy Office: „Fair Trade Rules!“, www.fairtradeadvocacy.org/documents/position_papers/WTO\%202005/Fair\%20Trad e\%20Rules!\%20WTO\%20OCT\%202005/Fair\%20Trade\%20Rules!_EN.p df, 03.05.2007.

Fair Trade Advocacy Office: „Fighting Poverty and Injustice through Fair Trade“, www.fairtrade-advocacy.org/documents/Fightingpovertyandin justicethroughFair'TradeDec06.pdf, 03.05.2007.

Fair Trade: „The Story“ (USA 2006, Regie: Ian Jay/Aaron Straight), eq.tv/fair_trade_the_story, 03.05.2007.

Fairtrade Labelling Organizations International e.V.: Annual Report 2006, Bonn 2007.

Forum Fairer Handel: Monitoring- und Zertifizierungssysteme im Fairen Handel, Mainz 2004.

Forum Fairer Handel: Herausforderungen des Fairen Handels durch neue Akteure wie Transnationale Unternehmen und Discounter, Mainz 2006.

Holzer, Boris/Sørensen, Mads: „Rethinking Subpolitics: Beyond the ,Iron Cage' of Modern Politics?", in: Theory, Culture \& Society, Jg. 20, Nr. 2, 2003, S. 79-102.

Kleinert, Uwe: „Inlandswirkungen des Fairen Handels“, in: Misereor/Brot für die Welt/Friedrich-Ebert-Stiftung (Hrsg.): Entwicklungspolitische Wirkungen des Fairen Handels, Aachen 2000, S. 19-110.

Nicholls, Alex/Opal, Charlotte: Fair Trade, London 2005.

The Economist: „Voting with your trolley“, in: The Economist, 9.12.2006, S. 71-73.

TransFair e.V.: Jahresbericht 2006, Köln 2007.

Université du Québec à Montréal: „Fair Trade and the Solidarity Economy: the Challenges Ahead,“ www.european-fair-trade-association.org/ FairProcura/Doc/Brochures/Fair_Trade_Workshop_Activity_Overview. pdf, 03.05.2007. 


\section{Thomas Löding/Kay O. Schulze/Jutta Sundermann}

\section{Geheimwaffe CSR - wozu braucht's noch Kampagnen?}

Lange Zeit fand die Auseinandersetzung mit den problematischen Seiten des Handelns von Konzernen einerseits durch Umwelt-, Entwicklungs- und Menschenrechtsorganisationen statt, die sehr spezifische Konflikte aufgriffen und dort ein Einlenken forderten. Um Siemens das Atomgeschäft zu verleiden, Nestlé von seiner gefährlichen Werbung für Baby-Ersatznahrung abzubringen oder Unilever zur tierfreundlicheren Putenzucht zu zwingen, arbeiteten gut informierte Kampagnengruppen an Boykotten oder Appellen und gewannen zahlreiche UnterstützerInnen.

Andererseits formulierte die globalisierungskritische Bewegung Kritik am Macht-Streben der Konzerne. Die Praxis der Großunternehmen selbst und ihr beträchtlicher Einfluss auf die Politik werden z.B. im Zusammenhang mit den Welthandelsrunden der WTO, den G8-Gipfeltreffen oder immer wieder auch am Rande von Aktionärsversammlungen einzelner Konzerne thematisiert. Meist bleiben die Vorwürfe aber allgemein und gelten zugleich für Dutzende von transnational agierenden Unternehmen.

Inzwischen gibt es immer häufiger Mischformen, z.B. wurde in der LidlKampagne von Attac ${ }^{1}$ versucht, klassische konzernkritische Kampagnen und globalisierungskritische Ansätzen zu verbinden. So unterstützte die Lidl-Kampagne die Forderung der Gewerkschaft ver.di, Betriebsratswahlen in den LidlFilialen zuzulassen. Sie stellte aber selbst den Billig-Trend in den Mittelpunkt und forderte: Stopp Preis-, Umwelt- und Sozialdumping! Damit eröffnete sie mit den bekannten Kampagnen-Mitteln eine Diskussion, die über die gewohnten Kampagnen-Zuspitzungen hinausging. Einerseits war der Discounter der richtige Adressat, denn Attac konnte ihm eine bedeutende Trendsetterrolle nachweisen. Andererseits traf die Kritik mitten in eine gesellschaftliche Entwicklung, die nicht die Discounter allein betreiben oder zu verantworten haben und die weitergehende Fragen eröffnet.

Im Rahmen ihrer Vorarbeiten setzte sich die Kampagnengruppe auch mit der Rolle von kleineren und größeren Unternehmen in der Weltwirtschaft auseinander sowie mit den verschiedenen Ansätzen, mit denen Konzerne dazu gebracht werden könnten, verantwortungsvoller mit Gesellschaft und Umwelt umzugehen.

1 Mit der Lidl-Kampagne beschäftigen sich auch die Artikel von Baringhorst/ Kneip/Niesyto und März in diesem Band. 


\section{Unheimliche Eminenzen - Konzerne als Global Player}

Konzerne sind die heimlichen Herrscher der heutigen Welt. Wir finden sie nicht nur an den Börsen, auf den Märkten oder in den Gewerbegebieten. Sie begegnen uns beim täglichen Einkauf, in Nachrichtensendungen und Talkshows (von der allgegenwärtigen Werbung ganz zu schweigen) und in vielen anderen Formen im öffentlichen Leben. Keine Regierung vermag sich mehr dem tatsächlichen oder vermeintlichen Druck wirtschaftlicher Interessen zu entziehen. Unternehmen wie Mercedes oder Canon sponsern den G8-Gipfel; Scharen von Lobbyist- und AnwältInnen klüngeln sich durch die Parlamente und Hinterzimmer; Think-Tanks diktieren Gesetzesvorhaben und nutzen die Macht der Medien zur Manipulation der herrschenden Meinung: Zu besten Sendezeiten verurteilen sie Regulierungsversuche und drohen mit Stellenabbau und Standortwechsel.

Konzerne gehorchen in erster Linie den Gesetzen des Marktes: Sie streben nach Profit bzw. höchstmöglicher Rendite für ihre Aktionäre. Allzu oft geht dies auf Kosten angemessener Löhne, zu Lasten von Arbeitsschutz und Arbeitsrechten, verhindert es den nachhaltigen Umgang mit Ressourcen. Dies ist die Kehrseite einer Wirtschaftsweise, in der Unternehmen unreguliert und weltweit miteinander um Märkte und Ressourcen konkurrieren.

Der konzernorientierten Globalisierung begegnen wir unter anderem im Einkaufswagen: Aus aller Welt stammen die Waren, die wir für wenig Geld in den Wagen legen können. Die Kehrseite der Billig-Welle zu erkennen, erfordert einen etwas schärferen Blick. Beim Discounter Lidl werden die Beschäftigten bis zur Schmerzgrenze gehetzt, es soll immer noch mehr Umsatz pro MitarbeiterIn möglich sein. Nahezu jedes einzelne Produkt kommt erst nach härtesten Verhandlungen des Discounters mit den Erzeugern ins Regal. Das führt zu katastrophalen, schonungslosen Arbeitsbedingungen rund um den Globus und zwingt viele kleinere Erzeuger zum Konkurs, so z.B. zahlreiche Milchbauern, die beim Verkauf an Aldi, Lidl und Co. für jeden Liter draufzahlen müssen.

Dem entgegen zu steuern scheint als Aufgabe kaum zu bewältigen. Die international agierenden Unternehmen profitieren seit Jahren vom Dogma Neoliberalismus, in dem die Wirtschaftswelt als unabhängiger Sektor mit eigenen Regeln gilt und Profitstreben als vorrangiges Ziel legitim ist. Die Konzerne haben sich sehr weit aus ihren nationalen Verbindlichkeiten befreit und streben danach, zu transnationalen Egoisten heranzuwachsen. Kein Wunder, dass sich zunehmend ein Netzwerk aus sozialen Bewegungen weltweit bildet, die diesen Prozess mit Sorge betrachten und versuchen, eine andere Politik durchzusetzen. Der Ansatz, Konzerne wieder stärker politisch zu regulieren, gewinnt an Popularität - und zwingt Unternehmen zum Handeln. 


\section{Corporate Social Responsibility als Flucht nach vorne}

Die Idee, Konzerne mittels weltweit gültiger Regeln und Auflagen zu kontrollieren, ist keineswegs neu. Schon in den 1970er Jahren gab es im Rahmen der UNO Bestrebungen, einen gerechten und entwicklungsfreundlichen Welthandel zu schaffen. 1974 verabschiedete die UNO-Vollversammlung eine Charta über die wirtschaftlichen Rechte und Pflichten der Staaten, die den nationalen Regierungen eine starke Position gegenüber den Investoreninteressen einräumte. Bereits zuvor gab es eine eigene UNO-Kommission für Konzerne (UN Centre on Transnational Corporations), die einen Verhaltenskodex für transnationale Konzerne (Draft Code of Conduct on Transnational Corporations) ausarbeitete. Dieser forderte die Einhaltung der Menschenrechte sowie die Achtung des Umweltschutzes, der Arbeits- und KonsumentInnenrechte, der soziokulturellen Werte des Gastlandes etc.

Keine dieser Initiativen hat jedoch zu einer rechtsverbindlichen Norm geführt. Im Gegenteil wurden mit dem Siegeszug der neoliberalen Weltwirtschaftspolitik durch Reagan und Thatcher Strategien durchgesetzt und Fakten geschaffen, durch die sich die Politik der Wirtschaft zunehmend unterordnete. Regulierungen werden in erster Linie im Sinne grenzenloser Investitionsfreiheit geschaffen: Sei es durch Abbau von Zollschranken samt zugehöriger Sanktionsmechanismen innerhalb der WTO oder durch entwicklungspolitische Kredite vom IWF, die daran geknüpft sind, Sozialleistungen zu kürzen und Staatsunternehmen zu privatisieren. Forderungen nach einer verstärkten Regulierung des Welthandels scheinen in diesem Klima vergeblich zu sein.

Gerade der neoliberale Vordenker Milton Friedman sprach sich gegen eine wie auch immer geartete Verantwortung von Unternehmen aus. Seinem Verständnis nach sind die Unternehmen ausschließlich für die Maximierung ihres Gewinns bzw. des Shareholder Values verantwortlich. Manager stehen in einem Vertragsverhältnis mit den Aktionären, welches sie dazu verpflichtet, die Gewinne der Aktionäre zu erhöhen. Jeder Dollar, der von Managern für andere Zwecke wie Umweltschutz oder Wohltätigkeiten eingesetzt werde, sei ein unverantwortlicher Umgang mit dem ihnen anvertrauten Eigentum anderer. Der Manager sei den Interessen der Aktionäre verpflichtet und sonst niemandem. ${ }^{2}$

Doch die neoliberale Globalisierung befindet sich in der Krise. Nicht nur die globalisierungskritische Bewegung ist den EntscheiderInnen ein Dorn im

2 Vgl. z.B. Friedman: „The Social Responsibility of Business is to Increase its Profits“. Seine Aussage „Put Profits First“ wiederholt Friedman in einer aktuellen Debatte zur sozialen Verantwortung von Unternehmen. Vgl. ders. u.a.: „Rethinking the Social Responsibility of Business". 
Auge. Die Verhandlungen der Industriestaaten scheitern an ihren Interessengegensätzen. Entwicklungs- und Schwellenländer folgen nicht mehr blind dem Diktat der vermeintlich wohlmeinenden Wirtschaftsmächte. Die Folgen dieser Form der Globalisierung sind inzwischen einer weltweiten Öffentlichkeit wohlbekannt und es regt sich Widerstand. Letzteres ist nicht nur für die Regierungschefs ein Problem, die sich in ihren G8-Runden und anderen Gesprächszirkeln mittels Symbolmaßnahmen darum bemühen, wieder mehr Akzeptanz für ihre Politik zu erringen. Auch die Konzerne selbst, angeschlagen von kritischen Kampagnen und Bestsellern wie No Logo, bemühen sich zunehmend um imagerettende Maßnahmen.

In der Fachwelt wird ein Großteil dieser Maßnahmen unter dem Stichwort Corporate Social Responsibility (CSR) zusammengefasst. Die EU definiert CSR dabei als „ein Konzept, das den Unternehmen als Grundlage dient, auf freiwilliger Basis soziale Belange und Umweltbelange in ihre Unternehmenstätigkeit und in die Wechselbeziehungen mit den Stakeholdern zu integrieren“3. Das Konzept boomt und wird seitens der Politik und der Wirtschaftsberatungsinstitute kräftig gefördert. Große Unternehmen wiederum schmücken sich gerne mit einem CSR-Engagement - freilich nicht nur aus reiner Menschenfreundlichkeit, sondern auch mit strategischen Hintergedanken.

CSR gilt als bedeutender Wirtschaftsfaktor, der die Wettbewerbsfähigkeit, Kunden- und Arbeitnehmerbindung sowie die Risikofestigkeit von Unternehmen erhöhe - nachzulesen beispielsweise auf der Homepage des von der EU ins Leben gerufenen Netzwerks CSR Europe ${ }^{4}$. In seiner Lohas-Studie 2007 empfiehlt das Zukunftsinstitut (ein Think-Tank für Trendforschung) die Etablierung von CSR als ,interaktives Kooperationsinstrument“ (zwischen Wirtschaft und Öffentlichkeit): Im aufkommenden „hypermoralischen Zeitalter“ würden verschiedene Megatrends konvergieren und dazu führen, dass Konzernkritik wesentlicher Bestandteil der KonsumentInnenentscheidung werde. ${ }^{5}$

Was nicht so deutlich ausgesprochen, aber stets mitgedacht wird: CSR hat auch eine bedeutende politische Funktion. Unternehmen sind sehr darauf erpicht, möglichst ohne staatliche Eingriffe oder gar Auflagen walten zu können. So werden Initiativen wie z.B. der Global Compact, CSR Europe oder die Global Reporting Initiative auch ins Feld geführt, um sich vor weitergehenden und - vor allem - verbindlichen Ansprüchen zu schützen. In der neuen Weltordnung der Public-Private-Partnerships, des schlanken Staates und der Haushaltskonsolidierung der öffentlichen Hand gelten Selbstverpflichtungen der Industrie als

3 Europäische Kommission: „Grünbuch Europäische Rahmenbedingungen für die soziale Verantwortung der Unternehmen“, S. 8.

4 CSR Europe: „CSR facts and figures“.

5 Vgl. Zukunftsinstitut: „Strategisches Wissen für die Wirtschaft von morgen“. 
kostenneutrales und bürokratiefreies Wundermittel. Unternehmen glauben, auf diese Art beweisen zu können, dass sie sich der Folgen der kapitalistischen Wirtschaftsweise bewusst seien und damit verantwortungsvoll umgehen könnten. Durch Verweis auf ein tatsächliches oder symbolisches Eigenengagement versuchen sie, den weitergehenden Ansprüchen kritischer bzw. betroffener Bevölkerungsgruppen auszuweichen und sich politisch-moralisch zu legitimieren. ${ }^{6}$

\section{Das wahre Gesicht von CSR}

Studien haben gezeigt, dass große Unternehmen bei weitem nicht einhalten, was sie mit ihrem CSR-Engagement versprechen. So hat beispielsweise Christian Aid in einer viel beachteten Publikation an den Beispielen Coca-Cola, Shell und British American Tobacco aufgedeckt, in welchem Missverhältnis deren (teilweise sogar unwirksamen) CSR-Aktivitäten und Unternehmensleitsätze zu ihrer sonstigen Wirtschaftsweise (mit teilweise tödlichem Ausgang) stehen. Die AutorInnen kommen zu dem Schluss, CSR sei eine „,vollkommen unangemessene Antwort auf die mitunter verheerenden Auswirkungen, die multinationale Unternehmen auf die zunehmend globalisierte Welt haben können “7. CSR werde sogar genutzt, „um die Auswirkungen zu verschleiern. Am meisten darunter zu leiden haben die notleidenden und schutzlosen Menschen in den Entwicklungsländern sowie die Umwelt, in der sie leben “8.

Ein Blick in die Mitgliederliste des Global Compact - einer CSR-Initiative der UN, die ohne Auflagen und Kontrollen auskommt und der daher die Funktion eines bluewashing ${ }^{9}$ vorgeworfen wird - bestätigt dieses Fazit. Dort sind Unternehmen wie Bayer, Shell oder Coca-Cola versammelt - Firmen, die immer wieder in den Listen der „zehn übelsten Unternehmen des Jahres“ des Magazins Multinational Monitor ausgelobt werden. ${ }^{10}$

Die Kritik zielt aber nicht ausschließlich auf ein rein symbolisches Engagement prominenter CSR-Fahnenträger. Die Krux des Konzepts besteht darin, dass unter den gegebenen Bedingungen zunächst Druckfaktoren vorhanden sein müssen, um bei Unternehmen überhaupt eine Verhaltensänderung zu er-

6 Zur gesellschaftlichen Verantwortungsübernahme durch Unternehmen als Legitimationsmechanismus vgl. Kneip in diesem Band.

7 Vgl. Christian Aid: „Behind the mask“, S. 2 (Übersetzung K.S.).

8 Ebd.

9 Analog zum Begriff des greenwashing durch ökologisches Engagement geht es hier um das Reinwaschen des Unternehmensimages mit dem blauen UN-Logo.

10 Vgl. exemplarisch: Mokhiber/Weissmann: „J'accuse“. 
zeugen: Kritische Stimmen auf Seiten der Angestellten, der VerbraucherInnen, von AktivistInnen oder seitens der Aktionäre bzw. Investoren. Dies führt zu einigen Nachteilen:

- MitarbeiterInnen fehlt aufgrund ihres Abhängigkeitsverhältnisses oft der Hebel, verantwortliches Handeln einzuklagen (gleichwohl in den USA und in Großbritannien für so genannte Whistleblower - Angestellte, die Missstände bei ihren Firmen öffentlich machen - sogar gesetzlicher Schutz existiert).

- Für viele KonsumentInnen sind Kriterien wie Preis, Leistung und Bequemlichkeit oft bedeutsamer als ethische Überlegungen (Wobei die Lidl-Kampagne gezeigt hat, dass gerade Discounter-KundInnen sehr offen für die Argumente von Attac waren). Zudem würde es jedeN KundIn überfordern, sich ausführlich mit der Beteiligung verschiedener Unternehmen an verschiedenen CSR-Maßnahmen zu beschäftigen, um so in mühevoller Recherchearbeit eine politisch korrekte Kaufentscheidung treffen zu können. (Der Londoner Journalist Leo Hickmann beschreibt in seinem Buch sehr anschaulich, vor welche Herausforderungen KonsumentInnen gestellt werden, die neu damit beginnen, den Anspruch bewussten Konsumierens im Alltag umzusetzen.) ${ }^{11}$

- Seitens der AktivistInnen und NGOs wird es schwerlich genügend Kapazitäten geben, um die Wirtschaftswelt effektiv zu beaufsichtigen und permanent schwarze Schafe mittels wirkungsvoller Kampagnen zur Räson bringen zu können.

- $\quad$ Die InvestorInnen schließlich haben selten das Interesse, die abhängigen Unternehmen zu unprofitablen Entscheidungen zu drängen (Zusammenschlüsse wie der Dachverband der kritischen Aktionäre bilden hier eine positive Ausnahme).

Diese Auflistung zeigt, dass CSR, solange es sich um freiwillige Maßnahmen handelt, immer nur ein Konzept für Unternehmen im Fokus der Öffentlichkeit bleiben wird. Doch was ist mit den zahlreichen Unternehmen ohne Markennamen, die sehr spezialisiert sind oder nur als Zulieferer oder Dienstleister tätig sind? Was ist mit jenen Unternehmen, die CSR lediglich als eine aktuell gefragte Form von Öffentlichkeitsarbeit auffassen? Wie können Unternehmen in die Pflicht genommen werden, deren Produkte trotz ausführlicher CSR-

11 Dabei wird allerdings auch deutlich, dass in England manches, was hierzulande mittlerweile selbstverständlich ist, noch als exotisch oder innovativ gilt. Vgl. Hickmann: Fast nackt. 
Aktivitäten als solche unverantwortlich bleiben (wie z.B. bei Waffenproduzenten)?

CSR hat den Vorteil, die Verantwortung von Unternehmen für die Folgen ihres Ressourcenverbrauchs, ihrer Produktionsweise und ihrer gesellschaftlichen Sonderstellung in die öffentliche Diskussion zu bringen. Sie hat den positiven Effekt, dass sich (manche) Firmen um einen Ausgleich für oder Vermeidung der Folgen kümmern - oder zumindest diesbezügliche Versprechungen kundgeben, anhand deren sich ihr Verhalten messen lässt. Und doch kann eine Strategie, die den Bock zum Gärtner macbt, nicht zukunftsfähig sein. Denn die Fixierung auf einzelne Unternehmen und das diesbezügliche Kundenverhalten kann leicht dazu führen, dass die eigentlich wichtigen Fragen nach der Verwirklichung sozialer und ökologischer Rechte weltweit ins Hintertreffen geraten.

\section{Aus der Kampagnenpraxis: Umgang mit PR-Maßnahmen}

Auch im Rahmen der Lidl-Kampagne haben wir uns ausführlich mit der Öffentlichkeitsarbeit unseres Unternehmens und dessen Auswirkungen auf die Kampagnenarbeit auseinander gesetzt. Bis heute werten wir es als Verdienst und Erfolg der Kampagne, den Einzelhändler zur Flucht nach vorne und in die öffentliche Auseinandersetzung getrieben zu haben, da dieser bekannt dafür war, sich konsequent bedeckt zu halten. Lidl spielt (noch) nicht in der Liga der CSR-Trikotträger, doch bleiben die im vorigen Absatz aufgeführten Fragen bezüglich Lidls PR- und Unternehmenspraxis dieselben. Für uns stand vor allem die Ernsthaftigkeit von Lidls plötzlicher Gesprächsbereitschaft ${ }^{12}$ und seiner Änderungen im Warensortiment im Vordergrund: Stehen wir vor dem Sieg der kritischen KonsumentInnen oder vor einem Nebelbombenproblem? Können 1000 Tonnen fair gehandelten Kaffees berechtigte Kritik am Gesamtkonzern aufwiegen? Wo ist der Wendepunkt vom bad guy zum good guy (bzw. Konzern)? Kann ein Konzern überhaupt mehrfach in Folge zum Einlenken gebracht werden?

In der Kampagnenpraxis bekommen Fragen um Sein und Schein verantwortungsvollen Konzernhandelns, wie sie im vorherigen Abschnitt aufgeworfen wurden, noch mal eine andere Dynamik. Lidl war durchaus für Überra-

12 Die Protestaktionen begannen im Sommer 2005, im November 2005 folgte eine erste Reaktion des Unternehmens in Form einer Stellungnahme, daraufhin fand im Dezember ein Treffen eines Lidl-Vorstands mit Attac und weiteren in der Kampagne vertretenen NGOs statt. Im Januar 2006 gab Lidl die Einstellung eines Pressesprechers bekannt. Zudem führte Lidl im Sommer 2006 unter dem Markennamen Fairglobe ein eigenes Sortiment an fair gehandelten Produkten ein. 
schungen gut. Vielleicht waren dem Konzern die ersten Protestaktionen im Sommer 2005 noch gleichgültig, doch als die Medien begannen, prekäre Arbeitsverhältnisse mit Lidlisierung zu umschreiben und selbst ganz andere Unternehmen den Beinamen der Lidl seiner Branche bekamen, konnten die Verantwortlichen nicht mehr darüber hinweg sehen. So zeigte sich erneut, dass es einem Unternehmen nicht egal sein kann, welchen Ruf es hat. Irgendwann bleiben Kunden aus oder drohen die Umsätze zurück zu gehen.

Eine häufig zu beobachtende Folge von Reaktionen angegriffener Konzerne ist das Ignorieren der Kritik, gefolgt von Widerspruch oder Gegenangriff, dann ein teilweises Einlenken. So gesehen hat Lidl bilderbuchmäßig agiert. In der mittleren Phase kam es zu Auflösungen von Filialen mit Betriebsräten, zur Entlassung einer Journalistin, die kritisch über den wichtigsten Anzeigenkunden geschrieben hatte, und zu heftigen Auslassungen vor allem gegenüber GewerkschafterInnen und Gewerkschaften. Auch bei Lidl erfolgte in einem nächsten Schritt das Einlenken. Lidls Einlenken bestand darin, Gesprächs- und Verhandlungsbereitschaft zu signalisieren, für einige Monate hausintern den Druck auf seine Angestellten zu lockern sowie schließlich acht von Transfair gesiegelte Produkte ins Sortiment zu nehmen. Da sich für Lidl die verschiedenen Kampagnen von Attac, ver.di und Greenpeace als ein kollektiver Angriff darstellten, müssen auch die Beratungen mit Greenpeace über die Verringerung der Pestizidbelastung von Obst und Gemüse dazu gezählt werden.

Unternehmerisches Einlenken wird jedoch immer auch ein strategischer Schritt sein. Wenn ein Konzern die Initiative ergreift, stehen ihm meist beachtliche Ressourcen zur Verfügung, seine Verbesserungen, so klein sie auch sein mögen, zu kommunizieren. Zu diesem Zeitpunkt läuft der mühsam aufgebaute Druck Gefahr, durch eine kleine Detailreform zu entweichen. Leicht wird aus der eben noch gespürten Macht der KonsumentInnen wieder Ohnmacht, denn neben spezifischen, am öffentlichen Druck orientierten Maßnahmen des Konzerns erfolgt meiste keine grundlegende Änderung der Unternehmenspolitik.

Die Lidl-Kampagne von Attac hat sich von Anfang an als eine Kampagne mit zwei Adressaten verstanden: dem Konzern, aber auch der Öffentlichkeit. Hinsichtlich öffentlicher Wirksamkeit - sowohl bei den Medien als auch beim Publikum auf der Straße und bei Veranstaltungen - war sie in jedem Falle ein Erfolg. Daher wurden die Träger der Kampagne auch nicht durch Lidls Versuche, auf einige der Forderungen scheinbar einzugehen, aus dem Konzept gebracht.

Die Forderungen an den Konzern blieben stets eingebettet in eine umfassendere Analyse der globalen wirtschaftlichen Zusammenhänge. Wir halten es für eine der Stärken von Attac, explizit keine Ein-Punkt-Bewegung sein zu 
wollen. Vor diesem Hintergrund gelangten die bei der Lidl-Kampagne Beteiligten zur folgenden Erkenntnis: Wenn Lidl sein Sortiment nach ethischen Kriterien ergänzt, ist das ein Fortschritt und auch ein Ergebnis der Arbeit von Attac. Doch haben wir Verbesserungen in der Unternehmenspolitik gefordert, und davon ist der Konzern bis heute noch weit entfernt. Insgesamt wurde damit deutlich: Widerstand lohnt sich und verändert etwas, es bedarf allerdings eines langen Atems und einigen Fingerspitzengefühls, sowohl Erfolge als auch den weiterhin vorhandenen Änderungsbedarf zu kommunizieren.

Gerade im Umgang mit Konzern-PR, sei es nun CSR im Allgemeinen oder speziell Lidls Aktivitäten, hat sich damit gezeigt, wie wichtig es ist, die mittel- und langfristigen Ziele der politischen Arbeit nicht aus den Augen zu verlieren. Im Alltagsgeschäft etablierter politischer Institutionen (das schließt große NGOs durchaus mit ein) werden die großen Ziele zur Veränderung sozialer und ökologischer Missstände leicht im Kampf um Detailreformen zerrieben. Außerparlamentarische Bewegungen bieten demgegenüber die Möglichkeit, inhaltliche Kompetenzen zu bündeln und trotzdem jenseits von Machtspielen und Kuschelkurs mit der Wirtschaft politische Alternativen in die Diskussion zu bringen. Es ist politisch wichtig, auf Konzernaktivitäten genauso wie auf Konzern-PR einzugehen und sie gegebenenfalls zu demaskieren. Konzernkritik hat innerhalb der Globalisierungskritik einen klaren und deutlich umrissenen Stellenwert.

\section{$5 \quad$ Von der Balance zwischen Sollen und Können - oder: Grenzen der Konzernkritik}

Als wirtschaftliche Akteure gestalten Konzerne aktiv den Austausch zwischen Mensch und Umwelt sowie zwischen Menschen, haben aber nur indirekten politischen Einfluss auf die Rahmenbedingungen, die ihrem Handeln gesellschaftlich auferlegt werden. Freilich handelt es sich dabei um ein hart umkämpftes Terrain, auf dem die Möglichkeiten von Konzernen und Unternehmerverbänden, Regularien mitzugestalten oder gar zu diktieren, zunehmend wachsen. Solange es aber noch Nationalstaaten mit eigenen Regierungen statt Konzernkonglomeraten mit quasi-staatlichem Einflussbereich - gibt, bleiben die politischen Vertretungen die Ansprechpartner von Attac für die systemisch bedingten Verfehlungen und Folgen der Wirtschaftspolitik.

Konzernkritik kann dennoch eine wichtige und vor allem praxisnahe Strategie für den politischen Einfluss außerparlamentarischer Bewegungen sein. Muss ein öffentlich angeprangerter Konzern einlenken, macht dies einen relevanten Unterschied. Im Falle Lidl können mehr Bananenpflanzer besser wirtschaften und leben, werden Umwelt und Gesundheit der Arbeiter im spa- 
nischen Almería geschont und bleibt das Lidl-Management aufgrund seines harten Stils bis heute unter Beschuss. ${ }^{13}$ In anderen Fällen konnte dank konzernkritischer Kampagnen der Bau problematischer Industrieanlagen, die Einführung von genmanipulierten Lebensmitteln oder die unsinnige Verarbeitung von Tropenhölzern gestoppt werden.

Darüber hinaus bietet Konzernkritik viele Möglichkeiten für die politische Bildung:

- Sie spitzt die komplexe und oft etwas abstrakte Globalisierungskritik zu und erleichtert es deshalb, Außenstehende anzusprechen. Sie kann auch Menschen erreichen, denen die Auseinandersetzung mit Finanzmarktzyklen oder Welthandelsabkommen zu lebensfern erscheint.

- Sie hebt Verantwortliche hervor. Die Kampagnenträger sagen: „Globalisierung wird gemacht", und doch kritisierte Attac bisher vor allem Strukturen und Institutionen. Mit einem Konzern wird ein Macher adressiert.

- Sie wirkt in nicht zu unterschätzendem Maße auf die allgemeine Diskussion ein: Durch konkrete Beispiele sensibilisiert Konzernkritik für die von vielen übersehenen Folgen des globalen Wirtschaftens und zeigt Möglichkeiten effektiven Widerstands auf.

- $\quad$ Auch für die Aktiven selber kann eine konzernkritische Kampagne aufgrund des klaren Adressaten, ihrer konkreten Forderungen und Erfolgsorientiertheit und ihrer meist guten Anschlussfähigkeit für eine breite Öffentlichkeit einen deutlichen Motivationsschub bringen.

- Konzernkritik kann - obwohl sie konkret und zugespitzt ist - für mehr, für weitergehende Kritik an der Globalisierung stehen: als Teil für das Ganze, als Beispiel.

Mit Blick auf konventionelle Kampagnen, auf die Vorbilder der großen, etablierten NGOs, erscheint es keineswegs einfach, die Verbindung zwischen konzernkritischer Kampagne und systemischer Analyse und Kritik herzustellen und durchzuhalten. Attac hatte bisher kaum Kampagnenerfahrung gesammelt, die Lidl-Kampagne haben wir daher bewusst als Experimentierfeld genutzt. Auch in dieser Hinsicht war die Kampagne ein Erfolg, denn sie hat gezeigt, dass es durchaus möglich ist, punktuelle Erfolge zu erzielen, ohne viele andere kritikwürdige Faktoren auszublenden.

Zahlreiche konzernkritische Kampagnen setzen sich aufgrund ihres punktuellen strategischen Framings der Gefahr aus, zunächst Wirkung zu erzielen

13 Vgl. z.B.: Hirn u.a.: „Lidl Rückschlag für den Aldi-Jäger“. 
und anschließend vom Unternehmen zu PR-Zwecken vereinnahmt zu werden. So musste sich selbst Greenpeace nach dem Sieg über Shell im Brent-SparKonflikt fragen lassen, ob sie nun unbedingt die Imagepflege des Konzerns (u.a. im Solar-Bereich) unterstützen müssen - während der gleiche Konzern international in heftiger Kritik wegen seiner Politik in Nigeria stand. Der ChefManager des Lidl-Konzerns bot in einem Gespräch unverblümt an, die Einführung der fairen Produkte mit Attac zusammen öffentlich zu feiern.

Für eine Kampagne aus der globalisierungskritischen Perspektive heraus wären solche Resultate kaum zufriedenstellend. Der Deutungsrahmen liegt ja gerade in der Offenlegung globaler wirtschaftlicher Zusammenhänge und politischer Strukturen. Bei der Lidl-Kampagne konzentrierte sich dieser Deutungsrahmen in der Forderung nach Globalen Sozialen Rechten, einer politischen Figur, die innerhalb Attacs (gerade auch im Zusammenhang mit der G8-Gipfelprotest-Mobilisierung) mehr und mehr an Raum gewinnt. Eine solche DachForderung kann helfen, die Diskrepanz zwischen Konzern- und Systemkritik in der Kampagnenpraxis zu überwinden. Das Ziel sind konzernkritische Kampagnen, die wirkungsvoll und aufklärend sind, dabei über den angeprangerten Missstand hinaus weisen und nur schwer vereinnahmt werden können.

Neben den bereits vorgestellten Überlegungen können dazu auch sehr weitreichende Konfrontationen ein Mittel der Wahl sein. So das Beispiel Kampagne zur Auflösung eines Konzerns aus unserem Basistext Konzern, Kritik, Kampagne!:

Angesichts der zahlreichen [...] Beispiele von konzerngetriebenen Verbrechen und angesichts des Wissens um die strukturelle Unreformierbarkeit von Unternehmen erscheint es nahe liegend und legitim, kurzerhand die Auflösung eines besonders unsozialen Exemplars anzustreben. Solch eine Kampagne hat ihren Reiz, ist aber nicht unproblematisch, da sie sich anderen Einwänden stellen müsste (z.B. ,Was geschieht mit den Arbeitsplätzen? Sind die Wettbewerber nicht genauso schlimm?') Andererseits gibt es schon viele Diskussionen, an die sich mit dem Ruf nach einer Konzernauflösung hervorragend anknüpfen lässt.

Beispielsweise hat das faktische Microsoft-Monopol die Diskussion über eine Konzernzerschlagung entfacht und inzwischen die Kartellbehörden in den USA auf den Plan gerufen. Der Softwaregigant war zu groß geworden, so dominant, dass jede Vorstellung von Wettbewerb zur Farce wurde.

Ein Blick in die Realität hilft bezüglich des reflexhaften Arbeitsplatz-Argumentes: Bei jeder Konzernfusion werden Arbeitsplätze gestrichen, zudem zerstören große Konzerne bei kleinen und mittleren Unternehmen viel mehr Arbeitsplätze, als sie selber schaffen. 
Und was den Unternehmensnutzen angeht: Will unsere Gesellschaft es sich wirklich leisten, Rüstungs- oder Atomkonzerne weiterhin zu ertragen? Eine Konzernauflösungskampagne, welche das Existenzrecht generell in Frage stellt, reicht deutlich weiter als eine Zerschlagung, die den Giganten lediglich aufteilt. Richtig angefasst, könnte eine Auflösungskampagne sogar dafür sorgen, dass sich viele neue Entwicklungsmöglichkeiten eröffnen. Z.B. könnte die Forderung nach der Auflösung eines Discounters wie Lidl dazu führen, eine neue, selbstverwaltete Kette von Einzelhandelsgeschäften oder gar Weltläden zu etablieren. Damit wäre so eine Kampagne erfrischend konsequent. Je nach Argumentation böte sie die Möglichkeit zur radikalen Verbindung von Konzern- und Systemkritik. ${ }^{14}$

Und, so ließe sich dem noch hinzufügen, liefe sie garantiert keine Gefahr, von dem betroffenen Unternehmen für eigene PR-Zwecke vereinnahmt zu werden.

\section{Keine Lust auf schlechte Gärtner: Gegenprojekt Corporate Accountability}

Weit weniger radikal als die Forderung nach Konzern-Auflösungen ist eine Kritik an der üblichen CSR-Praxis und die Suche nach einem möglichen Alternativansatz, beispielsweise dem Prinzip der Corporate Accountability (CA). Corporate Accountability könnte mit Verantwortlichkeit von Unternebmen übersetzt werden und ist Ausgangspunkt der Forderung zahlreicher Verbände. So hat sich beispielsweise in Deutschland 2005 das so genannte CorA-Netzwerk ${ }^{15}$ gegründet. CA versteht sich dabei explizit als Gegenentwurf zu CSR. Seit CSR sogar von den vielen Industrieverbänden nicht mehr als marktverzerrend bekämpft, sondern als verkaufsförderndes Konzept zur Bearbeitung schädlicher Auswüchse marktwirtschaftlicher Produktion willkommen geheißen wird, sind viele NGOs nicht mehr bereit, in die Rolle kostenloser Berater und geduldeter Hackentreter gedrängt zu werden. CA baut auf der oben bereits erläuterten Erkenntnis auf, dass die Praxis der ökologischen und sozialen Eigenverantwortung von Unternehmen unter den gegebenen Rahmenbedingungen eben nicht ausreicht, die erforderlichen Effekte im Sinne des Naturschutzes, der Menschenrechte und der globalen Gerechtigkeit zu erzielen. CA platziert die politische Forderung, international verbindliche Regeln zur Produktion und zum Handel einzuführen. Die von Konzernhandlungen Betroffenen sollen in

14 Löding u.a.: Konzern, Kritik, Kampagne!, S. 58f.

15 Die Abkürzung CorA steht für „Corporate Accountability - Unternehmensverantwortung jetzt!“‘. Weitere Informationen unter www.cora-netz.de. 
die Lage versetzt werden, diese Handlungen kontrollieren und sanktionieren zu können. Die Idee besteht darin, Manager und Geschäftsführer mit sozialen und ökologischen Pflichten zu belegen. Verstoßen sie bzw. der Konzern gegen diese Pflichten, erhalten die Betroffenen das Recht auf Kompensation. Auf diese Weise soll ein Gegengewicht zu der üblicherweise sehr eindimensionalen Aufgabe der Renditemaximierung geschaffen werden.

Während CSR also eher auf den einzelnen Konzern setzt sowie die mündigen VerbraucherInnen, die das Konzernhandeln belohnen sollen, betont CA die Werte und Interessen der Gemeinschaften, innerhalb derer Konzerne agieren. Dennoch fungieren die Reformvorschläge im Kontext der CA überwiegend als Ergänzung zu den wirtschaftlichen Pflichten und Interessen der Konzerne. Der Frage nach der politischen Ökonomie und nach der Ursache der beklagten Missstände weicht auch die CA-Bewegung aus. Innerhalb von Attac haben sich dennoch viele entschieden, diesen politischen Drahtseilakt zu unterstützen und auch auf dieser Ebene an Alternativen zur heute realen Konzernmacht mit zu arbeiten.

Nichtsdestoweniger wird man sich wohl häufiger vor den Konzerntoren und auf der Straße treffen - denn als Teil der globalisierungskritischen Bewegung setzt Attac auf den Druck von unten und breite, offensiv geführte gesellschaftliche Diskussionen. Diese lassen sich auch durch ein geschickteres Konzept zur Konzernverantwortung nicht ersetzen.

\section{Literaturverzeichnis}

Christian Aid: „Behind the mask. The real face of corporate social responsibility“, 2004, www.christian-aid.org.uk/indepth/0401csr/, 22.06. 2007.

CSR Europe: „CSR facts and figures“, www.csreurope.org/aboutus/ CSRfactsandfigures_page397.aspx, 22.06.2007.

Europäische Kommission: „Grünbuch Europäische Rahmenbedingungen für die soziale Verantwortung der Unternehmen“, 2001, ec.europa.eu/employment_social/publications/2001/ke3701590_de.pdf, 22.06.2007.

Friedman, Milton: „The Social Responsibility of Business is to Increase its Profits“, in: The New York Times Magazine, 13.09.1970.

Friedman, Milton u.a.: „Rethinking the Social Responsibility of Business“, www.reason.com/news/show/32239.html, 18.06.2007.

Hickmann, Leo: Fast nackt. Mein abenteuerlicher Versuch, ethisch korrekt zu leben, Pendo 2006. 
Hirn, Wolfgang u.a.: „Lidl Rückschlag für den Aldi-Jäger: Chaos-Kommando“, in: Manager Magazin, Jg. 20, Nr. 2, 2007.

Mokhiber, Russel/Weissman, Robert: „J'accuse: The 10 Worst Corporations of 2006", in: Multinational Monitor, Jg. 27, Nr. 6, www.multinational monitor.org/mm206/112006/mokhiber.html, 22.06.2007.

Löding, Thomas u.a.: Konzern, Kritik, Kampagne! Ideen und Praxis für soziale Bewegungen, Hamburg 2006.

Zukunftsinstitut: „Strategisches Wissen für die Wirtschaft von morgen“, www.zukunftsinstitut.de/ueberuns.php, 22.06.2007. 


\section{Hans Hubbertz}

\section{Arm sein ist geil - Schnäppchenjäger und Smart Shopper in der Kampfzone}

Seit Ende der 1990er Jahre verlangen immer mehr Kunden nicht nur immer mehr, sie verlangen auch immer mehr für immer weniger Geld. Überbordend medial beworbene Glückspielangebote, Internet-Suchmaschinen als Booster der Preistransparenz, kostenlose Zugaben, Ein-Euro-Shops, Versteigerungen bei eBay etc. sowie Spekulationen an der Börse bieten dabei Arenen zur Verfolgung diverser Konsumbedürfnisse. Die Warenmärkte passen sich in weiten Teilen den spekulativen Mechanismen des Finanzmarktes an, ${ }^{1}$ auf dem die Verheißung und das Versprechen gilt, man könne problemlos reich werden, ohne viel dafür bezahlen zu müssen. Was den alltäglichen Einkauf von Lebensmitteln betrifft, werden Kunden bereits seit längerer Zeit zur Preissensitivität erzogen: Im Deutschland der Nachkriegszeit begannen im gewerkschaftsnahen Arbeitnehmermilieu Einkaufsmärkte unter dem Label KONSUM, dem späteren Coop, mit klassischen Rabattsystemen und Eigenmarken ihre Kundschaft an sich zu binden. Mit antikapitalistischer Dignität trugen die Waren einen über sich selbst hinausweisenden Mehrwert, der damit narzisstische Bedürfnisse eines ideologisch besetzten Einkaufs bediente. ${ }^{2}$ Heutige marktbeherrschende Discounter wie Aldi, Lidl, Plus und Schlecker knüpfen zwar nicht an die genossenschaftliche Tradition an, sorgten jedoch für den dauerhaften Durchbruch der Kultur des günstigen Einkaufs. Einer der Claims, der für diese Kultur geschaffen wurde, ist der Saturn-Slogan Geiz ist geil. Er ist nach wie vor einer der meistzitierten Claims und spiegelt wie kaum ein anderer den Wandel kollektiver Konsum-Mentalitäten wider, die sich in veränderten ökonomischen Entscheidungsprioritäten, sozialpolitischen Neujustierungen und nicht zuletzt im individuellen Verhalten (etwa in Form abnehmender Spendenbereitschaft ${ }^{3}$ gesellschaftlich manifestieren.

1 Vgl. Davis/Meyer: Blur, S. 96-110.

2 Vgl. Pfabigan: Nimm 3, zahl 2, S. 23.

3 Vgl. Deutscher Spendenrat e.V.: „Spenden gehört dazu“. 


\section{$1 \quad$ Die Magie des Geizes}

\subsection{Zur Werbekampagne Geiz ist geil}

Produzierte die Werbewirtschaft in den 1990er Jahren vielfach Werbung, die sich zur Bewältigung von Sinnkrisen sozial und moralisch ambitioniert zeigte ${ }^{4}$, so kehrte man Ende des Jahrzehnts in einer Gegenbewegung mehr und mehr zu Formen des traditionellen Anpreisens zurück. ${ }^{5}$ Die Werbewirtschaft reagierte damit auf das Problem zunehmender Individualisierung und Pluralisierung ihrer Zielgruppen, die immer weniger in homogene Käufergruppen einteilbar waren. Im Bereich des Privatfernsehens hielt Trendforscher Matthias Horx diese Wendung in einer frühen Phase fest: „Die raue, aber reelle Art der Anpreisung (,Billig! Geil! Gut') überschwemmt unsere Privatkanäle. "6 Mit der Alliteration Geiz ist geil griff Saturn diesen Trend in prägnanter Form auf. Das Fachblatt werben \& verkaufen meldete 2002:

Saturn positioniert sich bei knauserigen Kunden. Der ElektronikMarkt Saturn, Ingolstadt, will sich deutlicher als Tiefpreis-Anbieter positionieren. Nächste Woche beginnt die umfangreiche Kampagne, die Jung von Matt/Fleet entwickelt hat. Zwei TV-Spots, die bei der Hamburger Markenfilm (Regie Kai Sehr) entstanden sind, erklären bis Ende Januar den Claim ,Geiz ist geil ${ }^{6}{ }^{7}$

Selbsterklärtes Ziel der Kampagne war es, „das Motto möglichst aggressiv bekannt zu machen. " ${ }^{\circ 8}$ Wie auch Media Markt strebt Saturn als so genannter Category Killer danach, die Kostenführerschaft mit Herstellermarken zu übernehmen und andere kleinere und mittelständische, weniger effiziente Anbieter vom Markt zu verdrängen. Mittels erhöhten Werbedrucks konnte die Kampagne hohe Erinnerungswerte in Tests bei Konsumenten erzielen. ${ }^{9}$ Im Jahr 2003 erzielte Saturn einen Umsatzzuwachs von beachtlichen 15 Prozent - im Gegensatz zum negativen Trend im gleichen Zeitraum im gesamten Einzel-

4 Vgl. Schmidt/Spieß: Die Kommerzialisierung der Kommunikation, S. 22 f.

5 Vgl. ebd., S. 26.

6 Horx: „Die Krise in der Werbung“, S. 23 zitiert nach Schmidt/Spieß: Die Kommerzialisierung der Kommunikation, S. 26.

7 w\&v: „Saturn positioniert sich bei knauserigen Kunden“.

8 Dies.: „Geiz bleibt geil bei Saturn“.

9 So gehörte Geiz ist Geil im Jahr 2004 zu den Top 20 der bekanntesten Slogans in Deutschland und Saturn zählte zu den zehn meistbeworbenen Marken. Vgl. dies.: „,Ich bin doch nicht blöd“ ist Deutschlands bekanntester Slogan“. 
handel, der seit längerem mit dem Problem der Überproduktion bei nachlassendem Käuferinteresse zu kämpfen hat.

Der Werbeslogan Geiz ist geil kleidet sich in einen jugendsprachlich inspirierten Protestlook, der vorgibt, sich von einer überholten Moral abzusetzen und an der Enthemmung der Spaßkultur teilzuhaben. ${ }^{10}$ Die nunmehr verkündete neue Moral ist, wie jede Moral nach Niklas Luhmann, polemogener Natur. ${ }^{11}$ Sie gewinnt ihre aktivierende Energie, indem sie sich von konventionellen (religiösen) Normen absetzt, ,gegen vorhandene Erwartungen und Schemavorstellungen verstößt und in den Empfängern gedankliche Widersprüche, Überraschungen und Konflikte auslöst" ${ }^{* 12}$. In einem fast nietzscheanischen Gestus einer Umwertung der Werte wird die vormalige Sünde des Geizes als Befreiung deklariert. Die antitraditionalistische Attitüde pointierter Differenz markiert sie als modern und souverän. Der provozierende und augenzwinkernde Claim Geiz ist geil spielt darüber hinaus mit der schillernden Referenz auf Geilheit als libidinöse Besetzung des eher zurückhaltenden Einkaufsverhaltens. Zugleich führt der paradox anmutende Werbeslogan den unverhoblenen Anklagepunkt des Warenfetischismus ironisch stets mit. So als habe man zum Regiebuch der Frankfurter Schule gegriffen, wo es noch hieß: „Der Schein von Lust und Unmittelbarkeit bemächtigt sich des Tauschwertes selber." ${ }^{\text {"13 }}$ Es wird das Spiel mit dem verpönten unmoralischen Fetischismus betrieben, um sich diesem umso mehr hinzugeben. Die neue Form des Massenkonsums hat, so scheint es, ihre eigene reflexive, paradoxe Rationalitätsform gefunden: Triebzurückhaltung (Geiø) wird zum Ausdruck der Lust (geil).

\subsection{Zur Semantik des Geizes}

Sparsamkeit gilt in der westlichen Zivilisation als moralisch-tugendhafter Wert und als eine der „Metaphern, nach denen wir leben“14. Das materielle Verständnis der Sparsamkeit ist in der Vorstellungswelt der verantwortlichen Haushaltsführung angesiedelt und zielt darauf ab, vorhandene Ressourcen umsichtig einzusetzen, womöglich zugunsten Bedürftiger Verzicht zu üben oder ökologisch orientiert - die Umwelt zu schonen. ${ }^{15}$ Im Alltagsverständnis wird der Begriff des Geizes in der Regel als übertriebene Sparsamkeit betrachtet

10 Vgl. Sloterdijk: Im Weltinnenraum des Kapitals, S. 107.

11 Vgl. Luhmann: Gesellschaftsstruktur und Semantik, S. 370.

12 Kroeber-Riel: Strategie und Technik der Werbung, S.126.

13 Adorno: „Über den Fetischcharakter in der Musik“, S. 331.

14 Lakoff/Johnson: Metaphors we live by, S. 23.

15 Vgl. Gerbig/Buchtmann: „Vom, Waldsterben“ zu,Geiz ist geil““, S. 97. 
und thematisiert ein Verhalten, in dessen Rahmen anderen bewusst etwas vorenthalten wird. In der Tradition der christlichen Begriffssemantik wird Geiz auch im Sinne von Habgier verstanden. Im Neuen Testament heißt es zur Pleonexia ${ }^{16}$ in der Einheitsübersetzung: „Dann sagte er zu den Leuten: Gebt Acht, hütet euch vor jeder Art von Habgier. Denn der Sinn des Lebens besteht nicht darin, dass ein Mensch aufgrund seines großen Vermögens im Überfluss lebt. “17 In der katholischen Glaubenslehre gehört Geiz neben Hochmut, Neid, Zorn, Trägheit, Völlerei und Wollust zu den so genannten Sieben Todsünden. Seit dem Mittelalter galt Habgier als die „,tödlichste aller Todsünden“18, im 17. Jahrhundert wurde sie die schlimmste Leidenschaft genannt.

Der Slogan Geiz ist geil codiert nun diese klassische Todsünde zur neuen Tugend um. Dabei wird sowohl an die Konnotation der Sparsamkeit als auch an die der Habgier angeknüpft. Sparsamkeit wird zur Handlungsmaxime, um den eigenen Genuss auszudehnen, denn die proklamierte Zurückhaltung zielt gerade auf den exzessiven Konsum. Auch bei Slavoj Žižek fallen ,in der Figur des Geizkragens der Exzeß mit dem Mangel“19 zusammen, womit zwei konträre Traditionslinien verbunden werden:

Das Paradox des Geizkragens besteht darin, dass er zwei unvereinbare Traditionen miteinander vereint: die aristotelische Ethik der Mäßigung und die kantische Ethik der bedingungslosen Forderung, die das Lustprinzip zum Entgleisen bringt - der Geizhals erhebt die Maxime der Mäßigung selbst zu einer kantischen bedingungslosen Forderung. 20

Wie in einem Vexierbild sollen vermehrte Ausgaben zu einem Ausdruck des Sparens umgedeutet werden. Diese Paradoxie entfaltet sich im Kontext gesättigter Märkte, auf denen sich die Anbieter - unter der Bedingung fallender Preise - gezwungen sehen, die Waren industrieller Überproduktion abzusetzen, oder anders formuliert: „Das Bedürfnis des Kunden ist zur knappen Ressource geworden. “21

16 Griechisch für Habgier; seit dem siebten Jahrhundert wurde Habgier auch mit Geiz übersetzt.

$17 \quad$ Lk 12,15.

18 Hirschman: „Leidenschaften und Interessen“, S. 50.

19 Žižek: Die gnadenlose Liebe, S. 18.

20 Ebd., S. 18f.

21 Bolz: Das konsumistische Manifest, S. 97. 


\subsection{Von Schnäppchenjägern und Smart Shoppern}

Der Werbeslogan Geiz ist geil trifft präzise den Zeitgeist des preissensitiven Konsumenten. In einer Studie zur Situation des Einzelhandels hielten die Autoren der Wirtschaftsprüfungsgesellschaft KPMG folgendes Orientierungsmuster für Kaufentscheidungen fest:

Der Preis war, ist und bleibt auch weiterhin das Entscheidungskriterium Nr. 1 für oder gegen einen Kauf. [...] Die preisorientierte Zielgruppe wächst weiter. Die Zielgruppe der Schnäppchenjäger (Preisgünstigkeit) und die der Smart Shopper (Preiswürdigkeit) vergrößert sich ebenso. ${ }^{22}$

Mit dem Konsumtyp des Smart Shoppers hat sich insbesondere Alfred Pfabigan intensiv auseinander gesetzt. Der Smart Shopper beschränkt sich nach Pfabigan nicht auf das Notwendige, sondern hat das traditionelle Markendenken internalisiert und zielt auf den Erwerb des „beste[n] Gut[es] zum niedrigsten Preis “23. In seiner Weigerung, den Marken die Aufwendungen für ihre Wertigkeit zurückzuzahlen, liegt ein parasitäres Verhaltensmuster, das geizig erscheint ${ }^{24}$ und zudem ein kalkulierendes Moment aufweist: „Dieser Typus ist misstrauisch, berechnend, zögerlich in seinen Kaufentscheidungen und gelangweilt vom übergroßen Angebot.“25 Er versucht gewissermaßen, die Tauschgesetze des Gebens und Nehmens, die auf Äquivalenz und prinzipieller Symmetrie basieren, ${ }^{26}$ zu seinen Gunsten außer Kraft zu setzen. Das Verhalten dieses neuen Konsumententypus ist widersprüchlich, nämlich kalkuliert und hedonistisch zugleich. Noch Anfang der 1980er Jahre betrachtete Pierre Bourdieu den Hedonismus anstelle von Kalkül als Triebkraft einer neuen Ökonomie:

An die Stelle der asketischen Moral von Produktion und Akkumulation, die sich auf Enthaltsamkeit, Nüchternheit, Sparsamkeit und Kalkül gründete, setzt die neue Wirtschaftslogik eine hedonistische Moral des Konsums, gegründet auf Kredit, Ausgaben, Genuß. ${ }^{27}$

22 KPMG: Trends im Handel 2005, S. 4.

23 Pfabigan: Nimm 3, zahl 2, S. 124.

24 Vgl. ebd., S. 125.

25 Ebd., S. 11.

26 Vgl. Waldenfels: Schattenrisse der Moral, S. $301 \mathrm{f}$.

27 Bourdieu: Die feinen Unterschiede, S. 489. 
Demgegenüber verschmelzen in der Figur des Smart Shoppers die alten Antipoden von Verschwendung und Sparsamkeit zu einer neuen, eigenständigen Konsumform der Mittelklasse. Smart Shopper repräsentieren mit ihren schnell wechselnden Konsumneigungen und ihrer Fähigkeit, massenmedial inspiriert interrelational zu horchen, ${ }^{28}$ eine Fortführung jenes außengeleiteten RadarTyps, den David Riesman bereits 1950 in den amerikanischen Städten beobachtete. $^{29}$ In dieser Figur wagte Riesman in bis dato ungewöhnlicher Weise, „Außenlenkung und Autonomie der Person zusammenzudenken. “30

Im Gegensatz zum Smart Shopper orientiert sich der Schnäppchenjäger vor allem an der Preisgünstigkeit. Er sieht sich gezwungen, zu sparen, um sich auf mögliche zukünftige Knappheiten einzustellen. Daher zeigt er sich unsicher gegenüber der Zukunft, er verbringt viel Zeit mit dem Einkaufen und bringt gegenüber Discountern und Handelsmarken hohe Akzeptanz auf. ${ }^{31}$ Während die einen nichts verschenken wollen, um mehr zu genießen, haben die anderen nichts zu verschenken, da sie weiteren sozialen Abstieg befürchten. Für diejenigen, die sich vom Abstieg bedroht fühlen, gilt im Sinne Ferdinand Rohrhirschs: „Der Erfolg der Erfolglosen ist das Schnäppchen.“32 Obwohl sich die Käufergruppen der Schnäppchenjäger und Smart Shopper voneinander unterscheiden, stiftet der Claim Geiz ist geil eine habituelle Nähe beider Gruppen: Der Slogan weist schwächer budgetierte Käufergruppen als Teil der Spaßgesellschaft aus, wertet sie durch die Zugehörigkeit auf und rückt sie in die Nähe der Smart Shopper, die als heimliche Leitfiguren eines cleveren, saturierten Konsums fungieren. Dem Schnäppchenjäger wird so die Möglichkeit gegeben, überhaupt geizig sein zu können. Er wird in die Lage versetzt, sich selbst als souveränen Konsumenten beschreiben zu können. Der Schnäppchenjäger schlägt sich mimetisch auf die Seite des Smart Shoppers und kann durch diese Selbstinszenierung imaginieren, nicht jedes Produkt zum angebotenen Preis kaufen zu müssen. Beide Gruppen können mit dieser Selbstbeschreibung gegenüber Anbietern ihre Verbrauchermacht durch geschicktes Einkaufsverhalten und Kaufzurückhaltung ausspielen. Dass womöglich auch der Anbieter aus Eigeninteresse selbst geizen könnte, gehört zum Setting eines symbolischen Spiels, in dem sich Kunde und Anbieter im Gegenüber wieder-

28 Vgl. Lethen: Verhaltenslehren der Kälte, S. 238.

29 Vgl. Riesman: Die einsame Masse, S. 13.

30 Vgl. Lethen: Verhaltenslehren der Kälte, S. 237; H.i.o. Vgl. auch Lamla in diesem Band hinsichtlich weiterer Verknüpfungen zwischen der Riesmanschen Figur des Außengeleiteten und des Konsumenten.

31 Vgl. KPMG: Trends im Handel 2005, S. 61.

32 Rohrhirsch: Erfolg. Ethik. Sinn., S. 74. 
erkennen. Gleichzeitig signalisiert man einander, dass man weiß, dass Verstellung zum Geschäft gehört.

Bei genauerer Betrachtung ist der Smart Shopper also nicht die primäre Zielgruppe des Slogans Geiz ist geil. Für diese Käufergruppe erscheint er zu

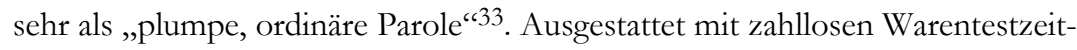
schriften trumpft der typische Smart Shopper dagegen mit dem Media-MarktSchlachtruf Ich bin doch nicht blöd! auf. Die damit einhergehende Käufersegmentierung ${ }^{34}$ ruft zusätzliche (Distinktions-)Profite hervor, denn durch sie lässt sich das traditionelle Markendenken und dessen Absatzformen stärken. ${ }^{35}$ Kulturelles und ökonomisches Kapital gehen somit eine homologe Verbindung ein.

\subsection{Konsumenten in der Bürgerrolle?}

Norbert Bolz geht davon aus, der Kunde wolle von der Werbung verführt werden und an der „Wiederverzauberung der entzauberten Welt ${ }^{\text {“36 }}$ in der Rolle des Betrogenen teilhaben. In diesem Habitus agiert er, so könnte man mit Peter Sloterdijk formulieren, wider besseres Wissen im Modus einer aynischen Vernunft, deren Kennzeichen das ,aufgeklärte falsche Bewusstsein “37 ist. Das eigene Konsumentenhandeln wird gegenüber dem Ganzen für folgenlos erklärt, selbst wenn sich in actu Konsumenteninteressen gegen Bürgerinteressen richten. ${ }^{38}$

Solange sich Bürgerinteressen nicht in Form von Preisen kommunizieren lassen, spielen diese für den Kapitalismus keine Rolle. Dieser zielt umso mehr darauf ab, „das gesamte Arbeits-, Wunsch- und Ausdrucksleben der von ihm erfassten Menschen in die Immanenz der Kaufkraft zu versetzen“'39; er entfaltet sich also nicht nur als Produktionsverhältnis. Wo eine Deflationsspirale fallender Preise initiiert wird, greift ein zerstörerischer Unterbietungswettbewerb mit dem Resultat von Konkursen und Monopolbildungen, der Ten-

33 Pfabigan: Nimm 3, zahl 2, S. 141.

34 Die hier beschriebene Käufersegmentierung kann auch vor dem Hintergrund betrachtet werden, dass Media Markt und Saturn als eigenständige Marken unter dem Dach der Media-Saturn-Holding GmbH geführt werden, die wiederum Teil der METRO Group ist.

35 Pfabigan: Nimm 3, zahl 2, S. 141.

36 Bolz: Das konsumistische Manifest, S. 98.

37 Sloterdijk: Kritik der zynischen Vernunft, S. 37; H.i.o.

38 Vgl. Hillenkamp: „Selbst schuld!“, S. 1ff.

39 Sloterdijk: Im Weltinnenraum des Kapitals, S. 276. 
denz zur Produktionsverlagerung und sinkenden Löhnen um sich. ${ }^{40}$ Damit kehren sich die Folgen des Verhaltens der Konsumenten am Ende gegen ihre eigenen Interessen. Darüber hinaus tangiert der Preisverfall das Verhältnis zu den konsumierten Waren selbst. Denn die Erziehung der Kunden zu Smart Shoppern und Schnäppchenjägern durch Niedrigpreiskampagnen verändert hinter dem Rücken der Akteure - die Wertschätzung gegenüber den unglaublich günstig erworbenen Produkten, deren Image in Mitleidenschaft gezogen wird. ${ }^{41}$ Verschiedene Stimmen im Einzelhandel beklagen inzwischen den Effekt aggressiver Werbekampagnen im eigenen Lager; er gehört zu den nichtintendierten Folgen ausgedehnter Preiskämpfe. ${ }^{42}$ Dazu passt ironischerweise, dass in der griechischen Mythologie der Gott Saturn (sic!) als der Gott des Geizes gilt, der am Ende sogar seine Kinder frisst - aus Angst, sie könnten ihn entmachten. Nur durch ein Gegengift, das ihm gegeben wird, würgt er sie wieder hervor. Wie könnte so ein Antidot aussehen?

\section{$2 \quad$ Arm sein ist geil - Gesellschafts- und Konsumkritik}

\subsection{Die Agenda 2010}

Das im Claim Geiz ist geil zum Ausdruck kommende Ziel eines Verzichts auf unnötige Ausgaben erreichte auch die Politik in Form eines neuen Preisbewusstseins. Nicht nur Preise für Produkte sollten abnehmen, auch der Sozialstaat wurde auf Diät gesetzt. Der neue Sozialstaat erklärte die Eliminierung jeglicher Verschwendung zu einer seiner leitenden Handlungsmaximen. Die Leitmotive der Smart Shopper fanden somit ihre adäquate Parallele in den Orientierungsmustern der Politik, mit der die Bundesregierung unter Bundeskanzler Gerhard Schröder und dem Label der Agenda 2010 begann, massive Sozial-

40 Bezeichnend ist in diesem Zusammenhang, dass der Beginn des Claims Geiz ist geil im Jahr 2002 zeitlich mit einem Annus Horribilis für die Einzelhandelsbranche zusammenfällt: Mit Umsatzrückgängen von 3,5 Prozent insgesamt und mit 5,5 Prozent Verlust im stationären Non-Food-Handel intensivierte sich die Konkurrenz der Anbieter, obwohl die Verkaufsflächen gleichzeitig ausgedehnt wurden. Unter anhaltender Massenarbeitslosigkeit verfestigte sich die Kaufzurückhaltung der Verbraucher, während sich deren Sparquote erhöhte. Das „Paradigma Preis“ (GfK) zeugte von zunehmendem Sicherheitsstreben der Verbraucher, deren Konsumbereitschaft erkennbar ausblieb. Vgl. Bauer Media KG: „Konjunktur und Werbung", S. 4.

41 Pfabigan: Nimm 3, zahl 2, S. 129.

42 Vgl. KPMG: Trends im Handel 2010, S. 5. 
kürzungen durchzusetzen, die in erster Linie einkommensschwache Gruppen treffen sollten. Am 14. März 2003 stellte Schröder die Agenda in seiner Regierungserklärung vor dem Deutschen Bundestag vor und erklärte: „Wir müssen den Mut aufbringen, in unserem Land jetzt die Veränderungen vorzunehmen, die notwendig sind, um wieder an die Spitze der wirtschaftlichen und sozialen Entwicklung in Europa zu kommen."“3 Ziel der Agenda 2010 sei es, die wirtschaftliche Dynamik in Deutschland kurz- und mittelfristig zu stärken, Arbeitsplätze zu schaffen und die Sozialsysteme zu modernisieren, um sie langfristig zu sichern. ${ }^{44}$ Das Wohlstandsversprechen und die Aussicht auf Konsum im Modell Deutschland wurde somit in erster Linie seinem ,produktiven Kern: den Akteuren im System verwertbarer Lohnarbeit “45 zugesprochen. Gegenüber denjenigen, die nicht mehr zu diesem produktiven Kern gehörten, wurde mit der Agenda 2010 in hohem Tempo die ,größte Kürzung von Sozialleistungen seit 1949“46 mit der Zustimmung der konservativen Opposition vollzogen. Im Gefolge dieses sozialpolitischen Umbruchs fühlten sich vor allem diejenigen entmutigt, die befürchteten, demnächst arbeitslos zu werden und nach einem Jahr Arbeitslosengeld nunmehr ein Einkommen auf Sozialhilfeniveau (Hartz IV) zu beziehen. Wie für Langzeitarbeitslose durch den gravierenden Sozialabbau Perspektiven auf neue Arbeitsstellen geschaffen werden sollten, konnte politisch nicht vermittelt werden. Stattdessen erwartete die Bundesregierung unter sozialdemokratischer Führung von den Bürgern zukünftig „,mehr Eigenverantwortung ${ }^{647}$.

Gegen die angebotsorientierte Ausrichtung des Konzepts der Agenda 2010 zog die traditionelle Linke mit dem Argument der Verteilungsasymmetrien kritisch zu Felde, musste aber in diesem Zusammenhang eigene Mobilisierungsschwierigkeiten beklagen. Aus der Sicht der Linken hatte sich bereits, wie beispielsweise Autoren aus dem Kreis der Rosa-Luxemburg-Stiftung konstatierten, die neoliberale Hegemonie durchgesetzt, der die eigenen Performanzprobleme zugerechnet wurden:

Die paradoxe Grundsituation, dass in der neoliberal dominierten öffentlichen Auseinandersetzung Arbeitslosigkeit und Armut nur als Beweis für die Notwendigkeit weiterer Sozialdemontage und Entgarantierung von Lebensansprüchen gelten, bringt die Linke in die Lage, dass sie mit einer isolierten Strategie der sozialen Skandalisierung

43 Schröder: „Regierungserklärung durch den Bundeskanzler““.

44 Vgl. ebd.

45 Hubbertz: „Adieu Modell Deutschland mit der Agenda 2010?“, S. 305.

46 Soldt: „Hartz IV“, S. 3.

47 Presse- und Informationsamt der Bundesregierung: agenda 2010, S. 10, 35. 
keine Ausstrahlung gewinnen kann. Sozialer Protest allein läuft ins Leere. $^{48}$

In dieser Analyse wird deutlich, dass Mobilisierung auf die Erzeugung von Leidenschaften angewiesen ist. ${ }^{49}$ Die Bundesregierung selbst versuchte mit Hilfe massenmedial erzeugter Öffentlichkeit in Form von Broschüren, die bundesweit an Bahnhöfen an die Bevölkerung verteilt wurden, und Plakatanzeigen für die Agenda 2010 zu werben. Vor diesem Hintergrund sah der Kirchenkreis Recklinghausen die Chance einer medialen Intervention jenseits der bekannten Darstellungsformen, mit denen die traditionelle Linke gescheitert war. Mit dieser Intervention sollte die Inszenierung von Politik aus der Perspektive der Werbung mit deren Mitteln kenntlich gemacht und gleichzeitig die Rolle von Konsumenten als Triebkräfte zunehmenden Preisverfalls problematisiert werden. Der neue Sozialstaat sollte auf der Folie der populären SchnäppchenjägerMentalität aufs Korn genommen werden, die nunmehr auf die Schnäppchenjäger selbst zurückschlägt. Diese sind im Bild der Agenda 2010 selbst zu Schnäppchen geworden, genauer zu Schnäppchen des Sozialstaats, der nicht zu teuer werden darf.

\subsection{Hintergrund und Verlauf der Kampagne}

Die oftmals beklagte Alternativlosigkeit, mit der die Regierung ihr Reformprogramm präsentierte, weckte im Evangelischen Kirchenkreis Recklinghausen die Motivation, ein kirchliches Antidot gegen die aufkommenden Ohnmachtserfahrungen in weiten Teilen der Bevölkerung zu entwickeln. So sollten in innovativer Weise Anstöße für die Diskussion von politischen Alternativen und eine Art Rückeroberung der Zeichen im Feld sozialethischer Diskurse seitens der Evangelischen Kirche befördert werden. Der traditionell besetzte Topos des Geizes sollte als Spielball aufgenommen werden, um auf der symbolischen Ebene - im Sinne von Culture Jamming ${ }^{50}$ - mit anderen Inhalten aufgeladen zu werden. Kirche trat quasi auf heimischem Boden in Konkurrenz zum „Konsumismus als Ersatzreligion“"51. Sie sollte in der Rolle des Anwalts der Betrof-

48 Rilling/Spehr: „Die Wahl 2006“, S. 3.

49 So konstatiert Sloterdijk, dass die moderne Gesellschaftsordnung ,auf der Abstraktion von Leidenschaften errichtet" wurde. Sloterdijk :Eurotaoismus, S. 224.

50 Culture Jamming kann als „eine Strategie, eine Marke umzucodieren, als eine soziale Kampagne der Entmarkierung“ definiert werden. Lasn: Culture Jamming, S. 15.

51 Bolz 2002: Das konsumistische Manifest, S. 98. 
fenen mit Rückblick auf ihren Ausgangspunkt „die Identifizierung mit einem Scheitern “52 artikulieren. In der Tradition der protestantischen Kreuzestheologie $^{53}$ sollte sich der Kirchenkreis Recklinghausen als Teil der Evangelischen Kirche in einer politisch gelähmten Atmosphäre öffentlich zu Wort melden. Dieser theologische Topos nimmt die ,vorrangige Option für die Armen, Schwachen und Benachteiligten “54 wahr, die das sozialethische Motiv gesellschaftlicher Einmischung seitens kirchlicher Akteure ausmacht.

In einer Gesellschaft, die sich durch Medien über sich selbst informiert, stößt die Kirche mit schwergewichtigen Topoi wie Ohnmacht und Hoffnung in den Massenmedien kaum auf Resonanz. Dies ändert sich, wenn sie glaubwürdig den Diskursformen dieser Medien entspricht und mit Themen wiederzuerkennen ist, die ihr traditionell zugeordnet werden. Ein Verlierer-Image auf der Basis der nicht unkomplizierten Tradition der Kreuzestheologie erzeugt jedoch kaum die erforderliche Magie, um ansteckende Begeisterung für gesellschaftskritische Einmischung zu wecken. Daher lag es nahe, eine Artikulationsform für den Protest zu finden, die traditionelle Erwartungen an Kirche befriedigt und diese gleichzeitig durchkreuzt, um das knappe Gut der Aufmerksamkeit zu erlangen. Die Strategie der ironischen Intervention sollte dazu dienen, komplexere Inhalte in unterhaltsamer Form zu transportieren: Es sollte nicht nur die relativ triviale Umverteilungspolitik der Agenda 2010 kritisiert werden, sondern auch das Verhalten der Konsumenten, die sich auf beiden Seiten der Medaille erkennen sollten, nämlich als Verlierer und Krisenprofiteure von Kostensenkungskampagnen. Die Zielgruppe war demnach möglichst breit konzipiert und sollte sich nicht nur auf Protestgruppen beschränken.

Mit einer öffentlichen Aktion wurde zunächst in einer Art Pilotprojekt versucht, attraktiv für eine klassische Erwachsenenbildungsveranstaltung zur Agenda 2010 mit Referent und Diskussion zu werben. Dazu wurde die Bevölkerung im Rahmen einer aktivierenden Straßenaktion befragt, ob sie die Einschnitte der Agenda 2010 für gerecht oder ungerecht hielte. Passanten und Passantinnen konnten mit Tennisbällen darüber abstimmen. Im Hintergrund wurde als einladend provokatives Plakat ein Werbe-Fake eingesetzt, das den Claim Geiz ist geil der Elektromarktkette Saturn auf die Probleme der Agenda 2010 umdeutete. Dessen Motto lautete dementsprechend tautologisch Geiz ist Geiz und Arm sein ist geil. Zu sehen war eine arbeitslose Familie, anhand derer mit konkreten Zahlen die Effekte des Sozialabbaus exemplarisch vorgerechnet

52 Žižek: Die Puppe und der Zwerg, S. 91, H.i.o.

53 Vgl. z.B. Bonhoeffer: Widerstand und Ergebung; Moltmann: „Gesichtspunkte der Kreuzestheologie“.

54 EKD: Für eine Zukunft in Solidarität und Gerechtigkeit, Abs. 3.3.2. 
wurden. Auch die Optik der Werbepersiflage entsprach der Werbung der Elektromarktkette Saturn. Nach spontan geäußerten Resonanzen zeigten sich die Passanten positiv überrascht und bekundeten ihre Kritik an der Agenda 2010.

Anfang Oktober 2003 boten zwei Postings in den Newsgroups von Attac und das Portal labournet das provokative Plakat gegen den Sozialabbau kostenlos zum Download an. Die erste Druckauflage betrug bescheidene 2.500 Stück, ganz wie die Vorlage auf einer billigen Papiersorte in den Farben des Saturn-Originals, um passende haptische und visuelle Reize zu unterstreichen. Bei einer Veranstaltung kurz vor der Großdemonstration gegen den Sozialabbau am 1. November 2003 in Berlin wurden die ersten Exemplare in größeren Stückzahlen verteilt. Später tauchten dann Fotos von Demonstrationsteilnehmern auf, die sich die Motive auf Pappen umgehängt hatten und damit umherzogen. Danach beschleunigte sich der Bekanntheitsgrad der Kampagne massiv. Die Gewerkschaften (ver.di, IG-Metall, DGB-Kreise) verteilten das Material schneeballsystemartig weiter. Im Windschatten der aggressiven Saturn-Werbung genoss der Kirchenkreis mit seiner Kampagne massive öffentliche Resonanz. Der Vertrieb der Drucke lief trotz bescheidener Mittelausstattung sehr unkompliziert: Über einen Webshop auf dem Kirchenkreis-Server konnte das Material zum Selbstkostenpreis bezogen werden. Weitere eigene Webseiten informierten über Hintergründe der Aktion. Privatleute, Arbeitsloseninitiativen, Kirchengemeinden, Einrichtungen des Diakonischen Werkes, Hochschulseminare, Firmen, Betriebsräte, Mitarbeitervertretungen etc. bestellten die Drucke in hoher Stückzahl. Die Nachfrage war kaum zu bewältigen. Das Material kam im Konfirmandenunterricht zum Einsatz, ebenso bei Gottesdiensten, im Schulunterricht, bei Versammlungen und Demonstrationen oder in Schaukästen vor Kirchen. Arbeitsloseninitiativen nutzten im Mai 2004 die Flyer und den Konflikt mit Saturn als Startpunkt eigener öffentlicher Aktivitäten, so etwa die Oldenburger Arbeitslosenzeitschrift quer und die Wuppertaler Arbeitslosen- und Sozialhilfeinitiative Tacheles. Noch im Juli 2005 fand sich in dem Lifestyle-Magazin Max ein ausführlicher bebilderter Hintergrundartikel unter der Überschrift „Adbusting: Geist ist geil“55, der die Kampagne im Kontext der Adbuster-Bewegung einordnete.

Nach wie vor existieren diverse Download-Möglichkeiten der Motive auf Webservern in den verschiedenen Dateigrößen und Formaten, allerdings nicht mehr auf den Seiten des Evangelischen Kirchenkreises Recklinghausen. ${ }^{56}$ Die Flyer beanspruchen kein Copyright, - im Gegenteil galt von Anfang an die ausdrückliche Erlaubnis zur eigenen Verwendung und zum Nachdruck. Anfra-

55 Bieber: „Adbusting“.

56 Dies ist auf die Verpflichtungserklärung gegenüber Saturn zurückzuführen, vgl. unten. 
gen von Zeitschriften zum Nachdruck kamen von der Zivil-Courage (Zeitschrift der Zivildienstleistenden), von Obdachlosenzeitschriften wie fiftyfifty ${ }^{57}$, die nach der Beendigung der Kampagne durch den Kirchenkreis eigenständig für eine Weiterverbreitung sorgten. Wer in den einschlägigen Suchmaschinen, z.B. bei Google, die Formulierung „Arm sein ist geil“" eingibt, stößt noch im Jahr 2007 auf mehr als dreihundert Treffer. Der Kirchenkreis hatte insgesamt 37.000 eigene Exemplare drucken lassen. Die Anzahl der Nachdrucke lag, soweit bekannt, doppelt so hoch.

Die initiale Ausbreitung der Kampagne in den Massenmedien wurde durch die Printmedien entfacht, als Mitte November 2003 die 35 größten Tageszeitungen in Deutschland einen Brief mit Flyern seitens des Kirchenkreises bekamen. Den Auftakt der Berichterstattung startete die Süddeutsche Zeitung am 28. November 2003 mit dem Artikel Arm sein ist geil - Ein Pfarrer fälscbt Werbung - mit ungeabntem Erfolg. Am Tag darauf folgte ein Interview mit der dpa. Danach stand das Telefon nicht mehr still. Es meldeten sich das ZDF mit einer Anfrage seitens Studio Berlin, das WDR-Fernsehen für die Sendung Gott und die Wel58; WDR-5 strahlte ein Live-Interview im Radioprogramm Nengier genügt aus ${ }^{59}$, Radio France International sendete ein Telefoninterview ${ }^{60}$, das Domradio in Köln hatte die Claims des Flyers zu Radiospots ${ }^{61}$ verarbeitet und produzierte ebenso wie später der Hessische Rundfunk ${ }^{62}$ ein Interview zu der Aktion. Das Manager-Magazin ${ }^{63}$, Chrismon ${ }^{64}$, die Frankfurter Rundschau ${ }^{65}$, die taz-Ruhr ${ }^{66}$, Neues Deutschland ${ }^{67}$ u.a. berichteten über die Auseinandersetzung mit Saturn. Den Abschluss bildete ein Bericht in MONITOR am 8. Januar 2004, in dem die Auseinandersetzung zwischen Saturn und dem Kirchenkreis geschildert wurde. Im Gefolge der MONITOR-Sendung zogen die

57 Fiftyfifty ist eine gemeinnützige Kunstgalerie, die von der Ordensgemeinschaft der Armen-Brüder des hl. Franziskus in Düsseldorf verwaltet wird und deren Einnahmen Obdachlosen zugute kommen. Unter dem gleichen Titel gibt der Verein eine Straßenzeitung in Düsseldorf, Duisburg und Essen heraus.

58 WDR-Fernsehen am 14.12.2003.

59 WDR 5 am 05.12.2003.

60 RFI am 05.12.2003.

61 Domradio am 05.12.2003.

62 HR 2 am 18.5.2004.

63 manager-magazin.de am 09.01.2004.

64 Chrismon, Januar 2004.

65 FR am 12.12.2003.

66 taz-Ruhr am 27.12.2003.

67 ND am 02.02.2004. 
Zugriffe auf die Webseiten des Kirchenkreises innerhalb von wenigen Stunden um mehrere Tausend an. Viele hinterließen Einträge auf den elektronischen Gästebüchern des Kirchenkreises und bei MONITOR, um ihre Begeisterung über die Aktion, aber auch ihre Verwunderung über die harsche Saturn-Reaktion im November 2003, zum Ausdruck zu bringen.

Am 27. November 2003 hatte sich die Elektromarktkette Saturn per Fax an den Ratsvorsitzenden der EKD, Bischof Wolfgang Huber, gewandt, obwohl das Impressum presserechtlich einwandfrei die Autorschaft des Kirchenkreises auswies. Saturn sah in den Flyern einen groben und justiziablen Missbrauch der Bildmarke und der Wortmarke von Saturn und hielt die Persiflagen für im hohen Maße imageschädigend und geschäftsschädigend. Außerdem seien die Persönlichkeitsrechte ihres Models, der Darstellerin der Werbefigur Blu verletzt, obwohl sie im Rahmen des Fake anonymisiert und markant verfremdet dargestellt wurde. Zunächst wolle man jedoch, so das erste Fax an Bischof Huber, auf die Einleitung rechtlicher Schritte verzichten. Bischof Huber wurde gedrängt, dafür zu sorgen, dass eine weitere Verwendung des Flyers unterbleibt. Eine Woche später wurde dem Kirchenkreis eine Frist gesetzt und der Klageweg angedroht. Dies geschah nach zwei Wendepunkten: Einerseits hatten in Gelsenkirchen und Frankfurt am Main Studenten bzw. Gewerkschaftsmitglieder die Flyer vor Saturn-Filialen verteilt und andererseits zitierte die dpa die Bischöfin der Hannoveraner Landeskirche, Margot Käßmann, mit ihrem Kommentar zur Kampagne des Kirchenkreises: „Ich finde sie gut, weil sie nachdenklich macht und die Saturn-Werbung entlarvt. Die Provokation tut gut. “68 Danach war Schluss mit lustig. Diejenigen, die ausgiebig die Spaßmachergesellschaft bedienten, verstanden selbst nun keinen Spaß mehr. Innerhalb der gesetzten Frist sah sich der Kirchenkreis nach internen Diskussionen gezwungen, am 10. Dezember 2003 eine gemeinsame Presseerklärung mit Saturn zu unterzeichnen, in der sich der Kirchenkreis verpflichtete, die Persiflagen nicht weiter zu vertreiben. Das Risiko hoher Prozesskosten und möglicher Schadensersatzansprüche erschien zu hoch. Nicht ohne Ironie geschah die Unterzeichnung am Tag der Menschenrechte.

\subsection{Kampagnenstrategien: Guerilla Marketing und Fake}

Das Antidot, zu dem die Kampagne des Evangelischen Kirchenkreises Recklinghausen griff, war eine Strategie des Guerilla-Marketing, nämlich die Umcodierung der Umcodierung oder Re-Recodierung: Hatte die Saturn-Werbung mit dem Regelbruch gestartet, aus einer Todsünde eine Tugend zu schmieden,

68 dpa am 29.11.2003. 
wurde dieser durch einen erneuten Regelbruch konterkariert, um in die Felder ökonomischer und sozialethischer Fragen vorzustoßen. Für die Saturn-Werbung wie für deren Parodie galt das Prinzip des Regelbruchs oder der NormAbweichung. Beide erfüllen damit nach René König eine positive soziale Funktion:

Das Verletzen einer sozialen Norm hat eine integrative Funktion für das Überleben des Gesamtsystems der sozialen Normen, das bei kontinuierlichem Befolgen, also bei totaler Konformität schnellstens verdämmern würde. ${ }^{69}$

Begrifflich gilt Guerilla-Marketing zunächst als unkonventionelle, zielgenaue Aktion mit überraschender Wirkung in der Lebenswelt der Zielgruppe. Solche Werbung wird seitens der Massenmedien gerne aufgenommen. Angesichts der Werbemüdigkeit vieler Menschen besteht jedoch stets die Gefahr, aufgrund der Verwechselungsgefahr übersehen zu werden. Ein einprägsamer Überraschungseffekt stellt sich jedoch umso intensiver ein, je stärker der Fake zuvor falsch eingeordnet wurde. Denn die Irritation gewohnter Erwartungsmuster wird quasi positiv enttäuscht:

Es gibt einem Energie, einen Megakonzern wie McDonald's, Nike oder Calvin Klein unter Ausnutzung des ungeheuerlichen Schwungs ihrer eigenen Ikonen und ihres eigenen Marketings auf die Matte zu werfen - indem man den Hebel genau an der Bekanntheit der Marke ansetzt, die das Unternehmen über Jahre hinweg in pingeliger Kleinstarbeit aufgebaut hat ${ }^{70}$

beschreibt Kalle Lasn diese Technik der so genannten Mem-Krieger. Der MemKrieger ist, folgt man den Überlegungen zur postmodernen Kultur von Dirk Baecker, ein Kulturarbeiter der Irritation, der Codes verwirrt, durcheinander bringt und politisiert, der die Gesellschaft in den Codes wiedereinführt und „den Gegner nicht mehr in den Klassen und Nationen, sondern in den Codes sucht“"71. Da sich die Codes von Politik, Wirtschaft oder Religion in einer ausdifferenzierten Gesellschaft voneinander entkoppelt haben, übernimmt der Kulturarbeiter die Rolle ,einerseits die Beharrlichkeit und Durchsetzungs-

69 Bernsdorf: Wörterbuch der Soziologie, S. 736 zitiert nach Gaede: Abweichen von der Norm, S. 620.

70 Lasn: Culture Jamming, S. 132.

71 Baecker: Wozu Kultur?, S. 73. 
fähigkeit der Grenzziehungen vorzuführen und andererseits mit den Mitteln dieser Vorführung kontingent zu setzen“"72.

Werbung professionell zu faken, gehört zu einer Kommunikationsstrategie, die mit den Begriffen Ad-Busting ${ }^{73}$ oder Cultural Hacking (Stewart Home) benannt wird. Dabei werden bekannte Formen bewusst kreativ missbraucht und in einem neuen Zusammenhang zwischen Kunst, Konsum und Werbung umcodiert - bisweilen auch als Piraterie. ${ }^{74}$ Franz Liebel identifiziert fünf Charakteristika solcher Praktiken der Orientierung durch Desorientierung:

- Störungspotentiale durch Doppeldeutigkeiten,

- Verknüpfung von Ernst und Spiel („dies ist ein Spiel, das wir ernst meinen"),

- $\quad$ experimentelles Vorgehen,

- $\quad$ Rekurs auf originäre Zwecke sowie

- „kalkulierte und präzise Intervention ins System“.75

Ausgangspunkt der Kampagne gegen die Agenda 2010 war die Idee, unter Rückgriff auf Praktiken des Ad-Busting den marktschreierischen Geiz-Topos von Saturn auf die Darstellung der Wende in der Sozialpolitik anzuwenden. Im Fokus des Saturn-Fakes stand die Kritik am Sozialabbau vor allem in den Politikfeldern von Arbeitsmarkt und Gesundheit. Es sollte deutlich gemacht werden, dass Leistungsempfänger aus der Sicht der Agenda 2010 kalkulatorisch als reine Kostenfaktoren betrachtet werden, die für den Staat Gegenleistungen zu erbringen haben, wie sie etwa in den so genannten Ein-Euro-Jobs gefordert werden. Die reduzierten Sozialleistungen und die menschliche Arbeit sollten als Tauschgeschäft mit $W$ arencharakter decouvriert werden. Dazu wurden die Elektroprodukte aus der Saturn-Werbung durch Personen oder Symbole ersetzt. Sozialpolitische Informationen traten mit einer Prise augenzwinkernder Ironie an die Stelle von Beschreibungen zu Elektroartikeln. Preise wurden wie in der Vorlage - optisch in den Vordergrund gerückt, um mit der Analogie des Warencharakters zu operieren. Die Ver-Wendung von Werbung sollte im Sinne einer sichtbaren Überschreitung mit dem Code der Werbung brechen und ,mit der augenblicklichen Dekonstruktion des herrschenden diskursiven

72 Ebd.

73 Weitere Informationen zu Ad-Busting finden sich unter www.adbusters.org. Vgl. auch März in diesem Band.

74 Vgl. Lasn: Culture Jamming, S. $129 \mathrm{ff}$.

75 Liebl: „Unbekannte Theorie-Objekte der Trendforschung (XLVII)“, S. 4. 
Codes“ ${ }^{\text {76 }}$ spielen. Die negativ besetzte Thematik des Umbaus des Sozialstaats sollte satirisch, persiflierend kommuniziert werden, um nicht sogleich mit Ablehnung rechnen zu müssen. Eingestreute Detailinformationen zur Agenda 2010 durchkreuzten die Ironie und eröffneten eine zusätzliche inhaltliche Ebene.

Mit der Persiflage der Saturn-Werbung rückte Kirche in einer ungewöhnlichen Debatte, bei der das Verhältnis von Ökonomie, Politik und Ethik neuartig bestimmt wurde, in die Rolle eines solchen Mem-Kriegers. Eine bissigironische Kommunikationsweise wurde bis dato kaum von kirchlichen Kampagnen praktiziert. Telefonische und schriftliche Rückmeldungen von Bestellern der Flyer bekundeten, etwas derartig Witriges von Kirche nicht erwartet zu haben. Darin lag eine der ersten Irritationen. Die David-gegen-GoliathKonstellation und der juristische Druck seitens der Elektromarktkette, den Flyer nicht weiter zu verbreiten, forcierte genau dieses Wahrnehmungsmuster zugunsten des Kirchenkreises und führte dazu, dass sich die Nachfrage nach dem Material massiv ausweitete. Sogleich intensivierte sich die Berichterstattung in den Medien, in denen die Motive aus diesem Grund weiter abgedruckt wurden. In der Phase, in der Saturn intervenierte und die Verbreitung des Materials verhinderte, konnte man den Eindruck gewinnen, der Kirchenkreis sei für Saturn zum Exorzisten im Tempel des Konsums geworden.

\section{Vom gesellschaftskritischen Klagenden zum Angeklagten?}

Wer mit Werbe-Fakes arbeitet, muss stets mit juristischen Auseinandersetzungen rechnen. Der häufigste Angriffspunkt sind erfahrungsgemäß urheberrechtlich geschützte Logos. Daher sollte das fremde Logo deutlich verändert werden, ohne dass es seinen Wiedererkennungswert verliert. Außerdem sollte auf solchen Nachahmungen immer unübersehbar stehen: „Keine Anzeige“. Selbstverständlich sollten keine rechtlich geschützten Bilder von anderen verwendet werden. Eine Möglichkeit sind eigene Bilder, die allerdings qualitativ und optisch passen müssen. Notfalls müssen Bilder externer Quellen so gravierend verfremdet werden, dass sie einen eigenen grafischen Wert darstellen. Originalgetreue Fakes berühren zumeist Fragen des Urheberrechts, Markenrechts, Wettbewerbsrechts und manchmal auch der Persönlichkeitsrechte. Wenn es zu einer Auseinandersetzung kommen sollte, erhält der Beklagte zunächst eine Abmahnung, mit der außergerichtlich der Anspruch einer Unterlassung geltend gemacht werden soll. Zumeist wird im Zuge dessen gefordert, eine Unterlassungsverpflichtungserklärung abzugeben. Mit dieser Erklärung ist

76 Baudrillard: Kool Killer oder der Aufstand der Zeichen, S. 112. 
die Gefahr einer einstweiligen Verfügung oder Klage allerdings gebannt. Der Abgemahnte hat im Regelfall bereits die Anwaltskosten des Rechteinhabers zu bezahlen, die mit der Erstellung der Abmahnung verbunden waren. Die Kosten hängen vom jeweiligen Streitwert ab. Die Erfahrung zeigt, dass größere Unternehmen Abmahnungen und überzogene Streitwerte oftmals dazu nutzen, um die Streitbereitschaft des Gegners zu erschüttern. Hinzu kommt, dass die Kosten einer gerichtlichen Auseinandersetzung für kleine Organisationen kaum aufzubringen sind, während große Konzerne eigens eine Art Kriegskasse für Auseinandersetzungen dieser Art bereithalten. Soll gegen den Abgemahnten eine so genannte einstweilige Verfügung erlassen werden, so muss ein Richter am Ort des Beklagten diese für zulässig erklären und den so genannten Streitwert festlegen. Dagegen kann Klage erhoben oder Widerspruch eingereicht werden. Kosten fallen damit in jedem Fall an.

Was die Kampagne Arm sein ist geil betrifft, wurde ein Fachjurist beim Deutschen Journalistenverband in Frankfurt am Main vor dem Druck des Werbe-Fakes mit der Prüfung der Entwürfe befasst, der zu dem Schluss kam, alle rechtlichen Bedingungen einer zulässigen Verfremdung seien eingehalten worden, ein Restrisiko sei jedoch nicht auszuschließen. Auch eine Anfrage bei einem Juristen des Deutschen Werberats in Berlin ergab - allerdings im Nachhinein - die Einschätzung, das Risiko eines juristischen Angriffs sei sehr gering, da die Satire unverkennbar in großen Lettern als solche gekennzeichnet sei. Ähnlich wie in Rechtsauseinandersetzungen um Plakate des politischen Künstlers Klaus Staeck stehe nach der Rechtssprechung des Bundesverfassungsgerichts erfahrungsgemäß die Meinungsfreiheit über dem Markenrecht. Und da Kirche nicht mit Saturn wirtschaftlich konkurriere, gebe es keinerlei wettbewerbsrechtliche Bedenken. Dennoch hatte sich der Kirchenkreis aus den genannten Gründen für eine Unterzeichnung der Verpflichtungserklärung entschieden.

Abschließend kann zudem kritisch festgehalten werden, dass mit der Konzentration auf die Auseinandersetzung mit Saturn der eigentliche Nebenschauplatz in den Vordergrund des medialen Interesses gerückt ist. Unabhängig davon gilt: Wer Persiflagen benutzt, wirbt nolens volens für eine Sache, die er für problematisch hält. Die Verfremdung der Saturn-Werbung hat sicher zu einer Bekanntheitssteigerung und damit zu einem zentralen Ziel der Kommunikationspolitik des Unternehmens beigetragen. Auf der Website der Agentur Jung von Matt wurde das Ziel der Kampagne Geiz ist geil dezidiert folgendermaßen beschrieben: „Eine Kampagne, die kurzfristig mehr Kunden in die Märkte und mittelfristig die kommunikative Marktführerschaft bringt" ${ }^{\text {“7 }}$ Dies hat Saturn ohne Zweifel erreicht. Daher wirken Fake-Aktionen stets wie

77 Jung von Matt: „Homepage“. 
ein zweischneidiges Schwert, das immer auch den Gegner stärkt, dem eine höhere Aufmerksamkeit geschenkt wird.

\section{Literaturverzeichnis}

Adorno, Theodor W:: „Über den Fetischcharakter in der Musik“, in: Zeitschrift für Sozialforschung, Jg. 7, Reprint der Ausgabe von 1938, München 1980.

Baecker, Dirk: Wozu Kultur? Berlin 2000.

Baudrillard, Jean: Kool Killer oder der Aufstand der Zeichen, Berlin 1978.

Bauer Media KG: „Konjunktur und Werbung“, 2004, www.bauermedia.com/ fileadmin/user_upload/pdf/service/konjunktur_werbung_2004.pdf, 28.03.2007.

Bernsdorf, Wilhelm: Wörterbuch der Soziologie, Frankfurt a.M. 1972.

Bieber, Alain: „Adbusting: Geist ist geil“, in: Max, Nr. 7, 2005, S. 162-164.

Bolz, Norbert: Das konsumistische Manifest, München 2002.

Bonhoeffer, Dietrich: Widerstand und Ergebung. Aufzeichnungen und Briefe aus der Haft, Gütersloh 2005.

Bourdieu, Pierre: Die feinen Unterschiede. Kritik der gesellschaftlichen Urteilskraft, Frankfurt a.M. 1982.

Davis, Stan/Meyer, Christopher: Blur. The Speed Of Change In The Connected Economy, Capstone 1989.

Deutscher Spendenrat e.V. (Hrsg.): „Spenden gehört dazu. Eine Image- und Medienkampagne des Deutschen Spendenrates“, 2002, www.spendenrat. de/content/download/E3F46EF2622E4C72887E3C25C711C60A.htm, 20.03.2007.

EKD (Hrsg.): Für eine Zukunft in Solidarität und Gerechtigkeit. Wort des Rates der EKD und der DBK zur wirtschaftlichen und sozialen Lage in Deutschland, (Gemeinsame Texte 9), Hannover 1997.

Gaede, Werner: Abweichen von der Norm. Enzyklopädie kreativer Werbung, München 2002.

Gerbig, Andrea/Buchtmann, Patricia: „Vom ,Waldsterben` zu ,Geiz ist Geil‘: Figurativer Sprachgebrauch im Paradigmenwechsel von der ökologischen zur ökonomischen Handlungsmotivation", in: metaphorik.de, Nr. 4, 2003, www.metaphorik.de/04/gerbigbuchtmann.htm, 28.03.2007. 
Hillenkamp, Sven: „Selbst schuld! Ob Niedriglöhne, Stellenabbau oder Umweltzerstörung: Was uns als Bürger empört, fördern wir als Kunden“, in: DIE ZEIT, 08.06.2006, www.zeit.de/2006/24/Selbst-schuldTitel_xml?page $=1,20.03 .2007$.

Hirschman, Albert O.: Leidenschaften und Interessen. Politische Begründungen des Kapitalismus vor seinem Sieg, Frankfurt a.M. 1987.

Horx, Matthias: „Die Krise der Werbung. Warum eine Zukunft in Schwierigkeiten gekommen ist", in: agenda, Nr. 10, 1993, S. 22-23.

Hubbertz, Hans: „Adieu Modell Deutschland mit der Agenda 2010?“, in: Sozialwissenschaften und Berufspraxis, Jg. 28, Nr. 2, 2005, S. 303-320.

Jung von Matt: „Homepage“ www.jvm.de/www/index_flash_de.php, 28.07.2007.

KPMG: Trends im Handel 2010. Consumer Markets \& Retail, Köln 2006.

KPMG: Trends im Handel 2005 - Ein Ausblick für die Branchen Food, Fashion \& Footware. Consumer \& Industrial Markets, Köln 2003.

Kroeber-Riel, Werner: Strategie und Technik der Werbung. Verhaltenswissenschaftliche Ansätze, Stuttgart 1993.

Lakoff, George/Johnson, Mark: Metaphors we live by, Chicago u.a. 1980.

Lasn, Kalle: Culture Jamming. Die Rückeroberung der Zeichen, Freiburg 2005.

Lethen, Helmut: Verhaltenslehren der Kälte. Lebensversuche zwischen den Kriegen, Frankfurt a.M. 1994.

Liebl, Franz: „Unbekannte Theorie-Objekte der Trendforschung (XLVII): Der Künstler als unberechenbarer Konsument“, 2004, www.gwk-udkberlin.de/e4/e18/e87/e840/e9765/e9904/e9920/374nstler_als_unberech enbarer_Konsument.pdf, 20.03.2007.

Luhmann, Niklas: Gesellschaftsstruktur und Semantik. Studien zur Wissenssoziologie der modernen Gesellschaft. Bd. 3, Frankfurt a.M. 1993.

Moltmann, Jürgen: „Gesichtspunkte der Kreuzestheologie heute“, in: Theolog. Jahrbuch 1992, S. 91-108.

Pfabigan, Alfred: Nimm 3, zahl 2. Wie geil ist Geiz? Wien 2004.

Presse- und Informationsamt der Bundesregierung (Hrsg.): agenda 2010: Deutschland bewegt sich. Antworten zur agenda 2010, Berlin 2003.

Riesman, David: Die einsame Masse. Eine Untersuchung des amerikanischen Charakters, Reinbek 1958. 
Rilling, Rainer/Spehr, Christoph: „Die Wahl 2006, die Linke und der jähe Bedarf an Gespenstern...", in: Rosa-Luxemburg-Stiftung. Gesellschaftsanalyse und Politische Bildung e.V. (Hrsg.): rls standpunkte, Berlin 2006.

Rohrhirsch, Ferdinand: Erfolg. Ethik. Sinn. Faktoren einer nachhaltigen Mitarbeiter- und Unternehmensentwicklung, Karlsruhe 2005.

Schmidt, Siegfried J./Spieß, Brigitte: Die Kommerzialisierung der Kommunikation. Fernsehwerbung und sozialer Wandel 1956-1989, Frankfurt a.M. 1997.

Schröder, Gerhard: „Regierungserklärung durch den Bundeskanzler: Mut zum Frieden und zur Veränderung“, Berlin 2003, www.bundestag.de/bic/ plenarprotokolle/pp/2003/15032a.zip, 28.03.2007.

Sloterdijk, Peter: Im Weltinnenraum des Kapitals. Für eine philosophische Theorie der Globalisierung, Frankfurt a.M. 2005.

Sloterdijk, Peter: Eurotaoismus. Zur Kritik der politischen Kinetik, Frankfurt a.M. 1989.

Sloterdijk, Peter: Kritik der zynischen Vernunft. Bd. 1 u. 2, Frankfurt a.M. 1983.

Soldt, Rüdiger: „Hartz IV. Die größte Kürzung von Sozialleistungen seit 1949“, in: Frankfurter Allgemeine Zeitung, 30.06.2004, Nr. 149, S. 3.

w\&v: „Ich bin doch nicht blöd“ ist Deutschlands bekanntester Slogan“, 11.05.2004, www.werbenundverkaufen.de/wuv/news/archiv/2004/05/ 30464/index.html, 27.03.2007.

w\&v: „Geiz bleibt geil bei Saturn“, 23.10.2003, www.werbenundverkaufen.de/ wuv/news/archiv/2003/10/18593/index.html, 27.03.2007.

w\&v: „Saturn positioniert sich bei knauserigen Kunden“, 17.10.2002, www.werbenundverkaufen.de/wuv/news/archiv/2002/10/01821/index. html, 27.03.2007.

Waldenfels, Bernhard: Schattenrisse der Moral, Frankfurt a.M. 2006.

Žižek, Slavoj: Die Puppe und der Zwerg. Das Christentum zwischen Perversion und Subversion, Frankfurt a.M. 2003.

Žižek, Slavoj: Die gnadenlose Liebe, Frankfurt a.M. 2001. 



\section{Autoren}

Sigrid Baringhorst, Dr. phil., ist Professorin für Politikwissenschaft an der Universität Siegen und leitet das Forschungsprojekt Protest-und Medienkulturen im Umbruch. Transnationale Corporate Campaigns im Zeichen digitaler Kommunikation am kulturwissenschaftlichen Forschungskolleg Medienumbrïche.

baringhorst@politikwissenschaft.uni-siegen.de

Michael Beetz, Dr. phil., lebt als freier Autor in Jena und ist dort an der Friedrich-Schiller-Universität als Lehrbeauftragter im Bereich Soziologie tätig.

Michael.Beetz@volksphilosophie.de

Christian Conrad, Dipl.-Volkswirt, ist Partner der Unternehmensberatung brands \& values (Deutschland). Er berät nationale wie internationale Kunden in der strategischen Ausrichtung und der Umsetzung wertschöpfender Kommunikation ihres gesellschaftlichen und ökologischen Engagements.

christian.conrad@brandsandvalues.com

Janina V. Curbach, Dipl.-Soziologin, ist Promotionsstipendiatin am interdisziplinären Graduiertenkolleg Märkte und Sozialräume der DFG an der Universität Bamberg und promoviert zur Corporate-Social-Responsibility-Bewegung. janina.curbach@gmx.de

Benjamin Diehl studiert Psychologie und ist für die Unternehmensberatung brands \& values als Analyst und Junior Consultant tätig.

benjamin.diehl@brandsandvalues.com

Simon Holler, Dipl.-Medienwirt, arbeitet seit Anfang 2006 für Fairtrade. Zurzeit ist er bei TransFair.e.V. im Marketing tätig und für internationale Kooperationen zuständig.

s.holler@transfair.org

Hans Hubbertz, Dr. phil., arbeitet im Evangelischen Kirchenkreis Recklinghausen in den Bereichen Industrie- und Sozialarbeit sowie Presse- und Öffentlichkeitsarbeit. Er initiierte die Kampagne Arm sein ist Geil als Kritik an der Agenda 2010.

hans.hubbertz@kk-ekvw.de 
Veronika Kneip, Dipl.-Medienwirtin, ist wissenschaftliche Mitarbeiterin im Forschungsprojekt Protest- und Medienkulturen im Umbruch an der Universität Siegen und promoviert über den Zusammenhang von Corporate Citizenship und Consumer Citizenship.

kneip@fk615.uni-siegen.de

Tanja Köhler, Dr. phil., arbeitet als Autorin und Journalistin für öffentlichrechtliche Sendeanstalten und verschiedene Verlage. Sie ist daneben als Lehrbeauftragte für Journalismus und PR unter anderem an der Ruhr-Universität Bochum tätig.

tanja.koehler@free.de

Jörn Lamla, Dr. phil., ist wissenschaftlicher Assistent am Institut für Soziologie der Justus-Liebig-Universität Gießen. Von 2005 bis 2007 hat er am Gießener Zentrum für Medien und Interaktivität ein DFG-Projekt zum Thema CyberCash - Konsumpraktiken in der virtuellen Alltagsökonomie durchgeführt.

Joern.Lamla@sowi.uni-giessen.de

Thomas Löding, Dipl.-Sozialwirt, ist bei Attac aktiv und hat unter anderem in der bundesweiten Attac-Lidl-Kampagnengruppe mitgearbeitet. Er ist Mitautor des Attac-Basistexts Konzern, Kritik, Kampagne!

thomas.loeding@gmx.de

Karin Lukas, LL.M., arbeitet am Ludwig Boltzmann Institut für Menschenrechte. Sie arbeitet dort zu Menschenrechten und Wirtschaft, Frauenrechten und Entwicklungszusammenarbeit in den Bereichen Forschung, Training und Consultancy.

karin.lukas@univie.ac.at

Antoine Mach, MA, ist Mitbegründer und Direktor von Covalence SA. Covalence bestimmt auf der Grundlage des dort entwickelten Ethical Quotation Systems die ethische Reputation multinationaler Unternehmen.

antoine.mach@covalence.ch

Annegret März, M.A., ist wissenschaftliche Hilfskraft im Forschungsprojekt Protest-und Medienkulturen im Umbruch an der Universität Siegen.

maerz@fk615.uni-siegen.de 
Johanna Niesyto, Dipl.-Medienwirtin, ist wissenschaftliche Mitarbeiterin im Forschungsprojekt Protest- und Medienkulturen im Umbruch an der Universität Siegen und promoviert zur Funktion von Konflikten für eine Europäisierung von Öffentlichkeit.

niesyto@flk615.uni-siegen.de

Lars Rademacher, Dr. des., leitet den Fachbereich Medienmanagement an der Mediadesign Hochschule München. Als Pressesprecher in der Konzernkommunikation der BASF AG war er zuvor verantwortlich für die Kommunikation des Unternehmensnetzwerks Wissensfabrik.

1.rademacher@mediadesign-fh.de

Kay O. Schulze ist bei Attac und dem BUND aktiv. Derzeit arbeitet er im Attac-Bundesbüro im Bereich Kampagnenunterstützung und Öffentlichkeitsarbeit. Er ist Mitautor des Attac-Basistexts Konzern, Kritik, Kampagne!

kay@attac.de

Jutta Sundermann, freie Journalistin, ist Gründungsmitglied von Attac Deutschland. Sie war und ist in diversen Kampagnengruppen aktiv, unter anderem der BUKO-Kampagne gegen Biopiraterie und der Attac-Lidl-Kampagne. Sie ist Mitautorin des Attac-Basistexts Konzern, Kritik, Kampagne! jutta.s@jpberlin.de 


\section{Medienumbrüche}

Stefan Eichhorn

Die Vermessung der virtuellen Welt

Von »Sacred« bis »GTA«:

Karten im Computerspiel

November 2007, ca. 120 Seiten,

kart., ca. $14,80 €$,

ISBN: 978-3-89942-755-4

Albert Kümmel-Schnur,

Jens Schröter (Hg.)

Äther

Ein Medium der Moderne

November 2007, ca. 350 Seiten,

kart., ca. 31,80 €,

ISBN: 978-3-89942-610-6

Sigrid Baringhorst,

Veronika Kneip,

Annegret März,

Johanna Niesyto (Hg.)

Politik mit dem

Einkaufswagen

Unternehmen und Konsumenten

als Bürger in der globalen

Mediengesellschaft

Oktober 2007, 394 Seiten,

kart., $28,80 €$,

ISBN: 978-3-89942-648-9

Isabel Maurer Queipo,

Nanette Rißler-Pipka (Hg.)

Dalís Medienspiele

Falsche Fährten und

paranoische Selbstinszenierun-

gen in den Künsten

September 2007, 416 Seiten,

kart., $36,80 €$,

ISBN: $978-3-89942-629-8$
Rainer Leschke,

Jochen Venus (Hg.)

Spielformen im Spielfilm

Zur Medienmorphologie des

Kinos nach der Postmoderne

August 2007, 422 Seiten,

kart., $33,80 €$,

ISBN: 978-3-89942-667-0

Peter Gendolla,

Jörgen Schäfer (eds.)

The Aesthetics of

Net Literature

Writing, Reading and Playing in

Programmable Media

Februar 2007, 394 Seiten,

kart., 33,80 €,

ISBN: $978-3-89942-493-5$

Walburga Hülk,

Gregor Schuhen,

Tanja Schwan (Hg.)

(Post-)Gender

Choreographien / Schnitte

2006, 236 Seiten,

kart., $24,80 €$,

ISBN: $978-3-89942-277-1$

Ralf Schnell (Hg.)

MedienRevolutionen

Beiträge zur Mediengeschichte der Wahrnehmung

2006, 208 Seiten,

kart., 23,80 €,

ISBN: $978-3-89942-533-8$

Leseproben und weitere Informationen finden Sie unter: www.transcript-verlag.de 


\section{Medienumbrüche}

Rainer Geißler,

Horst Pöttker (Hg.)

Integration durch

Massenmedien / Mass

Media-Integration

Medien und Migration im

internationalen Vergleich

Media and Migration:

A Comparative Perspective

2006, 328 Seiten,

kart., $27,80 €$,

ISBN: $978-3-89942-503-1$

Isabel Maurer Queipo,

Nanette Rißler-Pipka,

Volker Roloff (Hg.)

Die grausamen Spiele des

"Minotaure"

Intermediale Analyse einer

surrealistischen Zeitschrift

2005, 206 Seiten,

kart., $25,80 €$,

ISBN: 978-3-89942-345-7

Josef Fürnkäs, Masato Izumi,

K. Ludwig Pfeiffer,

Ralf Schnell (Hg.)

Medienanthropologie und

Medienavantgarde

Ortsbestimmungen und

Grenzüberschreitungen

2005, 292 Seiten,

kart., $25,80 €$,

ISBN: $978-3-89942-380-8$

Rainer Geißler,

Horst Pöttker (Hg.)

Massenmedien und die

Integration ethnischer

Minderheiten in Deutschland

Problemaufriss -

Forschungsstand -

Bibliographie

2005, 546 Seiten,

kart., 32,80€,

ISBN: 978-3-89942-280-1
Isabel Maurer Queipo,

Nanette Rißler-Pipka (Hg.)

Spannungswechsel

Mediale Zäsuren zwischen den

Medienumbrüchen 1900/2000

2005, 220 Seiten,

kart., $23,80 €$,

ISBN: $978-3-89942-278-8$

Nicola Glaubitz,

Andreas Käuser,

Hyunseon Lee (Hg.)

Akira Kurosawa und

seine Zeit

2005, 314 Seiten,

kart., 27,80 €,

ISBN: 978-3-89942-341-9

Ralf Schnell,

Georg Stanitzek (Hg.)

Ephemeres

Mediale Innovationen

$1900 / 2000$

2005, 242 Seiten,

kart., 24,80 €,

ISBN: 978-3-89942-346-4

Ralf Schnell (Hg.)

Wahrnehmung - Kognition Ästhetik

Neurobiologie und

Medienwissenschaften

2005, 264 Seiten,

kart., $24,80 €$,

ISBN: $978-3-89942-347-1$

Marijana Erstic,

Gregor Schuhen,

Tanja Schwan (Hg.)

Avantgarde - Medien -

Performativität

Inszenierungs- und

Wahrnehmungsmuster zu

Beginn des 20. Jahrhunderts

2004, 370 Seiten,

kart., $29,80 €$,

ISBN: 978-3-89942-182-8

Leseproben und weitere Informationen finden Sie unter: www.transcript-verlag.de 


\section{Medienumbrüche}

Peter Gendolla,

Jörgen Schäfer (Hg.)

Wissensprozesse in der

Netzwerkgesellschaft

2004, 286 Seiten,

kart., $26,80 €$,

ISBN: 978-3-89942-276-4

Michael Lommel,

Isabel Maurer Queipo,

Nanette Rißler-Pipka,

Volker Roloff (Hg.)

Französische Theaterfilme zwischen Surrealismus und Existentialismus

2004, 334 Seiten,

kart., $28,80 €$,

ISBN: $978-3-89942-279-5$

Uta Felten, Volker Roloff (Hg.)

Spielformen der Inter-

medialität im spanischen

und lateinamerikanischen

Surrealismus

2004, 364 Seiten

kart., $27,80 €$,

ISBN: $978-3-89942-184-2$

Jens Schröter,

Alexander Böhnke (Hg.)

Analog/Digital - Opposition oder Kontinuum?

Zur Theorie und Geschichte einer Unterscheidung

2004, 438 Seiten,

kart., $32,80 €$,

ISBN: $978-3-89942-254^{-2}$

Matthias Uhl, Keval J. Kumar

Indischer Film

Eine Einführung

2004, 174 Seiten,

kart., $18,80 €$,

ISBN: $978-3-89942-183-5$
Michael Lommel,

Isabel Maurer Queipo,

Nanette Rißler-Pipka (Hg.)

Theater und Schaulust im aktuellen Film

2004, 172 Seiten,

kart., 19,80 €,

ISBN: 978-3-89942-181-1 